\title{
INTEGRATED PHYSICALLY-BASED MULTI-HAZARD MODELLING
}





\title{
Integrated Physically-Based Multi-Hazard Modelling
}

\author{
DISSERTATION
}

to obtain

the degree of doctor at the University of Twente, on the authority of the rector magnificus, prof.dr. T.T.M. Palstra,

on account of the decision of the Doctorate Board, to be publicly defended

on Friday September $11^{\text {th }}, 2020$ at $16: 45$ hrs

by

Bastiaan van den Bout

born on 07-07-1993.

in Hardinxveld-Giessendam, The Netherlands 
This thesis has been approved by

Prof. dr. V.G. Jetten, supervisor

Prof. dr. C.J. van Westen, co-supervisor

ITC dissertation number 385

ITC, P.O. Box 217, 7500 AE Enschede, The Netherlands

ISBN 978-90-365-5048-2

DOI $10.3390 / 1.9789036550482$

Cover designed by Marianne van den Bout

Printed by ITC Printing Department

Copyright (c) 2020 by

\section{UNIVERSITY OF TWENTE.}

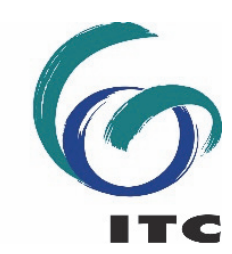


Graduation committee:

\section{Chairman/Secretary}

Prof.dr. F.D. van der Meer

\section{Supervisor(s)}

prof.dr. V.G. Jetten

prof.dr. C.J. van Westen

Universiteit Twente, ITC, ESA

Universiteit Twente, ITC, ESA

\section{Co-supervisor(s)}

\section{Members}

Prof.dr.ir. A. Veldkamp

Prof. dr. M. van der Meijde

Prof.dr. S.M. de Jong

Prof.dr. P. Cui

Dr. M. Mergili

University of Twente

University of Twente

Utrecht University

Mountain Hazard Research Institute

University of Graz 



\section{Acknowledgements}

The dissertation that you are currently reading is the end product of four years of research. This journey has been both a challenging and rewarding endeavour. Between my internship and the end of my PhD research I have developed a strong passion for the research topic and process, especially solving the hard questions to improve understanding and help people. The completion of this dissertation has been made possible by the support of, inspiration from, and cooperation with many others. The famous scientist Niels Bohr defined an expert assomeone that has made all possible mistakes within his narrow field. While this most definitely applies to myself, I am incredibly grateful for being surrounded by people that enabled me to learn, overcome and grow throughout this doctoral research.

First of all, I would like to thank my supervisory team, Cees van Westen (supervisor) and Victor Jetten (promoter). Even before starting my PhD journey, during my internship at ITC, it became evident that I could not have wished for better supervision. Victor, immediately there was a strong mutual passion for the same research topic. In particular the usage of programming to solve issues connected us both. You were able to motivate and inspire the research and cultivate new ways of thinking. Without your guidance to direct my creative chaos in coding, there would be hardly any usable results. You showed me how to work efficiently, and make more time for games. Cees, your patience and throrough feedback on my ideas and writings have been invaluable in progressing as a scientist. You were able to help me develop steadily in conveying my ideas. Moreover, your kindness, not only to me but to everyone you meet, provided balance to an otherwise hectic research project and inspires me to better myself.

My heartfelt thanks go to all colleagues and collaborators who have provided both assistance and the incredible working environment at ITC. In particular, thanks to all the ESA staff for the positive environment where I was able to grow as a researcher. Additionally, all the fellow PhD's at the Earth System Analysis department: Evelien, Oscar, Shoban, Yakob, Saman, Jonathan, Sofia, Fardad, Matthew, Riswan, Hakan, Saad, Thea and many others. Thank you for the research advice, friendship and fun times. ESA is a welcoming place thanks to you. A special thanks to Luigi, whose incredible passion and enthousiasm for research helped me find joy in the work on many occasions. Additionally, your cullinary advice has brightened the dinners of my family. Finally, I want to express my gratitude to Chenxiao, whose kindness and great scientific collaboration are well-worth the many lost games over the years. Without your friendship I would have been a flightless bird for sure.

Additionally, I want to thank my dear friends and family. My parents, for being there for me with unconditional support. You always provide a warm home for me and those I hold dear. Your love inspires me every day. Thank you to my brothers, for challenging me and being there throughout the years. Similarly I would like to thank my family-in-law, for all the wondrous travels and welcoming home you provide. Finally, I would like to thank my friends Peter and Jesper for their support. You are both brilliant and crazy, challenging my 
wit and klaverjas skills. Throughout the PhD research, you have provided invaluable distraction and joy.

In all of this, I cannot overstate my deepest gratitude to my lovely wife and daughter. Marline, thank you for your never-ending support in the past years. Your love and kindness provide, in many ways, the solid rock on which this research was founded. Thank you for sticking with me through all the challenges of life. Marianne, you are the joy of my life. Thank you for the sparkling happiness you infused into the most boring parts of the research. Thank you also for painting a debris flow entering the coast during the 2009 Messina disaster for the cover of this book. 


\section{Table of Contents}

Acknowledgements.........................................................

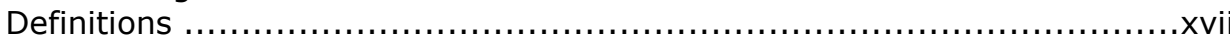

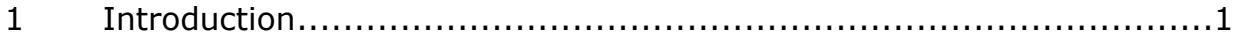

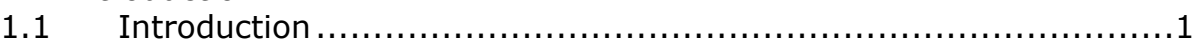

1.2 Multi-Hazard Risk Assessment .......................................

1.3 Defining the Hazard Component........................................4

1.4 Towards Integrated Multi-hazard Physically-based Modelling .........7

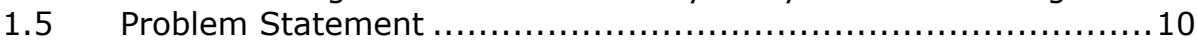

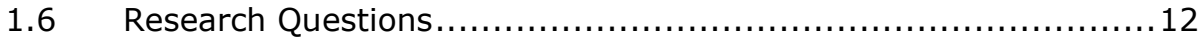

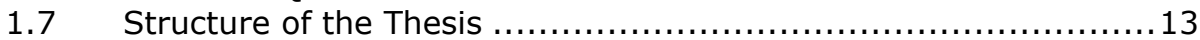

2 Flow Approximations for Hydrology-Integrated Flood Simulations ..... 15

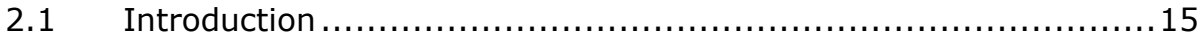

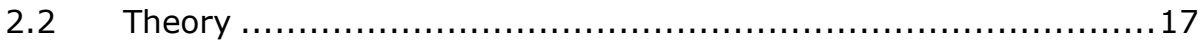

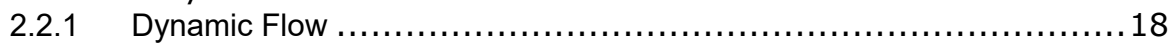

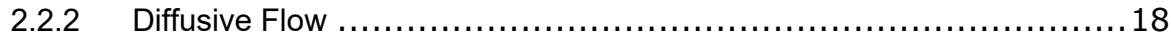

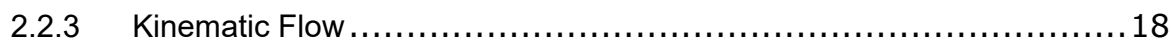

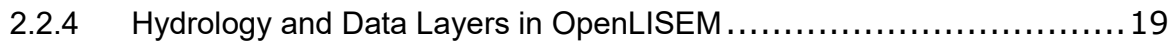

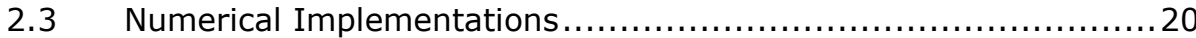

2.3.1 Saint-Venant Flow - Cell-Boundary Fluxes................................. 20

2.3.2 Diffusive Flow - Bilinear Interpolation .............................. 21

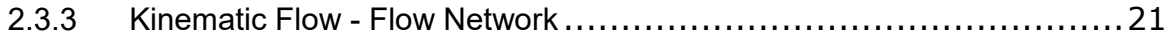

2.3.4 Connecting One and Two-dimensional Flow ........................... 22

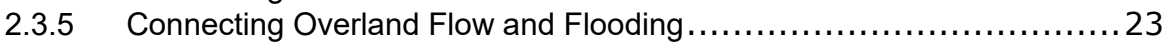

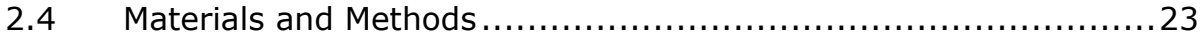

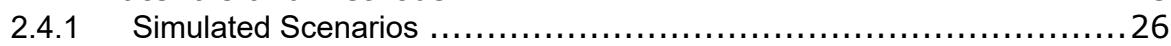

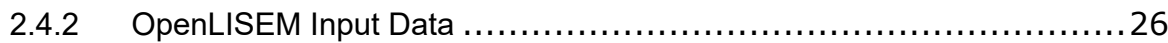

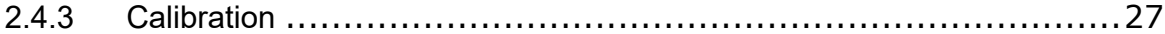

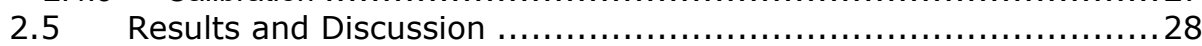

2.5.1 Danangou and Prado Catchments ................................... 28

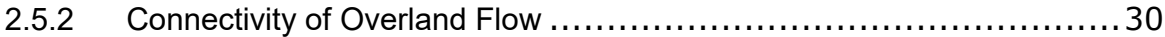

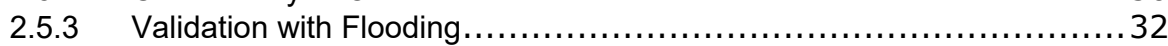

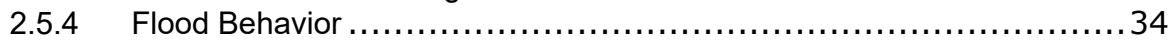

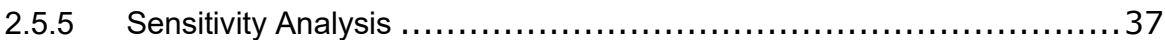

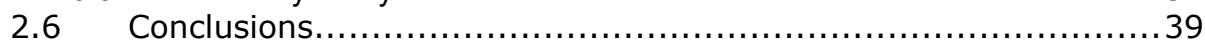

2.6.1 Acknowledgements ........................................... 40

3 An Iterative Method for Regional Hydrology-based Prediction of Shallow

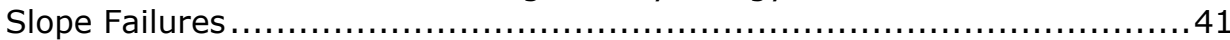

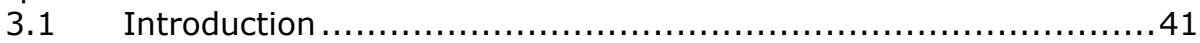

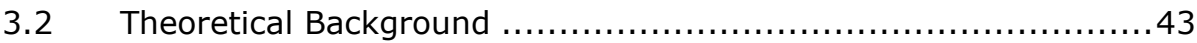

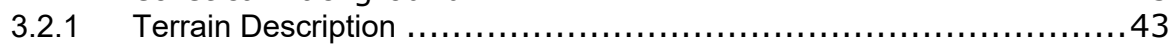

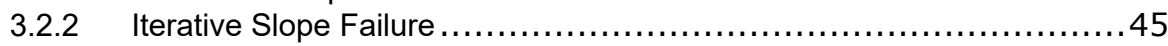

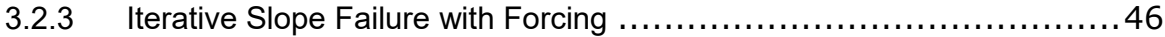

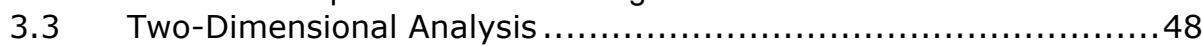

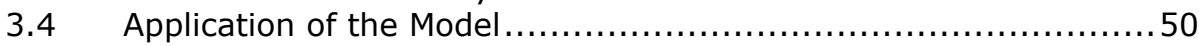

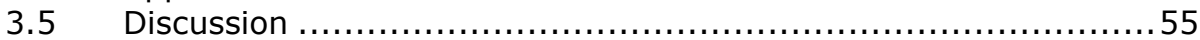

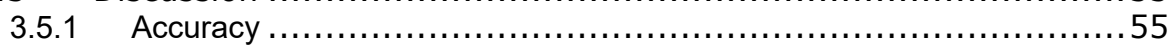

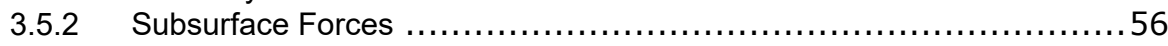

3.5.3 Influence of Approximation on Depth Patterns ...................... 57 


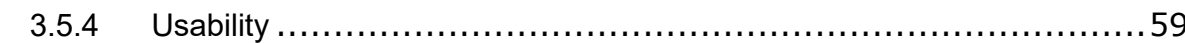

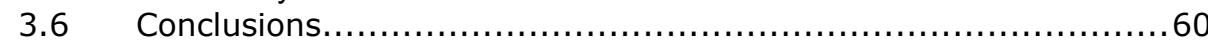

4 Integration of Two-phase Solid Fluid Equations in a Catchment Model

for Flashfloods, Debris Flows and Shallow Slope Failures .....................61

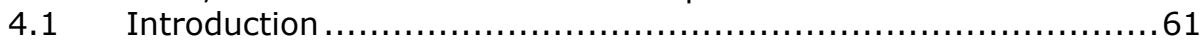

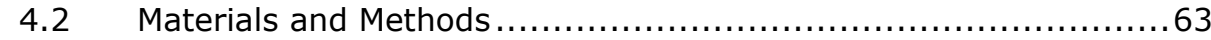

4.2.1 Schematic Model Description ........................................ 63

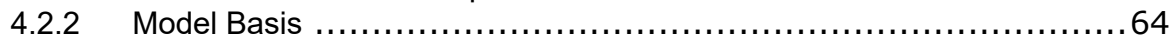

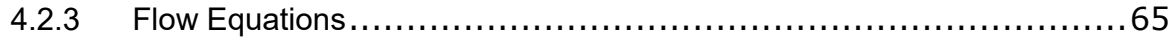

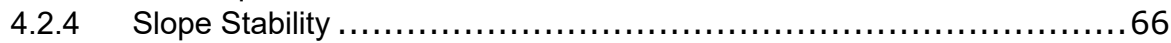

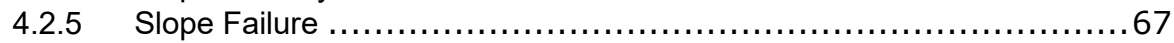

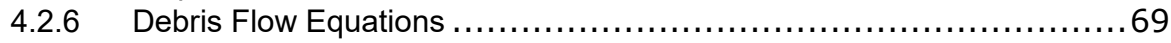

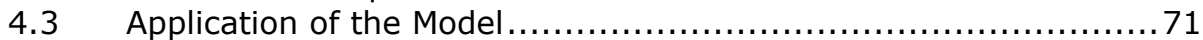

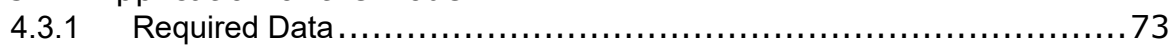

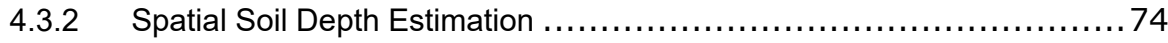

4.3.3 Simulations and Calibration Method ................................. 76

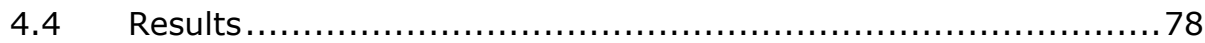

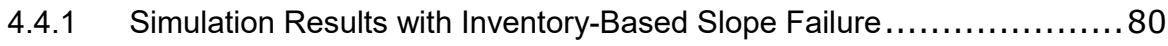

4.4.2 Simulations with Coastal Deposition ................................ 82

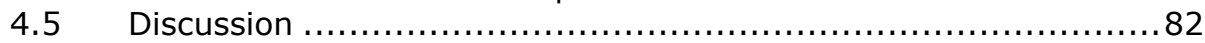

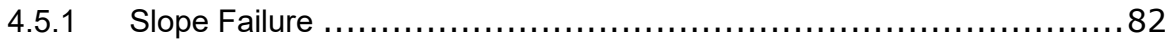

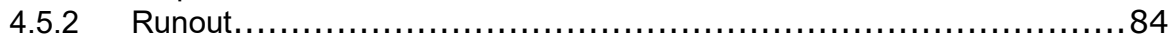

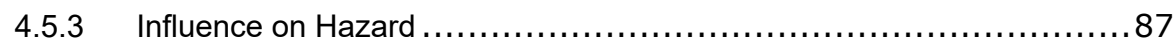

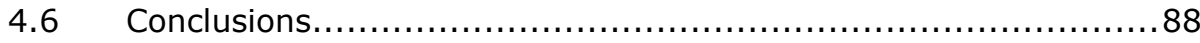

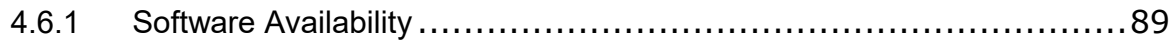

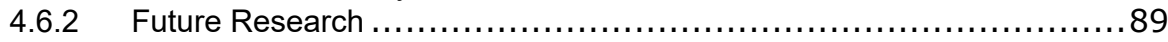

4.6.3 Acknowledgements ............................................. 90

5 Generalized Mass Movements Equations for Semi-Structured Runout 92

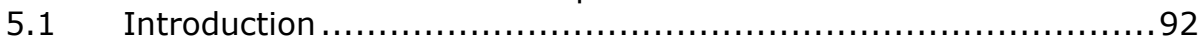

5.2 A Set of Debris Flow Equations Incorporating Internal Structure .. 93

5.2 .1 Structured Mass Movements......................................... 93

5.2 .2 Model Description................................................. 94

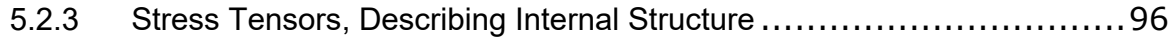

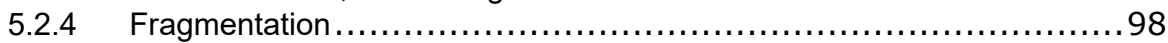

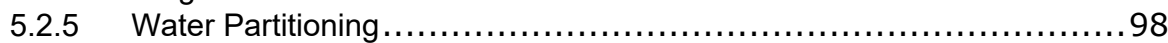

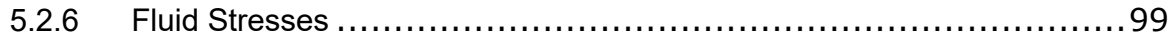

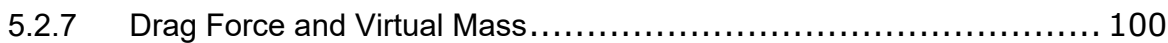

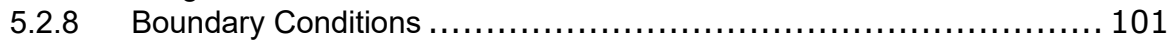

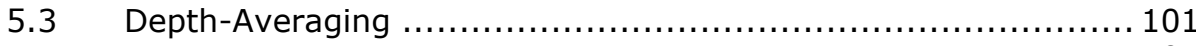

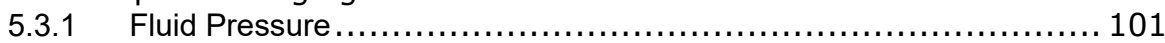

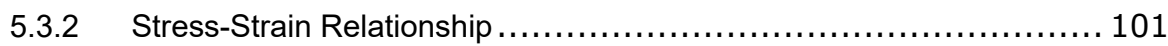

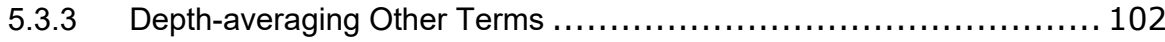

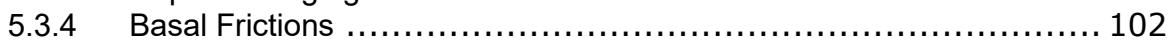

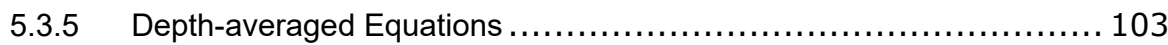

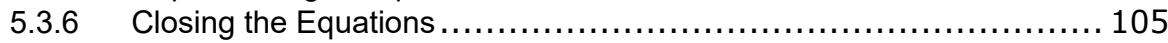

5.4 Implementation in the Material Point Method ...................... 105

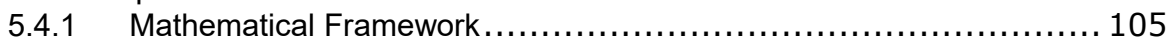

5.4 .2 Particle Placement................................................ 107

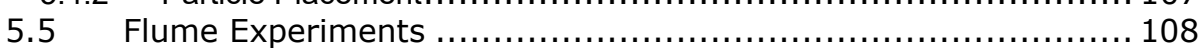

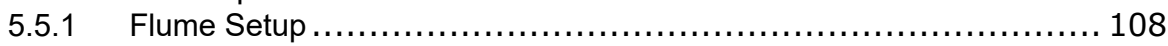




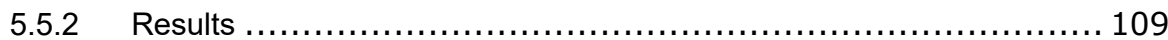

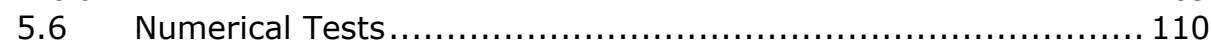

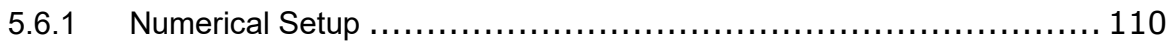

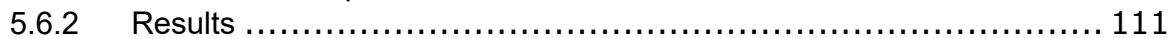

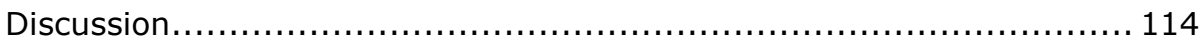

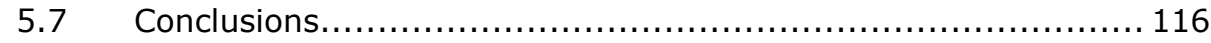

6 Challenges in Physically-based Spatial Modelling of a Landslide Hazard

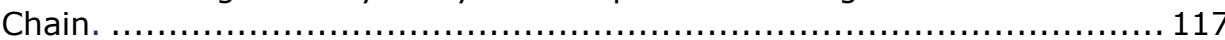

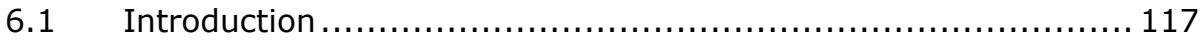

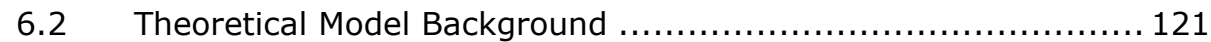

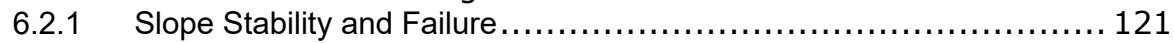

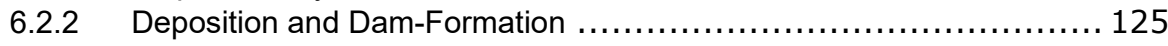

6.2.3 Entrainment Equations ............................................ 126

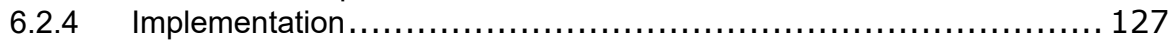

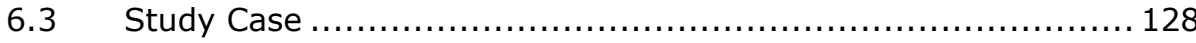

6.3.1 Hongchun Catchment .............................................. 128

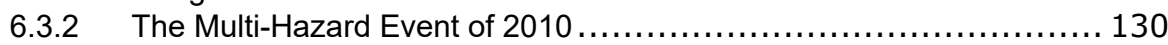

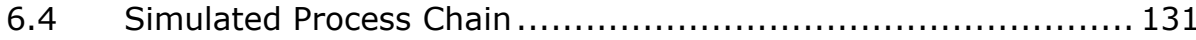

6.4.1 Model Input and Parameters ...................................... 132

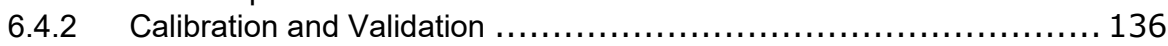

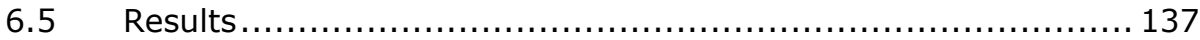

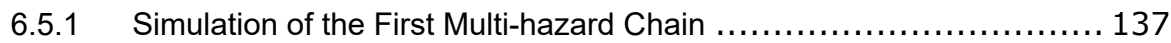

6.5.2 Runout and the Blocking of the Hongchun Stream ...................... 139

6.5.3 Validation of Failure and Runout for the Major Central Landslide Using

Elevation Model Differences .............................................. 141

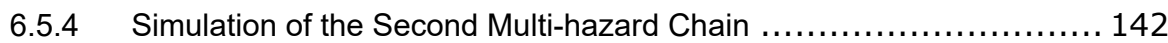

6.5.5 Ensemble Simulations ............................................ 144

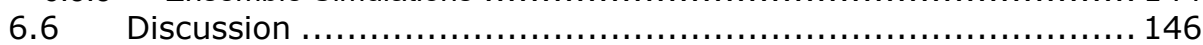

6.6.1 Uncertainties in Modeling the Multi-hazard Chains ..................... 146

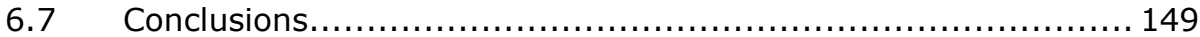

6.7.1 Acknowledgements ................................................. 150

7 Application of Local Time Stepping to Multi-process Catchment

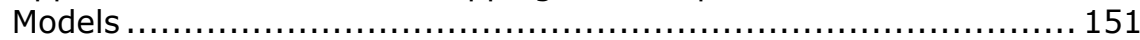

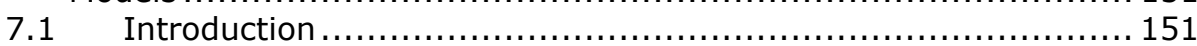

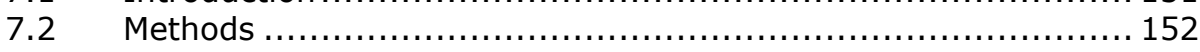

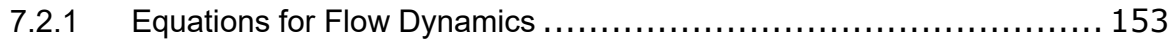

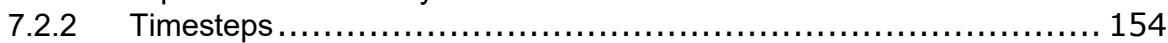

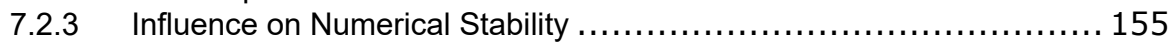

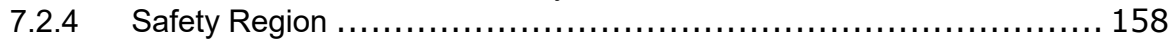

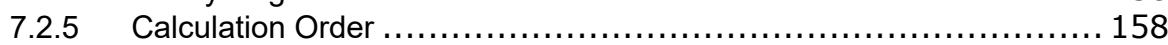

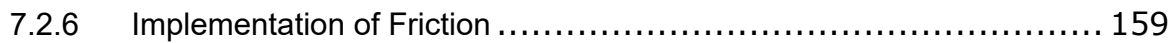

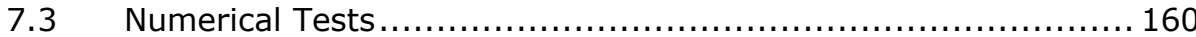

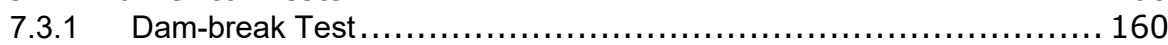

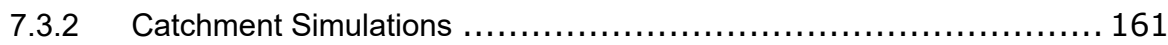

7.4 Results \& Discussion .............................................. 163

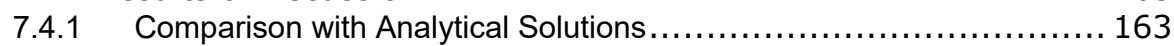

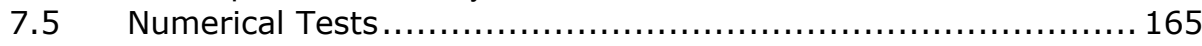

7.5.1 Results Local Time Stepping....................................... 165

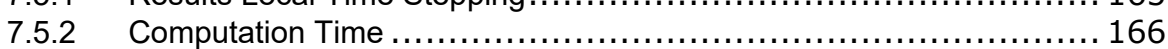

7.6 Application to Multi-Hazard Modelling .............................. 168

7.6.1 Results .......................................................... 169 


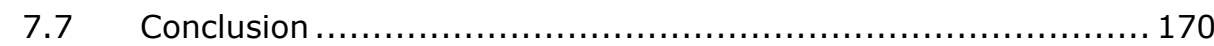

8 Physically-based Simulations for Hydrometeorological Hazard and Risk

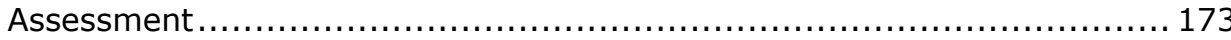

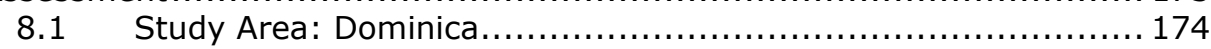

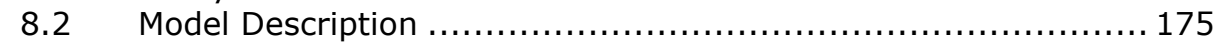

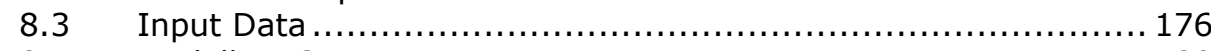

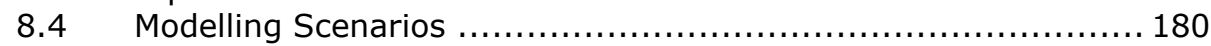

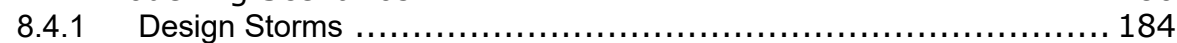

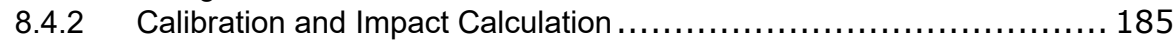

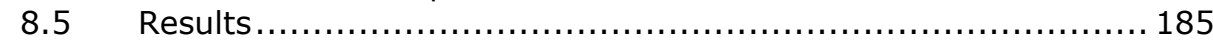

8.5.1 Simulating the Maria Event .............................................. 185

8.5.2 Comparison to Traditional Multi-hazard Approach ....................... 189

8.5.3 Scenario Differences ............................................. 191

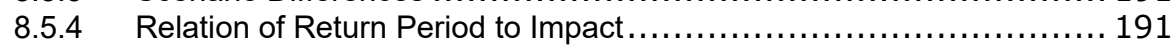

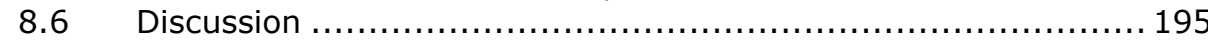

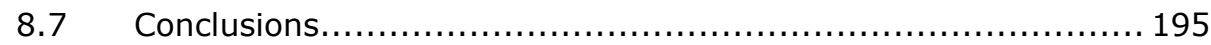

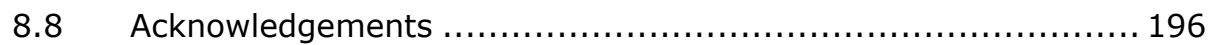

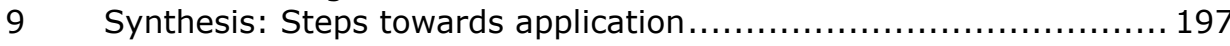

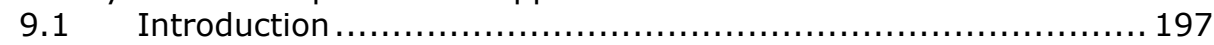

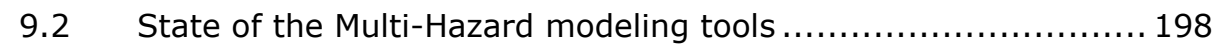

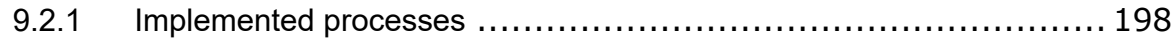

9.2.2 Benefits of integrated physically-based multi-hazard modelling ......... 199

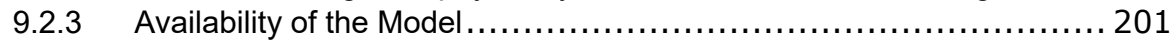

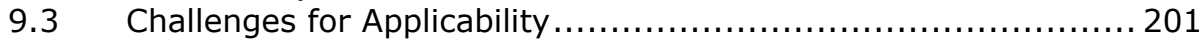

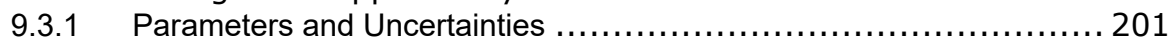

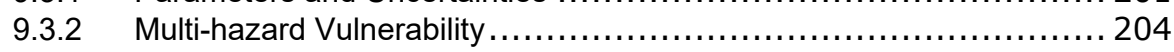

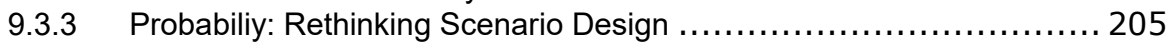

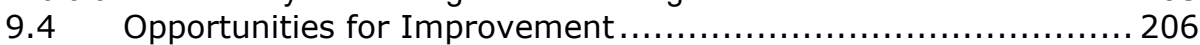

9.4.1 Finishing the Hydro-meteorological Hazard Group ..................... 206

9.4.2 Temporal Integration using Continuous Modelling .................... 207

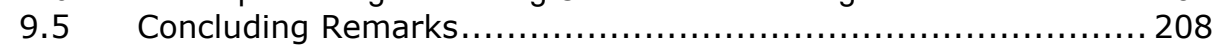

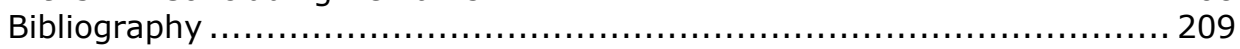

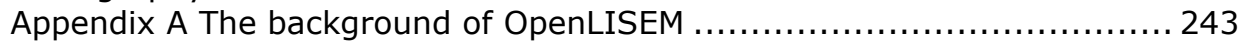

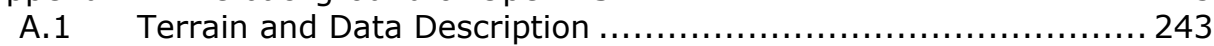

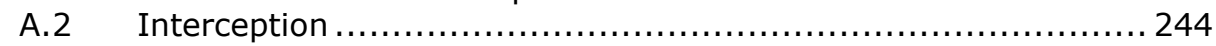

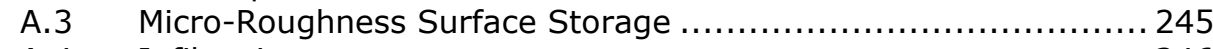

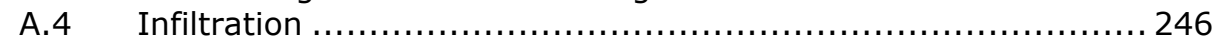

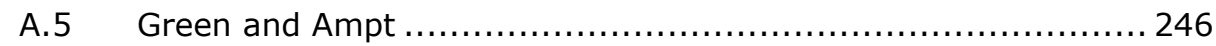

A.6 Saturated Zone Groundwater flow ................................ 246

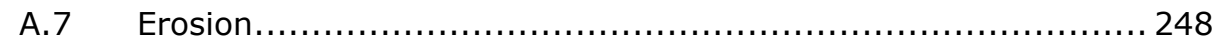

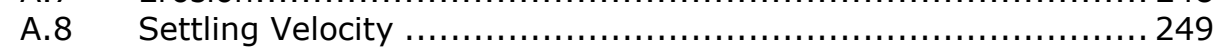

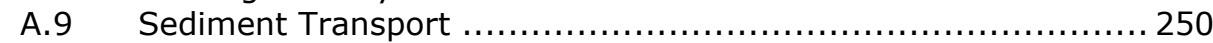

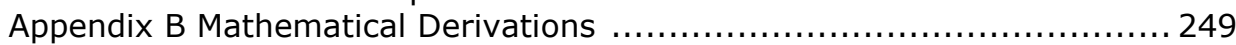

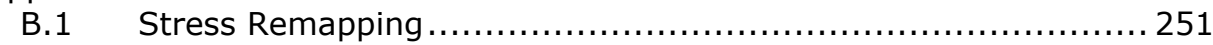

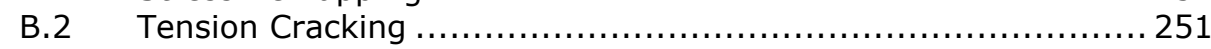

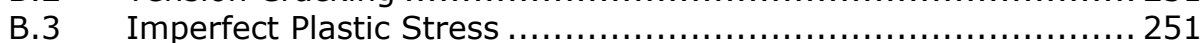

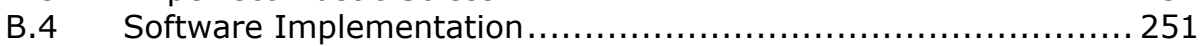

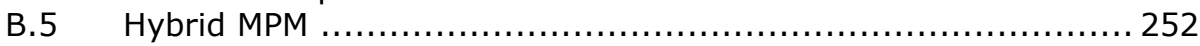

B.6 Finite Element Solution .......................................... 252

B.7 GPU Acceleration Using OpenCL/OpenGL ....................... 253 
Appendix C .

List of Symbols

255

Summary

261

Samenvatting.

263 
FIGURE 1-1 A SIMPLIFIED DIAGRAM OF HAZARD INTERACTIONS, WITH POSSIBLE GROUPINGS OF HAZARDOUS PROCESSES THAT ARE CURRENTLY BEING COMBINED IN INTEGRATED PHYSICALLY-BASED MULTI-HAZARD SIMULATIONS. BLACK LINES INDICATE THE GROUPS WHERE PAST RESEARCH HAS SUCESFULLY PROVIDED LIMITED MULTI-HAZARD APPROACHES. G1 INCLUDES MAJOR SEISMICLY TRIGGERED HAZARDS. G2 INCLUDES MAJOR PRECIPITATION-TRIGGERED HAZARDS. G3 INCLUDES LONG-TERM HYDROLOGY (DROUGHTS IN PARTICULAR) AND WILDFIRES. NOTE THAT NO MODEL CURRENTLY COMBINES ALL PROCESSES IN G2. BLUE ARROWS INDICATE A ONE-WAY LINK, ORANGE ARRAYS SHOW A TWO-WAY LINK.

FIGURE 2-1 THE INPUT DATA FOR OPENLISEM (LEFT), AND A SIMPLIFIED FLOWCHART (RIGHT) ........ 20

FIGURE 2-2 THE MUSCL SCHEME PERFORMS PIECE-WISE LINEAR INTERPOLATION ........................... 21

Figure 2-3 CELL COORDINATES, DISCHARGE AND AN ADVECTED CELL. $\triangle \mathrm{X}$ AND $\triangle \mathrm{Y}$ ARE THE CELL LENGTH

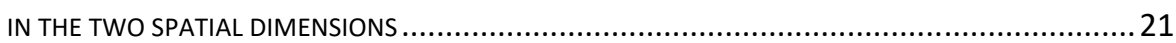

FiguRE 2-4 AN EXAMPLE OF A LOCAL DRAINAGE DIRECTION FILE (KARSSENBERG ET AL., 2001) .......... 22

FigurE 2-5 COUPLING OF OVERLAND FLOW, CHANNEL FLOW AND FLOODING. THE CHANNEL ACTS AS A MAIN LINK BETWEEN THE FLOW DOMAINS.

FIGURE 2-6 AN OVERVIEW OF TOPOGRAPHY SATURATED CONDUCTIVITY AND MANNING'S N FOR THE DANANGOU CATCHMENT.

FIGURE 2-7 AN OVERVIEW OF TOPOGRAPHY SATURATED CONDUCTIVITY AND MANNING'S N FOR THE PRADO CATCHMENT.

FIGURE 2-8 AN OVERVIEW OF TOPOGRAPHY SATURATED CONDUCTIVITY AND MANNING'S N FOR THE FELLA CATCHMENT.

FIGURE 2-9 CALIBRATION RESULTS FROM DIFFERENT FLOW APPROXIMATIONS FOR THE CATCHMENT IN THE LOESS PLATEAU. RAINFALL EVENTS FROM 01-08-1998 (TOP), 20-07-1999 (MIDDLE) AND 23-08-1998 (BOTTOM).

FIGURE 2-10 CALIBRATION RESULTS FROM DIFFERENT FLOW APPROXIMATIONS FOR THE PRADO CATCHMENT. RAINFALL EVENTS FROM 29-09-1997 (TOP), 09-12-2003 (MIDDLE) AND 17-102003(BOTTOM).

FIGURE 2-11 MAXIMUM SIMULATED OVERLAND FLOW DEPTH IN THE DANANGOU CATCHMENT FOR THE 20-07-1999 RAINFALL EVENT.

FiguRE 2-12 OVERLAND FLOW DEPTH FOR THE NORTHERN PART OF THE PRADO CATCHMENT AT IDENTICAL TIMES IN THE SIMULATION FOR THE 17-10-2003 RAINFALL EVENT. ........................... 32

Figure 2-13 MEASURED AND SIMULATED DisChARGE FOR THE 2003 FELLA-BASIN FLOOD EVENT....... 33

FigURE 2-14 FLOOD DEPTH MAPS FOR THE 2003 FELLA-BASIN FLOOD EVENT. USE FLOW APPROXIMATIONS ARE: DifFUSIVE FLOW AND SAINT-VENANT CHANNEL FLOODING (LEFT) AND

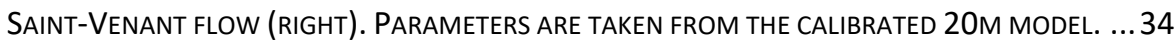

FIGURE 2-15 FLOOD DEPTH TRENDS FOR THE CALIBRATED SETTINGS WITH DYNAMIC WAVE FLOODING IN THREE LOCATIONS IN THE FELLA AREA.

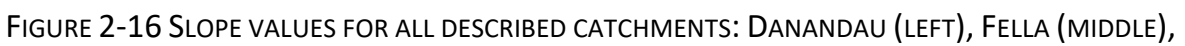
PRADO (RIGHT).

Figure 2-17 Sensitivity ANALYSIS FOR THE 2003 FELLA-BASIN FLOOD EVENT. VALUES INDICATE RELATIVE CHANGE IN OUTPUT VARIABLE COMPARED TO THE CHANGE IN INPUT PARAMETER.........38

FIGURE 3-1 A SCHEMATIC OVERVIEW OF SEVERAL SLOPE STABILITY AND SLOPE FAILURE MODELLING METHODS. FOR ALL OF THEM, VARIETIES EXIST, AND TYPICAL REPRESENTATION IS SHOWN. SOIL DEPTH AND AN EFFECTIVE GROUNDWATER LEVEL ARE SHOWN IN THE TERRAIN DESCRIPTION. IN THE MIDDLE, A FORCE DIAGRAM INDICATES THE ESTIMATION OF LOCAL SOURCES (FD, FC), LATERAL 
INTERACTIONS (FLAT), VERTICAL INTERACTIONS (FVERT), OR A FULL STRESS TENSOR (LI, J). ON THE RIGHT, THE GOVERNING EQUATIONS ARE DISPLAYED. FOR MORE DETAIL ON THE EQUATIONS SEE: 1)MATSUI \& SAN (1992), 2) BOUT ET AL. (2018), 3) BAUM ET AL. (2005), 4) MERGILI ET AL. (2014A), 5,6) SEE SECTION 2.2 AND 2,3 OF THIS WORK, 7) COHEN ET AL. (2009), 8,9) MASE ET AL. (2009). WHERE FoS IS THE FACTOR OF SAFETY (-), C'IS THE EFFECTIVE COHESION INCLUDING MATRIX SUCTION (PA), WB IS THE UNIT WEIGHT MINUS PORE PRESSURE $(\Gamma \cdot 1-\Theta-\Gamma W \cdot \Theta)$ (KG M-1), W IS THE UNIT WEIGHT ( $\Gamma \cdot 1-\Theta+\Gamma W \cdot \Theta))(\mathrm{KG} \mathrm{M-1)}$ ) $\Theta$ IS EITHER THE EFFECTIVE WATER LEVEL, DEPENDING ON THE MODEL EITHER A FRACTIONAL GROUND WATER LEVEL (METERS WATER DIVIDED BY METERS SILL = HGWHSOIL) OR A SOIL MATRIX WATER CONTENT (-), RIJ IS THE DISTANCE FROM THE SPHEROID CENTER TO THE POTENTIAL FAILURE PLANE (M), B IS THE FAILURE PLANE SLOPE ANGLE (RADIANS), H IS THE HEIGHT THE FAILURE PLANE (M), H0 IS THE HEIGHT OF THE BEDROCK INTERFACE (M), DX IS THE WIDTH OF THE COLUMN (M), FUP IS THE LATERAL FORCE FROM UPSLOPE (NM-1), C IS THE FORCE CAPACITY (TOP OF FOS EQUATION) (NM-1), D IS THE UNIT FORCE DEMAND (BOTTOM OF FOS EQUATION) (NM-1), S IS THE SLOPE VECTOR (M M-1), E IS THE Elastic Modulus (PA), G IS THE SHEAR MOdulus (PA), I IS THE STRESS TENSOR (NM-2), $\in$ IS THE STRAIN TENSOR (M), P IS THE DISTRIBUTION OF FIBER STRENGTH (-), S IS THE DEVIATORIC STRESS TENSOR (PA), G IS THE PLASTIC POTENTIAL FUNCTION (-), $\Lambda$ IS THE PLASTIC RATE MULTIPLIER

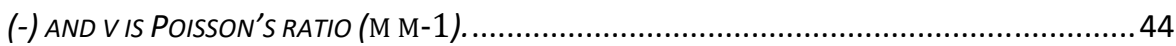

FIGURE 3-2 SCHEMATIC OVERVIEW OF SUBSURFACE FORCES IN THE ITERATIVE FAILURE METHOD.........47

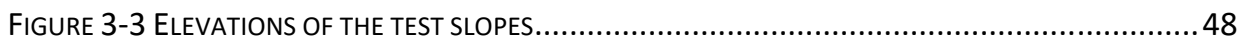

FIGURE 3-4 RESULTS FOR THE FAILURE VOLUME SIMULATIONS USING RANDOM ELLIPSOID SAMPLINGS(LEFT), ITERATIVE SLOPE FAILURE AND ITERATIVE SLOPE FAILURE WITH FORCING (MIDDLE) ANd FINITE ElEMENT Modelling (RIGHT). GREY SHADES REPRESENT THE DENSITY OF UNSTABLE ELLIPSOIDS.

FIGURE 3-5 OVERVIEW OF THE STUDY AREA. LANDSLIDE INVENTORY, ELEVATION MODEL, SOIL DEPTH PREDICTION AND LAND USE AND SOIL CLASSES ARE SHOWN.

FigURE 3-6 PREDICTED FAILURE LOCATION COMPARED WITH MAPPED LANDSLIDES FOR EACH MODEL. A: INFINITE SLOPE B: RANDOM ELLIPSOID SAMPLING; C: ITERATIVE FAILURE WITHOUT FORCING; D: ITERATIVE FAILURE WITH FORCING. TN: TRUE NEGATIVE, TP: TRUE POSITIVE, FP: FALSE POSITIVE 52

FiguRE 3-7 PREDICTED FAILURE DEPTHS IN METERS. A: INFINITE SLOPE B: RANDOM ELLIPSOID SAMPLING; C: ITERATIVE FAILURE WITHOUT FORCING; D: ITERATIVE FAILURE WITH FORCING

Figure 3-8 AREA-FreQuency CURVES FOR THE PREDICTED SLOPE FAILURES AND AREA-VolUME PLOTS FOR THE PREDICTED SLOPE FAILURES. DATA ON THE FREQUENCY AREA DISTRIBUTION CURVES: INVENTORY: ROLLOVER = 80, B=1.82; INFINITE: ROLLOVER = -, B=1.268; RANDOM ELLIPSOID SAMPLING:

FIGURE 3-9 SPATIAL PREDICTION OF ADDITIONAL FORCING FROM UPSLOPE INSTABILITIES FOR THE SCALETTA CATCHMENT.

Figure 3-10 Profile PLOTS THROUGH FOUR SLOPE FAILURES IN THE SCALETTA AREA. BLUE BACKGROUND INDICATES THE PRESENCE OF SLOPE FAILURE IN THE INVENTORY ALONG THE PROFILE. THE PROFILES SHOW THE LOCATIONS OF THE INVENTORY (ABOVE THE TERRAIN) AND THE MODELLED FAILURES (BELOW THE TERRAIN).

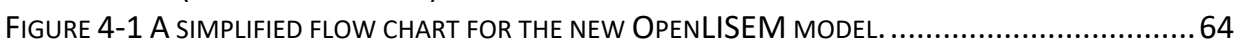

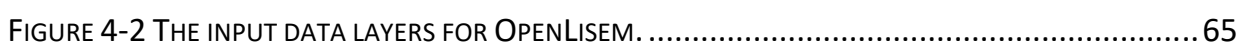

FIGURE 4-3 AN EXAMPLE OF A SIMPLIFIED PHYSICAL DESCRIPTION OF THE SOIL LAYER. .....................67 
FIGURE 4-4 A FORCE DIAGRAM FOR THE LANDSLIDE TOE. AN EQUILIBRIUM POINT MUST EXIST IMMEDIATELY DOWNSTREAM OF THE TOE.

FIGURE 4-5 A 2D EXAMPLE OF THE RESULT OF USING ITERATIVE SLOPE FAILURE WITH A FINITE ELEMENT FACTOR OF SAFETY.

FIGURE 4-6 RAINFALL DATA FOR THE 1-10-2009 RAINFALL EVENT IN SOUTH-WEST SICILY. TEMPORAL RESOLUTION OF THE RAINFALL IS 10 MINUTES. SOURCE:

(HTTP://WWW.OSSERVATORIOACQUE.IT/).

FIGURE 4-7 INPUT DATA FOR THE SCALETTA CATCHMENT. LOCATION (TOP) ELEVATION MODEL AND SOIL TEXTURE (MIDDLE), LANDSLIDE INVENTORY AND LAND USE MAP (BOTTOM).

FIGURE 4-8 THE SPATIAL DISTRIBUTION OF PREDICTED SOIL DEPTH, AND THE CORRELATION BETWEEN PREDICTED AND ESTIMATED SOIL DEPTH

Figure 4-9 IMAges OF THE SCALETTA CATCHMENT BEFORE AND AFTER THE 1-10-2009 EVENT (LeFT). PHOTOGRAPH OF THE GIAMPILLIERI CATCHMENT OUTLET ONE DAY AFTER THE EVENT (RIGHT). ....76

FIGURE 4-10 A COMPARISON OF SIMULATED SLOPE FAILURE WITH THE LANDSLIDE INVENTORY FOR THE SCALETTA CATCHMENT (LEFT). THE SIMULATED FAILURE DEPTH (RIGHT).

FIGURE 4-11 MAXIMUM DEBRIS FLOW DEPTH, BOTH WITH HYDROLOGY (LEFT) AND WITHOUT HYDROLOGY (RIGHT), AND A COMPARISON OF DEBRIS FLOW RUNOUT WITH THE LANDSLIDE INVENTORY, WITH CHANNELS REMOVED (BOTTOM)

FIGURE 4-12 DEBRIS FLOW RUNOUT AND A MASKED COMPARISON OF DEBRIS FLOW RUNOUT WITH THE LANDSLIDE INVENTORY

FIGURE 4-13 FINAL SOLID AND FLUID HEIGHT WITH THE SIMULATION OF A PART OF THE COAST. SIMULATION USES PREDICTED SLOPE FAILURE AND DEBRIS FLOW RUNOUT

FIGURE 4-14 AN OVERVIEW OF SEVERAL PATTERNS IN THE PREDICTED SLOPE FAILURE AND DEBRIS FLOW RUNOUT. A) MOSTLY CORRECT B) OVER-ESTIMATES SMALL SLOPE FAILURE ALONG CHANNEL SIDES C) INITIATION ALONG THE SAME STREAM, BUT NOT CORRECTLY PLACED.

FIGURE 4-15 ONE OF THE LOCATIONS IN THE CATCHMENT WHERE A SHALLOW LANDSLIDE REDUCED FLOW VELOCITIES IN THE CHANNEL, PARTLY BLOCKING FLOW.

FIGURE 4-16 A COMPARISON OF MAXIMUM FLOW HEIGHT FOR THE SCENARIO'S WITH (LEFT) AND WITHOUT (RIGHT) PREDICTED SHALLOW SLOPE FAILURE.

FIGURE 5-1 A SCHEMATIC DEPICTION OF THE FLOW CONTENTS. BOTH STRUCTURED AND UNSTRUCTURED SOLIDS ARE PRESENT. FLUIDS CAN BE EITHER FREE, OR CONFINED BY THE STRUCTURED SOLIDS.......95

FIGURE 5-2 EXAMPLE OF A KERNEL FUNCTION USED AS INTEGRATION DOMAIN FOR MATHEMATICAL OPERATIONS.

FIGURE 5-3 EXAMPLE PARTICLE DISTRIBUTIONS USING THE R_2 SEQUENCE, NOTE THAT, WHILE NOT ALL PARTICLES ARE EQUIDISTANT, THE METHOD PRODUCES DISTRIBUTED PARTICLE PATTERNS THAT ADAPT WELL TO VARYING DENSITY.

FIGURE 5-4 THE DIMENSIONS OF THE FLUME EXPERIMENT SETUP USED IN THIS WORK...................... 109

FIGURE 5-5 A COMPARISON OF THE FINAL DEPOSITS OF THE SIMULATIONS AND THE MAPPED FINAL DEPOSITS AND CRACKS WITHIN THE MATERIAL. FROM LEFT TO RIGHT: PHOTOGRAMMETRY MOSAIC, COMPARISON OF SIMULATION RESULTS TO MAPPED FLUME EXPERIMENT, STRAIN, FINAL STRENGTH FRACTION.

FIGURE 5-6 THE DIMENSIONS OF THE NUMERICAL EXPERIMENT SETUPS USED IN THIS WORK. SETUP 1 (LEFT) AND SETUP 2 (RIGHT)

Figure 5-7 SeVERAL tIME-SLICES FOR NUMERICAL SCENARIOS 2(A/B/C). SEe FIGURE 5-6 FOR THE DIMENSIONS AND TERRAIN SETUP. 
Figure 5-8 SeVeral time-Slices for numerical scenarios 3(A/B/C). See Figure 5-6 for the

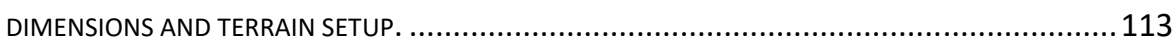

FIGURE 6-1 A SCHEMATIC OVERVIEW OF PROCESSES, FLUXES AND STORAGES WITHIN THE OPENLISEM HAZARD MODEL.

FIGURE 6-2 SUB-SURFACE FORCE DISTRIBUTION IS SOLVED THROUGH ITERATIVELY FINDING A STEADY STATE (FD = DRIVING FORCE, FC = RESISTING FORCE).

FIGURE 6-3 A SCHEMATIC OVERVIEW OF THE OPENLISEM HAZARD MODEL, INCLUDING THE LINK WITH THE MOST RELEVANT INPUT DATA

Figure 6-4 AN OVERVIEW OF THE HONGCHUN WATERSHED: (TOP) HILLSHADE IMAgE WITH CO-SEISMIC LANDSLIDE MAP FROM TANG ET AL. (2016) (BOTTOM) POST-EVENT NATURAL COLOUR COMPOSITE

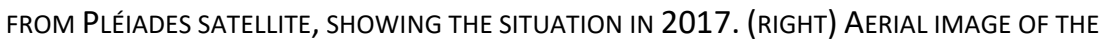
2010 DEB.

FIGURE 6-5 A SCHEMATIC OVERVIEW OF THE STAGES OF THE DESCRIBED EVENT. THE EVENTS FOR SIMULATION 1 OCCURRED DIRECTLY AFTER THE EARTHQUAKE IN 2008. THE EVENTS FOR SIMULATION 2 AFTER THE RAINFALL EVENT IN 2010.

FIGURE 6-6 AN OVERVIEW OF THE INPUT DATA FOR THE HONGCHUN CATCHMENT: ELEVATION MODEL (LEFT), NDVI (MIDDLE), MODELLED SOIL DEPTH (RIGHT)

FIGURE 6-7 SOIL DEPTH SIMULATION RESULTS. (LEFT) A COMPARISON OF PREDICTED VS OBSERVED VALUES. (RIGHT) PROBABILITY DISTRIBUTION FOR OBSERVED AND SIMULATED SOIL DEPTH VALUES. THIS INCLUDES ONLY VALUES AT THE SAMPLE LOCATIONS ( $N=246)$. .135

FIGURE 6-8 A COMPARISON OF SIMULATED SLOPE FAILURE EXTENT WITH MAPPED CO-SEISMIC SLOPE faILURES. (LEFT) OPENLISEM HAZARd ITERATIVE FAILURE METHOD WITH SUb-SURFACE FORCING, (MIDDLE) SCOOPS3D RANDOM SPHEROID SAMPLING. (RIGHT) R.SLOPE.STABILITY RANDOM ELLIPSOID SAMPLING.

Figure 6-9 (A) MAXIMUM LANDSLIDE RUNOUT FLOW DEPTH. (B) THE SIMULATED FINAL DEPOSIT DEPTH OF THE LANDSLIDES. (C) A COMPARISON OF MODELLED LANDSLIDE RUNOUT WITH THE MAPPED LANDSLIDE INVENTORY. (D) INITIATION DEPTH FROM THE SLOPE FAILURE SIMULATION. .............140

Figure 6-10 AN OVERVIEW OF THE CENTRAL LARGEST LANDSLIDE IN THE HONGCHUN WATERSHED. (A) THE SIMULATED FAILURE DEPTH, (B) THE SIMULATED MAXIMUM RUNOUT DEPTH, (C) THE SIMULATED DEPOSITION DEPTH, (D) POST-EARTHQUAKE SATELLITE IMAGE (WORLDVIEW, 2011)

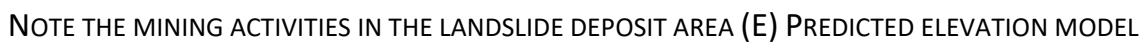
DIFFERENCES DUE TO CO-SEISMIC LANDSLIDES. (F) OBSERVED ELEVATION MODEL DIFFERENCES FROM PRE-AND POST-EARTHQUAKE LIDAR DATA.

FIGURE 6-11 CALIBRATED SIMULATION RESULTS FOR THE SECOND CHAIN IN THE HONGCHUN WATERSHED. (A) MAXIMUM TOTAL FLOW DEPTH; (B) FINAL DEPOSIT DEPTH; (C) ENTRAINMENT DEPTH; (D) RIVER FLOOD DEPTH; ( E \& F): ZOOM OF HONGCHUN OUTLET WITH (E): DEPOSITION DEPTH COMPARED WITH MAPPED EXTENT, (F) RIVER FLOOD DEPTH COMPARED TO MAPPED FLOOD EXTENT; (G \&H) ZOOM OF HONGCHUN LANDSLIDE DAM WITH (G) ENTRAINMENT DEPTH AND (H)MAXIMUM FLOW DEPTH.

FIGURE 6-12 TIME SERIES DATA FOR RAINFALL, TOTAL FLOW HEIGHT AND SOLID FLOW HEIGHT AT THE HONGCHUN OUTLET. REPORTED DEBRIS FLOW OCCURRENCE TIME IS INDICATED AS 'DEBRIS FLOW'. THIS TIME WAS REPORTED IN TANG ET AL. (2011) AS THE INITIAL ARRIVAL OF THE FIRST DISCHARGE.

FIGURE 6-13 ENSEMBLE SIMULATION RESULTS FOR THE HONGCHUN WATERSHED. VISUALIZED IS THE NORMALIZED PROBABILITY, BASED ON THE ENSEMBLE OF RUNS WITH VARYING INPUT PARAMETERS, 
OF THE HAZARD OCCURRING AT EACH LOCATION. (A) CO-SEISMIC SLOPE FAILURE. (B) CO-SEISMIC LANDSLIDE RUNOUT. (C) POST-SEISMIC DEBRIS FLOW DEPOSITION. (D) POST-SEISMIC RIVER

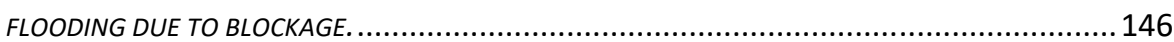

FIGURE 6-14 THE UPSLOPE (LEFT) AND DOWNSLOPE (RIGHT) ADDITIONAL FORCING THAT IS ESTIMATED BASED ON AN ITERATIVE SOLUTION FOR SUB-SURFACE FORCE REDISTRIBUTION.

FIGURE 7-1 SPATIALLY VARYING TIMESTEP VALUES FOR NUMERICAL INTEGRATION OF FLOW EQUATIONS.

FIGURE 7-2 THE DEFINITION OF CELLS, BOUNDARIES, AND CELL BOUNDARY FLUXES.

FIGURE 7-3 THE UNDERESTIMATION OF THE REQUIRED TIMESTEP DUE TO INCOMING FLOW AND MOMENTUM. LEFT: TIMESTEP IN RIGHT CELL IS LARGE DUE TO SMALL FLUXES. RIGHT: TIMESTEP HAS DECREASED DUE TO INCOMING FLOW. THE TIME SINCE THE LAST TIMESTEP IS LARGER THAN REQUIRED FOR STABILITY.

FIGURE 7-4 OVER- AND UNDER-ESTIMATIONS OF VELOCITY DUE TO OSCILLATORY BEHAVIOR OF SEMIEXPLICIT FRICTION AT LARGER TIMESTEPS.

Figure 7-5 Catchment overview for the Fella Basin, Northern Italy. The eleVation model, LAND USE TYPE AND SOIL TEXTURES ARE SHOWN. 162

FIGURE 7-6 AN OVERVIEW OF THE ST. LUCIA CATCHMENT. HILL SHADED ELEVATION, LAND USE AND SOIL TEXTURE ARE SHOWN.

FIGURE 7-7 NUMERICAL SIMULATION OF FRICTION-LESS DAM BREAK USING TRADITIONAL AND SDT SCHEME, COMPARED WITH ANALYTICAL SOLUTION BY RITTER (1892). CELl SIZE FOR SIMULATION: 0.5 METERS

FIGURE 7-8 NUMERICAL SIMULATION OF FRICTION-LESS DAM BREAK USING TRADITIONAL AND SDT SCHEME, COMPARED WITH ANALYTICAL SOLUTION BY RITTER (1892). CELL SIZE FOR SIMULATION: 0.5 METERS .....

FIGURE 7-9 COMPARISON OF A NUMERICAL AND ANALYTICAL SOLUTION OF WATER HEIGHT AFTER A DAM BREAK ON A SLOPED SURFACE. ANALYITCAL SOLUTION BY ANCEY ET AL. (2008).

FIGURE 7-10 MAXIMUM FLOOD DEPTH FOR THE ST. LUCIA SIMULATION, AND THE DIFFERENCE BETWEEN SIMULATIONS WITH A TRADITIONAL AND SDT SCHEME. 165

FiguRE 7-11 MAXIMUM FLOOD DEPTH FOR THE FELLA BASIN SIMULATION, AND THE DIFFERENCE BETWEEN SIMULATIONS WITH A TRADITIONAL AND SDT SCHEME. ....................................... 166

FIGURE 7-12 THE ST. LUCIA HYDROGRAPHS USING TRADITIONAL AND SDT SCHEME SIMULATIONS, AND

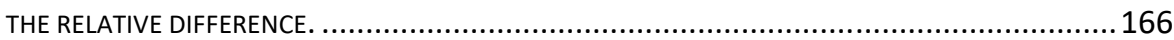

FIGURE 7-13 FLOW HEIGHTS AND LOCAL TIME STEP AT A FIFTH OF THE SIMULATED EVENT. ..............167

FiguRE 7-14 GRAPH OF THE EFFECTIVE TIMESTEP IN THE ST. LUCIA SIMULATION. ............................167

FIGURE 7-15 AN OVERVIEW OF THE TERRAIN, LAND COVER AND SOIL TEXTURE FOR A SOUTHERN

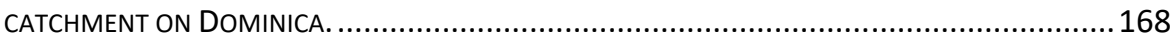

Figure 7-16 PREDICTED FLASH FLOOdING ON DOMINICA FOR THE HURRICANE MARIA EVENT. DIFFERENCES WITH LTS ARE SHOWN.

Figure 7-17 Predicted SLope failure on Dominica for the Hurricane Maria eVEnt. DIFFERENCES WITH LTS ARE SHOWN.

FIGURE 7-18 PREDICTED DEBRIS FLOWS ON DOMINICA FOR THE HURRICANE MARIA EVENT. DIFFERENCES WITH LTS ARE SHOWN.

FiguRE 8-1 RAINFALL INTENSITY MEASURED AT CANEFIELD AIRPORT FOR HURRICANE MARIA. TIME INDICATED IN LOCAL TIME. 
Figure 8-2 RAINFALL PATTERNS FOR HURRICANE MARIA MOVING OVER DOMINICA ON SEPTEMBER 19 (METEO FRANCE).

FIGURE 8-3 FLOWCHART OF THE METHODOLOGY USED FOR ANALYZING CHANGING MULTI-HAZARDS IN DOMINICA, USING A SET OF SCENARIOS WITHIN THE PHYSICALLY-BASED MULTI-HAZARD MODEL OPENLISEM.

FIGURE 8-4 (LEFT) A COMBINED LANDSLIDE/FLASH FLOOD HAZARD CLASSIFICATION MADE AS PART OF THE CHARIM PROJECT. (RIGHT) THE AVAILABLE LIDAR DATA FOR THE ISLAND OF DOMINICA... 177

FigURE 8-5 THE HILLSHADED ELEVATION MODEL (GOVERNMENT OF DOMINICA) , LAND COVER (CHARIM, 2016) AND SOIL TEXTURE MAPS (CHARIM, 2016).

Figure 8-6 AN OVERVIEW OF A FOREST IN SOUTH-EAST DOMINICA. NOTABLE IS THE ABSENCE OF GREEN BRANCHES ON THE TREES DUE TO HURRICANE WINDS, AND INSTEAD THE PRESENCE OF INVASIVE VINES.

Figure 8-7 (TOP) THE MAPPED LANDSLIDES FOR THE HURRICANE MARIA EVENT. HIGHLIGHTED ARE THE HYPOTHETICAL CHECK DAMS AND SLOPE STABILIZATION THAT IS INCLUDED IN THE SIMULATED SCENARIOS TO PROTECT PICHELIN.

FIGURE 8-8 CUMULATIVE RAINFALL FOR EACH OF THE DESIGN RAINFALL EVENTS USED IN THE SIMULATIONS

FIGURE 8-9 SIMULATION RESULTS FOR THE REPLICATES THE IMPACT OF HURRICANE MARIA ON THE GRANDE BAY CATCHMENT ON DOMINICA. COMPARISONS USE NON-CORRECTED DATA............. 186

FIGURE 8-10 PIXEL-BASED COMPARISON BETWEEN PREDICTED MULTI-HAZARD IMPACT AND MAPPED MULTI-HAZARD IMPACT. COMPARISON USES CORRECTED DATA.

FIGURE 8-11 COMPARISON OF LANDSLIDE HAZARD AS ESTIMATED BY THE CHARIM PROJECT WITH MAPPED PROCESSES DURING MARIA.

FIGURE 8-12 THE AREA AROUND PICHELIN FOR SEVERAL OF THE SIMULATED SCENARIOS. SHOWN EVENT IS THE DESIGN STORM WITH A 5 YEAR RETURN PERIOD. HIGHLIGHTED ARE SEVERAL CHANGES CAUSED BY THE SCENARIO SETUPS. 1: INCREASED RUNOUT SINCE PREVIOUS ERIKA LANDSLIDES ARE NOT SUBTRACTED FROM SOIL DEPTH; 2: DECREASED SOLID DEPOSITS ALONG RIVER DUE TO POST-MARIA DRAINING; 3: INCREASED RUNOUT DUE TO FOREST DEATH AND STABILITY REDUCTION. 4: DEPOSITION OF SOLIDS BEHIND CHECK DAM.

FIGURE 8-13 TOTAL OF RELATIVE IMPACT AS INDICATED BY VULNERABILITY CURVES EXPOSED TO CRITICAL IMPACT BY THE MULTI-HAZARD EVENT. LEFT: SCENARIOS ON HORIZONTAL AXIS. RIGHT: YEARLY PROBABILITY ON VERTICAL AXIS.

FIGURE 8-14 A COMPARISON OF MAXIMUM FLOW HEIGHTS FOR THE 10 AND 20 YEAR RETURN PERIOD EVENTS ON THE POST-ERIKA LANDSCAPE. NOTICE THAT, ALTHOUGH GENERALLY, INCREASED RAINFALL LEADS TO INCREASED MAXIMUM FLOW HEIGHT, INTERACTIONS BETWEEN LANDSLIDES, DEBRIS FLOWS AND FLASH FLOODS CAN ALTER THE MAXIMUM HEIGHTS IN COMPLEX WAYS. TWO CASES ARE HIGHLIGHTED NEAR PICHELIN, WHERE THE 10 YEAR RETURN PERIOD EVENT HAS HIGHER MAXIMUM FLOW HEIGHTS. A PROFILE OF FLOW HEIGHTS, SOLID CONTENT AND VELOCITIES ARE SHOWN IN FIGURE 13.

FIGURE 8-15 TIMESERIES OF FLUID HEIGHT, SOLID HEIGHT AND FLUID VELOCITY AT THE LOCATIONS INDICATED NEAR PICHELIN IN FIGURE 11. TIME IS PRESENTED IN MINUTES RELATIVE TO THE START OF THE SIMULATION.

FIGURE 9-1 A SCHEMATIC DEPICTION OF MAJOR NATURAL HAZARD, THEIR TRIGGERS AND INTERACTIONS BETWEEN THEM (SIMPLIFIED BASED ON KAPPES ET AL. 2012). PLACED WITHIN THE 
HYDROMETEOROLOGICAL GROUP IS THE CURRENT SET OF PROCESSES AS IMPLEMENTED WITHIN

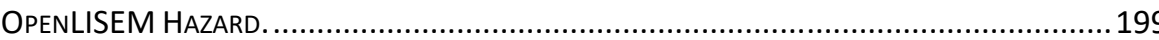

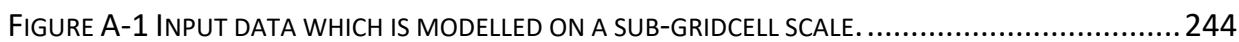

FIGURE B-1 THE SUB-STEPS TAKEN BY THE SOFTWARE TO COMPLETE A SINGLE STEP OF NUMERICAL

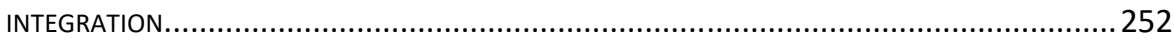

FIGURE B-2 PIECEWISE LINEAR RECONSTRUCTION IS USED BY THE MUSCL SCHEME TO ESTIMATE VALUES OF FLOW HEIGHTS, VELOCITIES AND TERRAIN AT CELL-BOUNDARIES...

FIGURE B-3 BY LIMITING THE KERNEL WITH AND SORTING PARTICLES BEFORE CALCULATION, ONLY THE DISTANCE OF PARTICLES IN NEIGHBORING CELLS NEED TO BE CHECKED, SIGNIFICANTLY REDUCING COMPUTATIONAL LOAD, PARTICULARLY FOR LARGER DATASETS. 
TABLE 1-1: AN OVERVIEW OF EXISTING PHYSICALLY-BASED MODELS AND MODELLING APPROACHES THAT INVOLVE MULTIPLE HAZARDOUS PROCESSES IN AN INTEGRATED MANNER..............................

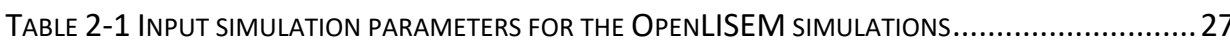

TABLE 2-2 NASH-SUTCLIFFE COEFFICIENTS AND CALIBRATION PARAMETERS FOR THE SIMULATED RAINFALL eVents for the Catchment in the Chinese Loess Plateau. Calibration parameters are RELATIVE TO BASE DATASET VALUE.

ERROR! BOOKMARK NOT DEFINED.

TABLE 2-3 NASH-SUTCLIFFE COEFFICIENTS AND CALIBRATION PARAMETERS FOR THE SIMULATED RAINFALL EVENTS FOR the PRADO CATCHMENT. CalibRation PARAMETERS ARE RELATIVE TO BASE DATASET VALUE.

ERROR! BOOKMARK NOT DEFINED.

TABLE 2-4 THE NASH-SUTCLIFFE CORRELATION COEFFICIENTS FOR THE SIMULATIONS OF THE 2003 FELLA-BASIN FLOOD EVENT. ERROR! BOOKMARK NOT DEFINED.

TABLE 2-5 COMPARISON OF ESTIMATED PEAK DISCHARGES AND SIMULATED PEAK DISCHARGES IN THE FELLA BASIN.

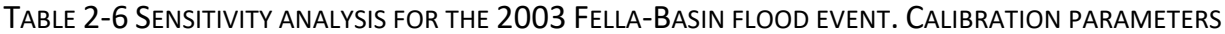
ARE RELATIVE TO BASE DATASET VALUE.

TABLE 3-1 ACCURACY OF THE TESTED SLOPE STABILITY METHODS. ${ }^{1}$ OVERLAP IS DEFINED AS (TP

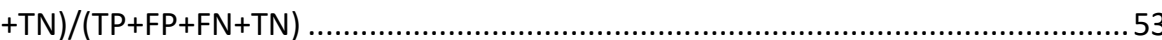

TABLE 4-1 THE DATA USED IN THE MODEL, THEIR SOURCES AND SPATIAL RESOLUTIONS. ..................... 74

TABLE 4-2 MAPS THAT ARE DERIVED FROM THE INPUT DATA MAPS, AND HOW THEY WERE VALIDATED. 74

TABLE 4-3 THE CONSTANTS DERIVED FROM THE STATISTICAL CORRELATION OF SOIL DEPTH TO TOPOGRAPHICAL PARAMETERS.

TABLE 4-4 PERFoRMEd SimULATIONS.

TABLE 4-5 COMPARISON BETWEEN MODEL RESULTS AND THE LANDSLIDE INVENTORY (TP = PERCENTAGE True Positive, TN = True negatives (\%), FP = FAsLe Positives (\%), FN = False negatives (\%))

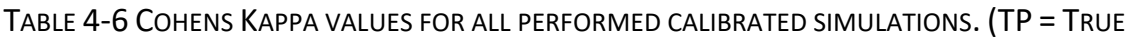
Positive (\%), TN = TRUe negatives (\%), FP = FASLE Positives (\%), FN = FALSE NEgATIVES $(\%))$

TABLE 6-1 LIST OF INPUT DATA AND SOURCES FOR THE MULTI-STAGE MULTI-HAZARD MODELLING WITH OPENLISEM HAZARD.

TABLE 6-2 STRENGTH PARAMETERS FOR THE DEBRIS FLOW MATERIAL IN THE HONGCHUN CATCHMENT (YANG, 2010; HAO ET AL., 2011; LI ET AL., 2011) AND SATURATED HYDRAULIC CONDUCTIVITY. AVERAGE VALUES ARE USED IN THE SIMULATIONS BECAUSE OF THE SPATIAL SIMILARITY OF THE LITHOLOGY AND SOILS.

TABLE 6-3 CALIBRATION PARAMETERS, THEIR INITIAL VALUES AND THEIR FINAL CALIBRATED VALUES FOR BOTH CHAINS. 1INPUT MULTIPLIERS ARE A CALIBRATION PARAMETER THAT MULTIPLIES AN ENTIRE INPUT MAP (SOIL DEPTH, COHESION OR OTHER) BY THIS FACTOR. ..................................... 137

TABLE 6-4 SLOPE STABILITY SIMULATION ACCURACY AND COHENS KAPPA VALUES........................... 138

TABLE 6-5 CONFUSION MATRIX FOR THE LANDSLIDE RUNOUT PREDICTION IN HONGCHUN WATERSHED.

TABLE 6-6 CONFUSION MATRIX, ACCURACY AND COHENS KAPPA VALUES FOR THE DEBRIS FLOW DEPOSITION AND FLOODING OF THE MIN RIVER

TABLE 6-7 PARAMETER SETTINGS FOR THE ENSEMBLE SIMULATIONS.......................................... 145

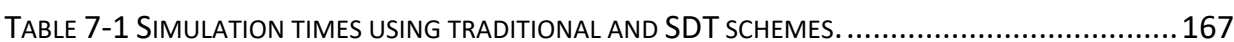

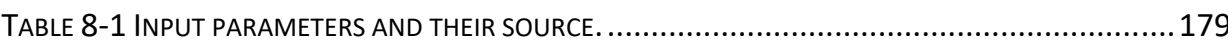




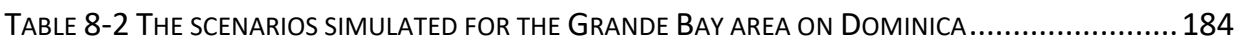

TABLE 8-3 OVERVIEW OF THE AVERAGE MAXIMUM FLUID AND SOLID HEIGHT, AND TOTAL SLOPE FAILURE VOLUMES FOR EACH OF THE SIMULATIONS.

TABLE 8-4 CALCULATED BUILDING IMPACT FOR EACH OF THE DESIGN STORM SIMULATIONS. ACTUAL CUMULATIVE FRACTIONAL DAMAGE FOR HURRICANE MARIA WITHIN THE GRANDE BAY AREA IS 181.35 (WEIGHING BOTH FLOORS AND WALLS AS $30 \%$ VALUE, AND ASSUMING ROOF DAMAGE IS CAUSED BY WIND AND CAN BE IGNORED FOR COMPARISON) 


\section{Definitions}

Slope Stability - The presence of conditions required for a sloping mass to critically fail and mobilize, typically expressed through a mechanical force description.

Slope Failure - The release and consequent mobilization of a section of sloping material acter a critical momentum or force threshold has been exceeded.

Mass Movement - The gravitationally driven dynamics of a mixed volume of solids, fluids and gas down a terrain.

Landslide - Specific type of mass movement referring to

Debris Flow - Specific type of mass movement referring to

Erosion - The mobilization of soil material by fluid flow through fluid-grain interfacial forces.

Entrainment - The mobilization of soil material by solid rich flows through grain-grain interfacial forces.

Runoff - The draining of water over the surface, when further infiltration is limited.

Evapotranspiration - The transfer of water from the soil or other surfaces to the atmosphere by evaporation, or transpiration of water from plants.

Mitigation - A measure taken to prevent a hazardous process from have impact.

Flood - The overflow of large volumes of waters beyond normal values, or on normally dry land

Infiltration - The entering of fluids into a soil driven by gravitation and matrix suction of the soil.

Interception - The capture and temporary storage of precipitation of leaves. Hazard - A phenomenon that can potentially have negative effects on something with value, either physical or abstract (economical, social, environmental or cultural)

Multi-Hazard - The relevance of several distinctly classified hazardous processes including potential interactions.

Risk - The combined sum of potential adverse events that might occur, their probability and their impact.

Impact - The consequences to a specific object of a process.

Modelling - Usage of a representation, either physical, schematic, or mathematical, that describes but is not identical to study a process.

Simulation - The imitation of a process using a model in order to study the process.

Spatially Distributed - Including spatial variation in dynamics

Physically-Based - A mechanical description of a process in terms of physicsbased mathematical equations.

Integrated - Two components coupled in such a manner that interactions are fully included and occur in an organic manner.

Empirical - A data-driven phenomenological or statistical approach to describing a process.

Finite Element Method - A method used for solving partial differential equations by expressing equations in terms of a discretized space.

Parameter - A variable or specific value used in the description of an object, terrain or process.

Vulnerability - The predisposition to be adversely affected. 



\section{Introduction}

\subsection{Introduction}

Natural hazards occur throughout the world, in a variety of environments and with large variation in types (Godschalk et al., 1998). They are a global concern for safety and sustainability, as they cause fatalities and financial damage in nearly all regions of the globe (Nadim and Kjekstad, 2009; Barrantes, 2018; Munich $\mathrm{Re}, 2019)$. The hazardous processes leading to these damages can overlap spatially or temporally, and interact. An example of this can be found in tropical storms that cause storm surges, extreme wind and rainfall, which in turn causes flashfloods, landslides and debris flows, as was experienced on Dominica during Hurricane Maria in 2018 (GDDRF, 2018). Multi-hazard events can result in increased impact, since hazard interactions can amplify hazard intensities, increase the exposure of elements-at-risk and prolong the duration of impact (Marzocchi, 2009; Joel and Bruce, 2014; Barrantes, 2018). The complexity of multi-hazard events has been recognized both in the scientific community and in policy making. Within the research field of natural hazards, the importance of developing an integrated approach to multi-hazard risk assessment has been stressed (Hewit and Burton, 1971; Van Westen and Hofstee, 2000; Van Westen et al., 2002; Bell and Glade, 2004; Grieving et al., 2006; Kappes et al., 2012). Many global and national-scale policy documents have recognized the need for gaining multi-hazard understanding (UNEP, 1992; FEMA, 1995; UN, 2002; UNDP; 2005; Burston et al., 2017). Since the start of the $21^{\text {st }}$ century, an increasing attention is given to multi-hazard risk assessment (Kappes et al., 2012). One of the first documents to call for multihazard action was the UNEP agenda 21 (UNEP, 1992). Later, it was incorporated into policy from the United Nations (UN, 2002) and into the UNISDR global agenda (UNISDR, 2005). Recently, the Sendai Framework for Disaster Risk Reduction 2015-2030 (SFDRR) (UNDRR, 2015) and the UNISDR 2030 agenda heavily stress the importance of integrated multi-hazard approaches in all stages of DRR, including early warning systems (UNISDR,2015).

Multi-hazard events occur when multiple hazardous processes influence the behavior of others in a significant way. Complex and interacting hazardous process chains are typically referred to as multi-hazard events, or cascading process chains depending on the intrinsic nature of the interaction. This intrinsic nature can be categorized based on the causal connection between the individual hazards. When multiple hazards are activated by the same trigger it is a coupled event and can be thought of as parallel activation (Kappes et al., 2012). An example is hurricanes triggering both floods, landslides and storm surges. Alternatively, in a cascading event, there is a chain of activation, where each process triggers a next one, which can be thought of as activation in series (either immediate or deferred). Here, an example is a landslide depositing in a river, which results in landslide dam formation and finally in flooding. Multi-hazard events do not neccesarily consists of a single type of interaction, but instead coupled hazard might cascade and vice versa. Additionally, hazard originating from distinct locations might move from their location of origin and interact. 
A range of multi-hazard dynamics has been studied in the past decades, in particular those with high impact and frequent occurrence, such as multihazard chains related to earthquakes, like tsunamis (Geist and Parsons, 2006; Geist et al, 2016) or co-seismic landslides (Cui et al., 2009; Fan et al., 2019). Also volcanic hazard chain (Marzocchi et al.2009; 2010) and multi-hazards associated with extreme weather events such as tropical storms have been studied extensively (Dupay et al., 2007; Bunya et al. 2010; Bout et al., 2018). Another type is gravitational surface hazards, which includes numerous mass movements and flow types such as flash floods and landslides (Mergili et al., 2018; Bout et al., 2018). Specific hazard interactions have been studied as well, such as Glacial Lake Outburst Floods (GLOF) (Mergili et al., 2018), landslide runout blocking rivers (Fan et al., 2012), the combined occurrence of (flash) flooding and runout of debris flows and landslides (Bout et al., 2018; Destro et al., 2018) and the occurrence of debris flows triggered by wildfires (Nikolopoulos et al., 2018).

In order to provide evidence-based strategies for mitigation and adaptation to the continuous thread posed by natural hazard, hazard and risk assessment is required (van Westen, 2014).

\subsection{Multi-Hazard Risk Assessment}

Multi-Hazard Risk Assessment was defined by Gallina as the assessment of risk arising from multiple hazards, where risk quantifies and classifies potential consequences of hazard events on the investigated areas and exposed elements, combining hazard, exposure and vulnerability. A useful overview of definitions is provided in Gallina et al. (2016). Total risk is calculated as the total average yearly damage from all hazards, which is the multiplication of probability, exposure and vulnerability (Varnes, 1984). Existing frameworks for MHRA contain a variety of strategies to convert the risk posed by individual hazards into a total risk. If the hazardous processes are causally unrelated (Kappes et al., 2012), the total damage is approximated by the integral in equation 1.1 (van Westen et al., 2014). This assumption can be valid for natural hazards that are not related in terms of triggering factors, or causal relationships (e.g. areas impacted by wind and seismic hazard, or other nonoverlapping hazards).

$$
1.1 \quad \mathrm{R}_{\text {Total }}=\sum_{\text {hazard }}\left[\int_{\mathrm{x}} \int_{\mathrm{T}=0}^{\mathrm{T}=\infty} \mathrm{P}(\mathrm{x}, \mathrm{T}) \cdot\left(\sum_{\mathrm{e}=\text { elements-at-risk }} \mathrm{V}_{\mathrm{e}}(\mathrm{I}(\mathrm{T})) \cdot \mathrm{A}_{\mathrm{e}}\right) \cdot \mathrm{dT} \cdot \mathrm{dx}\right]
$$

Where $T$ is the return period of the event, $\mathrm{x}$ is the location, $I(T)$ is the intensity of the event with return period $\mathrm{T}, P(x, T)$ is the probability of the event with return period $\mathrm{T}$ at location $\mathrm{x}, V(I(T))$ is the vulnerability of a specific elementat-risk to the impact of an event with a certain return period and intensity and $A$ is the amount of value for a specific element-at-risk.

The use of equation 1.1 requires the integration of the losses for hazard events with all possible return periods, ranging from frequent small events to very rare extreme events. The integral over the return period (area under risk curve) can be approximated numerically by discretizing return period values and applying a numerical integration scheme such as the trapezoid rule (Davis \& Rabinowitz, 2007). For each hazard event the hazard intensity is recorded for each element-at-risk and translated into degree of loss using vulnerability 
functions for the specific hazard and element type (van Westen et al. 2006; Uzielli et al., 2008).

An important choice when implementing equation 1.1 is the method used to link hazard intensities to probability or return period. Commonly, the analysis of the historical occurrences of the hazardous process are used for frequency analysis (e.g. utilization of a flood record for flood intensity probability estimations). For certain other hazard types, it is possible to obtain return periods through the analysis of the triggering event. For example, the probability of flash floods can be approximated through the frequency analysis of the rainfall events that triggering them and the conditions of the surface (Kay et al., 2006).

When the set of defined natural hazard does interact in some manner, the risk calculation must be altered both in regards to hazard, vulnerability and exposure. Instead of individual hazardous processes, specific chains or groups are used for analysis in order to include interactions and compensate for multihazard events probabilities (Liu et al., 2015). These groups are then activated or induced by a triggering process (trigger). In the past decade, the usage of fault trees or event trees has been proposed (Marzocchi et al., 2009; GarciaAristizabel and Marzocchi, 2013, Van Westen, 2014; Liu et al., 2016). There, the summation over all hazards in equation 1.1 is further specified into hazards chains that can be either one hazard itself, or a set of parallel or series activations. Each of these sets of activations (e.g. paths in the event tree) are then given an individual probability. Estimating these probabilities can be done based on statistical analysis historical records and landscape properties (e.g. through multivariate statistical analysis, principal component analysis (Cutter et al., 2000) or fuzzy comprehensive evaluation (Dixon, 2005)). Using this method, inclusion of multi-hazard chains and interactions gives a more accurate picture of multi-hazard risk. However, the quantification of the individual probabilities in the event tree, and specifically the spatial variation is very difficult in applications that cover larger areas, and do not deal with site-specific risk analysis. For example, the prediction of earthquake-induced landslide dam break out floods for a mountainous area depends on many individual hazard interactions, which are extremely difficult to quantify spatially (Fan et al., 2012b).

Considering vulnerability, issues arise since the total of all damages will lead to double counting (Van Westen, 2014) (e.g. a landslide and flood triggered by the same event can both contribute $100 \%$ destruction leading to a total 200 $\%$ counted damages). Strategies have been proposed (Kappes et al., 2012) to cope with this such as taking the maximum damage of all hazards, or more complex approaches (FEMA , 2011), that calculate the actual damage between the maximum and the sum of all damages $\left(\max \left(V_{1}, V_{2}\right)<V_{\text {actual }}<\min \left(1, V_{1}+\right.\right.$ $V_{2}$ ), limited by the total loss. Ideally, multi-hazard vulnerability functions are required that take into account the multi-dimensional variability of hazard intensity parameters to estimate damage (kappes et al., 2012).

To alter equation 1.1, we thus replace the individual hazard by the summation over triggers that can activate a group of hazardous processes. This leads to different intensity parameters that occur simultaneously, and which are analyzed together with multi-hazard vulnerability functions in the damage calculations. The adapted version of equation 1.1 is shown in equation 1.2. 


$$
\text { 1. } 2 \mathrm{R}_{\text {Total }}=\sum_{\text {trigger }}\left[\int_{\mathrm{x}} \int_{\mathrm{T}=0}^{\mathrm{T}=\infty} \mathrm{P}(\mathrm{x}, \mathrm{T}) \cdot\left(\sum_{\mathrm{e}=\text { elements-at-risk }} \mathrm{V}_{\mathrm{e}}\left(\mathrm{I}_{\alpha}(\mathrm{T}), \mathrm{I}_{\beta}(\mathrm{T}), \mathrm{I}_{\gamma}(\mathrm{T}), \ldots\right) \cdot \mathrm{A}_{\mathrm{e}}\right) \cdot \mathrm{dT} \cdot \mathrm{dx}\right]
$$

Where $I_{\alpha}$ is the first intensity parameter of the hazards caused by the triggering process at time $T, I_{\beta}$ is the second intensity parameter, etc.

\subsection{Defining the Hazard Component}

Defining the hazard intensity in equation 1.1 (for hazard assessment without interactions) or 1.2 (for multi-hazard events) is generally done using either statistical or physically-based modelling. For many types of hazard (e.g. flooding, storm surge, wind..) hazard assessment generally involves physically-based modelling, as it has proven to be valuable approach for the assessment of natural hazards (van Westen, 2014). This group of techniques can predict the dynamics of hazardous processes using either empirical or physically-based equations. The physical properties of the process (e.g flow height, velocity or density) can be directly correlated to physical damage with an appropriate vulnerability curve. Physically-based models are generally able to provide more insight into the underlying causes of hazardous processes and how physical parameters affect their behavior (Wainwright and Mulligan, 2002). Additionally, they are generally better able to model the changes resulting from future climate and land use change scenarios and risk mitigation alternatives (Terzi et al., 2019). International guidelines on DRR such as the Sendai Framework have noted the importance of empirical or physically-based spatial modelling (UNISDR,2015).

Physically-based simulations can occur on a variety of spatial and temporal scales. Site or local-scale simulations focus on specific areas where a process is active (e.g. a bridge, building, single landslide runout area or street) (Ernst et al., 2010). Regional modelling approaches are taken to cover an area that contains more than a single object and process of interest. Here, river basins, sub-catchments and slope units can be typical study areas (Braud et al. 2014). Finally, national-scale simulations cover full countries, and generally contain multiple river basins.

A variety of modelling applications have become standard practice in the assessment of singular hazards. These include hydrology and flood modelling tools such as HEC-RAS (Brunner, 2010) or OpenLISEM (De Roo \& Jetten, 1999; Bout et al., 2018), mass movement runout models such as RAMMS (Bartelt et al., 2013) and Flo-2D (O'Brien, 2006), landslide initiation models such as TRIGRS (Baum et al., 2002) and SIMTOP (Lee \& Ho, 2009), slope failure surface models such as Scoops3D (Reid et al., 2014) and r.slope.stability (Mergili et al., 2012). Tsunami wave models have been developed for local (Baba et al., 2015) and global application (Geist et al., 2016). Storm surge simulations similarly exist at both local scale (Tho Sao, 2008) and global scale (Vousdoukas, 2018). Hurricane models exist in numerous varieties, typically used for real-time forecasting, such as HWRF (Liu et al., 2006) and GDFL (Kurihara, 1995). Seismic and Vulcanic hazard models are predominantly understood in probabilistic hazard assessment (Jordan et al., 2011; Cipta et al., 2017; Marzoghi et al., 2010). However, here physically based models are similarly making their way into common practice. Examples are volcanic hazard models for pyroclastic flow runout (Ciona et al., 2003), or ash deposits (Searcy 
et al., 1998). Other examples are seismic wave propagation models such as SpecFem3D which have been used successfully for detailed simulation of ground shaking motion (Komatitsch et al., 2010).

The methods mentioned above focus on isolated natural hazard, and simulate their behavior while ignoring possible interactions. Given that interactions between hazards do not occur, these models can be applied to multi-hazard and risk assessment. Each of the simulated events coincides with a specific probability, and for each event, the simulations provide a spatial indication of hazard intensity (Gallina et al., 2016). Usage of these models can introduce significant errors if multi-hazard interactions do occur. For example, simulations of floods and debris flows can be performed using separate modelling tools to predict peak flow height of both processes. However, in case of interactions between the two, the dynamics of the event are not captured by the governing physics of either one of the processes. Hazard Interactions can thus require distinct multi-hazard modelling tools since interactions significantly alter the behavior of an event.

An additional aspect of multi-hazard modeling that has to be taken into account is the landscape on which the hazardous process occurs. The physical properties of this landscape can determine the dynamics of hazardous processes, and vary continuously. Changes in, for example, soil water conditions, vegetation characteristics, and soil material can vary seasonally (e.g. ground water or vegetation properties) due to slow processes (e.g. soil weathering) or based on earlier hazards (e.g. landslides alter distribution of slope material and destroy vegetation) (van Beek, 2002). When a hazardous process induces another through landscape changes it be thought of as a deferred cascading event. An example of this can be found in wildfires, that change the vegetation and soil characteristics, making the landscape more susceptible to erosion or debris flows. Hazard and risk assessment must thus take into account both properties of the trigger (e.g. storm) as well as the state of the landscape. Changes in a landscape caused by a previous hazardous event alter the hazard and risk in the future. After natural hazard alter the landscape, risk might therefore need to be re-assessed.

A thorough review of multi-hazard interactions, their nature and type are provided by Gill and Malamud (2014) and Gill and Malamud (2017) (See Figure 1-1). 


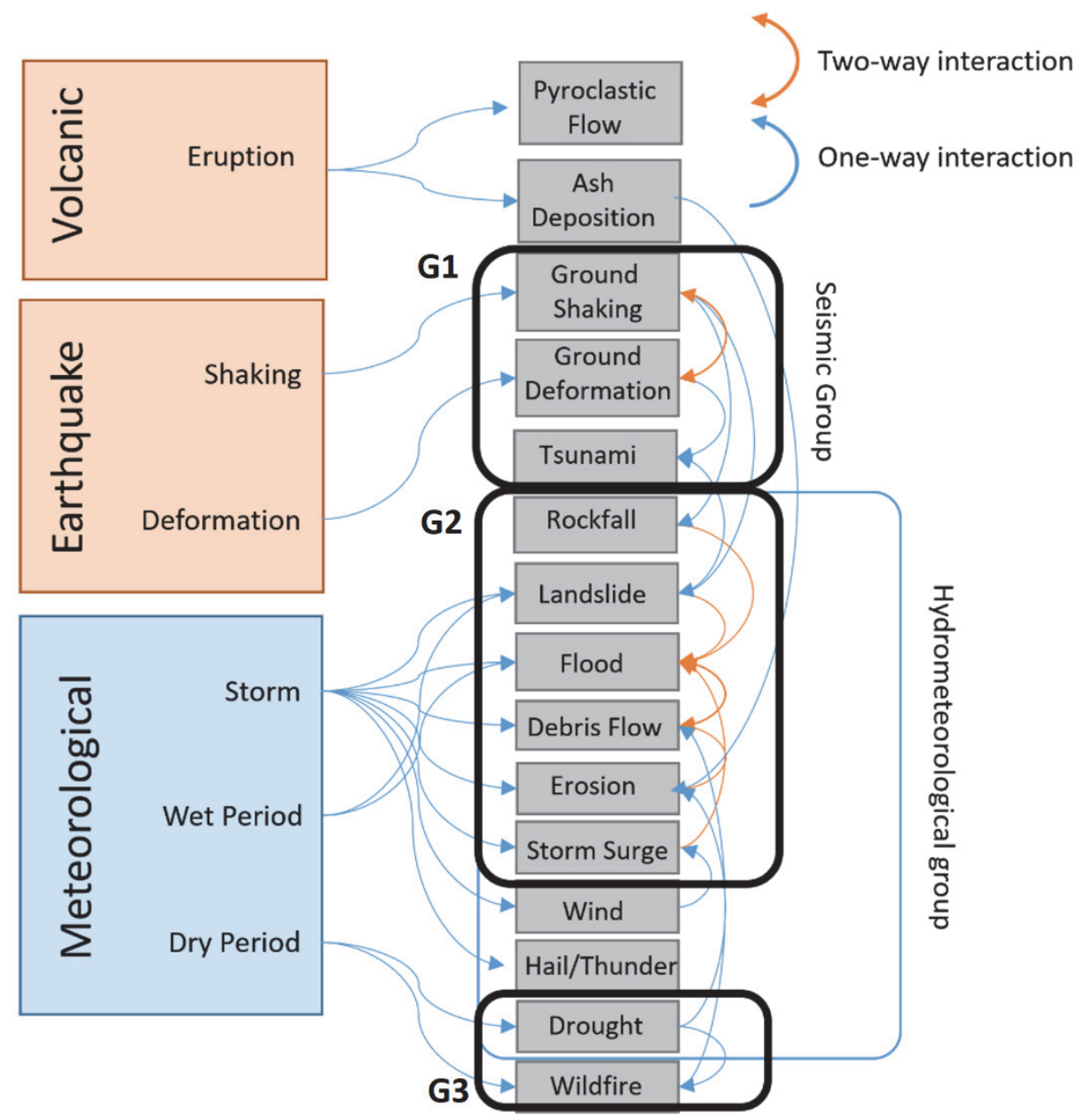

Figure 1-1 A simplified diagram of hazard interactions, with possible groupings of hazardous processes that are currently being combined in integrated physically-based multi-hazard simulations. Black lines indicate the groups where past research has sucesfully provided limited multi-hazard approaches. G1 includes major seismicly triggered hazards. G2 includes major precipitation-triggered hazards. G3 includes longterm hydrology (droughts in particular) and wildfires. Note that no model currently combines all processes in G2. Blue arrows indicate a one-way link, Orange arrays show a two-way link.

The lack of multi-hazard models for hazard (and risk) assessment to complex multi-hazard events has led to a number of problems (Kappes et al., 2012; Liu et al., 2016). If a multi-hazard modelling tool is not used, the varying dynamics of the processes are lost, leading to a simplified depiction of the actual hazards. Moreover, when gravitational surface hazards merge (floods, flash floods, debris flows, mud flows, landslides, soil slips etc..) the resulting dynamics might be beyond their original classification. Using multi-hazard models could increase understanding in the way in which these interactions influence the final risk (Wainwright and Mulligan, 2002). Thus, hazard assessment using 
physically-based modelling must attempt to implement interactions between hazardous processes within its framework. Since multi-hazard interactions are often complex, and were traditionally not well-represented in physically-based modelling, the statistical approach had significant practical advantages. However, in the past decade, increased understanding of the physical principles at work, numerous interactions are now understood at a level where inclusion in a physically-based model is possible, as will be discussed in the next section.

\subsection{Towards Integrated Multi-hazard Physically- based Modelling}

In the past decade, a series of fundamental developments have introduced new innovations and methods into the field of physically-based modelling of multi-hazard events. There are a number of recent developments, particularly related to hydro-meteorological hazards, that may lead to important improvements in multi-hazard risk assessment:

1. The move towards regional physically-based modelling of rainfall-runoff, channel flow and inundation in an integrated manner. Due to increased availability of computational power and availability of detailed data, flood modelling setups can include entire catchments, for example by clumping of upslope areas or empirical relationships to reduce model complexity (Bravo et al., 2011; Nguyen et al., 2016; Huxley and Syme, 2016). Others utilize a regular grid to perform a physically-based simulation of hydrology, flow and flooding at a detailed resolution (OpenLISEM; Bout and Jetten, 2018).

2. The development of regional landslide failure surface models, which search a terrain for potential slip surfaces, and can predict probability of failure together with the depth of the failure surface on a regional scale. Examples of such models are Scoops3D (Reid et al., 2015) and r.slope.stability (Mergili et al., 2014).

3. Improved regional prediction of soil water behavior, combined with limit equilibrium modelling for shallow failures, that incorporate runout. This allows for substantially faster simulations, incorporating both antecedent moisture conditions and the effect of extreme precipitation. Whereas most applications use infinite slope models, which do not allow to analyze deepseated landslides, nor failure volume, recent developments open up these possibilities, such as the Fibre Bundle Model (Cohen et al., 2009), Iterative Failure Method (Bout et al., 2018) and models such as SIMTOP (Lee and Ho, 2009). Additionally, the failure component has been linked with runout of the induced mass movements (Fan et al., 2017; Bout et al., 2018).

4. The refinement of modelling techniques for non-newtonian flows. Nonnewtonian type flows, such as Bingham-plastic, pseudoplastic and Herschel-Bulkley describe complex constitutive models for flow processes. Such types of rheologies are common for gravitational surface flows (Pudasaini, 2012). Efficiently and accurately predicting their behavior has been done for both small and large scale simulations (Vuong et al., 2019; Han et al., 2019). However, these flows have not been coupled with other catchment-scale processes that influence multi-hazard behavior. For example, runoff resulting in sediment rich floods. This limits applicability 
5. The development of flow models that implement rheologies with support for wide ranges of mass movement types and their interactions, specifically the development of equations for two-phase solid fluid mixture flows. These equations of internal solid-fluid interactions and drag forces are based on the contents of the mixture and can deal with flows colliding, mixing and interacting. When the forces change magnitude, the effective rheology is altered in real-time (Pudasaini and Hutter, 2003; Pitman and Lee, 2005; and Pudasaini, 2012). Another approach to the two-phase flow interactions, using dynamically evolving dilatency, has been developed by Iverson and George (2014). In the past several years, this has led to a variety of two-phase flow equations supporting behavior in complex runout scenarios (Iverson et al., 2015), landslides hitting reservoirs (Mergili et al., 2017), lake outburst floods (Mergili et al., 2018), and events including mass movement and (flash) flooding (Bout et al., 2018).

6. The development of modelling techniques for self-altering flows, specifically the effect of entrainment on debris flow initiation. The physical properties of flows, e.g. mixture consistency and density, can change due to entrainment (Frank et al., 2015). Recent models simulate a combination of water flow and the initiation and runout of debris flows through erosion and entrainment (Chen and Zhang ,2015; Hu et al., 2016; Melo et al., 2018; Ouyang et al. , 2018).

7. The combined assessment of inland and coastal water dynamics, to model the effect of storms where storm surge interact with fluvial flooding, increasing the level of flooding in the river mouth (Chen and Liu, 2014; McGuian et al., 2015). Recent models utilize a full water flow description in a flexible $2 \mathrm{~d} / 3 \mathrm{~d}$ domain and a computational grid with a flexible triangular mesh. Examples of such approaches can be found in McGuian et al. (2015), Ikeuchi et al. (2017), Yin et al. (2016) or Chen and Liu (2014).

8. The quality of simulated earthquake-induced ground acceleration, leading to improved accuracy when simulating interactions with other hazardous processes, such as tsunamis (De Risi and Goda, 2017; Goda and De Risi, 2018). A second example is the simulation of slope failure based on seismic accelerations for local (Tiwari et al., 2015a; Tiwari et al., 2015b), or regional application (Locat et al., 2016; Raghukanth et al., 2012). Studies can use specific earthquake scenarios, combined with seismic wave simulation, in order to predict possible future impact (Liu et al., 2018).

For nearly all of the research mentioned above, there have been major improvements data availability and computational power in the last decades. Advances in data quality for elevation and physical terrain properties were required for the successful innovation of the regional physically-based modelling methods. Simulations of integrated multi-hazard events requires large computational power. For example, integration of catchment runoff in a flood model can require simulation of the Saint-Venant shallow flow equations for all flow, while the faster kinematic flow assumption provides accurate results when only runoff is simulated (Bout and Jetten, 2018).

Using the developments mentioned above, research has started to move towards physically-based models for simulation of multiple simultaneous hazardous processes. We use the term "multi-hazard model" to refer to a model that simulates at least more than one hazardous process in an integrated manner. A single hazardous process is considered in traditional categories such as used by Gill and Malamud (2017). A more significant issue 
occurs with the term "all-hazard model", as claiming a full coverage of all possible processes and their interactions is an extraordinary difficult claim to prove, effectively rendering the term unusable. Table 1-1 gives an overview of integrated physically-based multi-hazard models that can be applied at regional (non-site investigation) scale, according to hazard types.

Table 1-1: An overview of existing physically-based models and modelling approaches that involve multiple hazardous processes in an integrated manner.

\begin{tabular}{|c|c|}
\hline Hazard Types & Available Regional Models \\
\hline $\begin{array}{l}\text { Storm Surge (coastal } \\
\text { waves), Wind }\end{array}$ & $\begin{array}{l}\text { Bunya et al. (2010), Janekovic et al. (2015), Xie } \\
\text { et al. (2016) }\end{array}$ \\
\hline Drought, Wildfire & $\begin{array}{l}\text { Taufik et al (2017), Miller et al (2017), Atchley et } \\
\text { al (2016) }\end{array}$ \\
\hline Wind, Windthrow & Dupay et al. (2007) \\
\hline Storm Surge, Fluvial Flood & $\begin{array}{l}\text { McGuian et al. (2015), Ikeuchi et al. (2017), } \\
\text { Yin et al. (2016) } \\
\text { Chen and Liu (2014) }\end{array}$ \\
\hline $\begin{array}{l}\text { Seismic and Wind on } \\
\text { buildings }\end{array}$ & Suksuwan and Spence (2018) \\
\hline $\begin{array}{l}\text { Tsunami, } \quad \text { Submarine } \\
\text { Landslide }\end{array}$ & $\begin{array}{l}\text { Lynett and Liu (2002), Kirby et al. (2016), } \\
\text { Yavari-Ramshe and Ataie-Ashtiani (2016) }\end{array}$ \\
\hline Flood, Erosion & $\begin{array}{l}\text { Delft3D (Delft-Hydraulics, 2006), Hu et al. } \\
\text { (2009) }\end{array}$ \\
\hline WildFire, Debris Flow & Rengers et al. (2016), McGuire et al. (2018) \\
\hline $\begin{array}{l}\text { Siesmic, Ash } \\
\text { Landslide, Lahar }\end{array}$ & Bernal et al. (2017) \\
\hline $\begin{array}{l}\text { Slope Failure, Mass } \\
\text { Movement }\end{array}$ & Flow-R (Horton et al., 2013) \\
\hline Hydrology, Slope Stability & $\begin{array}{l}\text { PROBSTAB+STARWARS (van Beek, 2002), } \\
\text { TRIGRS (Baum et al., 2002), CHASM (Grelle et } \\
\text { al., 2013), iCRESTRIGRS (Zhang et al., 2016), } \\
\text { GeoTop (Formetta et al., 2016), Tao and } \\
\text { Barros (2014) }\end{array}$ \\
\hline $\begin{array}{l}\text { Hydrology, Slope Stability, } \\
\text { Seismic }\end{array}$ & Hess et al. (2017) \\
\hline $\begin{array}{l}\text { Hydrology, Slope Stability, } \\
\text { Slope Failure }\end{array}$ & r.slope.stability (Mergili et al., 2014) \\
\hline $\begin{array}{l}\text { Hydrology, Slope Stability, } \\
\text { Slope Failure }\end{array}$ & $\begin{array}{l}\text { Step-Tramm (Fibre-Bundle Model), (Ruette et } \\
\text { al., 2013) }\end{array}$ \\
\hline $\begin{array}{l}\text { Hydrology, Slope Stability, } \\
\text { Slope Failure, Mass } \\
\text { Movement }\end{array}$ & Fan et al. (2017) \\
\hline $\begin{array}{l}\text { Hydrology, Slope Stability, } \\
\text { Slope Failure, Seismic }\end{array}$ & Scoops3D (Reid et al., 2015) \\
\hline $\begin{array}{l}\text { Runout of several types of } \\
\text { mass movements }\end{array}$ & $\begin{array}{l}\text { r.avaflow (Mergili et al., 2017), RAMMS } \\
\text { (Christen et al., 2010), Flo-2D (O'Brien et al., } \\
\text { 1993), DualSPHysics (Canelas et al., 2013), } \\
\text { Gao et al. (2018) }\end{array}$ \\
\hline
\end{tabular}




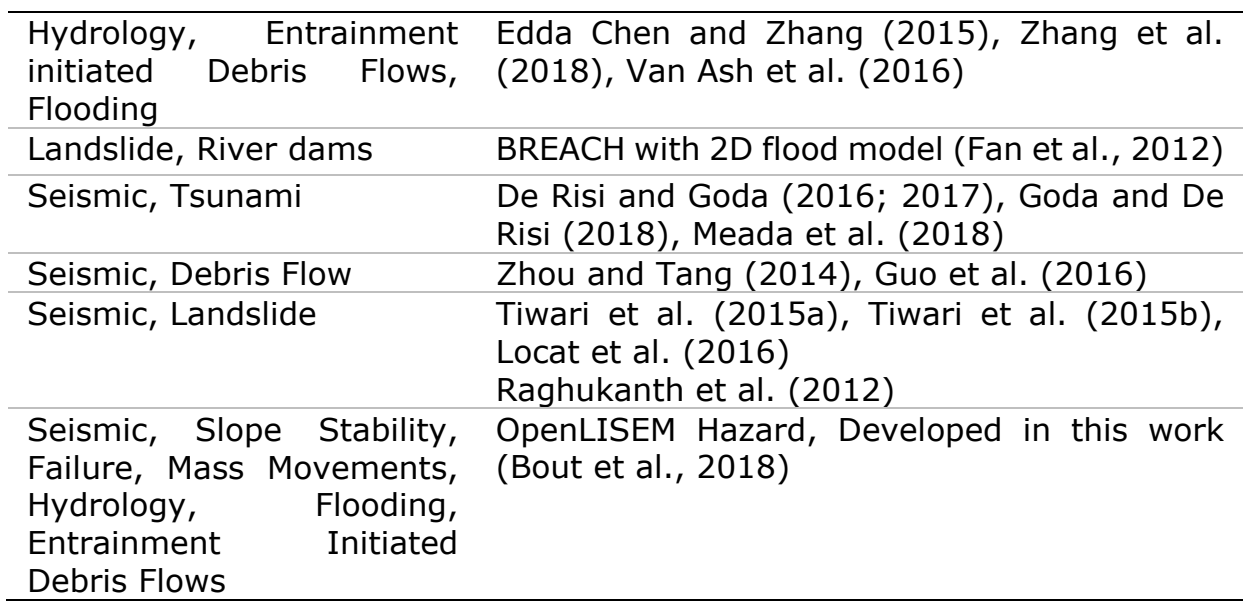

Implementation of integrated multi-hazard modelling into a hazard and risk assessment framework is not straightforward. In order to better consider multi-hazard interactions, specific combinations of hazards might be grouped for integrated analysis. These hazards should have a certain relationship, either because they appear in chains, are linked to the same trigger, or are affecting the same area at the same time. Ideally, a chosen group should not have any two-way links move in and out of its confined hazards.

Figure 1-1 gives three examples of groups of hazards that are currently being combined in modelling: earthquake related hazards, drought and wildfires, and hydro-meteorological surface hazards. The modelling of these processes in separate groups is logical as the main triggers (earthquakes, extreme rainfall and drought) are likely be independent events. Despite this, these groups are not strictly disconnected. For example, earthquakes can induce landslides which in turn may cause debris flows or dam rivers, leading to breakout floods. These interactions can be accounted for by using the simulation of the hydrometeorological group with an earthquakes ground motion as input. Similarly, droughts are very much related to long-term hydrology and rainfall records, and their influence in wildfires can lead to a higher susceptibility to debris flows. For this reason, the full hydrometeorological hazard group might be an effective final candidate for multi-hazard integration.

Currently available modelling techniques typically combine only several hazardous processes. In the sections above we have presented a detailed motivation for moving towards fully integrated physically-based multi-hazard modelling of, for example, the hydrometeorological hazard group. In this work, some significant steps in this direction are carried out.

\subsection{Problem Statement}

As stated above, integrated multi-hazard modelling can enhance understanding and accuracy for Hazard and Risk assessment. This in turn benefits decision making for DRR. Several key building blocks for multi-hazard modelling are already present within the literature. In particular, many aspects of hydrometeorological surface hazard are well understood on an individual level. Therefore, this group of hazardous processes will be the focus of this 
work. Despite the recent progress in this field, several fundamental issues impede the potential for fully integrated multi-hazard modelling. The common problem is insufficient integration between individual methods and techniques and thus a lack of fully integrated simulation tools for multi-hazard events. The creation of an integrated methodology that incorporates several hazardspecific techniques faces several additional issues, which will be addressed throughout this work. These issues can be divided into five primary categories: i) Spatial Integration ii) Process Integration iii) Feedbacks iv) Self-evolving dynamics v) Parameterization.

\section{Spatial Integration}

In order to allow individual hazardous processes to interact with others, the full spatial domain of all relevant hazards must be incorporated (Kappes et al., 2012). For hydrometeorological surface hazards, the catchment designates a suitable isolated subset of space where multihazard interactions will not exceed the boundaries (van Beek, 2002). Current modelling approaches only integrate floods or debris flow simulations with catchment-scale processes in a simplified manner (Baum et al., 2002; Bravo et al., 2011). To provide a fully integrated multi-hazard methodology, a fully spatially-distributed approach must be developed. Additionally, other processes such as slope failures and landslides must be integrated.

II. Process Integration

Once the catchment-scale spatial domain is realized, numerous relevant processes that act within this domain must be implemented to provide a full multi-hazard methodology. Current techniques are generally limited to one or several hazardous processes. Examples are hydrology and erosion (Delft-Hydraulics, 2006), floods and hydrology (Bravo et al., 2011) or debris flows (Christen et al., 2010). Integration of erosion, floods, slope failures and mass movements could provide a stronger foundation for simulation of multi-hazard events (van Beek., 2002; Chen \& Zhang, 2015; Mergili et al., 2017; Fan et al., 2017).

III. Feedbacks

For the various processes and interactions that might arise in a catchment, feedback processes become relevant. Feedbacks are circulary dependent, sometimes voletile types of interacting process chains. Examples are erosive processes such as entrainment. Entrainment alter the consistency and momentum of the flow, which in turn alters erosive processes (van Asch et al., 2016). While feedbacks are implemented in various physically-based modelling tools, they provide a challenge for the stability of multi-hazard methods (DelftHydraulics, 2006; Zhen \& Chang, 2015).

IV. Self-evolving dynamics

For accurate hazard assessment, it is important to correctly predict flow types and properties. Due to multi-process interactions and feedbacks, hazardous processes can show self-altering or evolving behavior (Pudasaini, 2012; Iverson \& George, 2014). For example, landslides can fragment, or dilute while interacting with terrain or other flow bodies (Dufresne et al., 2018). As a result, the landslide can evolve into 
rockfalls, debris flows or other types of mass movements. Such types of behavior have been implemented in models using two-phase generalized flow equations (Chen \& Zhang, 2015; Mergili et al., 2017). However, the self-evolving dynamics have not been linked with multi-hazard interactions or catchment-scale processes. Additionally, no depthaveraged mass movement models implement runout of arbitrarily structures material and fragmentation.

\section{Parameterization}

Finally, the additional complexities arising from capturing multiple hazardous processes and interactions in a single methodology can increase the number of parameters required. This can degrade applicability and increase uncertainty in the ouput of a model (Berbic et al., 2016). Quantification of such uncertainties is required to be able to provide appropriate interpretation of model outcomes (Haynes et al., 2007; Hagemeier-Klose \& Wagner, 2009).

\subsection{Research Questions}

The general objective of this thesis is to develop an integrated physically-based modelling method that includes key hazardous processes from the hydrometeorological hazard group. The development of this method will be done by continuously validated extension of a regional, event-based modelling tool for hydrology, runoff and erosion. Within this thesis, we present the development by means of answering successive research questions related to the problems stated in the section above. Each research question attempts to answer part of the problems that have been identified.

I. How do flood approximations influence flood model accuracy and efficiency when integrated into spatially distributed hydrology?

II. What is the most effective approach to linking real-time simulation of hydrology with slope failure volume prediction?

III. To what extent can strong coupling of multi-phase generalized mass movement equations with catchment-scale hydrology and slope failure improve modelling of cascading hazard chains?

IV. To what extent does shear-stress based entrainment of basal material provide a foundation for simulating runoff-induced mass movements?

v. How can regional-scale simulation of mass movements with arbitrary cohesive structure be achieved?

VI. How do the epistemic uncertainties in the developed multi-hazard model influence the usability of model outcomes for hazard assessment?

We do not endeavor the creation of an integrated physically-based multihazard model without using a solid starting point. In this work, the existing OpenLISEM model is extended (Jetten and de Roo, 2001). This open-source tool aims at catchment-scale simulation of hydrology and erosion. An overview of the methods implemented in the hydrology of the OpenLISEM model are provided in Appendix $A$, as these have significant influence on the behavior of any additional processes that are added in later chapters. 


\subsection{Structure of the Thesis}

The chapters of the thesis follow generally the sub-objectives as provided in the previous section.

Chapters 2 describes the integration of (flash) flood equations in a spatially distributed hydrological model. Here, focus lies both on the integration of a hazard, and additionally on the spatial distributed nature of the integration.

Chapters 3 to 6 focus on further extensions to the model by integration of additional hazardous processes. Similar to chapter 2, calibration and validation is generally presented using a variety of study sites and events that show the accuracy of the integrated process.

Chapter 7 aims to improve the numerical efficiency of the designed tool by implemented a numerical scheme named local time stepping, which can speed up simulations when local complexities require detailed numerical integration. Chapter 8 aims to assess the usability of the developed model in hazard assessment, as would be required for implementation in hazard and risk assessment. It does so by exploring real and design events using both the actual landscape, and a potential landscape including mitigation measures. Finally, chapter 9 summarizes the research and aims to answer some of the initial questions posed here. In particular, how far has the development of multi-hazard tools progressed in their usability in hazard and risk assessment and which additional issues need to be addressed to justify their implementation. 


\section{Flow Approximations for Hydrology- Integrated Flood Simulations}

This chapter is reproduced as published in Bout \& Jetten (2018) with minor modifications.

\subsection{Introduction}

Both due to climate change and population growth, global risk for fluvial floods has been found to increase (Kron et al., 1999; IPCC, 2012; Hirabayashi et al., 2013). Different processes can lead to flooding in an area, and based on the perception of the dominant process, different types of floods are recognized in Disaster Risk Management. Flash floods are characterized by both the spatial and temporal scales in which they take place. They often take place in or close to upstream runoff generating areas and are characterized by rapid release of water from a catchment. This type of flood event often takes place within a few hours of the rainfall event and often lasting less than a day. The dynamics of a flash flood are closely related to the dynamics of the rainfall event. The dynamics of floods that are generated by an overflowing river channel vary according to the spatial and temporal scales of the catchment. When the dynamics of the flood depend less on the rainfall characteristics and more on the characteristics of the contributing river system (the incoming wave) we tend to term these slower and long lasting floods as 'fluvial floods'. Other mechanisms of flooding are a rise of groundwater above the surface, and poor drainage in flat areas with excessive rainfall. While physically similar, it makes sense to recognize and define different flood types from a disaster risk reduction perspective, as people have developed a sense of the associated problems, the timing needed for early warning, and a certain impact with these different flood types. In this analysis, we focus on flash flood events, which cause substantial damage in various regions around the world (Munich Re, 2005; Schiermeier, 2006). Thus, research into understanding of the hydrological processes that precede (flash) flood events and analyzing best ways of simulating flow dynamics is of key importance.

Spatial numerical modelling is commonly used to investigate both flash floods and the preceding hydrological processes. Within numerical models, flow approximations are widely used to provide appropriate and efficient simulation of water flow (Chow, 1964; Tsai, 2003). Water flow on the surface can be simulated by solving a mass and momentum balance, using gravity, pressure differences and momentum. Under different environmental conditions, pressure differences and/or inertial momentum are not included in numerical solutions for flow. In practice, two types of model systems are used for flood modeling: a) decoupled systems, in which the source areas are separated from the flooded areas; and b) integrated catchment models. The decoupled model systems have essentially two models, one that generates an incoming discharge wave and one that simulates the flood process from this incoming discharge. The advantage is that both model systems can be separate, with different principles, scales and resolutions. Upstream models divide space in regular gridcells or polygons representing landscape elements, and even entire subcatchments that generate runoff which is collected in a stream network to create a discharge wave. Downstream flood models can adopt a gridcell size 
optimal for flood modelling. The disadvantage is the assumption that there are a few clearly defined inflow points (which is not always the case). Examples of this type of models are Hec-HMS (Scharffenberg \& Fleming, 2006), Hec-Ras (Brunner, 2010), TuFlow (BMT WBM, 2010) and Mike-She (Prucha et al., 2016). The second type of models are integrated catchment models, that simulate the complete hydrology and flow, generating runoff, leading to discharge and then to flooding. The advantages are that there are no entry points but instead open boundaries where runoff can lead directly to flooding, the disadvantages are that there is generally one spatial resolution for the entire domain, and computationally these models can be less efficient.

While integrated catchment models require more computation, depending on the event they can be required for accurate simulations. In many situations, flash floods cannot be simulated with a decoupled model system. Often a flash flood is not strictly related to an overflowing channel, as they occur in accentuated terrain. Sloping areas are prone to overland flow that adds directly to the flood water, especially in hilly urban areas where impermeable surfaces dominate. Flash floods are often a combination of an overflowing channel, overland flow and even direct rainfall. Also, rapid changes in water height and fluxes may occur over short distances which need robust numerical solutions to cope with. Examples of integrated catchment models are FLO-2D (O'brien, 2007) and TREX (Velleux, England \& Julien, 2008). Both these models however use simplified equations to describe flow behavior. Recent approaches to integrated flood simulations in a catchment model use hybrid modelling. Bellos and Tsakiris (2015) combined the FLO-R2D model (Tsakiris \& Bellos, 2014) and unit hydrograph theory. Nguyen et al. (2016) developed the HiResFloodUCI model, which uses the output from a lumped rainfall-runoff model for their flood simulation. However, both methods use clumped runoff, and have limited interactions between flood water and other hydrological processes such as rainfall and infiltration. While both these approaches thus provide improvement over traditional methods, a fully integrated approach to simulate floods in a catchment model could improve understanding of the processes that lead to floods.

In the majority of models that include hydrology and flow routing, three ways of routing are used to simulate surface and channel flow. The kinematic flow approximation, which simplifies water flow by neglecting pressure and inertial momentum, gained popularity in the early years of numerical modelling for its computationally efficient and robust estimations of flow patterns. Kinematic wave solutions use a predefined converging flow network that connects the spatial elements (e.g. through the steepest slope) and the channel system. This means that there is always connectivity between the spatial elements, the flow does not have to fill up small storages before it can continue. The only way to influence the timing of the flow is by the surface friction parameters. Models such as SWAT (Arnold et al., 1998), and Trex (Velleux, England \& Julien, 2008) use clumped and spatially routed kinematic flow respectively. The diffusive flow approximation implements pressure in the momentum equations. Using this method, models such as LISFLOOD (Van Der Knijff et al., 2010) approximate flood behavior. For detailed spatial modelling of flood behavior, the Saint-Venant equations (dynamic wave) for shallow flow are commonly used. This approximation, which requires more computation, is used by models such as CCHE2D, CH3D (Wu, 2011), Hec-Ras (Brunner, 2010), TuFlow (Syme, 2001) and Delft 2D (Deltares Hydraulics, 1999). Both the diffusive wave and 
dynamic wave use the DEM directly and water pressure differences between spatial elements and momentum allow the flow to converge and diverge. Connectivity is not pre-defined, local storages can exist and need to fill before the flow continues.

While the implementation of flow approximations improves efficiency, both the spatial and temporal scale of the simulation determine the validity of the approximation. The validity then limits the possible application of models to the temporal and spatial scales of flash floods (Tsai, 2003). In practice this is largely ignored: the availability of high-resolution data has increased strongly in the past decades (with for instance LIDAR derived digital terrain models). The general tendency in thinking is that a higher resolution offers greater accuracy, but it ignores the validity of flow approximations. Furthermore, during flash flood events, high water heights, flow velocities, and small spatial resolutions influence the validity of kinematic and diffusive flow further. Therefore, a detailed investigation into the influence of flow approximations on flash flood modelling is required.

The objective of this paper is to investigate the influence of spatial resolution on the validity of the kinematic, diffusive and dynamic flow approximations for use in integrated flood modelling. This investigation is separated into two parts. First, the behavior of these flow approximations for spatial runoff modelling is investigated for several spatial resolutions. Secondly, the flow approximations are coupled with channel flooding, and the influence of flow approximations on the flood simulation is investigated. Study catchments from China (Hessel et al, 2003) and Spain (Baardmans et al., 2013) are used with a spatial resolution of 10 and $20 \mathrm{~m}$ to investigate runoff behavior. For flooding, calibration is performed on 20, 40 and $80 \mathrm{~m}$ spatial resolution from the Italian alps (Borga et al., 2003). Calibration is performed on discharge data for those catchments. The open source Limburg Soil Erosion Model (OpenLISEM) (Jetten, 2002; Starkloff et al., 2014; Hu et al., 2015) is to perform the simulations. Kinematic, diffusive and dynamic flow are implemented for overland and channel flow dynamics. In order to simulate flooding in a catchment environment, dynamic wave channel flooding is included in all three combinations. For each combination, flow types are fully linked with both each other and other hydrological processes (explained below).

\subsection{Theory}

For the simulation of overland and channel flow, three commonly used approximations for water flow have been implemented: Kinematic flow, diffusive flow and Saint-Venant flow. For the simulation of channel flooding, Saint-Venant flow is used. In this section, the derivation and required assumptions for these flow approximations are described.

In order to describe continuity of any substance with advection, the mass balance equation is the basis (equation 2.1).

$$
\frac{\partial \mathrm{h}}{\partial \mathrm{t}}+\frac{\partial(\mathrm{hu})}{\partial \mathrm{x}}+\frac{\partial\left(h \mathrm{u}_{\mathrm{y}}\right)}{\partial \mathrm{y}}=\mathrm{R}-\mathrm{I}
$$

Where $\mathrm{h}$ is the flow height $(m), \mathrm{u}$ is the flow velocity $\left(m^{-1}\right), \mathrm{R}$ is the rainfall $(m)$ and $\mathrm{I}$ is the infiltration $(m)$. 
This equation is valid for all the implemented flow approximations and forms the basis for the numerical methods. In the rest of this section, equations that describe conservation of momentum for the flow approximations are stated.

\subsubsection{Dynamic Flow}

The momentum balance equations for water flow approximations are typically derived from the Navier-Stokes equations for incompressible flow. When this set of equations is depth averaged and internal friction forces are neglected, the Saint Venant equations result (Barre de Saint-Venant, 1871) (Equations 2.2 and 2.3 ).

$$
\begin{aligned}
& \frac{\partial h u_{x}}{\partial t}+\frac{\partial\left(h u_{x}^{2}+\frac{1}{2} g h^{2}\right)}{\partial x}+\frac{\partial\left(h u_{x} u_{y}\right)}{\partial y}=g h\left(S_{x}-S_{f, x}\right) \\
& \frac{\partial h u_{y}}{\partial t}+\frac{\partial\left(h u_{y}^{2}+\frac{1}{2} g h^{2}\right)}{\partial y}+\frac{\partial\left(h u_{x} u_{y}\right)}{\partial x}=g h\left(S_{y}-S_{f, y}\right)
\end{aligned}
$$

here $\mathrm{g}$ is the gravitational acceleration $\left(\mathrm{m} \mathrm{s}^{-2}\right), \mathrm{S}$ is the bed slope term (-) and $\mathrm{S}_{\mathrm{f}}$ is the bed friction term $(-)$.

The friction slope terms, which are the friction forces divided by the water height and the gravitational acceleration, can be calculated using the DarcyWeisbach friction law (Chow, 1959) (Equations 2.4 and 2.5).

$$
\begin{aligned}
& S_{f, x}=n^{2} \frac{u_{x}|\vec{u}|}{h} \\
& S_{f, y}=n^{2} \frac{u_{y}|\vec{u}|}{h}
\end{aligned}
$$

Where $\mathrm{n}$ is Manning's $\mathrm{n}$ friction coefficient $\left(\mathrm{s} \mathrm{m}^{-\frac{1}{3}}\right)$.

\subsubsection{Diffusive Flow}

In the diffusive flow approximation, inertial terms are assumed very small when compared to other acceleration terms. When the inertial terms are neglected, velocity is determined predominantly by hydraulic gradient, friction forces and the gravitational force. This assumption leads to a simplified set of equations (Equation 2.6 and 2.7)

$$
\begin{aligned}
& g\left(\frac{d h}{d x}\right)=\left(S_{f_{x}}-S_{x}\right) \\
& g\left(\frac{d h}{d y}\right)=\left(S_{f_{y}}-S_{y}\right)
\end{aligned}
$$

\subsubsection{Kinematic Flow}

In the kinematic flow approximation, both inertial acceleration and acceleration due to a hydraulic gradient are assumed very small when compared to the other acceleration terms. In this assumption, velocity is, at any moment, determined by the friction and gravitational force (Equations 2.8 and 2.9).
2.8

$$
0=\left(\mathrm{S}_{\mathrm{f}_{\mathrm{x}}}-\mathrm{S}_{\mathrm{x}}\right)
$$




$$
0=\left(\mathrm{S}_{\mathrm{f}_{\mathrm{y}}}-\mathrm{S}_{\mathrm{y}}\right)
$$

In this set of equations, the velocity depends directly on a balance between gravitational and friction forces and flow always moves in the direction of steepest descent. Solving the kinematic flow equations with Manning's friction law leads to Manning's law for overland flow velocity (Chow, 1959) (Equation 2.10).

$$
\mathrm{u}=\mathrm{R}^{\frac{2}{3}} \frac{\sqrt{\mathrm{S}}}{\mathrm{n}}
$$

Where $u$ is the flow velocity $\left(m^{-1}\right), R$ is the hydraulic radius $(m)$ and $n$ is the

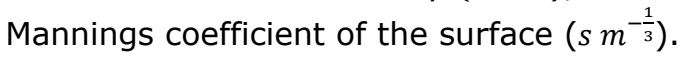

\subsubsection{Hydrology and Data Layers in OpenLISEM}

The flow methods described in this paper have been used to further the development of OpenLISEM, which is open source and freely available. The integration of flooding into the model allows the detailed investigation into the processes that lead to the flood event. The OpenLISEM model implements multiple types of infiltration models such as Smith \& Parlange (Smith \& Parlange, 1978) and the SWATRE full vertical soil water balance model (Bastiaanssen et al., 1996). The simulations in this paper use the Green \& Ampt infiltration model, which assumes a wetting front moving down into the soil due to infiltrating rainfall (Green \& Ampt, 1911). The resulting potential infiltration is subtracted from the available surface water (Equation 2.11).

$$
\mathrm{f}_{\text {pot }}=-\mathrm{K}_{\mathrm{s}}\left(\psi \frac{\theta_{\mathrm{s}}-\theta_{\mathrm{i}}}{\mathrm{F}}+1\right)
$$

Where $f_{\text {pot }}$ is the potential infiltration rate $\left(\mathrm{ms}^{-1}\right), F$ is the cumulative infiltrated water $(m), \theta_{s}$ is the porosity $\left(\mathrm{m}^{3} \mathrm{~m}^{-3}\right), \theta_{i}$ is the initial soil moisture content $\left(\mathrm{m}^{3} \mathrm{~m}^{-3}\right), \psi$ is the matric pressure at the wetting front $(h=\psi+Z)(m)$ and $K_{S}$ is the saturated conductivity $\left(\mathrm{ms}^{-1}\right)$.

Input data consists of soil, land surface and terrain properties, and can be defined on a sub-cell basis by using fraction maps as input (Figure 2-1). The infiltration of water and routing of overland flow are fully coupled and thus computed for each numerical timestep. Further details on the underlying physical principles of OpenLISEM can be found in Baartman et al. (2012) and 


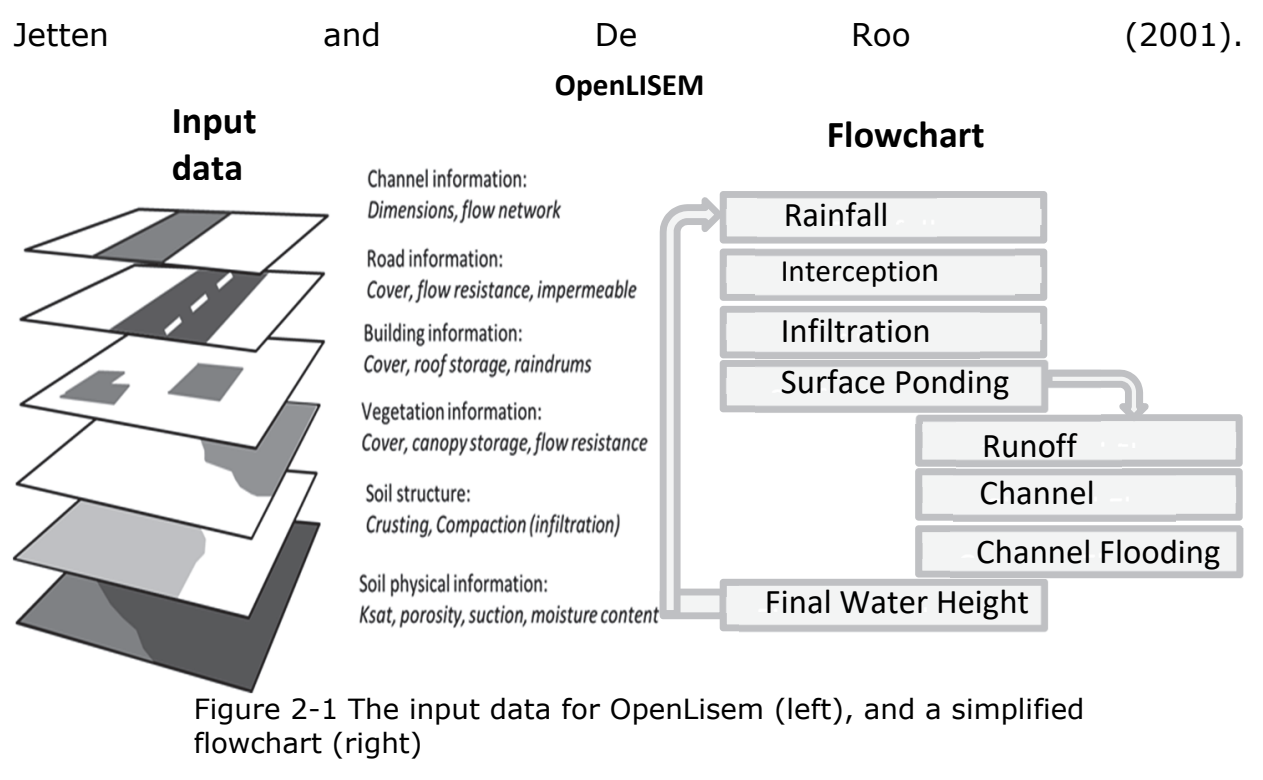

\subsection{Numerical Implementations}

The numerical implementations of flow equations can, if not appropriate, influence behavior and validity. A numerical method should be appropriate to the assumptions of the equations and provide a stable, accurate and realistic simulation. Therefore, separate numerical methods were implemented for the flow approximations. The numerical methods that were implemented during the development stages of OpenLISEM are presented in this section.

\subsubsection{Saint-Venant Flow - Cell-Boundary Fluxes}

The implemented solution for Saint-Venant flow is based on the FullSWOF2D library (Delestre et al., 2014). This library uses a Monotonic Upstream CellCentered (MUSCL) scheme to provide a second order spatial accurate solution. This method uses a linear approximates of the flow parameters on the cell boundaries in order to calculate the flux at these boundaries (Figure 2-2). The estimation of cell interface fluxes furthermore corrects for elevation differences based on a hydrostatic reconstruction (Audusse et al., 2004). This results in a solution that is both Total Variation Diminishing and preserves a steady state at rest. Using the Harten-Lax-van Leer Riemann-solver, shock-wave behavior is captured (Harten et al., 1983). Finally, new water heights are calculated using the hydrostatic reconstruction. In order to gain second order accuracy in time, Heun's predictor-corrector method is used, which is a 2 step-Runga Kutta solver. 


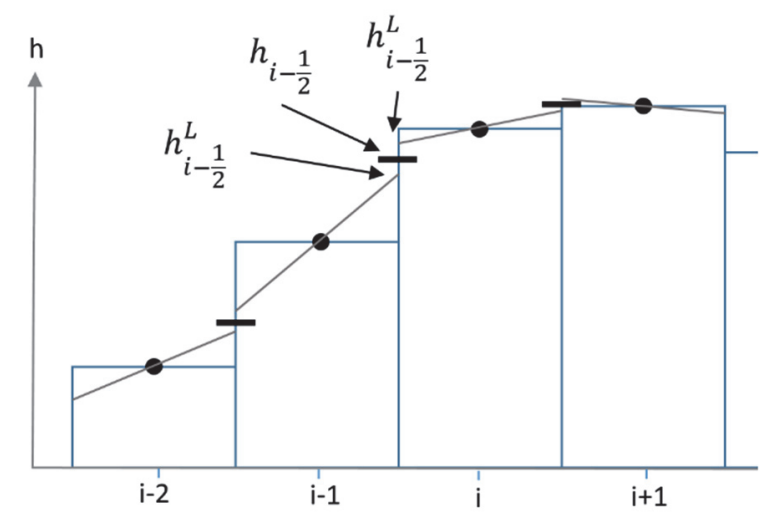

Figure 2-2 The MUSCL scheme performs piece-wise linear interpolation

\subsubsection{Diffusive Flow - Bilinear Interpolation}

If inertial acceleration terms are ignored, behavior will become unnatural surrounding local depressions in elevation. While Tayfur and Kavas (1994) use a cell-boundary based method to solve diffusive and kinematic flow, Liu et al. (2004) note that irregularities in the Digital Elevation Model (DEM) cause difficulties for such a method. Thus, we implement a distinct advection scheme in order to solve diffusive flow. For any cell, the location of the water volume is updated by the velocity (Figure 2-3). The water volume is then distributed to the cells that surround the new location (Courant et al., 1952).

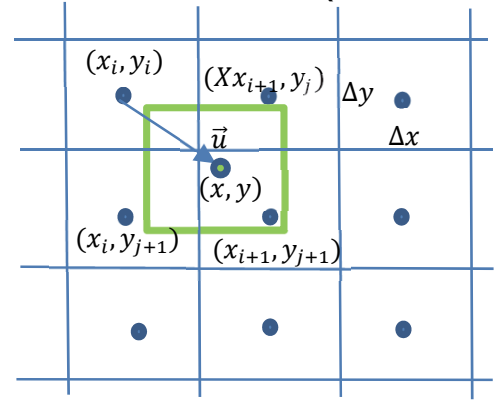

Figure 2-3 Cell coordinates, discharge and an advected cell. $\Delta x$ and $\Delta y$ are the cell length in the two spatial dimensions

\subsubsection{Kinematic Flow - Flow Network}

A numerical solution for kinematic flow must be coherent with the assumptions that lead to the kinematic flow approximations. Pressure forces are ignored and flow directions are completely determined by terrain slope. Because of this, converging slopes will cause unnatural, oscillating, behavior. To avoid this unnatural behavior, kinematic flow is implemented using a pre-defined flow direction network (Figure 2-4). 


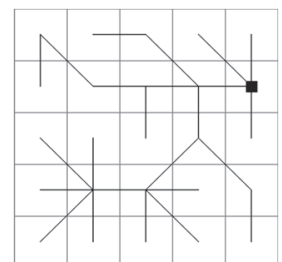

Figure 2-4 An example of a local drainage direction file (Karssenberg et al., 2001)

This network must ignore any local depressions to ensure validity of kinematic flow. Furthermore, the flow direction network allows for a one-dimensional implementation of kinematic flow along the network, strongly increasing computational speed. Creation of this network is done using the Open-Source freeware Raster GIS PCRASTER (Karssenberg et al., 2001).

\subsubsection{Connecting One and Two-dimensional Flow}

Channel flow can be simulated in one dimension using the same equations as for overland flow. Within the model, the channel is assumed to be rectangular, with limited flow depth. To calculate the inflow from the land surface into the channel, it is assumed that the direction of overland flow, in cells containing channels, is perpendicular to the channel direction. The channel is furthermore assumed to be located in the middle of the cell. This way, using the channel width and flow velocity, the fraction of runoff water that flows into the channel can be calculated (Equation 2.12).

$$
\mathrm{f}_{\mathrm{qch}}=\frac{\mathrm{dt} \mathrm{u}}{0.5\left(\mathrm{C}_{\mathrm{xy}}-\mathrm{B}_{\mathrm{c}}\right)}
$$

Where $\mathbf{B}_{c}$ is the channel width at the surface $(m)$.

Similar methods have been shown to provide accurate estimations of channel inflow (Brandbrook et al., 2004; Yin et al., 2013). Channel overflow immediately adds to flooding. If the channel has extra capacity, available flooding water is likewise immediately transported into the channel (Figure 2-5)

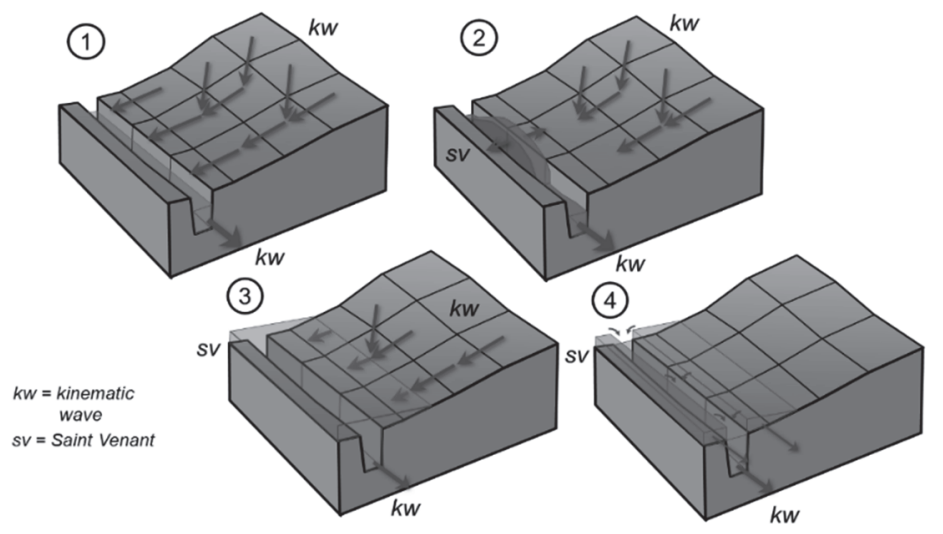

Figure 2-5 Coupling of overland flow, channel flow and flooding. The channel acts as a main link between the flow domains. 


\subsubsection{Connecting Overland Flow and Flooding}

Besides channel water, overland flow enters and thus adds to the flood volume. When overland flow and channel flooding are not approximating using the same method, their interactions cannot be solved based on normal SaintVenant flow. In reality, overland flow water must be added to the flood depth and an exchange of momentum takes place. For the kinematic and diffusive wave, momentum conservation neglects important terms that are present in the flood water. Therefore, the process of overland flow mixing with flood water is approximated using an empirical relationship (Equation 2.13).

$2.13 \quad \mathrm{f}_{\mathrm{rf}}=\min \left(1.0,1-\mathrm{e}^{-\frac{\mathrm{c}_{\mathrm{r}} \mathrm{h}_{\mathrm{f}}}{\mathrm{h}_{\mathrm{r}}}}\right)$

Where $f_{r f}$ is the fraction of runoff water transferred to the flood water, $c_{r}$ is a coefficient $(-), h_{f}$ the flood depth $(\mathrm{m})$ and $h_{r}$ is the overland flow depth $(\mathrm{m})$. Here, the $h_{f}$ and $h_{r}$ are at each moment taken from the local flow properties. The coefficient $c_{r}$ is, purely based on modelling experience generally taken to be 2.0 , since flood artifacts disappear at this value.

Using this approximation, Overland flow water is gradually transferred to the flood water while it does not unnaturally affect flood momentum

\subsection{Materials and Methods}

Three study sites are used to investigate the validity of the implemented flow approximations. An overview of the topography, saturated conductivity and manning's $\mathrm{N}$ for these catchments are shown in figure Figure 2-6, Figure 2-7 and Figure 2-8.

The first of these is the Danangou catchment, a rural area in the Loess plateau in China, where soil erosion is a major problem due to agriculture on steep slopes and the erodibility of loess soil (Hessel et al., 20113). This area was previously used by Hessel et al. (2003a, see also Hessel et al., 2003b; Hessel \& van Asch, 2003 and Hessel \& Jetten, 2007) to calibrate and validate a previous version of the LISEM model. This 257 ha region is characterized by steep slopes $\left(>20^{\circ}\right)$ large eroded gullies. Land use consists predominantly of woods, wild grasslands and parts of cropland in the upper regions. For this catchment three precipitation events from 20-07-1999, 23-08-1998 and 0108-1998 will be used. The events were recorded by three rainfall gauges in the area, and rainfall maps based on the nearest station are therefore used as input. The rainfall events are typically characterized by shorts burst of intense precipitation, with durations around 30 minutes, intensities up to $100 \mathrm{~mm} /$ hour and high spatial variability. During such events, hydraulic conductivity is a limiting factor in the amount of infiltration. Together with measured rainfall intensity, discharge after these events is available for every two minutes. More details on the events and area are available in Hessel et al. (2003a). The spatial resolution of this dataset is 10 meters. The channel network in the area consists of small not-channelized streams and gullies that converge near the main outlet. For validation and calibration, discharge data is available at a 2 minute interval. Discharge values have been estimated using water height timeseries at a weir and a stage-discharge curve. 


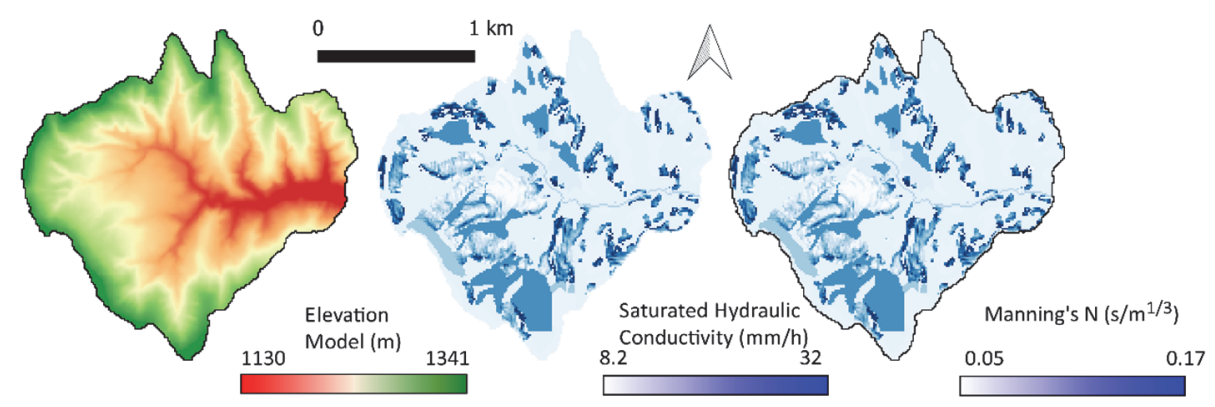

Figure 2-6 An overview of topography saturated conductivity and Manning's $\mathrm{N}$ for the Danangou catchment.

A second catchment in Prado, South-Eastern Spain, will be used. This $50 \mathrm{~km}^{2}$ semi-arid region experiences between $250 \mathrm{~mm}$ and $530 \mathrm{~mm}$ of rainfall each year. The area has previously been used with LISEM by Baardmans et al. (2013, see also Baardmans et al., 2012a; Baardmans et al., 2012b). Land cover consists mainly of natural shrubs, forests and dryland farming such as cereals. Soil information was obtained by Baardmans et al (2013) using in-situ measurements of all parameters required for OpenLISEM. The soil types are primarily Calcic Cambisols and Calcaric Fluvisols. Rainfall data is available for three rainfall events on 29-09-1997 (top), 09-12-2003 (middle) and 17-102003(bottom) (Baardmans et al., 2012a). The events have a total rainfall of 19.7, 26.9 and $49 \mathrm{~mm}$ respectively, and a duration of around 2 hours. The channel network in the area consists of small not-channelized streams and gullies that converge near the main outlet. Discharge data has been gathered at the outlet of the described catchment at a 5 minute interval. Discharge values have been estimated using water height timeseries at a weir and a stage-discharge curve. The spatial resolution of this dataset is 20 meters. 

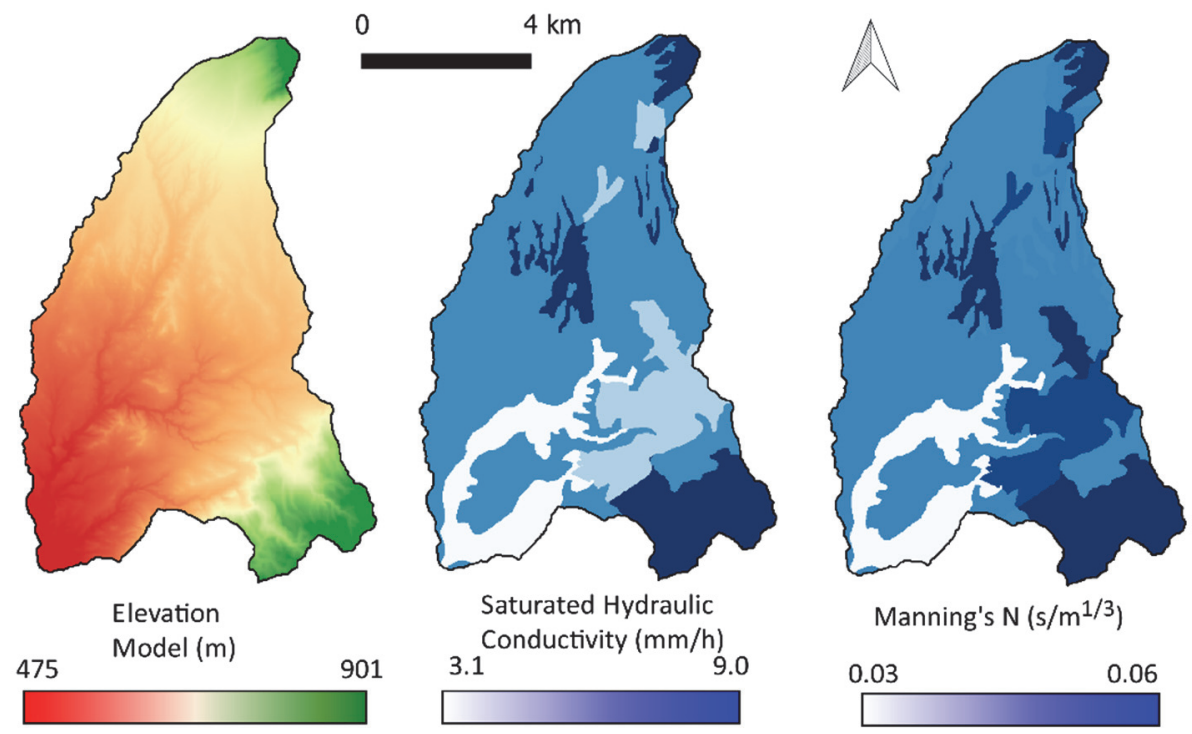

Figure 2-7 An overview of topography saturated conductivity and Manning's $\mathrm{N}$ for the Prado catchment.

The third catchment is a $164.5 \mathrm{~km}^{2}$ region along the northern Italian Alps that has been investigated by Chen et al. (2014). Land use in the region consists mainly of multiple types of forest and heathland in the upslope areas, and small build-up regions in the lower. Rainfall data is available for an intense precipitation event on the $29^{\text {th }}$ of august 2003, which took place after several weeks of droughts and had a return period between 200 to 500 years (Norbiato et al., 2007). Peak rainfall intensity reached $81 \mathrm{~mm} / \mathrm{h}$ during an hour at Pontebba, located at the outlet of the selected catchment. Here, total precipitation for the event of $389 \mathrm{~mm}$. For a detailed description of the precipitation event on the $29^{\text {th }}$ of august 2003 and the methodology in estimating the rainfall intensities, see Borga et al. (2007). Multiple upslope branches of tributaries of the Fella River experienced flash flooding at small drainage areas (Borga et al., 2007; Nikolopolous et al, 2013). Besides flooding, the area experienced severe geomorphic impacts during the event, which might have influenced the flow dynamics (Marchi et al., 2009). The river network in the area consists of many non-channelized steep side branches, leading to the fella river. The main river branch has a wide base ( $>25$ meters) and features culverts near the local highway. The outlet discharge data for this event is based on a stage-discharge relationship, and is available for every half hour. The location of this outlet is the Fella river at Pontebba (Borga et al., 2007). During a post-event survey, peak discharge estimates were determined for one additional location in the catchment: Uqua at Ugovizza (Borga et al., 2007). The dataset for this catchment was made as part of the IncREO project (Increasing Resilience through Earth Observation-IncREO). An elevation model and land use map were made available from the project. The alpine area features steep slopes and the majority of the area is covered by coniferous forest. Soil information was collected from the ISRIC database, Wageningen (Hengel et al., 2017) and literature data from Saxton and Rawls (2006). The majority 
of the area has loam-like soil characteristics. The vegetation index was derived from spot- 4 satellite images. The available spatial resolutions are 20, 40 and 80 meters.

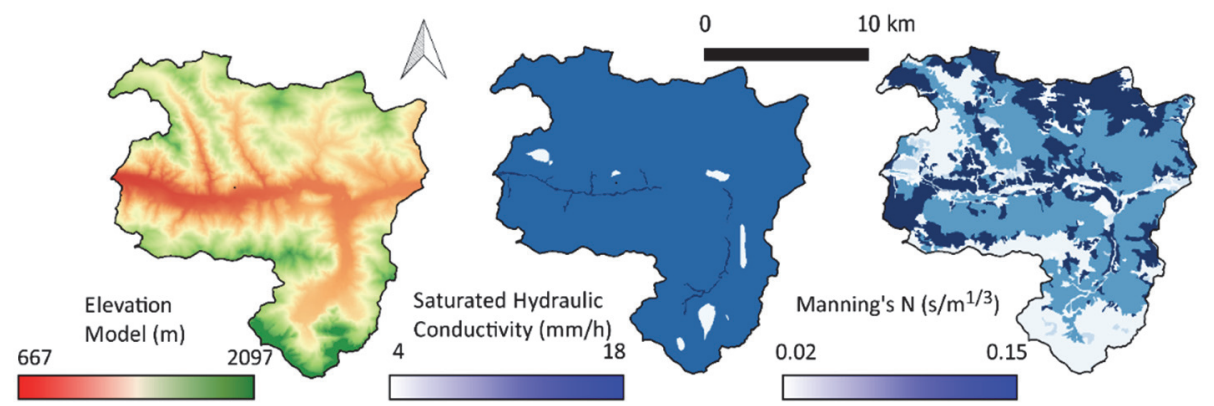

Figure 2-8 An overview of topography saturated conductivity and Manning's $\mathrm{N}$ for the Fella catchment.

\subsubsection{Simulated Scenarios}

To investigate the performance of the described flow approximations, several are used to simulate identical scenarios on the Danangou and Prado catchments. The used flow approximations are: kinematic, diffusive and dynamic flow for overland flow and respectively kinematic, kinematic and dynamic flow for channel flow. Based on the best calibrated simulation, performance of the flow approximation will be analyzed. Furthermore, spatial patterns in flow height are used to see how the flow approximations and processes such as infiltration influence each other.

To investigate the performance of the flow approximations in flash flood modelling, the Fella basin is simulated using all combinations of flow approximations. This includes kinematic, diffusive and dynamic overland flow. These types of overland are combined with respectively kinematic, kinematic and dynamic flow for the channels. Finally, these flow approximations are combined with dynamic channel flooding, leading to a total of 5 combinations of flow approximations. To investigate the influence of spatial resolution on the performance of these flash flood simulations, spatial flood depth is analyzed for the distinct flow approximations and spatial resolutions.

\subsubsection{OpenLISEM Input Data}

The input data of OpenLisem can be separated into three categories. Firstly, a catchment description has to be provided in the form of spatial rasters. The provided catchment data was already available in the correct raster format. Preparation of the dataset was performed using the PCRaster open-source GIS package (Karssenberg et al., 2010). For both the Danangou and Prado catchment, maps of soil and land cover parameters were available. In the case of the fella river basin, the original dataset has a spatial resolution 20 meters. Using PCRaster, this dataset was resampled to 40 and 80 meters resolution. On the resampled elevation models, a simple pit filling algorithm was used to restore flow pathways. Secondly, boundary conditions have to be provided to complete the description of the event. Time series of catchment-averaged 
rainfall intensity were available as text tables for the Prado and Fella Catchments. These were used as input in OpenLISEM. From these tables, spatially homogeneous rainfall over the catchment area was assumed. A list of four rainfall stations combined with station locations were available for the Danangou catchment. Based on these rainfall stations, spatial maps of rainfall intensity were made that assigned every cell the rainfall intensity of the closest rainfall station. These were then used as input for OpenLISEM to provide spatial rainfall during the simulation. Outflow boundary conditions were set to allow outflow at any point. No inflow besides rainfall was specified for the simulations. Finally, the OpenLISEM simulation parameters are required. A table of these parameters for the described datasets is shown in Table 2-1.

Table 2-1 Input simulation parameters for the OpenLISEM simulations

\begin{tabular}{|c|c|c|c|}
\hline & Danangou & Prado & Fella \\
\hline Timestep (s) & 10 & 10 & 60 \\
\hline Min Timestep & 0.5 & 0.5 & 0.5 \\
\hline Courant Factor (-) & 0.2 & 0.2 & 0.2 \\
\hline Simulation duration (m) & 1000 & 1000 & 2000 \\
\hline $\begin{array}{l}\text { Runoff to } \text { flood } \\
\text { Coefficient (-) }\end{array}$ & 2.0 & 2.0 & 2.0 \\
\hline Canopy Openess factor (- & 0.450 & 0.450 & 0.450 \\
\hline Spatial resolution & $\begin{array}{l}10 \mathrm{~m} \\
200 \times 200\end{array}$ & $20 \mathrm{~m} 583 \times 380$ & $\begin{array}{l}20 \mathrm{~m} \\
881 \times 1196\end{array}$ \\
\hline
\end{tabular}

\subsubsection{Calibration}

For all the described study sites, the simulations are calibrated to discharge data. Discharge data was available with a 10 minute resolution for the Prado catchment, a 30 minute resolution for the Fella catchment and a 15 minute resolution for the Danangou catchment. While several measurements were removed for several reasons, the available data provided enough certainty in the calibration process. To calibrate the simulations, the saturated conductivity, Manning's coefficient and initial soil moisture content is varied. These parameters have been found to have the highest influence on simulation behavior (Hessel et al., 2007). The values for these parameters are kept between 50 and $200 \%$ of their original values in order to maintain a physically meaningful simulation.

The Nash-Sutcliffe model efficiency coefficient is used as the measure of performance (Equation 2.14), where 1 indicates perfect correlation and increasing negative value a decreasing correlation.

$$
\mathrm{E}=1-\sum \frac{\left(\mathrm{Q}_{\mathrm{o}}^{\mathrm{t}}-\mathrm{Q}_{\mathrm{m}}^{\mathrm{t}}\right)^{2}}{\left(\mathrm{Q}_{\mathrm{o}}^{\mathrm{t}}-\overline{\mathrm{Q}_{\mathrm{o}}}\right)^{2}}
$$

Where, $\mathrm{E}$ is the Nash-Sutcliffe model efficiency coefficient, $Q_{o}^{t}$ is the observed discharge at time $\mathrm{t}\left(\mathrm{m}^{3} \mathrm{~s}^{-1}\right), Q_{m}^{t}$ is the modelled discharge at time $\mathrm{t}\left(\mathrm{m}^{3} \mathrm{~s}^{-1}\right)$ and $\overline{Q_{o}}$ is the average observed discharge $\left(\mathrm{m}^{3} \mathrm{~s}^{-1}\right)$. 


\subsection{Results and Discussion}

\subsubsection{Danangou and Prado Catchments}

Both measured and simulated discharge for the Danangou and Prado catchment are shown in Figure 2-9 and Figure 2-10. Calibrated simulations for the kinematic, diffusive and Saint-Venant flow approximations are provided. Calibration parameters had to be altered from the original values used by Hessel et al. (2007) due to the usage of different model efficiency functions. The values of the Nash-Sutcliffe correlation coefficients and average calibration parameters for each are provided in Error! Reference source not found. and Error! Reference source not found. .

Table 2-2 Nash-Sutcliffe coefficients and calibration parameters for the simulated rainfall events for the catchment in the Chinese Loess Plateau. Calibration parameters are relative to base dataset value.

\begin{tabular}{llll}
\hline Nash-Sutcliffe & $01-08-1998$ & $20-07-$ & $23-08-1998$ \\
Coefficients & & 1999 & \\
\hline Kinematic Flow & -0.71 & 0.61 & 0.12 \\
Diffusive Flow & -0.22 & 0.78 & 0.89 \\
Saint-Venant Flow & 0.58 & 0.81 & 0.88
\end{tabular}

\begin{tabular}{llll}
\hline $\begin{array}{l}\text { Average Calibration } \\
\text { Parameters }\end{array}$ & Kinematic & Diffusive & Dynamic \\
\hline Mannings N & 1.86 & 1.09 & 0.87 \\
Saturated & 1.67 & 0.68 & 0.74 \\
Conductivity & & & \\
Initial Moisture & 1.49 & 0.93 & 0.86 \\
\hline
\end{tabular}




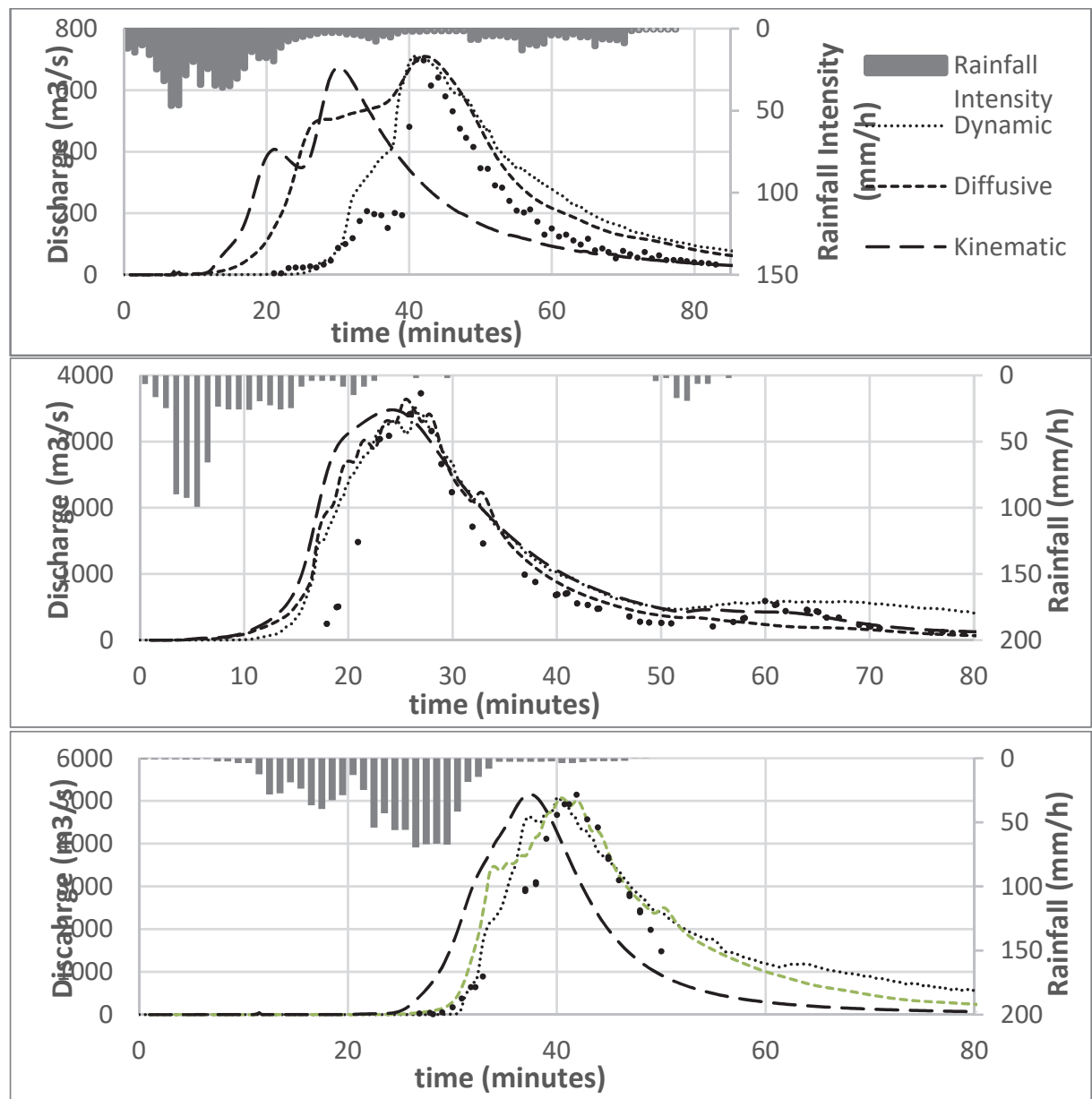

Figure 2-9 Calibration results from different flow approximations for the catchment in the Loess Plateau. Rainfall events from 01-08-1998 (top), 20-07-1999 (middle) and 2308-1998 (bottom).

Table 2-3 Nash-Sutcliffe coefficients and calibration parameters for the simulated rainfall events for the Prado catchment. Calibration parameters are relative to base dataset value.

\begin{tabular}{llll}
\hline $\begin{array}{l}\text { Nash-Sutcliffe } \\
\text { Coefficients }\end{array}$ & $29-09-1997$ & $\begin{array}{l}09-12- \\
2003\end{array}$ & $17-10-2003$ \\
\hline Kinematic Flow & 0.242 & 0.613 & 0.793 \\
$\begin{array}{l}\text { Diffusive Flow } \\
\text { Dynamic Flow }\end{array}$ & 0.302 & 0.770 & 0.845 \\
& 0.519 & 0.891 & 0.875 \\
\hline $\begin{array}{l}\text { Average Calibration } \\
\text { Parameters }\end{array}$ & Kinematic & Diffusive & Dynamic \\
\hline Mannings N & 1.44 & 0.78 & 0.72 \\
Saturated Conductivity & 1.25 & 0.87 & 0.93 \\
Initial Moisture & 1.28 & 0.91 & 0.94 \\
\hline
\end{tabular}




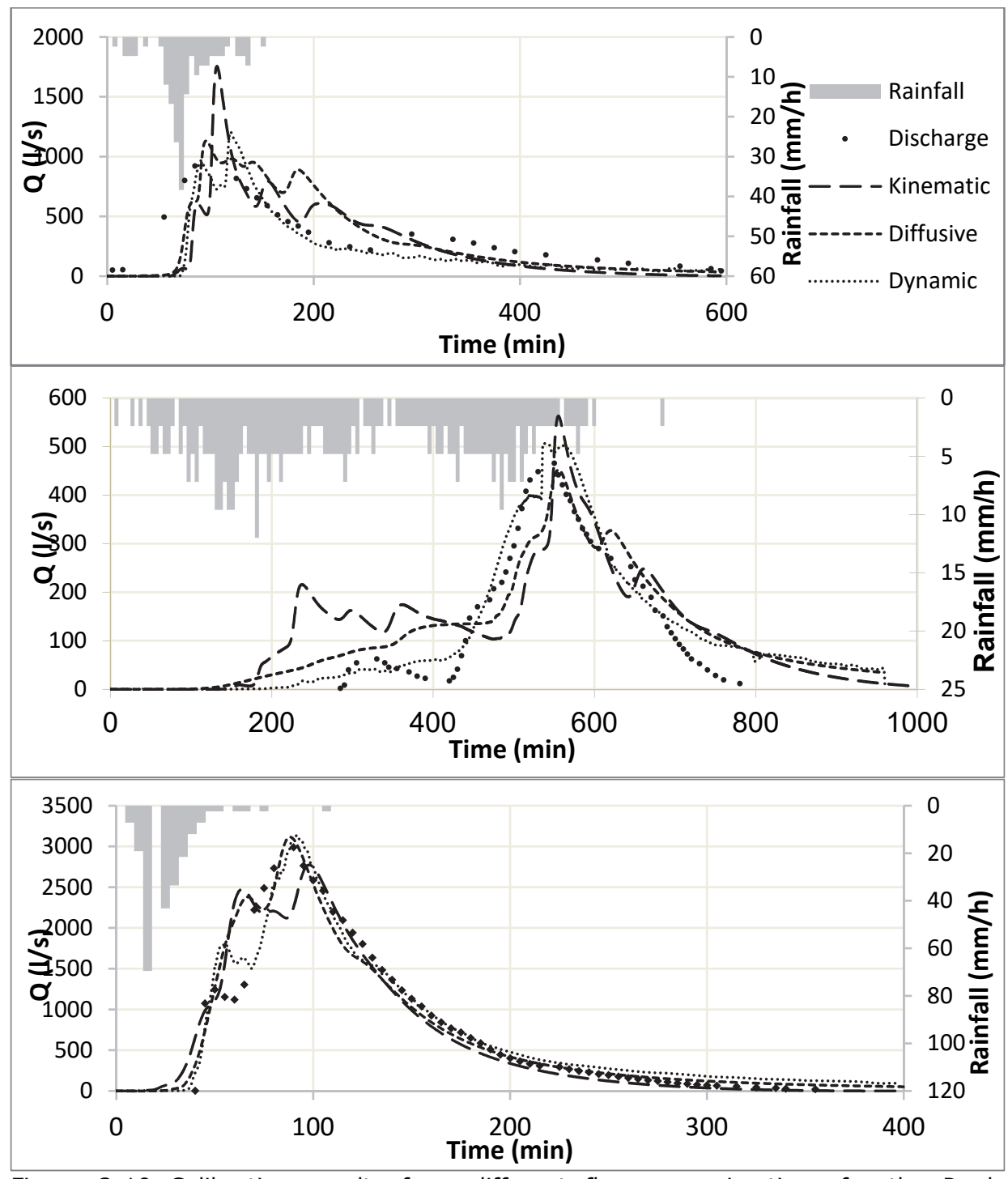

Figure 2-10 Calibration results from different flow approximations for the Prado Catchment. Rainfall events from 29-09-1997 (top), 09-12-2003 (middle) and 17-102003(bottom).

\subsubsection{Connectivity of Overland Flow}

The simulation results for the Danangou catchment show significant differences in performance for the various flow approximations. The time of peak discharge is simulated with substantially higher accuracy by diffusive and Saint-Venant flow. Both the timing and general shape of the simulated hydrographs lead to substantially higher correlation coefficients for the diffusive and Saint-Venant flow when compared to kinematic flow. 
Hessel et al. (2003) concluded that, for this catchment, the timing of the discharge peak was especially difficult to predict. The authors mentioned that inaccuracy of the digital elevation could have led to steeper slopes. This would have increased average overland flow velocity. However, comparison with dynamic and diffusive wave simulations showed that flow velocities have been increased by the inherent properties of the kinematic flow approximation.

Where diffusive and Saint-Venant flow spread due to pressure forces, kinematic flow concentrates to the width of a single cell. When the spatial resolution is high, this leads to unrealistically high water heights. Because of this increase in flow height, flow velocity increases. This effect is furthermore strengthened by the fact that the routing network ignores local depressions. In Figure 2-11, maximum flow depth for the July rainfall event are shown. While kinematic flow forces a direct path through any rough terrain, diffusive and dynamic flow are partly blocked and re-routed. Both of these effects increase the average flow velocity of kinematic flow and cause the approximation to over-estimate connectivity in the catchment. The results of this overestimation can be seen in the form of the early peak discharge time for the kinematic flow simulations. Therefore, the kinematic flow approximation, instead of the digital elevation model, was the dominant reason for the inaccuracy. The influence of flow approximations on average flow velocities is furthermore visible in the final calibration parameters, where manning's' $N$, the frictional coefficient, is significantly lower for kinematic flow. This indicates that during calibration, the flow had to be artificially slowed down to gain accuracy.

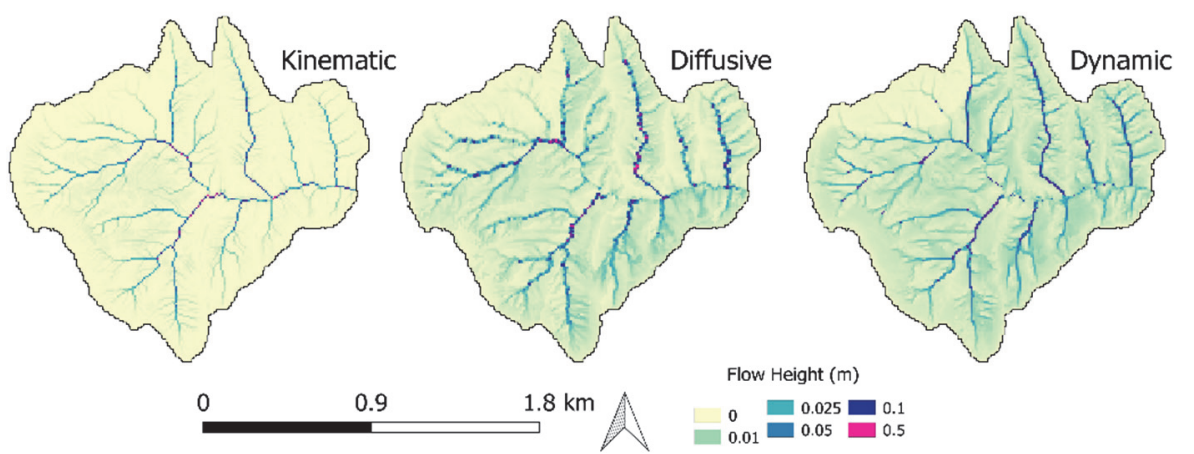

Figure 2-11 Maximum simulated overland flow depth in the Danangou catchment for the 20-07-1999 rainfall event.

The simulation results for the Prado catchment show significant differences in performance for the distinct flow approximations. All three flow approximations provided satisfactory results in calibration for the three rainfall events. Dynamic overland flow performed best in recreating the shape of measured hydrographs. Both diffusive and dynamic flow showed an increase in accuracy when compared to the kinematic flow approximation.

Figure 2-12 shows the simulated spatial patterns of overland flow for the July rainfall event in the Prado catchment. A predominant difference in these patterns is the concentration of flow. Compared to the dynamic flow, which performed best in calibration, kinematic and diffusive flow respectively overestimate and under-estimate flow concentration. This is evident from the 
mathematical and numerical descriptions of their behavior. Kinematic flow forces flow through the width of a single cell, artificially concentrating flow. Diffusive flow adds pressure terms, which act as a diffusive force, and neglects other forces, causing an overestimation of flow diffusion. A second difference between the flow approximations is caused by differences in infiltration. On locations where flow concentrates, infiltration is limited by the infiltration capacity and the active surface for infiltration. Flow concentration strongly influences the available surface area for infiltration. In the north of the Prado catchment, runoff is generated that flows South through an area of high infiltration. Kinematic flow concentrates and limits the active surface area of infiltration, thus flowing through areas with high infiltration capacity quicker. The diffusive and dynamic flow are predominantly infiltrated due to their more diffusive flow. Within the final calibration parameters, the same effect is visible. Due to the larger amount of infiltration with diffusive flow, the calibration lead to lower values for the saturated conductivity, which increases final discharge.

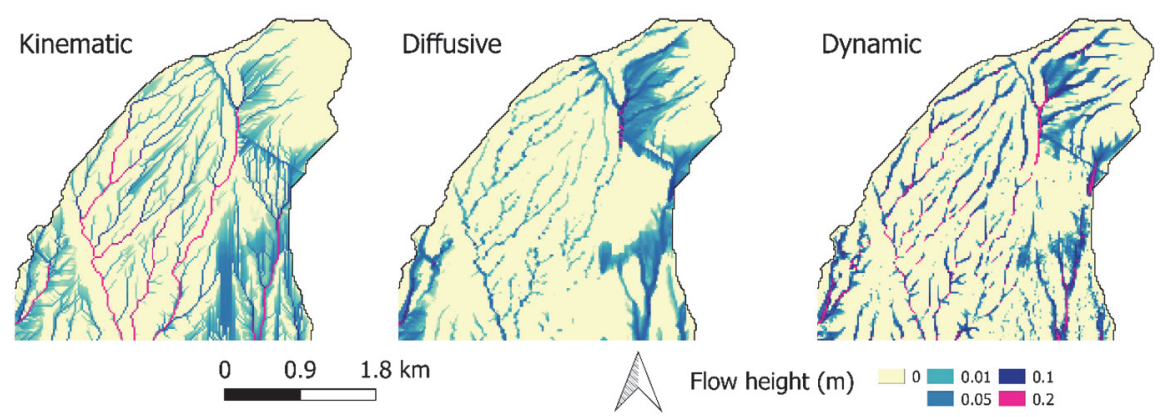

Figure 2-12 Overland flow depth for the northern part of the Prado catchment at identical times in the simulation for the 17-10-2003 rainfall event.

Based on the results of both the Danangou and Prado catchment, kinematic flow is highly accurate and efficient in the correct setting. When flow heights relative to spatial resolution is low, velocity and flow diffusion are correctly estimated. Mathematical analysis for the use of flow approximations such as those by Vieira (1982) can be used to support the use of flow approximation. A crucial difference in behavior is however caused by spatial modelling. In the case of spatial flow modelling, concentration of flow can quickly change flow properties. Due to several effects, hydrological connectivity can be substantially over-estimated by kinematic flow. Furthermore, because the routing scheme for kinematic flow is bound by cell size, errors increase with increasing spatial resolution. Therefore, in the case of spatial modelling, the ratio of catchment size versus cell size plays an important role in the applicability of the kinematic flow approximation.

\subsubsection{Validation with Flooding}

Simulated and measured discharge for the 2003 Fella-Basin flood event are shown in Figure 2-13. Simulations using kinematic, diffusive and Saint-Venant approximations both with and without Saint-Venant based channel flooding have been calibrated and are provided. The Nash-Sutcliffe correlation 
coefficient for the discharge simulations of the Fella-Basin flood event are provided in Error! Reference source not found..

Table 2-4 The Nash-Sutcliffe correlation coefficients for the simulations of the 2003

Fella-Basin flood event.

\begin{tabular}{rccc}
$\begin{array}{c}\text { Simulation } \\
\text { Method }\end{array}$ & $\begin{array}{c}\text { Nash-Sutcliffe } \\
\text { Correlation } \\
\text { Coefficient }\end{array}$ & $\begin{array}{c}\text { Simulation Time } \\
\text { (Minutes) } \\
\text { 20m. resolution }\end{array}$ & $\begin{array}{c}\text { Mass } \\
\text { Balance } \\
\text { Error } \\
\text { (\%) }\end{array}$ \\
\hline Kinematic & 0.42 & 108 & $7.4 \mathrm{e}-12$ \\
Kinematic \& SV & 0.76 & 432 & $1.3 \mathrm{e}-3$ \\
Diffusive & 0.65 & 389 & $7.6 \mathrm{e}-12$ \\
Diffusive \& SV & 0.93 & 532 & $2.5 \mathrm{e}-11$ \\
Saint Venant & 0.91 & 621 & $8.7 \mathrm{e}-2$
\end{tabular}

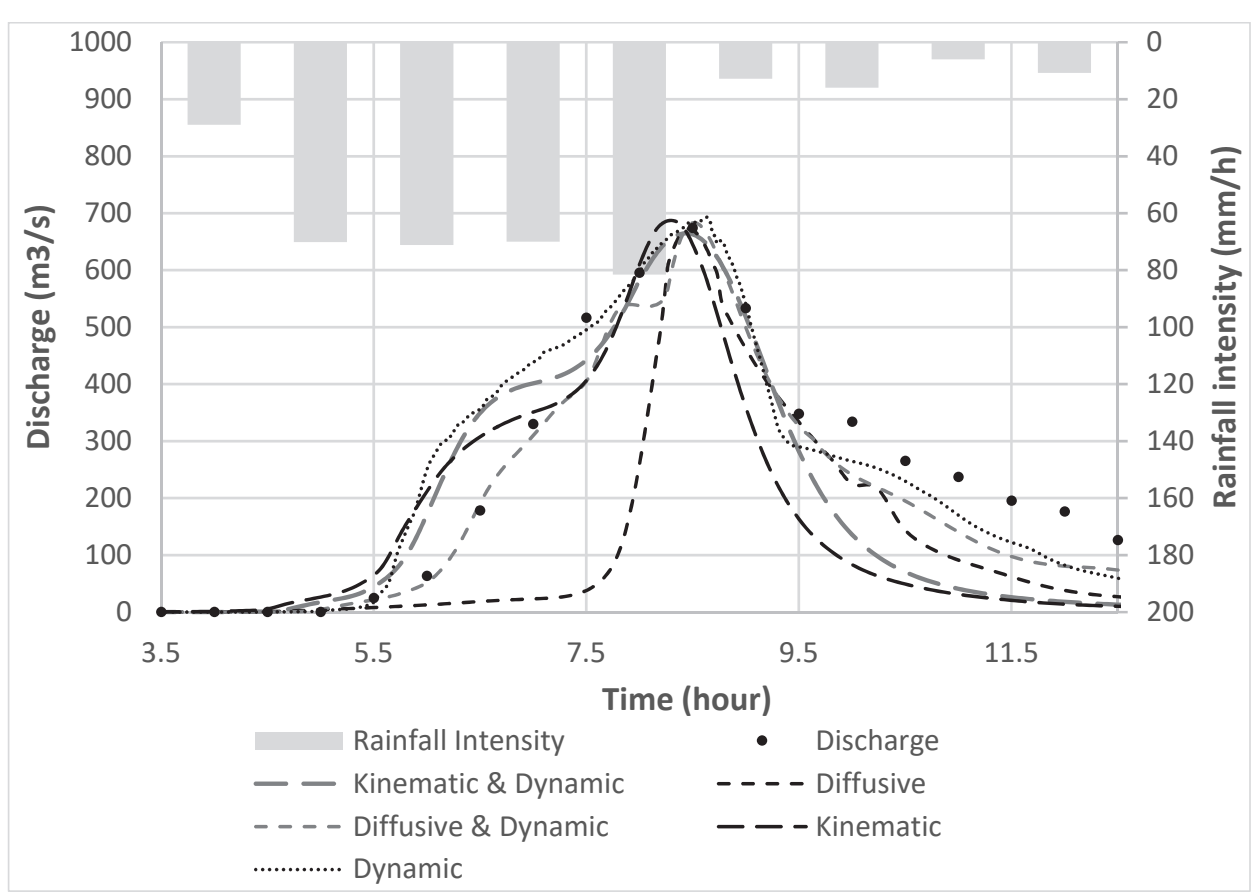

Figure 2-13 Measured and simulated discharge for the 2003 Fella-Basin flood event.

Table 2-5 Comparison of estimated peak discharges and simulated peak discharges in the fella basin.

\begin{tabular}{lllllll}
$\begin{array}{l}\text { Outlet } \\
\text { Point }\end{array}$ & $\begin{array}{l}\text { Estimated } \\
\text { Peak } \\
\text { Discharge } \\
\left(\mathrm{m}^{3} \mathrm{~s}^{-1}\right)\end{array}$ & Kinematic & $\begin{array}{l}\text { Kinematic } \\
\text { \& SV }\end{array}$ & $\begin{array}{l}\text { Diffusive } \\
\text { Diffusive }\end{array}$ & $\begin{array}{l}\text { Saint } \\
\text { \& SV }\end{array}$ & Venant \\
\hline $\begin{array}{l}\text { Uqua at } 200 \\
\begin{array}{l}\text { Ugovizza } \\
\text { Fella at } 680\end{array}\end{array}$ & 325 & 292 & 245 & 231 & 182 \\
Pontebba & 692 & 673 & 677 & 678 & 697 \\
\hline
\end{tabular}




\subsubsection{Flood Behavior}

In the case of the 2003 flood event in the Fella river basin, the gradual decline in measured discharge after the event confirms the reports of flooding. The decrease in flow height and slope outside of the channel causes a gradual return of flood water into the channel. Flood depth maps for the coupled Kinematic, diffusive and Saint-Venant simulations with channel flooding are provided in Figure 2-14. For three representative locations, flood depth time series for the same simulations are shown in Figure 2-15.

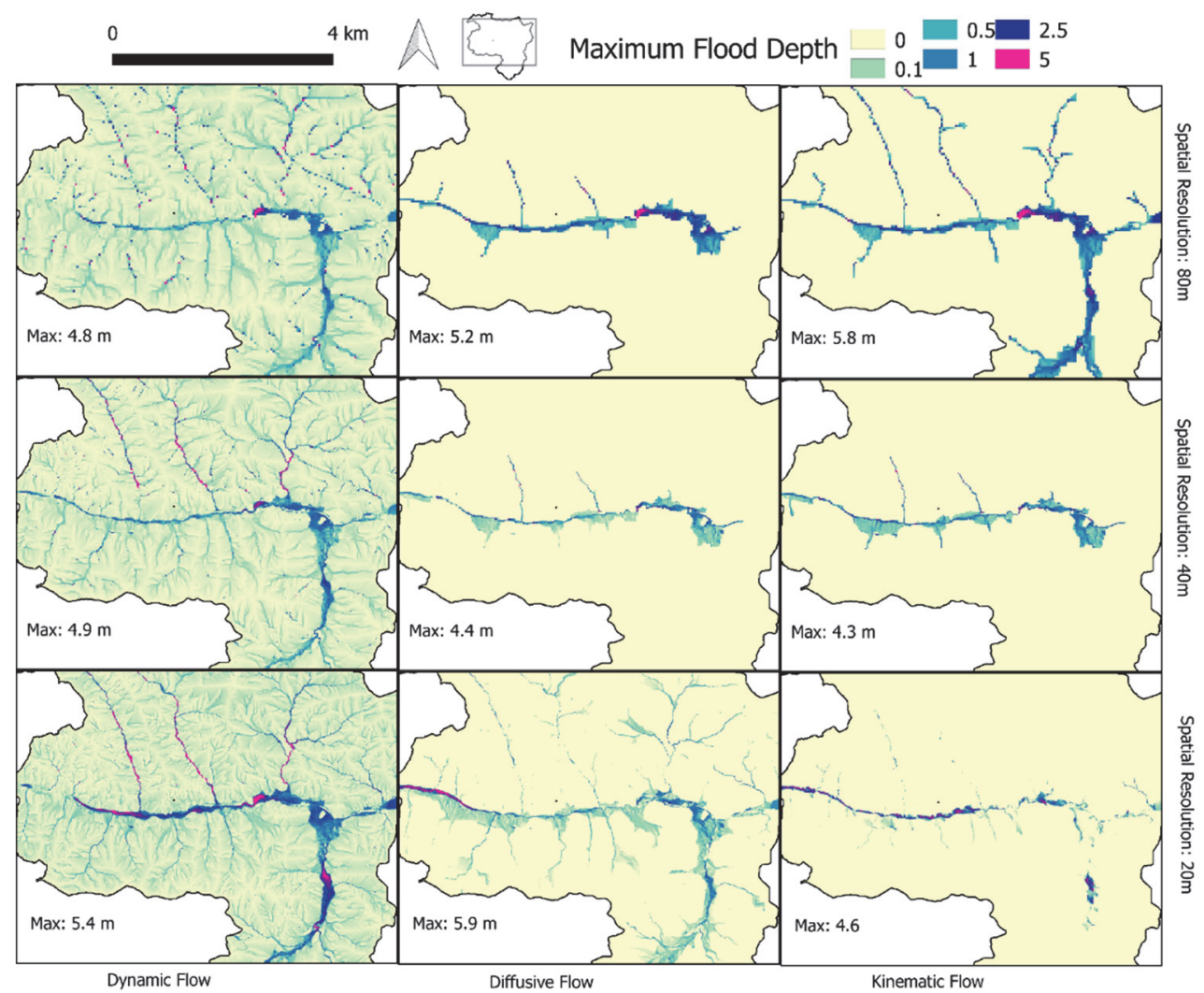

Figure 2-14 Flood depth maps for the 2003 Fella-Basin flood event. Use flow approximations are: Diffusive flow and Saint-Venant channel flooding (left) and SaintVenant flow (right). Parameters are taken from the calibrated $20 \mathrm{~m}$ model. 


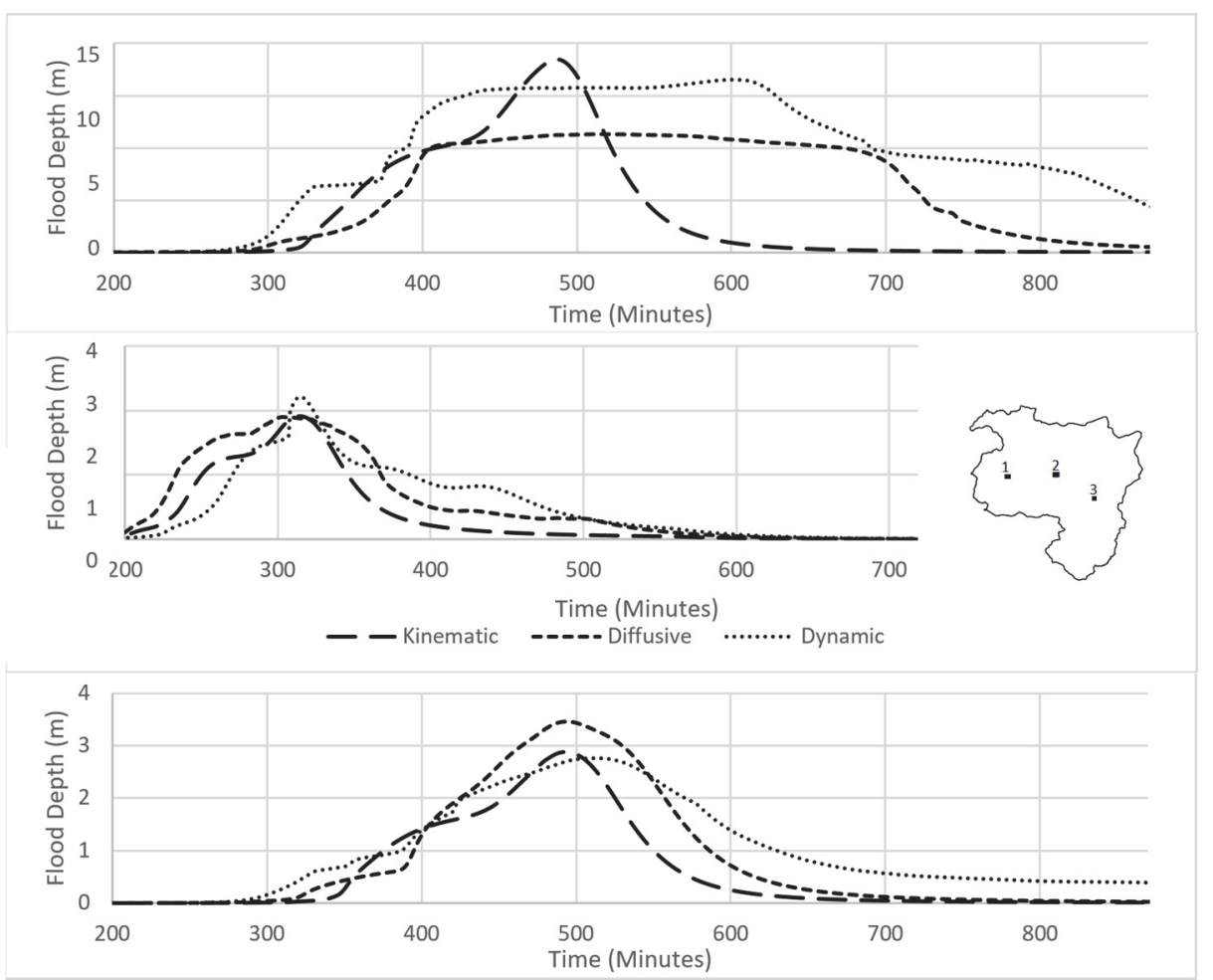

Figure 2-15 Flood depth trends for the calibrated settings with Dynamic Wave flooding in three locations in the fella area.

The difficulty in recreating the hydrograph differed for the distinct flow approximations. Without channel flooding, kinematic and diffusive flow were not able to provide an accurate recreation of the measured hydrograph. The kinematic flow approximation completely neglects the flooding behavior. The diffusive flow approximation strongly underestimates flow velocities at the incline of the hydrograph. This leads to a late increase in discharge. The cause of the underestimated velocities can be found in the over-estimation of the spread of the water flow. This is due to the presence of pressure term but lack of inertia related acceleration. The inertia-related acceleration terms would increase flow concentration in sharp incised channels.

When the kinematic flow approximation is combined with Saint-Venant based channel flooding, accuracy increases substantially. However, channel flooding only slightly increases accuracy in the tail of the hydrograph. The combination of diffusive flow with Saint-Venant channel flooding and a full Saint-Venant approximation show accurate recreation of the 2003 Fella-basin floodhydrograph. The main reason for this is shown in figure 7 . The flooding during the simulation with kinematic flow is mainly present near the main channel. When this flood water re-enters the channel, it can quickly leave the area. For the diffusive and Saint-Venant flow, flooding takes place substantially more in the upstream areas. Because of this, water takes a longer time to reach the outlet once it re-enters the channel. Thus, while addition of channel-based flooding improved calibration accuracy for kinematic flow, this method has 
limited predictive power when compared to diffusive and dynamic overland flow. For these flow approximations, flooding behavior can take place at any location, allowing a greater degree of accuracy in the simulations.

While dynamic and diffusive flow outperform kinematic flow when using a spatial resolution of 20 meters, difficulties arise in the case of 40 and 80 meters. For both 40 and 80 meters resolution, the coarser resolution creates local depressions in the digital elevation model. The routing network that is used for kinematic flow neglects these local depressions, while diffusive and saint Venant flow first fill these, leading to spurious flooded cells. Correction to the elevation model could be made to increase connectivity for diffusive and dynamic flow. However, such corrections are a difficult process and can substantially alter slopes on a complex topography. Another disadvantage of diffusive and dynamic flow on coarse resolutions, is that flow spread is generally over-estimated when pressure terms are included. When spatial resolution is coarse, flow spread should not be wider than a single cell. However, due to pressure terms, diffusive and dynamic flow generally use two or more cells.

However, despite the inaccurate flooding of local depressions, both flooding extent and flooding depth are substantially more consistent with the results of the 20-meter simulation in the case of diffusive or dynamic flow. For kinematic flow, it is visible that a decrease in spatial resolution causes the flooding to take place increasingly upstream. This can be explained by the strong overestimation of connectivity in the Fella-basin. Because of terrain with high spatial variability, flow velocities are lower when details are included. On coarser resolution, kinematic flow ignores an increasing amount of details in the topography, increasing the over-estimation of connectivity and flow velocity. This would cause the runoff to arrive at the channel earlier, causing flooding in increasingly upstream areas.

Summarizing: in the performed simulations, due to the strong over-estimation of connectivity on both higher and lower spatial resolutions, the usage of a kinematic flow approximation could not accurately recreate flow behavior. Thus, both the calibration performance, and the consistency of flood extent and volume for varying spatial resolution are substantially higher in the case of diffusive and dynamic flow.

The influence of spatial resolution on flood connectivity has been described earlier by Haile \& Rientjes (2005). In their case, re-sampling of flood-plain elevation influenced the hydraulic connectivity, and thus the simulated flood extent. They conclude that, especially in terrain with high spatial variability, important details in elevation are lost in coarser resolutions. When simulating flooding within a catchment model, that includes rough upstream topography, the effect of spatial resolution on flow connectivity should therefore be of even higher importance. The manner in which flow approximations are influenced by the topography has been recognized previously (Kazezyilmaz-Alhan \& Medina, 2007). In their simulations, steeper slopes (> 0.11 degrees) show higher accuracy in using kinematic and diffusive wave approximations in a onedimensional setting. In our two-dimensional simulations, similar effect are visible. Steep slopes tend to provide larger gravitational acceleration. Therefore, inertial and primarily pressure forces, which are ignored by the kinematic flow approximation, lose relative magnitude when compared to the gravitational forces. The slope values for the described catchments are shown in figure 16. Particularly the Danandau catchment, which features steep slopes, 
and. While the catchment edges in the fella basin feature very steep slopes (> 40 degrees), the central river area is very flat, leading to inaccurate behavior of kinematic flow. Finally, the Prado catchment features mostly gentle slopes (< 5 degrees). As expected, performance differences between flow approximations are less noticeable when compared to the other catchments.
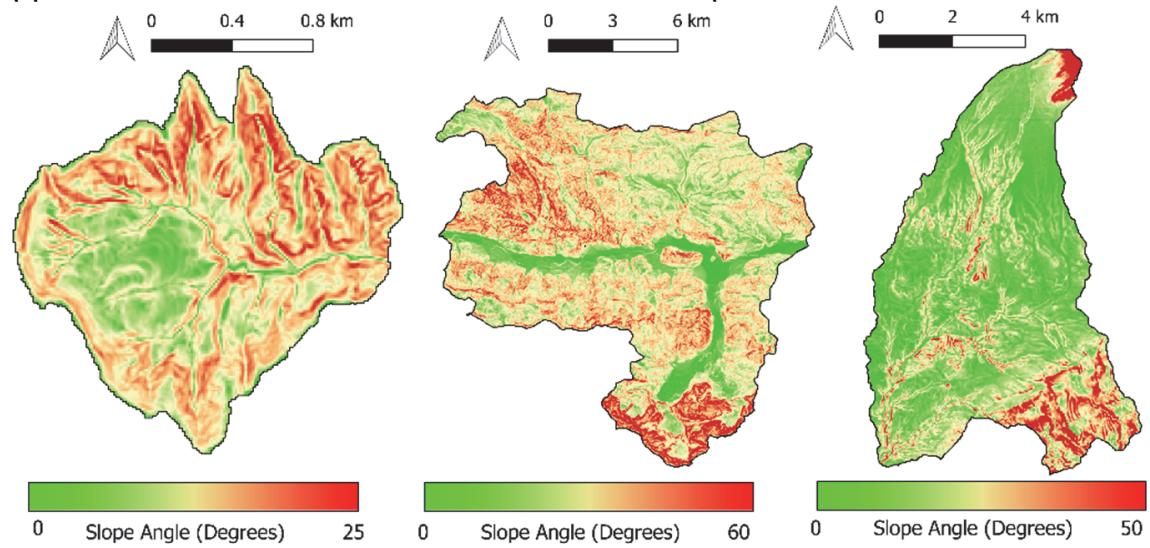

Figure 2-16 Slope values for all described catchments: Danandau (left), Fella (middle), Prado (right).

A final consideration in the performance of the flow approximations in flash flood modelling is mass conservation. Typically, numerical flow computations loss or gain water outside of the normal water balance when computational errors are made. An overview of the water balance errors in the fella flash flood simulations are shown in table 5 . Within the implementation of the kinematic and diffusive flow, numerical errors are strictly limited to machine precision rounding errors, since the flow advection is implemented in a strictly massconserving manner. For dynamic flow, this is not the case, and mass balance errors increase during the simulations. The total amount of water lost in the full dynamic flow simulation is $8.7 e-2$. Due to the insignificant amounts of water lost during the simulation, there is no relationship with the quality of the simulation.

\subsubsection{Sensitivity Analysis}

Results from a sensitivity analysis are shown in Figure 2-17. Calibrated parameters for the fella flash flood simulations are shown in Table 2-6. 


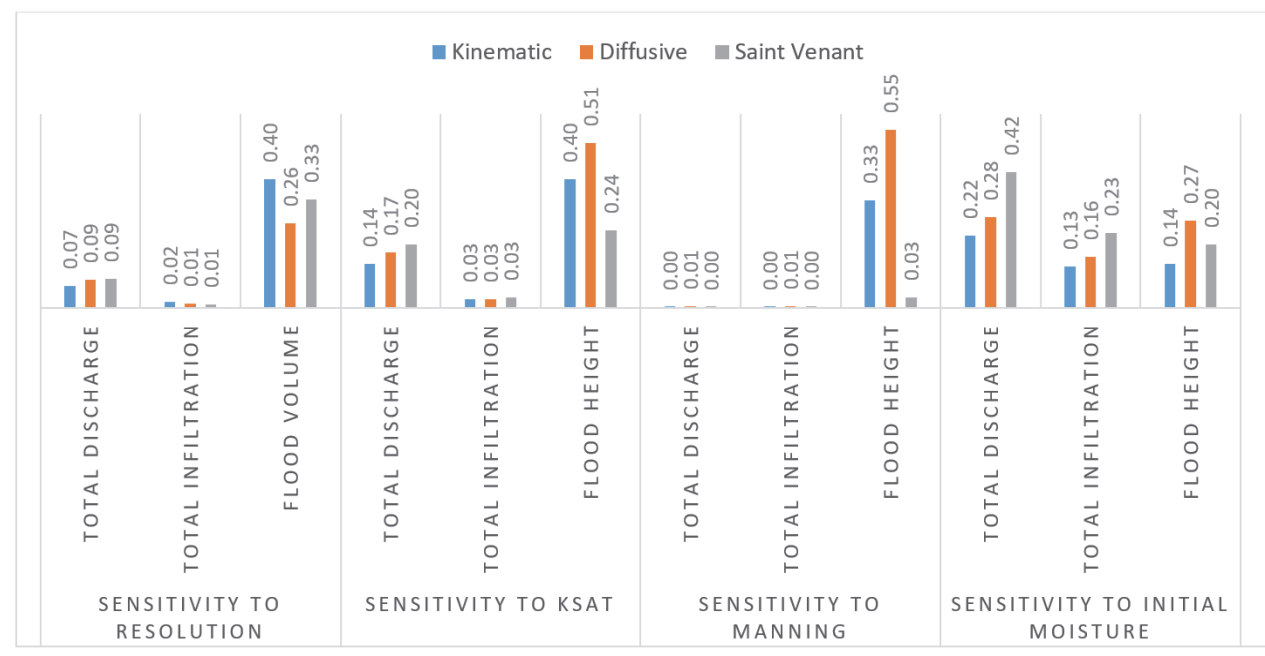

Figure 2-17 Sensitivity analysis for the 2003 Fella-Basin flood event. Values indicate relative change in output variable compared to the change in input parameter.

Table 2-6 Sensitivity analysis for the 2003 Fella-Basin flood event. Calibration parameters are relative to base dataset value.

\begin{tabular}{|c|c|c|c|c|c|}
\hline $\begin{array}{l}\text { Calibrated } \\
\text { Parameters }\end{array}$ & Kinematic & $\begin{array}{l}\text { Kinematic } \\
\& \\
\text { Dynamic }\end{array}$ & Diffusive & $\begin{array}{l}\text { Diffusive } \\
\& \\
\text { Dynamic }\end{array}$ & Dynamic \\
\hline $\begin{array}{l}\text { Initial Moisture } \\
\text { Multiplier }\end{array}$ & 0.74 & 0.71 & 1.42 & 1.63 & 1.69 \\
\hline $\begin{array}{l}\text { Saturated } \\
\text { Conductivity } \\
\text { Multiplier }\end{array}$ & 1.8 & 1.45 & 1.57 & 1.14 & 1.12 \\
\hline $\begin{array}{l}\text { Manning's } \\
\text { Multiplier }\end{array}$ & 2.1 & 1.68 & 1.24 & 0.89 & 0.82 \\
\hline
\end{tabular}

The result of the sensitivity analysis show several variables to which the flow methods is highly sensitive. Both saturated conductivity and Manning's coefficient have a strong influence on the output of the model. The influence of model resolution on the simulation is relatively low when compared to the saturated conductivity and the Manning's coefficient. Especially average flood depth and flood velocity are substantially affected by the input parameters. The distinct flow approximations have substantial differences in sensitivity. The kinematic flow approach has the highest sensitivity to resolution changes. This is caused by the usage of the local drainage network. This causes flow to move through the width of a single cell. When cell sizes are changes, this significantly influences flow height and thus velocity. For the other methods, the sensitivity of flood properties is comparable to similar detailed flood models (Haile \& Rientjes, 2005; Horrit \& Bates, 2001).

Generally, the kinematic flow approximation shows the lowest sensitivity to the Manning's coefficient and the saturated conductivity. In these cases however, it is important to note that a lower sensitivity does not necessarily mean higher accuracy. In the case of kinematic flow, infiltration for example, is not limited by the hydraulic conductivity, but rather by the flow width. This decreases 
sensitivity to a change in hydraulic conductivity. The diffusive flow approximation shows an especially high sensitivity for maximum flood depth and maximum flood velocity. Finally, the Saint-Venant flow shows an average sensitivity for all investigated variables

\subsection{Conclusions}

Based on the simulation results, diffusive and dynamic flow overland flow provide a substantial increase in calibration performance when compared to kinematic flow. In both the Danangou and Prado catchment, kinematic, diffusive and dynamic flow performed respectively least to most accurate in calibration to measured hydrographs. For these catchments, with a spatial resolution of 10 and 20 meters, kinematic flow performed substantially less. In both catchments, the kinematic flow approximation over-estimated connectivity within the catchment. Both due to flow concentration, the use of a routing network and decreased infiltration, hydrological connectivity is in some cases highly over-estimated when kinematic flow is used. Therefore, the assumptions that lead to kinematic flow have a high influence on hydrological connectivity.

For simulations of flood events, kinematic flow similarly provides the least accuracy. The implementation of Saint-Venant based channel flooding strongly increased calibration performance. The transition to Diffusive and Saint-Venant equations for overland flow further increased accuracy and realism. The best results were obtained with a combination of diffusive overland flow and dynamic flow for channel flooding. Both this combination and full dynamic flow were able to recreate the hydrograph of the 2003 Fella-Basin flood event. The primary cause of this was that for diffusive and dynamic flow, flood behavior is not limited by the presence of a channel. For kinematic flow, flooding is initiated along the channels, limiting the predictive nature of the model. Spatial resolution of the dataset has a significant impact on the performance of the flow approximations. In the case of coarser resolutions (40 meters or higher), local depressions were ignored by kinematic flow. This improved the relative accuracy of this method. In the case of higher spatial resolutions, pressure forces within water flow become important. As a result of the substantial overestimations of connectivity and flow velocity on both lower and higher spatial resolutions, the usage of kinematic flow could not accurately recreate flow behavior in the simulated flood event.

The performed simulations show that validity of the approximation is highly dependent on the type of event and the spatial resolution. With the increasing availability of detailed elevation data and increasing computational power, simulations with high spatial resolutions become more common. For higher spatial resolutions, the usage of kinematic flow can have a significant impact on the model. Usage of this flow approximation should then be based on a thorough investigation. The extent in which a kinematic, diffusive or dynamic wave can be used in flow simulations at different spatial resolutions depends on the type of area and particularly the slopes and spatial variability of the topography. In the case of flood simulations, the implementation of channelbased flooding with dynamic flow is required for catchment-based simulations of flooding. Ignoring pressure terms by assuming infinite channels results in unrealistic flow heights and velocities. For the same reason, kinematic flow 
was, for the fella river simulations, not an appropriate method for simulating overland flow. The usage of a flow network artificially increases flow concentration and ignores pressure terms, which are crucial in describing the behavior of flood water. Similarly, in applications related to spatial hazard susceptibility, usage of routing networks and kinematic flow should generally only be considered as a viable alternative when the investigations shows the topography, slopes and spatial resolution do not lead to inaccurate behavior of the flow approximation.

\subsubsection{Acknowledgements}

We want to gracefully acknowledge the help of researchers that kindly allowed for the use of their datasets for this research project. Dr. J. E. Baartman provided the dataset for the Prado-Catchment. Dr C. J. van Westen and Dr. D Shrestha provided the dataset for the Fella Basin. Part of the datapreperation process was part of the Increo Project (Increasing Resilience through Earth Observation-IncREO, Grant Agreement No. 312461). Finally, Dr. R. Hessel provided the dataset for the Danangou catchment. 


\section{$3 \quad$ An Iterative Method for Regional Hydrology-based Prediction of Shallow Slope Failures}

This chapter has been submitted as B. van den Bout, L. Lombardo, M. Chiyang, C. J. van Westen and V. G. Jetten (under review) Physically-based regional prediction of slope failure volume and shapes

\subsection{Introduction}

Many regions within mountainous areas are prone to slope instability, resulting from a combination of susceptible factors and triggering events. The released volume of mass movements often gains velocity under gravity, after which the material deposits downslope. These flow-type mass movements cause large amounts of damage and casualties worldwide (Froude \& Petley, 2018). Slope stability analysis is of crucial importance for hazard and risk assessment in inhabited areas with sloping terrain (van Westen, 2006).

Slope failures are the result of a complex set of processes (Carson \& Kirby, 1972; Cruden \& Varnes, 1996), and predicting them spatially and temporally is challenging (van Westen, 2006). There is a wide variety of approaches to landslide predictions, including knowledge driven, data driven and physically based modelling (Crosta, 1998; Glade et al., 2000; Guzzetti et al., 2007). While the first two can provide relative information on landslide susceptibility, they lack the capability to predict the frequency and spatially distributed hazard intensity, which are needed for proper hazard and risk assessment, and for analyzing possible future scenarios (Guzzetti et al., 2009; Amirahmadi et al., 2016). Therefore, physically-based modelling of slope stability is the preferred method to analyze slope failures, even at regional scale, although the parameterization might often be the limiting factor. The current methods for regional slope failure prediction include the infinite slope method, fiber bundle method and random sampling method, which will be shortly discussed below. One of the most used and most well-known approximations is the infinite slope method (Matsui \& San, 1992; Griffiths \& Lane, 1999; Van Westen, 2006; Alkasawneh et al., 2008; Wilkinson et al., 2002; Kuriakose et al., 2009; He et al., 2016). In this method, slope failures are assumed to extend parallel to the terrain, and to take place along an infinite slope (Van Westen \& Terlien, 1996). The resulting criteria for failure ignore the surrounding forces, and instead take the ratio of the local resisting and driving forces. The simplicity of this method allows for fast computation over large areas, and combination with hydrological modelling such as in TRIGRS (Baum et al., 2008), GEOtop (Formetta \& Capparelli, 2019) or HIRESS (Rossi et al., 2013). The slope stability equation can furthermore be combined with probabilistic elements, such as in STARWARS and PROBSTAB (Van Beek, 2002). Finally, integration in a catchment scale runout model (OpenLISEM) allows for automated estimation of runout in case of slope failure (Bout et al., 2018; Fan et al., 2017). Despite the ease of use in large-scale assessments, there are several severe shortcomings. The model is suited for shallow landslides, and these models provide inaccurate assessments for deep-seated landslides, where the initial assumptions of the model do not hold (Griffiths et al., 2011a; Tiwari et al., 
2014; Mergili et al., 2014). Secondly, the stability estimation is highly dependent on the input of the depth of the shear plane, and assumption of planar failure parallel to the slope surface often not realistic. Thirdly, slope stability is calculated based on local properties, for the slope is assumed of infinite length. Because of this, failures do not progress through a slope and spatially scattered failures frequently result. Fourthly, as failure is only analyzed for individual pixels, it is also difficult to convert the results of infinite slope modelling into realistic landslide volumes used for runout analysis.

Fiber Bundle Models are another group of slope stability models that are based on the assumption that subsurface strength is probabilistic in nature an analogous to bundles of fibers with varying strength parameters (Cohen et al., 2009). Within a regular grid, the sloping terrain is discretized, and all directly neighboring grid cells are connected by bundles of fibers. Each individual fiber is assigned strength parameters randomly taken from a distribution of MohrCoulomb parameters (Goodman, 1980). Iteratively, the forces on the resulting network of slope materials connected by fibers is solved. Excess loads are propagated through the fibers and predicted failure are spatially clumped because of subsurface force propagation. The model STEP-TRAMM (Luette et al., 2017) uses these type of inter-cell connections to estimate progressive failure of slope material on a regional scale. While this model improves on traditional infinite slope models and is able to provide new insights in propagating failures on regional scales, it suffers from some of the same problems as the infinite slope model. Failure is still estimated in an all-ornothing manner, being either the total soil depth or no failure. This can lead to unrealistic predictions particularly in the case of rotational slides.

A different group of slope stability models are based on the Finite Element Method (FEM) which simulate the subsurface of slopes as a dynamic continuum. Local stress, strain and displacement are iteratively solved using a Mohr-Coulomb type of constitutive equation, which can include groundwater effects. In order to solve the equations, the subsurface is divided into numerous small elements, allowing for numerical integration (Roozbeh, 2017). While this method arguably provides the most detailed insights into the behavior of materials in a sloping terrain, it is highly demanding in terms of computational power. The method has been used in slope investigation in three dimensions, but it is not practical to apply them over larger areas (Ukritchon et al., 2017).

Two-dimensional analysis of rotational failures has been implemented using the method of slices (Fellenius, 1936; Morgenstern \& Price, 1956; Duncean \& Wright, 2004). Later, the method of slices was also extended to three dimensions (Hovland, 1977; Hungr, 1987). While this method allows for highly accurate Factor of Safety (FoS) estimates, it does not provide a possible failure volume. The methods requires an initial landslide geometry to estimate the forces. To overcome this problem, multiple samples can be tested, in order to find the most likely failure volume for a specific slope. This idea has been extended to regional estimation of safety factors and failure volumes by using a large number of sample volumes throughout an entire region. The Scoops3D model uses random spherical shapes to estimate subsurface FoS and failure volumes (Baum et al., 2005; Reid \& Brien, 2012). Conversely, r.slope.stability uses random ellipsoids allowing for more diversity in failure shapes (Mergili et al., 2014a,b). Many ellipsoids are projected through the digital elevation model to better cope with a variety of topographic types and large regions. Due to 
their strong theoretical foundations and detailed output, both random sampling methods are highly useful tools for regional studies, although they also have some limitations. Due to the large number of samples required for this method, the computational burden is high. Because of this, usability may be limited, especially when combining random sampling with real-time hydrological modelling. The lack of hydrological dynamics in the model might decrease the accuracy, since groundwater dynamics play a crucial role in slope instabilities (Kim et al., 2004; Brooks et al., 2004; Tohari et al., 2007). Furthermore, while random sampling provides detailed information about possible failure shapes, and subsurface stability, it is difficult to estimate actual slope failures purely based on this. From the large collection of possible failure volumes, many overlap, and choosing the correct volumes can be a complicated process. Scoops3D provides an estimate of the new elevation model by subtracting all instable spheroids from the original elevation.

In summary: the current methods for regional slope failure prediction either use pre-defined depths and volumes as input, or require intensive computation that cannot be performed on a regional scale. At site-investigation level, it is possible to identify probable failure surfaces based on knowledge of the subsurface structure. However, in regional hazard and risk assessment, the location and geometry of possible slope failures is highly uncertain, as well as the hydrological triggers. Thus, there is a need for a regional slope stability method that is able to predict failure surfaces at low computational costs, allowing for the integration with a real-time hydrological model.

In this paper, we present a physically-based, numerically efficient method for estimating regional slope stability, and calculating expected failure surfaces, within the multi-hazard OpenLISEM model (Bout et al., 2018). We present the equations that take into account horizontal subsurface forces in Section 3.2, and present a comparative analysis at the slope scale between the developed method and existing methods such as infinite slope, random ellipsoid sampling, and finite element modelling in Section 3.3. The improved iterative slope failure method is also applied in a study case, and compared with available and alternative methods in Section 3.4.

\subsection{Theoretical Background}

\subsubsection{Terrain Description}

For the derivation of existing slope stability methods, and the newly developed method, a short description of a typical application is provided. The slope consists of two layers, a bedrock material with high cohesion and a top layer of loose or weathered material (Figure 1). The bedrock layer is assumed to be a fixed boundary condition in the calculations. The depth of the top layer can spatially vary, and the slope of the bedrock layer is therefore not directly equal to the slope of the terrain surface. A saturated zone is present at the base of the top layer, with appropriate hydraulic head and matric suction. The terrain is discretized in local cells or slices (See Figure 3-1). 

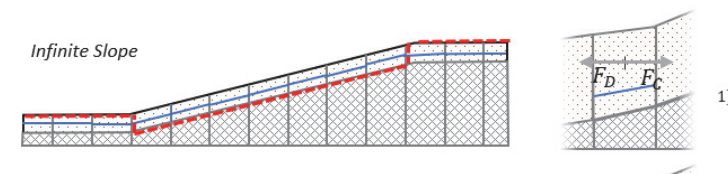

1) $F o S=\frac{c^{\prime}+w_{b} \cdot \cos (\beta)^{2} \cdot \tan (\varphi)}{w \cdot \sin (\beta) \cdot \cos (\beta)}$
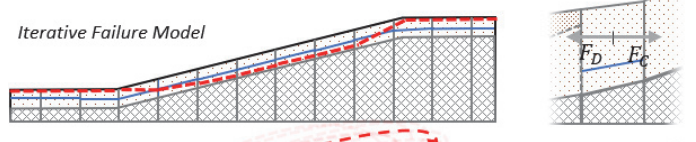

2) FOS $=1=\frac{c+w_{r} \cdot \cos \left(\operatorname{atan}\left(\frac{\mathrm{h}-\mathrm{h}_{0}}{d x}\right)\right)^{2} \cdot \tan (\phi)}{w \cdot \sin \left(\operatorname{atan}\left(\frac{\mathrm{h}-\mathrm{h}_{0}}{d x}\right)\right) \cdot \cos \left(\operatorname{atan}\left(\frac{\mathrm{h}-\mathrm{h}_{0}}{d x}\right)\right)}$
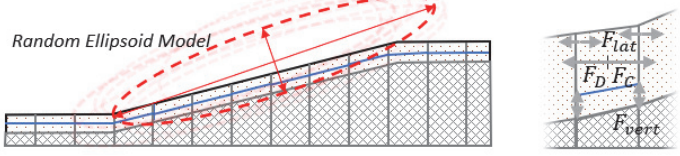

3) $F o S=\frac{\sum R_{i j}\left(c^{\prime}+\left(w \cdot \frac{\cos (\beta)^{2}}{\cos (e)}-p_{p}\right) \cdot \tan (\varphi)\right)}{\sum R_{i j}(w \cdot \sin (\beta) \cdot \cos (\beta))}$

4) $F o S=\frac{\sum\left(c^{\prime}+w_{b} \cdot \cos (\beta)^{2} \cdot \tan (\varphi)\right)}{\sum(w \cdot \sin (\beta) \cdot \cos (\beta))}$
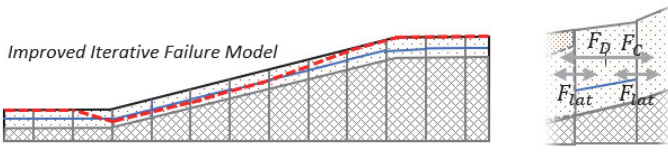

5) FOS $=1=\frac{c+\mathrm{h} \cdot F_{u p}+w_{r} \cdot \cos \left(\operatorname{atan}\left(\frac{\mathrm{h}-\mathrm{h}_{0}}{d x}\right)\right)^{2} \cdot \tan (\phi)}{\mathrm{h} \cdot F_{\text {down }}+w \cdot \sin \left(\operatorname{atan}\left(\frac{\mathrm{h}-\mathrm{h}_{0}}{d x}\right)\right) \cdot \cos \left(\operatorname{atan}\left(\frac{\mathrm{h}-\mathrm{h}_{0}}{d x}\right)\right)}$

6) $\nabla \overrightarrow{F_{u p}}+(\vec{C}-\vec{D}) *\left(\vec{s} \cdot \overrightarrow{F_{u p}}\right)=0$
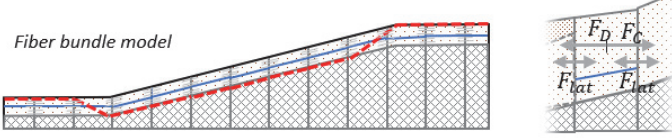

7) $\sigma(\epsilon)=E \epsilon[1-P(E \epsilon)]+\alpha E \int_{0}^{\epsilon} E \epsilon p(E \epsilon) d \epsilon$
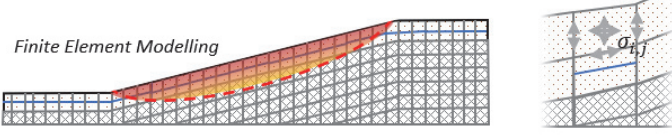

8) $\dot{\epsilon}_{\theta}^{\alpha \beta}=\frac{\dot{j}^{\alpha \beta}}{2 G}+\frac{1-2 v}{B} \dot{\sigma}^{m} \delta^{\alpha \beta}$

9) $\dot{\epsilon}_{p}^{\alpha \beta}=\dot{\lambda} \frac{\delta g}{\delta \sigma^{\alpha \beta}}$

Fiber Bundere $\square$ Bedrock $\square$ Topsoil $\square$ Effective water level $\square$ Failure Surface $\square$ Numerical Element

Figure 3-1 A schematic overview of several slope stability and slope failure modelling methods.

For all of them, varieties exist, and typical representation is shown. Soil depth and an effective groundwater level are shown in the terrain description. In the middle, a force diagram indicates the estimation of local sources $\left(F_{D}, F_{C}\right)$, lateral interactions $\left(F_{\text {lat }}\right)$, vertical interactions $\left(F_{\text {vert }}\right)$, or a full stress tensor $\left(\sigma_{i, j}\right)$. On the right, the governing equations are displayed. For more detail on the equations see: 1)Matsui \& San (1992), 2) Bout et al. (2018), 3) Baum et al. (2005), 4) Mergili et al. (2014a), 5,6) see Section 2.2 and 2,3 of this work, 7) Cohen et al. (2009), 8,9) Mase et al. (2009). Where FoS is the Factor of Safety $(-), c^{\prime}$ is the effective cohesion including matrix suction (Pa), $w_{b}$ is the unit weight minus pore pressure $\left(\gamma \cdot(1-\theta)-\gamma_{w} \cdot \theta\right)\left(\mathrm{kg} \mathrm{m}^{-1}\right), w$ is the unit weight $\left(\left(\gamma \cdot(1-\theta)+\gamma_{w} \cdot \theta\right)\right)\left(\mathrm{kg} \mathrm{m}^{-1}\right), \theta$ is either the effective water level, depending on the model either a fractional ground water level (meters water divided by meters sill $\left(=\frac{h_{g w}}{h_{\text {soil }}}\right)$ ) or a soil matrix water content $(-), R_{i j}$ is the distance from the spheroid center to the potential failure plane $(\mathrm{m}), \beta$ is the failure plane slope angle (radians), $h$ is the height the failure plane $(m), h_{0}$ is the height of the bedrock interface $(m), d x$ is the width of the column $(m), F_{u p}$ is the lateral force from upslope $\left(\mathrm{Nm}^{-1}\right), C$ is the force capacity (top of FoS equation) $\left(\mathrm{Nm}^{-1}\right)$, $D$ is the unit force demand (bottom of FoS equation) $\left(\mathrm{Nm}^{-1}\right), S$ is the slope vector $\left(\mathrm{m} \mathrm{m}^{-1}\right), E$ is the Elastic Modulus $(\mathrm{Pa}), G$ is the Shear Modulus $(\mathrm{Pa}), \sigma$ is the stress tensor $\left(\mathrm{Nm}^{-2}\right), \epsilon$ is the strain tensor $(\mathrm{m}), P$ is the Distribution of fiber 
strength $(-), s$ is the deviatoric stress tensor $(\mathrm{Pa}), g$ is the plastic potential function $(-), \lambda$ is the plastic rate multiplier $(-)$ and $v$ is Poisson's ratio $\left(\mathrm{m} \mathrm{m}^{-1}\right)$.

\subsubsection{Iterative Slope Failure}

The iterative slope failure method consists of an upslope iterative process, determining failure depth from toe to top. Several assumptions are used in the process. Initially, the failure surface is, at any point, assumed to be parallel to the surface gradient. We calculate the force capacity and force demand, leading to a local safety factor similar to the infinite slope model (Equation 3.1).

$$
\text { FOS }=\frac{c^{\prime}+w_{r} \cdot \cos (\beta)^{2} \cdot \tan (\varphi)}{w \cdot \sin (\beta) \cdot \cos (\beta)}
$$

In this method, the angle of the potential failure plane $(\beta)$ is assumed parallel to the surface slope. Spatial slope values and directions dynamically depend on the evolution of the elevation model (Equation 3.2). Within a discretized environment, changing elevation due to failure directly influences neighboring cells.

$$
\text { 3. } 2 \quad \beta=\operatorname{atan}\left(\frac{\max \left(\mathrm{h}_{\mathrm{x}-1}-\mathrm{h}_{\mathrm{x}}, \mathrm{h}_{\mathrm{x}}-\mathrm{h}_{\mathrm{x}+1}\right)}{\mathrm{dx}}\right)
$$

re $h_{x}$ is the elevation of the current cell $(m), h_{x-1}$ is the elevation of the downslope cell $(\mathrm{m}), \mathrm{h}_{\mathrm{x}+1}$ is the elevation of the next cell $(\mathrm{m})$ and $d x$ is the cell size $(\mathrm{m})$.

We take the maximum of the slope on both sides as the effective slope used in the calculations for slope failure. Then, in case of instability, we reverse the safety factor equation to reduce the depth of the soil layer and achieve local stability (Equation 3.3).

$$
\text { FOS }=1=\frac{\mathrm{c}+\mathrm{w}_{\mathrm{r}} \cdot \cos \left(\operatorname{atan}\left(\frac{\mathrm{h}-\mathrm{h}_{0}}{\mathrm{dx}}\right)\right)^{2} \cdot \tan (\phi)}{\mathrm{w} \cdot \sin \left(\operatorname{atan}\left(\frac{\mathrm{h}-\mathrm{h}_{0}}{\mathrm{dx}}\right)\right) \cdot \cos \left(\operatorname{atan}\left(\frac{\mathrm{h}-\mathrm{h}_{0}}{\mathrm{dx}}\right)\right)}
$$

Where $c$ is the cohesion $(\mathrm{Pa}), w_{r}$ Is the weight of the column with excess pore pressure subtracted $\left(\mathrm{N} \mathrm{m}^{-2}\right)$ and $w$ is the full weight of the column $\left(\mathrm{N} \mathrm{m}^{-2}\right)$. Solving this equation can be done using the trigonometric identities (Equation 3.4 and 3.5 ).

$$
\begin{aligned}
& \operatorname{Cos}(\operatorname{atan}(\mathrm{x}))=\frac{1}{\sqrt{1+\mathrm{x}^{2}}} \\
& \operatorname{Sin}(\operatorname{atan}(\mathrm{x}))=\frac{\mathrm{x}}{\sqrt{1+\mathrm{x}^{2}}}
\end{aligned}
$$

Finally, we find the lowest real root to the second-order polynomial equation of the form

3.6

With

$$
\begin{gathered}
\mathrm{h}=\mathrm{a}+(\mathrm{b}) \mathrm{x}+(\mathrm{c}) \mathrm{x}^{2} \\
a=c h_{0}^{2}-\mathrm{cdx} \mathrm{dx}^{2} \\
b=2 \operatorname{ch} 0-w h_{0} \text { FOS }-w h_{0} \text { FOS } d x w_{r} d x^{2} \\
c=c-w_{r} \text { FOS } d x
\end{gathered}
$$

Removing material due to failure alters the slopes of the surrounding areas, potentially creating new instable areas. Consequently, equations $3.1-3.6$ are applied iteratively to remove any material that is required to obtain a stable slope. Thus, the algorithm iteratively solves for a failure volume. In practice, 
this generally means that a landslide toe is found (unstable cell), after which material is removed on that location. The downslope angle of upslope cells is thereby increased. This repeats until a full. The model thus assumes that at any moment, the cell under consideration is the toe of a potential failure, where no net stability is gained from downslope neighbors.

While the propagating effect of the iterations provides some interaction between columns of material, the initiation of failure is based on a local description of forces. No description of lateral or shearing forces between material columns is implemented. The failure propagation can only take place in an upslope direction, since reduction of the material depth will always decrease the steepness in the downslope direction, and increase the steepness in the upslope direction. Therefore, it would only activate failures in upslope cells.

It seems that for translational slope failures, where local forces provide an accurate estimation of the actual safety factor, the iterative method is appropriate. Rotational failures are not described well by local forces, but are better analyzed through total rotational moment. For a potential failure, excess moment (or forcing) from upper parts of an ellipsoid might counteract the stability of lower parts. As a result, slope material that is stable when local forces are considered only, can be involved in failure by the forces propagating in the subsurface. Thus, to reproduce this effect, an extended version of the iterative method is required.

\subsubsection{Iterative Slope Failure with Forcing}

An improved iterative slope failure method is here proposed. Propagation of subsurface forces is estimated, hence inter-slice forcing is not neglected. We adapt the expression for the safety factor to include this (Equation 3.7)

$$
\mathrm{FoS}=\frac{\mathrm{F}_{\mathrm{up}}+\mathrm{c}^{\prime}+\mathrm{w}_{\mathrm{r}} \cdot \cos (\beta)^{2} \cdot \tan (\varphi)}{\mathrm{F}_{\text {down }}+\mathrm{w} \cdot \sin (\beta) \cdot \cos (\beta)}
$$

With this method, excess force demand is transferred downslope until it is finally negated by excess force capacity. In a two dimensional situation, the forcing can be found by a summation of the upslope or downslope excess force capacity and demand, respectively (Figure 2). 


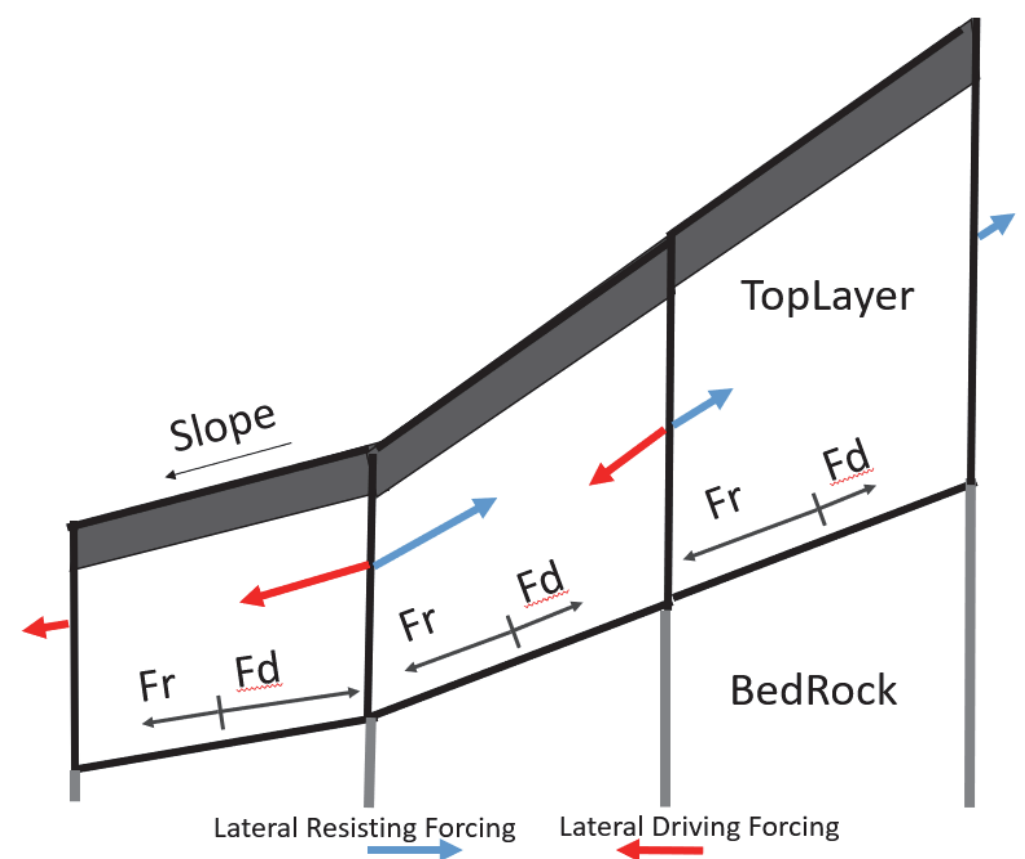

Figure 3-2 Schematic overview of subsurface forces in the iterative failure method.

In a complete terrain description, a sum of all upslope forces would entail the sum of forces for the entire catchment that lies above any given point. Due to changes in slope, the lateral force interactions between soil columns partially act on the bedrock interface. The effective lateral force is the portion parallel to the slope of the terrain. We assume that, in case where lateral forces are included, the effective forcing that propagates through the subsurface is determined by the in-product between the forcing and the normal direction of the interface between the soil columns (Equation 3.8 and 3.9).

$$
\begin{aligned}
& \mathrm{F}_{\text {down }}=\sum_{\text {upslope }} \max (0, \mathrm{D}(\mathrm{i})-\mathrm{C}(\mathrm{i})) *\left(\overrightarrow{\mathrm{S}}_{\mathrm{i}} \cdot \overrightarrow{\mathrm{S}}_{\mathrm{i}+1}\right) \\
& \mathrm{F}_{\text {up }}=\sum_{\text {downslope }} \max (0, \mathrm{C}(\mathrm{i})-\mathrm{D}(\mathrm{i})) *\left(\overrightarrow{\mathrm{S}}_{\mathrm{i}} \cdot \overrightarrow{\mathrm{S}}_{\mathrm{i}-1}\right)
\end{aligned}
$$

Raster-based slope stability using lateral subsurface forces has been implemented earlier in the work of Zhou \& Cheng (2013) and Zhou et al., (2014). Within their implementation, only directly neighboring cells exert lateral forcing on a soil column. In the proposed implementation, forces are iteratively solved throughout the entire terrain. In the three-dimensional case, where the $x$-and $y$ - components of the forcing and slopes influence the propagation, this can be expressed as follows:

$$
3.10 \quad \nabla \overrightarrow{\mathrm{F}_{\text {up }}}+(\overrightarrow{\mathrm{C}}-\overrightarrow{\mathrm{D}}) *\left(\overrightarrow{\mathrm{S}} \cdot \overrightarrow{\mathrm{F}_{\text {up }}}\right)=0
$$

We assume that excess force is transferred downslope, but the fractured top material is unable to transfer force resistance upslope.

The final expression of FoS, depending on the depth of the material, is provided in Equation 3.11. Here, we assume a straightforward linear relationship 
between the fraction of the material, and the fraction of the down- and upslope forcing that acts on the regolith.

$$
\text { FOS }=1=\frac{\mathrm{c}^{\prime}+\mathrm{hF}_{\mathrm{up}}+\mathrm{w}_{\mathrm{r}} \cdot \cos \left(\operatorname{atan}\left(\frac{\mathrm{h}-\mathrm{h}_{0}}{\mathrm{dx}}\right)\right)^{2} \cdot \tan (\phi)}{\mathrm{hF}_{\text {down }}+\mathrm{w} \cdot \sin \left(\operatorname{atan}\left(\frac{\mathrm{h}-\mathrm{h}_{0}}{\mathrm{dx}}\right)\right) \cdot \cos \left(\operatorname{atan}\left(\frac{\mathrm{h}-\mathrm{h}_{0}}{\mathrm{dx}}\right)\right)}
$$

To solve for a stable depth using a safety factor equation with upslope forcing, we can use the trigonometric identities from Equations 3.4 and . Finally, we find the lowest real root to the third-order polynomial equation of the form

3.12

$$
h=a+(b) x+(c) x^{2}+(d) x^{3}
$$

with

$$
\begin{aligned}
& a=c^{\prime} h_{0}^{2}-c^{\prime} \mathrm{dx}{ }^{2} \\
& b=2 c^{\prime} h 0-w_{r} h_{0} \text { FOS }-w_{r} h_{0} \text { FOS } d x F_{u p} d x^{2} \\
& c=c^{\prime}-w_{r} \text { FOS } d x \\
& d=F_{\text {down }}-w \text { FOS } d x
\end{aligned}
$$

Generally, the addition of subsurface forces within a slope stability description changes the FoS, and the slip depth, particularly at the lower end of the failure. Here, additional forcing from upslope will decrease stability and mobilize more material. By including an estimate of subsurface forces, lateral interactions are implemented, and the method of slices is numerically mimicked.

\subsection{Two-Dimensional Analysis}

A 2D analysis of the effect of the iterative slope stability methods on the predicted failure volumes has been performed. This both validates the methods against accurate alternatives (random ellipsoid sampling), and highlights the additional behavior included in the iterative slope failure model with forcing. Four elevation curves were created, based on typical slope shapes: concave, convex, and the combination of both. These curved slopes can highlight the differences between model results. The equations and shaped of the slopes are provided in Figure 3.

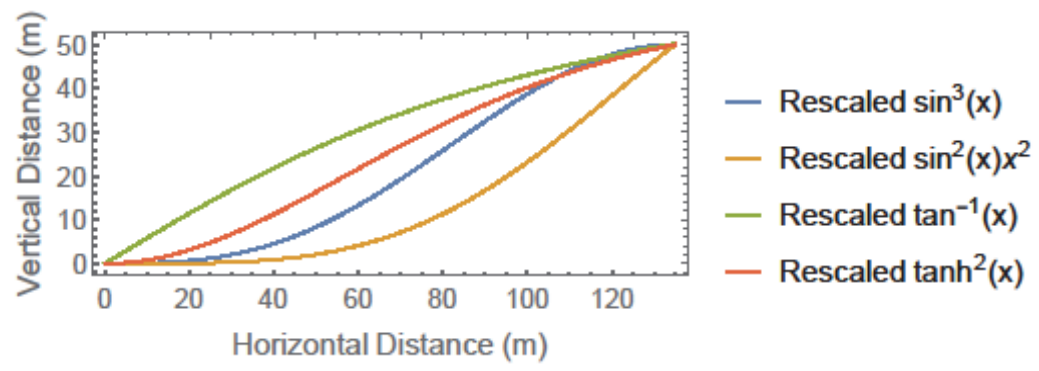

Figure 3-3 Elevations of the test slopes

A topsoil layer is assumed, with bedrock underneath. The depth of the topsoil layer is calculated using Equation 3.13.

$$
\mathrm{SD}=5.0-1.5 * \frac{\text { elevation }}{\text { elevation }_{\max }}
$$

A two-dimensional implementation of the random spheroid sampling found in the work of Mergili et al (2014) and Xie et al. (2002) is used. Both the iterative 
failure model and iterative failure model with forcing are then compared to the results of random ellipsoid sampling. An overview of two-dimensional failure volume predictions is shown in Figure 4. The results of the random ellipsoid sampling are shown a transparent overlay of all found instable samples. The most
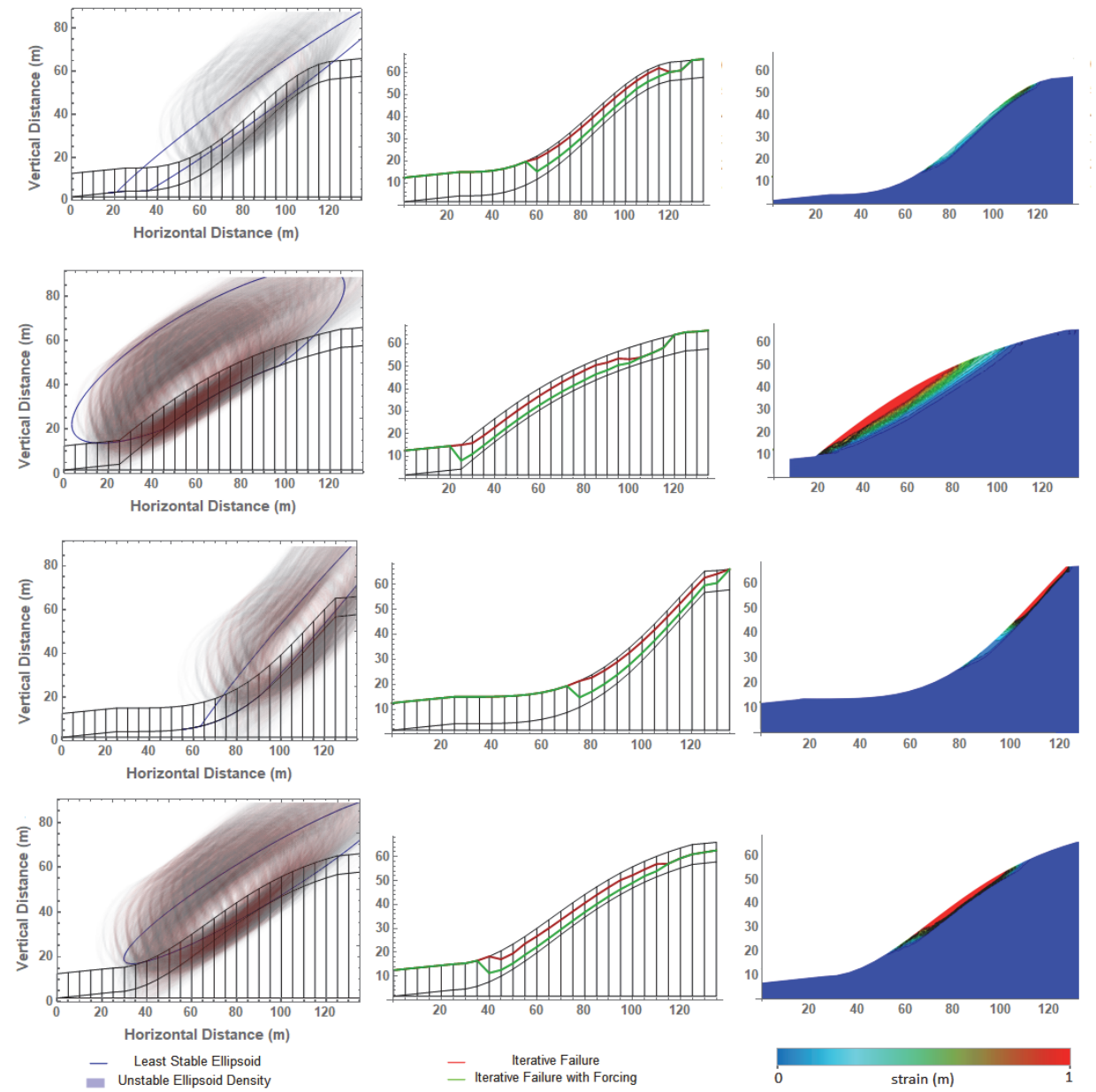

Figure 3-4 Results for the failure volume simulations using random ellipsoid samplings(left), iterative slope failure and iterative slope failure with forcing (Middle) and Finite Element Modelling (Right). Grey shades represent the density of unstable ellipsoids.

The two-dimensional results show significant differences between estimated failure volumes for different methods. The Finite Element Modelling and Random Ellipsoid Sampling methods show consistent results in the location of shallow failures. On average, the FEM results indicate slightly smaller failures compared to all possible unstable ellipsoids. This is expected, as the failure on ellipsoid will positively influence the stability of other by means of removing 
critical mass on the slope. While the failure extents of all methods are highly similar, significant differences are visible when it comes to failure depths. In particular, the iterative method shows similar starting points for the failures but features an unrealistically shallow toe. This is caused by the lack of a subsurface lateral force description that ads weight from upslope instabilities downslope. In the case of random ellipsoid sampling, forces are summed to estimate the total safety factor of an ellipsoid failure volume. Thus, upslope weight can compensate for downslope stability. This leads to the typical rotation shapes of the failures. Similarly, in the FEM, displacements propagate downslope through increased stress. In the case of the iterative slope failure method, this effect is missing entirely. Despite this absent effect, general predicted volumes are close to the FEM and random ellipsoid sampling results. Conversely, the iterative slope failure method with subsurface forces is better suited to capture the effect of additional upslope driving force. Using this method, the predicted failure volumes continue into the stable downslope areas to create a more realistic landslide shape. This increases the accuracy of the prediction in the sense that it improves likeness with the random ellipsoid sampling results. The necessity of including an upslope forcing effect depends on the type of slope investigated. In the case of the first test slope (Figure 3-4), with a concave-convex shape, the difference is minimal. For the other cases, there is a larger amount of upslope instability, which increases the magnitude of the effect.

\subsection{Application of the Model}

The improved model for progressive slope failure analysis was tested in a study area in Sicily, Italy. Both the study site and the event are described in more detail in Bout et al (2018). On the $1^{\text {st }}$ October 2009, hundreds of debris flows were triggered as a result of a cloudburst which released $250 \mathrm{~mm}$ of rain in a few hours, whereas the area also received around $250 \mathrm{~mm}$ in the previous two weeks. As a result, the already saturated soils draping over rough terrains failed either as debris slides of which many evolved into debris flows, eroding the slope down to approximately two meters. It entrained a sandy gravelly and relatively highly organic material (Lombardo et al., 2018a) originated from the underlying weathered layer of medium to high grade metamorphic rocks (Cama et al., 2015). Several of these flows followed the main stream incisions along the slope, interacting with each other and merging into a larger and single mass, which caused severe damage in the downstream villages (37 victims and 500M€ of damage). The trigger rainfall had an extreme intensity of $120 \mathrm{~mm} / \mathrm{hr}$ (Schillaci et al., 2017), for which the return period was estimated to correspond to a 30 year interval (Aronica et al., 2011).

The area exposed to the storm spans over 12 coastal catchments (see Fig. 1 in Lombardo et al., 2018b and references therein). In this contribution, we selected just the Scaletta watershed, where a debris flow inventory was previously built, with 395 slope failures (details in Lombardo et al., 2014) and modeled for susceptibility (Lombardo and Mai, 2018) and hazard (Bout et al., 2018) purposes.

Data requirements for deterministic simulations consist of: i) DEM, ii) Soil Texture, iii) Soil depth, iv) Land Use, v) NDVI, and vi) Precipitation regime. The $2 \mathrm{~m}$ resolution DEM was pre-event and generated from a LIDAR survey (for 
details, see Cama et al. 2016). The $200 \mathrm{~m}$ resolution Soil Texture comes from a national survey and highlights the presence of clayey sands in the Peloritani ridge transitioning to clay and then to sand towards the coastline (Schillaci et al. 2017). Soil properties were re-scaled based on 13 texture measurements within the study site. A $10-\mathrm{m}$ resolution land use map was generated from semi-automated classification of Sentinel-2 scenes (Bout et al. 2018). The NDVI was calculated from $4 \mathrm{~m}$ resolution KompSat- 2 data. While land use data is used for the majority of surface properties in the model, ndvi is used to empirically estimate leaf area index and vegetation cover (Bout et al., 2018). Rainfall time series with 10 min resolution was obtained from local rain-gauges. Soil depth was derived using multivariate statistics. Specifically, an Ordinary Least square was run between soil depth measurements and terrain properties (Bout et al., 2018).

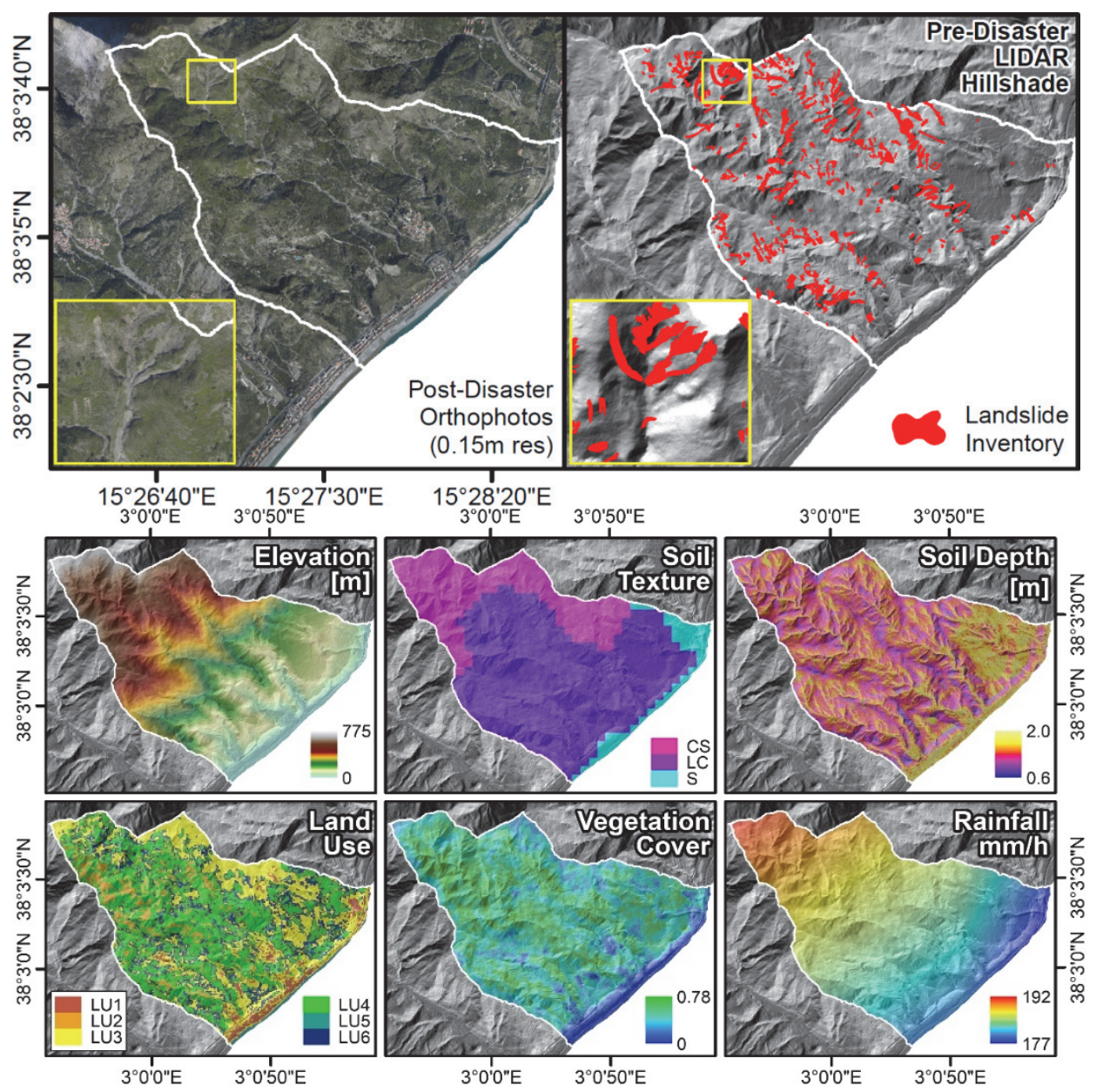

Figure 3-5 Overview of the study area. Landslide inventory, elevation model, soil depth prediction and land use and soil classes are shown. 
The slope failure models use a groundwater and soil moisture state derived from ground water simulations performed by Bout et al (2018). Failure predictions occur for the ground water state after the 2009 event has occurred. The predicted slope failures for the Scaletta catchment were modelled using four different methods (infinite slope, random ellipsoid sampling, and iterative failure with and without forcing. The results are shown in Figure 3-6, together with the landslide inventory.

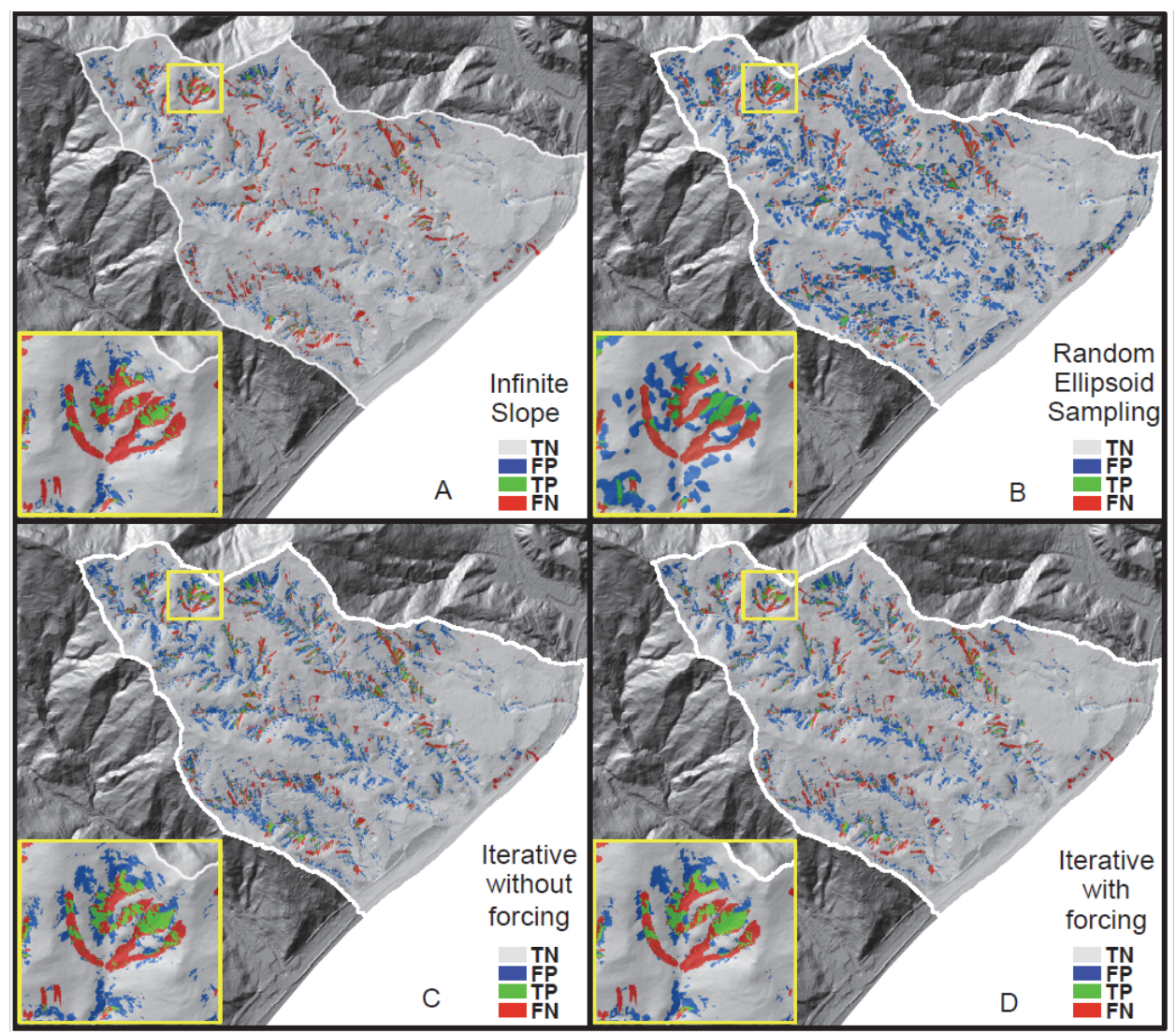

Figure 3-6 Predicted failure location compared with mapped landslides for each model. A: infinite slope $B$ : random ellipsoid sampling; $C$ : iterative failure without forcing; $D$ : iterative failure with forcing. TN: True negative, TP: true positive, FP: false positive

Both the shapes and sizes of predicted slope failures vary between the used methods. General locations of failures are identical, primarily due to the calibration process. The infinite slope predictions are spatially scattered while the iterative methods (with and without forcing) introduce spatially connected failures. Random ellipsoid sampling provides the largest area of failures, with smooth ellipsoid failure areas. The accuracy of the predicted slope failures for the Scaletta catchment using different methods are shown in Table 3-1. As a measure of fit, we use Cohens Kappa, since it is able to compensate for accidental correlations that are expected (Bout et al. 2018). 
Table 3-1 Accuracy of the tested slope stability methods. ${ }^{1}$ Overlap is defined as (TP $+\mathrm{TN}) /(\mathrm{TP}+\mathrm{FP}+\mathrm{FN}+\mathrm{TN})$

\begin{tabular}{|c|c|c|c|c|c|c|}
\hline Method & $\begin{array}{l}\text { Percentage } \\
\text { overlap }^{1}\end{array}$ & $\begin{array}{l}\text { Cohens } \\
\text { Kappa }\end{array}$ & TP & FP & $\mathbf{F N}$ & TN \\
\hline Infinite Slope Method & 0.87 & 0.28 & 142183 & 380840 & 159100 & 3657263 \\
\hline Iterative Slope Failure & 0.86 & 0.29 & 179205 & 468245 & 147234 & 3544675 \\
\hline $\begin{array}{l}\text { Iterative Slope Failure } \\
\text { With Forcing }\end{array}$ & 0.88 & 0.39 & 214054 & 166040 & 336365 & 3622900 \\
\hline $\begin{array}{l}\text { Random } \\
\text { Sampling }\end{array}$ & 0.87 & 0.37 & 198532 & 273818 & 251401 & 3615608 \\
\hline
\end{tabular}

The predicted failure depths are shown in Figure 3-7. The failure depths of the infinite slope implementation are restricted to either the full soil depth, or no failure at all. The other methods provide more smooth predictions of slope failure, with the smaller failure depths typically found at the edges of failures. Both the ellipsoid sampling and iterative method with forcing predominantly predict the deepest part of the failure at the lower center of the failure.
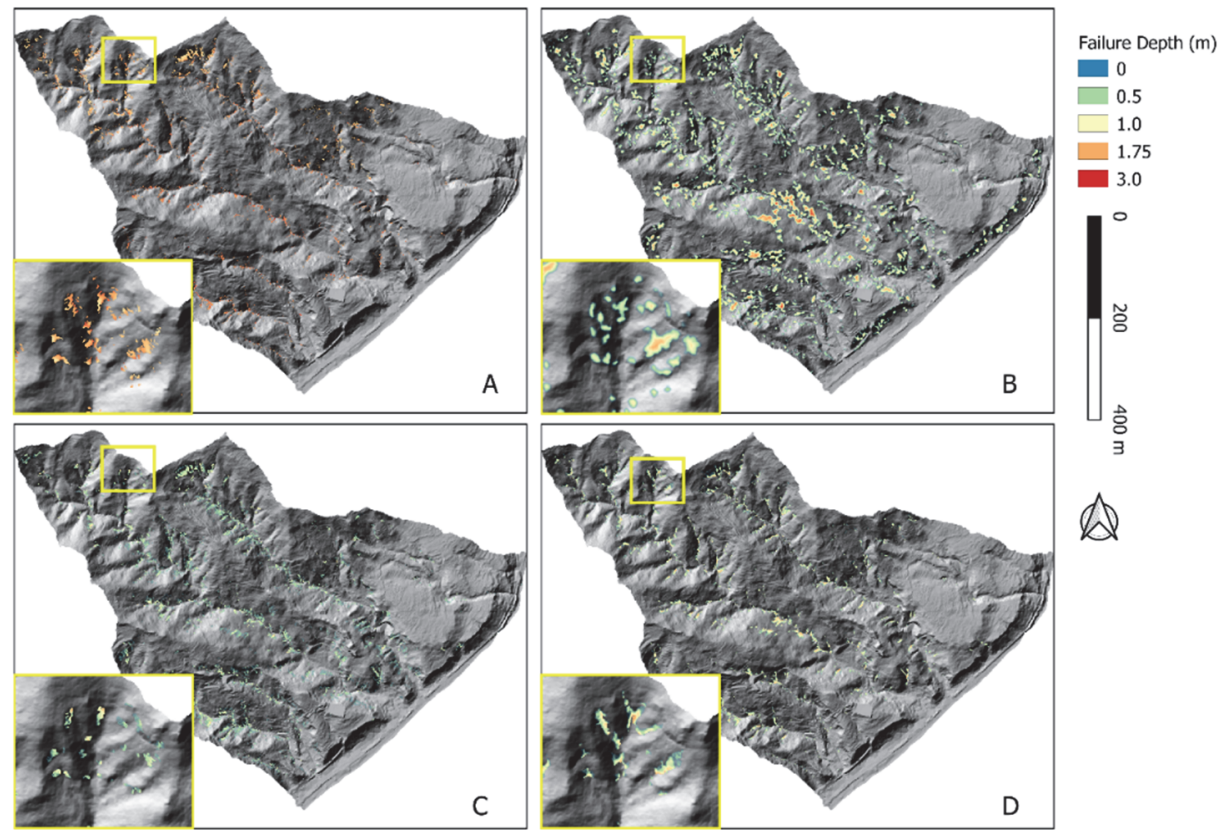

Figure 3-7 Predicted failure depths in meters. A: infinite slope B: random ellipsoid sampling; $C$ : iterative failure without forcing; $D$ : iterative failure with forcing

For each of the used methods, the size-frequency distribution and area-volume data is shown in Figure 3-8. 

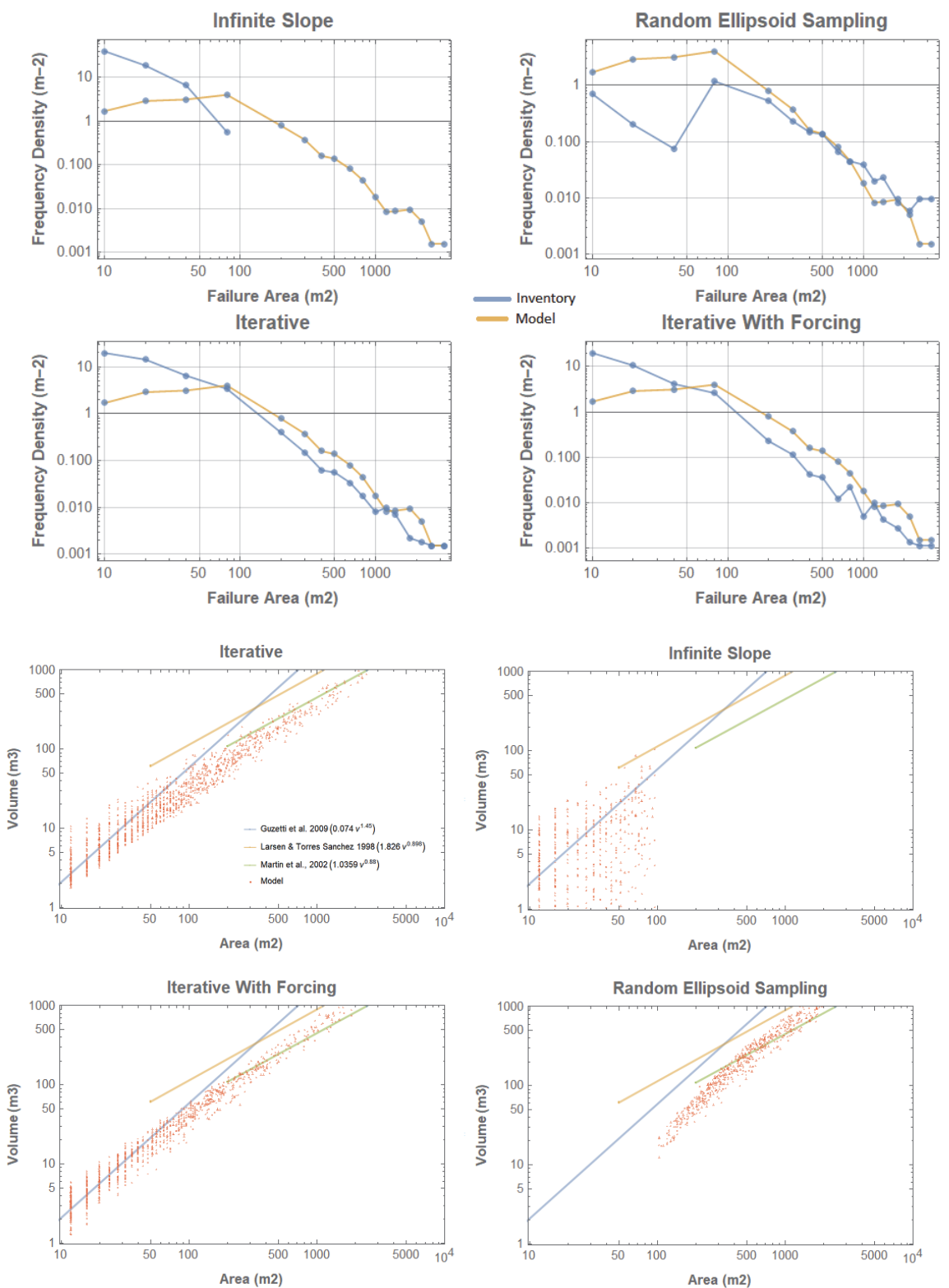

Figure 3-8 Area-Frequency curves for the predicted slope failures and Area-Volume plots for the predicted slope failures. Data on the Frequency Area Distribution curves: Inventory: Rollover $=80, \beta=1.82$; Infinite: Rollover $=-, \beta=1.268$; Random Ellipsoid Sampling: 


\subsection{Discussion}

\subsubsection{Accuracy}

Each of the considered models shows influences of underlying assumptions in the slope failure predictions. Specifically, the infinite slope method, due to its simple approximation, provides the least overlap between predicted and observed failures. On the other hand, while the iterative slope failure method initially uses the same physical principles for stability, failure volumes are calculated by including some spatial interactions through changing slopes. This alters the final calibrated parameters and slightly improves failure patterns. A more significant improvement is found in the area-frequency distribution of the slope failures. Here, infinite slope lacks any expected pattern since larger slope failures are completely absent due to the lack of lateral interactions. The iterative methods match the Frequency Area Distributions (FAD) of the inventory with higher likelness. Random ellipsoid sampling finally shows similar Cohens kappa to the iterative method with forcing, but better matches the FAD for larger failures.

The Area-Volume scatter plots in figure 8 are shown together with three slidefailure empirical relationships from Guzetti et al. (2009),Larsen \& Torres Sanches (1998) and Martin et al., (2002). Here, the weakness of the infinite slope method on small grid sizes is evident, as only the smaller failures exist, and show non of the expected pattern. The iterative methods follow Guzetti et al. first and Martin et al. above an area of $200 \mathrm{~m}^{2}$. Random Ellipsoid sampling follows Martin et al above an area of $200 \mathrm{~m}^{2}$ and drops beneath the empirical relationships below this value.

Some of the reasons for the differences in prediction accuracy can be found in the physical principles behind each model. The first major difference in model workings is the spatial connectivity of failure calculations. While the infinite slope model only takes into account local forces, the other used methods include some lateral interactions. Without these lateral interactions, individual cells can experience failure without surrounding areas being influenced. As is visible in Figure 3-8, this results in a large over-estimation of the frequency of smaller failures. Although significantly less, the iterative methods similarly over-estimate small failures when compared to the inventory, while random ellipsoid sampling under-estimates these.

A second difference is found in the roll-over point, the location within the areafrequency distribution across which smaller slope failures are less frequent. This effect is partially caused by inherent properties of slope failure inventories. The smallest of landslides are increasingly difficult to map, often leading to a roll-over point. The presence of a roll-over point within the random ellipsoid sampling results from the assumed shape of failures and practical model limitations. The tested ellipsoids sample at least multiple cells and can not predict failures on individual cells. To provide more accurate results, more and smaller ellipsoids must be sample, increasing computational costs exponentially. Opposed to this, the iterative methods organically shape along the elevation model and can predict failures that are the size of a singular grid cell when required by the terrain description.

In the FAD curves, additional differences emerge, both between the models and with the inventory data. The infinite slope prediction both over-estimates 
small slope failures (compared to the inventory) and underestimates larger slope failures. The iterative methods with and without forcing more closely match the frequency of larger failures but similarly over-estimate smaller failures. The inventory only shows a roll-over point at around $80 \mathrm{~m} 2$. The random ellipsoid sampling results similarly show a roll-over point at an area of approximately $80 \mathrm{~m} 2$. This method however under-estimating the frequency of small failures in the inventory. The results indicate a crucial matter of methodology in regional landslide prediction. Current methodologies on regional modelling of landslide areas and volumes are often calibrated and validated against inventory data. It is, however, in the nature of landslide inventories to underestimate the theoretically expected number of smaller landslides due to mapping limitations. If the method itself does not feature some rollover point, or if the rollover effect is of different magnitude, calibration can lead to non-optimal results. Such is the case for each of the presented modelling methods. Figure 3-8 shows that the area-frequency density distribution of random ellipsoid sampling is more accurate for larger failures than the iterative methods. The inaccuracy of the iterative methods could be caused either my modelling assumptions, as the iterative methods inherit some weaknesses from the infinite slope model, as well from the invalid method of calibration. A more valid way of comparing modelling and mapping results might be to exclude the smaller slope failures from comparison, as they are not completely represented in the inventory data.

\subsubsection{Subsurface Forces}

The iterative model with forcing includes a lateral sub-surface force that propagates through the terrain. An overview of the simulated subsurface forcing in the improved iterative failure method is shown in Figure 3-9. 


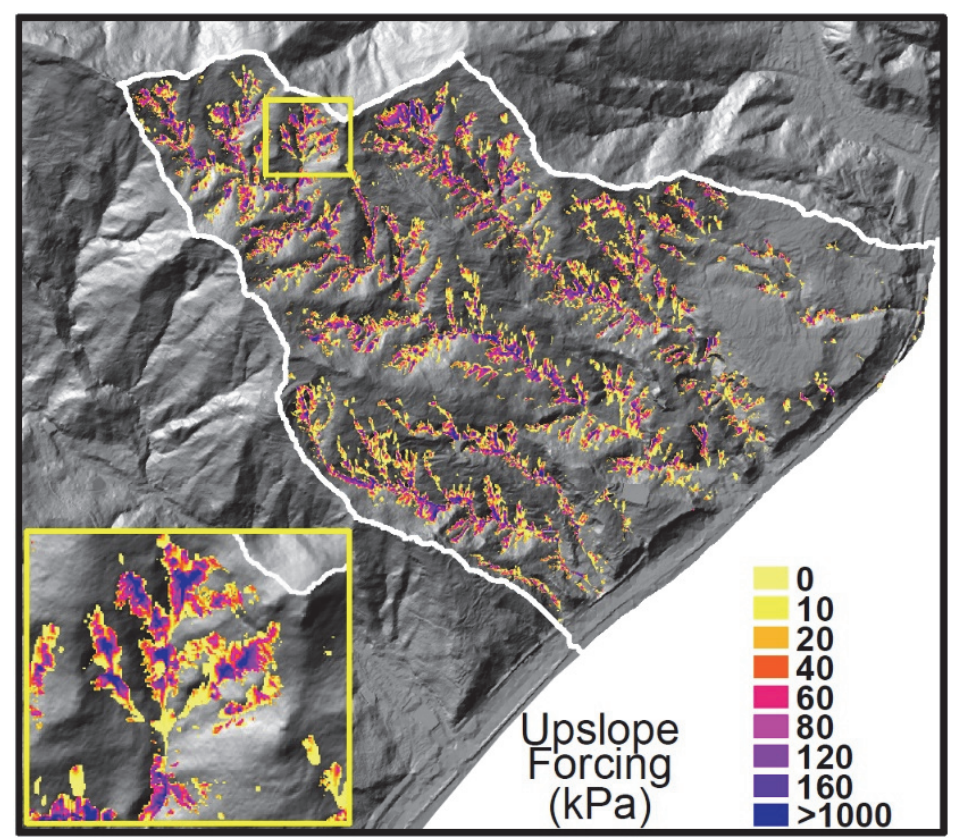

Figure 3-9 Spatial prediction of additional forcing from upslope instabilities for the Scaletta catchment.

The patterns in upslope forcing arise from excess force demand in upslope areas (Equation 20). Areas with low stability provide forcing that works through the subsurface towards downslope areas. The particular shapes and extends to which the forcing influences the extent of the instability largely depend on the topography. This is caused partially by the relatively homogeneous strength parameters and soil depth. The primary benefits of the subsurface force simulation are visible in the improved accuracy and failure extents. Scattered small failures become connected through the subsurface forces, and merge into a single larger body. This solves a well-known issue with the infinite slope model, where due to dependency on local parameters, slope failures could be pixel-sized and scattered. Another improvement caused by the addition of upslope forcing is the imitation of rotational behavior. In many cases, excess forcing concentrates downslope, leading to a smaller safety factor and finally a deeper failure at the bottom. This pattern is typical of larger landslides, where failures can frequently extend beyond the locally stable areas, and be deepened at the lower end of the failure.

\subsubsection{Influence of Approximation on Depth Patterns}

For a better comparison of failure depths using the described regional slope failure methods, several profiles of failure are shown in Figure 3-10 together with a profile of the elevation model and the inventory. 

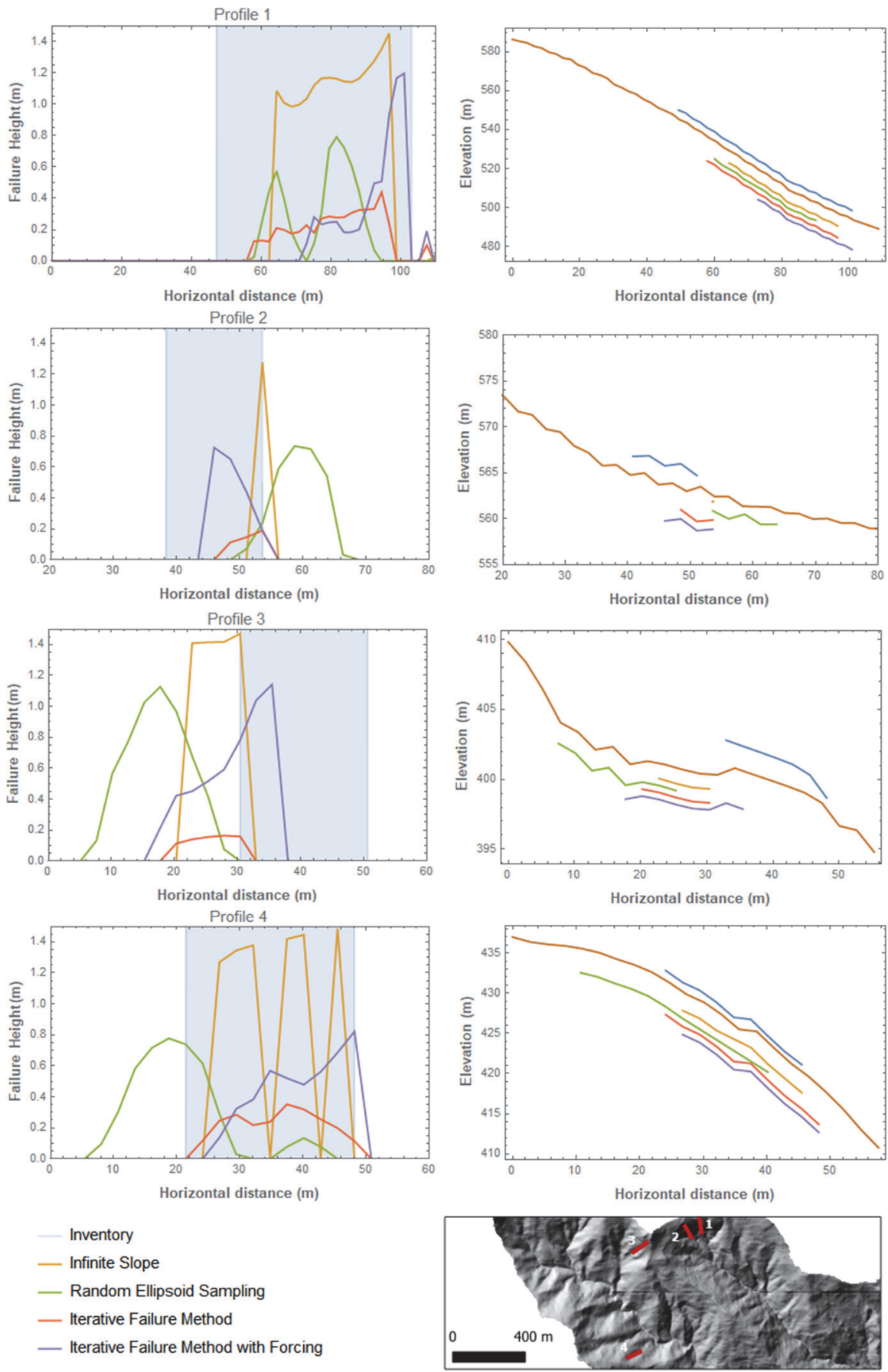

Figure 3-10 Profile plots through four slope failures in the Scaletta area. Blue background indicates the presence of slope failure in the inventory along the profile. The profiles show the locations of the inventory (above the terrain) and the modelled failures (below the terrain). 
The profiles in Figure 3-10 show the shapes of the predicted slope failures differ based on the method used to estimate them. The used implementation of the infinite slope model provides an "all-or-nothing" prediction of failure, and the depth is therefore either zero or the total soil depth, resulting in unnatural failure shapes. The iterative methods that are presented in this paper show patterns that are distinctly different from both random sampling and the infinite slope prediction. In the case of the Scaletta catchment, ellipsoids are not the predominant shape of slope failures, since the failures were mainly translational in nature. For application to this area, the assumptions underlying random ellipsoid sampling method might not be fully met for every slope failure. Despite this, the methods predicts spatial patterns well. Failure depths match the general observation of depths around 2 to 3 meters (Bout et al., 2018). In the three-dimensional application of the iterative method with and without forcing we observe identical trends in failure shapes as in the twodimensional tests. The iterative method with forcing shows rotational behavior dependent on the topography, and creates more connection between predicted failures locations.

\subsubsection{Usability}

Each of the models exhibits a specific niche in which its application is useful and justified. In the case of course data and little knowledge about terrain parameters, an indicative estimate of slope stability and possible failure can be made with the infinite slope model. With increasing spatial resolution and detail, other methods become more suited. The iterative slope failure methods with and without forcing and the random ellipsoid sampling method provide a way to deal with higher spatial resolutions and detailed data. In particular, in case of shallow landslides, the assumptions of the iterative methods hold well and the method provides a fast and efficient estimate of spatial failure depths. When deep-seated landslides are of interest, lateral sub-surface forces become a dominant factor, random sampling methods provide both the detail and valid assumptions to assess failure depths. However, there is a major difficulty with finding regional failure depths based on random sampling, namely finding a set of ellipsoid describing the failure surfaces. Due to the large number of overlapping ellipsoid, all material on unstable cells can be removed, or a minimum remaining terrain elevation based on all ellipsoids can be calculated. The first option provides similar issues as the infinite slope (all-or-nothing failure pattern). The second option might strongly over-estimate failure depths. Random sampling methods ignore the changes in stability caused by failure of a specific shape on the stability of other shapes.

A final consideration in the usability of the mentioned slope failure methods is the calculation time for each approach. The infinite slope method provides the lowest computational cost. This makes this method applicable within a spatial physically-based soil moisture model. For a detailed analysis of local threedimensional slope stability, the random ellipsoid method is most suited, but has the largest computational load. This model provides closest to analytical solutions for slope stability, but requires large amounts of processing time, due to the large number of ellipsoid samples. The iterative methods require more calculation time than the infinite slope method, especially with upslope forcing. However, the computation speed is high enough to be used in real-time spatially distributed high resolution physically-based simulations of hydrology, 
slope stability and slope failure (Bout et al., 2018). This makes the iterative methods suited for multi-hazard modeling, were failure volumes can be used to directly introduce runout of the material in the simulation.

\subsection{Conclusions}

In this article we have presented the iterative slope failure method with forcing (developed as part of the Open-Source OpenLISEM Hazard model). This method is a variation on the iterative failure model used in Bout et al. (2018). Regional application for Scaletta has shown minor improvements when using either infinite slope or iterative method. Random ellipsoid sampling performs better on especially larger slope failures, but does not have the numerical efficiency for integration into real-time simulation of hydrology. The iterative failure method with forcing can thus be applied to hydrology-influenced slope stability and failure volumes. The availability of a fast regional model for both slope failure and failure depths allows for new advanced in multi-hazard modelling. The developed method can act a link between slope stability and runout models, such as has been done by Bout et al. (2018).

Analysis of the properties of model predictions showed a variety of key differences. The infinite slopes tendency to predict isolated failures and its allor-nothing failure estimations lead to inaccuracies. A further issue arose in methodological considerations. While both the inventory and random ellipsoid sampling method showed rollover points, the iterative methods did not. Here, the expected power law distribution of landslide frequency density continues up until the grid cell size. This poses the question of the validity of calibration methods. In calibration, these methods are compared against inventories that underestimate, by their very nature, the smallest failures. Future studies might investigate the viability of calibration of regional slope failure models that ignores predicted landslides that are below the rollover point of the inventory. 


\section{Integration of Two-phase Solid Fluid Equations in a Catchment Model for Flashfloods, Debris Flows and Shallow Slope Failures}

This chapter is reproduced as published in Bout et al. (2018) with minor modifications.

\subsection{Introduction}

Shallow landslides are frequently occurring natural hazards, which may be triggered by extreme rainfall events, snow melt and earthquakes, and are characterized by a relatively small and shallow failure plane. Because the triggering of these landslides takes place predominantly during intense precipitation, the sliding soil, mixed with water, may evolve into debris flows, that have a devastating impact on villages, roads and other elements-at-risk. In order to understand and predict the behavior of debris flows, numerical models have been frequently used as both predictive and analytical tools. However, in current modeling approaches, processes that relate to debris flows, such as hydrology, shallow landslides and runout, are mostly simulated separately.

The simulation of debris flow dynamics is performed by debris flow runout models. These models use (semi-) physically-based estimations of the internal forces in debris flows to numerically calculate flow depths, velocities and routing based on topography and surface properties. A large number of runout models exist, varying both in modeling approach and used equations. Both one-dimensional channel-simulations, full depth-varied grid methods and Smooth Particle Hydrodynamics have been used to estimate debris flow behavior (Pudasaini, 2012; Huang et al., 2012). Other implementations, such as SCIDDICA S4C (D'Ambrosio et al., 2007), approximate debris flow behavior by means of cellular automata. Depth averaged equations are used in a large variety of two-dimensional models (Scheidl et al., 2013). A variety of depth averaged finite-element models, such as Ramms (Bartelt et al, 2013), Flo-2D (O'Brien, 2006) and use a fixed volume as input for the debris flow. Others, such as MassMove2D (Begueria et al., 2009), Debris Mobility Model (Kwan \& Sun, 2006) and AschFlow (Luna et al., 2015), include entrainment and the addition of water flow.

The processes that cause shallow slope failures and their transition into debris flows are often also numerically simulated, although empirical methods are also often used. Hydrological models are frequently used to predict behavior of both surface and sub-surface hydrological processes. Through flow simulations, overland flow and the resulting infiltration patterns can be estimated (Van Beek, 2003). Similar to debris flows, hydrology is simulated in spatially distributed numerical models such as GEOtop (Rigon et al., 2006). From the available catchment-scale hydrological models, some are opensource, such as JGrass-NewAge (Formetta et al., 2014). Furthermore, hydrological models can predict soil water flow, and the resulting soil water has been used as a direct proxy for slope stability (van Ash et al., 1999). Slope 
stability models are used to predict both volume and timing of shallow landslides. A variety of regional slope stability models have been developed based on the limit equilibrium, which uses finite elements to estimate the forces acting on a failure plane. The infinite slope models furthermore assume that inter-cell forces can be neglected, and structural finite elements are used to calculate the local Factor of Safety (SoF). This resulting FoS, which depends on a soil description and soil water behavior, are successfully applied as a prediction for slope failure in a variety of regions around the world (van Beek \& Van Asch, 2004; Kuriakose et al., 2009; Mergili et al., 2014a). Recent approaches, such as the method by Mergili et al. (2014b), are focused on providing estimation of failure probability by using more accurate estimates of stability based on three dimensional rotational slip surface analysis following Xie et al. (2004). A similar approach, but instead using Bishops Simplified method, is used in Scoops3D to find approximate failure volumes for rotational slides (Reid et al., 2015). Specialized models are thus frequently used to investigate shallow landslides and debris flows.

Despite all the currently available models, combined approaches to debris flow initiation and runout are scarce. Empirical initiation and runout models, such as Flow-R combine landslide failure criteria and possible flow patterns to create susceptibility maps (Horton et al., 2013). However, their method is semiphysical in nature and doesn't include failure volumes, rheology nor entrainment. Fan et al. (2017) introduced an innovative way to approach catchment-scale landslide modeling. For their approach, the failure plane is static, and defined as the lithic contact. Furthermore, hydrological processes are still generally neglected, and the stability and runout models are coupled through a one-way link. Finally, Mergili et al. (2011), provided a more in-depth analysis of the what sort of approaches to integrated simulation of debris flows could be taken. Their analysis covered wetting front based slope stability and failure in a small catchment, and simulation of erosion by runoff, both leading to debris flow runout. The authors solved runout by using a two-parameter semi-deterministic frictional model routed over the terrain. While the currently available models provide useful investigative and predictive tools, integrated simulations using fully physically based descriptions of all related processes could still increase understanding and usability of numerical simulations.

Most existing hydrological, slope stability and debris flow runout models focus on specific processes without the possibility of interactions or feedbacks between the processes. However, in practice processes such as slope failure, flow directions, infiltration and flow properties such as viscosity all influence each other. Flooding and debris flows in particular have frequent interactions due to their common metrological trigger. In many cases, interactions between debris flows and flooding substantially influence the behavior of both processes. When these phenomena are neglected, the predictive power of models is substantially limited. A major example of these interactions are blocked rivers or drainage channels by debris flows, resulted in alternating waves of debris flows and flooding (Tan et al., 2012; Adegbe et al., 2013; Luna et al., 2014). Debris flows can also interact with overland flow causing decreased viscosity. Hieu et al. (2010) found that dilution of a debris flow by directed overland flow caused runout over a larger area, including the streets of a nearby village. In order to increase the understanding of hydrology, shallow landslides and the debris flows that are caused by these, a holistic and integrated approach should be considered. 
A common obstacle in the modeling and prediction of shallow landslides and debris flows is the accuracy of input data and parameters (van Westen, 2006; van Westen, 2008; Mergili et al., 2011 ;Nikolopoulos et al., 2015). Physicallybased models are often limited in accuracy by the spatial resolution of elevation and soil data. Slope instability caused by structural weakness provides a particularly large challenge for current modeling methods since the sub-surface structure is generally unknown over larger areas (van Westen, 2006). The availability of accurate soil data, both in terms of their spatial variation in type and thickness, and associated geotechnical and hydrological properties can be a major limiting factor. An integrated approach to model slope failure, debris flows and hydrology could only be used when sufficient input data is available. In the past decade however, the data problem has become less severe due to increasing availability of detailed data. High-resolution elevation products such as Lidar DEMs have become widely available (Tarolli, 2014). Major improvements have been made in estimating soil data from various sources such as national soil maps and satellite data (Hengl et al., 2017). Furthermore, soil depth estimations based on statistical correlation of topographical parameters have shown increasing accuracy. Lastly, when slope failure is not estimated an initial volume is often used for runout calculation. In this case, the influence of hydrology and other processes on debris flow runout is still neglected. Thus, an integrated model can provide further improvements compared to traditional methods even when insufficient data is available for prediction of slope failure.

The objective of this paper is to develop and test an integrated model to analyze the influence of rainfall-triggered shallow landslides and debris flows in a hydrological catchment model. Slope failures are estimated by using an adaptation on the classic infinite slope stability method. To simulate debris flows, the two-phase generalized debris flow equations by Pudasaini (2012) are implemented. These methods are included in the OpenLISEM model (Bout $\&$ Jetten, 2018). In order to test the performance of the aforementioned model, we attempt to model the impact of a convective storm that hit the southeastern coast of Sicily in 2009 (Lombardo et al., 2015; Lombardo et al., 2018a). Finally, several alternatives of the developed modeling method are tested and a sensitivity analysis is performed.

\subsection{Materials and Methods}

\subsubsection{Schematic Model Description}

Combining the discussed methods, we created a modeling method that incorporates both hydrological processes such as rainfall, interception, infiltration, flow, and morphological processes such as shallow landslides, slope failure, and landslide runout. A simplified flow chart for the final model is shown in

Figure 4-1. When sediment components are absent, the model reduces to a fully functioning hydrological catchment model. 


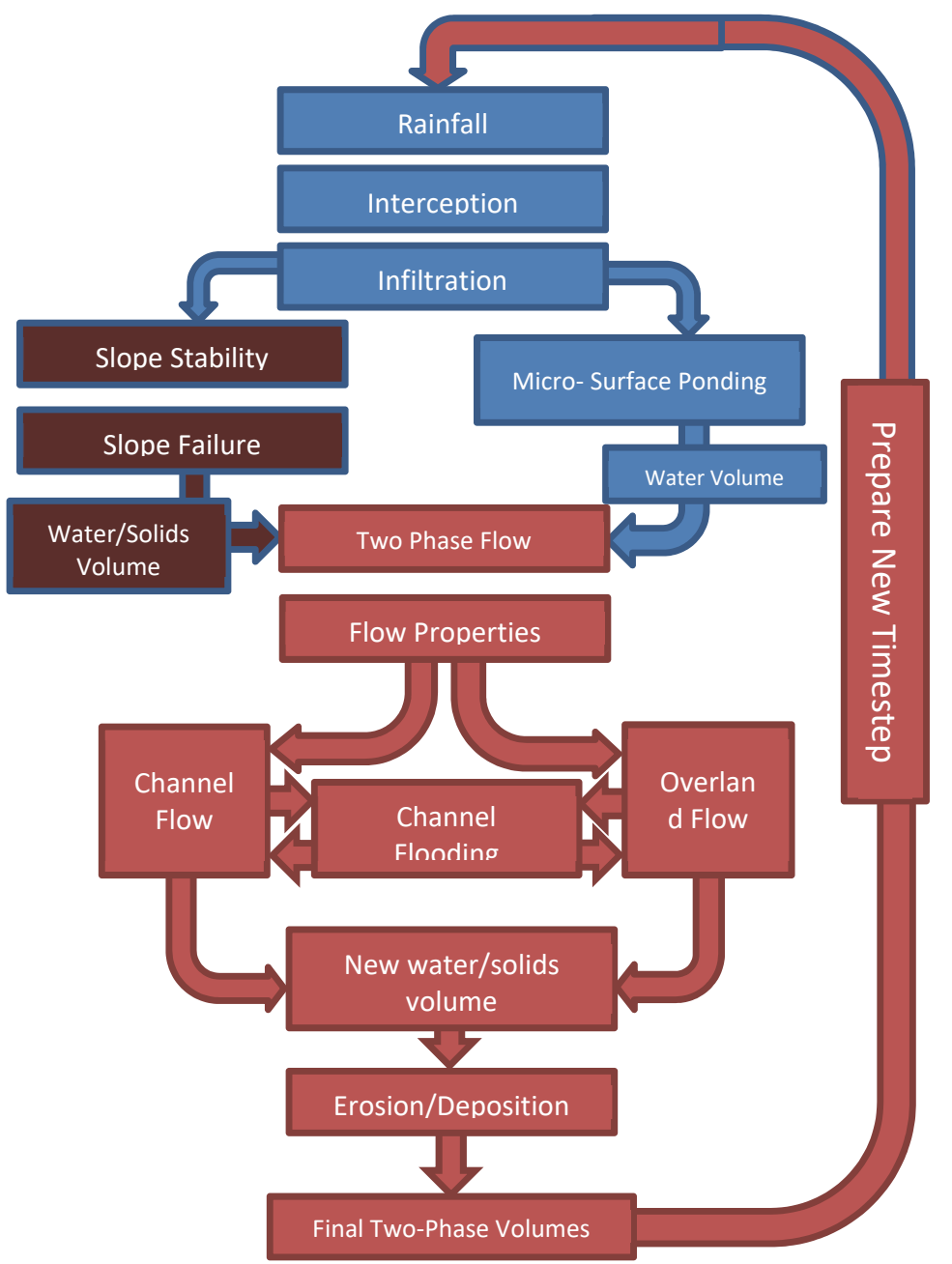

Figure 4-1 A simplified flow chart for the new OpenLISEM model.

\subsubsection{Model Basis}

In order to integrate the occurrence of shallow landslides, debris flows and flash flooding within a single model, we used the Open Source Limburg Soil Erosion Model (OpenLISEM) as a basis. OpenLISEM is a physically-based numerical model with the purpose of event-based runoff, flooding and erosion modeling on a catchment scale. LISEM is fully spatially distributed and uses a topography-following grid to solve both cell specific processes, and the differential equations governing flow.

The OpenLISEM model implements multiple types of infiltration models such as Smith \& Parlange (1978) and the SWATRE full vertical soil water balance model (Bastiaanssen et al., 1996). The simulations in this paper use the Green \& Ampt infiltration model, which assumes a wetting front moving down into 
the soil due to infiltrating rainfall (Green \& Ampt, 1911). The resulting potential infiltration is subtracted from the available surface water (4.1).

$$
4.1 \quad \mathrm{f}_{\text {pot }}=-\mathrm{K}_{\mathrm{s}}\left(\psi \frac{\theta_{\mathrm{s}}-\theta_{\mathrm{i}}}{\mathrm{F}}+1\right)
$$

Where $f_{\text {pot }}$ is the potential infiltration rate $\left(m s^{-1}\right), F$ is the cumulative infiltrated water $(m), \theta_{s}$ is the porosity $\left(\mathrm{m}^{3} \mathrm{~m}^{-3}\right), \theta_{i}$ is the initial soil moisture content $\left(\mathrm{m}^{3} \mathrm{~m}^{-3}\right), \psi$ is the matric pressure at the wetting front $(m)$ and $K_{S}$ is the saturated conductivity $\left(\mathrm{m} \mathrm{s}^{-1}\right)$.

Input data consists of soil, land surface and terrain properties (Figure 4-2). Surface properties such as buildings, roads and channels are defined as fraction of a cell's surface. The hydrological processes that are simulated within OpenLisem are extensive and include interception by vegetation, surface micro-ponding and dynamic flow. Further details on the underlying physical principles of OpenLISEM can be found in Baartman et al. (2012) and Jetten and De Roo (2001).

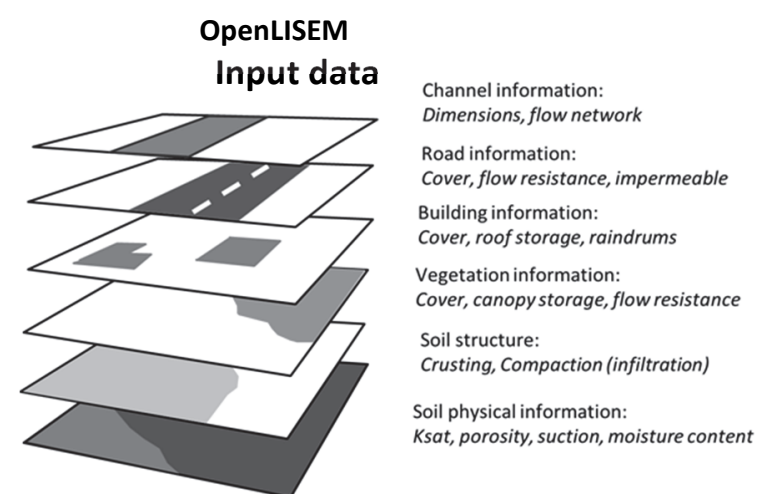

Figure 4-2 The input data layers for OpenLisem.

\subsubsection{Flow Equations}

Overland flow within OpenLISEM is a combination of runoff and flooding. All flow computations are based on the full Saint-Venant equations for shallow flow (Equation $4.2-4.7$ ).

$$
\frac{\partial \mathrm{h}}{\partial \mathrm{t}}+\frac{\partial\left(\mathrm{hu}_{\mathrm{x}}\right)}{\partial \mathrm{x}}+\frac{\partial\left(\mathrm{hu}_{\mathrm{y}}\right)}{\partial \mathrm{y}}=\mathrm{R}-\mathrm{I}
$$

$$
\frac{\partial h u_{x}}{\partial t}+\frac{\partial\left(h u_{x}^{2}\right)}{\partial \mathrm{x}}+\frac{\partial\left(h u_{x} u_{y}\right)}{\partial y}=\operatorname{gh}\left(S_{x}-S_{f, x}\right)
$$

$$
\frac{\partial \mathrm{hu}_{\mathrm{y}}}{\partial \mathrm{t}}+\frac{\partial\left(\mathrm{hu}_{\mathrm{y}}^{2}\right)}{\partial \mathrm{y}}+\frac{\partial\left(\mathrm{hu}_{\mathrm{x}} \mathrm{u}_{\mathrm{y}}\right)}{\partial \mathrm{x}}=\operatorname{gh}\left(\mathrm{S}_{\mathrm{y}}-\mathrm{S}_{\mathrm{f}, \mathrm{y}}\right)
$$

Where $\mathrm{h}$ is the flow height $(\mathrm{m}), \mathrm{u}$ is the flow velocity $\left(\mathrm{m} \mathrm{s}^{-1}\right), \mathrm{R}$ is the rainfall $(m), \mathbf{I}$ is the infiltration $(m), \mathbf{g}$ is the gravitational acceleration $\left(m^{-2}\right), \mathrm{S}$ is the friction term $\left(\mathrm{m} \mathrm{s}^{-2}\right)$ and $\mathrm{S}_{\mathrm{f}}$ is the momentum source term $\left(\mathrm{m} \mathrm{s}^{-2}\right)$ 
4.5

$$
\begin{gathered}
S_{x}=-\frac{d\left(\frac{g h^{2}}{2}\right)}{d x}-g h S_{f_{x}} \\
S_{y}=-\frac{d\left(\frac{g h^{2}}{2}\right)}{d y}-g h S_{f_{y}}
\end{gathered}
$$

The friction slope terms, which are the friction forces divided by the water height and the gravitational acceleration, can be calculated using the DarcyWeisbach friction law (Chow, 1959) (Equation 7).

$$
\mathrm{S}_{\mathrm{f}}=\frac{\mathrm{g}}{\mathrm{n}^{2}} \frac{\overrightarrow{\mathrm{u}}|\overrightarrow{\mathrm{u}}|}{\mathrm{h}^{\frac{4}{3}}}
$$

Where $\mathrm{n}$ is the Manning's $\mathrm{n}$ friction coefficient $\left(s m^{-\frac{1}{3}}\right)$.

\subsubsection{Slope Stability}

The implemented method for estimating slope stability is based on the infiniteslope method. In this method both the local downslope and local resisting forces are calculated. Downslope force is based on the assumption that the failure plane is parallel to the surface plane. The weight of the soil section is calculated by using soil density, porosity and effective soil saturation. The effective soil saturation is the average of the saturation above the wetting front and below the wetting front (Equation 4.8).

$$
4.8 \quad \mathrm{~W}=\left(\gamma-\mathrm{m} \gamma_{\mathrm{w}}\right) \mathrm{z}
$$

Where $\mathrm{W}$ is the weight of the soil column (N), $\gamma$ is the soil density $\left(\mathrm{kg} \mathrm{m}^{-3}\right), \gamma_{w}$ is the density of water $\left(\mathrm{kg} \mathrm{m}^{-3}\right), \mathrm{z}$ is the soil depth $(\mathrm{m})$ and $\mathrm{m}$ is the ratio between the depth of the saturated zone and the soil depth.

Force capacity is based on the Mohr-Coulomb failure criterion (Equation 4.9)

$$
4.9 \quad \mathrm{t}=\mathrm{c}+\mathrm{N} \tan \left(\phi^{\prime}\right)
$$

Where $t$ is the shear stress, $\mathrm{c}$ is the cohesion $(\mathrm{kPa}), \mathrm{N}$ the normal force acting on the soil column $(\mathrm{N}), \phi^{\prime}$ the internal friction angle $\left(^{\circ}\right)$.

Within the soil description, a wetting front is assumed, together with a homogeneous initial soil moisture content (Figure 4-3). Combining the provided equations, the factor of safety is calculated based on simple raster-based soil data (Equation 4.10).

$$
\mathrm{SF}=\frac{\mathrm{c}^{\prime}+\mathrm{c}+\left(\left(\gamma-\mathrm{m} \gamma_{\mathrm{w}}\right) \mathrm{z}+\mathrm{m} \gamma_{\mathrm{w}} \mathrm{z}\right) \cos (\beta)^{2} \tan \left(\phi^{\prime}\right)}{\left(\left(\gamma-\mathrm{m} \gamma_{\mathrm{w}}\right) \mathrm{z}\right) \sin (\beta) \cos (\beta)}
$$

Where $S F$ is the safety factor $(-), \beta$ is slope of the soil section $(-), \mathrm{c}$ is the cohesion of the soil ( $\mathrm{kPa}), c^{\prime}$ is the apparent cohesion of the soil ( $\mathrm{kPa}$ ) and $\phi^{\prime}$ is internal friction angle of the soil (-). Here the apparent cohesion consists of additional root cohesion and a matric suction term. 


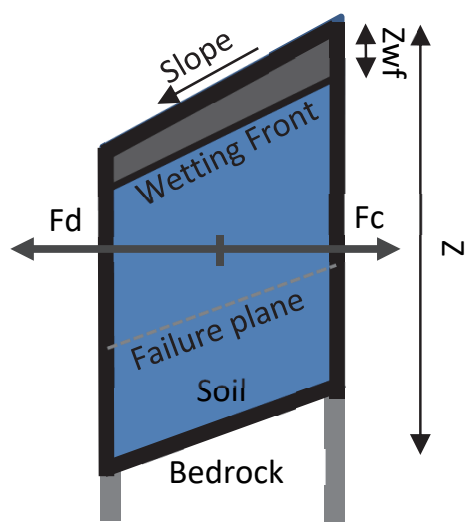

Figure 4-3 An example of a simplified physical description of the soil layer.

When the safety factor decreases below 1 , the soil section is unstable and failure depth will be calculated. Within the safety factor equation, stability decreases when soil depth increases. Calculations for the entire soil depth thus provide the lowest possible safety factor. Therefore, by calculation stability for the complete soil column, failure of smaller surfaces is similarly detected.

\subsubsection{Slope Failure}

When a raster element with a particular slope is determined to be unstable based on equation 10, the next step is to determine the failure volume. Within the infinite-slope method, several assumptions should be made to estimate failure volume. In reality, forces propagate through the subsurface, and stability should be calculated through the method of slices, using circular or irregular sliding surfaces with methods such as Fellenius (Fellenius, 1936), Janbu (Janbu, 1973) and Morgenstern (Morgenstern, 1956). For the stability of a row of soil sections in pixels, the total of force capacity and demand must therefore be taken into account. However, we assume there is no information about subsurface structure. There is therefore, no knowledge about subsurface forces and any possible plane that lies parallel to the surface is allowed to act as failure plane. To overcome this, we utilize another approach. For every group of unstable cells at any moment, a toe can be defined between the lowest unstable cells, and the stable cells underneath those. Here the downstream cell provides enough force capacity and the upstream cell does not. Therefore, a force equilibrium must be present between these cells. A visual representation of such as situation is provided in Figure 4-4, where Fd is the force demand, and Fc is the resisting force. 


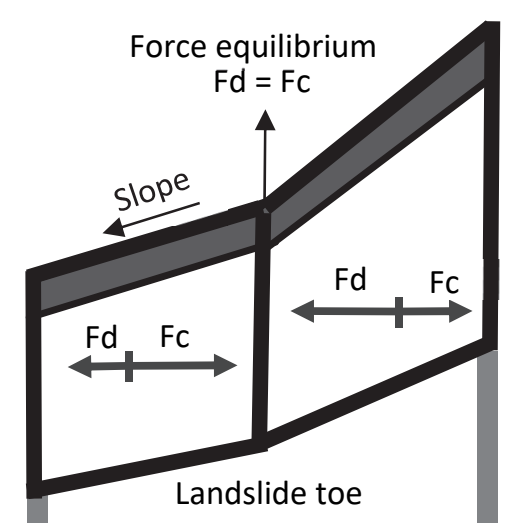

Figure 4-4 A force diagram for the landslide toe. An equilibrium point must exist immediately downstream of the toe.

At the toe location, slope failure is initiated for the upslope cell. Based on this assumption, the safety factor equation is solved to find the depth of the remaining soil that is required for stability. This is possible since we assume any plane parallel to the surface could be the failure plane. Any material above this stable depth is indicated as slope failure. Due to the slope failure, the slope of the surrounding cells changes. In particular, the upslope cells experience an increase in slope, leading to a decrease in stability. We thus repeat the process of finding the stable depth, and initiate slope failure repeatedly, until no unstable cells are left. This iterative method of finding stable soil depth, provides an estimation of failure volume.

In reality, the change in stability is not caused by changing slope, but rather by a change in force propagation through the subsurface. Any cell directly upslope of a failure could experience a change in resisting force. Thus, the stability of the upslope cell changes. Since there is no detailed knowledge about the forces that propagate through the subsurface, we use the assumption that the failure plane must be parallel to the surface. When the local slope changes, the local failure plane direction and thus stability similarly changes.

An example of results from the iterative slope failure method is shown in Figure 4-5. The safety factor of the fourth cell indicates instability. A stable soil depth is calculated and the slope is altered. Based on the altered slope, the safety factor is recalculated for upslope cells. In this particular example, three upslope cells become unstable, and slope failure is initiated in four iterations. After the iterative process, the full failure volume is instanteneously added to the flow equations. 


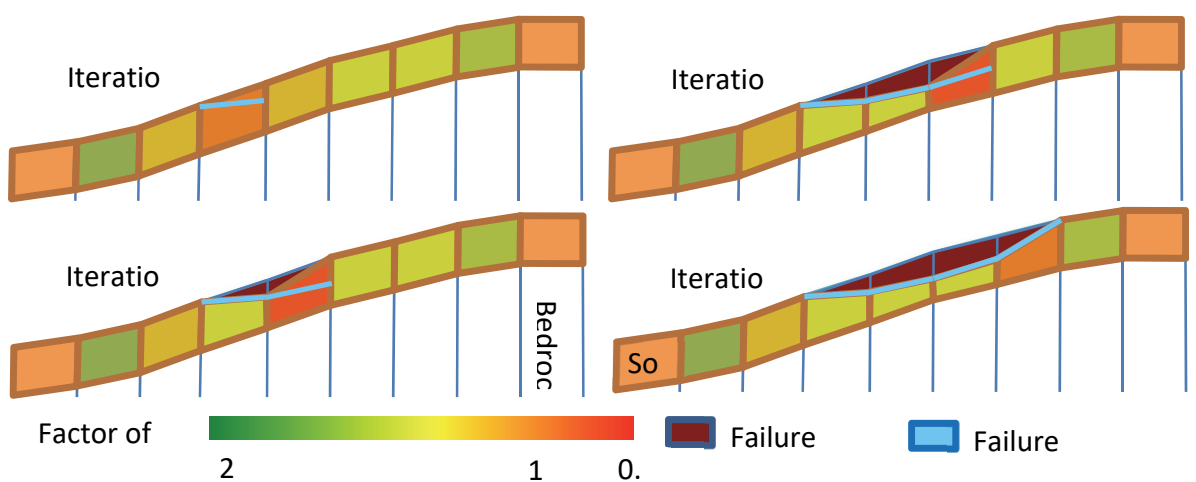

Figure 4-5 A 2D example of the result of using iterative slope failure with a finite element factor of safety.

\subsubsection{Debris Flow Equations}

To simulate the flow dynamics and interactions of floods and nun-uniform debris flows, a set of two-phase equations is required. An extensive set of twophase debris flow equations are available from Pudasaini (2012). This set of equations contains a physically based two-phase momentum balance. Besides pressure and gravitational forces, it includes viscous forces, non-Newtonian viscosity, two-phase drag and a Mohr-Coulomb type friction force for the solid phase (Equations 4.11 - ). Based on the current and local state of flow, forces increase in magnitude. This approach allows for a smooth transition between non viscous flow, hyper concentrated streamflow and debris flows. Furthermore, the interactions between distinct flow types are automatically solved.

$4.11 \mathrm{~S}_{\mathrm{x}, \mathrm{s}}=\alpha_{\mathrm{s}}\left(\mathrm{g}\left(\frac{\partial \mathrm{b}}{\partial \mathrm{x}}\right)-\frac{\mathrm{u}_{\mathrm{s}}}{\left|\overrightarrow{\mathrm{u}}_{\mathrm{s}}\right|} \tan \left(\partial \mathrm{P}_{\mathrm{b}_{\mathrm{s}}}\right)-\varepsilon \mathrm{P}_{\mathrm{b}_{\mathrm{s}}}\left(\frac{\partial \mathrm{b}}{\partial \mathrm{x}}\right)\right)-\varepsilon \alpha_{\mathrm{s}} \gamma \mathrm{P}_{\mathrm{b}_{\mathrm{f}}}\left(\frac{\partial \mathrm{h}}{\partial \mathrm{x}}+\frac{\partial \mathrm{b}}{\partial \mathrm{x}}\right)+\mathrm{C}_{\mathrm{DG}}\left(\mathrm{u}_{\mathrm{f}}-\mathrm{u}_{\mathrm{s}}\right)\left|\overrightarrow{\mathrm{u}}_{\mathrm{f}}-\overrightarrow{\mathrm{u}}_{\mathrm{s}}\right|^{\mathrm{j}-1}$

$4.12 \mathrm{~S}_{\mathrm{y}, \mathrm{s}}=\alpha_{\mathrm{s}}\left(\mathrm{g}\left(\frac{\partial \mathrm{b}}{\partial \mathrm{y}}\right)-\frac{\mathrm{v}_{\mathrm{s}}}{\left|\overrightarrow{\mathrm{u}}_{\mathrm{s}}\right|} \tan \left(\partial \mathrm{P}_{\mathrm{b}_{\mathrm{s}}}\right)-\varepsilon \mathrm{P}_{\mathrm{b}_{\mathrm{s}}}\left(\frac{\partial \mathrm{b}}{\partial \mathrm{y}}\right)\right)-\varepsilon \alpha_{\mathrm{s}} \gamma \mathrm{P}_{\mathrm{b}_{\mathrm{f}}}\left(\frac{\partial \mathrm{h}}{\partial \mathrm{y}}+\frac{\partial \mathrm{b}}{\partial \mathrm{y}}\right)+\mathrm{C}_{\mathrm{DG}}\left(\mathrm{v}_{\mathrm{f}}-\mathrm{v}_{\mathrm{s}}\right) \mid \overrightarrow{\mathrm{u}}_{\mathrm{f}}-\overrightarrow{\mathrm{u}}_{\mathrm{s}} \mathrm{j}^{\mathrm{j}-1}$

$$
\begin{aligned}
S_{x, f}=\alpha_{f}\left\{g\left(\frac{\partial b}{\partial x}\right)-\varepsilon\right. & {\left[\frac{1}{h} \frac{\partial}{\partial x}\left(\frac{h^{2}}{2} P_{b_{f}}\right)+P_{b_{f}} \frac{\partial b}{\partial x}-\frac{1}{\alpha_{f} N_{R}}\left(2 \frac{\partial^{2} u_{f}}{\partial x^{2}}+\frac{\partial^{2} v_{f}}{\partial y \partial x}+\frac{\partial^{2} u_{f}}{\partial y^{2}}-\frac{\chi u_{f}}{\varepsilon^{2} h^{2}}\right)\right.} \\
& +\frac{1}{\alpha_{f} N_{R}}\left(2 \frac{\partial}{\partial x}\left(\frac{\partial \alpha_{s}}{\partial x}\left(u_{f}-u_{s}\right)\right)+\frac{\partial}{\partial y}\left(\frac{\partial \alpha_{s}}{\partial x}\left(v_{f}-v_{s}\right)+\frac{\partial \alpha_{s}}{\partial y}\left(u_{f}-u_{s}\right)\right)\right) \\
& \left.\left.-\frac{\xi \alpha_{s}\left(v_{f}-v_{s}\right)}{\varepsilon^{2} \alpha_{f} N_{R_{\mathcal{A}}} h^{2}}\right]\right\}-\frac{1}{\gamma} C_{D G}\left(u_{f}-u_{s}\right)\left|\vec{u}_{f}-\vec{u}_{s}\right|^{j-1}
\end{aligned}
$$




$$
\begin{aligned}
S_{y, f}=\alpha_{f}\left\{g\left(\frac{\partial b}{\partial y}\right)-\right. & \varepsilon\left[\frac{1}{h} \frac{\partial}{\partial y}\left(\frac{h^{2}}{2} P_{b_{f}}\right)+P_{b_{f}} \frac{\partial b}{\partial y}-\frac{1}{\alpha_{f} N_{R}}\left(2 \frac{\partial^{2} v_{f}}{\partial y^{2}}+\frac{\partial^{2} u_{f}}{\partial y \partial x}+\frac{\partial^{2} v_{f}}{\partial y^{2}}-\frac{\chi v_{f}}{\varepsilon^{2} h^{2}}\right)\right. \\
& +\frac{1}{\alpha_{f} N_{R}}\left(2 \frac{\partial}{\partial y}\left(\frac{\partial \alpha_{s}}{\partial y}\left(v_{f}-v_{s}\right)\right)+\frac{\partial}{\partial y}\left(\frac{\partial \alpha_{s}}{\partial y}\left(u_{f}-u_{s}\right)+\frac{\partial \alpha_{s}}{\partial x}\left(v_{f}-v_{s}\right)\right)\right) \\
& \left.\left.-\frac{\xi \alpha_{s}\left(u_{f}-u_{s}\right)}{\varepsilon^{2} \alpha_{f} N_{R_{\mathcal{A}}} h^{2}}\right]\right\}-\frac{1}{\gamma} C_{D G}\left(u_{f}-u_{s}\right)\left|\vec{u}_{f}-\vec{u}_{s}\right|^{j-1}
\end{aligned}
$$

4.14

Where $\alpha_{\mathrm{s}}$ and $\alpha_{\mathrm{f}}$ are the volume fraction for solid and fluid phases $(-), \mathrm{P}_{\mathrm{b}}$ is the pressure at the base surface $\left(\mathrm{Kg} \mathrm{m}^{-1} \mathrm{~s}^{-2}\right)$, b is the basal surface of the flow $(\mathrm{m})$, $\mathrm{N}_{\mathrm{R}}$ is the Reynolds number $(-), \mathrm{N}_{\mathrm{R}_{\mathrm{A}}}$ is the quasi-Reynolds number $(-), \mathrm{C}_{\mathrm{DG}}$ is the drag coefficient $(-), \rho_{\mathrm{f}}$ is the density of the fluid $\left(\mathrm{kg} \mathrm{m}^{-3}\right), \rho_{\mathrm{s}}$ is the density of the solids $\left(\mathrm{kg} \mathrm{m}^{-3}\right), \gamma$ is the density ratio between the fluid and solid phase(),$\chi$ is the vertical shearing of fluid velocity $\left(\mathrm{m} \mathrm{s}^{-1}\right), \varepsilon$ is the aspect ratio of the model $(-), \xi$ is the vertical distribution of $\alpha_{s}\left(\mathrm{~m}^{-1}\right)$.

Within the momentum equations, the Reynolds number is used to scale turbulent and viscous forces.

Here, we follow Pudasaini (2012) for the definitions of the normal and quasiReynolds number (Equation 4.15 and 4.16 ).

$$
\begin{aligned}
\mathrm{N}_{\mathrm{R}} & =\frac{\sqrt{\mathrm{gL}} H \rho_{\mathrm{f}}}{\alpha_{\mathrm{f}} \eta} \\
\mathrm{N}_{\mathrm{R}_{\mathrm{A}}} & =\frac{\sqrt{\mathrm{gL}} H \rho_{\mathrm{f}}}{\mathrm{A} \eta}
\end{aligned}
$$

Where $L$ is the length scale of the flow $(\mathrm{m}), H$ is the height of the flow $(\mathrm{m}), \eta$ is the viscosity $\left(\mathrm{kg} \mathrm{s}^{-1} \mathrm{~m}^{-1}\right)$ and $A$ is the mobility of the interface (-)

To apply these two-phase equations successfully in a catchment-based model, we replace the frictional force for the water phase with the Darcy-Wiesbach equation for water flow friction. To complete the set of equations that govern debris flow-dynamics, several flow properties are estimated based on the volumetric sediment content. Viscosity is based on an empirical relation by O'Brien and Julien (1985) (Equation 4.17).

4. 17

$$
\eta=\alpha e^{\beta \alpha_{s}}
$$

Where $\alpha$ the first viscsosity parameter (-) and $\beta$ the second viscosity parameter $(-)$.

The drag coefficient is based on the relation provided by Pudasaini (2012) (Equation 4.18 - 4.21).

$$
C_{D G}=\frac{\alpha_{\mathrm{f}} \alpha_{\mathrm{s}}\left(1-\frac{\rho_{\mathrm{f}}}{\rho_{\mathrm{s}}}\right)}{\varepsilon \mathrm{U}_{\mathrm{T}}(\mathrm{PF}(\mathrm{Re})+(1-\mathrm{P}) \mathrm{G}(\mathrm{Re}))}
$$

$$
\operatorname{Re}=\frac{\rho_{\mathrm{f}} \mathrm{dU}_{\mathrm{T}}}{\eta_{\mathrm{f}}}
$$

$$
\begin{gathered}
F=\frac{\rho_{f}}{180 \rho_{s}}\left(\frac{\alpha_{f}}{\alpha_{s}}\right)^{3} \operatorname{Re} \\
G=\alpha_{f}^{M(R e)-1}
\end{gathered}
$$


Where Re is the Reynollds number $(-), d$ is the median grain diameter $(-), \mathrm{U}_{\mathrm{T}}$ the settling velocity $\left(\mathrm{m} \mathrm{s}^{-1}\right)$ and $\mathrm{M}$ is an empirical parameter depending on the Reynolds number (-).

Finally, the settling velocity of small $(\mathrm{d}<100 \mu \mathrm{m})$ grains is estimated by Stokes equations for a homogeneous sphere in water. For larger grains, the equation by Zanke (1977) is used (Equation 4.22).

$$
\mathrm{w}_{\mathrm{s}}=10 \frac{\frac{\eta^{2}}{\rho_{\mathrm{f}}}}{\mathrm{d}}\left(\sqrt{1+\frac{0.01\left(\frac{\left(\rho_{\mathrm{s}}-\rho_{\mathrm{f}}\right)}{\rho_{\mathrm{f}}} \mathrm{gd}^{3}\right)}{\frac{\eta}{\rho_{\mathrm{f}}}}}-1\right)
$$

\subsection{Application of the Model}

The described methods were applied in a test area to model the initiation and runout of the debris flows that were caused by the 1 October, 2009 convective storm hitting the North-Eastern part of Sicily, Italy. This event had a maximum rainfall intensity of $120 \mathrm{~mm} /$ hour and a return period of 1 in 30 years (Aronica et al., 2011). Rainfall data for the S. Stefano Briga and Fiumedinisi rainfall stations are shown in Figure 4-6, being provided by the local administration. The event caused landslides, debris flows and flash flooding in the area between St. Stefano Briga and Fiumedinisi. A statistical analysis of the landslides and causal factors was carried out by Lombardo et al. (2016) and Trigila et al. (2015). Furthermore, debris flow simulations have been performed for several villages that were hit by debris flows during this event (Cama et al., 2017; Lupiano et al., 2016; Stancanelli et al, 2013).

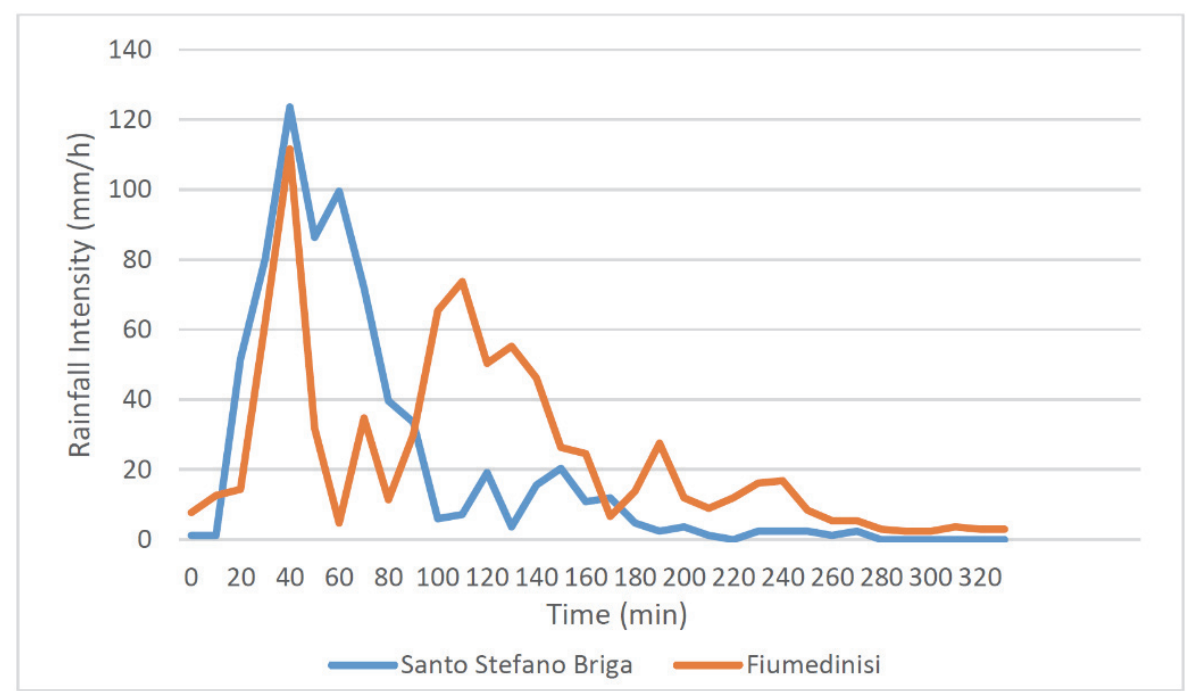

Figure 4-6 Rainfall data for the 1-10-2009 rainfall event in south-west Sicily. Temporal resolution of the rainfall is 10 minutes. Source: (http://www.osservatorioacque.it/)

For this study, the Scaletta catchment, a $4.3 \mathrm{Km}^{2}$ area between St. Stefano Briga and Fiumedinisi has been selected as study site (Figure 4-7). A landslide 
inventory for the event is available, based on areal images (Lombardo et al., 2014). A total of 395 shallow landslides took place during or directly after the event in the selected area. Landslides in the neighboring catchment consisted mostly of the layer of weathered surface material, between 0.5 and 2.5 meters in depth (Lombardo et al., 2015). The inventory does not distinguish between source and deposition areas of each individual shallow landslide. Instead, the full impact area is delineated by the polygons. Figure 5 illustrates the elevation, landslide inventory, land use types and soil types. This coastal region is characterized by steep slopes, and three small channels that drain towards the sea. Infrastructure, in the form of a highway and railway lines are predominantly located parallel to the coast, flanked with a string of small settlements. The highway is partly tunneled, or built on bridges, and does not actively block any flow. Land use types consist predominantly of shrubs/sparse forest mixed with areas of agriculture. Small patches of forest are present in the inland regions. The most common soil is of colluvial origin and consists of sandy soils upstream, and clayey soils near the coast. These are the result of pedogenetic processes taking place on a medium to high grade metamorphic parent rock primarily consisting of paragneiss, micaschists, phyllites and metaarenites (Cama et al., 2015). Their weakening, transport and deposition in the form of unstable unconsolidated soils is further facilitated by a long history of compressional and more recent extensional tectonic regimes (Somma et al., 2005). 

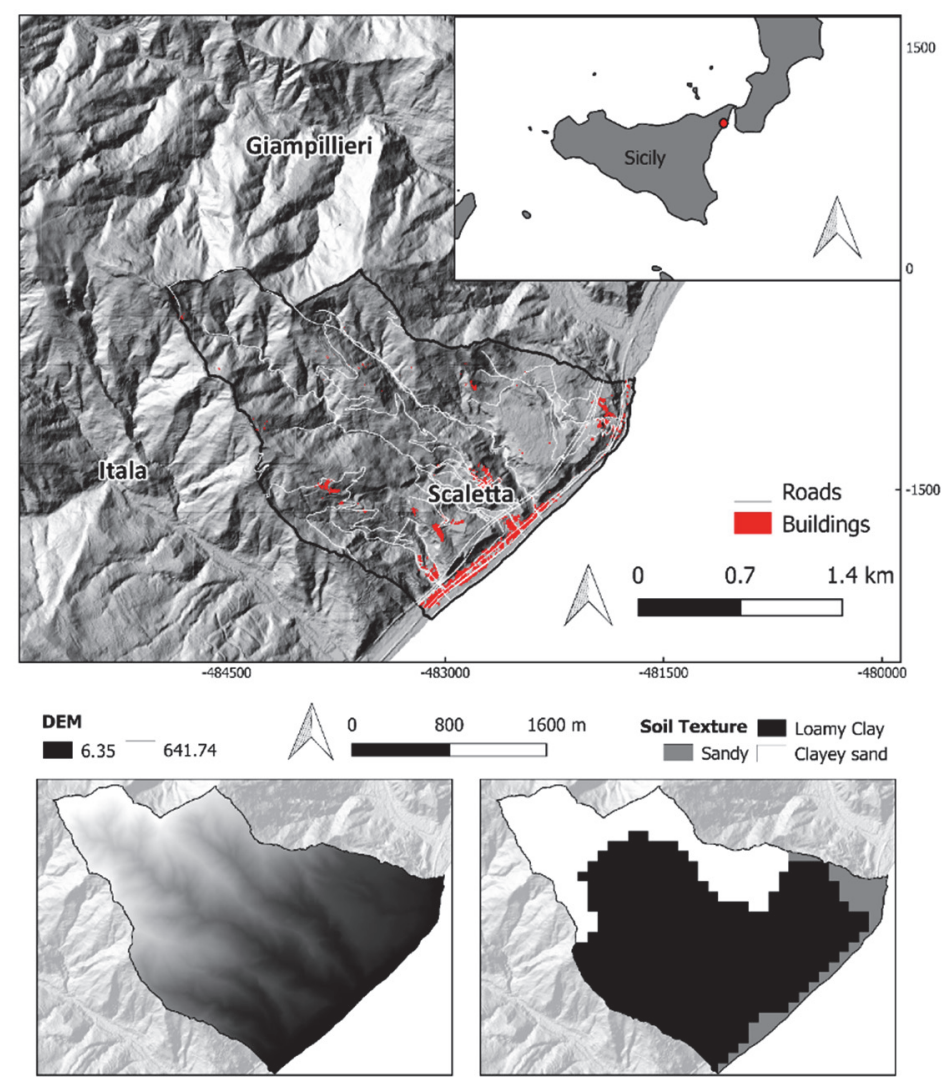

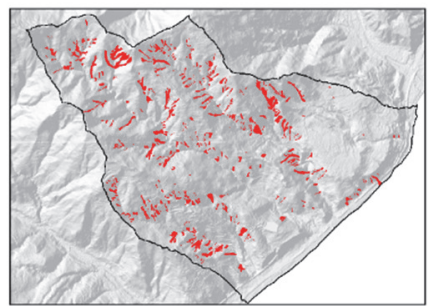

Landslides

Landslide/Debris Flow
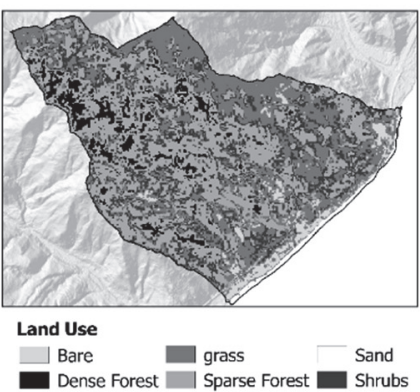

Figure 4-7 Input data for the Scaletta catchment. Location (top) Elevation model and soil texture (middle), landslide inventory and land use map (bottom).

\subsubsection{Required Data}

An overview of the input data for the model, the data sources, and the spatial resolution are provided in Table 4-1. Most of the required input parameters were estimated based on the digital elevation model (DEM), land use map and soil texture map (Table 4-2). The native spatial resolution of the national soil texture map of Sicily is course (Lombardo et al., 2018b). The soil texture map was therefore validated and adapted with field measurements, collected by 
Costantini et al. (2014) and Schillaci et al. (2017). Initial conditions for soil moisture content were based on the hydrological modeling by Aronica et al. (2012). The landslide inventory was interpreted from high resolution images, field checked and rasterized. Rainfall data, with a temporal resolution of 10 minutes, was collected for two nearby station, S. Stefano and Fiumedinisi.

\begin{tabular}{|c|c|c|c|}
\hline $\begin{array}{l}\text { Input } \\
\text { Data }\end{array}$ & Method & $\begin{array}{l}\text { Spatial } \\
\text { resolution }\end{array}$ & Source \\
\hline $\begin{array}{l}\text { Elevation } \\
\text { Model }\end{array}$ & $\begin{array}{l}\text { Lidar DEM (0.22 } \mathrm{m} \\
\text { vertical-accuracy) }\end{array}$ & 2 meters & A.R.T.A. (2008) \\
\hline $\begin{array}{l}\text { Land Use } \\
\text { Map }\end{array}$ & $\begin{array}{l}\text { Sentinel-2 Supervised } \\
\text { Classification }\end{array}$ & 10 meters & $\begin{array}{l}\text { Copernicus } \\
\text { Sentinel Data, } \\
2015\end{array}$ \\
\hline $\begin{array}{l}\text { Soil } \\
\text { Texture } \\
\text { Map }\end{array}$ & $\begin{array}{l}\text { Country-wide } \\
\text { Texture Product }\end{array}$ & 200 meters & Fierotti et al., 1988 \\
\hline NDVI & Spot-6 Satellite Product & 4 meters & $\begin{array}{l}\text { KompSat } 2 \text { Data, } \\
2010\end{array}$ \\
\hline
\end{tabular}

Table 4-2 Maps that are derived from the input data maps, and how they were validated.

\begin{tabular}{llll}
$\begin{array}{l}\text { Elevation } \\
\text { Model }\end{array}$ & Soil Texture Map & Land Use Map & NDVI \\
\hline Slope & $\begin{array}{l}\text { Saturated } \\
\text { Conductivity }\end{array}$ & Mannings N & \begin{tabular}{l} 
Vegetation $_{\text {Cover }^{1}}$ \\
\hline Soil Depth
\end{tabular} \\
\hline $\begin{array}{lll}\text { Channel } \\
\text { Location }^{1}\end{array}$ & Porosity & $\begin{array}{l}\text { Surface } \\
\text { roughness }\end{array}$ & Leaf Area Index $^{1}$ \\
\hline Channel Depth $^{1}$ & Soil Cohesion & $\begin{array}{l}\text { Vegetation } \\
\text { Height }^{1}\end{array}$ & \\
\hline${ }^{1}$ Validated with areal and site images & ${ }^{2}$ Validated with field measurements
\end{tabular}

We calculated both the leaf area index and vegetation cover based on the Normalized Differential Vegetation Index (NDVI). For vegetation cover, we linearly scale between minimum and maximum NDVI value (Choudhury et al. 1994). For the leaf area index, the vegetation cover is used in an empirical relationship (Equation 4.23) (Choudhurt, 1987).

$$
\mathrm{LAI}=\frac{\ln (1-\text { vegetationcover })}{9.1}
$$

With LAI the leaf area index (-).

\subsubsection{Spatial Soil Depth Estimation}

Unfortunately there was no spatial data concerning soil depth available within the extent of the study area, except for a limited number of field measurements, and estimations based on the interpretation of oblique photographs of landslide scars after the event. Soil depth forms one of the most vital parameters in the case of shallow landslides, and a spatial estimate had to be made (Kuriakose et al., 2009). Spatial soil depth was estimated using the method described by Kuriakose et al. (2009). In this method, variables 
such as slope, profile curvature, distance form channels, wetness index and distance from the coast are statistically related to the measured soil depth. This statistical model was used to provide an estimation of soil depth in the entire catchment. For our case, the final statistical model took the form of equation 4.24 .

$$
\text { 4.24 } \mathrm{SD}=\text { Intersect }+\mathrm{a} * \mathrm{~d}_{\text {coast }}+\mathrm{b} * \mathrm{~d}_{\text {channel }}+\mathrm{c} * \mathrm{~s}+\mathrm{d} * \mathrm{c}
$$

Where SD is the soil depth $(m), a, b, c, d$ are constants $(-)$ derived from statistical analysis, $d_{\text {coast }}$ is the distance to the coast $(m), d_{\text {channel }}$ is the distance to the nearest channel $(\mathrm{m}), \mathrm{s}$ is the slope of the surface $\left(\mathrm{m} \mathrm{m}^{-1}\right)$ and $\mathrm{c}$ is the profile curvature of the surface $\left(\mathrm{m}^{-1}\right)$.

Based on the statistical correlation, the values for the constant are provided in Table 4-3.

Table 4-3 The constants derived from the statistical correlation of soil depth to topographical parameters.

\begin{tabular}{l|l} 
intersect & 2.37 \\
\hline $\mathrm{a}$ & 0.01 \\
\hline $\mathrm{b}$ & 0.12 \\
\hline $\mathrm{c}$ & 1.03 \\
\hline $\mathrm{d}$ & 2.73
\end{tabular}

The fitted relationship between predicted and estimated soil depth has a slope of 0.90 and $R^{2}$ of 0.69 (Figure 4-8). Due to the low number of available soil depth measurements, the $\mathrm{R}^{2}$ is relatively low. However, the trend line between predicted and measured soil depth gives a slope of 0.90 , which confirms the expected trend. The resulting average soil depth of the study catchments is 1.29 meters. The spatial distribution of soil depth is shown in Figure 4-8. Schiliro et al, (2015) have used the soil depth model by Saulnier et al. (1997) which relates soil depth to slope, and depends on the maximum and minimum soil depth as parameters. The results from these calculations show similar trends as the results from equation 23. However, besides our higher spatial resolution, our statistical correlation uses a higher number of variables to predict soil depth and can therefore account for a greater variability. 


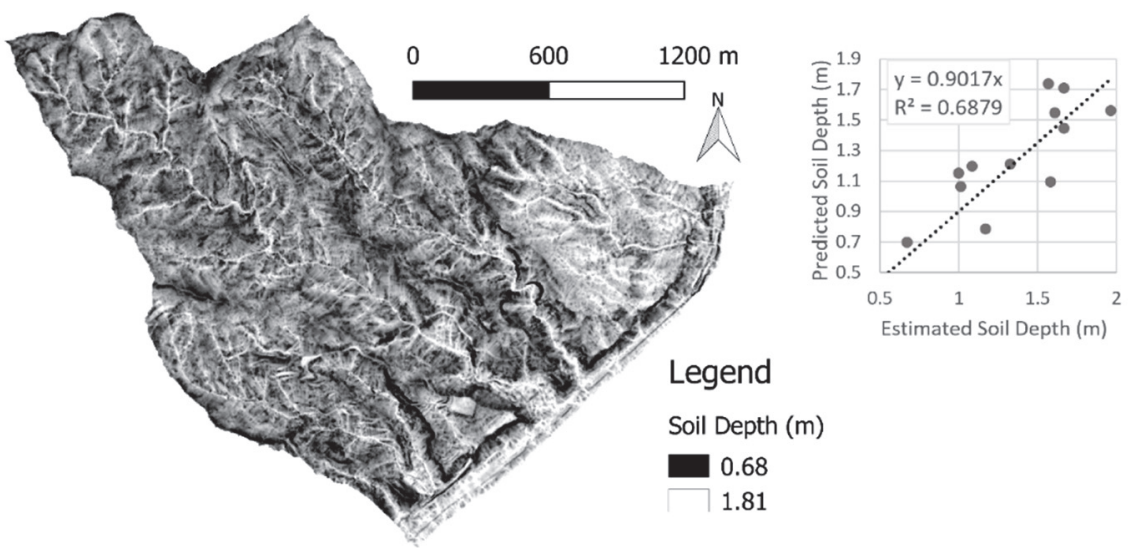

Figure 4-8 The spatial distribution of predicted soil depth, and the correlation between predicted and estimated soil depth

\subsubsection{Simulations and Calibration Method}

To compare our modeling method to existing similar methodologies, several simulations were performed (Table 4-4). Firstly, the full method was used, simulating slope failure locations, timing and runout, together with catchment hydrology. Secondly, the landslide inventory was used to provide a predefined failure volume. The highest 20 percent of the inventory impacted areas was taken as initiation area. The depth of failure was varied to be 50, 70 and 90 percent of the soil depth. This volume is introduced in the middle of the precipitation event. Finally, both these simulations were repeated without the addition of the hydrology component. When hydrology is not simulated, rainfall is neglected and soil moisture contents are equal to their initial value. This simplifies the model to a more traditional catchment model. However, without additional infiltration, slopes can not become unstable. Therefore, we alter the initial moisture content to an estimation of soil moisture after 50 percent of the rainfall event has passed. This causes the slope failure to be initiated immediately.

From satellite images, reports and photos it can be observed that a debris flow fan was formed during the event (Figure 4-9).
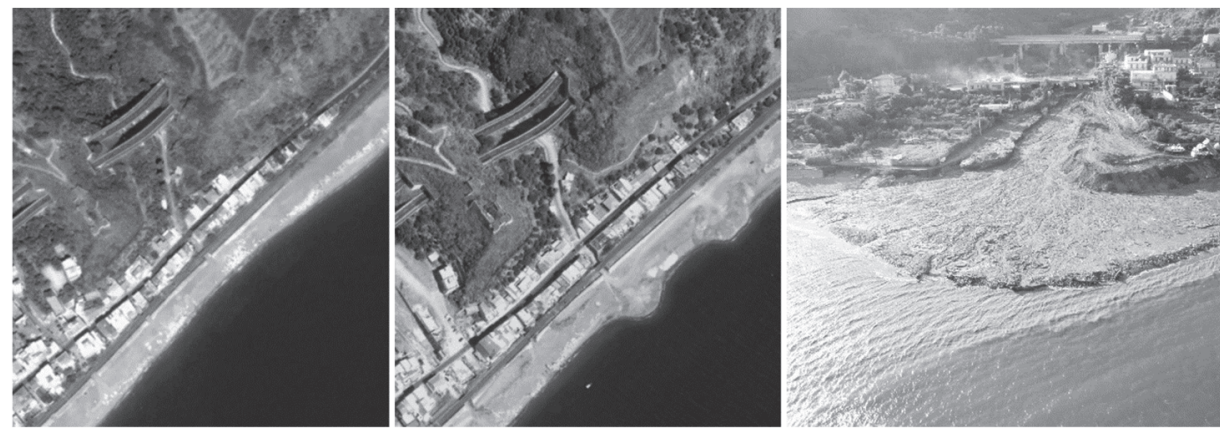

Figure 4-9 Images of the Scaletta catchment before and after the 1-10-2009 event (left) Photograph of the Giampillieri catchment outlet one day after the event (right). 
Finally, in order to validate the transportation of debris flow solids, a simulation was performed where coastal water is included in the model. This allowed for the formation of the debris fan. A section of 100 meters of linearly decreasing elevation was added along the coast line. Slope was estimated from the coastal elevation published by Casalbore et al. (2011). At the computational boundaries, forced water volumes were set to simulate the sea level. Initial velocities were set to zero, since no information was available considering sea currents during the event.

\begin{tabular}{lllll}
$\begin{array}{l}\text { Table 4-4 Performed Simulations. } \\
\text { Simulation }\end{array}$ & $\begin{array}{l}\text { Includes } \\
\text { Hydrology }\end{array}$ & $\begin{array}{l}\text { Failure } \\
\text { from } \\
\text { Inventory }\end{array}$ & $\begin{array}{l}\text { Fraction of } \\
\text { soil used in } \\
\text { failure }\end{array}$ & Coast \\
\hline A1 & No & Yes & 0.5 & No \\
\hline A2 & No & Yes & 0.7 & No \\
\hline B3 & No & Yes & 0.9 & No \\
\hline B1 & Yes & Yes & 0.5 & No \\
\hline B2 & Yes & Yes & 0.7 & No \\
\hline B3 & Yes & Yes & 0.9 & No \\
\hline D & Yes & No & - & No \\
\hline
\end{tabular}

All simulations were calibrated to the runout patterns in the landslide inventory. Calibration was performed manually by altering important input parameters. Based on theoretical considerations, the soil cohesion, internal friction angle, infiltration rate and initial moisture were varied by multiplying these input maps with a scalar value. Accuracy was calculated using Cohen's Kappa (Equation 4.25). This measure of model efficiency takes into account both correctly predicted positives, negatives, and incorrectly predicted areas.

$$
\kappa=\frac{\mathrm{p}_{0}-\mathrm{p}_{\mathrm{e}}}{1-\mathrm{p}_{\mathrm{e}}}
$$

Where $p_{0}$ is the total accuracy $(-)$ and $p_{e}$ is the probability of uncorrelated agreement $(-)$.

The probability of uncorrelated agreement indicated the chance that simulated and predicted maps agreed due to chance. For a binary system with two observers, $p_{e}$ can be calculated with equation 4.26 .

$$
\mathrm{p}_{0}=\frac{\mathrm{N}_{\mathrm{agr}}}{\mathrm{N}_{\text {total }}} \quad \mathrm{p}_{\mathrm{e}}=\frac{\mathrm{N}_{1, \text { pos }} * \mathrm{~N}_{2, \text { pos }}}{\mathrm{N}_{\text {total }}} * \frac{\mathrm{N}_{1, \text { neg }} * \mathrm{~N}_{2, \text { neg }}}{\mathrm{N}_{\text {total }}}
$$

Where $N_{\text {total }}$ is the total number of measurements $(-), N_{\text {agr }}$ is the number of agreed measurements and $\mathrm{N}_{\mathrm{i} \text {,pos }}$ and $\mathrm{N}_{\mathrm{i} \text {,neg }}$ are the numbers of measurements where observer $\mathrm{i}$ is respectively positive or negative (-).

Since our inventory of the event consists only of full shallow landslide/debris flow impact areas and does not distinguish between source and deposition areas, the validation of failures is performed using the 20 percent highest elevations for each landslide impact polygon. An overlap of a failure area might not overlap with the actual source area of the inventory, but instead with part 
of the runout. For completeness with give the correlation between failures and the inventory as a mere indication of correlation between the two.

\subsection{Results}

First we analyzed the runout of shallow landslides and debris flows with the inventory. The resulting slope failure patterns and debris flow runout patterns were compared with the inventory. However, the comparison was complicated due to several aspect. The landslides in the inventory were only mapped to the point where they reached a channel. In reality, however, the runout often extended much further, and landslide materials were incorporated in debris flows. Since the model counts any location, including a channel, with high solids content as a debris flow, the channel regions have been masked to be excluded from the accuracy calculation.

The simulated slope failure depth, and a comparison between simulated slope failure and the landslide inventory are shown in Figure 4-10 respectively. A comparison of the failures with the estimated failure zones shows an accuracy of 95.9 percent, with a kappa value of 0.27 . This is an over-estimation of actual accuracy since failures can overlap with the runout regions.

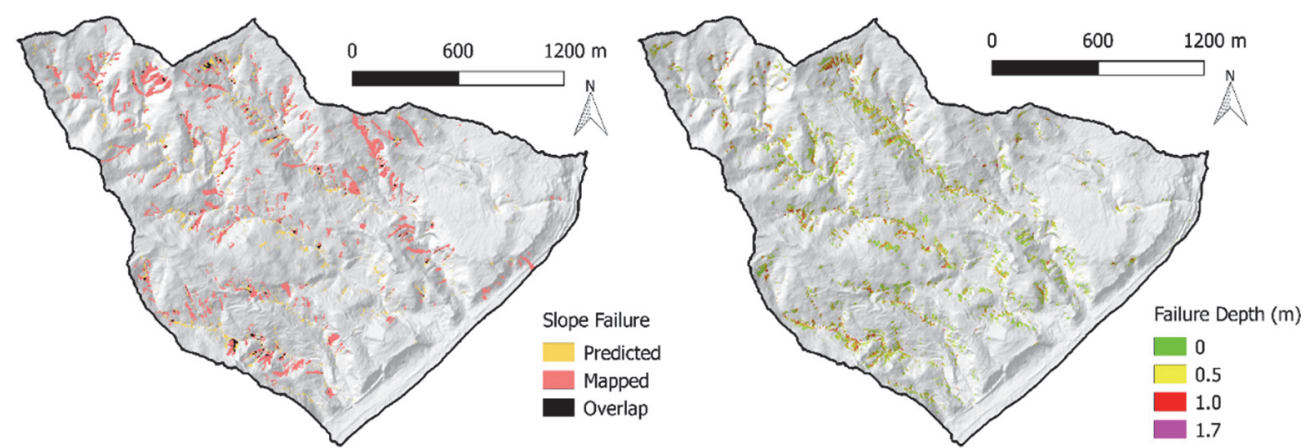

Figure 4-10 A comparison of simulated slope failure with the landslide inventory for the Scaletta catchment (Left). The simulated failure depth (Right).

Figure 4-11 shows maximum debris flow height during simulations with and without hydrology. Here, both slope failure and runout are simulated. Furthermore, the comparison between simulated runout patterns and the landslide inventory is shown. Table 4-5 shows the accuracy of the predicted debris flow runout and slope failures. The accuracy of the simulated runout patterns are 89.9 and 91.8 percent with kappa coefficients of 0.211 and 0.216 with and without hydrology, respectively. 

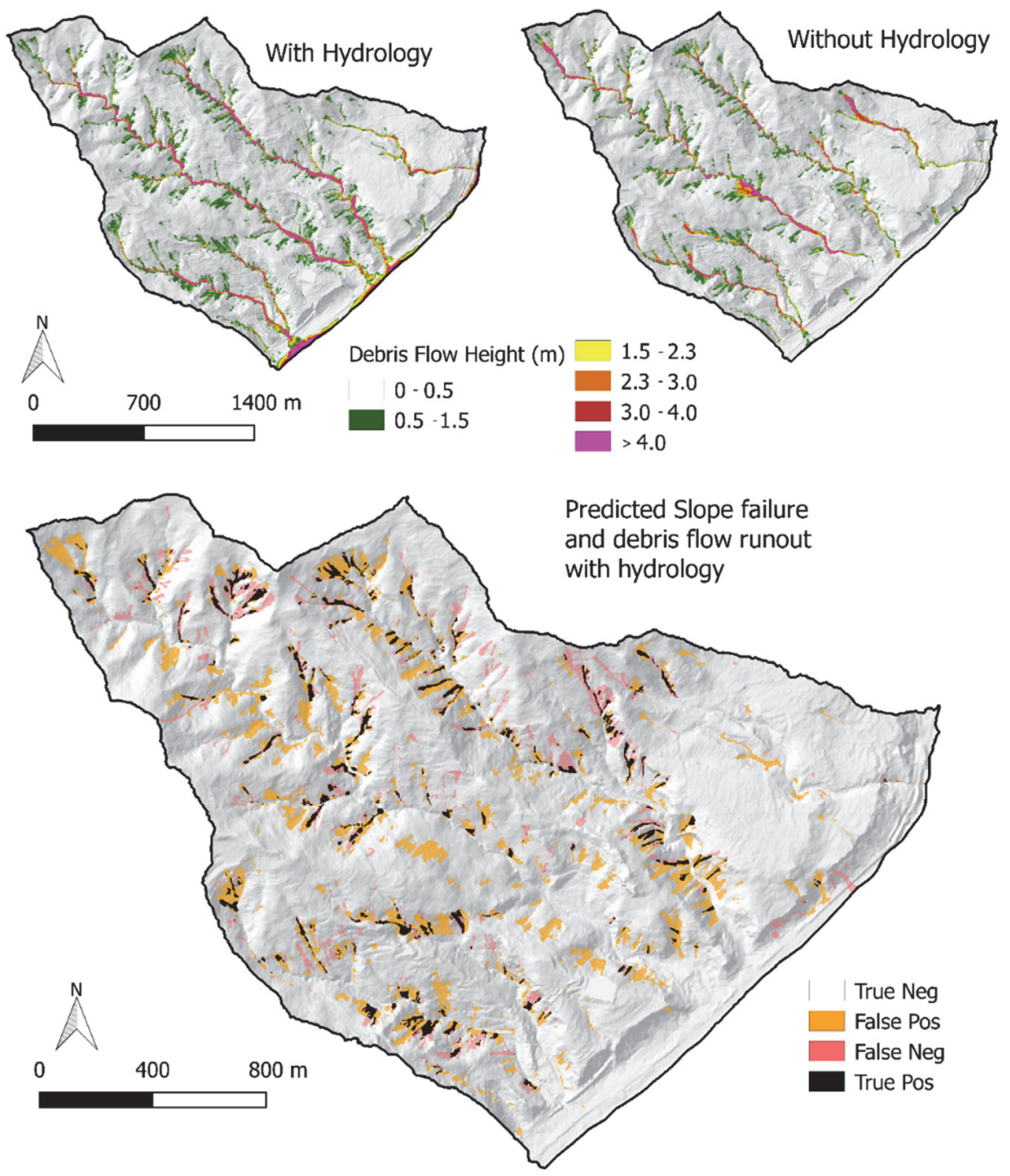

Figure 4-11 Maximum debris flow depth, both with hydrology (left) and without hydrology (right), and a comparison of debris flow runout with the landslide inventory, with channels removed (bottom)

Table 4-5 Comparison between model results and the landslide inventory (TP = Percentage True Positive, $\mathrm{TN}=$ True negatives (\%), FP = Fasle positives (\%), FN = False negatives (\%))

\begin{tabular}{|c|c|c|c|c|c|c|c|c|}
\hline 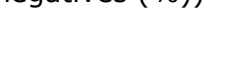 & $\begin{array}{l}\text { TP } \\
(\%)\end{array}$ & $\begin{array}{l}\text { TN } \\
(\%)\end{array}$ & $\begin{array}{l}\text { FP } \\
(\%)\end{array}$ & $\begin{array}{l}\text { FN } \\
(\%)\end{array}$ & $\begin{array}{l}\text { Cohens } \\
\text { Kappa }\end{array}$ & $\begin{array}{l}\text { Accuracy } \\
(\%)\end{array}$ & $\begin{array}{l}\text { Predicted Nr } \\
\text { Landslides }\end{array}$ & $\begin{array}{l}\text { Missed Nr } \\
\text { Landslides }\end{array}$ \\
\hline Landslide Inventory & 4.9 & 95.1 & 0 & 0 & 1 & 100 & 395 & 0 \\
\hline \multicolumn{9}{|l|}{ Debris Flow Runout } \\
\hline With Hydrology & 2.0 & 87.9 & 7.0 & 3.2 & 0.224 & 89.9 & 496 & 42 \\
\hline Without Hydrology & 1.6 & 89.2 & 5.6 & 3.4 & 0.216 & 91.8 & 403 & 81 \\
\hline
\end{tabular}




\subsubsection{Simulation Results with Inventory-Based Slope Failure}

To further investigate the influence of added hydrology on the runout, we carried out another simulation in which we did not simulate the slope failures themselves in the model. Instead, we took the slope failures from the landslide inventory and used the volumes of these as the starting points for the debris flows. A comparison of debris flow runout patterns and the landslide inventory are shown in Figure 4-12. Here, initiation of shallow landslides is simultaneous, and based on the inventory instead of physically predicted. Furthermore, Figure 4-12 compares maximum debris flow height for inventory-based landslides with and without hydrology. The accuracies for these simulations are $0.64,0.60,0.60$ and $0.56,0.58,0.60$ for simulations with and without hydrology respectively, with a failure fraction of $0.5,0.7$ and 0.9 , respectively. A full overview of accuracies is provided in 
Table 4-6.
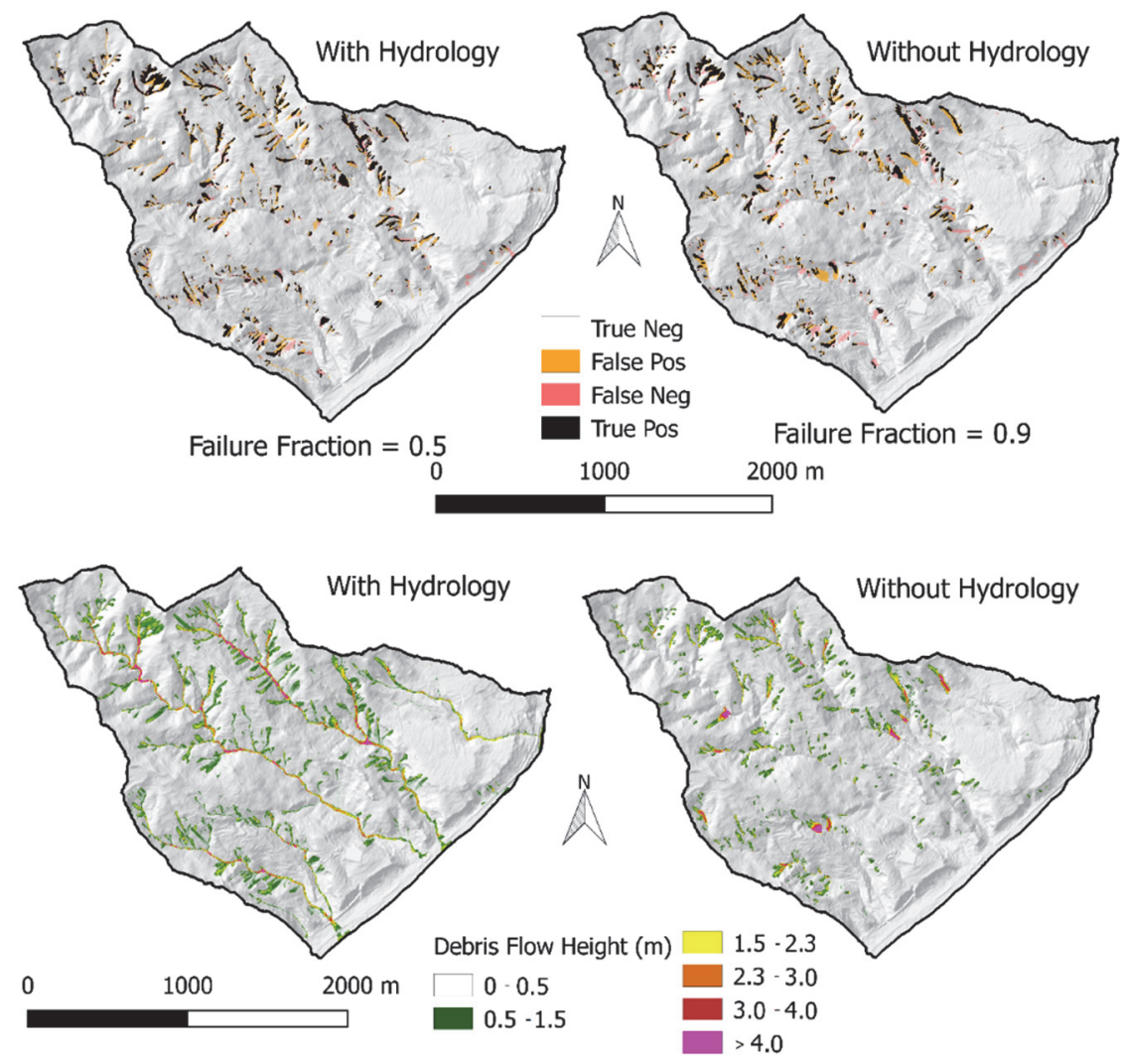

Figure 4-12 Debris flow runout and a masked comparison of debris flow runout with the landslide inventory 
Table 4-6 Cohens Kappa values for all performed calibrated simulations. (TP $=$ True Positive $(\%), \mathrm{TN}=$ True negatives $(\%), \mathrm{FP}=$ Fasle positives $(\%), \mathrm{FN}=$ False negatives $(\%))$

\begin{tabular}{lllllll} 
& $\begin{array}{l}\text { TP } \\
(\%)\end{array}$ & $\begin{array}{l}\text { TN } \\
(\%)\end{array}$ & $\begin{array}{l}\text { FP } \\
(\%)\end{array}$ & $\begin{array}{l}\text { FN } \\
(\%)\end{array}$ & $\begin{array}{l}\text { Accuracy } \\
(\%)\end{array}$ & $\begin{array}{l}\text { Cohens } \\
\text { Kappa }\end{array}$ \\
\hline Inventory & 4.9 & 95.1 & 0 & 0 & 100 & 1 \\
\hline \multicolumn{7}{c}{ Debris Flow Impact Area With Hydrology } \\
\hline Failure Fraction $=0.5$ & 3.6 & 92.5 & 2.5 & 1.4 & 96.1 & 0.638 \\
\hline Failure Fraction $=0.7$ & 3.3 & 92.5 & 2.4 & 1.8 & 95.8 & 0.597 \\
\hline Failure Fraction $=0.9$ & 4.3 & 90.4 & 4.4 & 0.9 & 94.8 & 0.596 \\
\hline \multicolumn{7}{c}{ Debris Flow Impact Area Without Hydrology } \\
\hline Failure Fraction $=0.5$ & 2.4 & 93.9 & 2.8 & 0.9 & 96.3 & 0.559 \\
\hline Failure Fraction $=0.7$ & 3.0 & 93.0 & 2.2 & 1.8 & 96.0 & 0.583 \\
\hline Failure Fraction $=0.9$ & 3.4 & 92.3 & 1.8 & 3.5 & 95.7 & 0.599
\end{tabular}

\subsubsection{Simulations with Coastal Deposition}

The results of the model simulations that included a coastal section are shown in Figure 4-13.
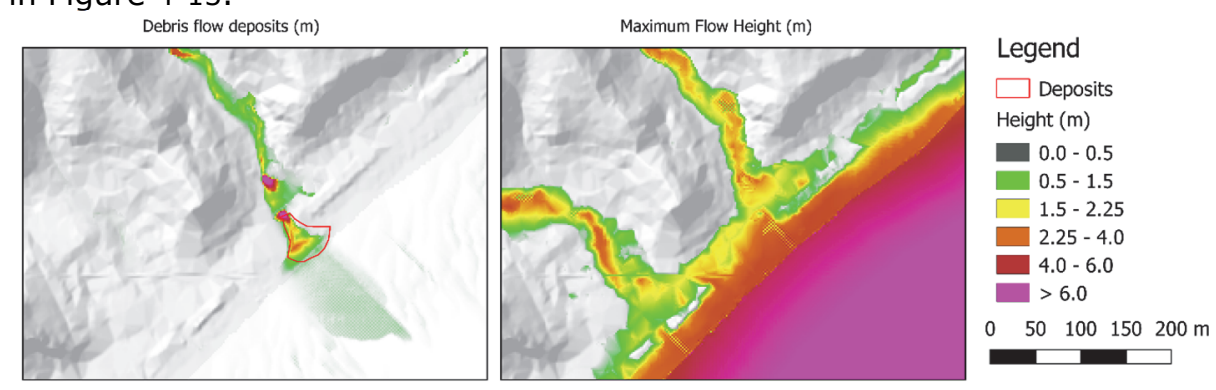

Figure 4-13 Final solid and fluid height with the simulation of a part of the coast. Simulation uses predicted slope failure and debris flow runout

\subsection{Discussion}

\subsubsection{Slope Failure}

The resulting slope failure patterns show a fairly good match with the highest 20 percent of elevation for each landslide impact polygon. While this does not directly confirm correlation with actual landslide source areas, it does provide confidence in the patterns predicted by the method. Individual landslides are in numerous cases predicted with high accuracy. Moreover, general patterns and areas of high hazard are well estimated. In terms of the number of landslides, 341 out of the 395 landslides overlap with the modelled slope failures. However, the modeled slope failures are over-estimated with 591 predicted landslide locations. But many of these may also be represented by numerous small failure locations located on the edges of the channels, which were not mapped in the landslide inventory. One of the possible reasons for this could be that these were subsequently eroded by the intense debris flood that also left deposits on the channel sides, making it harder to map small slope failure events. Since the over-predicted landslides were small in volume, 
they added relatively small volumes to the total runout. Thus, while predictions for single landslides can still increase in accuracy, general patterns of slope instability in the catchment are well predicted.

Many factors might be the cause of inaccuracies in predicting landslide locations. Primarily, the digital elevation model and estimations of soil depth appear to influence the location of slope failure in the performed simulations. In the case of relatively small shallow landslides, high spatial detail is required for accurate slope failure estimations. For both the calculation of slope, and in estimating soil depth, the quality of the elevation model determines the level of detail. In our study case, limited knowledge was available on the spatial distribution of soil depth. Soil depth was not varying for the various types of soils (e.g. colluvial, alluvial, residual soils). This could be responsible for most of the incorrect estimation of slope failure. Furthermore, landslides are complex processes where sub-surface structural details are important. These details, often formed by the morphological history of an area, can determine spatial patterns in slope failure. In the case of the Scaletta area, knowledge on subsurface structure was not available, limiting the accuracy of the model.

The method that was implemented to estimate the failure fraction of slope failure provided values between 0.1 and 1.7 meters. Data on the actual depth of slope failure in the Scaletta catchment is only available from photographs. Based on field photographs taken after the event, it can be concluded that the slope failure depth provides reasonable estimations of the depth of the failure plane for the modelled landslides. The average failure depth within the Giampillieri region, which is the neighboring catchment with identical characteristics, is estimated to be near 0.75 based on field visits several days after the event. Within the iterative slope failure model, the slope failure depth is significantly influenced by calibration for the stability margin parameter. While over-estimating failure volumes caused an over-estimation of runout, decreasing viscosity could, to a limited extent, compensate this. Due to the nature of the model, and the large number of free parameters that determine the outcome, there is an unavoidable equifinality. Because of this, runout patterns alone are not sufficient evidence in determining accurate failure depths.

In recent years, several models have attempted to estimate both slope failure and failure volumes. Mainly, approaches are based on random ellipsoid sampling of slopes. With this method, each slope segment is approached by a large number of randomly shaped elipsoids. The soil within this ellipsoid is then taken as a possible failure volume, and stability is calculated using a limit equilibrium method. SCOOP3D (Reid et al., 2015) and the modeling method by Mergili et al. (2014), implement this method. This method provides a highly detailed simulation of subsurface stability in a region with the best accuracy in the field. However, since the iterative method used in this research does not requires the sampling of large amounts of random ellipsoids, it can be performed for each hydrological calculation step. Compared to random ellipsoid methods, the iterative slope failure method allows for a quick assessment of slope stability and possible failure volume. Thus, while the assumptions in the iterative slope failure method are more ambiguous, calculation time strongly improves applicability.In another type of model, infiltration simulations are included in slope stability models to predict event-based slope failure on a catchment scale. Examples of this are iCRESTRIGRS (Zhang et al., 2016) and CRESLIDE (He et al., 2016). In both these models, the methods that are used 
to estimate slope stability are highly similar. Slope stability equations are coupled with a dynamic soil moisture simulation. Accuracy results are therefore similar. The accuracy of the proposed iterative slope failure method produces similar accuracy in estimating slope failures, when compared to other methods. All current models are forced to make similar assumptions considering subsurface structure due to a lack of available data. However, in the case of iterative slope failure, failure volumes are provided without the increase in computation time required with random ellipsoid sampling.

\subsubsection{Runout}

Debris flow simulations were performed for two types of situations, with predicted initiation and inventory-based initiation. It is important to note that the experts only mapped the landslides from the 1-10-2009 event up to the channel intersection, without including the full runout. Because of this, debris flow runout was masked out in channel locations. Based on reports, photographs and the resulting debris flow deposits in the area, it is known that debris flows took place, and a substantial amount of material was transported downstream towards the coast. However, debris flow runout in channels is completely dependent on the channel location. Including these areas in the runout comparison would artificially increase performance of the runout simulations without indicating improved performance. Another important factor in the accuracy of the model comes from the small slope failures directly nest to the channels. These small side-channel slope failures are not included in the landslide inventory. Because of the debris flooding, mapping these landslides is a difficult processes after the event. However, since no data is known considering these shallow slope failures, they are indicated as inaccurate predictions. However, based on images and reports, numerous of these landslides occurred in the region (Goswami et al., 2011; Ardizzone et al., 2012).

In the case of prediction-based runout simulations, debris flow initiation is determined by predicted slope failure. Therefore, correlation with the landslide inventory is highly bound by the accuracy of the slope failure predictions. The runout patterns of predicted slope failure show reasonable correlation with the landslide inventory. General patterns in runout distance and debris flow density throughout the catchment are well predicted. Examples of the types of patterns that are visible in the map are provided in Figure 4-14. 


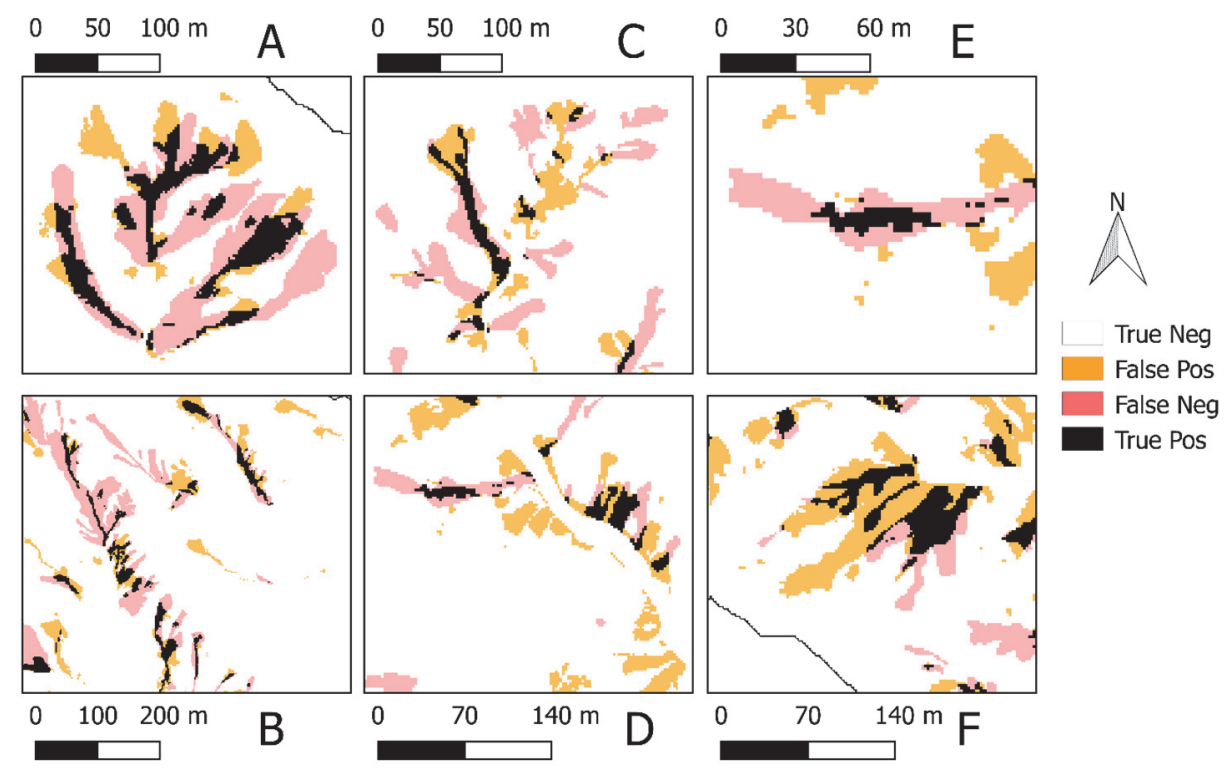

Figure 4-14 An overview of several patterns in the predicted slope failure and debris flow runout. A) mostly correct $B$ ) over-estimates small slope failure along channel sides $C$ ) initiation along the same stream, but not correctly placed

Firstly, areas where debris flows are accurately predicted are visible in Figure 4-14a. In such patterns, that form the predominant area of the catchment, both runout and initiation are simulated with substantial accuracy. Secondly, Figure $14 \mathrm{~b}$ shows areas where debris flow runout is overestimated due to small slope failures on the channel sides. Thirdly, several areas of the catchment are similar to the patterns in Figure 4-14c. Here debris flow correlation is low. However, general patterns are highly similar, providing a good estimation of debris flow susceptibility. Based on the data that is available for the catchment, a perfect prediction of slope failure and debris flows can furthermore not be expected. To further validation of the debris flood behavior, the maximum flow depth can be compared to photographs from the days after the event. In the calibrated simulation, the maximum flow height is equal to 2.8 meters. When compared with field photos, this shows the realistic estimation of debris flood properties by the model.

Simulation results for catchment-scale debris flow runout with inventory-based initiation show a good correlation with the landslide inventory. The values for Cohens Kappa reach 0.638 with simulated hydrology and a failure fraction of 0.5. One of the causes of the reached accuracy is the lack of individual calibration. Due to the complex behavior of debris flows, calibration is required to achieve sufficient correlation. In the case of individual debris flows, parameters such as viscosity, yield stress and surface flow resistance are altered in order to match simulated behavior with measurements. In the case of catchment-scale estimations of debris flow runout, individual calibration is too time-consuming, and reduces predictive power. However, two important properties of the used methodologies compensated the lack of calibration. Due to the scalability of the two-phase debris flow equations by Pudasaini (2012), 
estimations of rheological parameters was automatically performed. Furthermore, because of the soil data provided by Schillaci et al. (2017), the automatic estimations increased in accuracy. Simulation for catchment-scale debris flow runout with inventory-based initiation were carried out with varying failure depth. From the achieved accuracies it can be seen that the addition of hydrology significantly improved the simulation results. Without hydrology, a failure depth of 90 percent of the soil depth provided the highest kappa value. In reality slope failures were shallow, and the simulation with hydrology, which was most accurate at 50 percent of the soil depth, was more consistent with the seen slope failures.

The simulated output for both inventory-based and prediction-based debris flow runout was highly influenced by the incorporation of a hydrological simulation. In both cases, the accuracy of simulations was significantly higher due to the addition of simulated hydrology. As it is shown in Figure 4-15, several aspects of the simulation are altered. Firstly, the runout distance of solid materials is highly increased. In the case of simulations without hydrology, runout distances often only reach near the closest channel. However, when a hydrological simulation is included, more material is taken through the channel toward the coast, where a fan of debris material was created at the channel outlet. Secondly, the further runout of solid material decreases the depth of deposits that are left on the slopes below a slope failure. Finally, debris material has a significant influence on the behavior of channel flow and flooding in the catchment. Compared to a simulation with only hydrology, flood velocities are reduced by the solid material that is taken through the channel. In some cases, debris material nearly stagnates channel flow, or temporarily blocks it entirely. An example of velocity reduction by the solid volume in the channel is shown is Figure 4-15.

Fluid Volume (m3/cell)

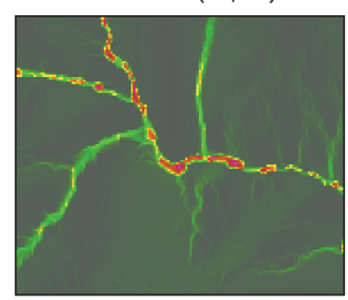

Solid Volume (m3/cell)
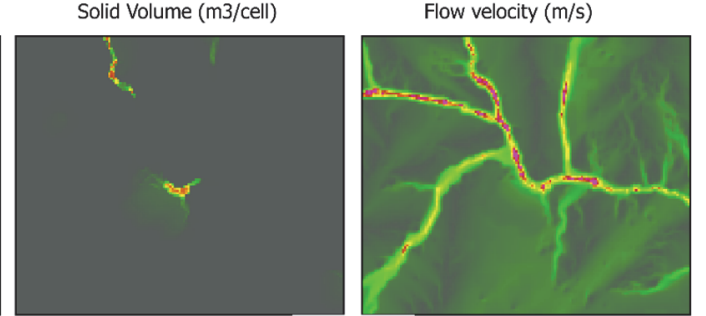

Legend

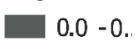

$0.3-0$.

$0.4-1$.

$1.0-1$.

$1.5-2$.

$>2.0$

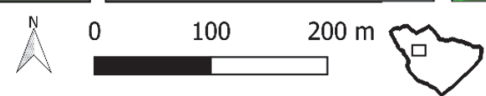

Figure 4-15 One of the locations in the catchment where a shallow landslide reduced flow velocities in the channel, partly blocking flow.

The addition of hydrology altered the behavior of the debris flow simulation due to several effects. Firstly, viscosity lowers when debris material is diluted with overland flow. Secondly, solid materials experience a higher drag force with a large volumes of water. Thus, due to the scalability and flexibility of the used two-phase debris flow equations, flow properties are continuously influenced by the flow composition. Because of this, a variety of emergent behaviors arise in the model.

Simulations of debris flow runout with hydrological modeling show the creation of a fan of debris material at the outlet of one of the sub-catchments in the 
Scaletta region. A similar fan of material has been described in reports, and shows on satellite images taken one year after the event. Based on the areal images and photographs of similar fans created during the event, the total volume of deposited solids in the fan is estimated to be around 2460 cubic meters. During the simulation that was calibrated on debris flow runout, a volume of 3490 cubic meters was deposited in the fan. The difference in the predicted and estimated volumes can be explained by the fact that the satellite image was taken one year after the event. Thus, erosion has most likely decreased the size of the fan, and shifted it towards the most common direction of the coastal current. The implementation of debris flow runout in a hydrological catchment model thus provided an acceptable approximation of the processes that caused and lead to the creation of a fan of debris deposits near the coast.

\subsubsection{Influence on Hazard}

Catchment scale risk assessment often incorporates simulations of debris flow runout. In the case of multi-hazard risk assessment, separate models are used to simulate debris flows and hydrological hazards. Since shallow landslides, debris flows and floods share a common meteorological trigger, these hazardous processes often occur simultaneously. Similarly, in the Scaletta catchment, hazardous processes took place simultaneously. Therefore, integrating debris flow simulations in a hydrological catchment model has significantly altered the behavior of the simulated hazardous processes. As a result, the estimation of hazard or risk for flooding and/or debris flows would have been different when these hazardous processes where approached separately.

In the case of the Scaletta catchment, downstream behavior of the hazardous processes has changed due the combined approach to debris flows and flooding. A comparison of maximum fluid/solid flow height for an integrated simulation and a flash flood simulation, is shown in Figure 4-16. In the case of the integrated simulation with slope failures, the reduced infiltration, and runout of solid materials and soil water strongly increases the total flow depth. A primary change in the risk is then caused by the exposure to the hazard. When bridges or other infrastructure are present, a further change in risk is created. Debris flows generally provide more impact force on blocking objects, such as bridges, and cause more destruction. Details such as these can, in scenarios considering hazardous event, make substantial difference concerning evacuation, and rescue travel times. 

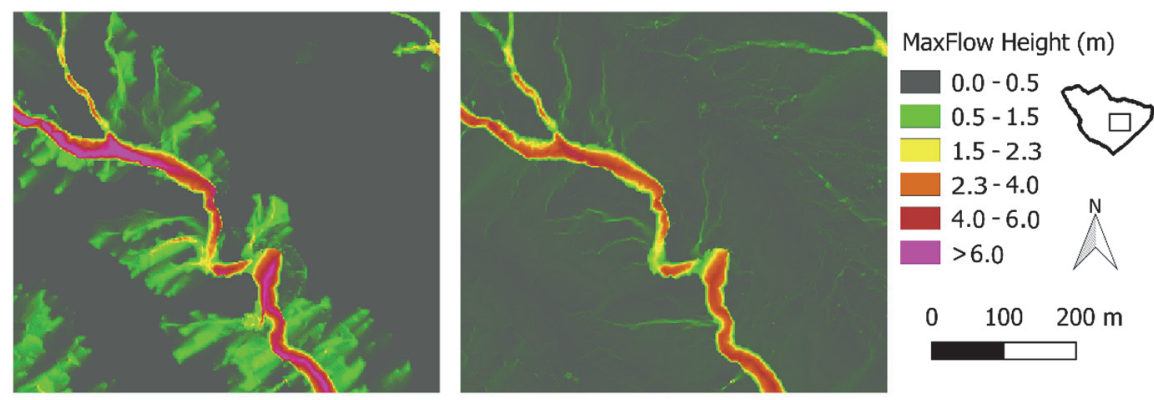

Figure 4-16 A comparison of maximum flow height for the scenario's with (left) and without (right) predicted shallow slope failure.

Finally, the hazard and risk are influenced by the presence of sediment in (flash) floods. Generally, flood simulations exclude sediment-related processes. The influence of flood deposits on the vulnerability of elements-atrisk, is therefore often ignored. However, in the case of the Scaletta catchment, debris floods left substantial amounts of deposits. Deposits often are required to be manually removed, which can be costly and time-consuming. More costs could be caused by these additional damage to crops, building and infrastructure. For an accurate representation of risk in the case of hazardous processes such as debris floods, the inclusion of sediment in flood vulnerability curves is required.

In the case of the presented research, calibration was required to obtain adequate results. In many applications of physical-based modelling, particularly related to hazard and risk assessment, forward analysis is useful. The current setup for the Scaletta area is not tested for such an application. Because of the physically-based implementation of all related processes, it seems forward predictions should be possible provided there is sufficient input data of high enough quality. In our case, particularly soil information was of low certainty, which made the soil strength parameters the values that required the most calibration. With all currently available methods, forward predictions of complex multi-hazard events should become increasingly accurate with more available data. Further research should investigate the possibility and accuract of forward modelling of complex multi-hazard events in an area with high-density measurements of soil and hydrological information.

\subsection{Conclusions}

Several aspects of the developed, integrated, modeling method provide added value above separated approaches to debris flows, shallow landslides and flood simulations. During the 2009 extreme event in the Scaletta catchment, a wide variety of processes such as slope failures, debris flooding, channel blocking and solids deposition occurred. Our developed modelling approach allowed for replication of the multi-hazard impact of the event. Application of a physically based multi-hazard model allows for simulating this broad spectrum of hazardous phenomena. When separated simulations are used in the analysis of event such as these, critical aspects of the event are not simulated. This 
affects both the potential for investigative use and predictive power. Furthermore, resulting risk and hazard could be seriously under-predicted when debris flows and flooding, which often take place simultaneously, are separately analyzed. Using a model that integrates (flash) flood behavior, shallow landslides, and debris flow runout, can thus increase the accuracy of hazard and risk assessment.

The purpose of the developed model in this case study is not the accurate prediction of the temporal and spatial location of slope failure. Lack of available data limits the predictions of slope failure to mere estimations and probabilities. Furthermore, the developed model does not provide a full description of all relevant processes. OpenLISEM is event-based in nature, and therefore neglects long-term physical processes, such as lateral ground water flow and evaporation, which are relevant in slope stability modeling on a longer time-scale. It is rather meant for physically based simulation of behavior of slope failure, debris flow runout and interactions with catchment hydrology. Detailed local knowledge of landslide risk requires both field visits by experts, and collecting subsurface structure data. While OpenLISEM is not meant for long-term slope prediction modeling, it can be used for several other important applications. Applications for the Investigation into the physical processes that lead to and cause hazardous processes in a catchment is the first and primary usage. A second important use is the simulation of scenarios in risk and hazard assessment. Finally, investigation into the effectiveness of measures, and the assessment of downstream hazards are an important functionality of OpenLISEM.

\subsubsection{Software Availability}

OpenLISEM is a freely available model that features a full interface and documentation (https://blog.utwente.nl/lisem/). It furthermore provides tools for erosion modeling and (flash) flood predictions. Development of OpenLISEM is an open-source process, and anyone can participate. Source-code of the model that is presented in this paper, and older versions of OpenLISEM are therefore available online (https://sourceforge.net/projects/lisem/).

\subsubsection{Future Research}

Before integrated modeling approaches could be applied in hazard and risk analysis, several research directions might require further investigation. Firstly, vulnerability curves are generally investigated separately for flood and debris flow processes. More-over, sediment is often completely neglected in flood vulnerability, while both debris flood and flood deposits provide substantial costs and possible hazard. The inclusion of sediment and the combination of debris flow and flood vulnerability should, for some regions, be investigated. Secondly, the proposed modeling approach was tested predominantly with data from remote sensing sources. While this allows for usage in data-poor regions, the model performance depends largely on the quality of the digital elevation model. The effect however, of digital elevation models of separate sources, is still to be investigated 


\subsubsection{Acknowledgements}

We wish to express our gratitude to the editorial team of the journal and the reviewers for the thorough efforts to help improve this research. The presented work is part of the Earth System Analysis group, ITC, Twente University, the Netherlands in corporation with Computational Earthquake Seismology and Extreme Statistic groups, King Abdullah University of Science and Technology. Satellite images were provided by the European Space Agency through the project titled: "A remote sensing based approach for storm triggered debris flow hazard modeling: application in Mediterranean and tropical Pacific areas", code: C1P.14151, PI: Luigi Lombardo. 


\section{$5 \quad$ Generalized Mass Movements Equations for Semi-Structured Runout}

This chapter has been submitted as B. van den Bout, T. van Asch, W. Hu, C. Tang, O. Mavrouli, V. G. Jetten, C. J. van Westen (under review) Towards a model for structured mass movements: the OpenLISEM Hazard model 2.0a

\subsection{Introduction}

The earths rock cycle involves sudden release and gravity-driven transport of sloping materials. These mass movements have a significant global impact in financial damage and casualties (Nadim et al., 2006; Kjekstad \& Highland, 2009). Understanding the physical principles at work at their initiation and runout phase allows for better mitigation and adaptation to the hazard they induce (Corominas et al., 2014). Many varieties of gravitationally-driven mass movements have been categorized according to their material physical parameters and type of movement. Examples are slides, flows and falls consisting of soil, rocks or debris (Varnes, 1987). Major factors in determining the dynamics of mass movement runout are the composition of the moving material and the forces during initiation and runout. Physically-based models attempt to describe the internal and external forces of all these mass movements in a generalized form (David \& Richard, 2011; Pudasaini, 2012; Iverson \& George, 2014). This allows these models to be applied to a wide variety of cases, while improving predictive range.

Dynamics of geophysical flows are complex and dependent on a variety of forces due to their multi-phase interactions (Hutter et al., 1996). Generally, understanding and prediction of geophysical flows takes place through numerical modelling of the flow. A variety of both one, two and threedimensional sets of equations exist to describe the advection and forces that determine the dynamics of geophysical flows. Examples that simulated a single mixed material (Rickenmann et al., 2006; O'Brien et al., 2007; Luna et al., 2012; van Asch et al., 2014). Two phase models describe both solids, fluids and their interactions and provide additional detail and generalize in important ways (Sheridan et al., 2005; Pitman \& Le, 2005; Pudasaini, 2012; George \& Iverson, 2014; Mergili et al., 2017). Recently, a three-phase model has been developed that includes the interactions between small and larger solid phases (Pudasaini \& Mergili, 2019). Typically, implemented forces include gravitational forces and, depending on the rheology of the equations, drag forces, viscous internal forces and a plasticity-criterion. However, a major assumption made for current models is a full mixed and fragmented nature of the material (Iverson \& Denlinger 2001; Pudasaini \& Hutter, 2003). Other models do include some depth-averaged strain to define a non-Newtonian viscous yield stress (Boetticher et al., 2016; Fornes et al., 2017; Pudasaini \& Mergili, 2019). Thus, within current mass movement runout models, there might be improvements available from describing the behavior of structured mixtures.

The general importance of the initial structured nature of mass movement material is observed for a variety of reasons. First, block slides are an important subset of mass movement types (Hayir, 2003; Beutner et al., 2008; Tang et al., 2008). This type of mass movement features some cohesive structure to the dynamic material in the movement phase. Secondly, during 
movement, the spatial gradients in local acceleration induce strain and stress that results in fracturing. This process, often called fragmentation in relation to structured mass movements, can be of crucial importance for mass movement dynamics (Davies \& McSaveney, 2009; Delaney \& Evans, 2014; Dufresne et al., 2018; Corominas et al. 2019). Lubricating effect from basal fragmentation can enhance velocities and runout distance significantly (Davies et al., 2006; Tang et al., 2009). Otherwise, fragmentation generally influences the rheology of the movement by altering grain-grain interactions (Zhou et al., 2005). The importance of structured material dynamics is further indicated by engineering studies on rock behavior and fracture models (Kaklauskas \& Ghaboussi, 2001; Ngekpe et al., 2016; Dhanmeher, 2017).

In this paper, existing two-phase generalized debris flow equations are adapted to describe runout of an arbitrarily structured two-phase Mohr-Coulomb material. The second section of this work provides the derivation of the extensive set of equations that describe structured mass movements in a generalized manner. The third section validates the developed model by comparison with results from controlled flume runout experiments. Additionally, this section shows numerical simulation examples that highlight fragmentation behavior and its influence on runout dynamics. Finally, in section four, a discussion on the potential usage of the presented model is provided together with reflection on important opportunities of improvement.

\subsection{A Set of Debris Flow Equations Incorporating Internal Structure}

\subsubsection{Structured Mass Movements}

Initiation of gravitational mass flows occurs when sloping material is released. The instability of such materials is generally understood to take place along a failure plane (Zhang et al., 2011, Stead \& Wolter, 2015). Along this plane, forces exerted due to gravity and possible seismic accelerations can act as a driving force towards the downslope direction, while a normal-force on the terrain induces a resisting force (Xie et al., 2006). When internal stress exceeds a specified criteria, commonly described using Mohr-Coulomb theory, fracturing occurs along the failure plane, and the material becomes dynamic. Observations indicates material can initially fracture predominantly at the failure plane (Tang et al., 2009 Davies et al., 2006). Full finite-element modelling of stability confirms no fragmentation occurs at initiation, and runout can start as a structured mass (Matsui \& San, 1992; Griffiths \& Lane, 1999). Once movement is initiated, the material is accelerated. Due to spatially nonhomogeneous acceleration, either caused by a non-homogeneous terrain slope, or impact with obstacles, internal stress can build within the moving mass. The stress state can reach a point outside the yield surface, after which some form of deformation occurs (e.g. Plastic, Brittle, ductile) (Loehnert et al., 2008). In the case of rock or soil material, elastic/plastic deformation is limited and fracturing occurs at relatively low strain values (Kaklauskas \& Ghaboussi, 2001; Dhanmeher, 2017). Rocks and soil additionally show predominantly brittle fracturing, where strain increments at maximum stress are small (Bieniawaski, 1967; Price, 2016; Husek et al., 2016). For soil matrices, cohesive bonds between grains originate from causes such as cementing, frictionl 
contacts and root networks (Cohen et al., 2009). Thus, the material breaks along either the grain-grain bonds or on the molecular level. In practice, this processes of fragmentation has been both observed and studied frequently. Cracking models for solids use stress-strain descriptions of continuum mechanics (Menin et al., 2009; Ngekpe et al., 2016). Fracture models frequently use Smooth Particle Hydrodynamics (SPH) since a Lagrangian, meshfree solution benefits possible fracturing behavior (Maurel \& Combescure, 2008; Xu et al., 2010; Osorno \& Steeb, 2017). Within the model developed below, knowledge from fracture-simulating continuum mechanical models is combined with finite element fluid dynamic models.

\subsubsection{Model Description}

We define two phases, solids and fluids, within the flow, indicated by $s$ and $f$ respectively. A specified fraction of solids within this mixture is at any point part of a structured matrix. This structured solid phase, indicated by $s c$ envelops and confines a fraction of the fluids in the mixture, indicates as $f c$. The solids and fluids are defined in terms of the physical properties such as densities $\left(\rho_{f}, \rho_{s}\right)$ and volume fractions $\left(\alpha_{f}=\frac{s}{f+s}, \alpha_{s}=\frac{f}{f+s}\right)$. The confined fractions of their respective phases are indicated as $f_{s c}$ and $f_{f c}$ for the volume fraction of confined solids and fluids respectively (Equations 5.1, 5.2 and 5.3).

5.1 $\alpha_{\mathrm{s}}+\alpha_{\mathrm{f}}=1$

5.2

5.3

$$
\begin{gathered}
\alpha_{\mathrm{s}}\left(\mathrm{f}_{\mathrm{sc}}+\left(1-\mathrm{f}_{\mathrm{sc}}\right)\right)+\alpha_{\mathrm{f}}\left(\mathrm{f}_{\mathrm{fc}}+\left(1-\mathrm{f}_{\mathrm{fc}}\right)\right)=1 \\
\left(\mathrm{f}_{\mathrm{sc}}+\left(1-\mathrm{f}_{\mathrm{sc}}\right)\right)=\left(\mathrm{f}_{\mathrm{fc}}+\left(1-\mathrm{f}_{\mathrm{fc}}\right)\right)=1
\end{gathered}
$$

For the solids, additionally internal friction angle $\left(\phi_{s}\right)$ and effective material size $\left(d_{s}\right)$ are defined. We additionally define $\alpha_{c}=\alpha_{s}+f_{f c} \alpha_{f}$ and $\alpha_{u}=\left(1-f_{f c}\right) \alpha_{f}$ to indicate the solids with confined fluids and free fluid phases respectively. These phases have an averaged density $\rho_{s c}, \rho_{f}$ We let the velocities of the unconfined fluid phase (u) be defined as $u_{u}=\left(u_{u}, v_{u}\right)$. We assume velocities of the confined phases (c) can validly be assumed to be identical to the velocities of the solid phase, $u_{c}=\left(u_{c}, v_{c}\right)=u_{s}=\left(u_{s}, v_{s}\right)$. A schematic depiction of the represented phases is shown in Figure 5-1. 


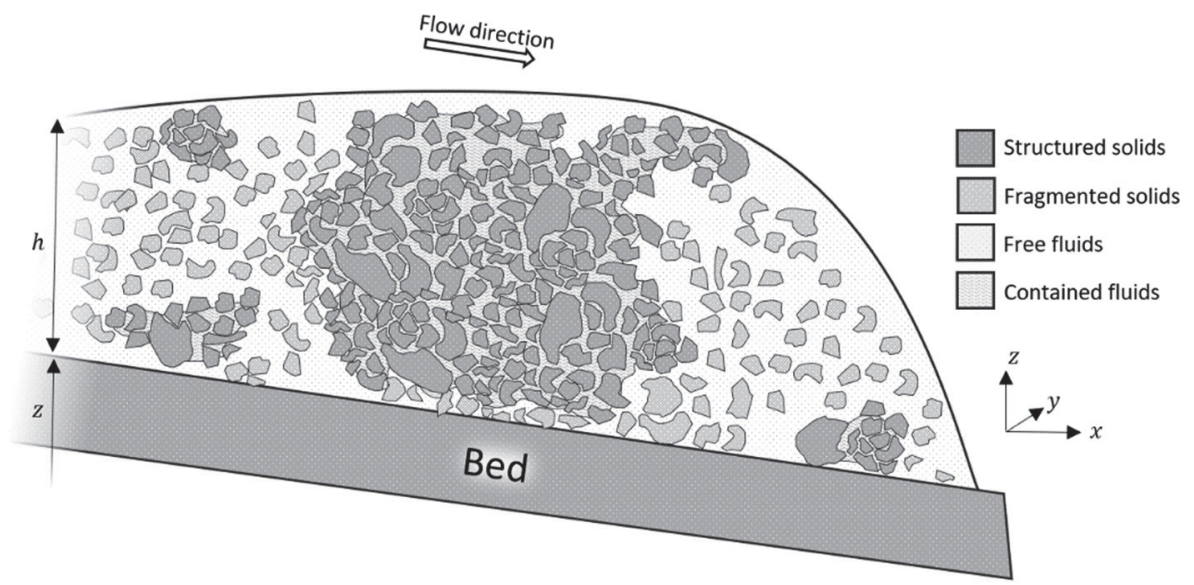

Figure 5-1 A schematic depiction of the flow contents. Both structured and unstructured solids are present. Fluids can be either free, or confined by the structured solids.

A major assumption is made here concerning the velocities of both the confined and free solids ( $\mathrm{sc}$ and $\mathrm{s}$ ), that have a shared averaged velocity $\left(u_{s}\right)$. We deliberately limit the flow description to two phases, opposed to the innovative work of Pudasaini \& Mergili (2019) that develop a multi-mechanical threephase model. This choice is motivated by considerations of applicability (reducing the number of required parameters), the infancy of three-phase flow descriptions and finally the general observations of the validity of this assumption (Ishii, 1975; Ishii \& Zuber, 1979; Drew, 1983; Jakob et al, 2005; George \& Iverson, 2016).

The movement of the flow is described initially by means of mass and momentum conservation (Equations 5.4 and 5.5).

$$
\begin{aligned}
& \frac{\partial \alpha_{\mathrm{c}}}{\partial \mathrm{t}}+\nabla \cdot\left(\alpha_{\mathrm{c}} \mathbf{u}_{\mathrm{c}}\right)=0 \\
& \frac{\partial \alpha_{\mathrm{u}}}{\partial \mathrm{t}}+\nabla \cdot\left(\alpha_{\mathrm{u}} \mathbf{u}_{\mathrm{u}}\right)=0
\end{aligned}
$$

Here we add the individual forces based on the work of Pudasaini \& Hutter (2003), Pitman \& Le (2005), Pudasaini (2012), Pudasaini \& Fischer (2016) and Pudasaini \& Mergili (2019) (Equations 5.6 and 5.7).

$$
\begin{aligned}
& \frac{\partial}{\partial \mathrm{t}}\left(\alpha_{\mathrm{c}} \rho_{\mathrm{c}} \mathbf{u}_{\mathrm{c}}\right)+\nabla \cdot\left(\alpha_{\mathrm{c}} \rho_{\mathrm{c}} \mathbf{u}_{\mathrm{c}} \otimes \mathbf{u}_{\mathrm{c}}\right)=\alpha_{\mathrm{c}} \rho_{\mathrm{c}} \mathbf{f}-\nabla \cdot \alpha_{\mathrm{c}} \mathbf{T}_{\mathrm{c}}+\mathrm{p}_{\mathrm{c}} \nabla \alpha_{\mathrm{c}}+\mathbf{M}_{\mathrm{DG}}+\mathbf{M}_{\mathrm{vm}} \\
& \frac{\partial}{\partial \mathrm{t}}\left(\alpha_{\mathrm{u}} \rho_{\mathrm{f}} \mathbf{u}_{\mathrm{u}}\right)+\nabla \cdot\left(\alpha_{\mathrm{u}} \rho_{\mathrm{f}} \mathbf{u}_{\mathrm{u}} \otimes \mathbf{u}_{\mathrm{u}}\right)=\alpha_{\mathrm{u}} \rho_{\mathrm{f}} \mathbf{f}-\nabla \cdot \alpha_{\mathrm{u}} \mathbf{T}_{\mathrm{u}}+\mathrm{p}_{\mathrm{f}} \nabla \alpha_{\mathrm{u}}-\mathbf{M}_{\mathrm{DG}}-\mathbf{M}_{\mathrm{vm}}
\end{aligned}
$$

Where $\boldsymbol{f}$ is the body force (among which is gravity), $\boldsymbol{M}_{D G}$ is the drag force, $\boldsymbol{M}_{v m}$ is the virtual mass force and $\boldsymbol{T}_{c}, \boldsymbol{T}_{u}$ are the stress tensors for solids with confined fluids and unconfined phases respectively. Both the confined and unconfined phases in the mixture are subject to stress tensors $\left(T_{c}\right.$, and $\left.T_{u}\right)$, for which the gradient acts as a momentum source. Additionally, we follow Pudasaini (2012) and add a buoyancy force. 


\subsubsection{Stress Tensors, Describing Internal Structure}

Our first step in defining the momentum source terms in equations 0 and 0 is the definition of the fluid and solid stress tensors. Current models typically follow the assumptions made by Pitman \& Le (2005), who indicate: "Proportionality and alignment of the tangential and normal forces are imposed as a basal boundary condition is assumed to hold throughout the layer of flowing material ... following Rankine (1857) and Terzaghi (1936), an earth pressure relation is assumed for diagonal stress components". Thus, unstructured columns of moving mixtures are assumed. Here, we aim to use the full Mohr-Coulomb relations. Describing the internal tress of soil and rock matrices is commonly achieved be elastic-plastic simulations of the materials stress-strain relationship. Since we aim to model a full stress description, the stress tensor is equal to the stress tensor (Equation 5.8).
5.8
$\mathbf{T}_{\mathrm{c}}=\boldsymbol{\sigma}$

Where $\boldsymbol{\sigma}$ is the stress tensor for solids. The stress can be divided into the deviatoric and non-deviatoric contributions (Equation 5.9). Note that we switch to tensor notation when describing the stress-strain relationship. Thus, superscripts represent the indices of basis vectors, and obtain tensor elements. Additionally, the Einstein convention is followed (automatic summation of nondefined repeated indices in a single term).

$$
5.9 \quad \sigma^{\alpha \beta}=s^{\alpha \beta}+\frac{1}{3} \sigma^{\gamma \gamma} \delta^{\alpha \beta}
$$

Where $s$ is the deviatoric stress tensor and $\delta^{\alpha \beta}$ is the Kronecker delta.

Here, we define the stress $(\sigma)$ based on a generalized hooke-type law in tensor notation (Equation 5.10 and 5.11) where plastic strain occurs when the stress state reaches the yield criterion (Spencer, 2004; Necas \& Hiavecek, 2007; Bui et al., 2008).

$$
\begin{gathered}
\dot{\epsilon}_{\text {elastic }}^{\alpha \beta}=\frac{\dot{s}^{\alpha \beta}}{2 \mathrm{G}}+\frac{1-2 v}{\mathrm{E}} \dot{\sigma}^{\mathrm{m}} \delta^{\alpha \beta} \\
\dot{\epsilon}_{\text {plastic }}^{\alpha \beta}=\dot{\lambda} \frac{\partial \mathrm{g}}{\partial \sigma^{\alpha \beta}}
\end{gathered}
$$

Where $\dot{\epsilon}_{\text {elastic }}$ is the plastic strain tensor, $\dot{\epsilon}_{\text {plastic }}$ is the plastic strain tensor, $\dot{\sigma}^{m}$ is the mean stress rate tensor, $v$ is Poisson's ratio, $E$ is the elastic Young's Modulus, $G$ is the shear modulus, $\dot{s}$ is the deviatoric shear stress rate tensor, $\dot{\lambda}$ is the plastic multiplier rate and $g$ is the plastic potential function. Additionally, the strain rate is defined from velocity gradients as equation 5.12 .

$$
\dot{\epsilon}_{\text {total }}^{\alpha \beta}=\dot{\epsilon}_{\text {elastic }}^{\alpha \beta}+\dot{\epsilon}_{\text {plastic }}^{\alpha \beta}=\frac{1}{2}\left(\frac{\partial \mathrm{u}_{\mathrm{c}}^{\alpha}}{\partial \mathrm{x}^{\beta}}-\frac{\partial \mathrm{u}_{\mathrm{c}}^{\beta}}{\partial \mathrm{x}^{\alpha}}\right)
$$

By solving equations 5.9, 5.10 and 5.11 for $\dot{\sigma}$, a stress-strain relationship can be obtained (Equation 5.130) (Bui et al., 2008).

$$
\dot{\sigma}^{\alpha \beta}=2 \mathrm{G} \dot{\mathrm{e}}^{\gamma \gamma} \delta^{\alpha \beta}+\mathrm{K} \dot{\epsilon}^{\gamma \gamma} \delta^{\alpha \beta}-\dot{\lambda}\left[\left(\mathrm{K}-\frac{2 \mathrm{G}}{3}\right) \frac{\partial \mathrm{g}}{\partial \sigma^{\mathrm{mn}}} \delta^{\mathrm{mn}} \delta^{\alpha \beta}+2 \mathrm{G} \frac{\partial \mathrm{g}}{\partial \sigma^{\alpha \beta}}\right]
$$

Where $\dot{e}$ is the deviatoric strain rate $\left(\dot{e}^{\alpha \beta}=\dot{\epsilon}^{\gamma \gamma}-\frac{1}{3} \dot{\epsilon}^{\alpha \beta} \delta^{\alpha \beta}\right), \psi$ is the dilatancy angle and $\mathrm{K}$ is the elastic bulk modulus and the material parameters defined from from $E$ and $v$ (Equation 5.14).

$$
\text { 5.14 } \mathrm{K}=\frac{\mathrm{E}}{3(1-2 v)}, \quad \mathrm{G}=\frac{\mathrm{E}}{2(1+v)}
$$


Fracturing or failure occurs when the stress state reaches the yield surface, after which plastic deformation occurs. The rate of change of the plastic multiplier specifies the magnitude of plastic loading and must ensure a new stress state conforms to the conditions of the yield criterion. By means of substituting equation 0 in the consistency condition $\left(\frac{\partial f}{\partial \sigma^{\alpha \beta}} d \sigma^{\alpha \beta}=0\right)$, the plastic multiplier rate can be defined (Equation 5.150) (Bui et al., 2008).

$$
\dot{\lambda}=\frac{2 \mathrm{G} \epsilon^{\alpha \beta} \frac{\partial \mathrm{f}}{\partial \sigma^{\alpha \beta}}+\left(\mathrm{K}-\frac{2 \mathrm{G}}{3}\right) \dot{\epsilon}^{\gamma \gamma} \frac{\partial \mathrm{f}}{\partial \sigma^{\alpha \beta}} \sigma^{\alpha \beta} \delta^{\alpha \beta}}{2 \mathrm{G} \frac{\partial \mathrm{f}}{\partial \sigma^{\mathrm{mn}}} \frac{\partial \mathrm{g}}{\partial \sigma^{\mathrm{mn}}}+\left(\mathrm{K}-\frac{2 \mathrm{G}}{3}\right) \frac{\partial \mathrm{f}}{\partial \sigma^{\mathrm{mn}}} \delta^{\mathrm{mn}} \frac{\partial \mathrm{g}}{\partial \sigma^{\mathrm{mn}}} \delta^{\mathrm{mn}}}
$$

The yield criteria specifies a surface in the stress-state space that the stress state can not pass, and at which plastic deformation occurs. A variety of yield criteria exist, such as Mohr-Coulomb, Von Mises, Ducker-Prager and Tresca (Spencer, 2004). Here, we employ the Ducker-Prager model fitted to MohrCoulomb material parameters for its accuracy in simulating rock and soil behavior, and numerical stability (Spencer, 2004; Bui et al., 2008) (Equation 5.16 and 5.17).
5.16
$\mathrm{f}\left(\mathrm{I}_{1}, \mathrm{~J}_{2}\right)=\sqrt{\mathrm{J}_{2}}+\alpha_{\phi} \mathrm{I}_{1}-\mathrm{k}_{\mathrm{c}}=0$
5.17$$
\mathrm{g}\left(\mathrm{I}_{1}, \mathrm{~J}_{2}\right)=\sqrt{\mathrm{J}_{2}}+\alpha_{\phi} \mathrm{I}_{1} \sin (\psi)
$$

Where $I_{1}$ and $J_{2}$ are tensor invariants (Equation 5.18 and 5.19).
5.18
$\mathrm{I}_{1}=\sigma^{\mathrm{xx}}+\sigma^{\mathrm{yy}}+\sigma^{\mathrm{zz}}$
5.19

$$
\mathrm{J}_{2}=\frac{1}{2} \mathrm{~s}^{\alpha \beta} \mathrm{s}^{\alpha \beta}
$$

Where the Mohr-Coulomb material parameters are used to estimate the Ducker-Prager parameters (Equation 5.20).

$$
\alpha_{\phi}=\frac{\tan (\phi)}{\sqrt{9+12 \tan ^{2} \phi}}, \quad \mathrm{k}_{\mathrm{c}}=\frac{3 \mathrm{c}}{\sqrt{9+12 \tan ^{2} \phi}}
$$

Using the definitions of the yield surface and stress-strain relationship, combining equations $5.13-5.17$, the relationship for the stress rate can be obtained (Equation 5.21 and 5.22).

$$
\begin{gathered}
\dot{\sigma}=2 \mathrm{Ge}^{\alpha \beta}+\mathrm{K} \dot{\epsilon}^{\gamma \gamma} \delta^{\alpha \beta}-\dot{\lambda}\left[9 \mathrm{Ksin} \psi \delta^{\alpha \beta}+\frac{\mathrm{G}}{\sqrt{\mathrm{J}_{2}}} \mathrm{~s}^{\alpha \beta}\right] \\
\dot{\lambda}=\frac{3 \alpha \mathrm{K} \dot{\epsilon}^{\gamma \gamma}+\left(\frac{\mathrm{G}}{\sqrt{\mathrm{J}_{2}}}\right) \mathrm{s}^{\alpha \beta} \dot{\epsilon}^{\alpha \beta}}{27 \alpha_{\phi} \mathrm{Ksin} \psi+\mathrm{G}}
\end{gathered}
$$

In order to allow for the description of large deformation, the Joumann stress rate can be used, which is a stress-rate that is independent from a frame of reference (Equation 5.23).

$$
\dot{\hat{\sigma}}=\sigma^{\alpha \gamma} \dot{\omega}^{\beta \gamma}+\sigma^{\gamma \beta} \dot{\omega}^{\alpha \gamma}+2 G \dot{e}^{\alpha \beta}+K \dot{\epsilon}^{\gamma \gamma} \delta^{\alpha \beta}-\dot{\lambda}\left[9 \operatorname{Ksin} \psi \delta^{\alpha \beta}+\frac{G}{\sqrt{J_{2}}} s^{\alpha \beta}\right]
$$

Where $\dot{\omega}$ is the spin rate tensor, as defined by equation 5.24 .

$$
\dot{\omega}^{\alpha \beta}=\frac{1}{2}\left(\frac{\partial \mathrm{v}^{\alpha}}{\partial \mathrm{x}^{\beta}}-\frac{\partial \mathrm{v}^{\beta}}{\partial \mathrm{x}^{\alpha}}\right)
$$

Due to the strain within the confined material, the density of the confined solid phase $\left(\rho_{c}\right)$ evolves dynamically according to equation 5.25 . 


$$
\rho_{\mathrm{c}}=\mathrm{f}_{\mathrm{sc}} \rho_{\mathrm{s}} \frac{\epsilon_{\mathrm{v} 0}}{\epsilon_{\mathrm{v}}}+\left(1-\mathrm{f}_{\mathrm{sc}}\right) \rho_{\mathrm{s}}+\mathrm{f}_{\mathrm{fc}} \rho_{\mathrm{f}}
$$

Where $\epsilon_{v}$ is the total volume strain, $\dot{\epsilon_{v}} \approx \epsilon_{1}+\epsilon_{2}+\epsilon_{3}, \epsilon_{i}$ is one of the principal components of the strain tensor. Since we aim to simulate brittle materials, where volume strain remains relatively low, we assume that changes in density are small compared to the original density of the material $\left(\frac{\partial \rho_{c}}{\partial t} \ll \rho_{c}\right)$.

\subsubsection{Fragmentation}

Brittle fracturing is a processes commonly understood to take place once a material internal stress has reached the yield surface, and plastic deformation has been sufficient to pass the ultimate strength point (Maurel \& Cumescure, 2008; Husek et al., 2016). A variety of approaches to fracturing exist within the literature (Ma et al., 2014; Osomo \& Steeb, 2017). FEM models use strainbased approaches (Loehnert et al., 2008). For SPH implementations, as will be presented in this work, distance-based approaches have provided good results (Maurel \& Cumbescure, 2008). Other works have used strain-based fracture criteria (Xu et al., 2010). Additionally, dynamic degradation of strength parameters have been implemented (Grady \& Kipp, 1980; Vuyst \& Vignjevic, 2013; Williams, 2019). Comparisons with observed fracture behavior has indicated the predictive value of these schemes (Xu et al., 2010; Husek et al., 2016). We combine the various approaches to best fit the dynamical multiphase mass movement model that is developed. Following, Grady \& Kipp (1980) and we simulate a degradation of strength parameters. Our material consists of a soil and rock matrix. We assume fracturing occurs along the intergranular or inter-rock contacts and bonds (see also Cohen et al., 2009). Thus, cohesive strength is lost for any fractured contacts. We simulate degradation of cohesive strength according to a volume strain criteria. When the stress state lies on the yield surface, during plastic deformation, strain is assumed to attribute towards fracturing. A critical volume strain is taken as material property, and the breaking of cohesive bonds occurs based on the relative volume strain. Following Grady \& Kipp (1980) and Vuyst \& Vignjevic (2013), we assume that the degradation behavior of the strength parameter is distributed according to a probability density distribution. Commonly, a Weibull-distribution is used (Williams, 2019). Here, for simplicity, we use a uniform distribution of cohesive strength between 0 and $2 c_{0}$, although any other distribution can be substituted. Thus, the expression governing cohesive strength becomes equation 5.26 .

$$
\frac{\partial \mathrm{c}}{\partial \mathrm{t}}=\left\{\begin{array}{cl}
-\mathrm{c}_{0} \frac{1}{2} \frac{\left(\frac{\epsilon_{\mathrm{v}}}{\epsilon_{\mathrm{v} 0}}\right)}{\epsilon_{\mathrm{c}}} & \mathrm{f}\left(\mathrm{I}_{1}, \mathrm{~J}_{2}\right) \geq 0, \mathrm{c}>0 \\
0 & \text { otherwise }
\end{array}\right.
$$

Where $c_{0}$ is the initial cohesive strength of the material, $\epsilon_{v 0}$ is the initial volume, $\left(\frac{\epsilon_{v}}{\epsilon_{v 0}}\right)$ is the fractional volumetric strain rate, $\epsilon_{c}$ is the critical fractional volume strain for fracturing.

\subsubsection{Water Partitioning}

During the movement of the mixed mass, the solids can thus be present as a structured matrix. Within such a matrix, a fluid volume can be contained (e.g. 
as originating from a ground water content in the original landslide material). These fluids are typically described as groundwater flow following Darcy's law, which poses a linear relationship between pressure gradients and flow velocity through a soil matrix. In our case, we assumed the relative velocity of water flow within the granular solid matrix as very small compared to both solid velocities and the velocities of the free fluids. As an initial condition of the material, some fraction of the water is contained within the soil matrix $\left(f_{f c}\right)$. Additionally, for loss of cohesive structure within the solid phase, we transfer the related fraction of fluids contained within that solid structure to the free fluids (Equations 5.27 and 5.28).

$$
\frac{\partial \mathrm{f}_{\mathrm{fc}}}{\partial \mathrm{t}}=-\frac{\partial\left(1-\mathrm{f}_{\mathrm{fc}}\right)}{\partial \mathrm{t}}=\left\{\begin{array}{cl}
-\mathrm{f}_{\mathrm{fc}} \frac{\mathrm{c}_{0}}{\mathrm{c}} \frac{\max \left(0.0, \dot{\epsilon}_{\mathrm{v}}\right)}{\epsilon_{\mathrm{f}}} & \mathrm{f}\left(\mathrm{I}_{1}, \mathrm{I}_{2}\right) \geq 0, \mathrm{c}>0 \\
0 & \text { otherwise }
\end{array}\right.
$$

$$
\frac{\partial \mathrm{f}_{\mathrm{sc}}}{\partial \mathrm{t}}=-\frac{\partial\left(1-\mathrm{f}_{\mathrm{sc}}\right)}{\partial \mathrm{t}}=\left\{\begin{array}{c}
-\mathrm{f}_{\mathrm{sc}} \frac{\mathrm{c}_{0}}{\mathrm{c}} \frac{\max \left(0.0, \dot{\epsilon}_{\mathrm{v}}\right)}{\epsilon_{\mathrm{f}}} \\
0
\end{array}\right.
$$

$$
\mathrm{f}\left(\mathrm{I}_{1}, \mathrm{~J}_{2}\right) \geq 0, \mathrm{c}>0
$$
otherwise

Beyond changes in $f_{f c}$ through fracturing of structured solid materials, no dynamics are simulated for in- or outflux of fluids from the solid-matrix. The initial volume fraction of fluids in the solid matrix defined by $\left(f f_{f c}\right.$ and $\left.s f_{s c}\right)$ remains constant throughout the simulation. The validity of this assumption can be based on the slow typical fluid velocities in a solid matrix relative to fragmented mixed fluid-solid flow velocities (Kern, 1995; Saxton et al., 2006). While the addition of evolving saturation would extend validity of the model, it would require implementation of pretransfer-functions for evolving material properties, which is beyond the scope of this work. An important note on the points made above is the manner in which fluids are re-partitioned after fragmentation. All fluids in fragmented solids are released, but this does not equate to free movement of the fluids or a disconnection from the solids that confined them. Instead, the equations continue to connect the solids and fluids through drag, viscous and virtual mass forces. Finally, the density of the fragmented solids is assumed to be the initially set solid density. Any straininduced density changes are assumed small relative to the initial solid density $\left(\frac{\rho_{c}}{\rho_{s}} \ll 1\right)$.

\subsubsection{Fluid Stresses}

The fluid stress tensor is determined by the pressure and the viscous terms (Equations 5.29 and 5.30). Confined solids are assumed to be saturated and constant during the flow.

$$
\begin{array}{cc}
\mathbf{T}_{\mathrm{u}}=\mathrm{P}_{\mathrm{f}} \mathbf{I}+\boldsymbol{\tau}_{\mathrm{f}} \\
5.29 & \boldsymbol{\tau}_{\mathrm{f}}=\eta_{\mathrm{f}}\left[\nabla \mathbf{u}_{\mathrm{u}}+\left(\nabla \mathbf{u}_{\mathrm{c}}\right)^{\mathrm{t}}\right]-\frac{\eta_{\mathrm{f}}}{\alpha_{\mathrm{u}}} \mathcal{A}\left(\alpha_{\mathrm{u}}\right)\left(\nabla \alpha_{\mathrm{c}}\left(\mathbf{u}_{\mathrm{u}}-\mathbf{u}_{\mathrm{c}}\right)+\left(\mathbf{u}_{\mathrm{c}}-\mathbf{u}_{\mathrm{u}}\right) \nabla \alpha_{\mathrm{c}}\right) \\
5.30 &
\end{array}
$$

Where $\boldsymbol{\tau}_{f}$ is the viscous stress tensor for fluids, $P_{f}$ is the fluid pressure, $\eta_{f}$ is the dynamic viscosity of the fluids and $\mathcal{A}$ is the mobility of the fluids at the interface with the solids that acts as a phenomenological parameter (Pudasaini, 2012).

The fluid pressure acts only on the free fluids here, as the confined fluids are moved together with the solids. In equation 0 , the second term is related to the non-Newtonian viscous force induced by gradients in solid concentration. 
The effect as described by Pudasaini (2012) is induced by a solid-concentration gradient. In case of unconfined fluids and unstructured solids $\left(f_{s f}=1, f_{s f}=1\right)$. Within our flow description, we see no direct reason to eliminate or alter this force with a variation in the fraction of confined fluids or structured solids. We do only consider the interface between solids and free fluids as an agent that induces this effect, and therefore the gradient of the gradient of the solids and confined fluids $\left(\nabla\left(\alpha_{s}+f_{f c} \alpha_{f}\right)=\nabla \alpha_{c}\right)$ is used instead of the total solid phase $\left(\nabla \alpha_{s}\right)$.

\subsubsection{Drag Force and Virtual Mass}

Our description of the drag force follows the work of Pudasaini (2012) and Pudasaini (2018), where a generalized two-phase drag model is introduced and enhanced. We split their work into a contribution from the fraction of structured solids $\left(f_{s c}\right)$ and unconfined fluids $\left(1-f_{f c}\right)$ (Equation 5.31).

5.31

$\mathcal{C}_{\mathrm{DG}}=\frac{\mathrm{f}_{\mathrm{sc}} \alpha_{\mathrm{c}} \alpha_{\mathrm{u}}\left(\rho_{\mathrm{c}}-\rho_{\mathrm{f}}\right) \mathrm{g}}{\mathrm{U}_{\mathrm{T}, \mathrm{c}}(\mathcal{G}(\mathrm{Re}))+\mathrm{S}_{\mathrm{p}}}\left(\mathbf{u}_{\mathrm{u}}-\mathbf{u}_{\mathrm{c}}\right)\left|\mathbf{u}_{\mathrm{u}}-\mathbf{u}_{\mathrm{c}}\right|^{\mathrm{j}-1}+\frac{\left(1-\mathrm{f}_{\mathrm{sc}}\right) \alpha_{\mathrm{c}} \alpha_{\mathrm{u}}\left(\rho_{\mathrm{s}}-\rho_{\mathrm{f}}\right) \mathrm{g}}{\mathrm{U}_{\mathrm{T}, \mathrm{uc}}\left(\mathcal{P F}\left(\mathrm{Re}_{\mathrm{p}}\right)+(1-\mathcal{P}) \mathcal{G}(\mathrm{Re})\right)+\mathrm{S}_{\mathrm{p}}}\left(\mathbf{u}_{\mathrm{u}}-\mathbf{u}_{\mathrm{c}}\right)\left|\mathbf{u}_{\mathrm{u}}-\mathbf{u}_{\mathrm{c}}\right|^{\mathrm{j}-1}$

Where $U_{T, c}$ is the terminal or settling velocity of the structures solids, $U_{T, u c}$ is the terminal velocity of the unconfined solids, $\mathcal{P}$ is a factor that combines solidand fluid like contributions to the drag force, $\mathcal{G}$ is the solid-like drag contribution, $\mathcal{F}$ is the fluid-like drag contribution and $S_{p}$ is the smoothing function (Equation 0 and 0 ). The exponent $j$ indicates the type of drag: linear $(j=0)$ or quadratic $(j=1)$.

Within the drag, the following functions are defined:

$$
\begin{gathered}
\mathrm{F}=\frac{\gamma}{180}\left(\frac{\alpha_{\mathrm{f}}}{\alpha_{\mathrm{s}}}\right)^{3} \operatorname{Re}_{\mathrm{p}}, \mathrm{G}=\alpha_{\mathrm{f}}^{\mathrm{M}\left(\mathrm{Re}_{\mathrm{p}}\right)-1} \\
\mathrm{~S}_{\mathrm{p}}=\left(\frac{\mathcal{P}}{\alpha_{\mathrm{c}}}+\frac{1-\mathcal{P}}{\alpha_{\mathrm{u}}}\right) \mathcal{K} \\
\mathcal{K}=\left|\alpha_{\mathrm{c}} \mathbf{u}_{\mathrm{c}}+\alpha_{\mathrm{u}} \mathbf{u}_{\mathrm{u}}\right| \approx 10 \mathrm{~ms}^{-1}
\end{gathered}
$$

5.34

Where $M$ is a parameter that varies between 2.4 and 4.65 based on the Reynolds number (Pitman \& Le, 2005). The factor $\mathcal{P}$ that combines solid-and fluid like contributions to the drag, is dependent on the volumetric solid content in the unconfined and unstructured materials $\left(\mathcal{P}=\left(\frac{\alpha_{s}\left(1-f_{s c}\right)}{\alpha_{f}\left(1-f_{f c}\right)}\right)^{m}\right.$ with $m \approx 1$. Additionally we assume the factor $\mathcal{P}$, is zero for drag originating from the structured solids. As stated by Pudasaini \& Mergili (2019) "As limiting cases: $\mathcal{P}$ suitably models solid particles moving through a fluid". In our model, the drag force acts on the unconfined fluid momentum $\left(u_{u c} \alpha_{f}\left(1-f_{f c}\right)\right)$. For interactions between unconfined fluids and structured solids, larger blocks of solid structures are moving through fluids that contains solids of smaller size. Virtual mass is similarly implemented based on the work of Pudasaini (2012) and Pudasaini \& Mergili (2019) (Equation 5.350). The adapted implementation considers the solids together with confined fluids to move through a free fluid phase.

$$
\mathcal{C}_{\mathrm{VMG}}=\alpha_{\mathrm{c}} \rho_{\mathrm{u}}\left(\frac{1}{2}\left(\frac{1+2 \alpha_{\mathrm{c}}}{\alpha_{\mathrm{u}}}\right)\right)\left(\left(\frac{\partial \mathrm{u}_{\mathrm{u}}}{\partial \mathrm{t}}+\mathrm{u}_{\mathrm{u}} \cdot \nabla \mathrm{u}_{\mathrm{u}}\right)-\left(\frac{\partial \mathrm{u}_{\mathrm{c}}}{\partial \mathrm{t}}+\mathrm{u}_{\mathrm{c}} \cdot \nabla \mathrm{u}_{\mathrm{c}}\right)\right)
$$

Where $C_{D G}=\frac{1}{2}\left(\frac{1+2 \alpha_{c}}{\alpha_{u}}\right)$ is the drag coefficient. 


\subsubsection{Boundary Conditions}

Finally, following the work of Iverson \& Denlinger (2001), Pitman \& Le (2005) and Pudasaini (2012), a boundary condition is applied to the surface elements that contact the flow (Equation 5.36).

5.36 $|\mathbf{S}|=\mathrm{N} \tan (\phi)$

Where $N$ is the normal pressure on the surface element and $S$ is the shear stress.

\subsection{Depth-Averaging}

The majority of the depth-averaging in this works is analogous to the work of Pitman \& Le (2005), Pudasaini (2012) and Pudasini \& Mergili (2019). Three major differences arise, which are discussed below.

\subsubsection{Fluid Pressure}

Previous implementations of generalized two-phase debris flow equations have commonly assumed hydrostatic pressure $\left(\frac{\partial p}{\partial z}=g^{z}\right)$ (Pitman \& Le, 2005; Pudasaini, 2012; Abe \& Konagai, 2016). Here we follow this assumption for the fluid pressure at the base and solid pressure for unstructured material (Equations 5.37 and 5.38).

5.37

5.38

Where $\gamma=\frac{\rho_{f}}{\rho_{s}}$ is the density ratio $(-)$.

$$
\begin{gathered}
P_{b_{s, u}}=-(1-\gamma) \alpha_{s} g^{z} h \\
P_{b_{u}}=-g^{z} h
\end{gathered}
$$

However, larger blocks of structure material can have contact with the basal topography. Due to density differences, larger blocks of solid structures are likely to move along the base (Pailhia \& Pouliquen, 2009; George \& Iverson, 2014). If these blocks are saturated, water pressure propagates through the solid matrix and hydrostatic pressure is retained. However, in cases of an unsaturated solid matrix that connects to the base, hydrostatic pressure is not present there. We introduce a basal fluid pressure propagation factor $\mathcal{B}\left(\theta_{\text {eff }}, \overline{d_{s c}}, ..\right)$ which describes the fraction of fluid pressure propagated through a solid matrix (with $\theta_{\text {eff }}$ the effective saturation, $\overline{d_{s c}}$ the average size of structured solid matrix blocks). This results in a basal pressure equal to equation 5.39 .

$$
5.39 \quad \mathrm{P}_{\mathrm{b}_{\mathrm{c}}}=-\left(1-\mathrm{f}_{\mathrm{sc}}\right)(1-\gamma) \frac{\left(1-\mathrm{f}_{\mathrm{sc}}\right) \alpha_{\mathrm{s}}}{\left(1-\mathrm{f}_{\mathrm{fc}}\right) \alpha_{\mathrm{f}}} \mathrm{g}^{\mathrm{z}} \mathrm{h}-\mathrm{f}_{\mathrm{sc}}(1-\gamma) \mathcal{B} \frac{\left(\mathrm{f}_{\mathrm{sc}}\right) \alpha_{\mathrm{s}}}{\left(\mathrm{f}_{\mathrm{fc}}\right) \alpha_{\mathrm{f}}} \mathrm{g}^{\mathrm{z}} \mathrm{h}
$$

The basal pressure propagation factor $(\mathcal{B})$ depends mostly on saturation level (Saxton et al., 2006), pedotransfer functions, and the size distribution of structured solid matrices within the mixture. For low-saturation levels, it can be assumed no fluid pressure is retained. Combined with an assumed soil matrix height identical to the total mixture height, this results in $\mathcal{B}=0$. Assuming saturation of structures solids results in a full propagation of pressures and $\mathcal{B}=1$.

\subsubsection{Stress-Strain Relationship}


Depth-averaging the stress-strain relationship in equations 0 and 0 requires a vertical solution for the internal stress. First, we assume any non-normal vertical terms are zero (Equation 0). Commonly, Rankines earth pressure coefficients are used to express the lateral earth pressure by assuming vertical stress to be induced by the basal solid pressure (Equation 5.40, 5.41 and 5.42) (Pitman \& Le, 2005; Pudasaini, 2012; Abe \& Konagai, 2016).

5. 40

$$
\begin{gathered}
\sigma^{\mathrm{zx}}=\sigma^{\mathrm{zy}}=\sigma^{\mathrm{yz}}=\sigma^{\mathrm{xz}}=0 \\
\overline{\sigma^{\mathrm{zz}}}=\frac{1}{2} \mathrm{P}_{\mathrm{b}_{\mathrm{s}}},\left.\sigma^{\mathrm{zz}}\right|_{\mathrm{b}}=\mathrm{P}_{\mathrm{b}_{\mathrm{s}}} \\
\mathrm{K}_{\mathrm{a}}=\frac{1-\sin (\phi)}{1+\sin (\phi)}, \quad \mathrm{K}_{\mathrm{p}}=\frac{1-\sin (\phi)}{1+\sin (\phi)}
\end{gathered}
$$

Here we enhance this with Bell's extension for cohesive soils (Equation 5.43) (Richard et al., 2017). This lateral normal-directed stress term is added to the full stress-strain solution.

$$
5.43 \quad \overline{\sigma_{\mathrm{xx}}}=\overline{\sigma_{\mathrm{yy}}}=\left.\mathrm{K} \sigma_{\mathrm{zz}}\right|_{\mathrm{b}}-2 \mathrm{c} \sqrt{\mathrm{K}}+\cdots
$$

Finally, the gradient in pressure of the lateral interfaces between the mixture is added as a depth-averaged acceleration term (Equation 5.44).

$$
\frac{1}{h}\left(\frac{\partial\left(h \sigma^{x x}\right)}{\partial x}+\frac{\partial\left(h \sigma^{y x}\right)}{\partial y}\right)
$$

\subsubsection{Depth-averaging Other Terms}

While the majority of terms allow for depth-averaging as proposed by Pudasaini (2012), an exception arises. Depth-averaging of the vertical viscosity terms is required. The non-Newtonian viscous terms for the fluid phase were derived assuming a vertical profile in the volumetric solid phase content. Here, we alter the derivation to use this assumption only for the non-structured solids, as opposed to the structured solids where $\frac{\partial \alpha_{s}}{\partial z}=0$ (Equation 5.45)

$$
\begin{gathered}
\int_{\mathrm{b}}^{\mathrm{s}} \frac{\partial}{\partial \mathrm{z}}\left(\frac{\partial \alpha_{\mathrm{s}}}{\partial \mathrm{z}}\left(\mathrm{u}_{\mathrm{u}}-\mathrm{u}_{\mathrm{c}}\right)\right) \mathrm{dz}=\left[\frac{\partial \alpha_{\mathrm{s}}}{\partial \mathrm{z}}\left(\mathrm{u}_{\mathrm{u}}-\mathrm{u}_{\mathrm{c}}\right)\right]_{\mathrm{b}}^{\mathrm{s}}=\left(\overline{\mathrm{u}_{\mathrm{u}}}-\overline{\mathrm{u}_{\mathrm{c}}}\right)\left[\frac{\partial \alpha_{\mathrm{s}}}{\partial \mathrm{z}}\right]_{\mathrm{b}}^{\mathrm{s}} \\
=\left(\overline{\mathrm{u}_{\mathrm{u}}}-\overline{\mathrm{u}_{\mathrm{c}}}\right)\left[\frac{\partial \alpha_{\mathrm{s}}}{\partial \mathrm{z}}\right]_{\mathrm{b}}^{\mathrm{s}}=\frac{\left(\overline{\mathrm{u}_{\mathrm{u}}}-\overline{\mathrm{u}_{\mathrm{c}}}\right)\left(1-\mathrm{f}_{\mathrm{sc}}\right) \zeta \overline{\alpha_{\mathrm{s}}}}{\mathrm{h}}
\end{gathered}
$$

Where $\zeta$ is the shape factor for the vertical distribution of solids (Pudasaini, 2012). Additionally, the momentum balance of Pudasaini (2012) ignores any deviatoric stress $\left(\tau_{x y}=0\right)$, following Savage and Hutter (2007), and Pudasaini and Hutter (2007). Earlier this term was included by Iverson and Denlinger (2001), Pitman and Le (2005) and Abe \&Kanogai (2016). Here we include these terms since a full stress-strain relationship is included.

\subsubsection{Basal Frictions}

Additionally we add the Darcy-Weisbach friction, which is a Chezy-type friction law for the fluid phase that provides drag (Delestre et al., 2014). This ensures that, without solid phase, a clear fluid does lose momentum due to friction from basal shear. This was successfully done in Bout et al. (2018) and was similarly assumed in Pudasaini and Fischer (2016) for fluid basal shear stress. 


$$
\mathrm{S}_{\mathrm{f}}=\frac{\mathrm{g}}{\mathrm{n}^{2}} \frac{\mathbf{u}_{\mathbf{u}}\left|\mathbf{u}_{\mathbf{u}}\right|}{\mathrm{h}^{\frac{4}{3}}}
$$

Where $n$ is Manning's surface roughness coefficient.

\subsubsection{Depth-averaged Equations}

The following set of equations is thus finally achieved for depth-averaged flow over sloping terrain (Equations 5.47 - 5.71).

5.47

$$
\frac{\partial \mathrm{h}}{\partial \mathrm{t}}+\frac{\partial}{\partial \mathrm{x}}\left[\mathrm{h}\left(\alpha_{\mathrm{u}} \mathrm{u}_{\mathrm{u}}+\alpha_{\mathrm{c}} \mathrm{u}_{\mathrm{c}}\right)\right]+\frac{\partial}{\partial \mathrm{y}}\left[\mathrm{h}\left(\alpha_{\mathrm{u}} \mathrm{u}_{\mathrm{u}}+\alpha_{\mathrm{c}} \mathrm{u}_{\mathrm{c}}\right)\right]=\mathrm{R}-\mathrm{I}
$$

5.48

$$
\begin{gathered}
\frac{\partial \alpha_{c} h}{\partial t}+\frac{\partial \alpha_{c} h u_{c}}{\partial x}+\frac{\partial \alpha_{c} h v_{c}}{\partial y}=0 \\
\frac{\partial \alpha_{u} h}{\partial t}+\frac{\partial \alpha_{u} h u_{u}}{\partial x}+\frac{\partial \alpha_{u} h v_{u}}{\partial y}=R-I
\end{gathered}
$$

5.50

$$
\begin{gathered}
\frac{\partial}{\partial \mathrm{t}}\left[\alpha_{\mathrm{c}} \mathrm{h}\left(\mathrm{u}_{\mathrm{c}}-\gamma_{\mathrm{c}} \mathrm{C}_{\mathrm{VM}}\left(\mathrm{u}_{\mathrm{u}}-\mathrm{u}_{\mathrm{c}}\right)\right)\right]+\frac{\partial}{\partial \mathrm{x}}\left[\alpha_{\mathrm{c}} \mathrm{h}\left(\mathrm{u}_{\mathrm{c}}^{2}-\gamma_{\mathrm{c}} \mathrm{C}_{\mathrm{VM}}\left(\mathrm{u}_{\mathrm{u}}^{2}-\mathrm{u}_{\mathrm{c}}^{2}\right)\right)\right]+ \\
\frac{\partial}{\partial \mathrm{y}}\left[\alpha_{\mathrm{c}} \mathrm{h}\left(\mathrm{u}_{\mathrm{c}} \mathrm{v}_{\mathrm{c}}-\gamma \mathrm{C}\left(\mathrm{u}_{\mathrm{u}} \mathrm{v}_{\mathrm{u}}-\mathrm{u}_{\mathrm{c}} \mathrm{v}_{\mathrm{c}}\right)\right)\right]=\mathrm{hS}_{\mathrm{x}_{\mathrm{c}}}
\end{gathered}
$$

5.51

$$
\begin{gathered}
\frac{\partial}{\partial \mathrm{t}}\left[\alpha_{\mathrm{c}} \mathrm{h}\left(\mathrm{v}_{\mathrm{c}}-\gamma_{\mathrm{c}} \mathrm{C}_{\mathrm{VM}}\left(\mathrm{v}_{\mathrm{u}}-\mathrm{v}_{\mathrm{c}}\right)\right)\right]+\frac{\partial}{\partial \mathrm{x}}\left[\alpha_{\mathrm{c}} \mathrm{h}\left(\mathrm{u}_{\mathrm{s}} \mathrm{v}_{\mathrm{s}}-\gamma_{\mathrm{c}} \mathrm{C}_{\mathrm{VM}}\left(\mathrm{u}_{\mathrm{u}} \mathrm{v}_{\mathrm{u}}-\mathrm{u}_{\mathrm{c}} \mathrm{v}_{\mathrm{c}}\right)\right)\right] \\
+\frac{\partial}{\partial \mathrm{y}}\left[\alpha_{\mathrm{c}} \mathrm{h}\left(\mathrm{v}_{\mathrm{c}}^{2}-\gamma \mathrm{C}_{\mathrm{VM}}\left(\mathrm{v}_{\mathrm{u}}^{2}-\mathrm{v}_{\mathrm{c}}^{2}\right)\right)\right]=\mathrm{hS}_{\mathrm{y}_{\mathrm{c}}}
\end{gathered}
$$

5.52

$$
\begin{gathered}
\frac{\partial}{\partial t}\left[\alpha_{u} h\left(u_{u}-\frac{\alpha_{c}}{\alpha_{u}} C_{V M}\left(u_{u}-u_{c}\right)\right)\right]+\frac{\partial}{\partial x}\left[\alpha_{u} h\left(u_{u}^{2}-\frac{\alpha_{c}}{\alpha_{u}} C_{V M}\left(u_{u}^{2}-u_{c}^{2}\right)+\frac{\beta_{x_{u}} h}{2}\right)\right]+ \\
\frac{\partial}{\partial y}\left[\alpha_{u} h\left(u_{u} v_{u}-\gamma_{c} C_{V M}\left(u_{u} v_{u}-u_{c} v_{c}\right)\right)\right]=h_{x_{u}}-I_{u}
\end{gathered}
$$

5.53

$$
\begin{gathered}
\frac{\partial}{\partial \mathrm{t}}\left[\alpha_{\mathrm{u}} \mathrm{h}\left(\mathrm{v}_{\mathrm{u}}-\frac{\alpha_{\mathrm{c}}}{\alpha_{\mathrm{u}}} \mathrm{C}_{\mathrm{VM}}\left(\mathrm{v}_{\mathrm{u}}-\mathrm{v}_{\mathrm{c}}\right)\right)\right]+\frac{\partial}{\partial \mathrm{x}}\left[\alpha_{\mathrm{u}} \mathrm{h}\left(\mathrm{u}_{\mathrm{u}} \mathrm{v}_{\mathrm{u}}-\frac{\alpha_{\mathrm{c}}}{\alpha_{\mathrm{u}}} \mathrm{C}_{\mathrm{VM}}\left(\mathrm{u}_{\mathrm{u}} \mathrm{v}_{\mathrm{u}}-\mathrm{u}_{\mathrm{c}} \mathrm{v}_{\mathrm{c}}\right)\right)\right]+ \\
\frac{\partial}{\partial \mathrm{y}}\left[\alpha_{\mathrm{u}} \mathrm{h}\left(\mathrm{v}_{\mathrm{u}}^{2}-\gamma_{\mathrm{c}} \mathrm{C}_{\mathrm{Vm}}\left(\mathrm{v}_{\mathrm{u}}^{2}-\mathrm{v}_{\mathrm{c}}^{2}\right)+\frac{\beta_{\mathrm{yu}} \mathrm{h}}{2}\right)\right]=\mathrm{hS}_{\mathrm{y}_{\mathrm{u}}}-\mathrm{Iv}_{\mathrm{u}}
\end{gathered}
$$

5.54

5.55

$$
\begin{aligned}
\mathrm{S}_{\mathrm{x}_{\mathrm{c}}}= & \alpha_{\mathrm{c}}\left[\mathrm{g}^{\mathrm{x}}+\frac{1}{\mathrm{~h}}\left(\frac{\partial\left(\mathrm{h} \sigma^{\mathrm{xx}}\right)}{\partial \mathrm{x}}+\frac{\partial\left(\mathrm{h} \sigma^{\mathrm{yx}}\right)}{\partial \mathrm{y}}\right)-\mathrm{P}_{\mathrm{b}_{\mathrm{c}}}\left(\frac{\mathrm{u}_{\mathrm{c}}}{\left|\overrightarrow{\mathrm{u}_{\mathrm{c}}}\right|} \tan \phi+\epsilon \frac{\partial \mathrm{b}}{\partial \mathrm{x}}\right)\right]- \\
& \epsilon \alpha_{\mathrm{c}} \gamma_{\mathrm{c}} \mathrm{p}_{\mathrm{b}_{\mathrm{u}}}\left[\frac{\partial \mathrm{h}}{\partial \mathrm{x}}+\frac{\partial \mathrm{b}}{\partial \mathrm{x}}\right]+\mathrm{C}_{\mathrm{DG}}\left(\mathrm{u}_{\mathrm{u}}-\mathrm{u}_{\mathrm{c}}\right)\left|\mathbf{u}_{\mathrm{u}}-\mathbf{u}_{\mathrm{c}}\right|^{\mathrm{J}-1}
\end{aligned}
$$

$$
\begin{aligned}
\mathrm{S}_{\mathrm{y}_{\mathrm{c}}}= & \alpha_{\mathrm{c}}\left[\mathrm{g}^{\mathrm{y}}+\frac{1}{\mathrm{~h}}\left(\frac{\partial\left(\mathrm{h} \sigma^{\mathrm{xy}}\right)}{\partial \mathrm{x}}+\frac{\partial\left(\mathrm{h} \sigma^{\mathrm{yy}}\right)}{\partial \mathrm{y}}\right)-\mathrm{P}_{\mathrm{b}_{\mathrm{c}}}\left(\frac{\mathrm{v}_{\mathrm{s}}}{\left|\overrightarrow{\mathrm{u}}_{\mathrm{s}}\right|} \tan \phi+\epsilon \frac{\partial \mathrm{b}}{\partial \mathrm{y}}\right)\right]- \\
& \epsilon \alpha_{\mathrm{c}} \gamma_{\mathrm{c}} \mathrm{p}_{\mathrm{b}_{\mathrm{u}}}\left[\frac{\partial \mathrm{h}}{\partial \mathrm{y}}+\frac{\partial \mathrm{b}}{\partial \mathrm{y}}\right]+\mathrm{C}_{\mathrm{DG}}\left(\mathrm{v}_{\mathrm{u}}-\mathrm{v}_{\mathrm{c}}\right)\left|\mathbf{v}_{\mathrm{u}}-\mathbf{v}_{\mathrm{c}}\right|^{\mathrm{J}-1}
\end{aligned}
$$


5.56

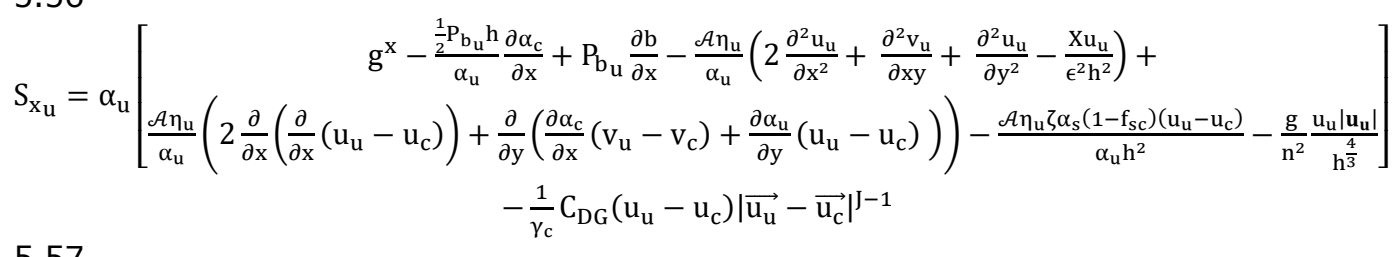

5.57

$\mathrm{S}_{\mathrm{y}_{\mathrm{u}}}=\alpha_{\mathrm{u}}\left[\begin{array}{c}\mathrm{g}^{\mathrm{y}}-\frac{\frac{1}{2} \mathrm{P}_{\mathrm{b}_{\mathrm{u}}} \mathrm{h}}{\alpha_{\mathrm{f}}} \frac{\partial \alpha_{\mathrm{c}}}{\partial \mathrm{y}}+\mathrm{P}_{\mathrm{b}_{\mathrm{u}}} \frac{\partial \mathrm{b}}{\partial \mathrm{y}}-\frac{\mathcal{A} \eta_{\mathrm{u}}}{\alpha_{\mathrm{u}}}\left(2 \frac{\partial^{2} \mathrm{u}_{\mathrm{f}}}{\partial \mathrm{y}^{2}}+\frac{\partial^{2} \mathrm{v}_{\mathrm{f}}}{\partial \mathrm{xy}}+\frac{\partial^{2} \mathrm{u}_{\mathrm{f}}}{\partial \mathrm{x}^{2}}-\frac{\mathrm{xu}_{\mathrm{f}}}{\epsilon^{2} \mathrm{~h}^{2}}\right)+ \\ \frac{\mathcal{A} \eta_{\mathrm{u}}}{\alpha_{\mathrm{c}}}\left(2 \frac{\partial}{\partial \mathrm{y}}\left(\frac{\partial}{\partial \mathrm{y}}\left(\mathrm{v}_{\mathrm{u}}-\mathrm{v}_{\mathrm{c}}\right)\right)+\frac{\partial}{\partial \mathrm{x}}\left(\frac{\partial \alpha_{\mathrm{c}}}{\partial \mathrm{y}}\left(\mathrm{u}_{\mathrm{u}}-\mathrm{u}_{\mathrm{c}}\right)+\frac{\partial \alpha_{\mathrm{c}}}{\partial \mathrm{x}}\left(\mathrm{v}_{\mathrm{u}}-\mathrm{v}_{\mathrm{c}}\right)\right)\right)-\frac{\mathcal{A} \eta_{\mathrm{u}} \zeta \alpha_{\mathrm{s}}\left(1-\mathrm{f}_{\mathrm{sc}}\left(\mathrm{v}_{\mathrm{u}}-\mathrm{v}_{\mathrm{c}}\right)\right.}{\alpha_{\mathrm{u}} \mathrm{h}^{2}}-\frac{\mathrm{g} \mathrm{v}_{\mathrm{u}} \mid \mathrm{u}_{\mathrm{ul}}}{\mathrm{n}^{2}} \frac{\mathrm{h}^{3}}{\mathrm{~h}^{3}}\end{array}\right]$ $-\frac{1}{\gamma_{\mathrm{c}}} \mathrm{C}_{\mathrm{DG}}\left(\mathrm{v}_{\mathrm{u}}-\mathrm{v}_{\mathrm{c}}\right)\left|\overrightarrow{\mathrm{u}_{\mathrm{u}}}-\overrightarrow{\mathrm{u}_{\mathrm{c}}}\right|^{\mathrm{J}-1}$

$5.58 \quad P_{b_{c}}=-\left(1-f_{s c}\right)(1-\gamma) \frac{\left(1-f_{s c}\right) \alpha_{s}}{\left(1-f_{f c}\right) \alpha_{f}} g^{z} h-f_{s c}(1-\gamma) \frac{\left(f_{s c}\right) \alpha_{s}}{\left(f_{f c}\right) \alpha_{f}} g^{z} h$

$5.59 \quad \mathrm{P}_{\mathrm{b}_{\mathrm{u}}}=-\mathrm{g}^{\mathrm{z}} \mathrm{h}$

$5.60 \quad \gamma_{\mathrm{c}}=\frac{\rho_{\mathrm{u}}}{\rho_{\mathrm{c}}}, \gamma=\frac{\rho_{\mathrm{f}}}{\rho_{\mathrm{s}}}$

$5.61 \quad C_{D G}=\frac{f_{s c} \alpha_{c} \alpha_{u}\left(\rho_{c}-\rho_{\mathrm{f}}\right) g}{U_{T, c}(\mathcal{G}(R e))+S_{p}}+\frac{\left(1-f_{\mathrm{sc}}\right) \alpha_{c} \alpha_{u}\left(\rho_{s}-\rho_{\mathrm{f}}\right) g}{U_{T, u c}\left(\mathcal{P F}\left(R_{\mathrm{p}}\right)+(1-\mathcal{P}) \mathcal{G}(\mathrm{Re})\right)+\mathrm{S}_{\mathrm{p}}}$

$5.62 \quad \mathrm{~S}_{\mathrm{p}}=\left(\frac{\mathcal{P}}{\alpha_{\mathrm{c}}}+\frac{1-\mathcal{P}}{\alpha_{\mathrm{u}}}\right) \mathcal{K}$

$5.63 \quad \mathcal{K}=\left|\alpha_{c} \mathbf{u}_{\mathrm{c}}+\alpha_{\mathrm{u}} \mathbf{u}_{\mathrm{u}}\right|$

5.64 $F=\frac{\gamma}{180}\left(\frac{\alpha_{f}}{\alpha_{s}}\right)^{3} R e_{p}, G=\alpha_{f}^{M\left(R e_{p}\right)-1}, R e_{p}=\frac{\rho_{f} d U_{t}}{\eta_{f}}, N_{R}=\frac{\sqrt{g L} H \rho_{f}}{\alpha_{f} \eta_{f}}, N_{R A}=\frac{\sqrt{g L} H \rho_{f}}{A \eta_{f}}$

5.65

$$
\mathrm{C}_{\mathrm{Vm}}=\left(\frac{1}{2}\left(\frac{1+2 \alpha_{\mathrm{c}}}{\alpha_{\mathrm{u}}}\right)\right)
$$

5.66

5.68

5. 70

$5.71 \quad \alpha_{\phi}=\frac{\tan (\phi)}{\sqrt{9+12 \tan ^{2} \phi}}, \quad \mathrm{k}_{\mathrm{c}}=\frac{3 \mathrm{c}}{\sqrt{9+12 \tan ^{2} \phi}}$
Where $\mathrm{X}$ is the shape factor for vertical shearing of the fluid $(X \approx 3$ in Iverson

$$
\dot{\hat{\sigma}}=\sigma^{\alpha \gamma} \dot{\omega}^{\beta \gamma}+\sigma^{\gamma \beta} \dot{\omega}^{\alpha \gamma}+2 \mathrm{G} \dot{\mathrm{e}}^{\alpha \beta}+\mathrm{K} \dot{\epsilon}^{\gamma \gamma} \delta^{\alpha \beta}-\dot{\lambda}\left[9 \operatorname{Ksin} \psi \delta^{\alpha \beta}+\frac{G}{\sqrt{J_{2}}} s^{\alpha \beta}\right]
$$

$$
\dot{\lambda}=\frac{3 \alpha \mathrm{K} \dot{\epsilon}^{\gamma}+\left(\frac{\mathrm{G}}{\sqrt{\mathrm{J}_{2}}}\right) \mathrm{s}^{\alpha \beta} \dot{\epsilon}^{\alpha \beta}}{27 \alpha_{\phi} \mathrm{Ksin} \psi+\mathrm{G}}
$$

$$
\mathrm{K}=\frac{\mathrm{E}}{3(1-2 v)}, \mathrm{G}=\frac{\mathrm{E}}{2(1+v)}
$$

$$
\sigma^{\alpha \beta}=s^{\alpha \beta}+\frac{1}{3} \sigma^{\gamma \gamma} \delta^{\alpha \beta}
$$

\& Denlinger, 2001), $R$ is the precipitation rate and $I$ is the infiltration rate. 


\subsubsection{Closing the Equations}

Viscosity is estimated using the empirical expression from O'Brien and Julien (1985), which relates dynamic viscosity to the solid concentration of the fluid (Equation 5.72).
5.72
$\eta=\alpha e^{\beta \alpha_{s}}$

Where $\alpha$ is the first viscosity parameter and $\beta$ the second viscosity parameter. Finally, the settling velocity of small $(\mathrm{d}<100 \mu \mathrm{m})$ grains is estimated by Stokes equations for a homogeneous sphere in water. For larger grains ( $>1 \mathrm{~mm}$ ), the equation by Zanke (1977) is used (Equation 5.73).

$$
\mathrm{U}_{\mathrm{T}}=10 \frac{\frac{\eta^{2}}{\rho_{\mathrm{f}}}}{\mathrm{d}}\left(\sqrt{1+\frac{0.01\left(\frac{\left(\rho_{\mathrm{s}}-\rho_{\mathrm{f}}\right)}{\rho_{\mathrm{f}}} \mathrm{gd}^{3}\right)}{\frac{\eta}{\rho_{\mathrm{f}}}}}-1\right)
$$

In which $U_{T}$ is the settling (or terminal) velocity of a solid grain, $\eta$ is the dynamic viscosity of the fluid, $\rho_{\mathrm{f}}$ is the density of the fluid, $\rho_{\mathrm{s}}$ is the density of the solids, $\mathrm{d}$ is the grain diameter $(m)$

\subsection{Implementation in the Material Point Method}

Implementing the presented set of equations into a numerical scheme requires considerations of that schemes limitations and strengths (Stomakhin et al., 2013). Fluid dynamics are almost exclusively solved using an Eulerian finite element solution (Delestre et al., 2014; Bout et al., 2018). The diffusive advection part of such scheme typically doesn't degrade the quality of modelling results. Solid material however is commonly simulated with higher accuracy using an Lagrangian finite element method or discrete element method (Maurel \& Cumbescure, 2008; Stomakhin et al., 2013). Such schemes more easily allow for the material to maintain its physical properties during movement. Additionally, advection in these schemes does not artificially diffuse the material since the material itself is discretized, instead of the space (grid) on which the equations are solved. In our case, the material point method (MPM) provides an appropriate tool to implement the set of presented equations (Bui et al., 2008; Maurel \& Cumbescure, 2008; Stomakhin et al., 2013). Numerous existing modelling studies have implemented in this method (Pastor et al., 2007; Pastor et al., 2008; Abe \& Kanogai, 2016). Here, we use the MPM method to create a two-phase scheme. This allows the usage of finite elements aspects for the fluid dynamics, which are so successfully described by the that method (particularly for water in larger areas, see Bout et al., 2018).

\subsubsection{Mathematical Framework}

The mathematic framework of smooth-particle solve differential equations using discretized volumes of mass represented by kernel functions (Libersky \& Petschek, 1991; Bui et al., 2008; Stomakhin et al., 2013). Here, we use the cubic spline kernel as used by Monaghan (2000) (Equation 5.74). 


$$
W(r, h)=\left\{\begin{array}{cc}
\frac{10}{7 \pi h^{2}}\left(1-\frac{3}{2} q^{2}+\frac{3}{4} q^{3}\right) & 0 \leq|q| \geq 2 \\
\frac{10}{28 \pi h^{2}}(2-q)^{3} & 1 \leq|q|<2 \\
0 & |q| \geq 2 \mid q<0
\end{array}\right.
$$

Where $\mathrm{r}$ is the distance, $\mathrm{h}$ is the kernel size and $q$ is the normalized distance $\left(q=\frac{r}{h}\right)$

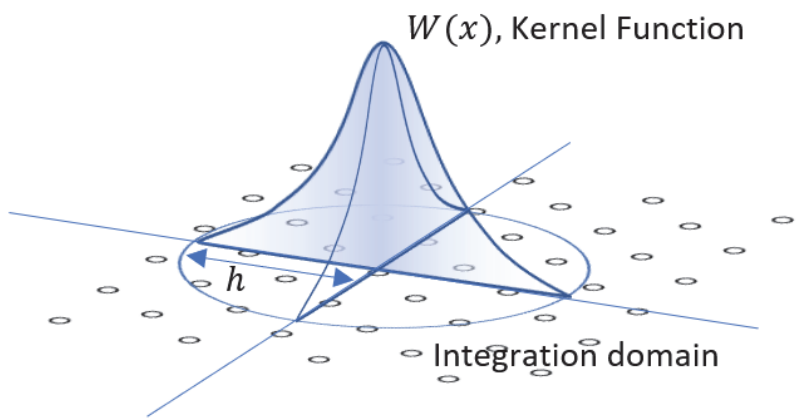

Figure 5-2 Example of a kernel function used as integration domain for mathematical operations.

Using this function mathematical operators can be defined. The average is calculated using a weighted sum of particle values (Equation 5.74) while the derivative depends on the function values and the derivative of the kernel by means of the chain rule (Equation 5.75) (Libersky \& Petschek, 1991; Bui et al., 2008).

$$
\begin{gathered}
\langle\mathrm{f}(\mathrm{x})\rangle=\sum_{\mathrm{j}=1}^{\mathrm{N}} \frac{\mathrm{m}_{\mathrm{j}}}{\rho_{\mathrm{j}}} \mathrm{f}\left(\mathrm{x}_{\mathrm{j}}\right) \mathrm{W}\left(\mathrm{x}-\mathrm{x}_{\mathrm{j}}, \mathrm{h}\right) \\
\left\langle\frac{\partial \mathrm{f}(\mathrm{x})}{\partial \mathrm{x}}\right\rangle=\sum_{\mathrm{j}=1}^{\mathrm{N}} \frac{\mathrm{m}_{\mathrm{j}}}{\rho_{\mathrm{j}}} \mathrm{f}\left(\mathrm{x}_{\mathrm{j}}\right) \frac{\partial \mathrm{W}_{\mathrm{ij}}}{\partial \mathrm{x}_{\mathrm{i}}}
\end{gathered}
$$

Where $W_{i j}=W\left(x_{i}-x_{j}, h\right)$ is the weight of particle $\mathrm{j}$ to particle I, $r=\left|x_{i}-x_{j}\right|$ is the distance between two particles. The derivative of the weight function is defined by equation 5.77 .

$$
\frac{\partial \mathrm{W}_{\mathrm{ij}}}{\partial \mathrm{x}_{\mathrm{i}}}=\frac{\mathrm{x}_{\mathrm{i}}-\mathrm{x}_{\mathrm{j}}}{\mathrm{r}} \frac{\partial \mathrm{W}_{\mathrm{ij}}}{\partial \mathrm{r}}
$$

Using these tools, the momentum equations for the particles can be defined (Equations 5.78 - 5.82). Here, we follow Monaghan (1999) and Bui et al. (2008) for the definition of artificial numerical forces related to stability. Additionally, stress-based forces are calculated on the particle level, while other momentum source terms are solved on a Eulerian grid with spacing $h$ (identical to the kernel size).

$$
\frac{d v_{i}^{\alpha}}{d t}=\frac{1}{m_{i}}\left(F_{g}+F_{\text {grid }}\right)+\sum_{j=1}^{N} m_{j}\left(\frac{\sigma_{i}^{\alpha \beta}}{\rho_{i}^{2}}+\frac{\sigma_{j}^{\alpha \beta}}{\rho_{j}^{2}}+F_{i j}^{n} R_{i j}^{\alpha \beta}+\Pi_{i j} \delta^{\alpha \beta}\right) \frac{\partial W_{i j}}{\partial x_{i}^{\beta}}
$$




$$
\begin{aligned}
& \dot{\epsilon}^{\alpha \beta}=\frac{1}{2}\left(\sum_{j=1}^{N} \frac{m_{j}}{\rho_{j}}\left(v_{j}^{\alpha}-v_{i}^{\alpha}\right) \frac{\partial W_{i j}}{\partial x_{i}^{\beta}}+\sum_{j=1}^{N} \frac{m_{j}}{\rho_{j}}\left(v_{j}^{\beta}-v_{i}^{\beta}\right) \frac{\partial W_{i j}}{\partial x_{i}^{\alpha}}\right) \\
& \dot{\omega}^{\alpha \beta}=\frac{1}{2}\left(\sum_{j=1}^{N} \frac{m_{j}}{\rho_{j}}\left(v_{j}^{\alpha}-v_{i}^{\alpha}\right) \frac{\partial W_{i j}}{\partial x_{i}^{\beta}}-\sum_{j=1}^{N} \frac{m_{j}}{\rho_{j}}\left(v_{j}^{\beta}-v_{i}^{\beta}\right) \frac{\partial W_{i j}}{\partial x_{i}^{\alpha}}\right)
\end{aligned}
$$

$$
\frac{\mathrm{d} \sigma_{\alpha \beta}}{\mathrm{dt}}=\sigma_{\mathrm{i}}^{\alpha \gamma} \dot{\omega}_{\mathrm{i}}^{\beta \gamma}+\sigma_{\mathrm{i}}^{\gamma \beta} \dot{\omega}_{\mathrm{i}}^{\alpha \gamma}+2 \mathrm{G}_{\mathrm{i}} \dot{\mathrm{e}}_{\mathrm{i}}^{\alpha \beta}+\mathrm{K}_{\mathrm{i}} \dot{\epsilon}^{\gamma \gamma} \delta_{\mathrm{i}}^{\alpha \beta}-\dot{\lambda}_{\mathrm{i}}\left[9 \mathrm{~K}_{\mathrm{i}} \sin \psi_{\mathrm{i}} \delta^{\alpha \beta}+\frac{\mathrm{G}_{\mathrm{i}}}{\sqrt{\mathrm{J}_{2_{\mathrm{i}}}}} \mathrm{s}_{\mathrm{i}}^{\alpha \beta}\right]
$$

$$
\dot{\lambda}_{\mathrm{i}}=\frac{3 \alpha \mathrm{K} \dot{\epsilon}_{\mathrm{i}}^{\gamma \gamma}+\left(\frac{\mathrm{G}_{\mathrm{i}}}{\sqrt{\mathrm{j}_{2_{\mathrm{i}}}}}\right) \mathrm{s}_{\mathrm{i}}^{\alpha \beta} \dot{\epsilon}_{\mathrm{i}}^{\alpha \beta}}{27 \alpha_{\phi} \mathrm{K}_{\mathrm{i}} \sin \psi_{\mathrm{i}}+\mathrm{G}_{\mathrm{i}}}
$$

Where $i, j$ are indices indicating the particle, $\Pi_{i j}$ is an artificial viscous force as defined by equations 0 and 0 and $F_{i j}^{n} R_{i j}^{\alpha \beta}$ is an artificial stress term as defined by equations 5.83 and 5.84 .

$$
\Pi_{i j}=\left\{\begin{array}{c}
\frac{\alpha_{\Pi} u_{\text {sound }_{i j}} \phi_{i j}+\beta_{\Pi} \phi^{2}}{\rho_{i j}} v_{i j} \cdot x_{i j}<0 \\
0 \quad v_{i j} \cdot x_{i j} \geq 0
\end{array}\right.
$$

$$
\phi_{i j}=\frac{h_{i j} v_{i j} x_{i j}}{\left|x_{i j}\right|^{2}+0.01 h_{i j}^{2}}, \quad x_{i j}=x_{i}-x_{j}, v_{i j}=v_{i}-v_{j}, \quad h_{i j}=\frac{1}{2}\left(h_{i}+h_{j}\right)
$$

$$
\begin{aligned}
& \mathrm{F}_{\mathrm{ij}}^{\mathrm{n}} \mathrm{R}_{\mathrm{ij}}^{\alpha \beta}=\left[\frac{\mathrm{W}_{\mathrm{ij}}}{\mathrm{W}\left(\mathrm{d}_{0}, \mathrm{~h}\right)}\right]^{\mathrm{n}}\left(\mathrm{R}_{\mathrm{i}}^{\alpha \beta}+\mathrm{R}_{\mathrm{j}}^{\alpha \beta}\right) \\
& \overline{\mathrm{R}_{\mathrm{i}}^{\gamma \gamma}}=-\frac{\epsilon_{0} \overline{\sigma_{\mathrm{i}}^{\gamma \gamma}}}{\rho_{\mathrm{i}}^{2}}
\end{aligned}
$$

Where $\epsilon_{0}$ is a small parameter ranging from 0 to $1, \alpha_{\Pi}$ and $\beta_{\Pi}$ are constants in the artificial viscous force (often chosen close to 1 ), $u_{\text {sound }}$ is the speed of sound in the material.

The conversion from particles to gridded values and reversed depends on a grid basis function that weighs the influence of particle values for a grid center. Here, a function derived from dyadic products of one-dimensional cubic Bsplines is used as was done by Steffen et al. (2008) and Stomakhin et al. (2013) (Equation 5.87).

$5.87 \quad N(x)=N\left(x^{x}\right) * N\left(x^{y}\right), \quad N(x)=\left\{\begin{array}{cc}\frac{1}{2}|x|^{3}-x^{2}+\frac{2}{3} & 0 \leq|x| \geq 2 \\ -\frac{1}{6}|x|^{3}+x^{2}-2|x|+\frac{4}{3} & 1 \leq|x|<2 \\ 0 & |x| \geq 2 \mid x=0\end{array}\right.$

\subsubsection{Particle Placement}

Particle placement is typically done in a constant pattern, as initial conditions have some constant density. The simplest approach is a regular square or triangular network, with particles on the corners of the network. Here, we use 
an approach that is more adaptable to spatially-varying initial flow height. The $R_{2}$ sequence approaches, with a regular quasirandom sequence, a set of evenly distributed points within a square (Roberts, 2020) (Equation 5.88).

5.88

$$
\mathrm{x}_{\mathrm{n}}=\operatorname{n\alpha } \bmod 1, \boldsymbol{\alpha}=\left(\frac{1}{\mathbf{c}_{\mathbf{p}}}, \frac{\mathbf{1}}{\mathbf{c}_{\mathbf{p}}^{2}}\right)
$$

Where $x_{n}$ is the relative location of the $\mathrm{n}^{\text {th }}$ particle within a gridcell, $c_{p}=$ $\left(\frac{9+\sqrt{69}}{18}\right)^{\frac{1}{3}}+\left(\frac{9-\sqrt{69}}{18}\right)^{\frac{1}{3}} \approx 1.32471795572$ is the plastic constant.

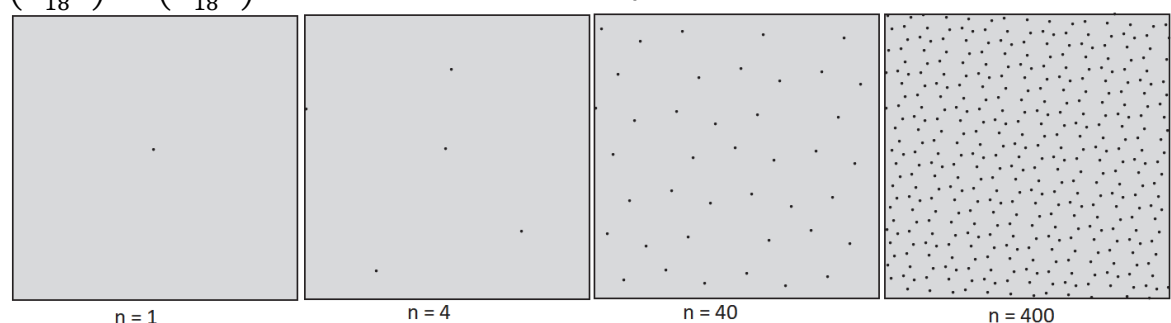

Figure 5-3 Example particle distributions using the R_2 sequence, note that, while not all particles are equidistant, the method produces distributed particle patterns that adapt well to varying density.

The number of particles placed for a particular flow height depends on the particle volume $V_{I}$, which is taken as a global constant during the simulation.

\subsection{Flume Experiments}

\subsubsection{Flume Setup}

In order to validate the presented model, several controlled experiments were performed and reproduced using the developed equations. The flume setup consists of a steep incline, followed by a near-flat runout plane (Figure 3 ). On the separation point of the two planes, a massive and attached obstacle is present that blocks the path of two fifth of the moving material. For the exact dimensions of both the flume parts and the obstacle, see Figure 5-4. 


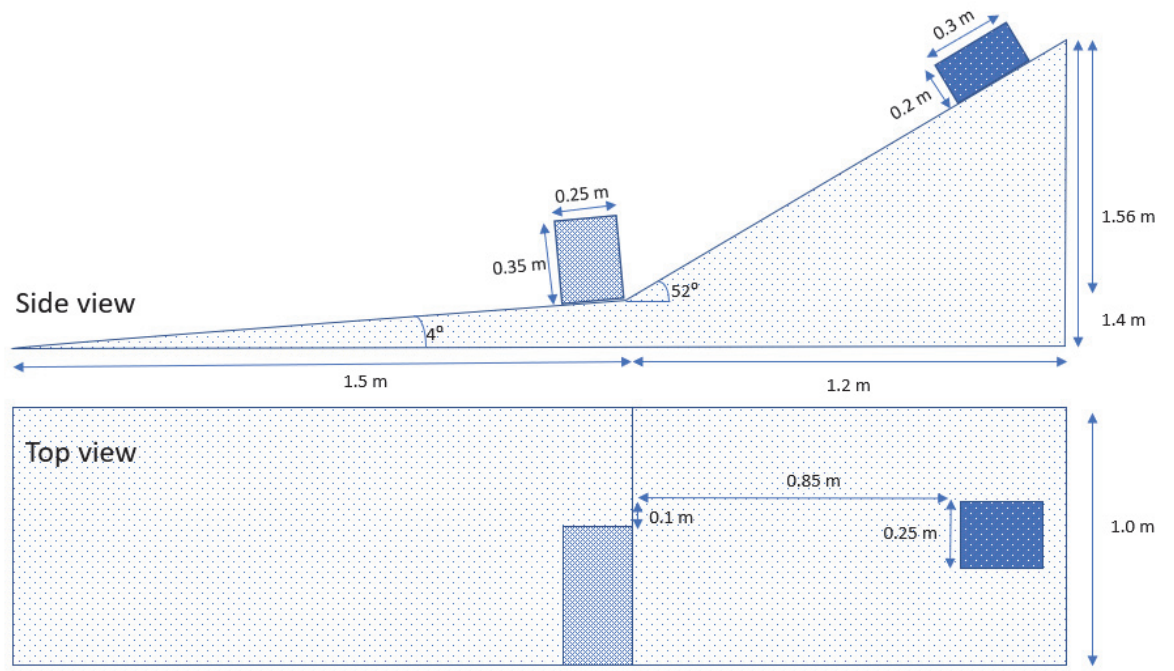

Figure 5-4 The dimensions of the flume experiment setup used in this work.

Two tests were performed whereby a cohesive granular matrix was released at the upper part of the flume setup. Both of these volumes had dimensions of $0.2 \times 0.3 \times 0.25$ meter (height, length, width). For both of these materials, a mixture high-organic content silty-clay soils where used. The materials strength parameters were obtained using tri-axial testing (Cohesion, internal friction angle Youngs modulus and Poisson Ration. The first set of materials properties where $c=26.7 \mathrm{kPa}$ and $\phi=28^{\circ}$. The second set materials properties where $c=18.3 \mathrm{kPa}$ and $\phi=27^{\circ}$. For both of the events, pre-and post release elevations models were made using photogrammetry. The model was set up to replicate the situations using the measured input parameters. Numerical settings were chosen as $\left\{\alpha_{s}=0.5, \alpha_{f}=0.5, f_{s c}=1.0, f_{f c}=1.0, \rho_{f}=1000, \rho_{s}=\right.$ $2400, E=12 \cdot 10^{6} \mathrm{~Pa}, K=23 \cdot 10^{6} \mathrm{~Pa}, \psi=0, \alpha_{\Pi}=1, \beta_{\Pi}=1, \mathrm{X}, \zeta, j=2, u_{\text {sound }}=600, d x=$ $\left.10, V_{I}, h=10, n=0.1, \alpha=1, \beta=10, \mathrm{M}=2.4, \mathcal{B}=0, \mathrm{~N}_{\mathrm{R}}=15000, N_{R A}=30\right\}$.

\subsubsection{Results}

Both the mapped extent of the material after flume experiments, as the simulation results are shown in Figure 5-5. 

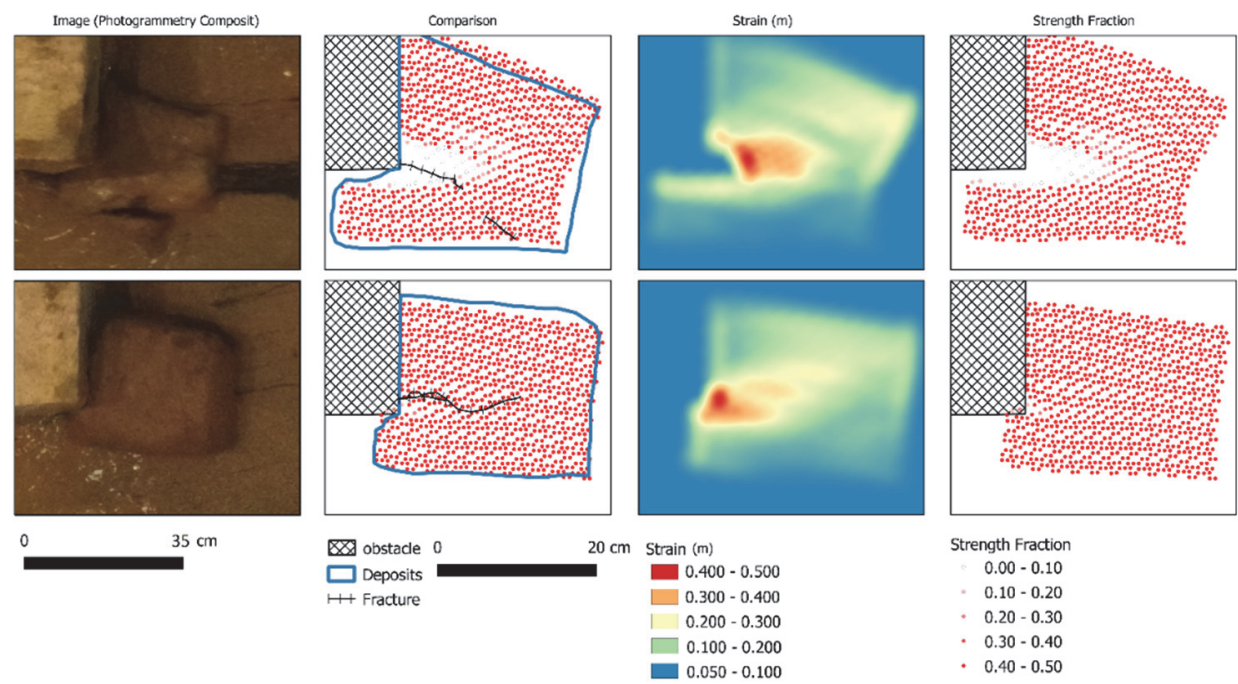

Figure 5-5 A comparison of the final deposits of the simulations and the mapped final deposits and cracks within the material. From left to right: Photogrammetry mosaic, comparison of simulation results to mapped flume experiment, strain, final strength fraction.

As soon as the block of material impacts the obstacle, stress increases as the moving objects is deformed. This stress quickly propagates through the object. Within the scenario with lower cohesive strength, as soon as the stress reached beyond the yield strength, degradation of strength parameters took place. In the results, a fracture line developed along the corner of the obstacle into the length direction of the moving mass. Eventually, this fracture developed to half the length of the moving body and severe deformation resulted. As was observed from the tests, the first material experienced a critical fracture while the second test resulted in moderate deformation near the impact location. Generally, the results compare well with the observed patters, although the exact shape of the fracture is not replicated. Several reasons might be the cause of the moderately accurate fracture patterns. Other studies used a more controlled setup where uncertainties in applied stress and material properties where reduced. Furthermore, the homogeneity of the material used in the tests can not completely assumed. Realistically, minor alterations in compression used to create the clay blocks has left spatial variation in density, cohesion and other strength parameters.

\subsection{Numerical Tests}

\subsubsection{Numerical Setup}

In order to further investigate some of the behaviors of the model, and highlight the novel types of mass movement dynamics that the model implements, several numerical tests have been performed. The setup of these tests is shown in figure 5 . 

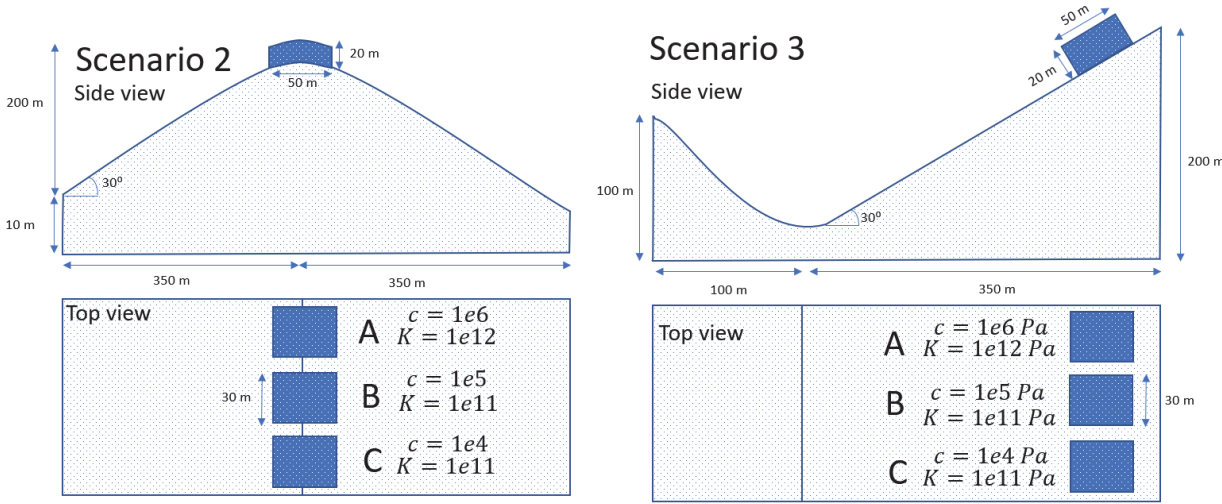

Figure 5-6 The dimensions of the numerical experiment setups used in this work. Setup 1 (left) and Setup 2 (right)

Numerical settings were chosen as $\left\{\alpha_{s}=0.5, \alpha_{f}=0.5, f_{s c}=1.0, f_{f c}=1.0, \rho_{f}=\right.$ $1000 \mathrm{kgm}^{-3}, \rho_{s}=2400 \mathrm{kgm}^{-3}, E=1 e 12 \mathrm{~Pa}, K=1 e 11 \mathrm{~Pa}, \psi=0, \alpha_{\Pi}=1, \beta_{\Pi}=1, \mathrm{X}, \zeta, j=$ $2, u_{\text {sound }}=600 \mathrm{~ms}^{-1}, d x=10 \mathrm{~m}, V_{I}, h=10 \mathrm{~m}, n=0.1, \alpha=1, \beta=10, \mathrm{M}=2.4, \mathcal{B}=0, \mathrm{~N}_{\mathrm{R}}=$ $\left.15000, N_{R A}=30\right\}$.

\subsubsection{Results}

Several time-slices for the described numerical scenarios are shown in figure 7 and 8. 

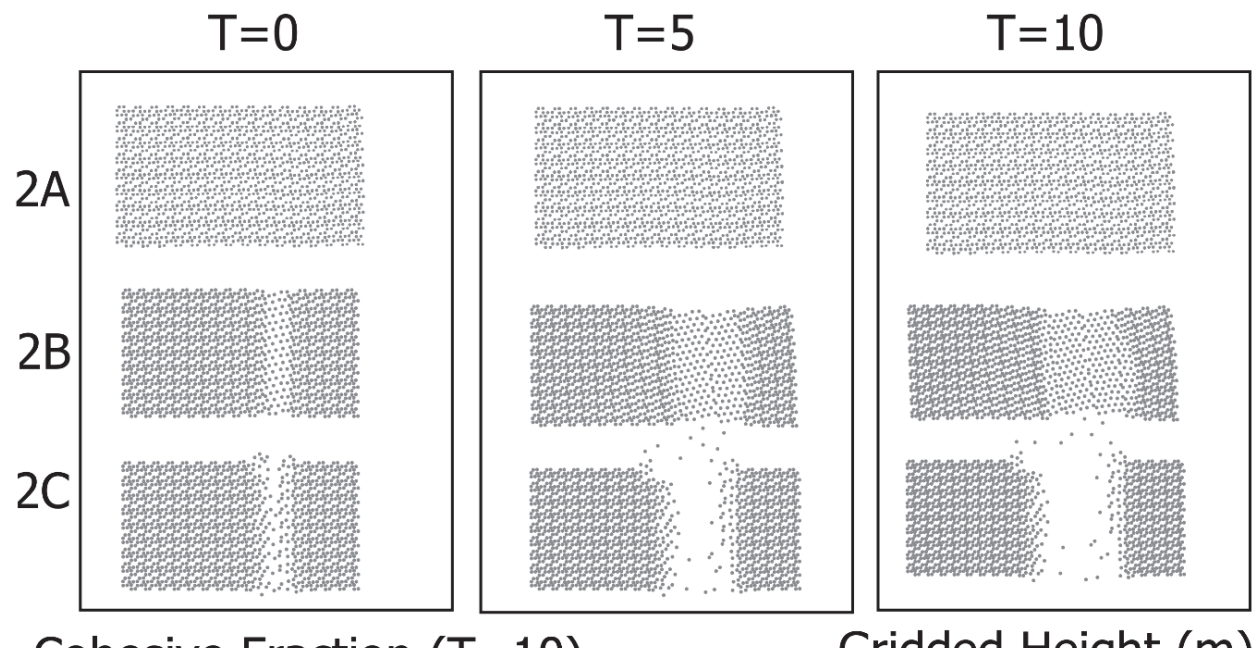

Cohesive Fraction ( $T=10)$

Gridded Height (m)
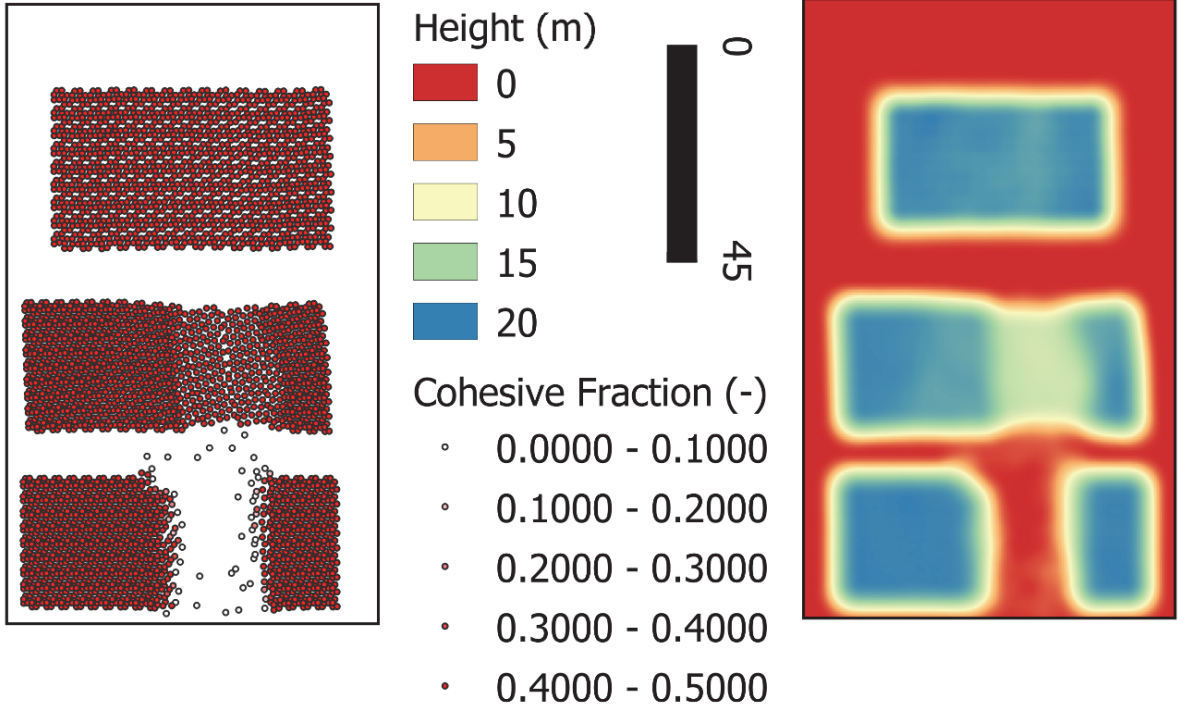

Figure 5-7 Several time-slices for numerical scenarios 2(A/B/C). See Figure 5-6 for the dimensions and terrain setup. 

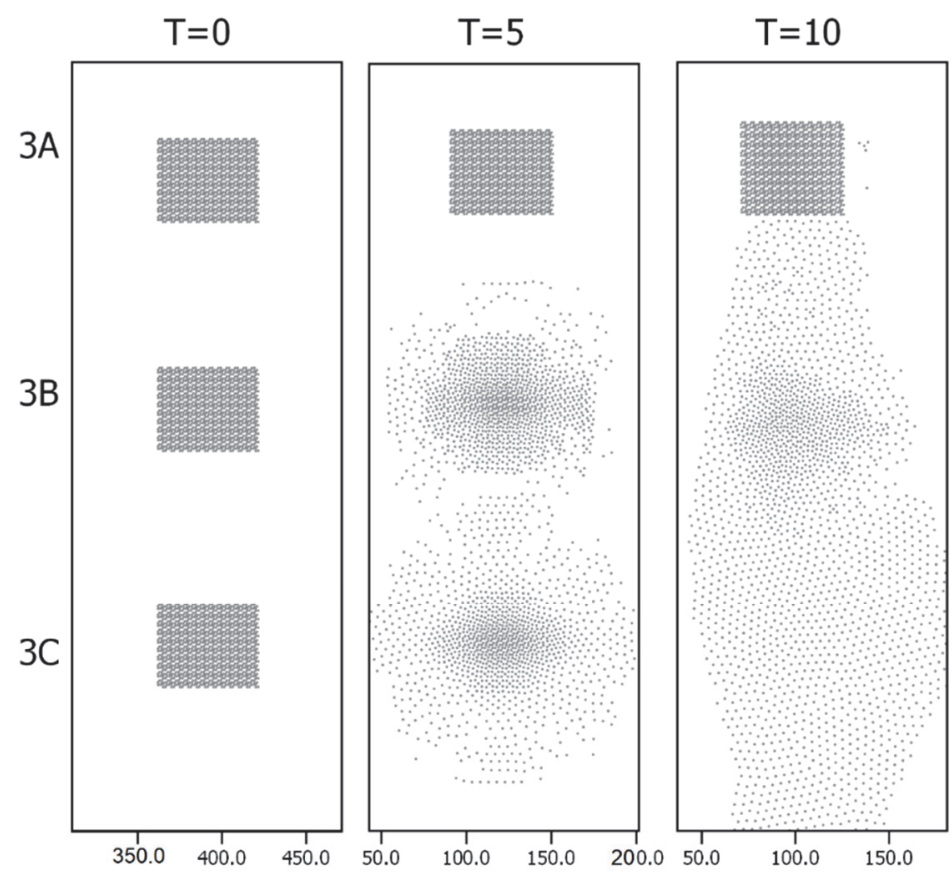

Cohesive Fraction ( $T=10)$

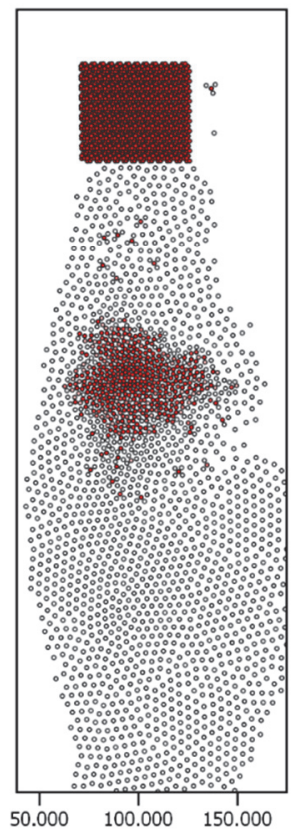

Height (m)

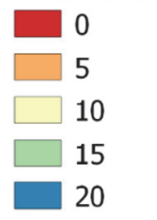

\section{Gridded Height (m)}

Cohesive Fraction (-)

- $0.0000-0.1000$

- $0.1000-0.2000$

- $0.2000-0.3000$

- $0.3000-0.4000$

- $0.4000-0.5000$

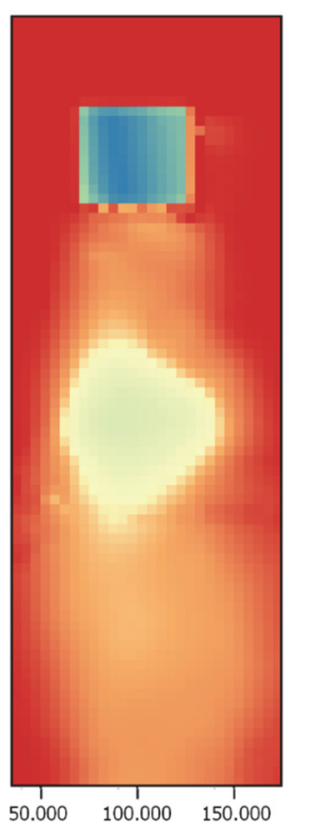

Figure 5-8 Several time-slices for numerical scenarios 3(A/B/C). See Figure 5-6 for the dimensions and terrain setup. 
Fractures develop in the mass movements based on acceleration differences and cohesive strength. For scenario $2 \mathrm{~A}$, the stress state does not reach beyond the yield surface, and all material is moved as a single block. Scenario 2B, which features lowered cohesive strength, fractures and the masses separate based on the acceleration caused by slopes.

Fracturing behavior can occur in MPM schemes due to numerical limitations inherent in the usage of a limited integration domain. Here, validation of real physically-based fracturing is present in the remaining cohesive fraction. This value only reduces in case of plastic yield, where increasing strain degrades strength parameters according to our proposed criteria. Numerical fractures would thus have a cohesive fraction of 1 . In all simulated scenarios, such numerical issues were not observed.

Fragmentation occurs due to spatial variation in acceleration in the case of scenario $3 \mathrm{~A}$ and $3 \mathrm{~B}$. For scenario $3 \mathrm{C}$, the yield surface is not reached and the original structure of the mass is maintained during movement. For $3 A$, fragmentation is induced be lateral pressure and buoyancy forces alone. Scenario 3B experiences slight fragmentation at the edges of the mass, but predominantly fragments when reaching the valley, after which part of the material is accelerated to count to the velocity of the mass. For all the shown simulations, fragmentation does not lead to significant phase separation since virtual mass and drag forces converge the separate phase velocities to their mixture-averaged velocity. The strength of these forces partly depends on the parameters, effects of more immediate phase-separation could by studied if other parameters are used as input.

\section{Discussion}

A variety of existing landslide models simulate the behavior of lateral connected material through a non-linear, non-Newtonian viscous relationship (Boetticher et al., 2016; Fornes et al., 2017; Pudasaini \& Mergili, 2019). These relationships include a yield stress and are usually regularized to prevent singularities from occurring. While this approach is incredibly powerful, it is fundamentally different from the work proposed here. These viscous approaches do not distinguish between elastic or plastic deformation, and typically ignore deformations if stress is insufficient. Additionally, fracturing is not implemented in these models. The approach taken in this work attempts to simulate a full stress-strain relationship with Mohr-Coulomb type yield surface. This does provides new types of behavior and can be combined with non-Newtonian viscous approaches as mentioned above. A major downside to the presented work is the steep increase in computational time required to maintain an accurate and stable simulations. Commonly, an increase of near a 100 times has been observed during the development of the presented model. The presented model shows a good likeness to flume experiments and numerical tests highlight behavior that is commonly observed for landslide movements. There are however, inherent scaling issues and the material used in the flume experiments is unlikely to form larger landslide masses. There is thus the need for more, real-scale, validation cases. The application of the presented type of model is most directly noticeable for block-type landslide movements that have fragment either upon impact of some obstacle or during transition phase. Another major opportunity for validation of the novel aspects 
of the model is the full three-dimensional application to landslides that were reported to have lubrication effects due to fragmentation of lower fraction of flow due to shear.

There are a variety of aspects of the model that could be significantly improved. Here, we list several major opportunities of future research.

\section{1) Groundwater mechanics}

The presented model allows for the a solid or granular matrix to be present within the flow. We have assumed the flows in and out of these matrices are sufficiently small to be ignored. In reality, there is a fluid flux in and out of structured solids. This could occur both due to pressure differences as due to stress and strain of the structured solids. Implementing this kind of mechanics required a full pedo-transfer function to be implemented (Saxton et al., 2006; Van Looy et al., 2017). An example of MPM soil mechanics with dynamic groundwater implementation can be found in Bandera et al. (2016).

2) Implementing Entrainment and Deposition

Current equations for entrainment (erosion with major grain-grain interactions) is limited to unstructured mixture flows (Iverson, 2012; Iverson \& Ouyang, 2015; Pudasaini \& Fischer, 2016). Extending these models to include a contribution from structured solids would be required to implement entrainment in the presented work.

3) Separation of phases

A major assumption in the presented work is that the velocities of structured solids, free solids and confined fluids are all equal. In reality, there might be separation of structured and free solids phases. Additionally, we already discussed the possibility of in-and outflux of confined fluids from the solid matrix. Recent innovations on three-phase mixture flows might be used to extend the presented work to a three, four or five-phase model by separating free solids, confined fluids or adding a Bingham-viscous solid-fluid phase (Pudasaini \& Mergili, 2019). However, while this would add, it would significantly increase complexity of the equations (in an exponential manner with relation to the number of phases) and the numerical solutions which could hinder practical applicability.

4) Application to large, slow moving landslides.

When confined fluids would act as a distinct phase, guided by the mechanics of water flow in granular matrix, ground water pressures and movement through the structured solids could be described. This might enable the model to do detailed deformation/groundwater simulation of large slow-moving landslides.

5) Numerical Improvements

Numerical techniques for particle-based discretized methods (SPH, MPM) have been proposed in the literature. A common issue is numerical fracturing of materials when particle strain increases beyond the length of the kernel function. Then, the connection between particles is lost and fracturing occurs as an artifact of the numerical method. This issue is partly solved by the artificial stress term as is also used by Bui et al. (2008). Additionally, geometric subdivide, as used by Xu et al. (2012) and Li et al. (2015), could counter these artificial fractures. Implementing this technique does require additional work to maintain mass and momentum conservation. 


\section{6) Three-dimensional solutions}

In a variety of scenarios, the assumptions made in depth-averaged application of flow models are invalid. A common example is the impact of mass movements into lakes, or other large water bodies. In such cases, the vertical velocity and concentration variables are not well-described by their depth-averaged counterparts. Additionally, the lubrication effect of basal fragmentation of landslides due to shear can not be described without velocity-profiles and a vertical stress-solution. Full threedimensional application would therefore have the potential to increase understanding on these important processes.

\subsection{Conclusions}

We have presented a novel generalized mass movement model that can describe both unstructured mixture flows and structured movements of MohrCoulomb type material. The model builds on the works of Pudasaini (2012) and Bui et al. (2008) to develop a single holistic set of equations. The model was implemented in a GPU-based Material Point Method (MPM) Code. The equations were validated on flume experiments and numerical tests, that highlight the new movement dynamics possible with the presented model. The integration of cohesive structure and a full stress-strain relationship for the structured solids allows for movement of block-type slides as a single whole. Interactions with terrain, other flow masses or obstacles lead to elastic-plastic deformation and eventually fragmentation. This type of self-alteration of flow properties is novel with mass movement models. Although the presented equations can provide additional detail for specific mass movement types, applicability of the model for real events need to be investigated as computational costs are significantly increased.

The presented simulation both validate the basic behavior of the model, as well as highlight the types of flow dynamics made possible by the presented equations. The models dependency of breaking to cohesive strength and internal friction angle matches the flume experiments. The numerical examples show commonly-described behavior for landslide movements. Although the simulations compare well to the flume experiments, validation is required for real-scale application to various types of mass movements. Additionally, the presented equations still lack descriptions of processes that might become important. Separating the fluid and solid phases such as done by Pudasaini \& Mergili (2019), could improve flow dynamics and phase separation. With added ground-water mechanics, such as done in Bandera et al. (2016), slow-moving landslide simulations might be described. 


\section{Challenges in Physically-based Spatial Modelling of a Landslide Hazard Chain.}

This chapter has been submitted as B. van den Bout, C. Tang, C.X. Tang, V.G. Jetten, C. J. van Westen (under review) Challenges in Physically-based Spatial Modelling of a Landslide Hazard Chain.

\subsection{Introduction}

Hazardous processes are those that may lead to human harm (Burton et al, 1978). The intensity such a process is typically defined in terms of processrelated variables such as a speed, or height of the process (Kappes et al., 2012). These intensities can lead to impact, or actual effective damage. Many of the damaging events that involve land surface processes are not caused by individual but multiple interacting hazardous processes. Such combinations can take place because the same triggering events (e.g. extreme rainfall) triggers various hazardous processes (e.g. flash floods, landslides and debris flows) that interact and that may impact the same anthropogenic elements. For multihazard assessment, the hazard intensities and impact can differ significantly when compared to the individual hazardous processes (Gill \& Malamud, 2014; Van Westen and Greiving, 2017). Hazardous events may also occur in sequence as cascading events whereby one hazardous process triggers another either directly or later in time (Mergili et al., 2017; 2018a). One particular hazardous example of such cascading hazard events is the natural damming of rivers by landslides (Costa \& Schuster, 1988; Walder \& O'Connor, 1997). Among other types of terrain, landslide-prone mountainous areas around the world are subject to these landslide dams (Swanson et al., 1986; Chai et al., 2000; Dai et al. 2005; Korup, 2005; Harp and Crone, 2006; Nash et al., 2008; Liu et al., 2009; Fan et al., 2014). The sequence of events surrounding a landslide dams formation can start with a catastrophic slope failure, often caused by intense rainfall, a seismic trigger, or a combination of these. The released material mobilizes and enters a channel or river. Here, mobility can be enhanced due to momentum production (Pudasaini and Fishcher, 2016) or in flat channels, momentum is lost due to friction and blockage by the channel walls. When the volume of the solid materials is sufficient, and when the moved landslide materials physical properties prevent direct drag by river flow, it will form a barrier for water flow which will accumulate to form a dammed lake. Depending on the strength of the materials composing the dam, the barrier may breach when the barrier lake level exceeds the height of the dam, either due to accelerated erosion, piping or barrier collapse (Ermini and Casagli, 2003; Mergili et al., 2019). During the breach, extreme discharges and solidladen floods with high velocity can occur in the downstream areas (Schuster, 1993; Walder and O'Connor, 1997).

Natural dynamical systems such as the one described above can be complicated, containing many interactions and numerous fundamental processes related to hydrology and sediments (Walder \& O'Conner, 1997). Slope failures, mass movement runout and flooding are influenced by catchment scale hydrology (van den Bout et al., 2018). Furthermore, interhazard interaction exist in many varieties, a review of which can be found in Kappes et al. (2012). In the case of landslide dam formation and breaching, 
many interactions exist between processes that are typically approached individually in modelling. Landslide dam break floods have been analyzed using both empirical and physically-based models (Evans, 1986; Costa and Schuster, 1988; Peng and Zhang, 2012). For an overview of the key differences for these types of models see Jajarmizadeh et al. (2012). Empirical models are simpler to apply but provide less comprehensive results than physically-based models. On the other hand, physically based models require detailed physical parameters as input, and can be computationally costly. Whereas the individual components of the hazard chain: landslide initiation, landslide run-out, dam breach and flooding, have been modelled using physically-based models, the interactions between these processes are generally not simulated within a single model due to their high complexity. Notable expections to this are Bout et al. (2018) and Mergili et al. (2018a; 2019). The last example has simulated such complex process chains and cascades in to a single and efficient computational tool r.avaflow (Mergili et al., 2017) using the general two-phase mass flow model by Pudasaini (2012).

Within the area impacted by the 2008 Wenchuan earthquake, in Sichuan province, central China, numerous landslide dams occurred (Tang et al., 2011). One particular case occurred in the Hongchun watershed, located adjacent to the Min River, opposite of Yinxiu town. Here, a co-seismic earthquake deposited large volumes of material in the central gully of Hongchun. In 2010, extreme rainfall lead to entrainment of this material, and the resulting debris flow blocked the Min river, which flooded into Yinxiu (Tang et al., 2011). This research aims to simulate this complex multi-hazard chain using a physicallybased integrated model. An implementation is presented of a complete spatial simulation of a landslide dam process chain, including initial slope failure, landslide runout, deposition, runoff-driven debris flow initiation, lake formation, and flooding. To test the behavior of the developed model, simulations and validation will be shown for a case study of a dam-break flood event in the Hongchun watershed. Finally, we investigate the predictive capabilities of complex multi-hazard multi-stage simulation by analyzing the sensitivity of the model to changes in input parameters.

The prediction of landslide volumes is a complex problem, and requires specialized numerical models. Several physically-based simulation tools for slope failure volume modelling have been developd, such as CLARA (Hungr et al., 1989), TSLOPE3 (Pyke, 1991), 3D-SLOPE (Lam and Fredlund, 1993), 3DSLOPEGIS (Xie et al., 2003), r.slope.stability (Mergili et al., 2014), Scoops3D (Reid et al., 2015), EDDA (Chen \& Zhang, 2015) and OpenLISEM Hazard (Van den Bout et al., 2018). CLARA, TSLOPE3, and 3D-SLOPE can only be applied on individual slopes, while r.slope.stability, Scoops3D, and OpenLISEM Hazard are spatially distributed models, which are based on Geographic Information Systems (GIS). These can be applied for landslide volume estimation over a large area up to several hundred $\mathrm{km}^{2}$. Of the regional models, Scoops3D implements seismic loading which enables simulation of co-seismic slope failures. Numerical modelling of mass movement run-out using 2-D approaches has been implemented in a variety of models (Malet et al., 2004; Rickenmann et al., 2006; Van Asch et al., 2007; Hürlimann et al., 2007; Domenech et al., 2019). They need detailed information on initial volume, rheology, entrainment and an accurate and detailed digital elevation model (DEM) (Hürlimann et al 2007). Erosion, the water-driven uptake of sediment, and entrainment, the grain-driven uptake of sediment, have been used in understanding mass flow 
- soil interactions. Erosion models come in great variety and provide insight into the flow-surface interactions. Examples are WEPP (Nearing et al., 1989), EUROSEM (Morgan et al., 1998) and Delft3D Sediment (Roelvink and Banning, 1995). However, these examples do not cover the behavior taking place in massive gravitational flows such as landslides or debris flows.

In the case of multi-hazard chains including landslide dams, integrated simulations face several critical issues. When a mass movement enters a channel, with a certain water level, the landslide material mixes with the water in a dynamic manner, which is generally ignored in existing flow models such as Flo-2D (O'Brien et al., 1993). Similarly, the volumetric sediment content of water increases when a landslide dam is breached, and the material of the dam is entrained by the water flow. The entrainment of bed material is simulated in a limited number of spatial two-dimensional mass movement models, but is rarely initiated from low-concentration water flow. Several models have shown this functionality, but most lack the capability of modelling breaching behavior, and ignore the resulting changes in the digital elevation model (Chen \& Zhang, 2015; Hu et al., 2016). An exception to this is r.avaflow, which does take into account the evolution of terrain (Mergili et al., 2019). Ignoring these changes makes the simulation of any breaching behavior less reliable, since increasing outflow must be the result of the entrainment of a flow path on the landslide dam.

To simulate more complex types of behavior, individual models can be coupled by linking output from one model to input for another or by merging the required equations into an integrated model. Simplified coupled modelling approaches have been tested using separate, and non-spatially distributed models for water flow and dam breaching. Empirical equations for dam-breach discharge have been developed and implemented by Singh \& Snorasson (1984), Wang et al. (2008) and in the BREACH model (Fread, 1988). In these models, mathematical equations for the dynamics of the outgoing discharge during a dam breach are derived from simplified landslide dam examples. Typically, a feedback loop between outflowing discharge and the amount of material entrained from the landslide dam determines the dynamics of the hydrograph (Fan et al., 2014). While empirical equations provide a useful estimation of the relevant physical processes during a dam breach, only outgoing discharge is simulated and downstream processes are not modelled. Moreover, the accuracy is generally low for more complicated cases (Zhu, 2006). The BREACH model simulates the increasing breach depth in a landslide dam using an iterative numerical solution. At the sides of the entrained channel, a limiting angle determines the additional collapse of material. Valiani et al. (2002) improved this by simulating dam breach discharge using a twodimensional finite element method.

Fan et al. (2014) provided an insightful step towards integrated modelling by linking a one-dimensional breach outflow model with a hydraulic 2D flood simulation. The outflow from the BREACH model determines the boundary condition for the Sobek flood model (Delft Hydraulics, 2000). With this combined setup, it was possible to predict the dynamic dam breaching and the resulting large scale flood behavior, with significant accuracy. However, this integrated setup was still limited by the assumptions in the model. The breach model is one-dimensional and uses a simplified shape for the estimation of breaching dynamics. The setup ignores catchment-scale hydrological processes that could influence the surface flow. Furthermore, breach outflow 
can typically contain large amounts of solid material, altering the dynamics of the mixture. Fan et al. (2014) implemented a flood model where flow is calculated using the Saint Venant equations for shallow flow, which ignores forces such as viscosity, and implements a fluid-based frictional model (Dhondia and Stelling, 2002). Li et al. (2011) provided a different approach to integrated simulations of landslide dams by linking the BREACH model with both a regional rainfall-runoff model and the Flo-2D debris flow model for modelling the runout of the breach material. Despite their improved method, the landslide dam breach modelling depends on assumptions such as constant flow material properties, a limiting region for entrainment and landslide initiation coming from pre-defined boundary conditions. More recently, Mergili et al (2017) show the application of diluting mass flows to modelling Glacial Lake Outburst floods. The authors developed the r.avaflow model, based on two-phase mixture equations by Pudasaini (2012) that allows for mixed flow of water and solids and implements a simplified entrainment process, also for cascading flows (Mergili et al., 2018a, 2019). While this allows for a more detailed description of multi-phase flows and internal forces, the catchmentprocesses that are crucial in runoff-triggered debris flow formation and landslide dam formation are not included.

Current approaches either lack the detail or processes to simulate the multiprocess chain as it occurred in Hongchun. Cascading multi-hazard behavior is simulated for a series of interacting earthquake, landslide, debris flow and flood processes in the Hongchun watershed. In order to simulate the behavior of the Hongchun event, an extended and improved version of OpenLISEM Hazard is presented. To analyze the uncertainties in modelling such process chains, we employ ensemble simulations and analyze spatial hazard probabilities to estimate reliability. Finally, we discuss the benefits, downsides and potential application of modelling methods that involve integrated multi-hazard process chains.

The investigation of the Hongchun watershed builds on previous works in literature. Tang et al. $(2011 ; 2015)$ describe the co-seismic and post seismic landslide events between 2008 and 2011 in this area. Several other studies have simulated the event using a variety of modelling techniques. Ouyang et al. (2015) applied shallow flow depth-averaged debris flow equations in order to understand the event as a simplified runout process. Zhang et al., (2018) utilized a depth-averaged smooth particle hydrodynamics model to simulate both runout from landslides and the later debris flow. The authors show a novel application of such methods to a multi-stage event, however, without an integration in catchment scale hydrology and a physical implementation of entrainment and breaching of the landslide dam. Domenech et al. (2019) used a multi-event debris flow model including entrainment to study the effect of material depletion on debris flow initiation in the Hongchun watershed. Using results of modelling studies, Chen et al. (2016) performed a cost-benefit analysis for the mitigation measures to protect the touristic town of Yinxiu, located directly opposite to the outlet of the Hongchun watershed on the other side of the Ming River. 


\subsection{Theoretical Model Background}

One of the important cornerstones is the work by Pudasaini (2012) who developed a set of physically-based two-phase mass movement equations that can adapt the interfacial forces in the flow based on the local volumetric solid concentration. This allows to simulate the behavior of landslides, the flow of water and the interactions between mass movements and water flow (Mergili et al., 2018a, 2019). Using these equations, Bout et al. (2018) developed an integrated model for slope hydrology, slope failure, mass movements and runout. Recently, Pudasaini and Mergili (2019) developed a three-phase mass flow model that addresses deposition morphology and related phenomena.

We have implemented a series of new processes within the physically-based OpenLISEM Hazard model. The development of this catchment-scale simulation tool started with hydrology, runoff and transport-capacity based erosion (Jetten \& de Roo, 2001). The OpenLISEM Hazard model implemented multi-phase flow and slope stability into the tool (Bout et al., 2018). Additionally, runoff is simulated by the multi-phase equations that reduce to the saint venant shallow water equations in the absence of solids. The twophase flow enters the channels according to a mannings-type velocity (Bout et al., 2018). All parts of the OpenLISEM Hazard model remain identical in this work, except for the interactions with the added processes, as described in this section. We implement the addition of terrain-altering entrainment by mixture flows, and the simulation of co-seismic shallow landslides. An overview of the processes is provided in Figure 6.1.

Figure 6-1

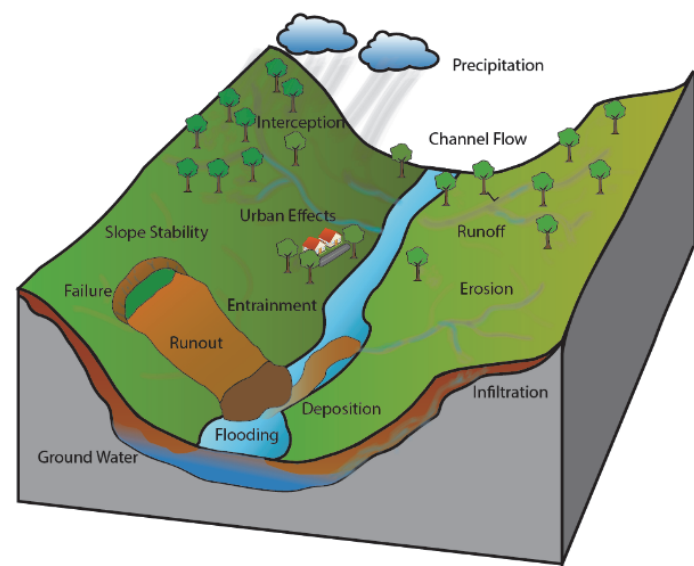

Figure 6-1 A schematic overview of processes, fluxes and storages within the OpenLISEM Hazard model.

\subsubsection{Slope Stability and} Failure

Hydrology influences slope stability and can eventually lead to failure. Slope failure is based on the Iterative Failure Method (Bout et al., 2018). This technique reverses the Factor of Safety (equation 6.1) to solve for the remaining depth of material at which the local situation becomes stable. The locally altered terrain then results in changed forces in the surrounding cells. Through iteration, the method keeps removing material until no unstable cell is left and the minimum required material for a stable terrain has been removed. We added the seismic forcing in the Factor of Safety calculation following Morgenstern \& Sangrey (1978). 
6.1 FOS $=\frac{\mathrm{c}^{\prime}+\left(\left(\left(\gamma-\mathrm{m} \gamma_{\mathrm{w}}\right) \mathrm{h}_{\mathrm{s}}+\mathrm{m} \gamma_{\mathrm{w}} \mathrm{z}\right) \cos (\beta)^{2}-\mathrm{h}_{\mathrm{s}} \gamma \alpha \sin (\beta) \cos (\beta)\right) \tan (\phi)}{\left(\left(\gamma-\mathrm{m} \gamma_{\mathrm{w}}\right) \mathrm{h}_{\mathrm{s}}\right) \sin (\beta) \cos (\beta)+\mathrm{h}_{\mathrm{s}} \gamma \alpha \cos (\beta)^{2}}$

Where FOS is the Factor of Safety $(-), \beta$ is the slope of the soil section $(-), c^{\prime}$ is the apparent cohesion of the soil $(\mathrm{kPa}), \alpha$ is the peak horizontal earthquake acceleration $\left(m^{-2}\right), \phi$ is the internal friction angle of the soil $(-), \gamma$ is the density of the slope material $\left(\mathrm{kg} \mathrm{m}^{-3}\right), \gamma_{\mathrm{w}}$ is the density of water $\left(\mathrm{kg} \mathrm{m}^{-3}\right)$, $\mathrm{m}$ is the fraction of the soil depth that is saturated from the basal boundary $(-)$ and $\mathrm{h}_{\mathrm{s}}$ is the depth of the failure plane $(\mathrm{m})$.

The apparent cohesion is corrected for an additional root cohesion and a matric suction term. The acceleration is assumed to be, as in the most critical situation, the estimated peak horizontal ground acceleration. To account for sub-surface force propagation, we include an iterative force solution. This is an extension of similar approaches in Zhou \& Cheng (2013) and Zhou et al., (2014). In the proposed implementation, forces are iteratively solved throughout the entire terrain description.

We assume that excess force is transferred downslope, but the fractured top material is unable to transfer force resistance upslope.

In the three-dimensional case, where the $x$-and $y$-components of the seismic forcing and slope steepness influence the propagation, this can be expressed as equation 6.2 .

6.2

$$
\nabla \overrightarrow{\mathrm{F}_{\text {up }}}+(\overrightarrow{\mathrm{C}}-\overrightarrow{\mathrm{D}}) *\left(\overrightarrow{\mathrm{S}} \cdot \overrightarrow{\mathrm{F}_{\text {lat }}}\right)=0
$$

where $C$ the force capacity (numerator of equation 3 ), D the force demand (denominator of equation 3 ), $\vec{S}$ is the normalized slope vector (-) and $\overrightarrow{F_{\text {lat }}}$ is the vector of laterally acting forces $\left(\mathrm{kg} \mathrm{m} \mathrm{s}^{-2}\right)$.

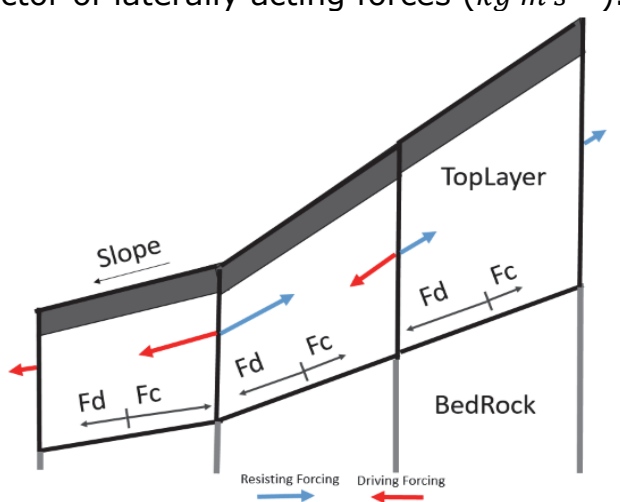

Figure 6-2 Sub-surface force distribution is solved through iteratively finding a steady state $(\mathrm{Fd}=$ driving force, $\mathrm{Fc}=$ resisting force)

We assume in the set-up of the model that a failure plane can develop in the soil materials at any depth. Equation 3 can be inverted to find the value of $h$, for which the safety factor is one. To solve this equation for $h$, we first express the slope based on the local elevation differences and create a shortened equation for the factor of safety (equation 6.3 and 6.4 ). 


$$
\begin{gathered}
\beta=\operatorname{atan}\left(\frac{\max \left(\mathrm{h}_{\mathrm{x}-1}-\mathrm{h}_{\mathrm{x}}, \mathrm{h}_{\mathrm{x}}-\mathrm{h}_{\mathrm{x}+1}\right)}{\mathrm{dx}}\right) \\
\text { FOS }=1=\frac{\mathrm{C}_{1}+\mathrm{C}_{2} \cdot \cos \left(\operatorname{atan}\left(\frac{\mathrm{z}-\mathrm{z}_{0}}{\mathrm{dx}}\right)\right)^{2} \cdot \tan (\phi)}{\mathrm{C}_{3} \cdot \sin \left(\operatorname{atan}\left(\frac{\mathrm{z}-\mathrm{z}_{0}}{\mathrm{dx}}\right)\right) \cdot \cos \left(\operatorname{atan}\left(\frac{\mathrm{z}-\mathrm{z}_{0}}{\mathrm{dx}}\right)\right)}
\end{gathered}
$$

where the simplified constants are given by equations $C_{1}=c, C_{2}=$ $\left(\left(\left(\gamma-m \gamma_{\mathrm{w}}\right) \mathrm{h}_{\mathrm{s}}+\mathrm{m} \gamma_{\mathrm{w}} \mathrm{h}_{\mathrm{s}}\right), C_{3}=\left(\left(\gamma-\mathrm{m} \gamma_{\mathrm{w}}\right) \mathrm{h}_{\mathrm{s}}\right), \beta\right.$ is the slope angle $(-), z$ is the elevation above the failure surface $(m)$ and $z_{0}$ is the lowest neighboring elevation $(\mathrm{m})$.

Solving this equation can be done using the trigonometric identities (Equation 6.5 and 6.6).

$$
\begin{aligned}
& \cos (\operatorname{atan}(\mathrm{x}))=\frac{1}{\sqrt{1+\mathrm{x}^{2}}} \\
& \sin (\operatorname{atan}(\mathrm{x}))=\frac{\mathrm{x}}{\sqrt{1+\mathrm{x}^{2}}}
\end{aligned}
$$

Finally, we find the lowest real root to the second-order polynomial equation of the form

6.7

$$
\mathrm{h}_{\mathrm{s}}=\mathrm{a}+(\mathrm{b}) \mathrm{x}+(\mathrm{c}) \mathrm{x}^{2}
$$

Where

$$
\begin{gathered}
a=C_{1} h_{0}^{2}-C_{1} \mathrm{dx}^{2} \\
b=2 C_{1} h 0-C_{3} h_{0} \text { FOS }-C_{3} h_{0} \text { FOS } d x C_{2} d x^{2} \\
c=C_{1}-C_{3} \text { FOS } d x
\end{gathered}
$$

Using equation 9 the critical depth can be found, where the material on the slope is in equilibrium. By multiplying the area of a pixel with the slope material height above this critical depth, a failure volume can be calculated. This volume consists of solids and water, depending on the soil saturation level, and is then added to the flow equations that simulate Mohr-Coulomb mixture flow.

The following set of equations by Pudasaini (2012) is used in the OpenLISEM Hazard model.

$$
\begin{aligned}
& \frac{\partial \alpha_{s} h}{\partial t}+\frac{\partial \alpha_{s} h u_{s}}{\partial x}+\frac{\partial \alpha_{s} h v_{s}}{\partial y}=0 \\
& \frac{\partial \alpha_{f} h}{\partial t}+\frac{\partial \alpha_{f} h u_{f}}{\partial x}+\frac{\partial \alpha_{f} h v_{f}}{\partial y}=0
\end{aligned}
$$

$$
\begin{gathered}
\frac{\partial}{\partial t}\left[\alpha_{s} h\left(u_{s}-\gamma C\left(u_{f}-u_{s}\right)\right)\right]+\frac{\partial}{\partial x}\left[\alpha_{s} h\left(u_{s}^{2}-\gamma C\left(u_{f}^{2}-u_{S}^{2}\right)+\frac{\beta_{x_{s}} h}{2}\right)\right] \\
+\frac{\partial}{\partial y}\left[\alpha_{s} h\left(u_{s} v_{s}-\gamma C\left(u_{f} v_{f}-u_{s} v_{s}\right)\right)\right]=h S_{x_{s}}
\end{gathered}
$$

$$
\begin{array}{r}
\frac{\partial}{\partial t}\left[\alpha_{s} h\left(v_{s}-\gamma C\left(v_{f}-v_{s}\right)\right)\right]+\frac{\partial}{\partial x}\left[\alpha_{s} h\left(u_{s} v_{s}-\gamma C\left(u_{f} v_{f}-u_{s} v_{s}\right)\right)\right] \\
+\frac{\partial}{\partial y}\left[\alpha_{s} h\left(v_{s}^{2}-\gamma C\left(v_{f}^{2}-v_{S}^{2}\right)\right)+\frac{\beta_{y_{s}} h}{2}\right]=h S_{y_{s}}
\end{array}
$$


6.13

$$
\begin{gathered}
\frac{\partial}{\partial t}\left[\alpha_{f} h\left(u_{f}-\frac{\alpha_{s}}{\alpha_{f}} C\left(u_{f}-u_{S}\right)\right)\right]+\frac{\partial}{\partial x}\left[\alpha_{f} h\left(u_{f}^{2}-\frac{\alpha_{s}}{\alpha_{f}} C\left(u_{f}^{2}-u_{S}^{2}\right)+\frac{\beta_{x_{f}} h}{2}\right)\right] \\
+\frac{\partial}{\partial y}\left[\alpha_{f} h\left(u_{f} v_{f}-\gamma C\left(u_{f} v_{f}-u_{s} v_{s}\right)\right)\right]=h S_{x_{f}}
\end{gathered}
$$

$$
\begin{gathered}
\frac{\partial}{\partial t}\left[\alpha_{f} h\left(v_{f}-\frac{\alpha_{s}}{\alpha_{f}} C\left(v_{f}-v_{S}\right)\right)\right]+\frac{\partial}{\partial x}\left[\alpha_{f} h\left(u_{f} v_{f}-\frac{\alpha_{s}}{\alpha_{f}} C\left(u_{f} v_{f}-u_{s} v_{s}\right)\right)\right] \\
+\frac{\partial}{\partial y}\left[\alpha_{f} h\left(v_{f}^{2}-\gamma C\left(v_{f}^{2}-v_{S}^{2}\right)\right)+\frac{\beta_{y_{f}} h}{2}\right]=h S_{y_{f}}
\end{gathered}
$$

$$
\beta_{x_{s}}=\epsilon K_{x} P_{b_{s}}, \beta_{y_{s}}=\epsilon K_{y} P_{b_{s}}, \beta_{x_{f}}=\beta_{y_{f}}=\epsilon p_{b_{f}}, P_{b_{f}}=-g^{z}, P_{b_{s}}=(1-\gamma) P_{b_{f}}
$$

6.15 $\mathrm{S}_{\mathrm{x}_{\mathrm{s}}}=\alpha_{\mathrm{s}}\left[\mathrm{g}^{\mathrm{x}}-\mathrm{P}_{\mathrm{b}_{\mathrm{s}}}\left(\frac{\mathrm{u}_{\mathrm{s}}}{\left|\overrightarrow{\mathrm{u}_{\mathrm{s}}}\right|} \tan \phi+\epsilon \frac{\partial \mathrm{b}}{\partial \mathrm{x}}\right)\right]-\epsilon \alpha_{\mathrm{s}} \gamma \mathrm{p}_{\mathrm{b}_{\mathrm{f}}}\left[\frac{\partial \mathrm{h}}{\partial \mathrm{x}}+\frac{\partial \mathrm{b}}{\partial \mathrm{x}}\right]+\mathrm{C}_{\mathrm{DG}}\left(\mathrm{u}_{\mathrm{f}}-\mathrm{u}_{\mathrm{s}}\right)\left|\mathrm{u}_{\mathrm{f}}-\mathrm{u}_{\mathrm{s}}\right|^{\mathrm{J}-1}$

$6.16 \mathrm{~S}_{\mathrm{y}_{\mathrm{s}}}=\alpha_{\mathrm{s}}\left[\mathrm{g}^{\mathrm{y}}-\mathrm{P}_{\mathrm{b}_{\mathrm{s}}}\left(\frac{\mathrm{v}_{\mathrm{s}}}{\left|\overrightarrow{\mathrm{u}}_{\mathrm{s}}\right|} \tan \phi+\epsilon \frac{\partial \mathrm{b}}{\partial \mathrm{y}}\right)\right]-\epsilon \alpha_{\mathrm{s}} \gamma \mathrm{p}_{\mathrm{b}_{\mathrm{f}}}\left[\frac{\partial \mathrm{h}}{\partial \mathrm{y}}+\frac{\partial \mathrm{b}}{\partial \mathrm{y}}\right]+\mathrm{C}_{\mathrm{DG}}\left(\mathrm{v}_{\mathrm{f}}-\mathrm{v}_{\mathrm{s}}\right)\left|\mathrm{v}_{\mathrm{f}}-\mathrm{v}_{\mathrm{s}}\right|^{\mathrm{J}-1}$

$$
\begin{aligned}
S_{x_{S}}=\alpha_{f}\left[g^{x}-\epsilon[\right. & \frac{\frac{1}{2} P_{b_{f}} h}{\alpha_{f}} \frac{\partial b}{\partial x}+P_{b_{f}} \frac{\partial b}{\partial x}-\frac{1}{\alpha_{f} N_{R}}\left(2 \frac{\partial^{2} u_{f}}{\partial x^{2}}+\frac{\partial^{2} v_{f}}{\partial x^{2}}+\frac{\partial^{2} u_{f}}{\partial y^{2}}-\frac{\mathrm{X} u_{f}}{\epsilon^{2} h^{2}}\right) \\
& +\frac{1}{\alpha_{f} N_{R_{A}}}\left(2 \frac{\partial}{\partial x}\left(\frac{\partial}{\partial x}\left(u_{f}-u_{s}\right)\right)+\frac{\partial}{\partial y}\left(\frac{\partial \alpha_{s}}{\partial x}\left(v_{f}-v_{s}\right)+\frac{\partial \alpha_{s}}{\partial y}\left(u_{f}-u_{s}\right)\right)\right) \\
& \left.\left.-\frac{\zeta \alpha_{s}\left(u_{f}-u_{s}\right)}{\epsilon^{2} \alpha_{f} N_{R_{A}} h^{2}}\right]\right]-\frac{1}{\gamma} C_{D G}\left(u_{f}-u_{s}\right)\left|\overrightarrow{u_{f}}-\overrightarrow{u_{s}}\right|^{J-1}
\end{aligned}
$$

6.18

$$
\begin{gathered}
S_{y_{s}}=\alpha_{f}\left[g^{x}-\epsilon\left[\frac{\frac{1}{2} P_{b_{f}} h}{\alpha_{f}} \frac{\partial b}{\partial x}+P_{b_{f}} \frac{\partial b}{\partial x}-\frac{1}{\alpha_{f} N_{R}}\left(2 \frac{\partial^{2} u_{f}}{\partial x^{2}}+\frac{\partial^{2} v_{f}}{\partial x^{2}}+\frac{\partial^{2} u_{f}}{\partial y^{2}}-\frac{\mathrm{X} u_{f}}{\epsilon^{2} h^{2}}\right)\right.\right. \\
+\frac{1}{\alpha_{f} N_{R_{A}}}\left(2 \frac{\partial}{\partial x}\left(\frac{\partial}{\partial x}\left(u_{f}-u_{s}\right)\right)+\frac{\partial}{\partial y}\left(\frac{\partial \alpha_{s}}{\partial x}\left(v_{f}-v_{s}\right)+\frac{\partial \alpha_{s}}{\partial y}\left(u_{f}-u_{s}\right)\right)\right) \\
\left.\left.-\frac{\zeta \alpha_{s}\left(u_{f}-u_{s}\right)}{\epsilon^{2} \alpha_{f} N_{R_{A}} h^{2}}\right]\right]-\frac{1}{\gamma} C_{D G}\left(u_{f}-u_{s}\right)\left|\overrightarrow{u_{f}}-\overrightarrow{u_{s}}\right|^{J-1} \\
6.19 \\
\mathrm{C}_{\mathrm{DG}}=\frac{\alpha_{s} \alpha_{\mathrm{f}}(1-\gamma)}{\left[\epsilon \mathrm{U}_{\mathrm{t}}\left(\mathrm{PF}\left(\operatorname{Re}_{\mathrm{p}}\right)+(1-\mathrm{P}) \mathrm{G}\left(\mathrm{Re}_{\mathrm{P}}\right)\right)\right]^{\mathrm{J}}}
\end{gathered}
$$

Where $h$ is the flow height, $s$ is the solid phase, $f$ is the fluid phase, $\boldsymbol{u}_{\boldsymbol{u}}$ is the velocity of the unconfined phase (free fluids), $\boldsymbol{u}_{\boldsymbol{c}}$ is the velocity of the solids, confining solids and confined fluids, $\rho_{f}$ is the density of fluids, $\rho_{s}$ is the density of solids, $\alpha_{f}$ is the volumetric fluid phase fraction, $\alpha_{s}$ is the volumetric solid phase fraction, $P_{f}$ is the fluid pressure, $\eta_{f}$ is the fluids dynamic viscosity, $\mathcal{A}$ is the mobility of the fluid at the interface, $\mathcal{C}_{D G}$ is the drag coefficient, $U_{T, u c}$ is the 
settling velocity of the unstructured solids, $\mathcal{F}$ is the drag contribution from solid-like drag, $\mathcal{G}$ is the drag contribution from fluid-like drag, $M\left(R e_{p}\right)$ is an empirical function weakly dependent on the Reynolds number, $\mathcal{P}$ the partitioning parameter for the fluid and solid like contributions to drag, $\mathcal{C}_{V M G}$ is the virtual mass coefficient, $K_{a}$ is the active lateral earth pressure coefficient, $K_{p}$ is the passive lateral earth pressure coefficient, $\zeta$ is a shape factor for the vertical gradient in solid concentration, $n$ is Mannings surface roughness coefficient, $\mathrm{X}$ is the shape factor for the vertical fluid velocity profile, $R e_{p}$ is the particle Reynolds Number, $N_{R}$ is the Reynolds Number, $N_{R A}$ is the interfacial Reynolds Number $H$ is the typical height of the flow, $L$ is the typical length of the flow and $\epsilon=\frac{H}{L}$ is the typical length of the flow

\subsubsection{Deposition and Dam-Formation}

Flows such as the ones described by the equations presented above have complex interactions with the topographic surface. In particular, material in the flow can be deposited, or material from the terrain can be entrained. Deposition occurs when the flow velocities of a solid-fluid mixture have sufficiently low velocities and drag forces do not overcome shear resistance. Then, water and solids are subtracted from flow volumes to form a deposits layer. The presented approach assumes a mixed and therefore vertically homogeneously saturated deposition layer. Laterally, the ratio of fluids and solids can vary, as can the properties such as grain size, internal friction angle and density. Within the model, the deposition process is described based on the flow momentum equations and the deposition equations of Takahashi (1992). The flow momentum equations determine the loss of momentum and stagnation of flow, but assume mixed flow of water and solids. The deposition equations by Takahashi are used to transfer solid material from flow to the deposits layer. These equations use local stability analysis and the ratio between the flow velocity and the critical velocity to estimate deposition of solids (Equations 6.20 - 6.23). The equations are applied spatially and temporally based on real-time flow properties (including mixture flows or channel discharge) and thereby automatically include topography and properties of the moving solids. Using these generalized deposition equations, a variety of more specific deposition-based processes is simulated. For example, deposition of landslide material in a river would equate to landslide dam formation in rivers.

$$
\mathrm{D}=\left(1-\frac{|\overrightarrow{\mathrm{u}}|}{\mathrm{p}|\overrightarrow{\mathrm{u}}|_{\mathrm{cr}}}\right) \frac{\alpha_{\mathrm{eq}}-\alpha}{\alpha^{\mathrm{b}}} \mathrm{V}
$$

$$
|\overrightarrow{\mathrm{u}}|_{\mathrm{cr}}=\frac{\frac{2}{5 \mathrm{~d}_{50}} \sqrt{\frac{\operatorname{gsin}\left(\theta_{\mathrm{c}}\right) \rho}{0.02 \rho_{\mathrm{s}}}}}{\left(\frac{\alpha^{\mathrm{b}}}{\alpha}\right)^{-\frac{1}{3}}-1} \mathrm{~h}^{1.5}
$$

$$
\tan \left(\theta_{\mathrm{c}}\right)=\frac{\alpha\left(\rho_{\mathrm{s}}-\rho_{\mathrm{w}}\right) \tan \left(\phi^{\mathrm{b}}\right)}{\alpha\left(\rho_{\mathrm{s}}-\rho_{\mathrm{w}}\right)+\rho_{\mathrm{w}}}
$$




$$
\alpha_{\text {eq }}=\frac{\rho_{\mathrm{w}} \tan (\theta)}{\left(\rho_{\mathrm{s}}-\rho_{\mathrm{w}}\right)\left(\tan \left(\phi^{\mathrm{b}}\right)-\tan (\theta)\right)}
$$

where $\mathrm{D}$ is the deposition rate $\left(m s^{-1}\right),|\overrightarrow{\mathrm{u}}|_{c r}$ is the critical velocity for deposition $\left(m s^{-1}\right), p$ is the calibration factor for the critical velocity for deposition $(-), \alpha_{e q}$ is the equilibrium volumetric solid concentration $(-), \alpha^{b}$ is the volumetric solid concentration of the bed material $(-)$, and $d_{50}$ is the median grain size $(m)$.

\subsubsection{Entrainment Equations}

In order to estimate entrainment, we implement the equations by Takahashi et al. (1992) in a similar manner as was done in the Edda model (Chen and Zhang, 2015). The expressions for the entrainment rate are provided by equation $6.24,6.25$ and 6.26 .

$$
\begin{array}{cc}
6.24 & \mathrm{E}=\mathrm{K}\left(\tau-\tau_{\mathrm{c}}\right) \\
6.25 & \tau=\rho g \mathrm{SS}_{\mathrm{f}} \\
6.26 & \tau_{\mathrm{c}}=c^{\mathrm{b}}+\left(1-\mathrm{C}_{\mathrm{s}}\right) \alpha\left(\rho_{\mathrm{s}}-\rho_{\mathrm{w}}\right) \operatorname{gh} \cos (\theta)^{2} \tan \left(\phi^{\mathrm{b}}\right)
\end{array}
$$

where $E$ Is the rate of change of the topographic surface (erosion rate) $\left(\mathrm{ms}^{-1}\right) ; \tau$ is the shear stress $(\mathrm{Pa}), \tau_{\mathrm{c}}$ is the critical shear stress $(\mathrm{Pa}), \mathrm{S}_{\mathrm{f}}$ is the surface friction term $(-), \tau_{y}$ is the yield stress $(\mathrm{Pa}), K$ is the entrainment coefficient (${ }, c^{b}$ is the cohesion of the bed material $(\mathrm{Pa})$ and $C_{s}$ is the coefficient of suspension (-).

The surface shear term is calculated from the momentum conservation equation as the sum of all surface frictional terms. Lateral entrainment is similarly included within the model. If the numerical scheme provides a contact between flow and a steep side, the same equations by Takahashi are applied to estimate shear force and entrainment.

Iverson and Ouyang (2015) noted that the momentum jump boundary condition, which must hold for to satisfy conservation of momentum, is not met by the expression from Takahashi. We adapt the expressions to conform to the momentum jump boundary condition, as provided by (Equation 6.27).

$$
\frac{\mathrm{dz}}{\mathrm{dt}}=\mathrm{E}=\frac{\tau-\tau_{\mathrm{c}}}{\rho_{\text {eff }} \mathrm{u}_{\mathrm{b}}}
$$

where $\rho_{e f f}$ is the total effective density of the flow $\left(\mathrm{kg} \mathrm{m}^{3}\right), u_{b}$ is the basal velocity $\left(m s^{-1}\right)$.

Iverson and Ouyang (2015) indicate that the equations by Takahashi do not include a distinction between basal and mean velocities and do not conserve momentum. The basal velocity differs from the mean velocity of the flow according to a vertical velocity profile. Our model description does not include an estimate of the basal flow velocity. However, the entrainment coefficient (a constant calibration parameter) can be inversed $K \rightarrow K^{-1}$ (and instead be used as a velocity scaling factor $\left(u_{b} \approx K \bar{u}\right)$, with $\bar{u}$ the depth-averaged velocity of the flow. This doesn't alter any of the possible behaviors of the model, but provides a stronger theoretical foundation for the entrainment rate. This approach was similarly taken by Pudasaini and Fischer (2016). Therefore,

$$
\frac{\mathrm{dz}}{\mathrm{dt}}=\mathrm{E} \approx \frac{\tau-\tau_{\mathrm{c}}}{\rho_{\mathrm{eff}} \mathrm{K} \overline{\mathrm{u}}}
$$

Furthermore, we ignore vertical velocities in the model setup, a both common and necessary assumption that has given good results in other models (Iverson 
and Ouyang, 2015). Finally, we alter the mass and momentum source terms to include the produced mass and momentum from entrainment and thereby hold to conservation of these quantities (Equation 40).

$$
\frac{\mathrm{dv}}{\mathrm{dt}}=\mathrm{E} \cdot(\mathrm{K} \overline{\mathrm{u}})+\cdots
$$

\subsubsection{Implementation}

The equations presented in the previous sections are implemented within the OpenLISEM Hazard model (Bout et al., 2018). The complete closed set of equations and variables is solves as one integrated whole and solves the dynamics of a consistently described terrain. This means, for example, that processes such as slope failure that alter the soil depth thereby alter infiltration and ground water processes. Since the integration of the presented equations within the model is a straightforward matter of consistent terrain description, we do not present the details here.

A flowchart of the full model is given in Figure 6-3. Hydrology forms the basis of the simulated cycle. From this, other sediment and solids-related processes are linked. At each timestep, properties of the flow are determined based on the simulated water and solid content. The numerical scheme within the model is based on the monotonic upstream cell-centered scheme (MUSCL) (Van Leer, 1979). This scheme uses piecewise linear reconstructions of both the terrain surface and the flow properties (for an implementation in flow simulations see Delestre et al., 2014; Bout et al. 2018). This terrain reconstruction estimates local slope, and in rough terrain also includes cell boundary elevation differences. Such terrain reconstruction can be required for stable numerical simulation of flow-entrainment feedback loops that alter elevation dynamically (Pudasaini, 2018). 


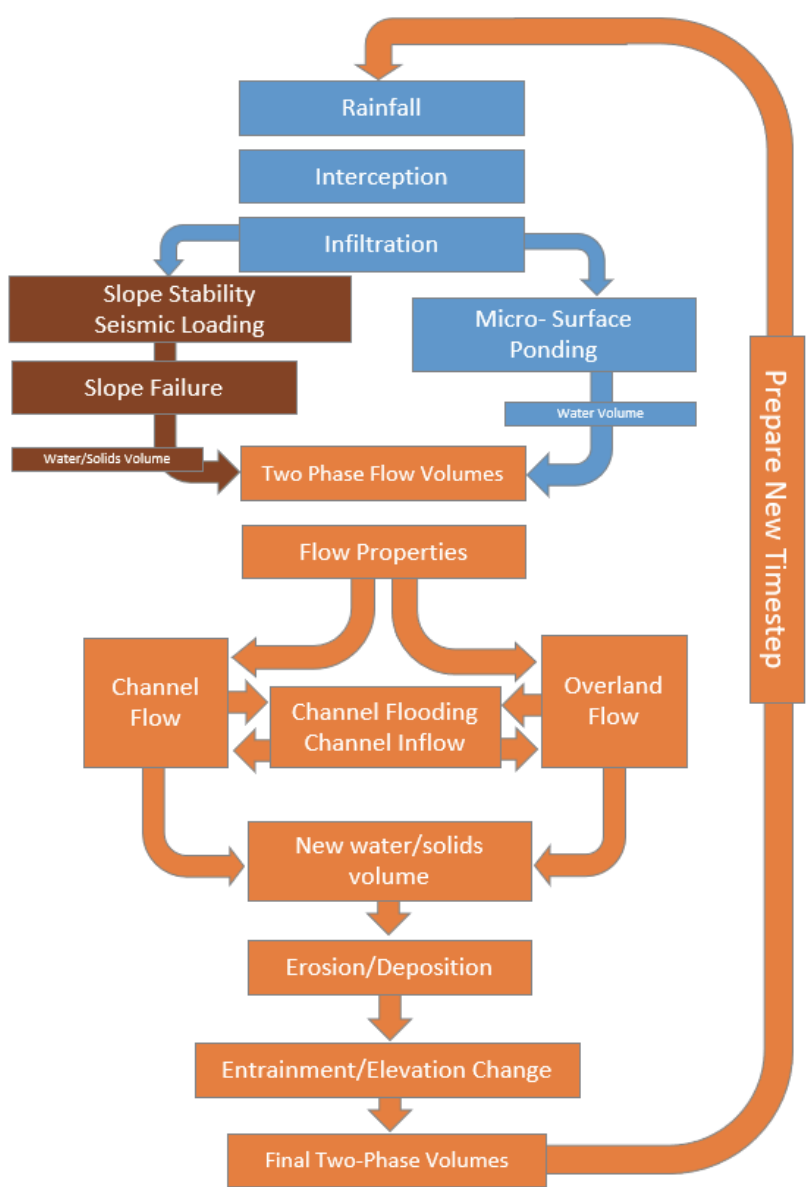

Figure 6-3 A schematic overview of the OpenLISEM Hazard model, including the link with the most relevant input data

\subsection{Study Case}

\subsubsection{Hongchun Catchment}

The integrated OpenLISEM multi-hazard model was applied in the Hongchun watershed, located near Yingxiu town in the epicentral area of the 2008 Wenchuan earthquake, in Sichuan province, China. Selection of this event was done based on the presence of a complex process chain and available data. This watershed has an area of $5.3 \mathrm{~km}^{2}$, and elevation ranges between 900 and 1700 meters. The very steep slopes (>30 degrees) were covered by dense vegetation before the earthquake, in 2008. The steep terrain and sharply incised channels provide few locations for human settlements. The touristic town of Yinxiu is located adjacent to the Min river, opposite and several hundreds of meters downstream of the outlet of Hongchun watershed. The lithology of the area consists mainly of highly fractured granitic rocks, with 
some pyroclastic rocks, limestones and sandstones (Tang et al., 2011). The texture of the weathered material is predominantly clay-loam with large amounts of gravel. The Beichuan thrust fault runs straight through the watershed (Figure 6-4; Mahodja et al., 2016). In 2008, the fault was ruptured in the Wenchuan earthquake ( $M_{w}$ 7.9). After the earthquake, numerous landslides occurred in the area, leaving large volumes of deposits in the streams and channels, and removing the vegetation in $50 \%$ of the area. An overview of co-seismic landslides mapped by Tang et al. (2016) is shown in figure 4. The northern part of the catchment, which is part of the hanging wall, was more impacted than the southern part. The main channel of the Hongchun catchment was predominantly filled by deposits from a central, larger coseismic landslide (Figure 4). According to Tang et al. (2011) these deposits formed a landslide dam within Hongchun Gully that was breached in 2010, as was visible in their photographic evidence. Ouyang et al. (2014) and Horton et al. (2019) do not describe a dam being formed, but provide a modelling approach that considers entrainment of homogeneously spread deposit material. Additionally, elevation model differences obtained by Tang et al. (2019) showed over 20 meter of deposited material caused by landslide L1 (figure 4, figure 10). Xu et al. (2010) stated that 6 different landslide can be indicated to have created blockages. 

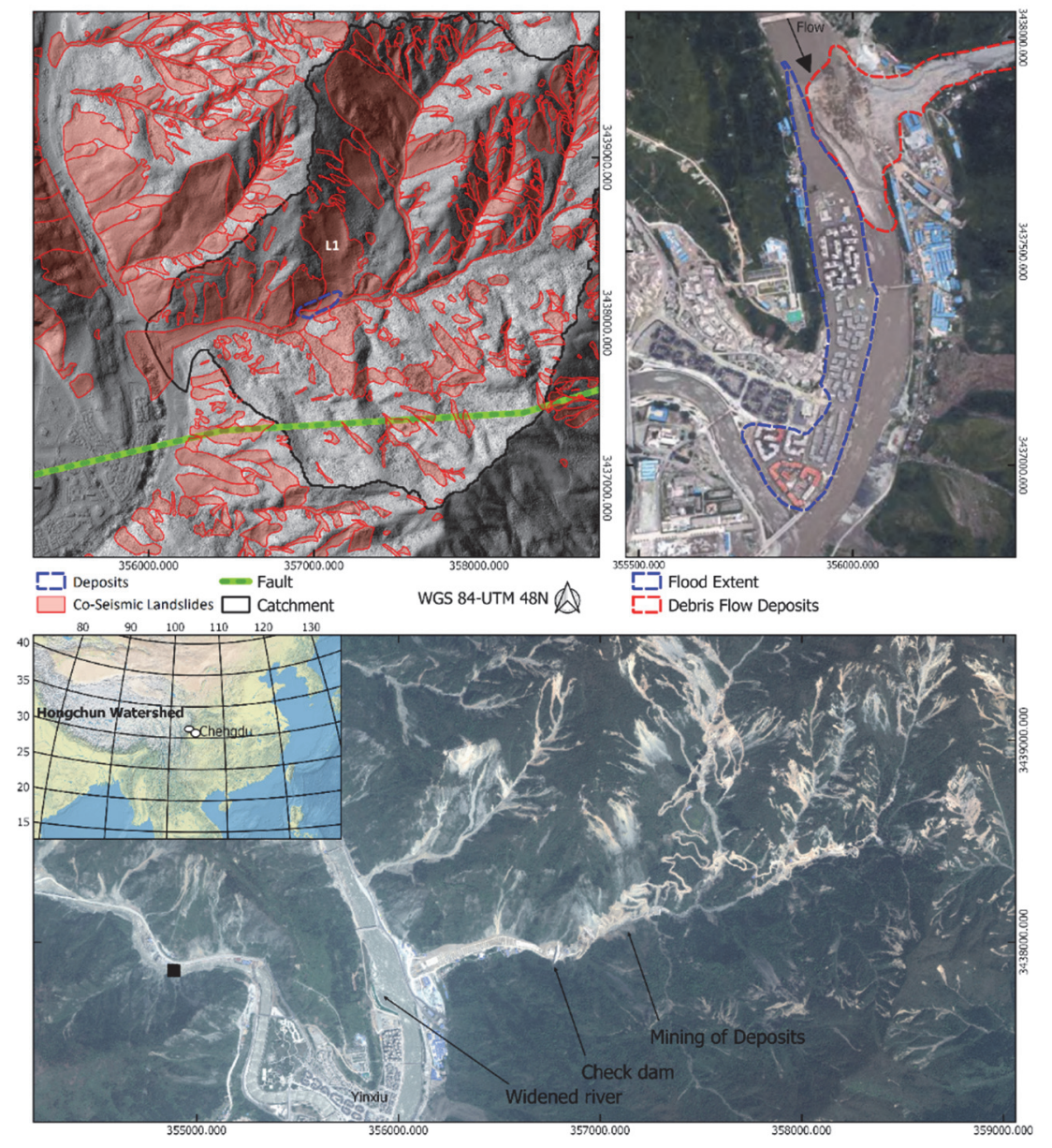

Figure 6-4 An overview of the Hongchun Watershed: (Top) Hillshade Image with coseismic landslide map from Tang et al. (2016) (bottom) Post-Event natural colour composite from Pléiades satellite, showing the situation in 2017. (right) Aerial image of the $2010 \mathrm{deb}$

\subsubsection{The Multi-Hazard Event of 2010}

In 2010, two years after the earthquake, the Hongchun watershed experienced several rainy weeks followed by a high intensity rainfall event. This event consisted of two peaks of several hours of rainfall, with intensities up to 33 millimeters per hour. In total, $220 \mathrm{~mm}$ of rainfall fell in two days. During this event, a debris flow was generated by entrainment of loose landslide deposits, and the landslide dam located in the central channel was breached. The debris flow was initiated by entrainment of deposits in the main three upper branches of Hongchun (Tang et al. (2011); Horton et al., 2019). The debris material breached the blocking deposits downstream, and the volume of the flow increased substantially due to more entrainment downstream. Upon leaving the Hongchun watershed, the debris flow material deposited in the Min River. 
Volume estimations in literature range from an estimated total volume of $7.11 \times$ $10^{5} \mathrm{~m}^{3}$ (Tang et al., 2011) with a thickness of up to 15 meters to $80.5 \times 10^{4} \mathrm{~m}^{3}$ of deposits ( $\mathrm{Li}$ et al., 2013). The Min River, which experienced a high discharge at this moment, was diverted laterally and flooded parts of the nearby newly reconstructed Yinxiu town (Figure 6-4). A schematic overview of the event is provided in figure 5 . The 2010 event was the first reported landslide or debris flow activity within the catchment since the earthquake (Tang et al., 2011; Li et al., 2013).

\subsection{Simulated Process Chain}

The simulated process chain follows the general description of the events by Tang et al. (2011) and Li et al. (2013). The 2008 earthquake induces coseismic landslides that deposit large volumes of material within the Hongchun watershed, some of which blocks the channel. We will consider only the blockage from landslide L1, as here, data was available for pre-and postdeposition elevation differences, and it was indicates as the largest blockage with depths at least over 15 meters (Tang et al., 2011; Tang et al., 2019). Similarly, we follow Tang et al. (2011) since their method of estimation is provided, and their estimate included debris flow deposits within the gully. We make a similar choice concerning the geometry of the deposits, which varies between Tang et al. (2011), Ouyang et al. (2015), Horton et al. (2019) and Xu et al. (2019). Two years later, in august, 2010, heavy rainfall lead to upstream initiation of debris flows by entrainment in multiple branches. These breached the blocking and entrained a channel over more than 10 meters depth. The final material deposited in the Min river, blocking flow and diverting the river to a newly constructed part of Yinxiu.

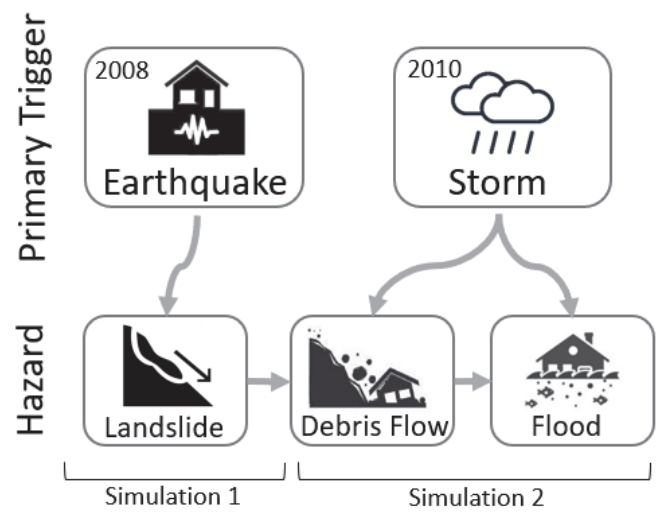

Figure 6-5 A schematic overview of the stages of the described event. The events for simulation 1 occurred directly after the Earthquake in 2008. The events for simulation 2 after the rainfall event in 2010 .

In summary, the study area experienced two different multi-hazard chains that will be simulated.

- Co-seismic chain: The first one was experienced during the earthquake, when ground shaking and topographic amplification triggered a series of co-seismic landslides, some of which blocked the Hongchun stream; 
- Post-earthquake chain: heavy rainfall triggered debris flows due to entrainment, which broke the co-seismic landslide dam. The resulting debris flow dammed the Min river, which was diverted into the town of Yingxiu.

All simulations include entrainment of available soil material, hydrology and the related surface processes as described in the theory section.

\subsubsection{Model Input and Parameters}

The input data are based on a combination of laboratory or field measurements and drone or satellite-based spatial data products (Table 6-1).

Table 6-1 List of input data and sources for the multi-stage multi-hazard modelling with OpenLISEM Hazard.

\begin{tabular}{|c|c|c|c|}
\hline \multicolumn{4}{|c|}{ Spatial input parameters } \\
\hline Base Map & Parameter & \multicolumn{2}{|c|}{ Source } \\
\hline \multirow[t]{2}{*}{ Elevation } & Pre-Earthquake DTM ( $z$ ) & \multicolumn{2}{|c|}{$\begin{array}{l}20 \mathrm{~m} \text { resolution elevation } \\
\text { interpolated contourlines. }\end{array}$} \\
\hline & Post-Earthquake DTM (z) & \multicolumn{2}{|c|}{$\begin{array}{l}\text { Drone photogrammetry } 2 \mathrm{~m} \text { resolution surface } \\
\text { elevation (filtered to DTM using PIX4D vegetation } \\
\text { filter). Manufactor reported accuracy of } 0.17 \\
\text { meter. }\end{array}$} \\
\hline \multirow[t]{5}{*}{ Land Surface } & Land cover classes & \multicolumn{2}{|c|}{$\begin{array}{l}\text { Sentinel-2 classification at } 10 \mathrm{~m} \text { resolution } \\
\text { (trained spectral angle mapper) }\end{array}$} \\
\hline & Mannings $\mathrm{N}(n)$ & \multicolumn{2}{|c|}{ Literature comparison with field photos } \\
\hline & NDVI & \multicolumn{2}{|c|}{$\begin{array}{l}\text { Landsat- } 8 \text { images at } 30 \mathrm{~m} \text { resultion }(2008) \\
\text { SPOT- } 4 \text { product at } 4 \mathrm{~m} \text { resolution }(2010)\end{array}$} \\
\hline & Vegetation Cover & \multicolumn{2}{|c|}{$\begin{array}{l}\text { Estimated from NDVI using empirical method } \\
\text { (Kalacska et al., 2004; Jiang et al., 2006) }\end{array}$} \\
\hline & Root Cohesion $\left(c_{r}\right)$ & \multicolumn{2}{|c|}{$\begin{array}{l}\text { Measured in field ( } 12 \text { samples) and extended } \\
\text { based on land cover classes. }\end{array}$} \\
\hline Soil & Texture $\left(d_{50}\right)$ & \multicolumn{2}{|c|}{ Measured from field samples (4 samples) } \\
\hline & Saturated Conductivity $\left(k_{\text {sat }}\right)$ & \multicolumn{2}{|c|}{ Measured from field samples (4 samples) } \\
\hline & Internal Friction Angle $(\phi)$ & \multicolumn{2}{|c|}{$\begin{array}{l}\text { Measured from field samples (16 samples) } \\
\text { Literature values }\end{array}$} \\
\hline & Cohesion $(c)$ & \multicolumn{2}{|c|}{ Measured from field samples (16 samples) } \\
\hline & Porosity $\left(\theta_{s}\right)$, Matric Suction $(\psi)$ & \multicolumn{2}{|c|}{$\begin{array}{l}\text { Literature Values derived from texture (Saxton et } \\
\text { al., 2006) }\end{array}$} \\
\hline & Density $(\rho)$ & \multicolumn{2}{|c|}{ Measured from field samples (16 samples) } \\
\hline & Initial Moisture $\left(\theta_{i}\right)$ & \multicolumn{2}{|c|}{$\begin{array}{l}\text { Ground water model run for three months using } \\
\text { GPM } 30 \text { minute interval satellite rainfall } \\
\text { estimates. }\end{array}$} \\
\hline & Soil Depth $\left(h_{s}\right)$ & \multicolumn{2}{|c|}{$\begin{array}{l}\text { Soil depth modelling calibrated using landslide } \\
\text { scarp depth (method from Ruette et al., 2013) }\end{array}$} \\
\hline Shakemap & Peak Ground Acceleration $\left(\theta_{s}\right)$ & USGS shakemap (Wald & I., 2005) \\
\hline Rainfall & Rainfall Intensities $(R)$ & $\begin{array}{l}\text { Rainfall station within } \\
\text { accuracy hourly data } \\
\text { minute interval global } \\
\text { for pre-event ground } w\end{array}$ & $\begin{array}{l}\text { axiu provided high- } \\
\text { dditionally GPM } 30- \\
\text { all product was used } \\
\text { modelling. }\end{array}$ \\
\hline Inventory & Landslide locations & $\begin{array}{l}\text { Mapped from high-resc } \\
\text { al., 2017) }\end{array}$ & on imagery (Tang et \\
\hline $\begin{array}{l}\text { Boundary } \\
\text { Condition }\end{array}$ & Min river Discharge (m3/s) & Estimate from literature & ng et al., 2011) \\
\hline $\begin{array}{l}\text { Global } \\
\text { (besides mult }\end{array}$ & 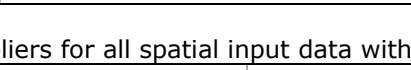 & & parameters \\
\hline & \begin{tabular}{l|l}
$\alpha$ & $\beta$ \\
\end{tabular} & \begin{tabular}{l|l}
$K$ & \\
\end{tabular} & $C_{V}$ \\
\hline & 10 & 0.05 & 0.65 \\
\hline
\end{tabular}


A pre-earthquake digital terrain model with 20 meters spatial resolution was obtained from the local government. Unfortunately, we were not able to obtain better quality pre-earthquake elevation data. Post-earthquake surface elevation data were available at 2-meters spatial resolution, acquired from fixed-wing drone flights (See Figure 6) and filtered using the Pix4D DTM filter to remove vegetation (Pix4D, 2017). This filtering process introduces severe uncertainties into the data (Tang et al., 2019), but is required for effective simulation of flow processes. Flow simulations typically are most dependent on the accuracy and spatial resolution of the elevation model. In order to have an effective compromise between detail and computation time, we resampled all base input to maps of 10 meters resolution.

Pre-earthquake NDVI values were calculated at 30 meter resolution Landsat-8 images from 2008. A post-earthquake NDVI map was obtained from 4 meter spatial resolution SPOT-images acquired in 2009. NDVI values were used to estimate Leaf Area Index (LAI) by applying an empirical relation obtained from tropical forest data (Kalacska et al., 2004). We used it to estimate fractional vegetation cover using a similar empirical relationship (Jiang et al., 2006).

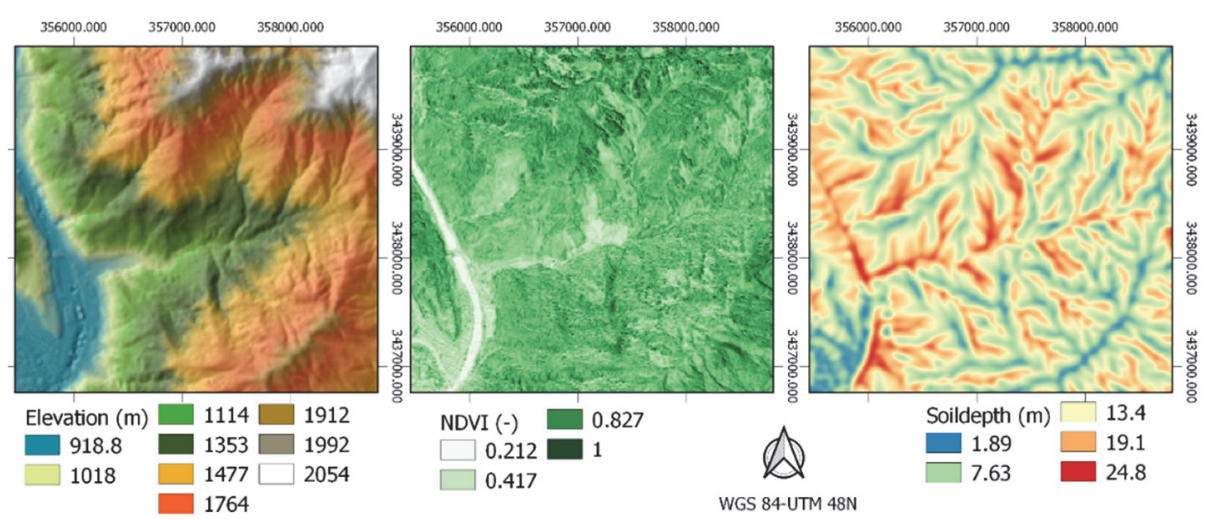

Figure 6-6 An overview of the input data for the Hongchun catchment: elevation mode (left), NDVI (middle), modelled soil depth (right).

Spatial seismic acceleration data were obtained from the USGS ShakeMap product (Wald et al., 2005), developed using combinations of measurements and intensity prediction equations. Peak Ground Acceleration (PGA) values were around $1.5 \mathrm{~g}$ for this earthquake in the Hongchun area. Landslide material strength parameters were obtained from tri-axial strength tests performed for engineering reports ordered by the local government (Table 6-2; Yang, 2010; Hao et al., 2011; Li et al., 2011). The consolidated-drained triaxial tests were performed on samples acquired from both the deposition and source areas, although exact locations are unknown. The resulting average values for cohesion of $7.3 \mathrm{kPa}$ and internal friction angle of 27 degrees were calculated from 16 samples. Because of the small size of the catchment, and the similarity of the debris material, we follow other authors in assuming an approximately homogeneous distribution of these parameters within the watershed (Ouyang et al., 2015; Domenech et al., 2019). While the cohesion and density matches the values found in other studies (Ouyang et al., 2015; Domenech et al., 2019), the internal friction angle was estimated to be between 30 and 40 
degrees in a previous study (Ouyang et al., 2015), based on measurements of internal friction angle on similar igneous rocks in the nearby Xiaojigou ravine. The difference between these values can be explained by the material used in the tri-axial tests. In our case, material from landslide depositions from deposition areas or source areas was used. These samples from deposits contain more fractured and loosened material since they have been fractured during the movement of the landslide. Thus, these measurements will provide a more appropriate value in post-earthquake entrainment simulations. However, for pre-earthquake slope stability estimations, a value of 35 degrees was used, as was done in other studies (Ouyang et al., 2015; Domenech et al., 2019). Textures were found to be clay-loam with large amounts of gravel. Saturated infiltration rates were measured in the field by using field ring infiltration tests. Because of the large amounts of gravel, and macro-pores within the materials structure, infiltration values were relatively high. Values were obtained for a total of four locations, which gave an average value of 65 $\mathrm{mm} / \mathrm{h}$ for saturated conductivity. Other soil related parameters such as porosity, density and matric suction were obtained using the pedotransfer functions from Saxton et al. (2006).

Table 6-2 Strength parameters for the debris flow material in the Hongchun catchment (Yang, 2010; Hao et al., 2011; Li et al., 2011) and saturated hydraulic conductivity. Average values are used in the simulations because of the spatial similarity of the lithology and soils.

\begin{tabular}{|c|c|}
\hline \multicolumn{2}{|r|}{ Average (16 samples) } \\
\hline Cohesion (kPa) & $7.3+/-2.3$ \\
\hline $\begin{array}{l}\text { Internal Friction angle } \\
\text { (Degrees) }\end{array}$ & $27.0+/-1.8$ \\
\hline \multicolumn{2}{|r|}{ Average (16 samples) } \\
\hline Density $(\mathrm{kg} / \mathrm{m} 3)$ & $2145+/-84$ \\
\hline Median Grain Size $(\mathrm{mm})$ & $3.1+/-0.21$ \\
\hline \multicolumn{2}{|r|}{ Average (4 samples) } \\
\hline $\begin{array}{l}\text { Saturated } \quad \text { Hydraulic } \\
\text { Conductivity }(\mathrm{mm} / \mathrm{h})\end{array}$ & $65 \mathrm{~mm} / \mathrm{h}+/-14.8$ \\
\hline
\end{tabular}

During the simulation, the Min river will have an initial discharge based on literature values from Tang et al. (2011). This flow will simulated using the full modelling setup and include drag and other forces. Soil depth values were obtained by applying the spatial soil depth model from Von Ruette et al. (2013), which uses steady-state assumptions to balance material production with soil movement according to an empirical formulation of erosion and lateral transport. The production of weathered material depends on the weathering rate of bedrock. Since weathering rates are generally difficult to obtain, this parameter becomes the main optimization parameter. Additionally, a global soil depth multiplier and soil movement rate parameter are optimized. Validation was done using soil depth values obtained from landslide scarps at 246 locations. For each landslide, several locations were picked along the scarp. In this study, we used the pre-and post- earthquake elevation model differences provided by Tang et al. (2019). From their data, we sampled elevation model differences in landslide source areas to obtain failure depths, assuming that the failures were at least as deep as the top layer of weathered material. In case of shallow landslides, we took the maximum landslide depth 
as soil depth. For the larger, deep-seated landslides, no samples were taken since it was not possible to obtain a good estimate of the depth of the top layer. Additionally, we simulated a second layer within the slope stability calculations with an additional depth of 20 meters. We assumed that this second layer did not contain groundwater, had an internal friction angle of 35 degrees, was subject to sub-surface lateral forcing, and influenced by the weight of the upper layer. Calibration results and cumulative distributions of depth values are shown in Figure 6-7.
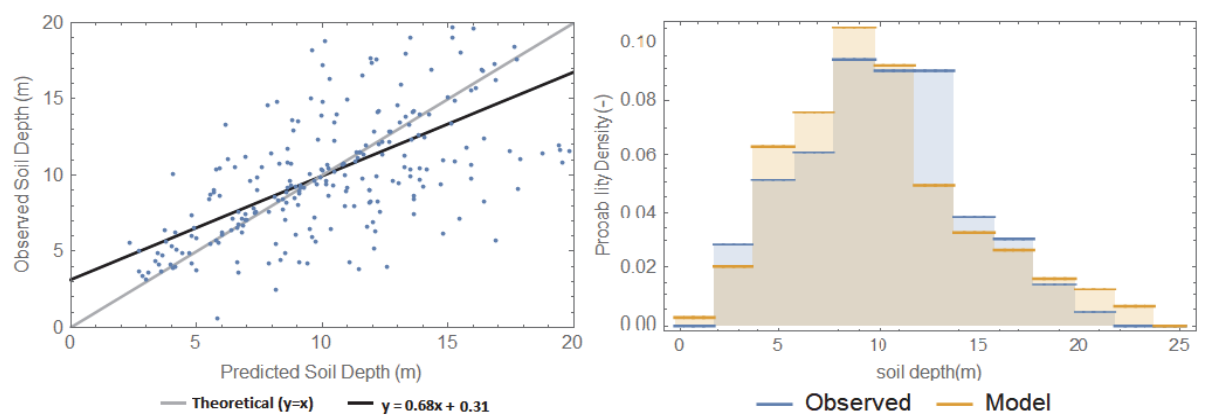

Figure 6-7 Soil depth simulation results. (Left) A comparison of predicted vs observed values. (Right) Probability distribution for observed and simulated soil depth values. This includes only values at the sample locations $(n=246)$.

The effect of vegetation on slope stability and entrainment rates were taken into account by adding root cohesion. We estimated the average root cohesion for the various vegetation classes using a combination of literature data and measurements (Schmidt et al., 2001; de Baets et al., 2008; Chock et al., 2015). We used the method as described by de Baets et al. (2008) which requires measuring root critical force and root diameters for all significant roots within a specific surface area. Then, after converting force to tensile strength, the total effect of the roots per unit area can be estimated using equation 40 . 40

$$
c_{\text {root }}=\frac{\sum T_{i} n_{i} a_{i}}{A}(\sin (\theta)+\cos (\theta) \tan (\phi))
$$

where $c_{\text {root }}$ is the added apparent root cohesive strength $(\mathrm{kPa}), i$ is the root diameter class, $T_{i}$ is the root tensile strength $(\mathrm{kPa}), n_{i}$ number of roots within the diameter class, $a_{i}$ is the cross-sectional area of the root, $A$ is the area of the soil occupied by roots ( $\mathrm{m} 2), \theta$ is the angle of shear distortion in the shear zone $\left(^{\circ}\right)$ and $\phi$ is the internal friction angle $\left(^{\circ}\right)$. Note that term that estimates the effective force contribution $(\sin (\theta)+\cos (\theta) \tan (\phi))$ is usually assumed to be approximately 1.2 (Baets et al.,2008). Here, we used a spatial calculation of this variable.

A total of 12 measurements of root cohesion averaged over a $0.1 \mathrm{~m}^{2}$ area were done. This was possible due to the small vegetation had regrown on the deposits and initiation locations of landslides, as is typical in this area (Huang et al., 2015). On average, 108 roots were found per test site of $0.1 \mathrm{~m}^{2}$, with an average diameter of $3.6 \mathrm{~mm}$. Average values for young, post-landslide vegetation where found to be $4.8 \mathrm{kPa}$, averages for medium-sized vegetation where found to be $6.2 \mathrm{kPa}$. For mixed forest, literature values were used, and root cohesion was estimated to have a value of $8 \mathrm{kPa}$ (Chock et al., 2015; Huang et al., 2015). The estimated cohesion values were combined with the 
land cover map in order to predict root cohesion spatially. Finally, within each land cover class, we linearly scaled the root cohesion to fractional vegetation cover values that were derived from the NDVI both before and after the earthquake.

\subsubsection{Calibration and Validation}

The predicted co-seismic failure areas were calibrated using the landslide inventory and mapped deposition based on aerial imagery and pre-and postevent elevation data differences obtained from Tang et al. (2019). The used data is a comparison of a 2008 Lidar and 1999 Lidar elevation model. In their work, standard deviation from ground control points was 2.8 and 4.8 meters respectively. While accuracy considerations data accuracy and georeferencing make direct elevation model comparison from different sources complex, we refer to the work of Tang et al. (2019) for a discussion on the novel methods applied and the resulting quality and possible usage in this area. Within the inventory, no separation between source and deposit areas was provided. Therefore we assumed that, based on field visits, on average the $25 \%$ highest part of each landslide polygon represented the source area from where the landslide initiated.

In order to validate the outputs of our adapted slope failure model, a comparison with other methods is performed. The Newmark displacement method (Newmark, 1965) was not used in our comparison. The primary reasons were the lack of predicted failure depths and the high similarity to the infinite slope model. Infinite slope types of models are not used because of their similarity to the presented method. Random ellipsoid/spheroid sampling is best suited for comparison due to its theoretical accuracy (Reid et al., 2015). Two models that are capable of regional application are finally compared.

The first of these is Scoops3D, which uses random spheroid sampling to find the landslides with the lowest- failure volumes, and lowest factors of safety for each pixel (Reid et al., 2015). This model can also use seismic shake maps as input. Scoops $3 d$ uses a regularized $3 d$ grid within the model space to sample a large number of spheroid shapes from the terrain. For each of these shapes, the FoS is calculated. This model is set to use the ordinary method of slices in its calculations. The final output consists of a map indicating the locations of failures, and a new elevation model from which all failures are removed. Calibration is done by altering soil depth, internal friction angle and soil cohesion. The second model is r.slope.stability, which uses random ellipsoid sampling to find the lowest factor of safety and failure depth for each pixel (Mergili et al., 2014). R.slope.stability does not use a regularized 3d grid, but instead determines sample ellipsoids from the terrain, varying the height above the terrain, and size and rotation of the ellipsoids. This model builds on the work by (Xie et al., 2012) to estimate the FoS of a sampled ellipsoid. This model cannot incorporate seismic acceleration, so output is calibrated without addition of a seismic forcing. Calibration is done by altering soil depth, internal friction angle and soil cohesion. For both Scoops3D and r.slope.stability, the subsurface description is identical as to the input for OpenLISEM Hazard. As a measure of model fit, we used the Cohens Kappa value. This metric shows benefit over simple accuracy, especially for modelling landslide occurrence (Bout et al., 2018). 
The second phase of the modelling first simulates hydrology and a debris flow initiated by entrainment. Then, within the same simulation, the Min River is blocked by debris flow material, and Yinxiu town is flooded. Calibration for this part of the modelling is based on mapped deposition extent in the Min River, the flood extent in Yinxiu Town, and the estimated depositional volume (approximately $7.11 \times 10^{5} \mathrm{~m}^{3}$ ).

Calibration of the entrainment and debris flow runout was based on the final spatial deposit extent at the catchment outlet. The calibration parameters for each part of the simulation are shown in Table 6-3. For each parameter, deviation from initial values was limited to 50 and 200 percent of the original estimated value. An exception to this was the entrainment constant, for which no clear guideline was known to determine the value for specific terrain types. Based on earlier simulations and flume tests from Takahashi et al. (1992), a starting value was chosen of 0.05 . For initial soil moisture content, the value is cut off at full saturation. Initially, each parameter was varied by choosing values between 60 and 140 percent of the original value. After initial calibration was done, the parameters were adjusted according to the steepest descent principle, in order to find the best set of parameter values. To have a level of validation in the simulations, the parameters resulting from calibration of the first chain were used as input for the second chain.

Table 6-3 Calibration parameters, their initial values and their final calibrated values for both chains. 1Input multipliers are a calibration parameter that multiplies an entire input map (soil depth, cohesion or other) by this factor.

\begin{tabular}{|c|c|c|c|}
\hline Co-Seismic Slope Failure & Soil Depth & $\begin{array}{ll}\text { Internal } & \text { Friction } \\
\text { Angle } & \\
\end{array}$ & Soil Cohesion \\
\hline Original Average & 4.5 & 27 & 7.3 \\
\hline Calibrated Input Multiplier ${ }^{1}$ & 1.3 & 0.91 & 1.2 \\
\hline Hydrology, Flow and Entrainment & $\begin{array}{l}\text { Entrainment } \\
\text { Constant }\end{array}$ & $\begin{array}{l}\text { Initial Soil Moisture } \\
\text { Content }\end{array}$ & Manning's N \\
\hline Original Average & 0.005 & $80 \%$ & 0.127 \\
\hline Calibrated Input Multiplier & 0.6 & 1.12 & 0.82 \\
\hline
\end{tabular}

\subsection{Results}

\subsubsection{Simulation of the First Multi-hazard Chain}

Simulation results for the first chain, co-seismic slope failure and runout, are shown in Figure 6-8. Both the accuracies and Cohens Kappa values for each of the used slope stability models are shown in Table 6-4. 

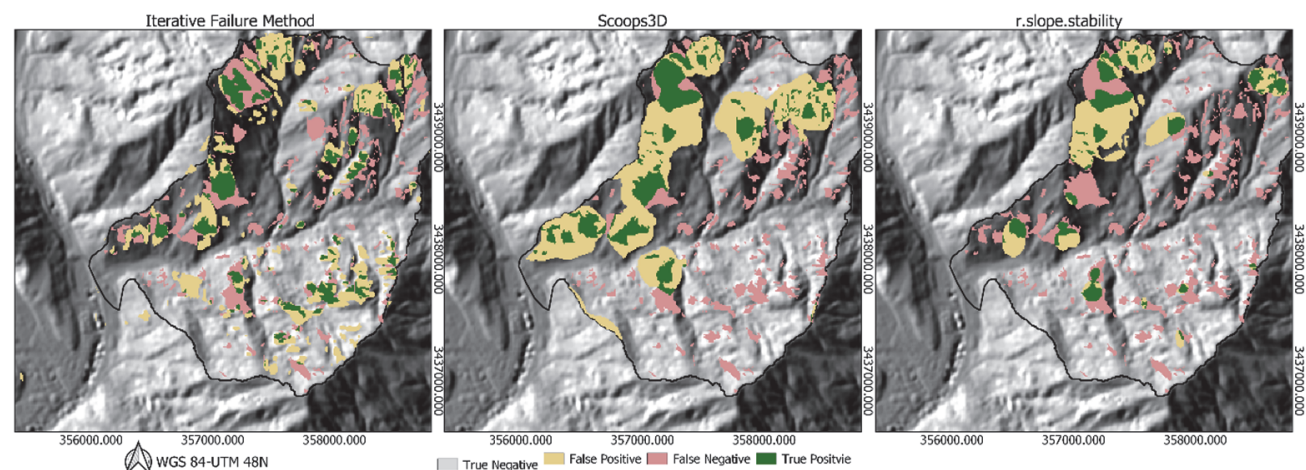

Figure 6-8 A comparison of simulated slope failure extent with mapped co-seismic slope failures. (Left) OpenLISEM Hazard Iterative Failure Method with sub-surface forcing, (Middle) Scoops3D random spheroid sampling. (Right) r.slope.stability random ellipsoid sampling.

Table 6-4 Slope stability simulation accuracy and Cohens Kappa values.

\begin{tabular}{lllll}
\hline Model & $\begin{array}{l}\text { Iterative Failure } \\
\text { Method }\end{array}$ & Scoops3D & r.slope.stability & Mapped \\
\hline True Negative $\left(\mathrm{m}^{2}\right)$ & 3775700 & 3420700 & 3971800 & 4258397 \\
False Positive $\left(\mathrm{m}^{2}\right)$ & 530100 & 476100 & 627800 & 0 \\
False Negative $\left(\mathrm{m}^{2}\right)$ & 587300 & 939300 & 391200 & 0 \\
True Positive $\left(\mathrm{m}^{2}\right)$ & 315400 & 369400 & 217700 & 950103 \\
Accuracy $(\%)$ & 79 & 72 & 81 & 100 \\
Cohens Kappa & 0.232 & 0.181 & 0.190 & 1 \\
Number & 152 & 11 & 20 & 214 \\
Average Size $\left(\mathrm{m}^{2}\right)$ & 36394 & 140253 & 94028 & 21547 \\
Max & 92200 & 628600 & 239400 & 131100 \\
St. Dev. & 14500.3 & 234500.9 & 60800.7 & 12500.5 \\
\hline
\end{tabular}

The general spatial patterns are predicted with mediocre accuracy by all models, but the models differ considerably in details. For the ellipsoid and spheroid sampling done by r.slope.stability and Scoops3D, the failures are larger than those actually mapped (Table 4). For the iterative method, sizes are mixed but much more similar. Major landslides, in particular in the north, are predicted with similar size, although not on the exact location, by all models. The highest accuracy $(81 \%)$ is obtained using r.slope.stability, and the highest Cohens Kappa (0.232) value with OpenLISEM Hazard. The OpenLISEM Hazard iterative method shows the best reproduction of the general pattern, in particular since both Scoops3D and r.slope.stability lack slope failures in the southern half of the catchment. Of the three models, r.slope.stabiltiy and OpenLISEM Hazard show similarity in total failure area when compared to the inventory. However, the results are not accurate enough for any reliable uncalibrated simulations of potential events. The primary challenges faced by the Scoopd3D and r.slope.stability is their focus on larger rotational failures. While these are better predicted by these models, they lack smaller translational failures which were present in the Hongchun watershed and better match the assumptions of the Iterative Failure Method. 


\subsubsection{Runout and the Blocking of the Hongchun Stream}

When slope failures are simulated, OpenLISEM Hazard automatically introduces landslide runout by transferring the failed volume and its properties to the Mohr-Coulomb solid-fluid mixture flow equations. The depth of slope failures determine directly the amount of solids and fluids introduced (Figure 6-9). The landslide material moved down the slopes into the main channel of the Hongchun watershed, blocking it in at least one location (Figure 6-9). The accuracy for the calibrated simulation was 64 percent with a Cohens Kappa value of 0.28 (Table 6-5), which is good, given the lower accuracy of the failures that started this process (Figure 6-9). Runout distances are similar to those mapped, indicated by the landslides reaching the main channels within the Hongchun catchment, but not reaching the Min river. In one location the channel was blocked by a deposit of 12 to 18 meter deep which was simulated with high accuracy as compared to the mapped blockage (Figure 9B). Engineering reports indicate a similar depth (16 meter) for the landslide dam (Yang et al., 2010; Hao et al., 2011; Li et al., 2011). We considered to use the landslide initiation polygons from the inventory to increase the accuracy of the runout simulation. However, since the aim of this research is to provide a true multi-stage modelling setup, we used the integrated prediction of slope failures as input in the runout modelling. 

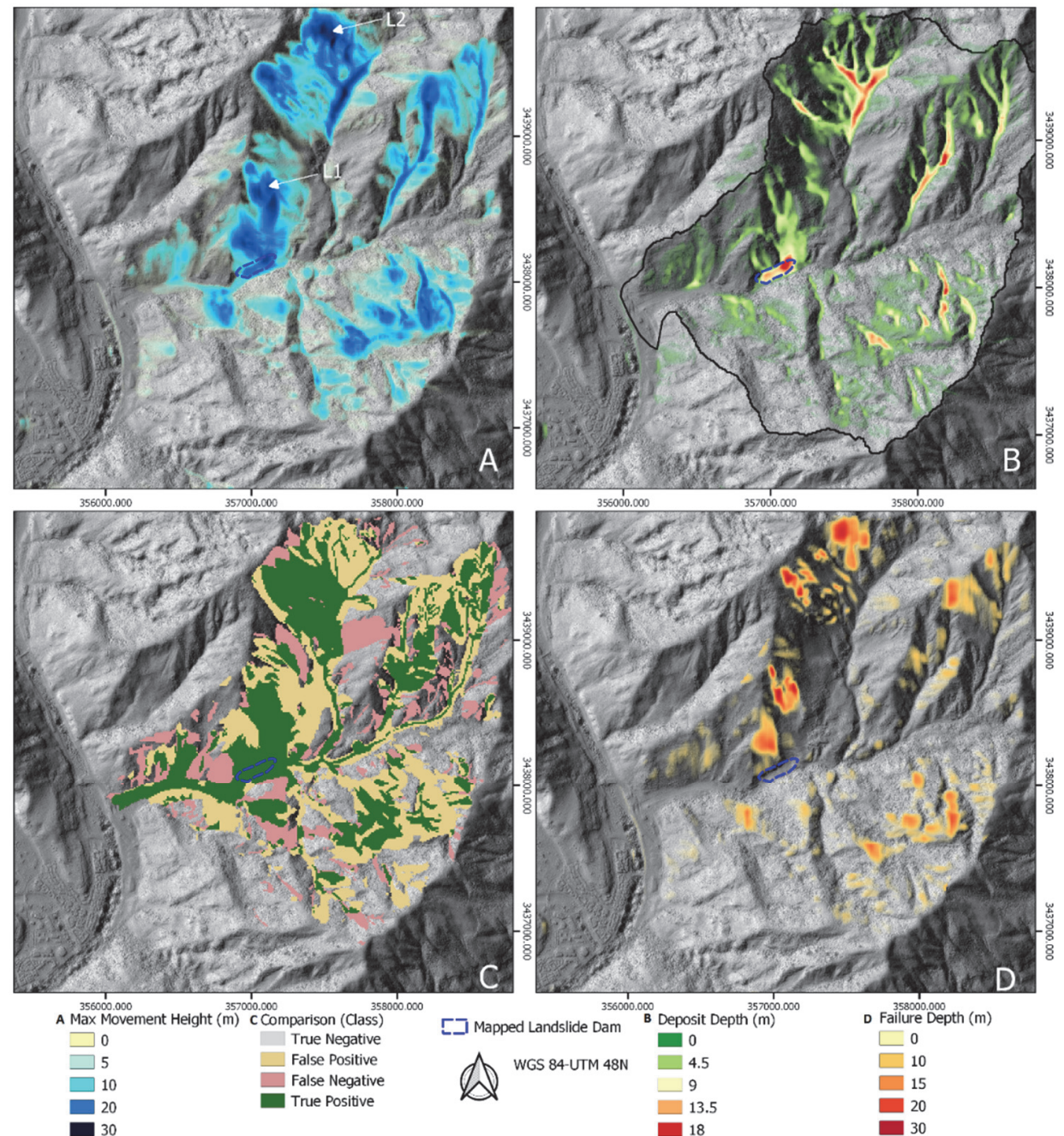

D Failure Depth (m)

$\square 30$

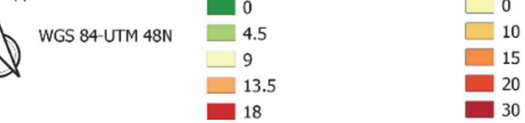

Figure 6-9 (A) Maximum landslide runout flow depth. (B) The simulated final deposit depth of the landslides. (C) A comparison of modelled landslide runout with the mapped landslide inventory. (D) Initiation depth from the slope failure simulation.

Table 6-5 Confusion matrix for the landslide runout prediction in Hongchun watershed.

\begin{tabular}{ll}
\hline Model & Runout $\left(\mathrm{m}^{2}\right)$ \\
\hline True Negative & 2092900 \\
False Positive & 1260500 \\
False Negative & 613900 \\
True Positive & 1241200 \\
Accuracy & 64 \\
Cohens Kappa & 0.28 \\
\hline
\end{tabular}




\subsubsection{Validation of Failure and Runout for the Major Central Landslide Using Elevation Model Differences}

Two large landslides ( $L 1$ and L2 in Figure 6-9) occurred in the northern part of Hongchun catchment. One of those, near the center of the area, blocked the main channel of the catchment. For this landslide, pre- and post-earthquake elevation models from LiDAR data are available (Tang et al., 2019), which were used to calculate the landslide volume. For this particular area, we compared the predicted elevation model differences based on slope failure and deposition from our modelling chain with the results from the LIDAR DEMs (Figure 6-10).
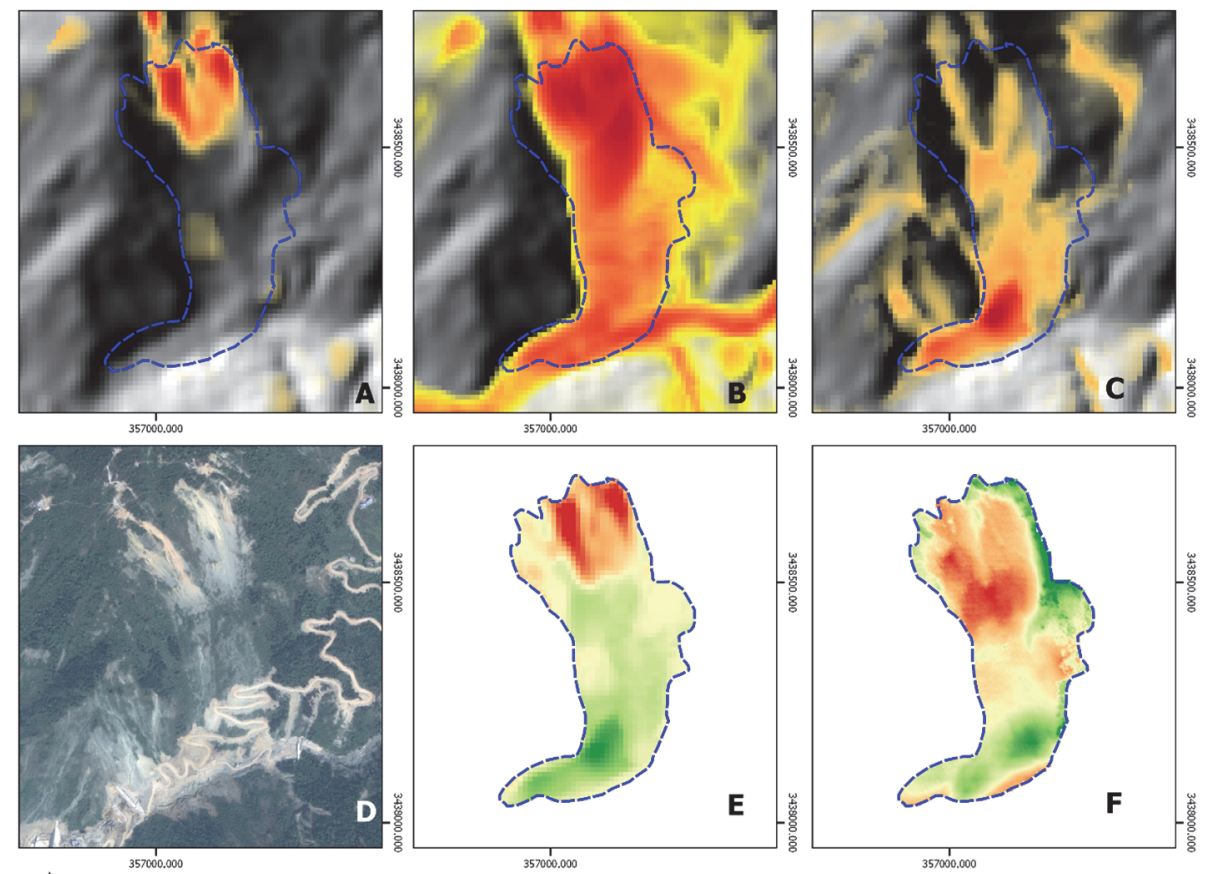

$$
\begin{aligned}
& \text { W WGS 84-UTM 48N E-I Mapped Landslide Depth (m) Elevation Difference (m) } \\
& \begin{array}{ccc}
\square & -20 \\
10 & -10 \\
15 & \square \\
15 & 0 \\
20 & 10 \\
30 & 20
\end{array}
\end{aligned}
$$

Figure 6-10 An overview of the central largest landslide in the Hongchun watershed. (A) The simulated failure depth, (B) The simulated maximum runout depth, (C) The simulated deposition depth, (D) Post-Earthquake satellite image (Worldview, 2011) Note the mining activities in the landslide deposit area $(E)$ Predicted elevation model differences due to co-seismic landslides. (F) Observed elevation model differences from pre-and post-earthquake LiDAR data.

Both the slope failure and runout thicknesses are predicted with high accuracy for this landslide. The comparison of the failure and deposit area of this landslide with the mapped landslide gives percentage accuracy of $91 \%$ and Cohens Kappa of 0.84 . The landslide deposits of around 20 meters thickness remained in the main channel without spreading significantly. These deposits have later been mined as materials for local construction. As can be seen in 
Figure 14 the failure, deposition and elevation differences are highly similar with matching spatial patterns.

\subsubsection{Simulation of the Second Multi-hazard Chain}

The results from the modelling of the second stage show a full physically-based simulation that reproduces the behavior and the impact of the event (Figure $6-11$ ). This rainfall event with two distinct peaks resulted in a rainfall amount of $220 \mathrm{~mm}$ in two days, which was modelled in time steps of 0.5 seconds. Due to the large rainfall volume, runoff increased rapidly leading to large amounts of sediments that were entrained from the co-seismic landslide deposits. Within the simulation, entrainment takes place after runoff has converged and flow height is increased. There, higher water pressures and velocities provide shear stress on the surface that is sufficient to overcome the materials internal stability. Near the outlet of the watershed, entrainment decreased due to a decrease in slope steepness. This decreased flow velocities, but also increased internal stability of the available material. Because of this, entrainment stopped, the flowing material lost momentum and was finally deposited partly in the main gully and in the Min River (Figure 6-11). 

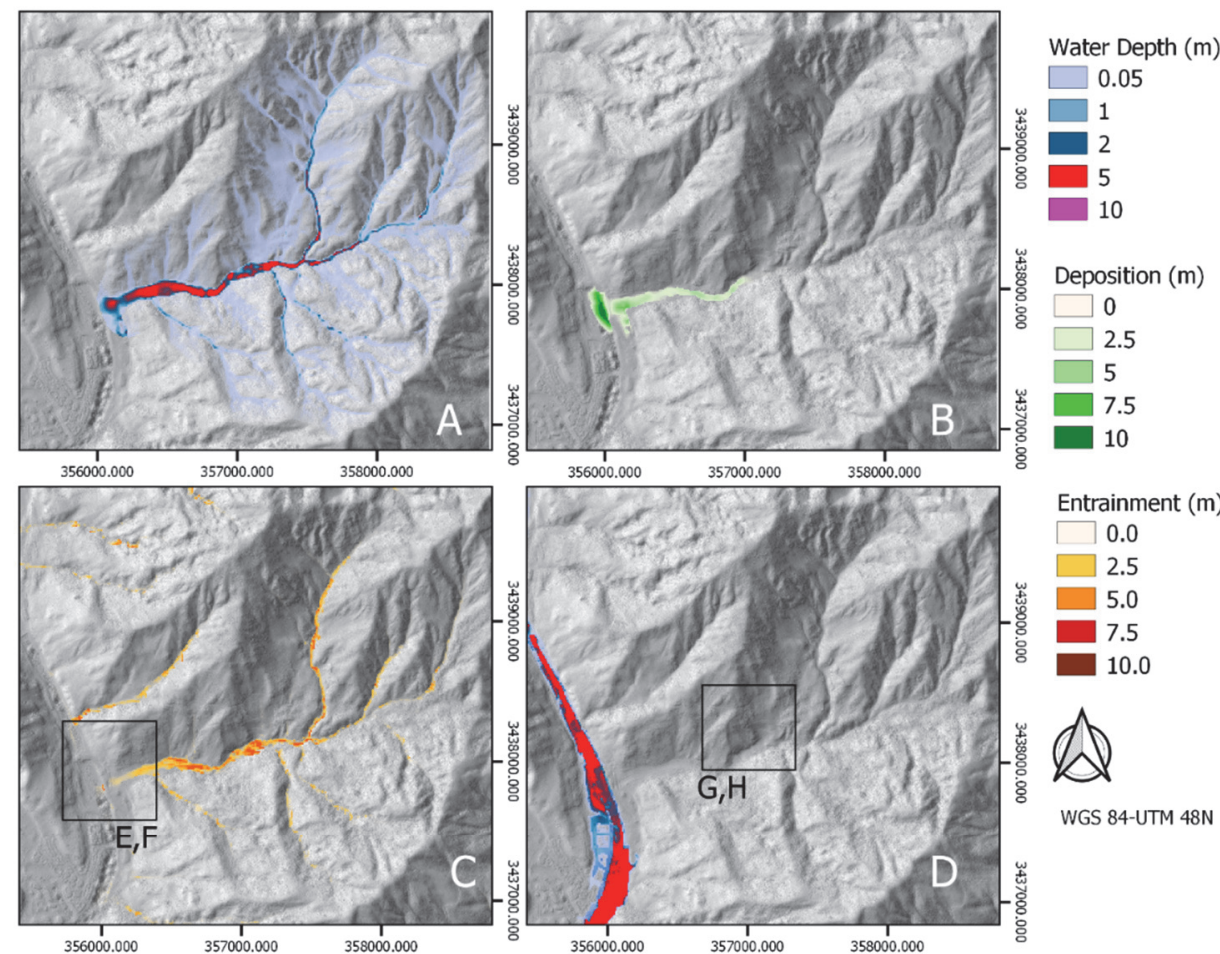

Entrainment $(\mathrm{m})$
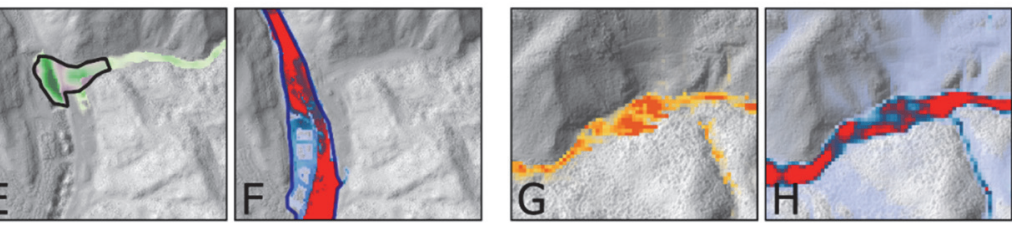

Mapped Deposits

Mapped Flood Extent

Figure 6-11 Calibrated simulation results for the second chain in the Hongchun watershed. (A) Maximum total flow depth; (B) Final deposit depth; (C) Entrainment depth; (D) River flood depth; ( E \& F): Zoom of Hongchun outlet with (E): Deposition depth compared with mapped extent, $(F)$ River flood depth compared to mapped flood extent; (G \&H) Zoom of Hongchun Landslide Dam with (G) Entrainment depth and (H)Maximum flow depth.

Table 6-6 Confusion matrix, accuracy and Cohens Kappa values for the debris flow deposition and flooding of the Min River.

\begin{tabular}{lll}
\hline Model aspect & Deposition & Flood \\
\hline True Negative $\left(\mathrm{m}^{2}\right)$ & 516000 & 331543 \\
False Positive $\left(\mathrm{m}^{2}\right)$ & 28000 & 34510 \\
False Negative $\left(\mathrm{m}^{2}\right)$ & 35000 & 51890 \\
True Positive $\left(\mathrm{m}^{2}\right)$ & 213000 & 546132 \\
Accuracy & 92 & 91 \\
Cohens Kappa & 0.84 & 0.81 \\
\hline
\end{tabular}


The simulated debris flow reaches the Min River and the deposits accumulate in the river. Most of the momentum has been lost before the material leaves the Hongchun watershed, and even though the Min River has a velocity of 7 $\mathrm{m} / \mathrm{s}$ the deposited volume is too large to be eroded by the Min river. Both the total deposit volume in the river, and the extent of the deposits compare well to the measured and mapped values. The deposits were modelled with an accuracy of $92 \%$ and a Cohens Kappa value of 0.84 (Table 6 ). The modelled deposited volume is $5.82 \times 10^{5} \mathrm{~m}^{3}$ (the observed estimation of the deposited volume is $7.11 \times 10^{5} \mathrm{~m}^{3}$ )

As a final stage of the event, the model predicted the flood behavior in the town of Yinxiu by the Min River, as its main course was blocked by the debris flow deposits. The modelled damming area correlates well with the observed deposit volumes and flood extents, obtained from the interpretation of aerial images and field photos from the event (Figure 14). The flood accuracy is 91 $\%$ with a Cohens Kappa value of 0.81 (Table 6-6). Since the elevation data was up scaled from 2 meters resolution to 10 meters, the multi-story buildings merged with small streets to become a joined obstacle for the flow, which corresponds to the visual observations.

While validation using comparison to mapped extent is a useful tool, it does not guarantee all aspects of the hazard are correctly simulated (e.g. timing, velocities, heights). The modelled timing of the debris flow (between 03:30 and 06:00) matched the reported of 03:30 (Figure 6-12).

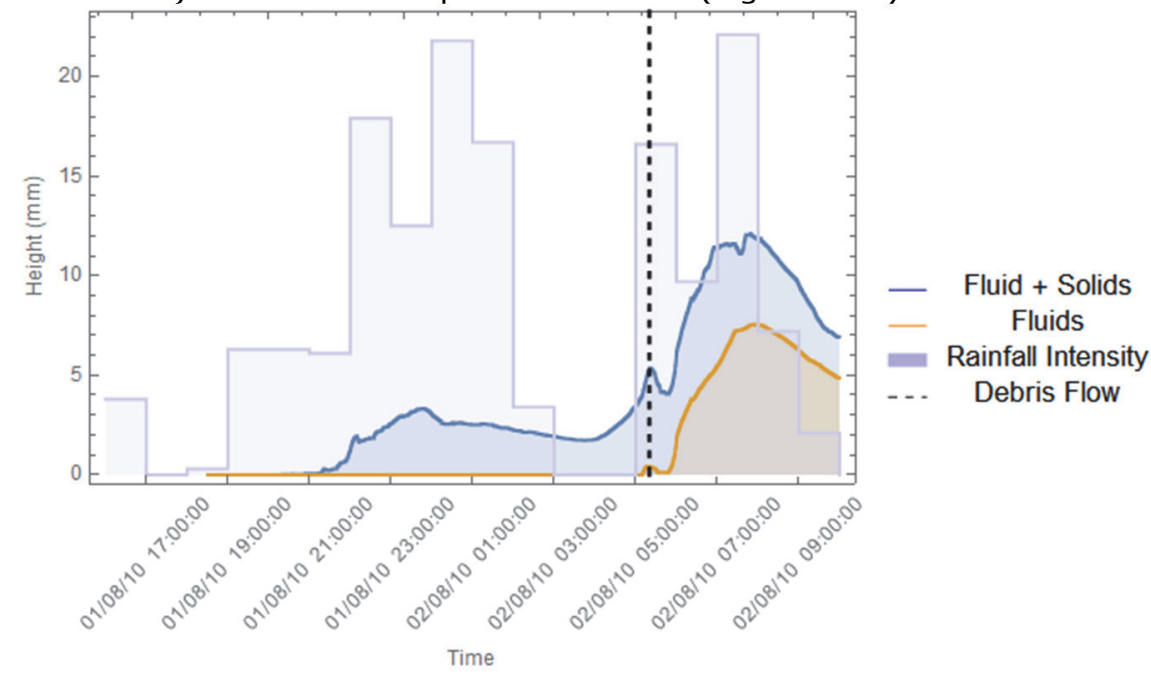

Figure 6-12 Time series data for rainfall, total flow height and solid flow height at the Hongchun outlet. Reported debris flow occurrence time is indicated as 'debris flow'. This time was reported in Tang et al. (2011) as the initial arrival of the first discharge

\subsubsection{Ensemble Simulations}

To analyze the uncertainties within the multi-hazard multi-stage modelling setup, we extended the calibration process to an ensemble analysis. In total, for each of the 6 calibration parameters, 3 equal-interval values were used (calibrated values, and the values plus or minus a given range of $10-50 \%$ based on their estimate uncertainty, as indicated in Table 6-7. Thus, the first 
simulation was repeated $27\left(=3^{3}\right)$ times. In order to efficiently link the first stage ensembles to the second stage simulations, three results from the first set of simulations are selected as inputs for the second stage. The selected outputs are the best estimate (no variation of input parameters), and the results with the most and least deposited material. For each of these three inputs, the second stage was similarly repeated $27\left(=3^{3}\right)$ times. In total, 112 simulations were thus performed, out of which normalized frequencies were generated for hazard occurrence by dividing the counts by the total number of simulations. In order to define the occurrence of a flood/debris flow we define a threshold of 0.25 meters above which a flow is counted as an actual hazard occurrence. This avoids results including runoff that produces insignificant damage.

Table 6-7 Parameter settings for the ensemble simulations.

\begin{tabular}{llll}
\hline Co-Seismic Slope Failure & Soil Depth (m) & $\begin{array}{l}\text { Internal Friction } \\
\text { Angle (degrees) }\end{array}$ & Soil Cohesion (kPa) \\
\hline Calibrated Value (average) & 5.85 & 24.57 & 8.8 \\
Variation range (+/- \%) & $30 \%$ & $30 \%$ & $30 \%$ \\
\hline Hydrology, Flow and Entrainment & $\begin{array}{l}\text { Entrainment } \\
\text { Constant }\end{array}$ & $\begin{array}{l}\text { Initial Moisture Content } \\
\text { Mal }\end{array}$ & Manning's N \\
\hline $\begin{array}{l}\text { Calibrated Value (average) } \\
\text { Variation range (+/- \%) }\end{array}$ & $\begin{array}{l}0.003 \\
50 \%\end{array}$ & $\begin{array}{l}89 \% \\
10 \%\end{array}$ & $\begin{array}{l}0.10 \\
20 \%\end{array}$ \\
\hline
\end{tabular}

Figure 6-13 shows an ensemble plot for each stage of the simulation. For each location, these maps show the normalized frequency of hazard occurrence within the ensemble of simulations. 

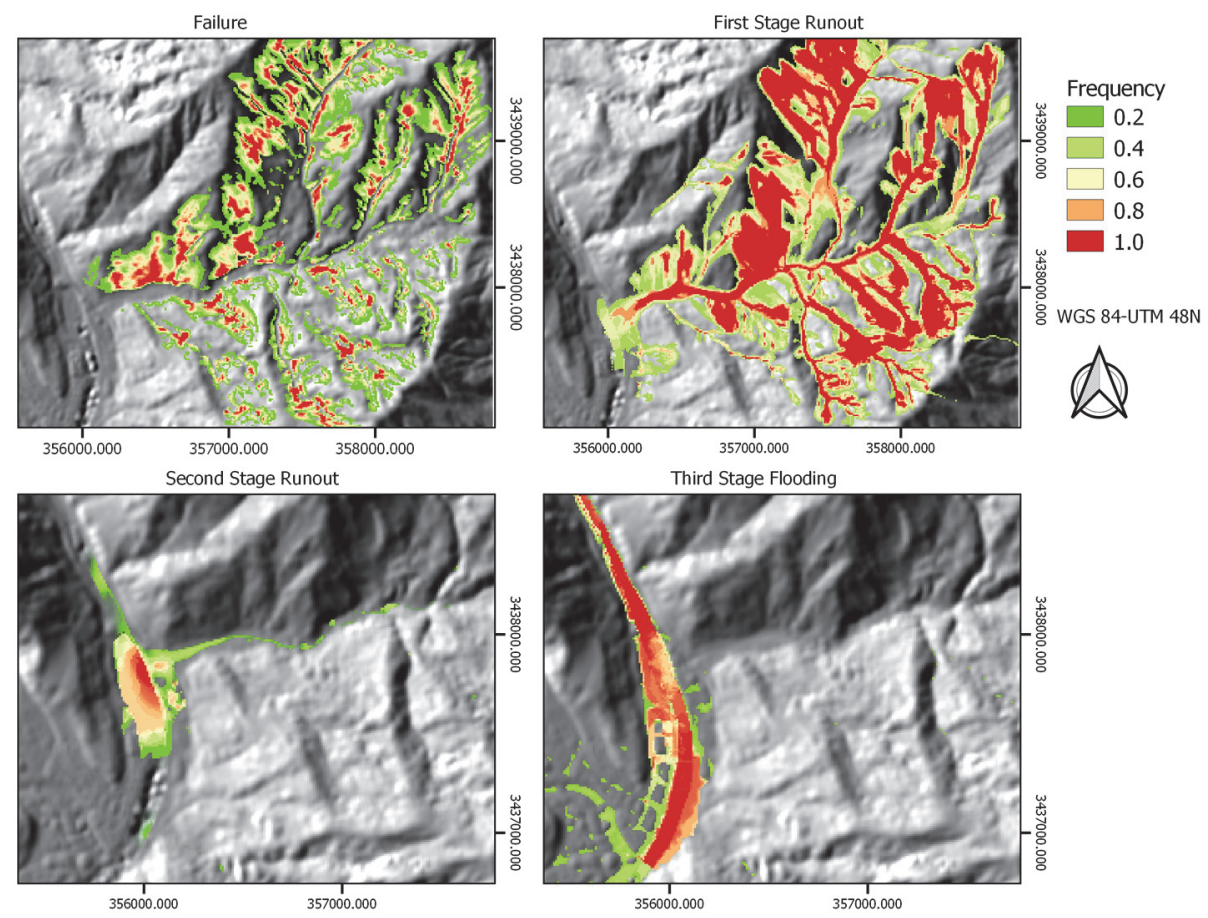

Figure 6-13 Ensemble simulation results for the Hongchun watershed. Visualized is the normalized probability, based on the ensemble of runs with varying input parameters, of the hazard occurring at each location. (A) Co-seismic slope failure. (B) co-seismic landslide runout. (C) Post-seismic debris flow deposition. (D) Post-seismic river flooding due to blockage.

\subsection{Discussion}

\subsubsection{Uncertainties in Modeling the Multi-hazard Chains}

Several major obstacles in the simulation of co-seismic landslide occurrence can be identified, which are related to the assumptions and techniques used in the models. The iterative method that is implemented in OpenLISEM Hazard, assumes that, at least initially, failure surfaces are parallel to the terrain surface. This assumption can lead to a variety of issues when the terrain has small-scale variations that do not represent the overall topography. This assumption is not present in the random ellipsoid sampling methods. The iterative method shows similar failure depths and locations, but generally separates slope failures more, where the other models show larger joined failures.

The predominant cause of this behavior most likely lies in the sub-surface force propagation. For ellipsoid or spheroid sampling, a locally stable cell might be involved in an unstable sample and therefore be included in a slope failure. The iterative failure methods has similar behavior, but depends on the sub-surface force estimation (Figure 6-14) which is theoretically less accurate then traditional sampling methods. The sub-surface force solution can have issues 
based on terrain slopes, that can block forces. The iterative failure method assumes initial failure plane estimates are parallel to the surface slope, and is therefore sensitive to surface slopes. Ellipsoid or spheroid samples are not dependent on surface slopes but instead provide their own failure plane estimation.
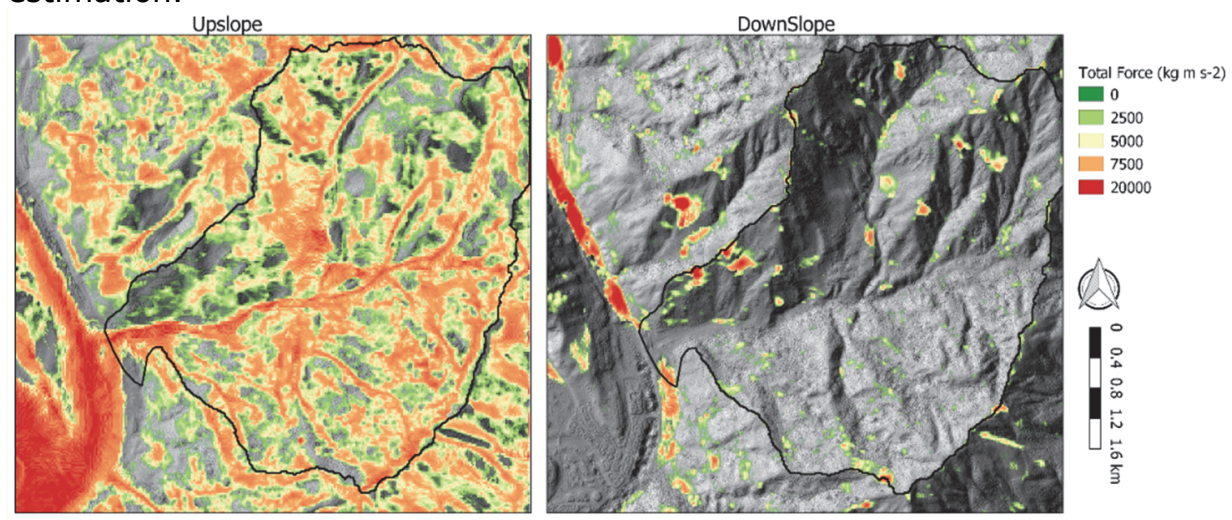

Figure 6-14 The upslope (left) and downslope (right) additional forcing that is estimated based on an iterative solution for sub-surface force redistribution.

Secondly, structural geological input data are not available, and cannot be used in the iterative method. For three-dimensional analysis using random ellipsoid sampling, structural weaknesses could be implemented by altering strength properties of specific layers. When such data are available, applications of the detailed random ellipsoid sampling method, can allow for a greater predictive value (Mergili et al., 2014; Cance et al., 2017; Tun et al., 2018).

Furthermore, seismic acceleration of material is a complex and dynamic process, driven by seismic waves compressing and stretching the sloping materials. Such waves reflect and refract based on material properties and boundary conditions, which leads to a variety of topography or material-based amplifications. These amplifications are generally important in landslide hazard modelling (Jafarzadeh et al., 2015). However, shake maps produced by the USGS utilize empirical predictive functions to spatially extent ground accelerations, and ignore these crucial local amplification effects. Within the study site, the USGS prediction was nearly homogenous, resulting in a high spatial uncertainty in the peak ground acceleration values we have used as input. Without accuracy spatial patterns the influence of seismic acceleration within the stability equations can be compensated by calibration. Evidence of this are the results of the r.slope.stability model which does not support seismic acceleration as input. Uncertainties in seismic input can be overcome by linking slope stability approaches to seismic wave modelling, a computationally heavy task that has not yet been performed for the Wenchuan earthquake.

Both in stability and flow calculations, the spatial resolution and accuracy of elevation data can be crucial. A 25 meter contour line elevation products was interpolated to 10 meter for the first-stage simulations. Although this input thus significantly lacks in detail, this most likely improved results for the iterative failure method. As discussed, this method assumes terrain slopes to be an initial estimate of the potential failure plane used for sub-surface force calculations. However, larger failures are typically not defined by terrain details 
at the scale of several meters. Furthermore, as visible in Figure 6-14, the spatially variable slopes would hinder the iterative solution employed in this method. For the second stage, a 10 meter LIDAR product was used. Here, no reason was found to conclude modelling errors were caused by the quality of this input data. Generally, flow predictions matched well with elevation features and errors tended to be caused by first stage of the simulation chain, slope failures.

The final calibrated values of the input parameters were within a reasonable range (between 50 and 150 percent ) with respect to the original estimated ones. Two parameters stood out significantly in the calibration process. The first of these, soil depth is a crucial parameter, as it determines the amount of material that is released, which is of direct influence in the runout modelling. This can indirectly influence the amount of material available for entrainment by flow at a later stage. In an active landscape, soil depth patterns are determined by rock weathering rates and mass transport/wasting. Soil depth increases until there is sufficient material to induce slope failures or significant erosion. As a results, at many locations, combinations of soil depth and slope can be near a critical state. The spatial component of soil depth is therefore of high importance. Despite its importance, soil depth is very difficult to measure over larger areas, and has a high uncertainty in most model applications (Kuriakose et al., 2009). Because information on soil depth is difficult to obtain through direct observation or remote sensing, it is generally obtained through modelling approaches (Kuriakose et al., 2009; Ruette et al., 2013). Another reason for the uncertainty in soil depth information is that a soil layer is a theoretical concept that does not always translate well into reality, where weathering is a more gradual process. A second variable which was difficult to estimate is the entrainment constant. Currently, there are several types of entrainment equations available in the literature, but most of these lack significant guidelines for selecting practical entrainment parameters (Iverson and Ouyang, 2015). Besides this coefficient, other parameters used in the entrainment equations, such as soil cohesion, internal friction angle and moisture content were measured in the laboratory and are common values for geotechnical research. However, the number of samples that are tested for these geotechnical parameters are always limited, and their spatial variability is generally high.

The four maps in Figure 14 illustrate how the spread in input parameters influences the simulated hazard for the four stages of the multi-hazard chain. The prediction of co-seismic slope failures shows the highest spread, and therefore the highest influence on the total event variability. Since we have simulated the multi-stage event as an integrated sequence, the uncertainties in one process influence various other processes. Despite the uncertainties, there is a substantial certainty that flooding of Yingxiu town will occur, independent of the input parameters. For all performed simulations, the deposition volume in the Min river is never below approximately a third $(2.1 \times$ $\left.10^{5} \mathrm{~m}^{3}\right)$ of the estimated volume $\left(7.11 \times 10^{5} \mathrm{~m}^{3}\right)$. For at least 80 percent of the simulations, there is at least some flooding experienced with a depth above 50 centimeters in Yinxiu. In comparison to the results from Mergili et al. (2018b) a higher frequency of outputs shows second-stage hazard exposure. Mergili et al. (2018b) reported that threshold behavior and non-linear effects dominated the alterations in model behavior with changing parameters. In this current study, threshold effects most likely exist related to the landslide dam behavior 
in both the Hongchun watershed and the Min river. If alternate input parameters lead to lower water flow heights, reduced entrainment or reduced debris flow height, the blockages in the catchment might not have been entrained. Such effects are typically highly non-linear and can act as a "threshold effect". A similar case is true for the depositions blocking the Min river. Thus, threshold like effect most likely exist within the simulation. However, we do not encounter scenarios that fall below the threshold of breaching in our ensemble.

There are several factors that drive the high likelihood of flooding in Yinxiu town. The event is initiated by several triggering conditions, or forcings, such as the seismic acceleration and rainfall, which occur in a very steep watershed, which determine the behavior of the hazardous processes. Seismic accelerations during the 2008 earthquake reached the $10^{\text {th }}$ and highest USGS category for seismic acceleration ( $>139 \% \mathrm{~g}$ ). Similarly, the 2010 rainfall event resulted in $220 \mathrm{~mm}$ of accumulated rainfall within 48 hours, with significant rainfall in the weeks before. The prediction of hazardous processes caused by less extreme triggering events, for example the occurrence of landslides induced by long duration and low intensity rainfall, is a much larger challenge for physically-based modelling (van Beek, 2002). In our case, material strength parameters must deviate significantly from their measured and estimated values in order not to result in slope failure under such extreme seismic acceleration. Thus, the severity of the triggering events causes the simulations to predominantly show major slope failures, debris flows, deposition in the Min river and finally flooding of Yinxiu town.

\subsection{Conclusions}

Simulating multi-hazard process chains involves the development of multiprocess models that incorporate process interactions in an integrated manner. The events between 2008 and 2010 in Hongchun watershed form such a complex process chain that involves co-seismic landslide, landslide deposition forming flow barriers, runoff initiated debris flows and breaching in multiple stages. The modelling setup is able to simulate the behavior and impact of multi-stage and multi-hazard events. The developed model code is available as part of the on-going development of the open-source OpenLISEM Hazard model (https://sourceforge.net/projects/lisem/).

Simulation of multi-hazard process chains comes with specific issues that can challenge the usability of such tools. The first key issue in the particular application of the developed model to the Hongchun process chain were the preparation of input data. In particular simulation of co-seismic landslides is challenged by usage of low-resolution empirical shake maps. Here, high-detail seismic wave modelling could, although at great computational cost, provide significant improvement.

A second major issue comes from the assumptions made by a variety of processes within the presented modelling methods. Co-seismic landslide initiation combined with real-time hydrological simulations is a challenge for current methods. Random sampling methods provide accuracy, but are uncapable to handle smaller failures and do not yet practically work together with catchment-scale hydrology. The used alternative, the iterative failure method, is numerically efficient but uses assumptions designed for shallow 
failures. Finally, the methods presented in this work take into account only highly simplified long-term hydrology but ignore many of the processes that have taken place in Hongchun watershed between the first and second stage of the event. These processes include erosion, ground water fluctuations, grain coarsening (Dominic et al., 2019) and others.

The third major issue is consideration of input uncertainties. In linking model stages and connecting the output and input of various processes, uncertainties propagate through the model in complex manners. This can invalidate model outcomes, in particular for uncalibrated predictions. To counteract this, calibration, uncertainty analysis and ensemble simulations can be used to obtain useful information from the complex setup. In the presented study case, ensemble simulations highlighted that, despite significant spread and uncertainty of hazard exposure with varying input parameters, several key behaviors of the model were highly frequent in the ensemble. Thus, despite the challenges, the usage of complex modelling setups such as presented here can add valuable information beyond traditional geomorphological and hydrological analysis. Future studies on multi-site calibration validation and complete probabilistic modelling could provide a framework for application of novel multi-hazard process chain models in decision making.

\subsubsection{Acknowledgements}

This research was supported by National Key Research and Development Program of China (2017YFC1501004) and National Natural Science Foundation of China (41672299). We would like to acknowledge the help of State Key Laboratory of Geohazard Prevention and Geo-environment. In particular, the assistance and advice from Dr. C. X. Tang, Dr. T. van Ash and Dr. X. Fan was used in improving the quality of this research. 


\section{Application of Local Time Stepping to Multi-process Catchment Models}

This chapter is reproduced as published in Bout \& Jetten (2020) with minor modifications.

\subsection{Introduction}

Numerical modelling has become the primary tool for understanding and predicting the behavior of water and sediment related land surface processes. Scientific investigations into these processes similarly use these models to investigate the physical principles that drive their behavior (Navok et al., 2010). Furthermore, models for hazardous land surface processes have been extensively applied in risk assessment, leading to usage by disaster risk reduction experts, policy makers and urban planners (Feng \& Lu, 2010; Brunner, 2010; Chen \& Zhang, 2015). It is thus crucial that numerical models are numerically efficient, decreasing delays between simulations and decision making.

The complexity of models influences their computational speed, which is one of the key factors that determine usage, application and thus impact of the underlying theories (Navok et al., 2010). The dynamics of hydrological or sediment related processes generally involve complex second-order differential equations. The progression of time requires integration of these equations. In the past decades, large amounts of research have been focused on highresolution numerical schemes for hyperbolic conservation laws (Harten, 1983; Toro, 1999; Leveque, 2002; Sohn, 2005). Within numerical integration schemes, the discretization of time primarily determines the magnitude of approximation errors. This discretization must allow for accurate integration of the differential equations, in order to maintain accurate and stable behavior. While timesteps should therefore be kept low, a decrease in timestep increases computation time, since the total number of integration steps, and therefore calculations, is directly determined by this. A reduction in computational speed then decreases usage and application of model.

A variety of computational schemes have been developed and used in the simulation of land surface processes. General integrations schemes such as the Euler, Heuns or Runga-Kutta schemes provide different orders of accuracy in time. Other methods, such as the Monotonic Upstream-centred Scheme for Conservations Laws (MUSCL) have been developed for the purpose of improving the second order conserving differential equations. The MUSCL scheme, which is Total Variation Diminishing (TVD) has successfully been applied for the saint-Venant equations for shallow water flow, and are now available open-source in the FullSWOF library (Delestre et al., 2014). The most frequently used method of decreasing numerical computations is the dynamic selection of a timestep. When the timestep is not fixed, but rather dependent on the current state of the simulation, calculations are automatically reduced when possible. A further extension of this method, varies the timestep both temporarily and spatially.

Local Time Stepping (LTS), a method where the timestep is varied both through time and space, has in the past been applied to a relatively small selection of models when compared to other numerical methods. Finite difference seismic 
models have utilized the method to successfully improve calculation time (Peter et al., 2017; Madec et al., 2018). In models for unsteady internal flows, Sedaghat, Ackroyd and Wood (1999) and Yee and Harten (1987) have applied LTS with a timestep condition based on finite grid-cell volume. They concluded that the method was useful in improving calculation time, depending on the used scenario. In later works, the applicability of a local time stepping scheme to water flow has been investigated, showing significant increases in computational efficieny can be reached. Recently, local time-stepping was applied in a flood model with wetting and drying (Sanders, 2008). Finally, Dazzi et al., (2018) implemented LTS in 2d shallow water flow using GPU-integrated methods.

Besides the aforementioned implementations of local time stepping, their application is still limited. Both commercially available software (Flo-2D, Delft3D etc.) and open-source alternatives do not implement such a scheme. Furthermore, the link between this method and broader environmental modelling is limited. In modelling of catchment-scale hydrology, ground water flow, surface flow and related processes, the method that could potentially provide drastic improvement to computation time has not yet been investigated.

Within this paper, we propose a flexible implementation of local time stepping method for solving mass-conserving differential equations for land surface processes. The scheme that is developed combines spatially and temporally dynamic time-steps with a MUSCL numerical schemes for simulation of land surface processes. This is furthermore combined with existing numerical methods such as a Heun's predictor-corrector and a semi-explicit implementation of Darcy-Weisbach-friction (Chow, 1959). Within this paper, the numerical method will be applied to a hydrological catchment model which uses the depth averaged saint Venant equations for shallow flow. Furthermore, we simulate a multi-hazard event using two-phase mixture flow equations. In order to investigate the influence of the numerical method on model behavior, the final model was tested on catchments on the Fella river basin and the Caribbean islands of St. Lucia and Dominca.

\subsection{Methods}

In order to apply and test sophisticated environmental modelling in a numerical solution that uses local time stepping, we use and extend the existing OpenSource multi-hazard model OpenLISEM.

The OpenLISEM model implements multiple types of infiltration models such as Smith \& Parlange (Smith \& Parlange, 1978) and a full vertical soil water balance model named SWATRE (Bastiaanssen et al., 1996). The simulations in this paper use the Green \& Ampt infiltration model which assumes a wetting front moving down into the soil due to infiltrating rainfall (Green \& Ampt, 1911). The resulting potential infiltration is subtracted from the available surface water (Equation 7.1).

7.1

$$
\mathrm{f}_{\text {pot }}=-\mathrm{K}_{\mathrm{s}}\left(\psi \frac{\theta_{\mathrm{s}}-\theta_{\mathrm{i}}}{\mathrm{F}}+1\right)
$$

With

$f_{p o t}$ the potential infiltration rate $\left(m s^{-1}\right), F$ the cumulative infiltrated water $(m), \theta_{s}$ the 
porosity $\left(\mathrm{m}^{3} \mathrm{~m}^{-3}\right), \theta_{i}$ the initial soil moisture content $\left(\mathrm{m}^{3} \mathrm{~m}^{-3}\right), \psi$ the matric pressure at the wetting front $(h=\psi+Z)(m)$ and $K_{s}$ the saturated conductivity $\left(m^{-1}\right)$.

Input data consists of soil, land surface and terrain properties, and can be defined on a sub-cell basis (Figure 1). The hydrological processes that are simulated within OpenLisem are extensive and include interception by vegetation, surface micro-ponding and dynamic flow. Further details on the underlying physical principles of OpenLISEM can be found in Baartman et al. (2012) and Jetten and De Roo (2001).

\subsubsection{Equations for Flow Dynamics}

The created numerical method is designed for use with hyperbolic conserving second order partial differential equations. In our case, mass conservation (Equation 7.2) and a momentum advection scheme with source terms for water flow form the basis of the model (Equation 7.3 and 7.4).

$$
\frac{\partial \mathrm{h}}{\partial \mathrm{t}}+\frac{\partial(\mathrm{uh})}{\partial \mathrm{x}}+\frac{\partial(\mathrm{vh})}{\partial \mathrm{y}}=0
$$

$$
\frac{\partial \mathrm{hu}}{\partial \mathrm{t}}+\frac{\partial\left(\mathrm{hu}^{2}\right)}{\partial \mathrm{x}}+\frac{\partial \mathrm{huv}}{\partial \mathrm{y}}+\frac{\mathrm{d}\left(\frac{\mathrm{gh}^{2}}{2}\right)}{\mathrm{dx}}-\mathrm{ghS}_{\mathrm{x}}=0
$$

$$
\frac{\partial \mathrm{hv}}{\partial \mathrm{t}}+\frac{\partial \mathrm{huv}}{\partial \mathrm{x}}+\frac{\partial\left(\mathrm{hv}^{2}\right)}{\partial \mathrm{y}}+\frac{\mathrm{d}\left(\frac{\mathrm{gh}^{2}}{2}\right)}{\mathrm{dy}}-\mathrm{ghS}_{\mathrm{y}}=0
$$

With $h$ the flow height $(m) u$ and $v$ the flow velocity in the $\mathrm{x}$ and $\mathrm{y}$ direction, $\mathrm{g}$ the gravitational acceleration and $S_{x}$ and $S_{y}$ the friction slope terms in the $\mathrm{x}$ and y direction $\left(\mathrm{m} \mathrm{m}^{-1}\right)$.

The friction slope terms include gravitational forces and a basal frictional force for shallow depth averaged water flow (Equation 7.5 and 7.6).

7.5

7.6

$$
\begin{aligned}
& S_{x}=-S_{0_{x}}+S_{f_{x}} \\
& S_{y}=-S_{0_{y}}+S_{f_{y}}
\end{aligned}
$$

$$
\text { is the bed slope }
$$

As a friction force, the Darcy-Weisbach type friction law will be used (Equation 6 ), based on the value of Mannings roughness coefficient (Chow, 1959).

$$
\mathrm{S}_{\mathrm{f}}=\frac{1}{\mathrm{n}^{2}} \frac{\overrightarrow{\mathrm{u}}|\overrightarrow{\mathrm{u}}|}{\mathrm{h}^{\frac{4}{3}}}
$$

With

$S_{f}$ the friction force per unit mass $\left(m^{2} s^{-1}\right), \vec{u}$ a velocity $\left(m^{1} s^{-1}\right)$ and $\mathrm{n}$ the mannings roughness coefficient (-).

Hydrology and slope failure are based taken from the OpenLISEM model and the iterative failure model (Bout et al., 2018). In case of multi-phase flow, initiated by slope failure, we implement the Pudasaini (2012) generalized debris flow equations. 
$7.8 \mathrm{~S}_{\mathrm{x}, \mathrm{s}}=\alpha_{\mathrm{s}}\left(\mathrm{g}\left(\frac{\partial \mathrm{b}}{\partial \mathrm{x}}\right)-\frac{\mathrm{u}_{\mathrm{s}}}{\left|\overrightarrow{\mathrm{u}}_{\mathrm{s}}\right|} \tan \left(\partial \mathrm{P}_{\mathrm{b}_{\mathrm{s}}}\right)-\varepsilon \mathrm{P}_{\mathrm{b}_{\mathrm{s}}}\left(\frac{\partial \mathrm{b}}{\partial \mathrm{x}}\right)\right)-\varepsilon \alpha_{\mathrm{s}} \gamma \mathrm{P}_{\mathrm{b}_{\mathrm{f}}}\left(\frac{\partial \mathrm{h}}{\partial \mathrm{x}}+\frac{\partial \mathrm{b}}{\partial \mathrm{x}}\right)+\mathrm{C}_{\mathrm{DG}}\left(\mathrm{u}_{\mathrm{f}}-\mathrm{u}_{\mathrm{s}}\right) \mid \overrightarrow{\mathrm{u}}_{\mathrm{f}}-\overrightarrow{\mathrm{u}}_{\mathrm{s}} \mathrm{j}^{\mathrm{j}-1}$
$7.9 \mathrm{~S}_{\mathrm{y}, \mathrm{s}}=\alpha_{\mathrm{s}}\left(\mathrm{g}\left(\frac{\partial \mathrm{b}}{\partial \mathrm{y}}\right)-\frac{\mathrm{v}_{\mathrm{s}}}{\left|\overrightarrow{\mathrm{u}}_{\mathrm{s}}\right|} \tan \left(\partial \mathrm{P}_{\mathrm{b}_{\mathrm{s}}}\right)-\varepsilon \mathrm{P}_{\mathrm{b}_{\mathrm{s}}}\left(\frac{\partial \mathrm{b}}{\partial \mathrm{y}}\right)\right)-\varepsilon \alpha_{\mathrm{s}} \gamma \mathrm{P}_{\mathrm{b}_{\mathrm{f}}}\left(\frac{\partial \mathrm{h}}{\partial \mathrm{y}}+\frac{\partial \mathrm{b}}{\partial \mathrm{y}}\right)+\mathrm{C}_{\mathrm{DG}}\left(\mathrm{v}_{\mathrm{f}}-\mathrm{v}_{\mathrm{s}}\right) \mid \overrightarrow{\mathrm{u}}_{\mathrm{f}}-\overrightarrow{\mathrm{u}}_{\mathrm{s}} \mathrm{j}^{\mathrm{j}-1}$

7.10

7.11

$$
\begin{aligned}
S_{x, f}=\alpha_{f}\left\{g\left(\frac{\partial b}{\partial x}\right)\right. & -\varepsilon\left[\frac{1}{h} \frac{\partial}{\partial x}\left(\frac{h^{2}}{2} P_{b_{f}}\right)+P_{b_{f}} \frac{\partial b}{\partial x}\right. \\
& -\frac{1}{\alpha_{f} N_{R}}\left(2 \frac{\partial^{2} u_{f}}{\partial x^{2}}+\frac{\partial^{2} v_{f}}{\partial y \partial x}+\frac{\partial^{2} u_{f}}{\partial y^{2}}-\frac{\chi u_{f}}{\varepsilon^{2} h^{2}}\right) \\
& +\frac{1}{\alpha_{f} N_{R}}\left(2 \frac{\partial}{\partial x}\left(\frac{\partial \alpha_{s}}{\partial x}\left(u_{f}-u_{s}\right)\right)\right. \\
& \left.\left.\left.+\frac{\partial}{\partial y}\left(\frac{\partial \alpha_{s}}{\partial x}\left(v_{f}-v_{s}\right)+\frac{\partial \alpha_{s}}{\partial y}\left(u_{f}-u_{s}\right)\right)\right)-\frac{\xi \alpha_{s}\left(v_{f}-v_{s}\right)}{\varepsilon^{2} \alpha_{f} N_{R_{\mathcal{A}}} h^{2}}\right]\right\} \\
& -\frac{1}{\gamma} C_{D G}\left(u_{f}-u_{s}\right)\left|\vec{u}_{f}-\vec{u}_{s}\right|^{j-1}
\end{aligned}
$$

$$
\begin{aligned}
S_{y, f}=\alpha_{f}\left\{g\left(\frac{\partial b}{\partial y}\right)\right. & -\varepsilon\left[\frac{1}{h} \frac{\partial}{\partial y}\left(\frac{h^{2}}{2} P_{b_{f}}\right)+P_{b_{f}} \frac{\partial b}{\partial y}\right. \\
& -\frac{1}{\alpha_{f} N_{R}}\left(2 \frac{\partial^{2} v_{f}}{\partial y^{2}}+\frac{\partial^{2} u_{f}}{\partial y \partial x}+\frac{\partial^{2} v_{f}}{\partial y^{2}}-\frac{\chi v_{f}}{\varepsilon^{2} h^{2}}\right) \\
& +\frac{1}{\alpha_{f} N_{R}}\left(2 \frac{\partial}{\partial y}\left(\frac{\partial \alpha_{s}}{\partial y}\left(v_{f}-v_{s}\right)\right)\right. \\
& \left.\left.\left.+\frac{\partial}{\partial y}\left(\frac{\partial \alpha_{s}}{\partial y}\left(u_{f}-u_{s}\right)+\frac{\partial \alpha_{s}}{\partial x}\left(v_{f}-v_{s}\right)\right)\right)-\frac{\xi \alpha_{s}\left(u_{f}-u_{s}\right)}{\varepsilon^{2} \alpha_{f} N_{R_{\mathcal{A}}} h^{2}}\right]\right\} \\
& -\frac{1}{\gamma} C_{D G}\left(u_{f}-u_{s}\right)\left|\vec{u}_{f}-\vec{u}_{s}\right|^{j-1}
\end{aligned}
$$

With $\alpha_{s}$ and $\alpha_{f}$ the volume fraction for solid and fluid phases $(-), P_{b}$ the pressure at the base surface $\left(\mathrm{Kg} \mathrm{m}^{-1} \mathrm{~s}^{-2}\right), b$ the basal surface of the flow $(m), N_{R}$ the Reynolds number $(-), N_{R_{A}}$ the quasi-Reynolds number $(-), C_{D G}$ the drag coefficient $(-), \rho_{f}$ is the density of the fluid $\left(\mathrm{kg} \mathrm{m}^{-3}\right), \rho_{S}$ is the density of the solids $\left(\mathrm{kg} \mathrm{m}^{-3}\right), \gamma$ the density ratio between the fluid and solid phase $(-), \chi$ the vertical shearing of fluid velocity $\left(\mathrm{m} \mathrm{s}^{-1}\right), \varepsilon$ the aspect ratio of the model $(-), \xi$ the vertical distribution of $\alpha_{s}\left(m^{-1}\right)$.

\subsubsection{Timesteps}

Current models generally use a Courant-Fredrich-Levy condition to determine the maximum timestep that can be taken while maintaining numerical stability. This conditions is provided by the requirement that the velocity of a water column must not exceed the cell length during one step of numerical 
integration, since otherwise cells are skipped and negative flow heights can result (Equation 8 ).

$$
7.12 \quad \frac{\mathrm{vdt}}{\mathrm{dx}}<\mathrm{c}
$$

With $v$ the velocity $\left(m s^{-1}\right), d x$ the grid cell size $(m), d t$ the timestep $(m)$ and $c$ the courant factor, generally between 0.1 and $0.4(-)$.

Typically, in order to reduce numerical integration errors, the timestep is reduced much more that the strict limit of positive mass conservation by reducing the Courant factor. Extensions of this conditions have been developed based on empirical flow velocity (Hunter et al., 2005, Delestre et al., 2014). Within this research, a similar adaptation of the Courant-Fredrich-Levy condition will be used. We include the acceleration and manning's velocity in the condition in order to automatically adapt the timestep to high accelerations (Equation 7.13).

7.13

$$
\frac{\max (v, v+a) d t}{d x}<c
$$

With $a$ the acceleration $\left(\mathrm{m} \mathrm{s}^{-2}\right)$, and

From the resulting condition, timestep requirements are separately calculated for every grid cell. Once every timestep is known, a global minimum timestep is determined. Then, for every grid cell, the timestep must equal a multiple of the global minimum timestep (Equation 7.14).

7. 14

$$
\mathrm{dt}_{\mathrm{r}, \mathrm{c}}=\min \left(\mathrm{dt}_{\text {max }}, \mathrm{dt}_{\min } \mathrm{n}\right) \quad \mathrm{n} \in \mathbb{N}
$$

With $d t_{r, c}$ the timestep for a specific cell $(r=$ row, $\mathrm{c}=$ column $)(s), d t_{\text {max }}$ the global common timestep $(s)$ and $d t_{\min }$ the global minimum timestep ( $s$ ) The global common timestep ensures that at specific moments, all grid cells are at the same moment in time (Figure 7-1). Specifically, at every multiple of $d t_{\text {max }}$, every grid cell will have its state at that same temporal position. On these moments, the overarching model is called to solve processes that do not substantially depend on the timestep for accuracy, such as interception, subsurface processes and empirical splash erosion.

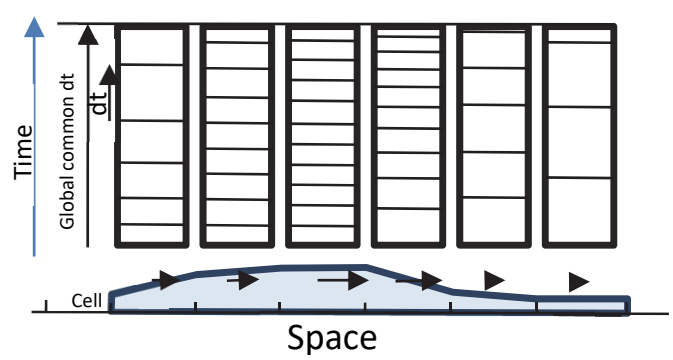

Figure 7-1 Spatially varying timestep values for numerical integration of flow equations.

\subsubsection{Influence on Numerical Stability}

Most widely-used numerical schemes for solving hyperbolic sets of partial differential equations are well-balanced, indicating that they at least maintain a steady state at rest. In the case of flow equations, this property is particularly important, as the still water level of lakes (a steady state at rest) should be maintained for an accurate and stable simulation. To work out the influence of 
a local time stepping on the stability of a numerical scheme, we will now look at the example of a hydrostatic reconstructing using cell boundary fluxes and a MUSCL-approximation for the cell boundary fluxes. This widely used numerical scheme, as adopted in FullSwof (Delestre et al., 2014), is based on the following principles; Cell boundary fluxes are estimated using step-wise linear approximations (Figure 7-2).

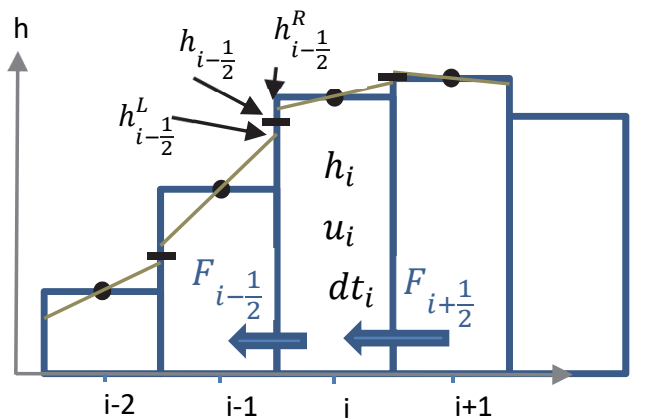

Figure 7-2 The definition of cells, boundaries, and cell boundary fluxes.

Water heights for each cell are reconstructed based in total incoming and outgoing flux (Equation 7.15)

7.15 $\Delta \mathrm{h}_{\mathrm{i}}=0.5 * \sum_{\mathrm{dt}_{\mathrm{i}}} \frac{\mathrm{DT}_{\mathrm{i}}}{\mathrm{DX}}\left(\mathrm{F}_{\mathrm{i}-\frac{1}{2}}+\mathrm{F}_{\mathrm{i}+\frac{1}{2}}\right)+0.5 * \sum_{\mathrm{dt}_{\mathrm{i}-\frac{1}{2}}} \frac{\mathrm{DT}_{\mathrm{i}-1}}{\mathrm{DX}}\left(\mathrm{F}_{\mathrm{i}-\frac{1}{2}}\right)+0.5 * \sum_{\mathrm{dt}_{\mathrm{i}+\frac{1}{2}}} \frac{\mathrm{DT}_{\mathrm{i}+1}}{\mathrm{DX}}\left(\mathrm{F}_{\mathrm{i}+\frac{1}{2}}\right)$

Where $\mathrm{h}_{\mathrm{i}, \mathrm{j}}^{\mathrm{n}}$ is the water height at location $\mathrm{i}, \mathrm{j}$ at time $\mathrm{n}(\mathrm{m})$, DT the time step (s), DX is the cell size $(\mathrm{m})$ and $F$ is the approximated flux through a cell boundary in either $x$ or $y$ direction $\left(m^{2} s^{-1}\right)$.

Fluxes are determined based on the linear reconstructions of water heights, velocities, and bed elevations from the cells that touch the cell boundary (equation 7.16).

$$
\mathrm{F}_{\mathrm{i}+\frac{1}{2}}=\mathcal{F}\left(\mathrm{h}_{\mathrm{i}+1}^{\mathrm{L}}, \mathrm{u}_{\mathrm{i}+1}^{\mathrm{L}}, \mathrm{z}_{\mathrm{i}+\frac{1}{2},}^{\mathrm{L}}, \mathrm{h}_{\mathrm{i}+1}^{\mathrm{R}}, \mathrm{u}_{\mathrm{i}+1}^{\mathrm{R}}, \mathrm{z}_{\mathrm{i}+\frac{1}{2}}^{\mathrm{R}}\right)
$$

Numerical schemes such as these, when combined with appropriate flux limiters, such as minmod, are proven to maintain a steady state at rest and furthermore diminish total variations in the solution. For every initial condition, the total variation in the state of the simulation must, without external influences, either remain equal or decrease. The usage of LTS can be done while maintaining the useful properties of such numerical schemes.

In particular, take a numerical scheme to the advection equation used with hyperbolic conserving laws (Equation 7.17).

$$
\mathrm{u}_{\mathrm{x}}^{\mathrm{t}+1}=\mathrm{u}_{\mathrm{x}}^{\mathrm{t}}+\mathrm{C}_{+, \mathrm{x}+\frac{1}{2}} \Delta_{\mathrm{x}+\frac{1}{2}} \mathrm{u}^{\mathrm{t}}-\mathrm{C}_{-, \mathrm{x}-\frac{1}{2}} \Delta_{\mathrm{x}-\frac{1}{2}} \mathrm{u}^{\mathrm{t}}
$$

Where the local change in variable $u$ is described by equation 7.18.

7. 18

$$
\Delta_{\mathrm{x}+\frac{1}{2}} \mathrm{u}^{\mathrm{t}}=\mathrm{u}_{\mathrm{x}+1}^{\mathrm{t}}-\mathrm{u}_{\mathrm{x}}^{\mathrm{t}}
$$

The total variation in the state of the variable $u$ is given by equation 7.19.

$$
\operatorname{TV}(\mathrm{t})=\sum_{-\infty}^{\infty}\left|\Delta_{\mathrm{x}+\frac{1}{2}} \mathrm{u}^{\mathrm{t}}\right|
$$


The condition for a total variation diminishing solution is then given by equation $7.20-7.22$.

7. 20

7.21

7.22

$$
\begin{gathered}
\mathrm{C}_{+, x+\frac{1}{2}} \geq 0 \\
\mathrm{C}_{-, \mathrm{x}-\frac{1}{2}} \geq 0 \\
\mathrm{C}_{-, \mathrm{x}-\frac{1}{2}}+\mathrm{C}_{+, \mathrm{x}+\frac{1}{2}} \leq 1
\end{gathered}
$$

The proof of this is provided by Harten (1983). First, he notes the local variation in $u^{t+1}$ (Equation 7.23).

$$
\Delta_{\mathrm{x}+\frac{1}{2}} \mathrm{u}^{\mathrm{t}+1}=\mathrm{C}_{-\mathrm{x}-\frac{1}{2}} \Delta_{\mathrm{x}-\frac{1}{2}} \mathrm{u}^{\mathrm{t}}+\left(1-\mathrm{C}_{-, \mathrm{i}+\frac{1}{2}}-\mathrm{C}_{+, \mathrm{i}+\frac{1}{2}}\right) \Delta_{\mathrm{x}+\frac{1}{2}} \mathrm{u}^{\mathrm{t}}+\mathrm{C}_{-\mathrm{x}+\frac{3}{2}} \Delta_{\mathrm{x}+\frac{2}{2}} \mathrm{u}^{\mathrm{t}}
$$

Then, based on the conditions for the parameters, equation 7.24 results.

$$
7.24\left|\Delta_{\mathrm{x}+\frac{1}{2}} \mathrm{u}^{\mathrm{t}+1}\right| \leq \mathrm{C}_{-\mathrm{x}-\frac{1}{2}}\left|\Delta_{\mathrm{x}-\frac{1}{2}} \mathrm{u}^{\mathrm{t}}\right|+\left(1-\mathrm{C}_{-, \mathrm{i}+\frac{1}{2}}-\mathrm{C}_{+, \mathrm{i}+\frac{1}{2}}\right)\left|\Delta_{\mathrm{x}+\frac{1}{2}} \mathrm{u}^{\mathrm{t}}\right|+\mathrm{C}_{-\mathrm{x}+\frac{3}{2}}\left|\Delta_{\mathrm{x}+\frac{3}{2}} \mathrm{u}^{\mathrm{t}}\right|
$$

Then, by altering the summation index, the total variation at time $t$ is acquired (Equation 7.25).

7.25

$$
\begin{gathered}
T V(t+1)=\sum_{-\infty}^{\infty}\left|\Delta_{x+\frac{1}{2}} u^{t+1}\right| \leq \sum_{-\infty}^{\infty} C_{-x-\frac{1}{2}}\left|\Delta_{x-\frac{1}{2}} u^{t}\right|+\sum_{-\infty}^{\infty}\left(1-C_{-, i+\frac{1}{2}}-\right. \\
\left.C_{\left.+, i+\frac{1}{2}\right)}\right)\left|\Delta_{x+\frac{1}{2}} u^{t}\right|+\sum_{-\infty}^{\infty} C_{-x+\frac{3}{2}}\left|\Delta_{x+\frac{3}{2}} u^{t}\right|=\sum_{-\infty}^{\infty} C_{-x+\frac{1}{2}}\left|\Delta_{x+\frac{1}{2}} u^{t}\right|+\sum_{-\infty}^{\infty}\left(1-C_{-, i+\frac{1}{2}}-\right. \\
\left.C_{+, i+\frac{1}{2}}\right)\left|\Delta_{x+\frac{1}{2}} u^{t}\right|+\sum_{-\infty}^{\infty} C_{-x+\frac{1}{2}}\left|\Delta_{x+\frac{1}{2}} u^{t}\right|=\sum_{-\infty}^{\infty}\left|\Delta_{x+\frac{1}{2}} u^{t}\right|=T V(t)
\end{gathered}
$$

Thus, finally, based on the conditions in equation 7.26, the total variation must remain either equal or diminish.

$$
7.26 \quad \operatorname{TV}(\mathrm{t}+1) \leq \mathrm{TV}(\mathrm{t})
$$

In our implementation, fluxes through a cell interface are immediately taken from one cell to another, and the simulation can be seen as a sequence of cell interactions through cell boundary interfaces. For each activated cell, fluxes for four cell boundaries are calculated, leading to indirect activation of five cells. As stated earlier, fluxes are halved, to compensate for every cell being activated twice. However, within this subset of calculations, the timestep of all activated cells is taken to be the same. These small subset of calculations, on five specific cells could, either through an open or closed boundary condition, be imagined to be an independent simulation. For this tiny, but independent simulation, the properties of the numerical scheme remain valid, since only the flux is multiplied by a factor of a half and the timesteps taken for every cell are identical. Now, when applying this logic to a larger sequence of cellinteractions, and identifying a full simulation as a collection of flux interactions between five cells, the properties of the numerical scheme must remain valid for the entire simulation. Thus, the properties that make a numerical scheme both well-balanced or total variation diminishing, are still valid when used with LTS, when the conditions on the coefficients in equation 16 are still met.

A possible case where not all conditions for a stable and TVD scheme are met could be a large amount of sudden inflow and increase of velocity. Figure 7-3 visualizes this process, where the cell on the right experiences incoming flow, leading to a sudden decrease in local timestep. 

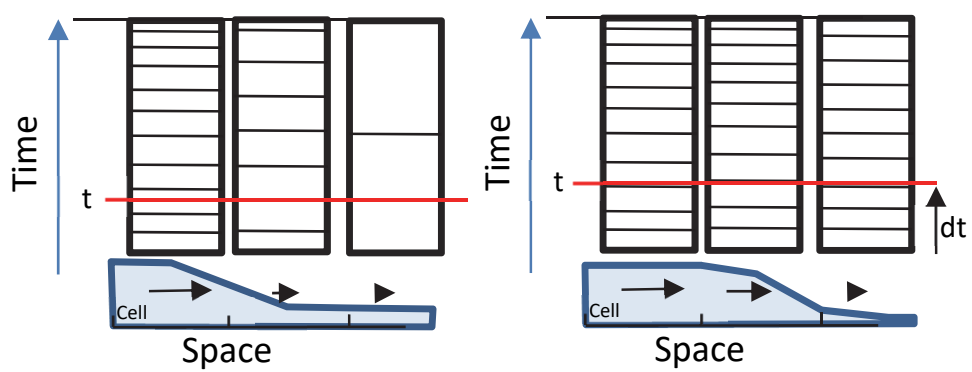

Figure 7-3 The underestimation of the required timestep due to incoming flow and momentum. Left: timestep in right cell is large due to small fluxes. Right: timestep has decreased due to incoming flow. The time since the last timestep is larger than required for stability.

Due to the decrease in local timestep, the actual time since its last timestep is much larger than the required timestep for a stable simulation. Two additional aspects must be implemented in the numerical scheme to prevent these instable large timesteps.

\subsubsection{Safety Region}

When using local time stepping, unnatural behavior might arise when there is a substantial difference in timestep between neighboring cells due to a difference in velocity. Since the MUSCL scheme uses velocities of both cells to calculate the cell boundary flux, this might lead to an overestimation of outflow for the low-velocity cell. This cell will drain, leading to a border of underestimations around areas of high velocity. To prevent this, each timestep is, for one iteration, compared with the neighboring values, and set to the lowest value (Equation 7.27).

$$
7.27 \mathrm{dt}_{\mathrm{r}, \mathrm{c}}=\min \left(\mathrm{dt}_{\mathrm{r}, \mathrm{c}}, \mathrm{dt}_{\mathrm{r}, \mathrm{c}+1}, \mathrm{dt}_{\mathrm{r}, \mathrm{c}-1}, \mathrm{dt}_{\mathrm{r}+1, \mathrm{c}}, \mathrm{dt}_{\mathrm{r}-1, \mathrm{c}}\right)
$$

This equation creates a region around cells with a small timestep, were a similarly small timestep is used. Thus, before incoming water flow increases velocity and decreases local timestep, the timestep is already decreased due to the safety region. This safety region thus prevents unnatural patterns from forming in the numerical solution. This equation can be used for any combination of surrounding cells, and weights can be dependent on the distance.

\subsubsection{Calculation Order}

When using LTS, the activation of cell processes can be done either at the start of its local timestep, or at the end. In both cases, the timesteps fill the global common timestep. However, if cells are activated at the start, inaccurate behavior can arise. When water flows into the cell, decreasing the required timestep, the local time of that cell is already ahead, due to the earlier larger timestep. Thus, for the front of a moving wave, the timestep is only adapted after a global common timestep. For this reason, we choose to activate processes at the end of a timestep. This ensures that the timestep of other cells can be adapted due to inflow of water. 
The movement of interface fluxes is implemented in a strictly mass-conserving manner. When a cell boundary interface is used for a specific cell, water is immediately added or subtracted from the relevant neighbor. Effectively, this causes the method to move water fluxes twice, since cells are activated by neighbors, and by itself. To compensate for this, we move half of the flux during the activation of the cell, and half during the activation by a neighbor cell.

\subsubsection{Implementation of Friction}

In the majority of flow types, the gravitational and frictional force predominantly determine the flow velocity. Due to the non-linearity of the friction law, solving the balance between these forces requires a small high temporal precision. Because of this, the stability of the interaction between these two forces can be increased by using a non-explicit solution (Fiedler \& Ramirez, 2000; risteau \& Coussin, 2001). A semi-implicit solution that provides a well-balanced and stable estimation of the frictional force was derived by Bristeau and Coussin (2001). This semi-implicit solution estimates friction based on all other acceleration terms (Equation $7.28 \& 7.29$ ).

$7.28 d \overrightarrow{u^{n+1}}+d t \frac{g}{n^{2}} \frac{\overrightarrow{\mathrm{u}}^{\mathrm{n}+1}\left|\overrightarrow{\mathrm{u}^{\mathrm{n}}}\right|}{\mathrm{h}^{\frac{4}{3}}}=\overrightarrow{\mathrm{u}}_{\text {nofriction }}^{\mathrm{n}+1}=\mathrm{u}^{\mathrm{n}}+\sum$ other accaleration terms And thus

$$
\overrightarrow{\mathrm{u}}^{\mathrm{n}+1}=\frac{\overrightarrow{\mathrm{u}}_{\text {nofriction }}^{\mathrm{n}+1}}{1+\mathrm{dt} \frac{\mathrm{g} \overline{\mathrm{u}^{\mathrm{n}}}\left|\overrightarrow{\mathrm{u}^{2}}\right|}{\mathrm{n}^{2} \mathrm{4}^{\frac{4}{3}}}}
$$

While the accuracy of this method is still dependent on the timestep, the possible timestep while maintaining accuracy is substantially larger.

A disadvantage of this method is however, that when timesteps increase above a stable level, there is increasing oscillation around the analytical solution (Figure 4a). These oscillations are especially significant in the case of shallow flow. In such conditions, the relative size of the frictional force increases, while the gravitational acceleration remains identical. Thus, the final stable velocity decreases (Figure $4 \mathrm{~b}$ ). This leads to a small required timestep, since overestimations of the velocity are otherwise present (Figure 4c). In the case of catchment-scale hydrological modelling, flow is frequently extremely shallow, leading to long computation times.

When flow height is low, inertial acceleration terms are many orders of magnitude smaller compared to other acceleration terms. Therefore, velocity would in reality be determined almost immediately by the balance of the friction and gravitational forces. Because of this, we counteract these velocityoscillations by limiting the oscillations of the friction solution at the stable velocity. A.e: In the case of Figure 7-4a, the decrease in velocity would not cause it to go below $1 \frac{3}{4} \mathrm{~ms}^{-1}$. This method thus allows a high increase in timestep for areas with low water height, while maintaining accuracy and realistic behavior. 

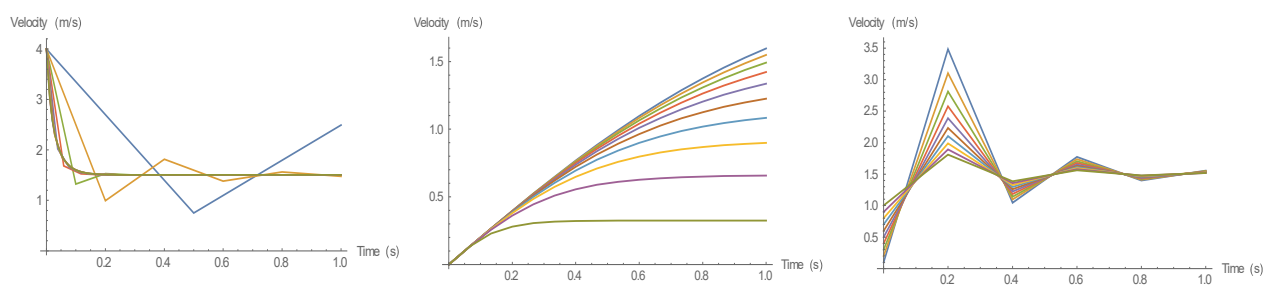

Figure 7-4 Over- and under-estimations of velocity due to oscillatory behavior of semi-explicit friction at larger timesteps

In order to activate the larger timestep for areas with a low water height, we further alter the courant condition (Equation 7.30 and 7.31)

$$
\frac{\max (\mathrm{v}, \mathrm{v}+\mathrm{ka}) \mathrm{dt}}{\mathrm{dx}}<\mathrm{c}
$$

With

$$
\mathrm{k}=1-\min \left(1.0, \max \left(0.0, \frac{1}{c_{k}}\left(c_{k}-h\right)\right)\right)
$$

With $k$ the kinematic factor $(-)$ and $c_{k}$ the kinematic depth $(\mathrm{m})$

Thus, below water depth $c_{k}$, the influence of acceleration on the required timestep decreases linearly to zero. The value for this depth must be chosen so that below this water depth, the velocities are well approximated by a kinematic flow. Therefore, we choose a value of 0.25 in later simulations. Finally, shallow overland is thus calculated using large timesteps, and velocity is immediately determined by the balance of gravity and friction, effectively mixing a full shallow water equation for the deeper water, and a kinematic flow for the shallow runoff.

\subsection{Numerical Tests}

\subsubsection{Dam-break Test}

The first scenarios tested with the LTS setup are 1D dam-break simulations. First, a numerical simulation is compared with an analytical solution of Ritter (1893). Here, a homogeneous water level is located in one-half of the simulation, with the other half dry. This initial water volume is released without obstacles, ignoring any frictional forces. In this type of simulation, sudden and large changes in local timestep are present, and thus forms a good test for the accuracy and possible influences of LTS. In a second comparison, the height of a point water release is compared to an analytical solution which is based on the dam-break solution by Ancey et al. (2007). For a frictionless water body on a sloped surface, they derived an analytical expression for water height after the release of the water body. Their analytical solution will be compared to a numerical solution with and without LTS. Friction forces will be similarly neglected in this simulation. 


\subsubsection{Catchment Simulations}

The created numerical method has undergone testing on catchment models for two study sites. The first catchment is a 1020 ha urban area from the St. Lucia Island (Figure 7-6). This catchment has a medium topography, generally with medium slopes $\left(5^{\circ} \sim 10^{\circ}\right)$, and altitudes between 0 and 400 meters above sea level. While the main land uses are tropical forest and agroforestry, many buildings and roads are present. These are included in the simulations automatically trough interception, infiltration and runoff. The hydrological connection to the sea is provided by a small $(\sim 5 \mathrm{~m})$ channel in the central region of the catchment. The climatic conditions of this area are tropical and the majority of the rainfall occurs during the strong monsoon season. Beyond the regular extreme rainfall events, the island of St. Lucia is recurrently hit by tropical hurricanes. These provide rainfall intensities beyond the normal distribution. For this catchment a spatially homogeneous 1 in 5 years design storm will be used, according to the frequency distribution of hurricane events. The dataset or this catchment is available in a resolution of 10 meters and was developed as part of the CHARIM project (Carribean Handbook on Risk Information Management) and is openly available on their website.

The second catchment is a 2000 ha region along the northern Italian Alps that has been investigated by Borga et al (2007) (Figure 7-5). The area has a medium topography, generally with medium slopes $\left(5^{\circ} \sim 10^{\circ}\right)$, and altitudes between 540 and 2240 meters above sea level. Land use in the region consists mainly of multiple types of forest and heathland in the upslope areas, and small build-up regions in the lower. Annual rainfall varies between 1600 and 1800 $\mathrm{mm}$ per year. Rainfall data is available for an extreme event on the $29^{\text {th }}$ of august 2003. During this event, multiple upslope branches of tributaries of the Fella River experienced flash flooding. Continuous discharge data for this event has been provided. The dataset for this catchment has a resolution of 20 meters. The dataset for this catchment was made as part of the IncREO project (Increasing Resilience through Earth Observation-IncREO).

For both simulations, we set the courant factor at 0.25 since this has provided accurate results in previous calibrations where no dynamic time step was used (Bout \& Jetten, 2018). The global common timestep is set at 20 seconds for the St. Lucia catchment and 60 seconds at the Fella river catchment. These values are estimated to provide accurate behavior for the catchment slopes and grid cell sizes. 

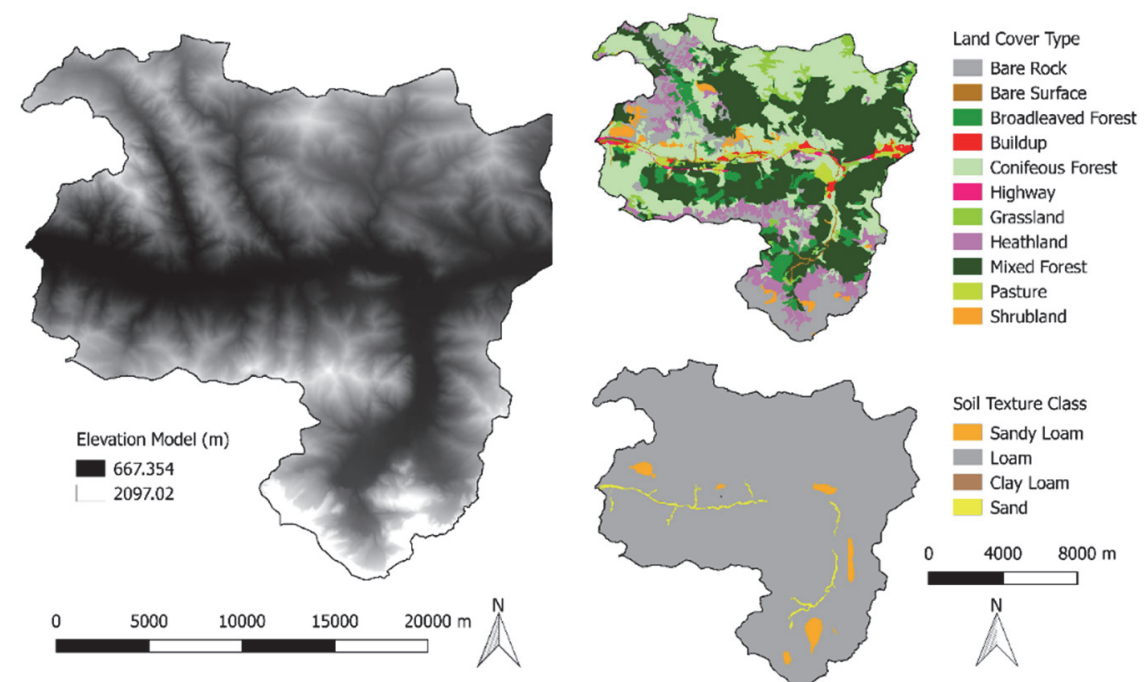

Figure 7-5 Catchment overview for the Fella Basin, Northern Italy. The elevation model, land use type and soil textures are shown.

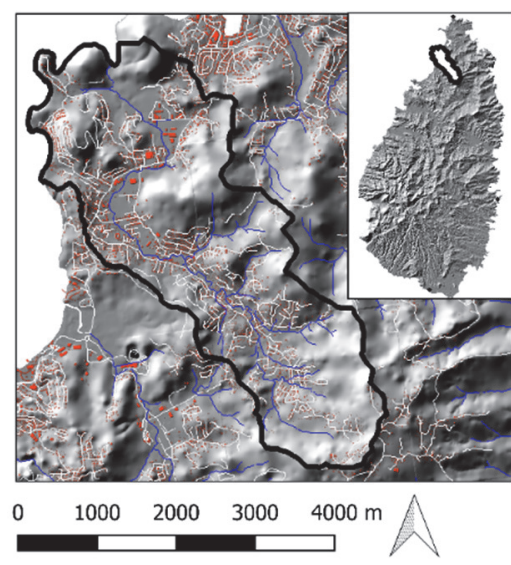

$\square$ Catchment Channels Roads Buildings

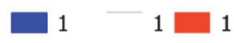

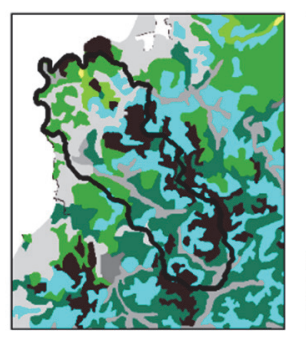

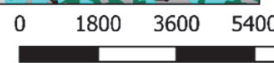

Land Use

Natural Tropical Forest

Mangrove

Scrub Forest

Grassland

Mixed Farming

Intensive Farming

Rural Settlement

Urban Settlement

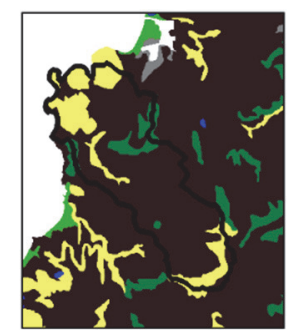

$7200 \mathrm{~m} \mathrm{~A}$ Soil Texture

Clay

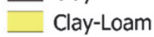

Loam

Silt

Silty Clay

Figure 7-6 An overview of the St. Lucia catchment. Hill shaded elevation, land use and soil texture are shown.

For the St. Lucia scenario, both spatial patterns of flow and outlet discharge are compared. The results from the simulations without SDT are used as a reference. 


\subsection{Results \& Discussion}

\subsubsection{Comparison with Analytical Solutions}

For several moments during the simulation, the flow height and flow velocities are displayed for comparison in Figure 7-7 and Figure 7-8. with the frictionless analytical dam-break solution from Ritter (1892).

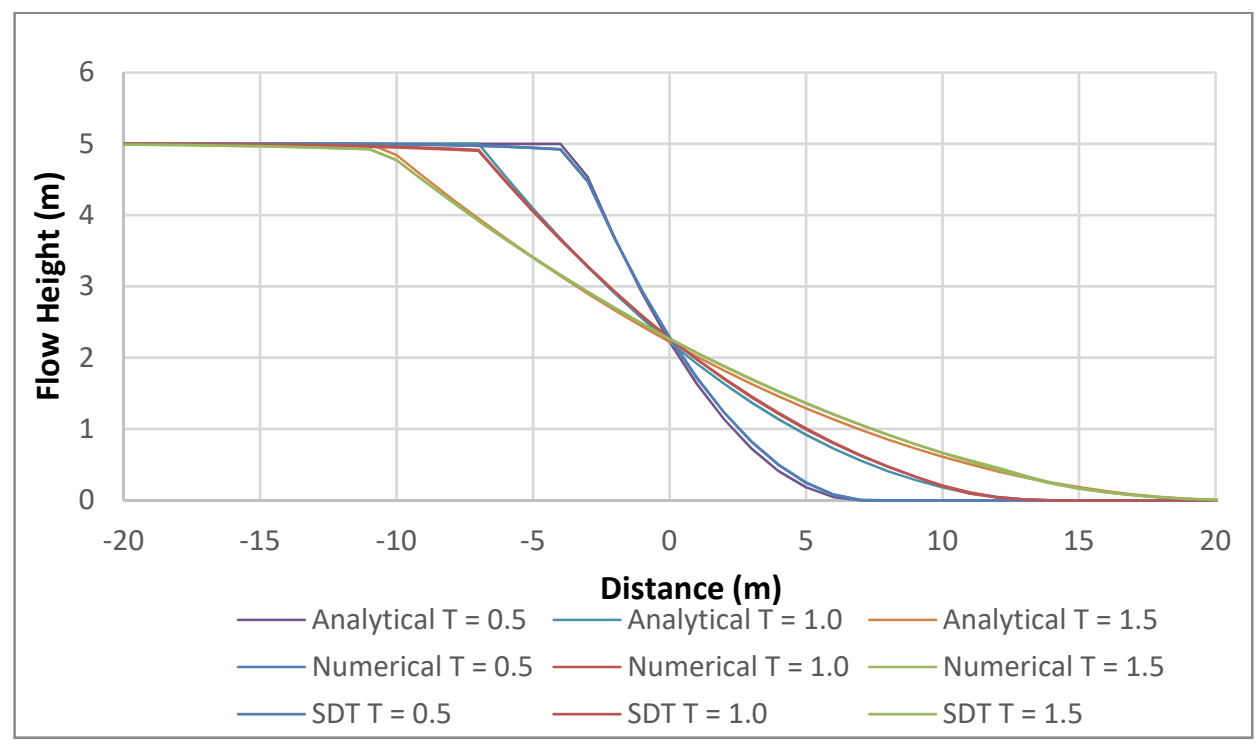

Figure 7-7 Numerical simulation of friction-less dam break using traditional and SDT scheme, compared with analytical solution by Ritter (1892). Cell size for simulation: 0.5 meters

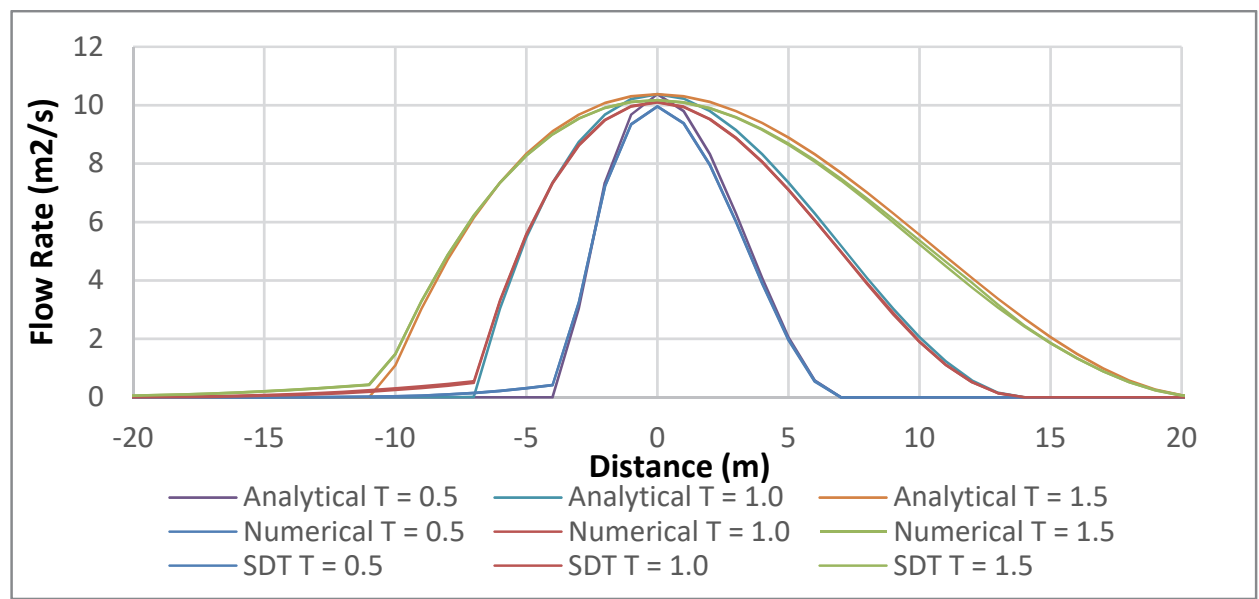

Figure 7-8 Numerical simulation of friction-less dam break using traditional and SDT scheme, compared with analytical solution by Ritter (1892). Cell size for simulation: 0.5 meters 
A comparison of the analytical and numerical solution of a water release, as described by Ancey et al. (2008) is shown in Figure 7-9. The peak water height at every second is provided for the analytical solution, and the numerical solutions with and without LTS.

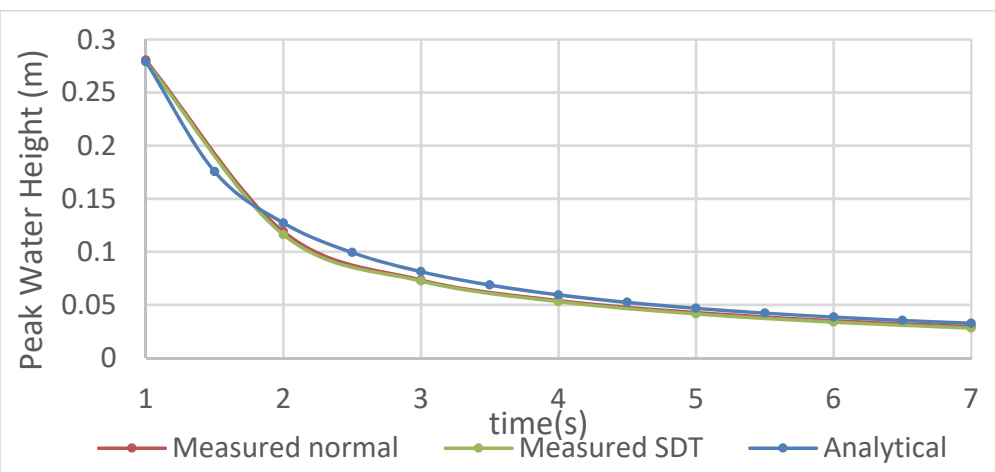

Figure 7-9 Comparison of a numerical and analytical solution of water height after a dam break on a sloped surface. Analyitcal solution by Ancey et al. (2008).

Based on the comparison, performance of the method numerical methods is similar to other numerical methods. The accuracy of these numerical schemes have furthermore been proven during their development [cite other publications about this]. The differences between the numerical solution with and without LTS are minor. Flow height is altered slightly with values below percent. This difference originates from a change in velocities, since these determine inter-cell fluxes. Velocities in the case of the normal simulation are slightly higher, leading to a slight advance in water flow. Reason for this changes in velocities is found in the approximations made in the numerical scheme. With altering timestep, the accuracy of the scheme changes slightly. In general, the normal simulation enforces the lowest found timestep on each cell, therefore increasing the accuracy. Typically, the normal simulation should be at least as accurate in its solution as the SDT simulation. However, where small accuracy errors are accepted for practical reasons in any numerical model, the same holds true for the LTS. The average timesteps during the numerical simulations are 0.079 and 0.032 seconds respectively for the normal and SDT simulation. Without significant differences in simulation results, the effective timestep and thus numerical efficiency has increased substantially. Finally, note that the inflow of water is sudden, which requires a quick change in local timestep. Here the cell calculation order becomes significant. When larger timesteps are calculated first, inflow from faster moving water is ignored until the cell is activated again, leading to unnatural flow boundaries. However, when small timesteps are executed first, cells with incoming flow automatically adapt and are activated when required. 


\subsection{Numerical Tests}

\subsubsection{Results Local Time Stepping}

In Figure 7-10, spatial patterns of maximum flow depth for the St. Lucia scenario, simulated without LTS, are shown. Figure 7-11shows these same patterns for the Fella Basin flood scenario. Figure 7-12 shows the output hydrograph for the St. Lucia catchment, and the relative difference between a normal and SDT scheme. The absolute difference between the resulting maximum flood depth with and without LTS is furthermore provided.

The usage of LTS causes minor changes in simulated maximum flood depth. On average, a deviation of 4.3 e-4 percent was found in the St. Lucia scenario. These differences are similar to the results of the sensitivity analysis of other numerical methods (Delestre et al., 2013; Haile \& Rientjes, 2005; Alcrudo \& Garcia-Navarro, 1993; Sanders et al., 2010). Differences in maximum flood depth are higher near higher water depths, but show separate patterns based on topography. On average, the SDT simulation shows higher flood depths, due to slightly smaller fluxes. The output hydrographs of the St. Lucia catchment similarly show minor differences. The relative difference is highest at the start of the event. Here, a sudden increase in discharge takes place when the flood event arrives at the outlet. When this occurs in one simulation and not the other, large relative differences occur for a small amount of time. Thus, a slight change in timing of the arrival of the flood event can lead to a larger difference at the start of the hydrographs.

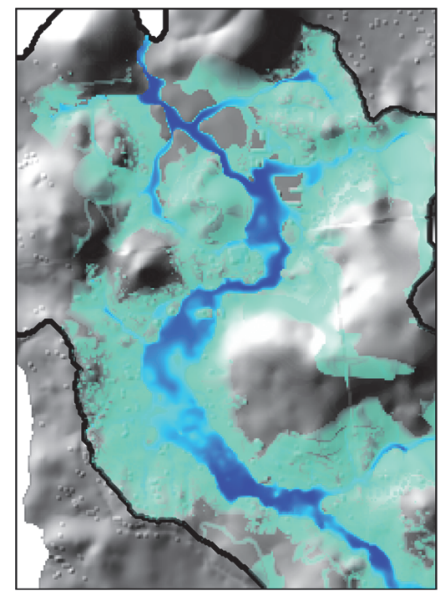

Maximum Flow Height $(\mathrm{m}) \square 0.1$

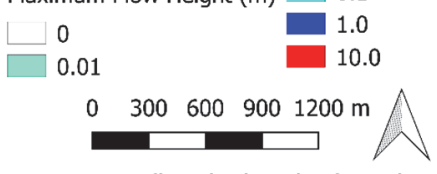

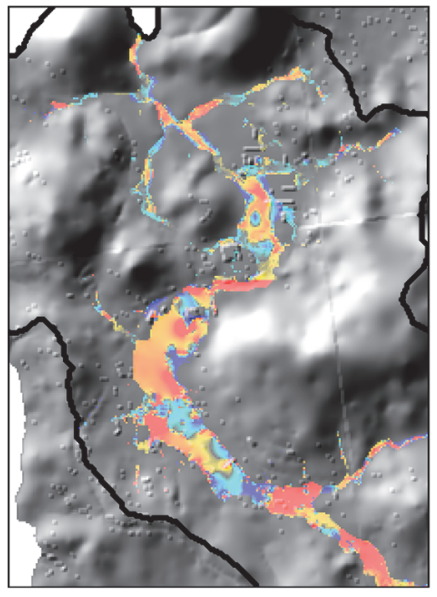

SDT Difference (m)

$-0.02$

$-0.01$

$-0.001$

Figure 7-10 Maximum flood depth for the ST. Lucia simulation, and the difference between simulations with a traditional and SDT scheme. 


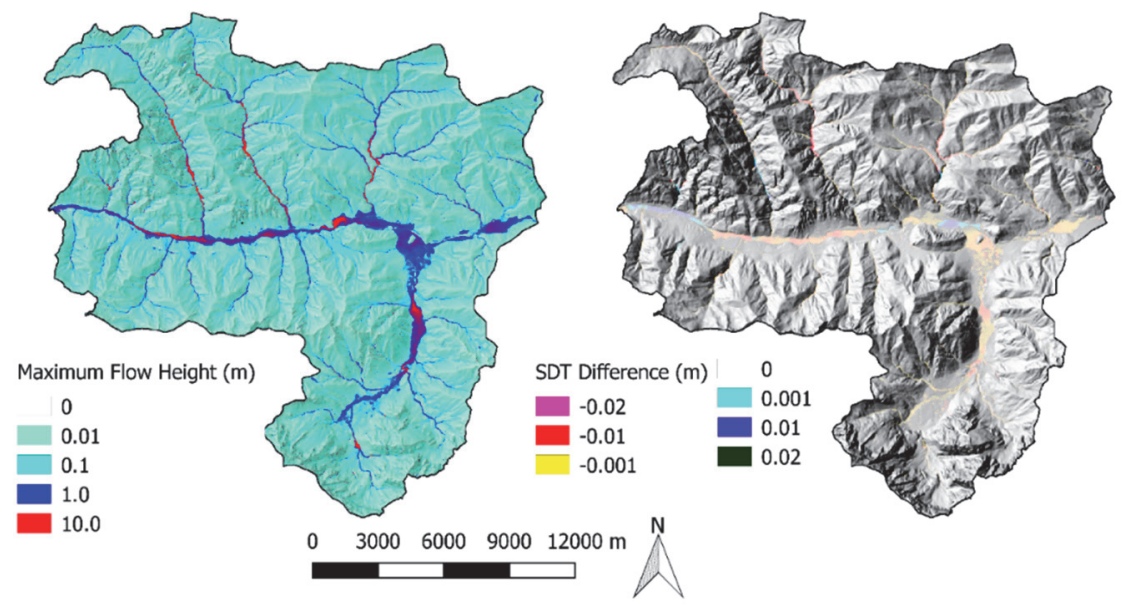

Figure 7-11 Maximum flood depth for the Fella Basin simulation, and the difference between simulations with a traditional and SDT scheme.

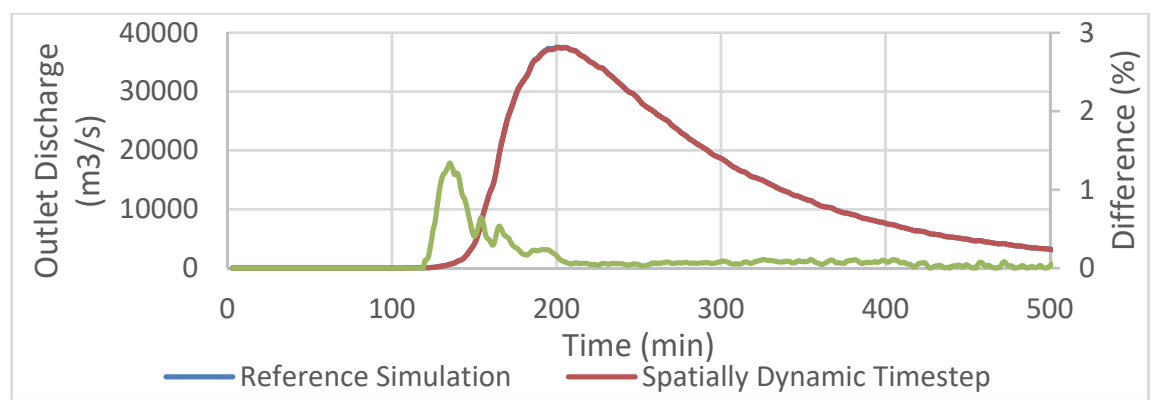

Figure 7-12 The St. Lucia hydrographs using traditional and SDT scheme simulations, and the relative difference.

\subsubsection{Computation Time}

For the St. Lucia catchment, the comparison between effective timestep throughout the simulation is shown in Figure 7-14. A map showing the spatial flow depths and timesteps at a fifth of the event are shown in Figure 7-13. 


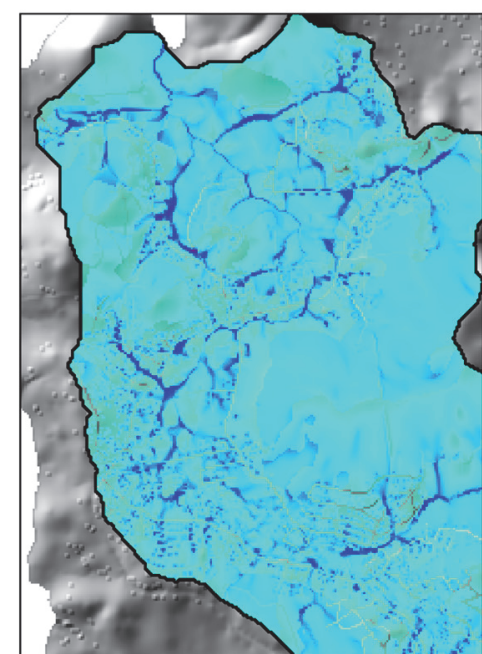

Flow height $(\mathrm{m})$

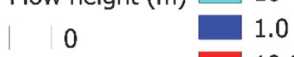

$\begin{array}{ll}\square & 1.0 \\ 1 & 10.0\end{array}$

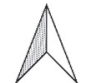

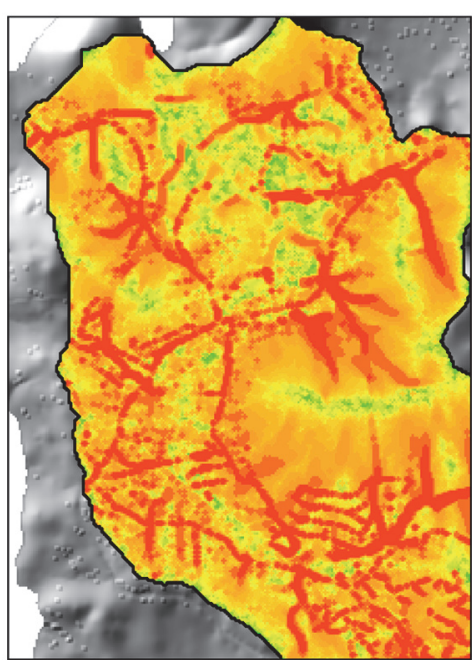

Local Timestep (s)

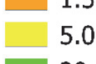

0

20.0

$03006009001200 \mathrm{~m}$

Figure 7-13 Flow heights and local time step at a fifth of the simulated event.

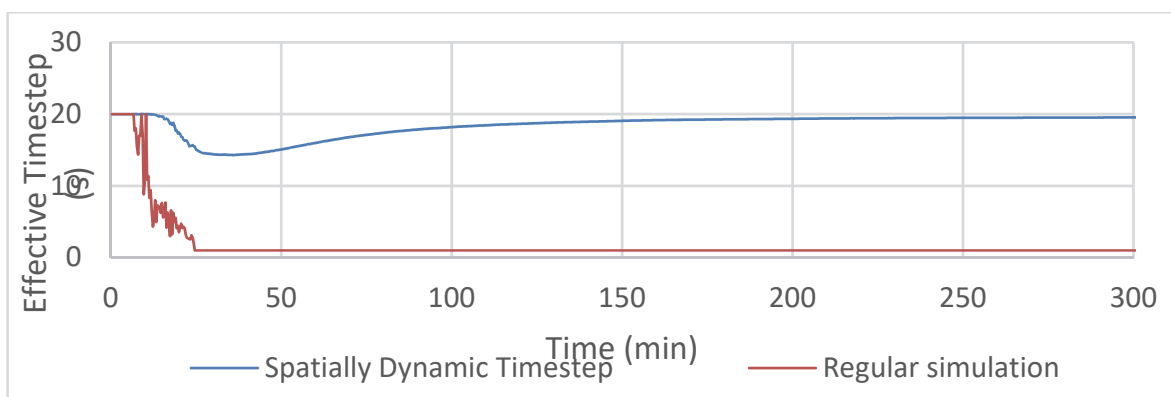

Figure 7-14 Graph of the effective timestep in the St. Lucia simulation.

A table of simulation times and the information of the used hardware is given in Table 7-1.

Table 7-1 Simulation times using traditional and SDT schemes.

\begin{tabular}{ll|l|l|l}
$\begin{array}{l}\text { Simulation } \\
\text { performed with } \\
\text { intel core i7 hq } 6700\end{array}$ & $\begin{array}{l}\text { Simulation property } \\
\text { Simulation } \\
\text { time with SDT }\end{array}$ & $\begin{array}{l}\text { Average } \\
\text { with SDT }\end{array}$ & $\begin{array}{l}\text { Simulation time } \\
\text { without SDT }\end{array}$ & $\begin{array}{l}\text { Average dt } \\
\text { without SDT }\end{array}$ \\
\hline St. Lucia & $\mathbf{4 5 9} \mathbf{~ m i n}$ & $\mathbf{1 1 . 5}$ & $\mathbf{1 0 3 3} \mathbf{~ m i n}$ & $\mathbf{3 . 7}$ \\
\hline Fella Basin & $\mathbf{1 2 3 2} \mathbf{~ m i n}$ & $\mathbf{3 7 . 4}$ & $\mathbf{2 8 8 9} \mathbf{~ m i n}$ & $\mathbf{3 . 2}$
\end{tabular}

For both simulations, there was a decrease of more than 50 percent in computation time. The gradual increase and decrease in average timestep in Figure 7-14 is caused by the gradual increase and decrease of flood area during 
the simulation. The decrease in computation time is not directly proportional to the decrease in average timestep. This is caused by several aspects of the model. Firstly, processes besides flow are computed during the global common timestep. Here processes such as interception, rainfall, infiltration and other slower processes take up computational time. Secondly, the usage of LTS requires the model to keep track of cell-specific time states and timestep values. This creates a certain amount of overhead that would not be present in a normal adaptive timestep approach. Especially the comparison with the timestep of neighboring cells provides substantial overhead computation.

\subsection{Application to Multi-Hazard Modelling}

In order to further test the developed implementation of LTS, we perform a multi-hazard simulation using the full two-phase generalized debris flow equations from Pudasaini (2012). We apply the model on a Catchment in Dominica, which was hit by hurricane Maria in 2017. An overview of the catchment, the land use and soil types found in the area are shown in Figure 7-15.

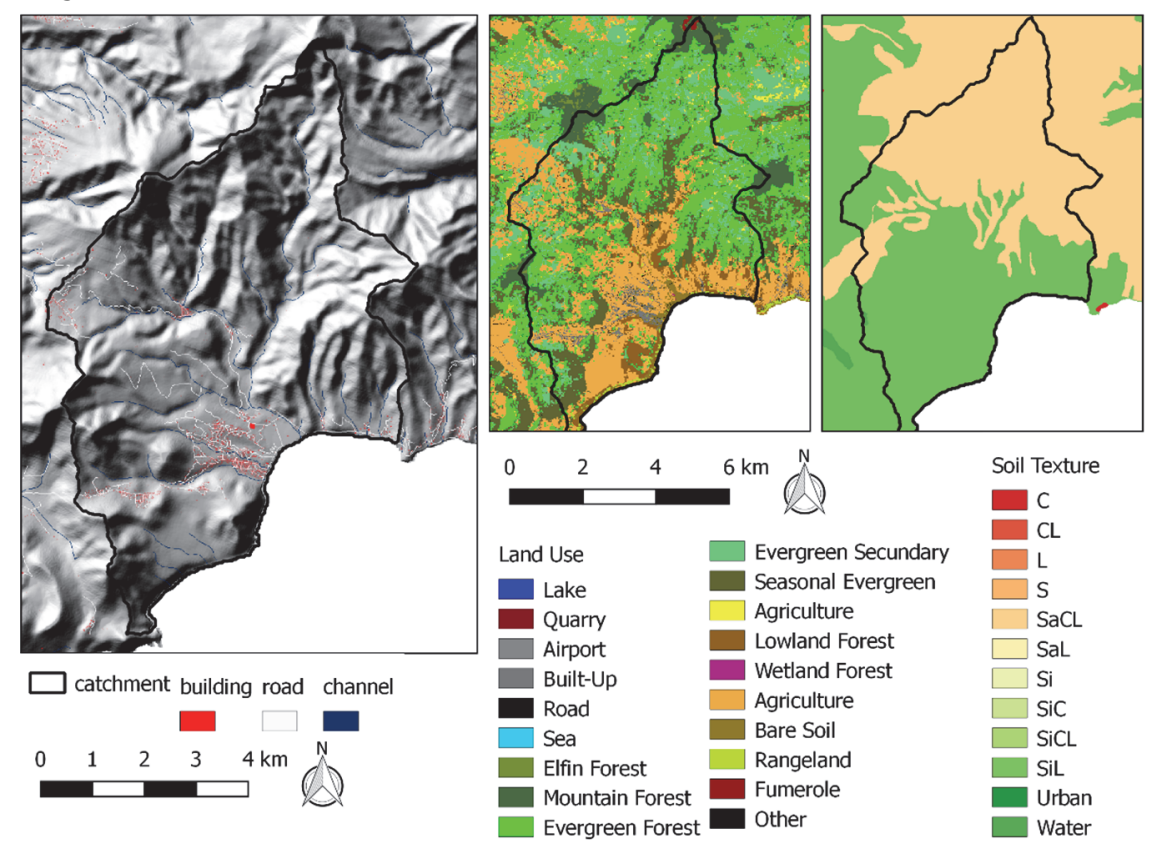

Figure 7-15 An overview of the terrain, land cover and soil texture for a southern catchment on Dominica.

The area is mostly covered by dense tropical forests and features very steep slopes prone to slope failure. The active landscape of the volcanic island consists of clay-rich weathering products of volcanic rock and pyroclastic flow deposits. Internal friction angles have been taken from literature to be 26 degrees. Soil parameters are used from pedotransfer functions by saxton et al. (2006). The rainfall input is a measurement of the Hurricane Maria event, with 
a total of $540 \mathrm{~mm}$ during a period of 24 hours, and peak intensities of over 130 $\mathrm{mm} / \mathrm{h}$. During the simulation, a large number of slope failures are initiated due to increased pore water pressure and weight of the soil columns on slopes. We simulate runout based on the slope failures.

\subsubsection{Results}

The results from the simulation of Hurricane Maria on the southern part of Dominica is shown in Figure 7-16, Figure 7-17 and Figure 7-18. The differences between simulations with and without LTS is highlighted.

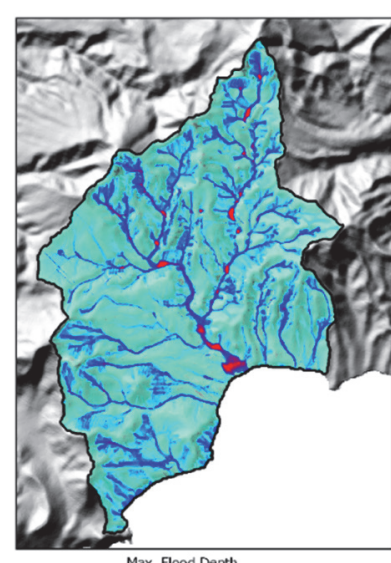

Max, Flood Depth

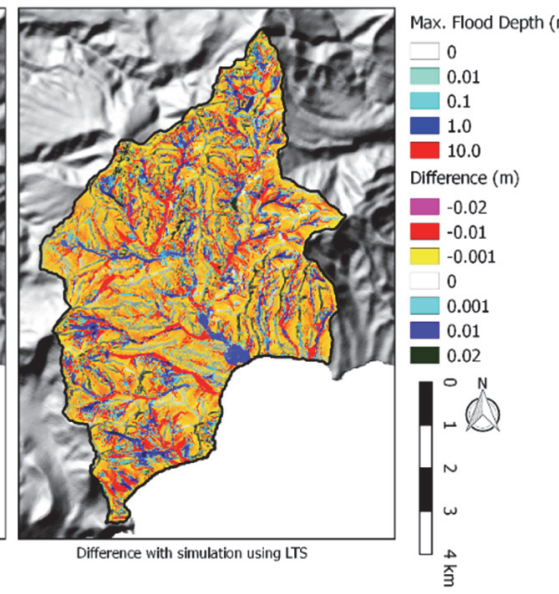

Figure 7-16 Predicted flash flooding on Dominica for the Hurricane Maria event. Differences with LTS are shown.
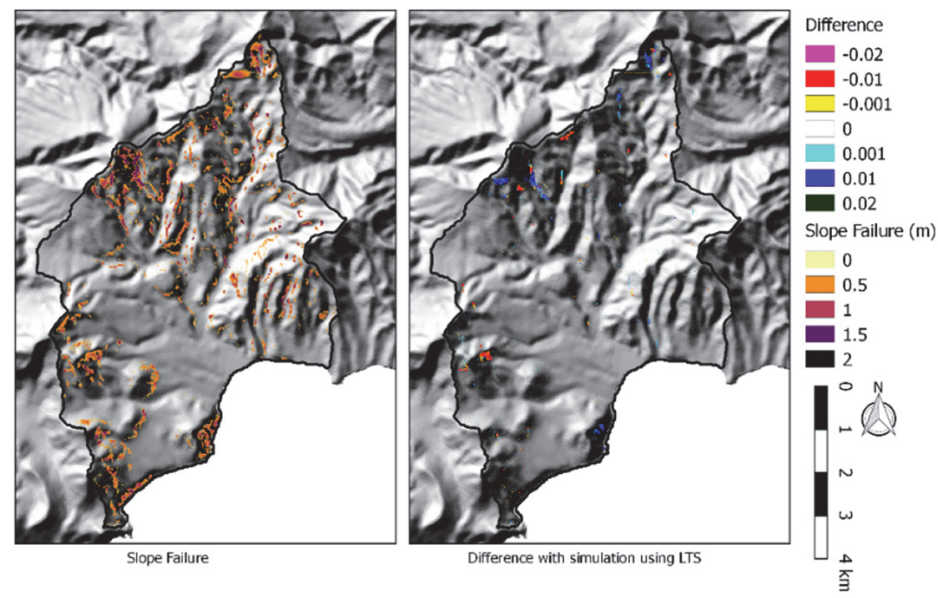

Figure 7-17 Predicted slope failure on Dominica for the Hurricane Maria event. Differences with LTS are shown. 

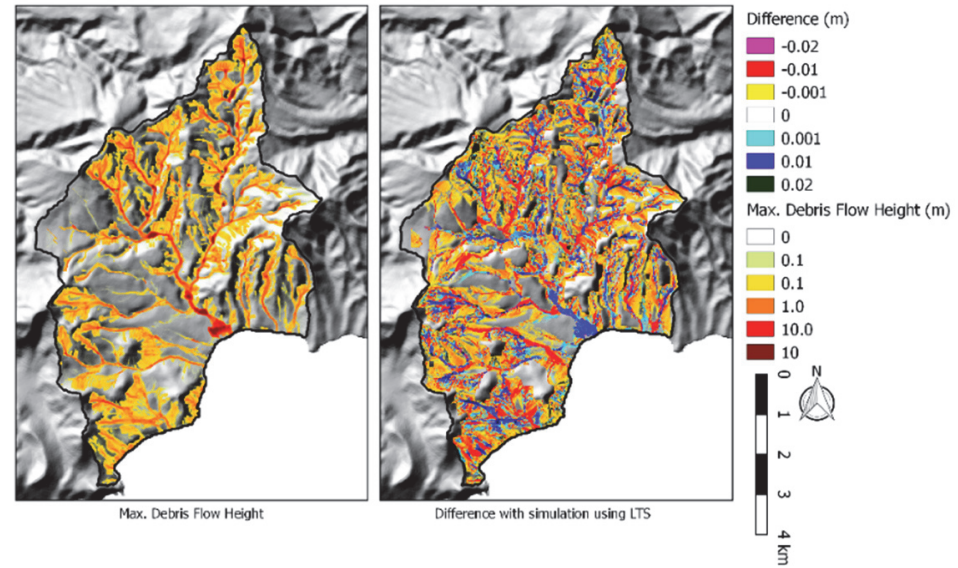

Figure 7-18 Predicted debris flows on Dominica for the Hurricane Maria event. Differences with LTS are shown.

Similar as was the case for the earlier simulations of catchment-integrated flash flood behavior using LTS, the model shows minimal differences between simulation results with or without LTS. The primary difference in the simulations treatment of differences induced by LTS, is the cascading nature of the processes. Due to the interactions, and threshold-like behaviors in the equations used to estimate slope failure, runout, and two-phase flow behavior, a more chaotic system with a higher number of degrees of freedom is simulated. Therefore, small changes in the simulation could later cascade into major differences in output. Here, the changes induced by LTS are relatively small so that even later differences in output remain insubstantial. Computation time for the multi-hazard simulation reduced from 1124 minutes to 673 minutes, with the average timestep increased from 2.8 to 10.3 seconds. Similar to the flood scenarios, the applicability of such methods increases with the efficiency of the model, opening the way for ensemble simulations, or real time application.

\subsection{Conclusion}

We have compared the performance of an adapted friction force implementation for the Saint-Venant equations, combined with LTS. The altered implementation of the friction force showed an increase in stability and accuracy, when timesteps are forced to be larger then allowed by the Courant condition. With increasing timesteps, it took longer before results deviated from a reference simulation. The kinematic timestep constant was furthermore varied. Results from these simulations indicated that the assumptions about shallow $(<0.1 \mathrm{~m}$ ) runoff did not significantly alter simulation results.

A comparison with an analytical solution for an ideal dam-break showed insubstantial differences between the numerical solutions with and without LTS. Numerical simulations in the study catchment of St. Lucia, Dominica and the Fella basin provided identical results, showing that in both small and largescale simulations, the usage of SDT can allow for a larger timestep while maintaining accuracy and stability. Based on the performed test, several varieties of LTS have shown more accurate results. Especially the calculation 
order substantially influenced the deviation from the regular numerical solution. The usage of a variety of neighborhoods to decrease timestep around unstable areas has a minor effect on the simulation results, but is in theory required for a TVD simulation.

While the usage of LTS maintains accuracy, it provides a substantial increase in computational efficiency. Due to the increase in effective timestep, computational costs for a stable simulation decreased. For the St. Lucia and Fella Basin study catchments, an average increase in computation time of 1.9 was found. Because of the decrease in computation time, LTS provides a good option for catchment-scale assessment of flood dynamics. Furthermore, we have shown this increase in efficiency translates to multi-processes land surface models for hydrology, flow and multi-hazard events. This indicates the wider potential benefit of LTS for a variety of models in environmental studies. 


\section{Physically-based Simulations for Hydrometeorological Hazard and Risk Assessment}

This chapter has been submitted as B. van den Bout, M. Dibaba, F. Brenner, S. Emtehani, V.G. Jetten, C. J. van Westen (under review) Assessment of hydro-meteorological multi-hazard and impact using an integrated physicallybased model

On the $19^{\text {th }}$ of September, 2017 , The category 5 hurricane Maria made landfall in Dominica (GFDRR; 2018; Commonwealth of Dominica, 2018). Extreme wind and precipitation triggered a variety of hazardous processes. The precipitation of over $500 \mathrm{~mm}$ in 24 hours led to flash flooding throughout the island. Additionally, numerous slope failures were caused resulting in debris flows and landslides impacting the channels and towns. The interactions between flood and mass movements hazard resulting in devastating debris floods rushing through the river systems. Simultaneously, a significant storm surge flooded major parts of the South-Western coastline. Finally, wind damaged the vast majority of buildings directly, and indirectly lead to damages through windthrow of trees, of which many entered debris flows, blocking culverts. The complexity of the processes induced by hurricane Maria, and in particular their interactions, raises questions on how we can understand the risk posed by such multi-hazard events.

Multi-hazard and risk assessment is generally used to both understand current hazard and risk, and their changes in future scenarios (Gallina et al., 2016). Intrinsically, risk is the multiplication of probability, exposure and vulnerability (Varnes, 1984). Thus, for each potential event, with a specific probability, exposure and vulnerability must be found. Commonly, both exposure and vulnerability are expressed in terms of hazard intensity. This generally involves a spatial prediction of the intensity of all relevant hazards for a variety of probability values, either using physically-based or statistical modelling (van Westen et al., 2014). Examples of application of multi-hazard and risk assessment can be found in Capra (Cordona et al., 2010), Matrix (Nadim et al., 2009; Marzocchi et al., 2012), Cluva (Garcia et al., 2012) or RISK-NAT (Douglas, 2007).

For many existing hazardous processes physically-based numerical modelling is an important tool for predicting spatial hazard intensity based on a specific triggering event. Examples this included (flash) flood modelling, such as done using the models HEC-RAS (Brunner, 2010) or OpenLISEM (De Roo \& Jetten, 1999; Bout et al., 2018), mass movement runout models such as RAMMS (Bartelt et al., 2013) and Flo-2D (O'Brien, 2006), landslide initiation models such as TRIGRS (Baum et al., 2002) and SIMTOP (Lee \& Ho, 2009). Despite the wide application of physically-based modelling in hazard and risk assessment, application of the methods mentioned above in multi-hazard assessment faces a variety of issues. Firstly, since commonly used models focus on individual hazard in an isolated manner. Since these do not implement the hazard interactions and can thereby introduce substantial errors (Kappes et al., 2014; Mergili et al., 2018; Bout et al., 2019;2020). 
Recent developments in integrated modelling approaches for hydrometeorological surface hazard have led to the development of several integrated physically-based multi-hazard models. Many of these, such as r.avaflow (Mergili et al., 2016) and OpenLISEM hazard (Bout al., 2018) extend existing modelling techniques to include the interactions and process chains present in complex multi-hazard events. While these models face issues related to parameterization and uncertainties (Mergili et al., 2018; Bout et al., 2020), their additional value in simulating multi-hazard interactions is significant (Bout et al., 2018).

The objective of this research is to investigate the usage of integrated physically-based modelling tools for both hazard assessment and scenario exploration. In this study we apply the integrated physically-based multihazard model OpenLISEM Hazard (Bout et al., 2018) for analyzing changing multi-hazard risk in the Caribbean island of Dominica, affected by tropical storms, and analyze both the hazard during Maria, after this event, and in future scenarios.

\subsection{Study Area: Dominica}

Dominica is a Small Developing Island State (SIDS), part of the Lesser Antilles. It is inhabited by approximately 70,000 people and has a GDP of 9,726 USD per capita (IMF, 2017). The island has a surface area of approximately 750 $\mathrm{km}^{2}$ and is covered mostly by natural tropical forest. The topography is characterized by steep slopes, and several central volcanic peaks up to 1400 meters altitude. Economic production consists mainly of financial services, cruise tourism, and agriculture although this sector, particularly banana production, suffers from the repeated impact of hurricanes.

In the past decades, several major tropical storms have hit the island, of which Hurricane David (1972), tropical storm Erika (2015), and Hurricane Maria (2017) were the most damaging. Tropical storm Erika passed the island on August 28, 2015, and the associated extreme rainfall $(850 \mathrm{~mm})$ lead to numerous landslides in the southern part of the island, and flashfloods taking out many bridges and culverts. The southeastern village of Petite Savanne was evacuated and the government started to build a relocation settlement near Bellevue Chopin. While the country was still in the recovery phase of tropical storm Erika, Hurricane Maria latter made landfall on Dominica on September 19, 2017 as a category 5 hurricane, after it experienced a short explosive intensification, unpredicted by local and regional forecasters. The hurricane lead to extreme wind speeds, storm surges and cumulative rainfall throughout the island. Damages where caused to virtually all buildings, both due to winds damaging the roofs or walls, or floods and landslides damaging the buildings. Over 70 percent of all buildings where reported to have been significantly damaged during the event (Dominican Government, 2018). Hurricane Maria lead to a total of 65 fatalities (Dominica News Online, 2018). The total damage was assessed to be 930.9 million USD and losses of 380.2 million (GFDRR; 2018; Commonwealth of Dominica, 2018), which equals 226 percent of Dominica's 2016 gross domestic product (GDP).

During the event, four of the six permanent rainfall stations remained operation. The time series of rainfall intensities for the raingauge at Canefield airport is shown in Figure 8-1, and Figure 8-2 shows the rainfall distribution 
derived from rainfall radar from Guadeloupe. The hurricane hit the island centrally, as is reflected in cumulative rainfall of $500 \mathrm{~mm}$ in a period of 24 hours at Canefield Airport.

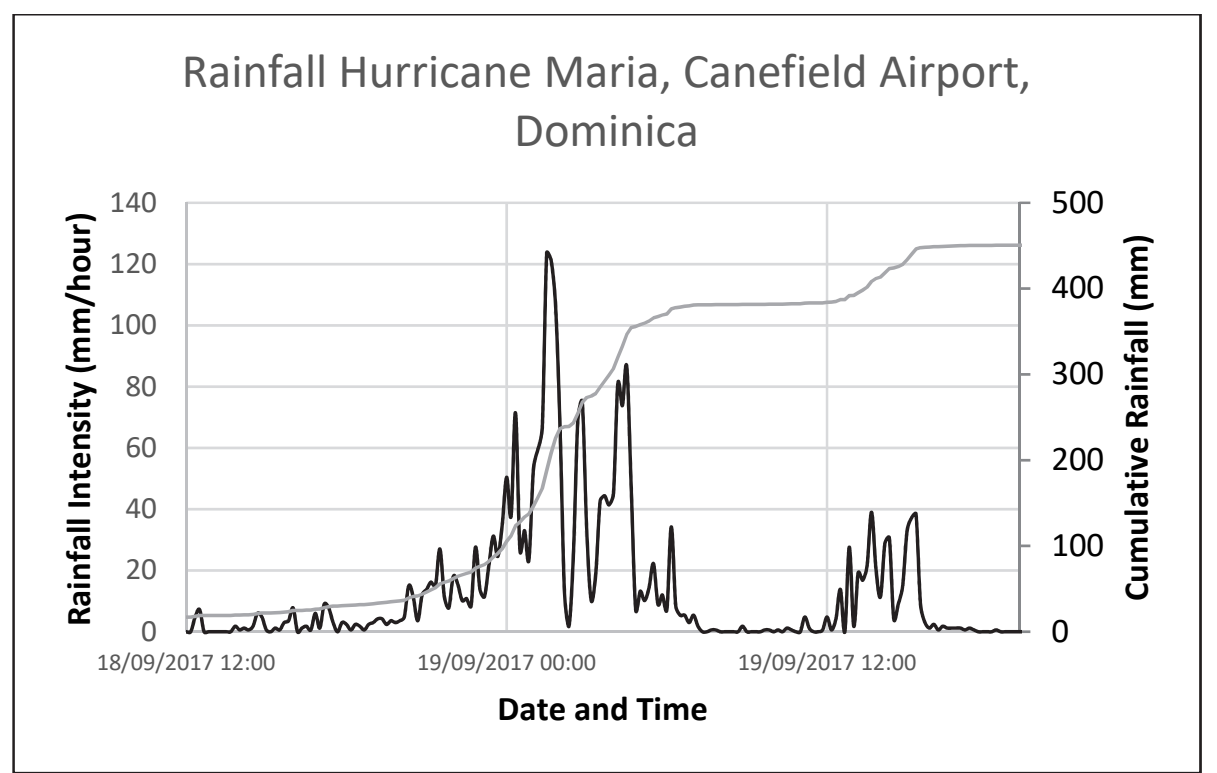

Figure 8-1 Rainfall intensity measured at Canefield Airport for Hurricane Maria. Time indicated in local time.
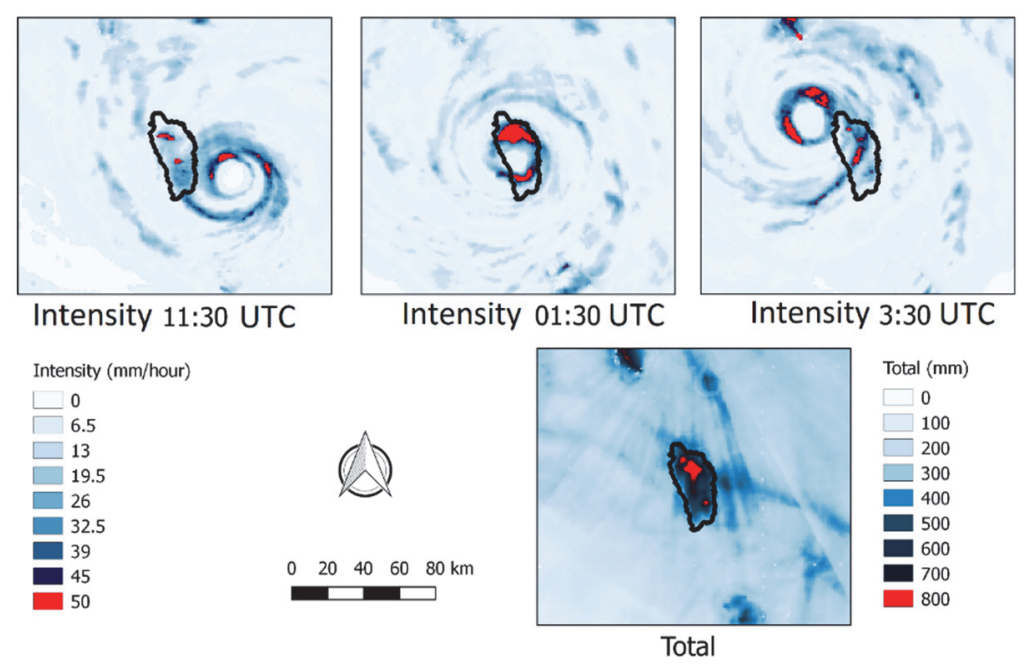

Figure 8-2 Rainfall patterns for Hurricane Maria moving over Dominica on September 19 (Meteo France).

\subsection{Model Description}

We applied the integrated physically-based multi-hazard model OpenLISEM Hazard (Bout et al., 2018). This model implements the generalized two-phase 
debris flow equations from Pudasaini (2012) with improvements presented in Pudasaini and Fischer (2017) and Pudasaini \& Mergili (2019). Slope stability is based on the iterative failure method (Bout et al., 2018). A schematic overview is shown in Figure 8-3.

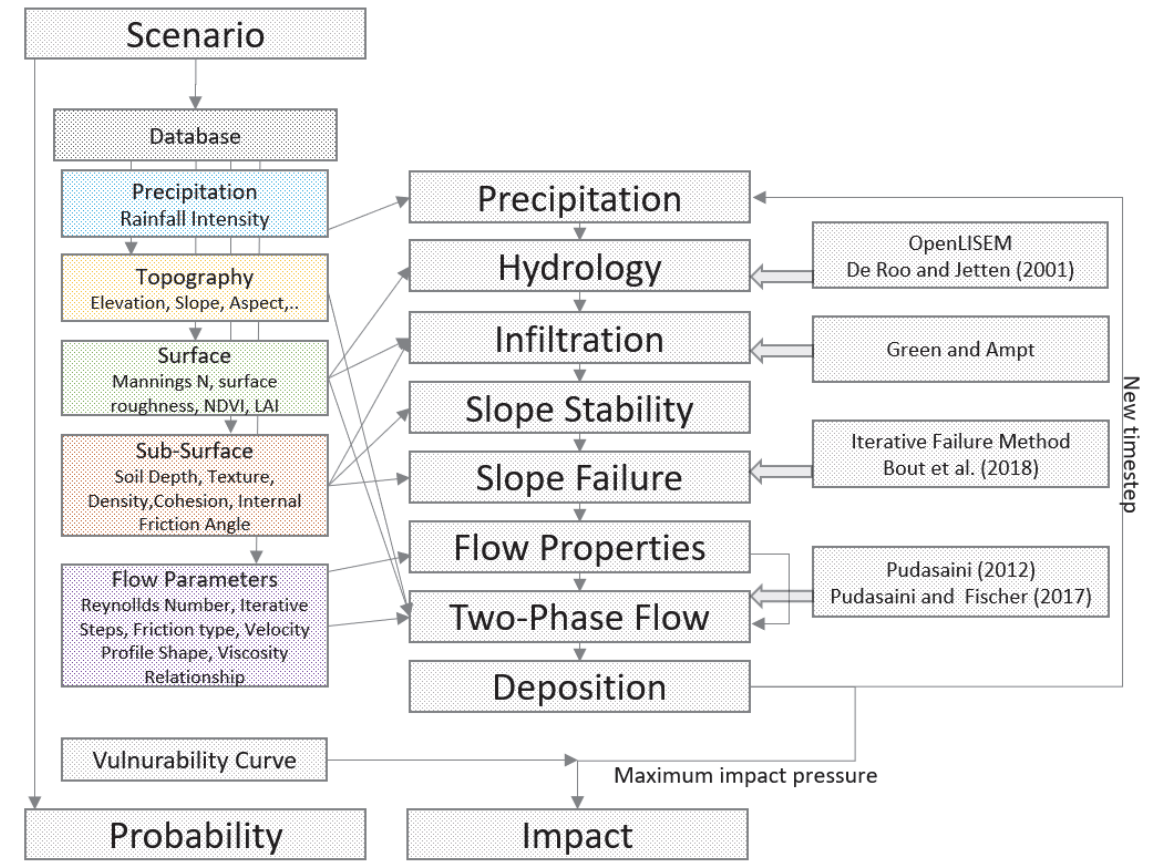

Figure 8-3 Flowchart of the methodology used for analyzing changing multi-hazards in Dominica, using a set of scenarios within the physically-based multi-hazard model OpenLISEM.

The current version of the OpenLISEM Hazard model allows to simulate interaction of rainfall runoff, soil water fluctuations, slope stability, water and sediment flow, entrainment, inundation and sediment deposition. It does not include the simultaneous effects of wind (e.g. windfall of trees interaction with landslides and flows) and storm surges (interacting with river flow at the outlet of the river). The model was also used to analyze how the hazard might change over time, in the period of recovery from the impact of hurricane Maria for different scenarios.

\subsection{Input Data}

Prior to Hurricane Maria a set of hazard maps was made through the World Bank funded CHARIM project (Caribbean Handbook on Risk Information Management), and distributed through an open online data repository (CHARIM, 2016). The Flash flood analysis was done using OpenLISEM simulations of flood behavior for 4 return period design storms with $5,10,20$ and 50 years return period (for a description of this version of the model, see Bout and Jetten, 2018). The landslide susceptibility was obtained using a combination of weights-of-evidence approach and expert opinion (Chen et al., 
2016). A combination of flash flood and landslide hazard are shown in Figure 8-4. A comparison between this approach to the multi-hazard on Dominica the integrated multi-hazard modelling is provided in the results section.
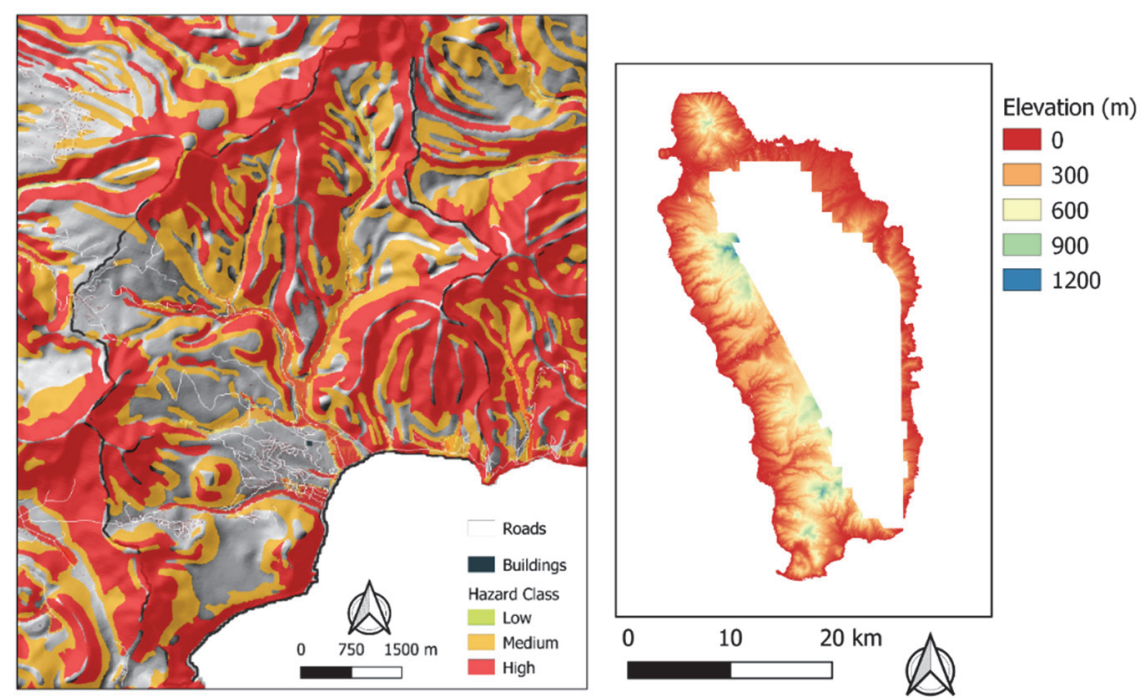

Figure 8-4 (left) A combined landslide/Flash flood hazard classification made as part of the CHARIM project. (right) The available LIDAR data for the island of Dominica.

The extreme rainfall during the passing of Hurricane Maria triggered a large number of landslides on the island. A complete inventory of shallow landslides, debris flows and flash floods was made available by Van Westen and Zhang (2018) (see figure 8-7).

The digital elevation model (DEM) is arguably the most important input for the OpenLISEM Hazard model. It influences a variety of pcrocess both directly (in particular through slope directions and steepness) and indirectly (such as by determining covariate parameters in the soil depth modelling). A gridded LiDAR dataset with 2.5 meter resolution was obtained which covered approximately $73 \%$ of the catchment area (Figure 8-4). The LiDAR survey was carried out between February and May 2018, five to eight months after the hurricane. Both the Digital Surface Model (DSM) as well as the Digital Elevation Model (DEM) were available. The remaining $27 \%$ of the area, which includes the highest part of the island, could not be surveyed with the LiDAR data due to the persistent cloud cover. The remaining gap in the DEM was filled using SRTM 30 meter resolution data. Finally, this merged elevation dataset was resampled to 10 meter resolution for improved balance between computation time and accuracy. The watershed of the Geneva and Micham River was selected as study area. This area is located in the Grand Bay area in the south, and includes the settlements of Pichelin, Lower Pichelin and Berekua, which were heavily impacted by hurricane Maria (Figure 8-5) 


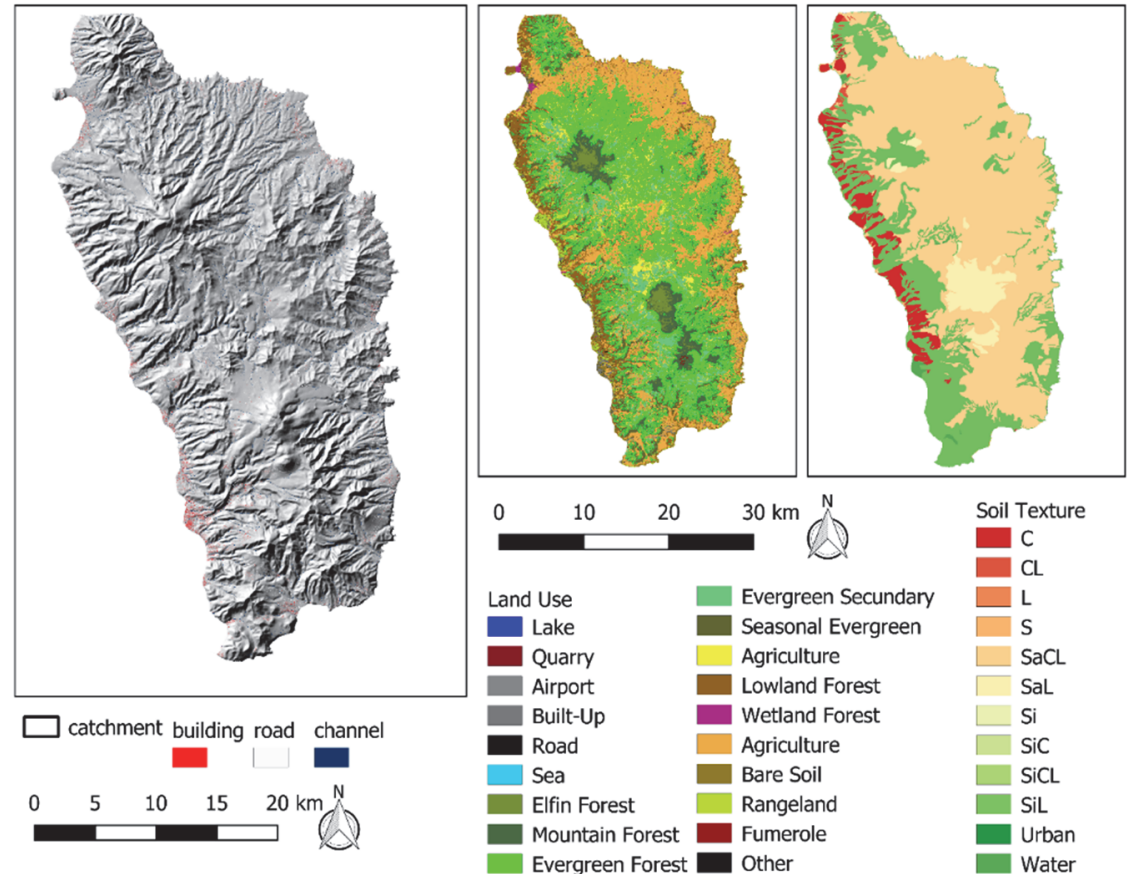

Figure 8-5 The hillshaded elevation model (Government of Dominica), land cover (CHARIM, 2016) and soil texture maps (CHARIM, 2016).

A landcover map for Dominica was generated by Coan et al. (2007) through image classification of Landsat and SPOT images. Roads, built-up areas, airports, lakes and quarries were added by the CHARIM project, and represent the situation in 2015 (CHARIM, 2015). The dataset was updated by a mapping effort following hurricane Erika, organized by the Humanitarian OpenStreetMaps Team (HOT). The final map contains 18 land cover classes (). For each of these classes, physical parameters such vegetation height, and canopy cover were measured using the subtraction of the LiDAR DSM and DEM, and samples measured in the field. Other parameters such as Manning's surface roughness and surface micro roughness were estimated in the field using comparison manuals.

A geological map of Dominica was generated by Roobol and Smith (2004). The Island consists predominantly of volcanic deposits, ranging in age from Miocene to recent, with a number of Pelean domes, pyroclastic apron of block and ash flow deposits, andesitic lavas and ignimbrites. Some uplifted patches of limestone and conglomerate exists at the western coastline. A pedological soil map was made by Lang (1967), through geomorphologic interpretation of aerial photographs from 1959, field surveys and laboratory testing. Soil properties were also obtained from the SoilGRIDS database, which was generated using machine learning methods to map the spatial distribution of soil properties globally with a spatial resolution of $250 \mathrm{~m}$ (Batjes et al., 2019). Most soils are weathering products of the volcanic deposits that form the island. Clayey soils are predominant, with different ages throughout the island. In many areas, there is a substantial layer of volcanic tuff with a smaller layer of 
more weathered and organic-rich material on top. For this study, the pedological soil map was used to obtain soil textures, after which pedotransfer functions were used to estimate hydrology and geotechnical parameters for the soils (Saxton and Rawls, 2006). Soil depth information for the island was not available from any previous study, except from the SoilGRIDS data, but that was too general with $250 \mathrm{~m}$ grid cells. Therefore, a new spatial soil depth prediction was made using a combination of a steady-state soil depth model and statistical spatial extrapolation. The steady state model from Ruette et al. (2013) was applied, using the depths of 130 landslides scarps as calibration and validation dataset. Then, a statistical model such as proposed by Kuriakose et al. (2009) was used to create a separate prediction. Similar conclusions were found as in the work of Bout et al. (2018) and Bout et al., (2020): while the steady-state model shows detailed patterns on steep slopes, it lacks diffusive deposition of alluvium in floodplains. Therefore, we combine, linearly interpolated based on the gradient of the terrain, the two separate soil depth predictions.

Table 8-1shows an overview of the input parameters, their value if applicable, and the methodology used to obtain them.

Table 8-1 Input parameters and their source.

\begin{tabular}{|c|c|}
\hline Elevation & $\begin{array}{l}\text { LIDAR data }(0.5 \mathrm{~m} \text { resolution) for over half of the island } \\
\text { (missing the central part) filled using SRTM ( } 30 \mathrm{~m} \text { resolution) } \\
\text { resampled to } 10 \text { meters resolution. }\end{array}$ \\
\hline Channel Network & Drainage network created from DEM \\
\hline Channel Properties & $\begin{array}{l}\text { Channel width and depth measured in field for } 10 \text { streams at } \\
\text { upstream point and outlet. Linear relationship obtained } \\
\text { between drainage area and channel dimensions. }\end{array}$ \\
\hline Land Use & Land use map from classified SPOT images obtained from. \\
\hline Vegetation Density & $\begin{array}{l}\text { Normalized Differential Vegetation Index from Sentinel-2 } \\
\text { imagery. }\end{array}$ \\
\hline \multicolumn{2}{|l|}{ Soil Texture } \\
\hline Soil Depth & $\begin{array}{l}\text { Multi-variable linear regression through soil depths measured } \\
\text { at landslide scarps, combined with steady-state soil depth } \\
\text { simulations as proposed by Ruette et al. (2013). }\end{array}$ \\
\hline Urban Elements & $\begin{array}{l}\text { OpenStreetMaps vector data for roads, buildings and bridge } \\
\text { locations }\end{array}$ \\
\hline 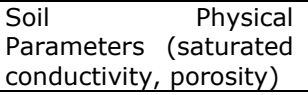 & $\begin{array}{l}\text { Texture-based spatial prediction of pedotransfer functions from } \\
\text { Saxton et al. (2006) }\end{array}$ \\
\hline $\begin{array}{lll}\text { Initial soil water } \\
\text { content }\end{array}$ & $\begin{array}{l}\text { Three-month ground water simulation for Dominica, using } \\
\text { SRTM hourly rainfall. Initial ground water levels and effective } \\
\text { moisture content estimated as } 50 \text { percent and } 80 \text { percent } \\
\text { respectively after a major event nearly three months before } \\
\text { arrival of maria. }\end{array}$ \\
\hline $\begin{array}{ll}\text { Soil } & \text { Strength } \\
\text { Parameters } & \end{array}$ & $\begin{array}{l}\text { Soil cohesion measured in field for } 23 \text { landslide locations in } \\
\text { Grande Bay area. Internal friction angle estimated based on } \\
\text { soil texture, but later calibrated. }\end{array}$ \\
\hline Precipitation & Locally-measured rainfall record with 1 minute interval \\
\hline Inventory & $\begin{array}{l}\text { High-resolution imagery used to map visible traces of mass } \\
\text { movements and flash floods. }\end{array}$ \\
\hline $\begin{array}{ll}\text { Global } & \text { numerical } \\
\text { Parameters } & \end{array}$ & $\begin{array}{l}\text { Courant Factor }=0.1 \text {, Sub-timestep iterations }=5 \text {, Parameters } \\
\text { in viscosity relationship }=\{1,10\}\end{array}$ \\
\hline
\end{tabular}




\subsection{Modelling Scenarios}

First we simulated the hazard interactions that occurred within the study area during the passing of hurricane Maria. As input for the model we used the soil, land cover, terrain, road and bridge properties as they existed before landfall on September 18, 2017. In order to study the effect of the changes in the landscape that were the results of a previous extreme event, we included the effects on the materials and vegetation of Hurricane Erika, which occurred two years before Maria. To do this, we reduced the modelled soil depth for the landslide scarps that occurred during Erika and reduced the vegetation on all areas that were stripped of vegetation during Erika in landslide scarps, transport zones and flash flood areas. The removal of and regrowth of vegetation was assessed using sentinel-2 imagery dated three months before Maria, which resulted in a reduction in leaf area index of 63 percent compared to neighboring areas with similar land cover. Root density was measured for new beginning vegetation growth on landslides. Root strength was measured according to the method outlined by Bout et al. (2020), and for 8 locations an average value of $4.6 \mathrm{kPa}$ was found. The post-Maria LIDAR elevation data was used. While there is a clear contradiction in using the LIDAR data, that was obtained after hurricane Maria, for simulating the impact of hurricane maria itself, the usage of other low resolution data sources created unreasonable errors in the predictions in slope failure locations.

After simulating the multi-hazards triggered by hurricane Maria, we introduced a number of possible future scenarios, for which we modelled the multi-hazard extend and intensity. The first simulated scenario was to analyze the hazards in case a similar strong hurricane would hit the island in the coming years, before the vegetation would be recovered, or any risk mitigation measure would be carried out. For this scenario we reconstructed the state of the landscape as it was after hurricane Maria. The soil depth map was reduced for the landslide scarps that were triggered by Maria, and enlarged for the accumulation areas. The deposits similarly fill channels and reduce discharge capacity by reducing effective depth. All vegetation was removed for all areas where the vegetation was destroyed during hurricane Maria, which was mapped by the multi-process inventory.

The second scenario relates to the state of the tropical forests on Dominica after hurricane Maria. Both in imagery and field visits, it was confirmed that large sections of forests within the study site lost their leaves. Hu and Smith (2018) observed a rapid decrease in NDVI after Maria, but a steady return to normal values within several months. However, the portion of this return is caused by fast-growing creepers and vines as indicated by field visits and the local forestry department (see Figure 8-6). This scenario assumes that a large part of the forest vegetation that was stripped of leaves and branches during the extreme wind accompanying hurricane Maria, would not recover completely in the coming years. After Maria most of the tropical forest in the area was in a critical condition. Without proper management, the possibility exists of significant portions of the forest dying off, and its root systems decaying in the coming years. To obtain a spatial estimate of forest cover in such a scenario, we mapped, based on field visit and post-Maria high resolution satellite imagery, the presence of forest that was in critical condition after Maria (mapped locations are shown in figure 8). The predominant invasive vine species on the island is Mikania Micrantha, from which the root network does 
not reach beyond 0.5 meters, and can thus effectively be ignored at potential shear planes in slope failure calculations. We assume approximately 30 percent of forest survives as a potential scenario, and ignore vine root networks. Thus, root cohesion is reduced to $30 \%$ of its original value.

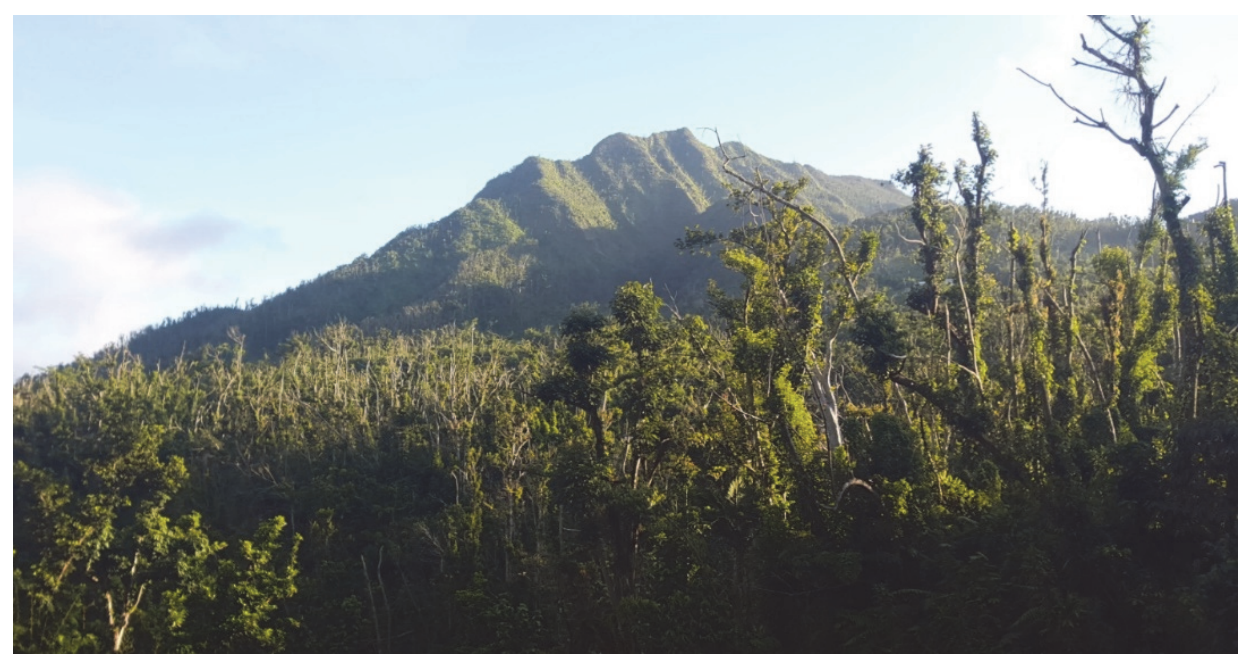

Figure 8-6 An overview of a forest in south-east Dominica. Notable is the absence of green branches on the trees due to hurricane winds, and instead the presence of invasive vines.

Three scenarios with mitigation measures were also simulated. The third scenario assumes that the landslide and debrisflow deposits in the lower sections of the stream channels were removed, in order to reduce the flood hazard in the downstream section. This measure was taken by the government of Dominica after hurricane Maria, with financial support of international donors. The amount of observed materials deposited by Maria are based on a simulations results of the Maria replication. In the simulations for scenario $3 a, b$ and $c, 25,50$ or 75 percent of the deposited material is respectively removed from the channels.

The fourth scenario assumes that apart from the removal of sediments ( $75 \%$, additional mitigation measures are carried out in the form of checkdams. These can effectively prevent basal erosion and retain sediments (Shresta et al., 2008). These implemented have a sediment-blocking height of 5 meters and width of 45 meters. We do not perform a cost-benefit analysis. The purpose of this scenario is rather to investigate the possibility of modelling mitigation efficiency within physically-based multi-hazard models. The locations of the checkdams are two highly active streams that feed the river near Pichelin, one of the most impacted areas. Within the model, the topography on the checkdam locations is altered based on the height. When solid deposits fill the checkdams, deposition automatically alters the elevations there, after which flow ignores them. The locations are shown in Figure 8-7.

The fifth scenario assumes that apart from the sediments removal (75\%) extensive slope stabilizing works are carried out through soil anchoring, as was proposed after Hurricane Dominica (CommonWealth of Dominica, 2015). Similar to the fourth scenario, we do not provide a detailed setup. Instead, we 
choose a selection of sloped areas with reasonable accessibility, vulnerable to slope failures, and with direct influence on downstream settlements (Figure 8). Within the model, we assume the mitigation is successful and these slopes are stable independent of their properties.

The final scenario contains land use changes in a more traditional sense. We include the buildings, both temporary and permanent, that were constructed and planned after hurricane Maria. These include the additional housing projects and abandoning of previously inhabited regions as part of risk reduction by the government of Dominica. The mapped building polygons were vectorized first from google earth imagery and later rasterized for usage within the model. Additionally, forested areas are being converted into agroforestry. We continue this trend by adding several low-steepness areas close to settlements to be converted to this. For an overview of new buildings and continued deforestation trends see figure 8 . The new surface parameters for deforested areas are obtained from the values from agroforestry class. In particular, organic matter content for the top soil layer, Mannings surface roughness and root cohesion are changed because of the land use changes. Within the modelling workflow, the lower organic matter causes a reduction of hydraulic conductivity and porosity in the pedotransfer functions from Saxtion et al. (2006). 


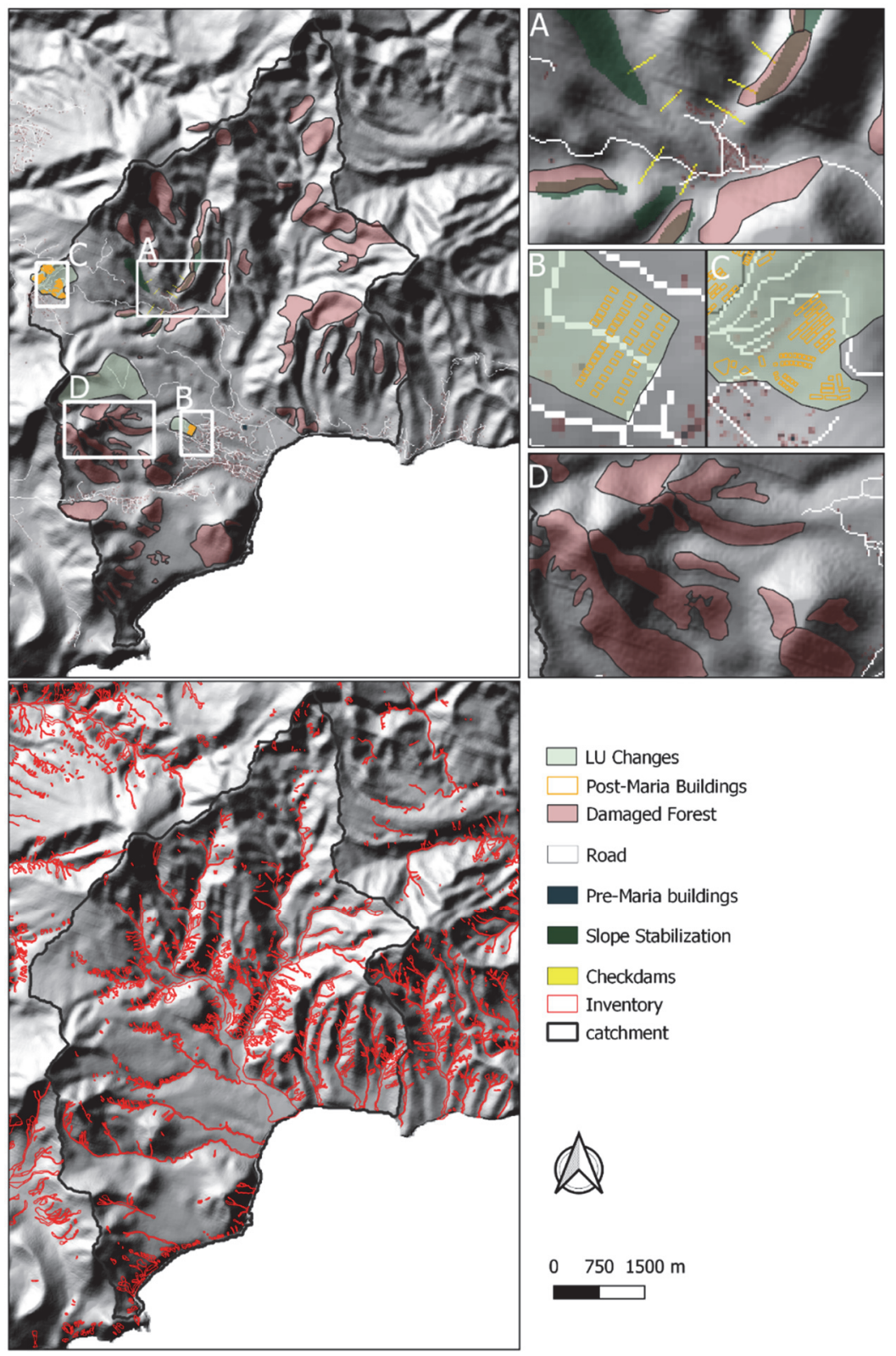

Figure 8-7 (Top) The mapped landslides for the hurricane Maria event. Highlighted are the hypothetical check dams and slope stabilization that is included in the simulated scenarios to protect Pichelin. 
Table 8-2 The scenarios simulated for the Grande Bay area on Dominica

\begin{tabular}{|c|c|c|c|}
\hline Scenario & Name & Events & What changes \\
\hline $\begin{array}{l}\text { Maria } \\
\text { Reconstruction }\end{array}$ & $\begin{array}{l}\text { Without taking into } \\
\text { account the effects of } \\
\text { Erika }\end{array}$ & $\begin{array}{l}\text { Maria/ } \\
\text { Design } \\
\text { Storms }\end{array}$ & \\
\hline $\begin{array}{l}\text { Maria } \\
\text { Reconstruction }\end{array}$ & $\begin{array}{lr}\text { With } & \text { landscape } \\
\text { changes } & \text { following } \\
\text { Erika } & \end{array}$ & $\begin{array}{l}\text { Maria/ } \\
\text { Design } \\
\text { Storms }\end{array}$ & $\begin{array}{l}\text { Adjusted vegetation map } \\
\text { Adjusted soil depth map }\end{array}$ \\
\hline Scenario 1 & $\begin{array}{l}\text { Future } \quad \text { Scenario: } \\
\text { Landscape post-Maria }\end{array}$ & $\begin{array}{l}\text { Design } \\
\text { Storms }\end{array}$ & $\begin{array}{l}\text { No vegetation on active } \\
\text { processes from Maria } \\
\text { No soil depth on landslide } \\
\text { scarps from Maria }\end{array}$ \\
\hline Scenario 2 & $\begin{array}{l}\text { Future Scenario: } \\
\text { Vegetation Death }\end{array}$ & $\begin{array}{l}\text { Design } \\
\text { Storms }\end{array}$ & $\begin{array}{l}\text { Adjusted vegetation cover, } \\
\text { density, leaf area index and } \\
\text { root cohesive strength for } \\
\text { impacted areas }\end{array}$ \\
\hline $\begin{array}{l}\text { Scenario } \\
3 a / 3 b / 3 c\end{array}$ & $\begin{array}{l}\text { Mitigation: Sediment } \\
\text { removal from channels }\end{array}$ & $\begin{array}{l}\text { Design } \\
\text { Storms }\end{array}$ & $\begin{array}{lrr}\text { Removal of } & \text { deposit } \\
\text { material from } & \text { channels } \\
(25 \% / 50 \% / 75 \% & \text { for } \\
\text { scenario } a, b & \text { and } \\
\text { respectively) } & & \end{array}$ \\
\hline Scenario 4 & $\begin{array}{l}\text { Mitigation: Retaining } \\
\text { walls. }\end{array}$ & $\begin{array}{l}\text { Design } \\
\text { Storms }\end{array}$ & $\begin{array}{l}\text { Flow obstacles placed in } \\
\text { three locations }\end{array}$ \\
\hline Scenario 5 & $\begin{array}{l}\text { Mitigation: } \\
\text { Stabilization }\end{array}$ & $\begin{array}{l}\text { Design } \\
\text { Storms }\end{array}$ & $\begin{array}{l}\text { Alteration in cohesive } \\
\text { strength of the slope } \\
\text { material at three slopes } \\
\text { sections. }\end{array}$ \\
\hline Scenario 6 & $\begin{array}{l}\text { Future Land use } \\
\text { scenario }\end{array}$ & $\begin{array}{l}\text { Design } \\
\text { Storms }\end{array}$ & $\begin{array}{l}\text { Added building cover and } \\
\text { house elements at planned } \\
\text { construction locations } \\
\text { within the study site. }\end{array}$ \\
\hline
\end{tabular}

\subsubsection{Design Storms}

Design storms are based on the work of the CHARIM project (CHARIM, 2016). Here, a 15 year daily rainfall record for st. Lucia was analyzed to obtain IDF curves. Afterwards, Johnson SB Probability Density distributions were fitted to the events with the nearest available return period, normalized for rainfall intensities provided by the IDF curves. An overview of the precipitation curves and their cumulative rainfall is provided in Figure 8-8.

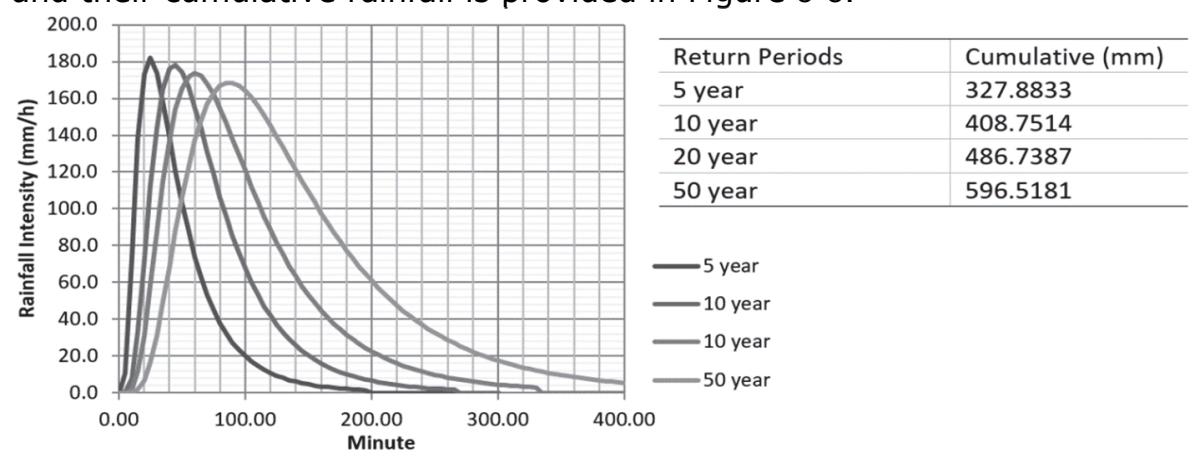

Figure 8-8 Cumulative rainfall for each of the design rainfall events used in the simulations 


\subsubsection{Calibration and Impact Calculation}

The simulations of the multi-hazards on Dominica that were triggered during Maria were calibrated using the impact extent. Mapped extents are available from the Hurricane Maria landslide and flash flood inventory for Dominica (Van Westen and Zhang, 2018). This inventory includes all visible traces of flash floods, debris flows, slope failures, landslides or other mass movements. From the model, we can not take all flow to count as visible flash flooding as minor runoff would be incorrectly counted as flash floods. Instead, a threshold of a certain height must be defined above which we assume flow would leave visible traces on satellite imagery. We assume flow to be visible for at least some weeks after the event if simulated depths are above 0.4 meters, and massmovement related processes when simulated depths are above 0.15 meters with a volumetric solid content of more than 20 percent (based on general definitions of debris flows and mass movements, see also Lavigne \& Suwa, 2004). Slope failures are assumed to be visible with any depth.

To further investigate the potential impact in the simulated scenarios, we estimated building impact by calculating the fractional damage provided by the debris flow vulnerability curve from Ciurean et al., 2017).

$$
\mathrm{V}(\mathrm{I})=\left\{\begin{array}{c}
\frac{2 \mathrm{I}^{2}}{\mathrm{R}^{2}} \quad \frac{\mathrm{I}}{\mathrm{R}} \leq \frac{1}{2} \\
1-\frac{2(\mathrm{R}-\mathrm{I})^{2}}{\mathrm{R}^{2}} \frac{1}{2}<\frac{\mathrm{I}}{\mathrm{R}} \leq 1 \\
1 \quad \frac{\mathrm{I}}{\mathrm{R}}>1
\end{array}\right.
$$

Where $V$ is the building damage (fractional), $I$ is the hazard intensity (which can be defined as the maximum debris flow height, Ciurean et al., 2017) and $R$ is the building resistance.

8. 2

$$
\mathrm{R}=\left(\zeta_{\mathrm{STR}} \cdot \zeta_{\mathrm{SHT}}\right)^{\frac{1}{2}}
$$

$\zeta_{S T R}$ is the structural typology factor (representative of the material of construction) and $\zeta_{S H T}$ is the building height factor (represented by the number of floors).

Finally, we choose the typology factor based on the work by Li et al. (2010) for wood constructions $\left(\zeta_{S T R}=0.2\right)$.

\subsection{Results}

\subsubsection{Simulating the Maria Event}

The results of the calibrated replication (taking into account the landscape changes from hurricane Erika) of the impact of hurricane Maria are shown in Figure 8-9. A common challenge with usage of a multi-hazard model, is the visualization of the multi-hazard intensities. While single-hazard approximations can show a single spatial variable to indicate presence or intensity of the hazard (e.g. flood depth, landslide height), multi-hazard intensity is not easily reduced to such a single parameter. For more complex flow processes, derived compound parameters such as impact pressure or momentum are used. However, reduction to a single parameter does not allow one to visualize the relevant complexity in multi-hazard modelling. In our case, 
we chose to present figures using a flow- height color scale, using a bi-color gradient to indicate sediment concentration at the moment of maximum flow height. Additionally, at the catchment scale, differences are minor, and not clearly visible. To show the differences when taking into account a variety of landscape changes, we present the averaged values of maximum water height, solid height and slope failure depth for each of the simulations (Table 8-3).

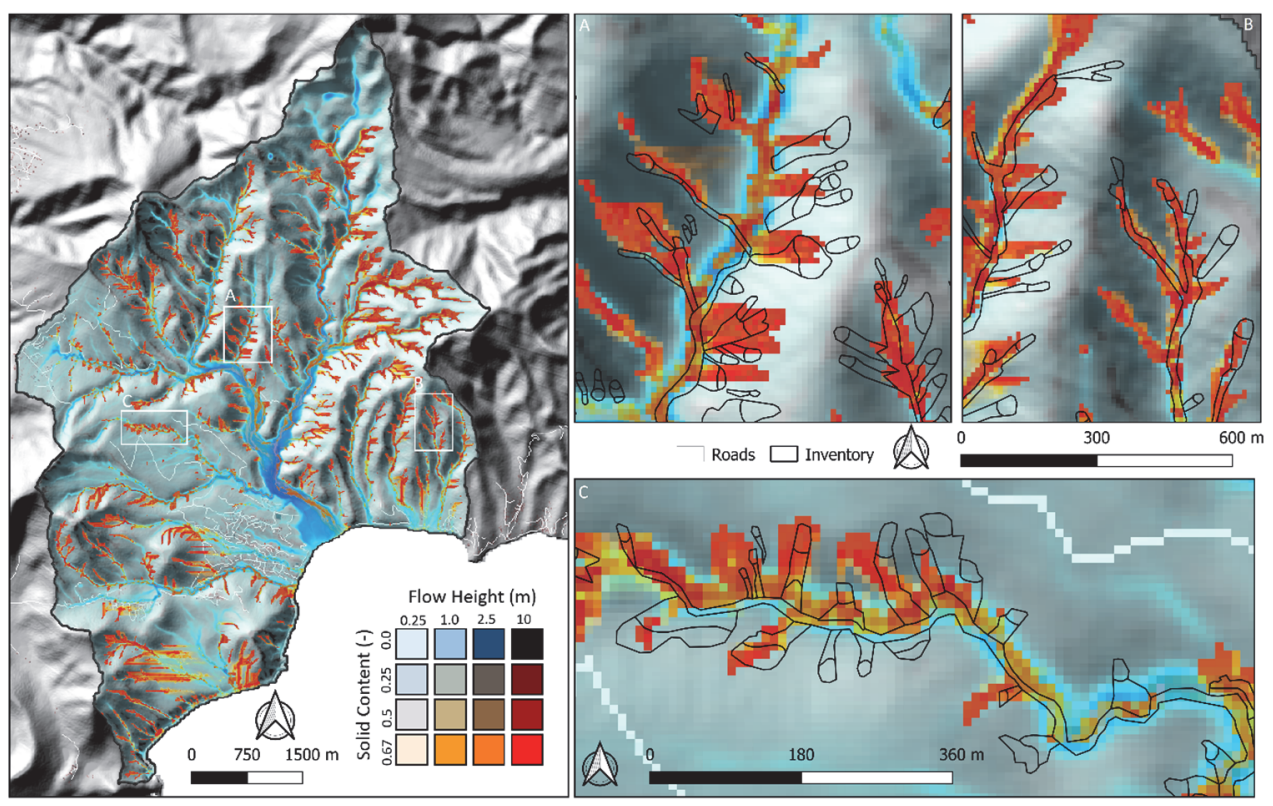

Figure 8-9 Simulation results for the replicates the impact of hurricane Maria on the Grande Bay catchment on Dominica. Comparisons use non-corrected data.

Table 8-3 Overview of the average maximum fluid and solid height, and total slope failure volumes for each of the simulations.

Return

\begin{tabular}{|c|c|c|c|c|c|c|c|c|c|c|c|c|}
\hline \multirow{3}{*}{$\begin{array}{l}\text { Period } \\
\text { Simulation } \\
\mathrm{Nr}\end{array}$} & 5 & 10 & 20 & 50 & 10 & & 20 & 50 & \multirow{2}{*}{\multicolumn{2}{|c|}{10}} & 20 & 50 \\
\hline & & & & & \multicolumn{4}{|c|}{ Average $\quad$ Maximum } & & & & \\
\hline & \multicolumn{4}{|c|}{ Average Maximum Fluid Height } & \multicolumn{3}{|c|}{ Solid Height } & & \multicolumn{4}{|c|}{ Total Slope Failure Volume } \\
\hline 1 & $\begin{array}{l}9.32 \mathrm{E}- \\
02 \\
\end{array}$ & $1.01 \mathrm{E}-01$ & $\begin{array}{l}1.09 \mathrm{E}- \\
01 \\
\end{array}$ & $\begin{array}{l}1.15 \mathrm{E}- \\
01 \\
\end{array}$ & $5.42 \mathrm{E}-02$ & $\begin{array}{l}5.43 \mathrm{E}- \\
02\end{array}$ & $\begin{array}{l}5.51 \mathrm{E}- \\
02\end{array}$ & $\begin{array}{l}5.59 \mathrm{E}- \\
02\end{array}$ & 146323 & 1.47E+05 & $1.47 \mathrm{E}+05$ & $1.49 \mathrm{E}+05$ \\
\hline 2 & $\begin{array}{l}8.76 \mathrm{E}- \\
02\end{array}$ & $9.57 \mathrm{E}-02$ & $\begin{array}{l}1.02 \mathrm{E}- \\
01\end{array}$ & $\begin{array}{l}1.07 \mathrm{E}- \\
01\end{array}$ & $3.70 \mathrm{E}-02$ & $\begin{array}{l}3.92 \mathrm{E}- \\
02\end{array}$ & $\begin{array}{l}4.07 \mathrm{E}- \\
02\end{array}$ & $\begin{array}{l}4.13 \mathrm{E}- \\
02\end{array}$ & 91210.3 & $9.33 E+04$ & $9.94 E+04$ & $1.01 E+05$ \\
\hline 1 & $\begin{array}{l}8.95 \mathrm{E}- \\
02\end{array}$ & $9.66 \mathrm{E}-02$ & $\begin{array}{l}1.02 \mathrm{E}- \\
01 \\
\end{array}$ & $\begin{array}{l}1.07 E- \\
01 \\
\end{array}$ & 4.01E-02 & $\begin{array}{l}4.00 E- \\
02 \\
\end{array}$ & $\begin{array}{l}4.09 \mathrm{E}- \\
02\end{array}$ & $\begin{array}{l}4.15 \mathrm{E}- \\
02\end{array}$ & 97726.8 & $9.78 \mathrm{E}+04$ & $9.93 \mathrm{E}+04$ & $1.00 \mathrm{E}+05$ \\
\hline 2 & $\begin{array}{l}\text { 9.67E- } \\
02 \\
\end{array}$ & $1.05 \mathrm{E}-01$ & $\begin{array}{l}1.14 \mathrm{E}- \\
01\end{array}$ & $\begin{array}{l}1.19 \mathrm{E}- \\
01 \\
\end{array}$ & $5.65 \mathrm{E}-02$ & $\begin{array}{l}\text { 5.67E- } \\
02 \\
\end{array}$ & $\begin{array}{l}5.73 E- \\
02\end{array}$ & $\begin{array}{l}5.82 \mathrm{E}- \\
02\end{array}$ & 130147 & $1.31 \mathrm{E}+05$ & $1.32 \mathrm{E}+05$ & $1.33 \mathrm{E}+05$ \\
\hline $3 a$ & $\begin{array}{l}8.91 \mathrm{E}- \\
02 \\
\end{array}$ & $9.63 \mathrm{E}-02$ & $\begin{array}{l}1.02 \mathrm{E}- \\
01\end{array}$ & $\begin{array}{l}1.08 \mathrm{E}- \\
01\end{array}$ & 4.07E-02 & $\begin{array}{l}4.07 E- \\
02 \\
\end{array}$ & $\begin{array}{l}4.14 \mathrm{E}- \\
02\end{array}$ & $\begin{array}{l}4.21 \mathrm{E}- \\
02\end{array}$ & 98443.2 & 9.87E+04 & $9.95 \mathrm{E}+04$ & $1.00 \mathrm{E}+05$ \\
\hline $3 b$ & $\begin{array}{l}8.95 \mathrm{E}- \\
02\end{array}$ & 9.67E-02 & $\begin{array}{l}1.03 \mathrm{E}- \\
01\end{array}$ & $\begin{array}{l}1.08 \mathrm{E}- \\
01\end{array}$ & 4.06E-02 & $\begin{array}{l}4.08 \mathrm{E}- \\
02 \\
\end{array}$ & $\begin{array}{l}4.14 \mathrm{E}- \\
02\end{array}$ & $\begin{array}{l}4.22 \mathrm{E}- \\
02\end{array}$ & 98495.2 & $9.85 \mathrm{E}+04$ & $9.95 \mathrm{E}+04$ & $1.00 \mathrm{E}+05$ \\
\hline $4 c$ & $\begin{array}{l}8.89 \mathrm{E}- \\
02 \\
\end{array}$ & $9.60 \mathrm{E}-02$ & $\begin{array}{l}1.02 \mathrm{E}- \\
01\end{array}$ & $\begin{array}{l}1.08 \mathrm{E}- \\
01\end{array}$ & $4.08 \mathrm{E}-02$ & $\begin{array}{l}4.07 E- \\
02\end{array}$ & $\begin{array}{l}4.15 E- \\
02\end{array}$ & $\begin{array}{l}4.22 E- \\
02\end{array}$ & 98366.6 & $9.87 E+04$ & $9.94 \mathrm{E}+04$ & $1.00 \mathrm{E}+05$ \\
\hline 4 & $\begin{array}{l}8.93 \mathrm{E}- \\
02\end{array}$ & $9.65 \mathrm{E}-02$ & $\begin{array}{l}1.03 \mathrm{E}- \\
01\end{array}$ & $\begin{array}{l}1.08 \mathrm{E}- \\
01\end{array}$ & 4.05E-02 & $\begin{array}{l}4.06 E- \\
02 \\
\end{array}$ & $\begin{array}{l}4.12 \mathrm{E}- \\
02\end{array}$ & $\begin{array}{l}4.20 \mathrm{E}- \\
02\end{array}$ & 98266.9 & $9.83 \mathrm{E}+04$ & $9.94 \mathrm{E}+04$ & $1.00 \mathrm{E}+05$ \\
\hline 5 & $\begin{array}{l}8.93 \mathrm{E}- \\
02\end{array}$ & $9.65 \mathrm{E}-02$ & $\begin{array}{l}1.03 \mathrm{E}- \\
01\end{array}$ & $\begin{array}{l}1.08 \mathrm{E}- \\
01\end{array}$ & 4.07E- 02 & $\begin{array}{l}4.09 E- \\
02\end{array}$ & $\begin{array}{l}4.14 \mathrm{E}- \\
02\end{array}$ & $\begin{array}{l}4.22 \mathrm{E}- \\
02\end{array}$ & 98539.7 & $9.85 E+04$ & $9.97 E+04$ & $1.01 \mathrm{E}+05$ \\
\hline 6 & $\begin{array}{l}8.81 E- \\
02\end{array}$ & $9.49 \mathrm{E}-02$ & $\begin{array}{l}1.01 \mathrm{E}- \\
01\end{array}$ & $\begin{array}{l}1.06 \mathrm{E}- \\
01\end{array}$ & 4.07E-02 & $\begin{array}{l}4.07 \mathrm{E}- \\
02\end{array}$ & $\begin{array}{l}4.16 \mathrm{E}- \\
02\end{array}$ & $\begin{array}{l}4.24 \mathrm{E}- \\
02\end{array}$ & 98438.3 & $9.84 E+04$ & $9.95 E+04$ & $1.01 E+05$ \\
\hline
\end{tabular}


Table 8-4 Calculated building impact for each of the design storm simulations. Actual cumulative fractional damage for Hurricane Maria within the Grande Bay area is 181.35 (weighing both floors and walls as $30 \%$ value, and assuming roof damage is caused by wind and can be ignored for comparison).

\begin{tabular}{llllllll} 
& $\begin{array}{l}5 \\
\text { Return }\end{array}$ & $\begin{array}{l}10 \\
\text { Return } \\
\text { Period }\end{array}$ & $\begin{array}{l}\text { Period } \\
\text { Return }\end{array}$ & $\begin{array}{l}\text { Period } \\
\text { Peturn }\end{array}$ & $\begin{array}{l}\text { Peariod } \\
\text { Pverage }\end{array}$ & $\begin{array}{l}\text { Hurricane } \\
\text { Maria }\end{array}$ \\
\hline $\begin{array}{l}\text { Maria Reconstruction } \\
142.888\end{array}$ & 180.334 & 134.299 & 214.928 & 168.1 & 243.12 \\
\hline $\begin{array}{l}\text { Post-Erika } \\
\text { Reconstruction }\end{array}$ & 65.0215 & 128.453 & 145.65 & 158.216 & 124.3 & 194.23 \\
\hline Scenario 1 & 117.739 & 144.275 & 190.475 & 128.533 & 145.2 & - \\
\hline Scenario 2 & 152.781 & 137.26 & 186.146 & 206.295 & 17.06 & - \\
\hline Scenario 3a & 148.918 & 115.903 & 124.516 & 198.222 & 146.8 & - \\
\hline Scenario 3b & 99.049 & 178.475 & 185.483 & 121.603 & 146.1 & - \\
\hline Scenario 3c & 95.2482 & 132.594 & 179.933 & 133.572 & 135.3 & - \\
\hline Scenario 4 & 75.3246 & 144.775 & 148.609 & 152.784 & 13.03 & - \\
\hline Scenario 5 & 115.993 & 139.439 & 194.605 & 197.924 & 14.06 & - \\
\hline Scenario 6 & 71.4438 & 144.834 & 163.93 & 182.372 & 16.19 & -
\end{tabular}

When comparing the modelled hazard process impact with the mapped impact during hurricane Maria, it is clear that differences in geo-alignment lead to calibration issues. One of the primary reasons for this is the relative differences in ortho-rectification in the different sources of data used for the model calibration. The landslide mapping was carried out on various satellite images, which were partly cloud-covered and which had varied viewing angles. As a result, high-quality ortho-rectification is required to line up these images with the LIDAR elevation model used in this modelling setup. This work was performed for the south-western sub catchments containing 113 debris flows and landslides. For this area, pixel-based comparison shows an accuracy of 90.2 percent with a Cohens Kappa value of 0.562 . For the larger catchment, which act as a validation, accuracy drops to 91.1 percent with a Cohens Kappa value of 0.41. Several areas of the simulation are highlighted in Figure 8-9 to indicate the real performance of the model setup. The pixel-based comparison is shown in Figure 8-10. 


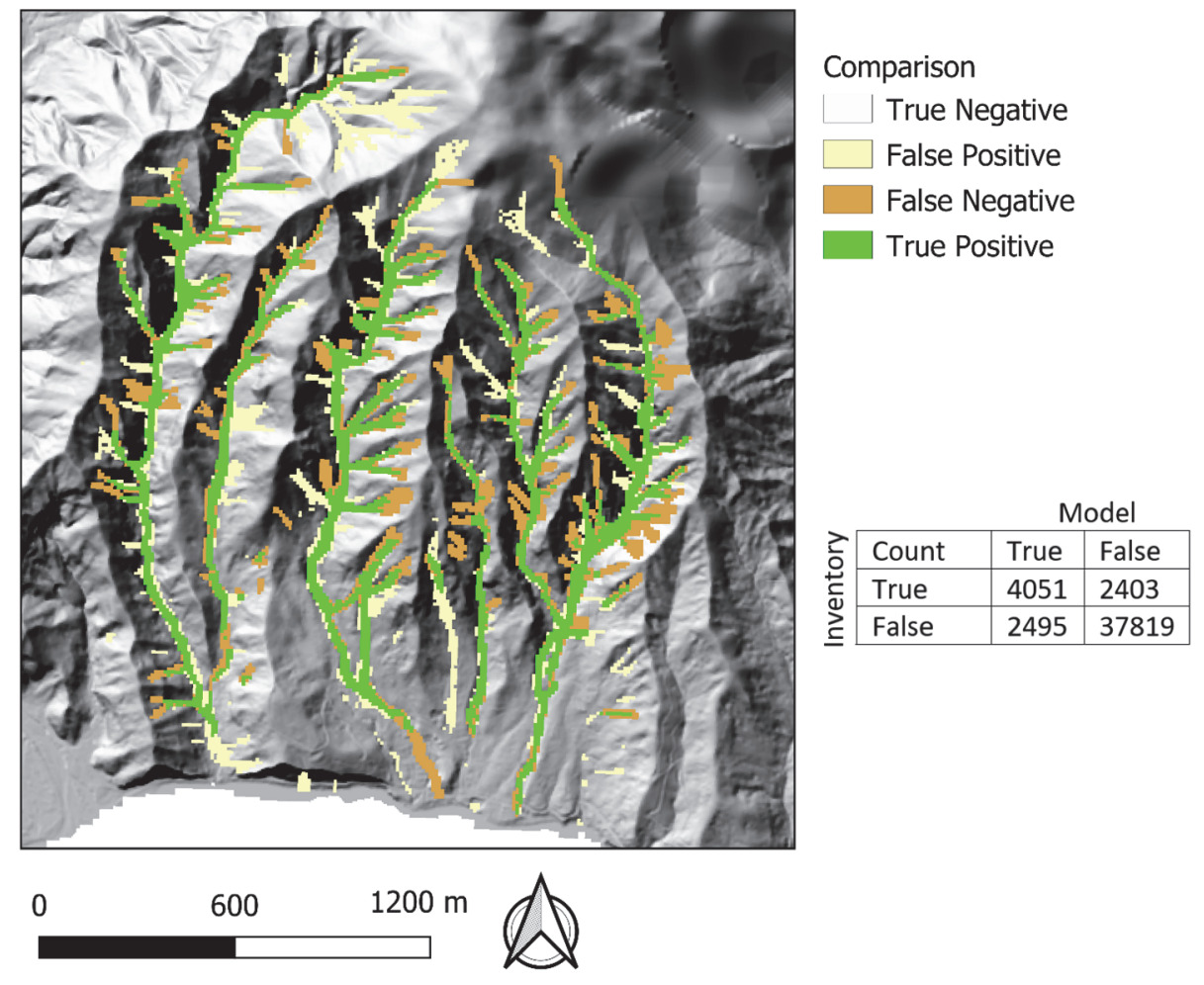

Figure 8-10 Pixel-based comparison between predicted multi-hazard impact and mapped multi-hazard impact. Comparison uses corrected data.

General patterns for the various simulations are highly similar to each other and mapped impact. Due to the large cumulative rainfall values in the simulated events, the majority of potential slope failures reaches instability during all of the events. When simulating the Maria event, a substantial change in impact is observed when taking into account the landscape changes induced by Erika. The alteration of soil depths due to Erika does significantly alter the amount of slope failures by approximately a third (see table 4). As was found in earlier studies using this kind of modelling setup (Bout et al., 2018), the overall landslide patterns are well represented, although the prediction of individual landslides remains a problem. This is primarily due to the spatial variability of soil thickness and soil properties, which directly influence stability, and for which data is scarce and difficult to obtain. The input data for the modelling contains generalized soil data and the model is therefore often not able to predict the individual landslides in all cases or in a pixel-perfect manner. While many of the mapped landslides coincide reasonably with a simulated slope failure and runout, a significant portion is not present in the model results. Despite this, runout patterns are highly similar, both in extent of the debris flood and the solids deposited by this mixed flow.

The modelling results clearly highlight how the integrated nature of the model influences the dynamics of the simulated event, in a way that would not have been possible when the processes were modelled independently. Landslide 
blocking of rivers and landslide dilution Occurred in several locations. These processes effectively blocked water flow, causing buildup of water and lateral spreading of the flood extent. This increased exposure and intensity in those locations. Additionally, flow densities are strongly increased downstream compared to traditional (flash) flood scenarios. The volumetric solid content of the flows within the simulation could reach up to $30 \%$ adding significant weight and impact to flows that impact buildings and infrastructure. Finally, velocities are altered in a major way by the interactions between solids and fluids. The friction model used by the solid phase differs strongly from traditional water approaches and influences, through drag, both fluid and solid velocities. This typically led to higher velocities in the upslope areas where slope failures provided solid content to the flow. In the rivers, the internal friction of solids provides increased friction and thereby hinders flow velocities.

\subsubsection{Comparison to Traditional Multi-hazard Approach}

Several differences can be observed when comparing Figure 8-9 to the traditional multi-hazard analysis as shown in Figure 8-4. A comparison of mapped impact for Maria and the traditional multi-hazard assessment for floods and landslides is shown in Figure 8-11. The resulting Cohens Kappa is 0.032 with an accuracy of 29.7 percent. While it is beyond the current scope of this work to perform a full post-Maria reflection on the work done by the CHARIM project, the key differences in the results show what value might be obtained from the output of an integrated multi-hazard model. It is important to note that the input data and validation data available for the CHARIM project differed from those available for this current work. The availability of a highresolution LIDAR elevation model improves accuracy of flow simulations. Additionally, an inventory of landslides and flash floods during Maria was available for calibration. 


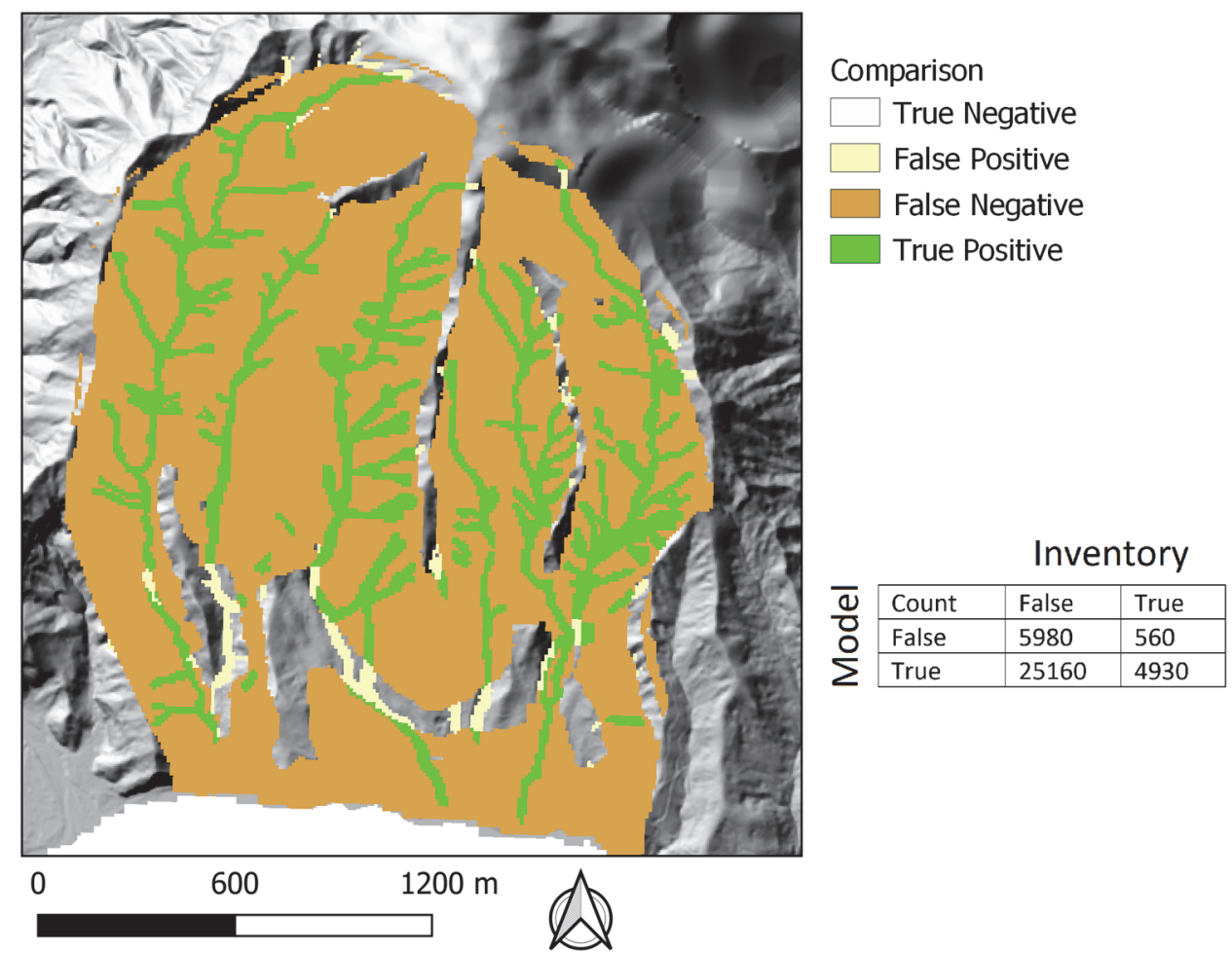

Figure 8-11 Comparison of landslide hazard as estimated by the CHARIM project with mapped processes during Maria.

The landslide susceptibility map, which was made using a combination of statistical methods and spatial multi-criteria evaluation (Charim, 2016) contains well all potentially hazardous areas. However, it strongly overpredicted the high hazardous zones on the Island. This issue is a long-standing problem of landslide susceptibility maps addressed among others by Van Westen (2006). Another difference between the modelling results and the earlier landslide susceptibility map is that the latter did not consider runout sufficiently. During the Maria event the runout of mass movements merged with channel flow and sediments were transported further downstream. The flood simulations performed by the CHARIM project were calibrated based on the extent of flash floods in the historic record. By doing so, the simulation framework compensates for potential errors the are the result from the isolated approach to flooding. Thus, both the CHARIM and currently presented flood extent prediction are very similar to the extent mapped for the Maria event. For impact assessment, the calibration of flood models does not solve the full issue, as other properties of the model are changed. These include the flow velocities and in particular densities, that differ greatly in the models and in reality with increasing solid content. 


\subsubsection{Scenario Differences}

Some results of the scenario simulations are shown in Figure 8-12 for the area surrounding the village of Pichelin, which was heavily impacted during hurricane Maria. Generally, the simulation results are highly similar, both in terms of spatial patterns as well as for absolute hazard intensities. Relevant details are mostly related to differences in runout behavior of mass movement, the occurrence of landslide damming, and deposition locations. Additionally, the interactions taking place between processes change significantly due to altered timing of slope failures and flash flood arrivals. These results indicate the potential for multi-hazard impact modelling and use in assessment of future scenarios. Interactions that can alter hazard and risk can be included in the hazard assessment. However, the changes as visible in the scenarios are induces by changes in parameters that are in several cases similar to the uncertainty present in the input data. A full uncertainty analysis would therefore be required to address whether the model outcomes for the various scenarios represent the most likely outcome given the input parameters and their uncertainty.
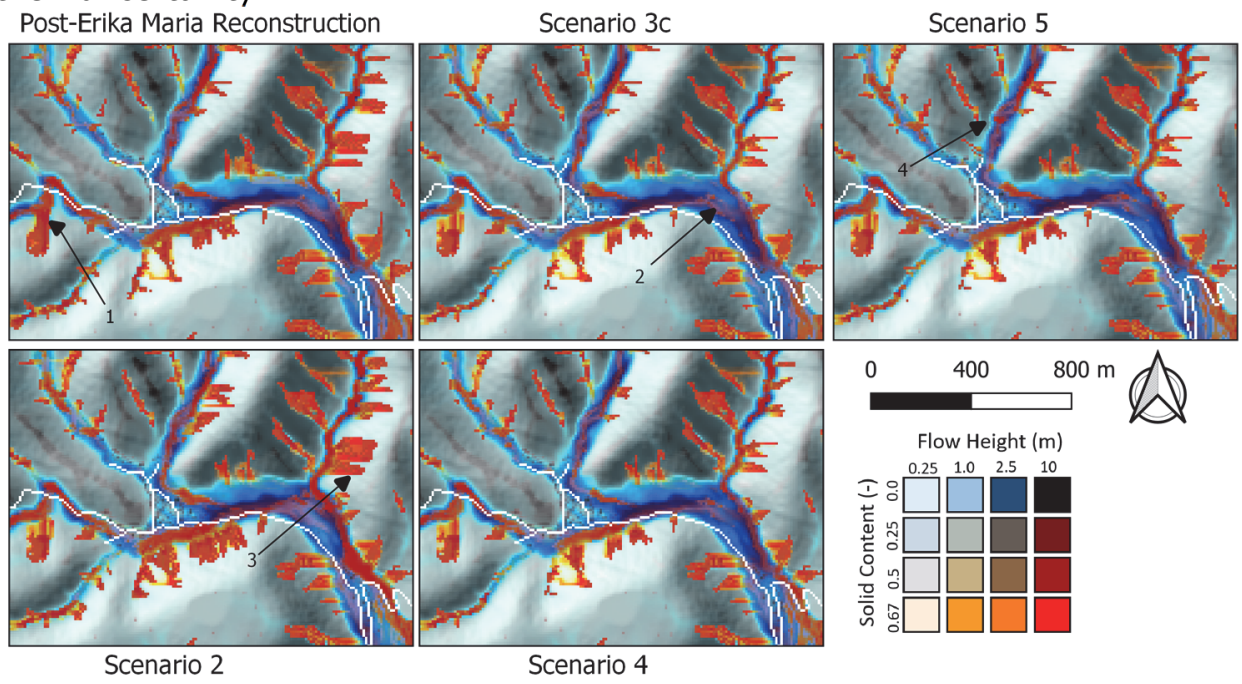

Figure 8-12 The area around Pichelin for several of the simulated scenarios. Shown event is the design storm with a 5 year return period. Highlighted are several changes caused by the scenario setups. 1: Increased runout since previous Erika landslides are not subtracted from soil depth; 2: Decreased solid deposits along river due to post-Maria draining; 3: Increased runout due to forest death and stability reduction. 4: Deposition of solids behind check dam.

\subsubsection{Relation of Return Period to Impact}

From the data seen in Table 8-3 and Table 8-4, several observations can be made. First, with increasing return period, and increasing maximum rainfall intensity, the catchment-averaged maximum flow heights and slope failure depths increase. This is as expected from theory and practice, as rainfall directly causes flood heights, and slope instability. However, this pattern is not uniformly present in the building damage data. Instead, while the 5 year return 
period typically has lowest damages, it does not always. Similarly, while 50 year return period damages are typically highest, they are not always. A visualization of the damage for each scenario is provided in Figure 8-13.
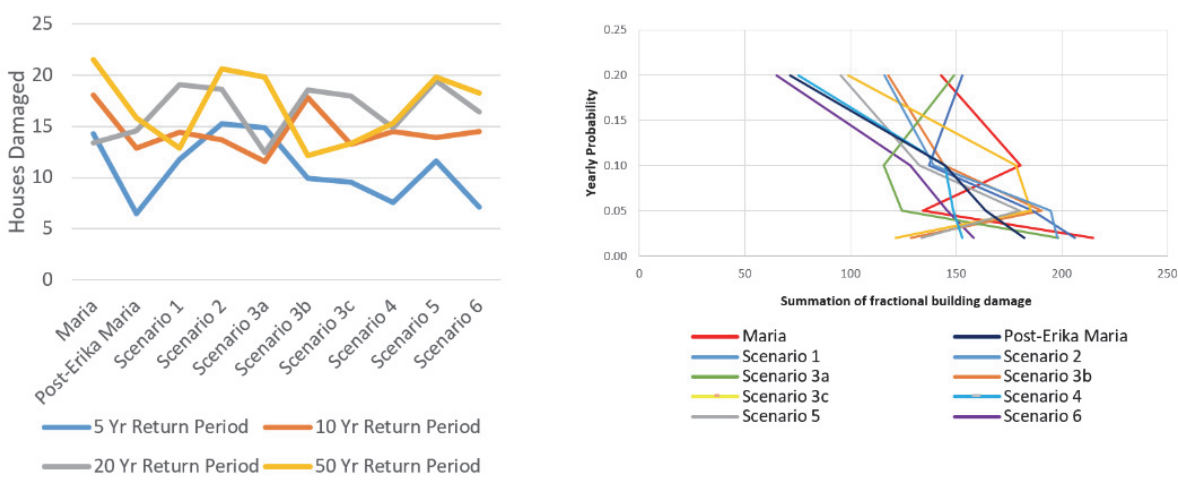

Figure 8-13 Total of relative impact as indicated by vulnerability curves exposed to critical impact by the multi-hazard event. Left: Scenarios on horizontal axis. Right: yearly probability on vertical axis.

The observed pattern of not uniformly increasing building damages with increasing return period is counter-intuitive at first consideration. However, when investigating the actual dynamics of the simulation, clear causes can be found for this behavior. To examine these, we investigate the differences between the 20 and 10 year return period simulations on the post-Erika landscape (Figure 8-14). 


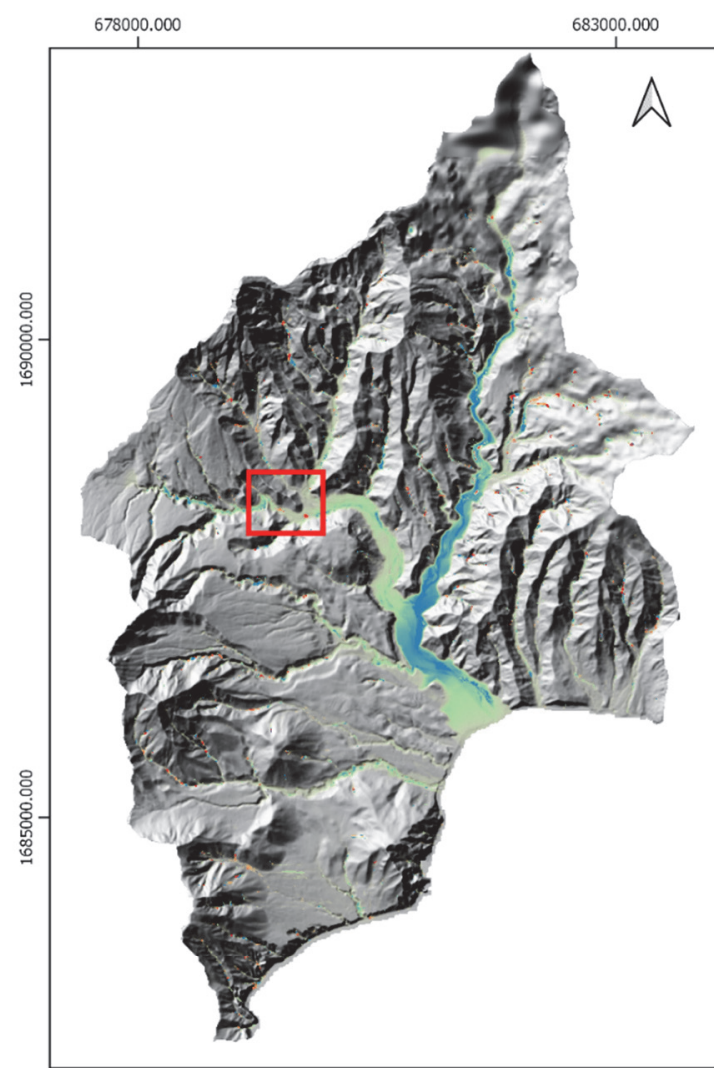

- Timeseries locations Difference in Max Height ( $\mathrm{m}$ ) Buildings
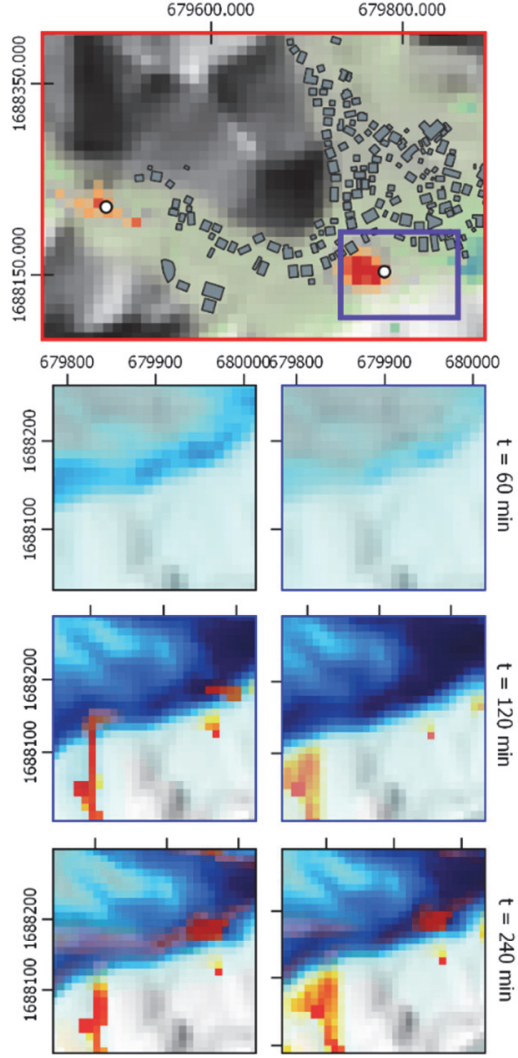

$\mathrm{T}=10$ Year
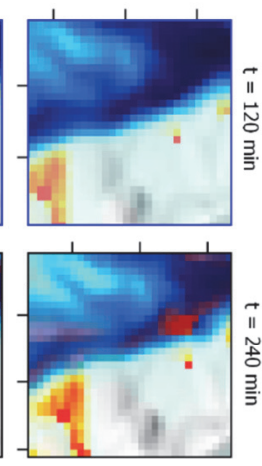

Flow Height (m)

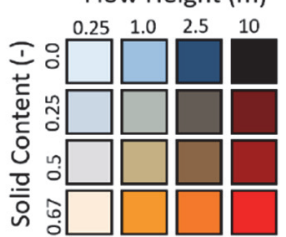

Figure 8-14 A comparison of maximum flow heights for the 10 and 20 year return period events on the post-Erika landscape. Notice that, although generally, increased rainfall leads to increased maximum flow height, interactions between landslides, debris flows and flash floods can alter the maximum heights in complex ways. Two cases are highlighted near Pichelin, where the 10 year return period event has higher maximum flow heights. A profile of flow heights, solid content and velocities are shown in figure 13.

For the vast majority of the simulation, differences in maximum flow height are positive, indicating that a 20 -year return period event has higher impact than a 10-year return period event. This is directly linked to increased cumulative rainfall for the design events. Flash floods heights are increased by up to 0.5 meters near the main outlet of the area. However, for a variety of smaller areas, predominantly located near intersections of mass movements 
and channels, a decrease in maximum flow height is simulated with increasing cumulative rainfall. The timeslices shown in Figure 8-14 indicate that the runout of the mass movement behaved significantly more diffusive. This behavior, caused predominantly by increased water content, came about by the increased amount of water present in the channel at the moment of failure. The diffusive runout was dragged along by similarly higher water flows in the channel. Thus, compared to the 10 year return period simulation, channel blocking was reduced, resulting in lower hazard intensities next to the river, where the some of the houses of Pichelin are located. Figure 8-15 shows timeseries of fluid heights, solid heights, and fluid velocities at the two locations indicated in Figure 8-14.
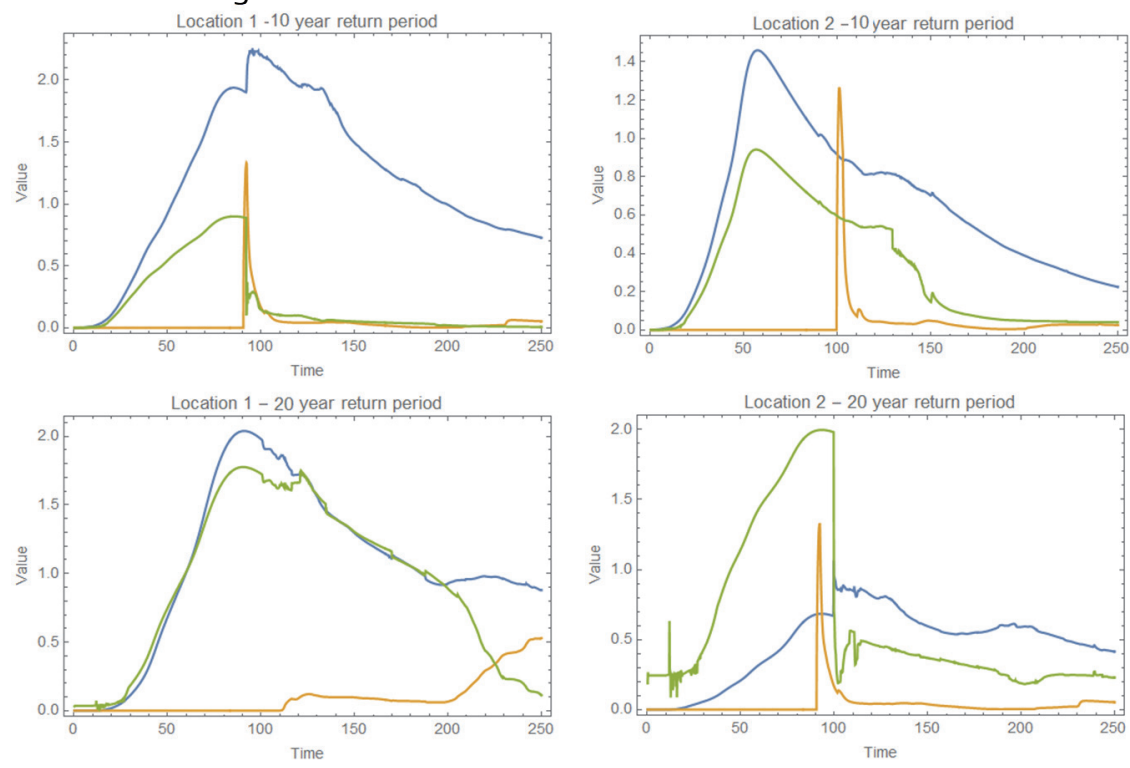

— Fluid Height (m) — Solid Height $(\mathrm{m})$ — Fluid Velocity $(\mathrm{m} / \mathrm{s})$

Figure 8-15 Timeseries of fluid height, solid height and fluid velocity at the locations indicated near Pichelin in figure 11 . Time is presented in minutes relative to the start of the simulation.

Within the timeseries of Figure 8-15, the moment of impact of mass movements is clearly recognizable. For location 1 , the 20 year return period simulation has a more spread impact of solid flow, blocking does not occur, and maximum flow heights are reduced. For location 2, the change in maximum flow heights comes about due to the timing of the mass movement relative to the arrival of the flash flood and upstream influences. In the 10 year return period simulation, the arrival of the mass movement is after the arrival of the main flash flood wave. In the 20 year return period simulation arrival is simultaneous, and partial blocking occurs, because of which water is diverted. Throughout the simulation, numerous of interactions as described above occur, that lead to the counter-intuitive patterns in building damage. Thus, as a consequence of non-linear and complex interactions between hazardous processes, the one-to-one relationship between cumulative rainfall in a single event and damages is partially lost. While the application in Dominica might 
be an isolated case, it significantly complicates further steps in the estimation of total risk.

\subsection{Discussion}

Generally, the usage of a physically-based integrated multi-hazard model shows suitability for application in scenario exploration and event reconstruction. The interactions that have been observed during the event are captured well by the model, including complex non-linear processes such as slope failures, landslide damming and debris floods. While it is not practically possible within this study case to confirm the precise behaviors of these processes beyond their general occurrence and patterns, the model provides a total hazard that has high accuracy.

For a full hazard analysis, applicability remains uncertain due to a number of factors. On the one hand, comparison with the CHARIM map, using statistical prediction of landslide hazard zones and flash flood modelling, shows additional value in usage of integrated multi-hazard modelling. A more complete representation of hazard is provided that includes multi-hazard interactions. The general flow height increase due to flow merging and transition zones of mass movements are absent in the traditional approach. Additionally, complex interactions such as landslide damming and landslide dilution are predicted by the model, and have been reported during the event. Despite these benefits, several complications arise in the interpretation of model outcomes. The presented approach strongly increases the number of input parameters and uncertainties in model output. In particular due to the number of implemented processes, the variety in model outputs is significantly increased. A further complication that is raised by the simulation results is the usability of design storms. Usage of designed scenario events relies heavily on the assumption of a one-to-one increasing relation between impact and trigger intensity. Within the presented modelling results, this relationship no longer holds uniformly. Currently, the question of applicability of physically-based multi-hazard models in hazard assessment seems dependent on weighing these factors for the particular use-case.

The issues mentioned above, related to uncertainties and design storm usage, could both be counter-acted by using a larger ensemble of events as input to the modelling stage. This could be done either by using a historic record and performing a longer sequence of simulations, or providing large ensembles of potential weather input. However, combining this with the computational load of complex multi-hazard models results in computational requirements beyond what is commonly available. A major obstacle facing the application of this type of modelling is thus the issue of simulating those scenarios that provide useful information in an efficient manner. New techniques for creation of design scenarios or smart ensembles of triggering events are required to provide a foundation for the application of physically-based models.

\subsection{Conclusions}

Hurricane Maria led to major damages throughout the Caribbean island Dominica. The event was multi-hazard, with (flash) floods, slope failures and mass movements interacting throughout the island to provide increased 
destruction. Event reconstruction using OpenLISEM Hazard showed good accuracy in slope failure prediction after correction of orthorectification of the landslide/debris flow inventory. Additionally, scenario exploration showed that land use/land cover changes and mitigation measures influence the predicted multi-hazard and multi-hazard interactions. This is an indication that these interactions are relevant and should be taken into account in scenario comparison. A major issue related to the applicability of the presented kind of modelling is the lack of uncertainty analysis. Full ensemble analysis might be required to adequately capture the probabilities of specific model outcomes with integrated multi-hazard models.

Simulations of designs storms for a variety of landscape states showed an unexpected complexity in the relationship between trigger intensity and hazard intensity. As a results, damage prediction and the connection between damage and return period, which can be crucial in insurance applications, becomes significantly more complex. New methods for hydro-meteorological scenario design need to be developed to provide a representative and efficient set of scenarios that cover the relevant range in hazard dynamics.

In conclusion, the issue of applicability of integrated physically-based multihazard models in hazard assessment remains an open challenge. While the model provided additional insight in comparison to a traditional approach, issues related to uncertainties in model outcomes need to be addressed if these kind of modelling tools are applied.

\subsection{Acknowledgements}

We kindly thank Lynn Baron and Annie Edward of the Physical Planning Department of Dominica for their immense help in completing this research and all effort for the acquisition of data. 


\section{Synthesis: Steps towards application}

\subsection{Introduction}

Multi-hazard and risk assessment is required for evidence-based decision making related to natural hazards (van Westen et al., 2014; Gallina et al., 2016). The development of improved toolsets for multi-hazard and risk assessment is of crucial importance for disaster risk reduction. Many examples reported in literature highlight the benefit of an integrated multi-hazard approach within decision support systems aimed at both urban/land use planning and mitigation design (Nadim et al., 2009; Cordona et al., 2010; Marzocchi et al., 2012; Burston et al., 2017; Taylor et al., 2018). For many types of hazard, the required assessment of (multi) hazard is done by means of physically-based modelling (Knighton et al., 2017; Strauch et al., 2019; Lee et al., 2019). These models use a description of processes in physically-based equations to both spatially and temporally solve the dynamics of relevant processes and estimate the behavior of the natural hazard for a specified event and landscape. It is crucial to incorporate the relevant interactions between hazard in these modelling tools for accurate hazard, and risk assessment (Marzocchi, 2009; Joel \& Bruce, 2014; Barrantes, 2018).

As evidenced by recent literature, integrated physically-based multi-hazard modelling has undergone significant advances. In particular, there has been a unification of modelling techniques related to hydrometeorological hazards that can capture a variety of process interactions and chains. The development of the OpenLISEM Hazard model resulted in a tool for hydrology, erosion, slope stability and failure mechanism, generalized mass movement runout and entrainment (Bout \& Jetten, 2018; Bout et al., 2018; Bout et al., 2020). This has shown benefit in recreating and understanding the behavior of several complex multi-hazard events. Other tools such as r.avaflow and StepTRAMM have seen similar advances that expand the possibilities of physically-based multi-hazard modelling (Mergili et al., 2017; Fan et al., 2017).

In light of the developments described above, it is relevant to address the primary issues set out in the introduction of this thesis. Are the available integrated physically-based multi-hazard models sufficiently developed for justified application in multi-hazard and risk assessment. In this chapter, we aim to analyze how the multi-hazard modelling tools developed within this work fit inside the larger field of multi-hazard research as described within chapter 1. Additionally, potential obstacles for application and opportunities for improvement are identified. We focus on both the range and accuracy of implemented processes and applicability in wider use-cases such as multihazard risk assessment. A summary of the work described within this thesis and parallel efforts from others is provided in section 9.2. Section 9.3 and 9.4 focus on the applicability and potential improvements respectively. We limit our discussion to hydrometeorological hazards as these have been the focus of the research within this Thesis. 


\subsection{State of the Multi-Hazard modeling tools}

\subsubsection{Implemented processes}

The development of OpenLISEM Hazard (OLMH) started with the catchmentscale hydrology and erosion model OpenLISEM (De Roo \& Jetten., 1999). Initially, verification of spatially integrated flash flood techniques resulted in implementation of a full dynamic wave description of water flow (Chapter 2). Unique to this approach is the full spatial integration of the flow equations into the hydrological processes. This allowed for direct simulation of flash flooding from upstream due to infiltration and runoff generation.

Secondly, a novel method for regional physically-based prediction of slope failures was developed (Chapter 3 ). This method is implemented to be an integrated part of the simulation, and directly connects with hydrology and flow aspects. Since the iterative failure method is an efficient method for regional application, it can be practically implemented in a multi-process model, where other methods such as random ellipsoid sampling only perform on a static landscape. Ground water flow and infiltration directly alter the stability of sloping materials by means of increased pore pressure at the potential slip surface, as is usual for physically-based models that implement slope stability linked with hydrology. In our integrated implementation, additional interactions are directly noticed through upstream runoff generation and overland flow patterns. All these processes in upstream areas of a catchment, that are individually considered to have a relatively minor influence, influence downstream hydrology and also the stability of slopes.

The third step in the development of the multi-hazard modelling tool presented in this thesis followed naturally from the implementation of slope failure predictions (Chapter 4). Once a sloping volume of mixed solids and fluids is released, its mobilization and dynamics need to be implemented using generalized two-phase mass movement equations. We adapted the work of Pudasaini (2012) to include shallow fluid surface flow as well as the wide range of mass movement types included in its original formulation. These two-phase equations automatically adapt and scale internal forces within the flow based on the consistency and material properties of the solids and fluids. The generalized drag force, virtual mass force, Newtonian and non-newtonian viscous forces and friction forces allow for prediction of the dynamics of debris flows, landslides, mudslides and various other types of mass movement. Additionally, during interactions with fluid bodies (e.g. channels or lakes) flow properties and forces adapt automatically to changing flow properties. Thus, the developed multi-hazard model not only implements various automaticallyestimated mass movement types, but captures evolving flow types.

The following phase in de development in the model focused on implementing erosive processes generalized to two-phase flow (Chapter 6). OpenLISEM contained a description of erosion by means of fluid-grain interactions. For twophase flows, erosion based on grain-grain interactions, generally named entrainment, is required as high solid-concentrations in mass movements can significantly enhance erosion. A full description of entrainment and deposition of non-suspended solid phase is was implemented based on the work of Takahashi (1992). The software solved these equations using a second-order 
accuracy stable numerical scheme to allow for emergent processes such as landslide dam formation and breakthrough.

The final phase of the development of an integrated physically-based multihazard model extended the two-phase generalized mass movement equations to implement runout of mass movements with any internal cohesive structure (Chapter 8 ). This adaptation was achieved by implementing a full stress-strain relationship into the material description and altering the internal forces by rederiving their mechanical description. As a result, cohesive blocks of material that have not lost internal structure due to fragmentation are accurately modelled during runout and potential fragmentation.

A schematic depiction of the current coverage of OpenLISEM Hazard is shown in Figure 9-1.

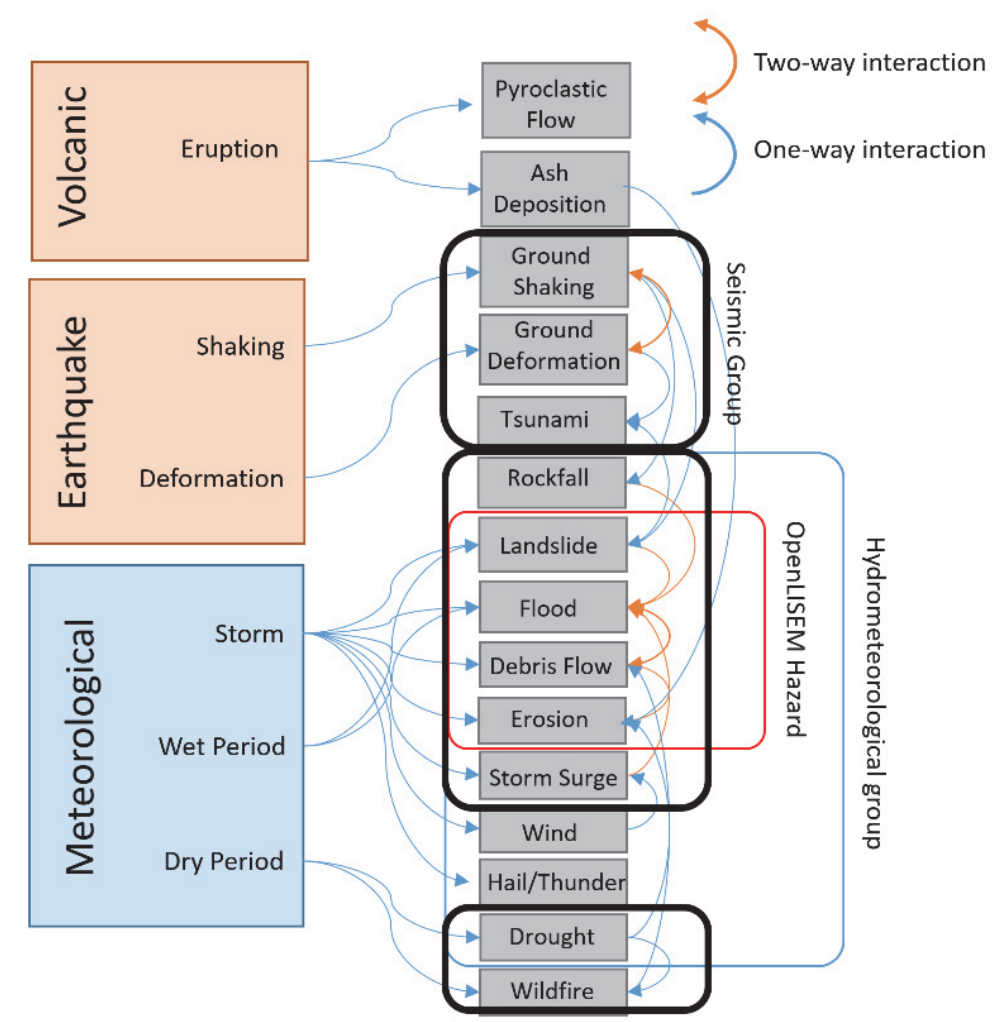

Figure 9-1 A schematic depiction of major natural hazard, their triggers and interactions between them (simplified based on Kappes et al. 2012). Placed within the hydrometeorological group is the current set of processes as implemented within OpenLISEM Hazard.

\subsubsection{Benefits of integrated physically-based multi-hazard modelling}

The first and predominant benefit in the usage of integrated physically-based multi-hazard models is that these tools implement multi-hazard interactions. 
This allows for increased insight into the processes that lead to the final dynamics of a multi-hazard event. For any event where multi-hazard interactions have some influence, understanding these interactions can be of crucial importance to understanding the physical causes for the final spatial hazard intensities. In the study case for the Fella river basin in northern Italy, the catchment-wide dynamics of upstream runoff generation and flow helped explain the locations and intensities of flooding in the main river. For the Scaletta event, where a 2009 convective storm in Eastern Sicily led to slopefailures, debris flows and flash flooding, the merging of flash floods and debris flows increased very strongly the total hazard downstream. In the Honchung study case, interactions such as landslide dam formation and erosion-initiated debris flows are key in how the flooding in Yinxiu town occurred. Understanding these processes in the context of physically-based modelling improves decision making for mitigation and adaptation. Finally, for the impact of Hurricane Maria on Dominica, interactions between flash flooding and mass movements played a similarly crucial role. Here, interactions such as mixing and evolving flow types altered the intensities of hazardous processes throughout the island.

Usage of integrated physically-based models has additionally shown benefits in application to event reconstruction and scenario exploration. Several specific multi-hazard interactions and process chains that could not be implemented previously in physically-based modelling tools can now be simulated in an integrated manner. For the Scaletta event, reconstruction without taking into account interactions between flash floods and debris flows led to calibration issues. Similarly, for the hurricane Maria event on Dominica, physically-based multi-hazard modelling of (flash) floods, landslides and debris flows compared well to mapped processes. Moreover, several benefits were found in comparison with the usage of multiple single-hazard assessments. Additionally, simulation of scenarios was used to support decision making for risk reduction measures and land use change scenarios.

Similar to OpenLISEM Hazard, a few other models have been developed to address multi-hazard interactions in the hydrometeorological hazard group. The r.avaflow model has been applied to a variety of complex interacting process chains such as glacial lake outburst floods (Mergili et al., 2017; Mergili et al., 2018). Here, the authors conclude that the integrated multi-hazard approach provides crucial insights into the behaviour of these process chains. However, the stacking uncertainties in the process chain lead to a wide range of potential output for a given range of input parameters. Thus, model outputs can be increasingly sensitive for uncertainty in input parameters. The StepTRAMM model has been applied to several study cases related to hydrology, slope stability and runout (Fan et al., 2017; Fan et al., 2019). For these works, similar conclusions have been found relating to the value and challenges to the application of multi-hazard modelling. While the reconstruction of past events is possible with increasing accuracy, prediction of future events thus remains hindered by issues related to uncertainty and limited coverage of multi-hazard models.

For all of the abovementioned work, their presence as a valuable research tool has been thoroughly established through repeated study cases and methodological improvements. The following sections aims to reflect on which steps are required to move applicability further into multi-hazard and risk assessment. 


\subsubsection{Availability of the Model}

The model developed in this work, OpenLISEM Hazard, is an open-source simulation tool under the GNU GPL v3 share-alike licence. The full source code is available on github and sourceforge. Additionally, a variety of datasets used for this work are made publicly available. In the past decades, the model has been under continuous development (see also Appendix A for an overview). Compiled windows binaries with support for multithreading are provided on the website. Compiling the source code is possible on other platforms as well, including common linux distributions.

\subsection{Challenges for Applicability}

\subsubsection{Parameters and Uncertainties}

One of the main issues identified in both development and study cases using physically-based multi-hazard modelling is the relationship between parameterization and outcome uncertainties. For all physically-based models, the accuracy of model outcomes depends both on the quality of the input parameters as well as the adequacy of the modelling methods. These are epistemic uncertainties that might feasibly be addressed and relate to unkowns in the model or data. Beyond this, aleatoric uncertainties exist for each aspect of processes implemented in a model. An extreme example here is molecularlevel movements and interactions of material. Other minor effects such as micro-turbulence and force chains between grain-loaded flows are examples of data that effect larger flow behavior. However, with current technology measuring and taking into account the effect of such processes is either impossible, or not feasible at the scale of flow simulations. Here, the potential solutions for epistemic uncertainties are explored.

For a significant subset of models, including those developed in this thesis, the required parameters are of a physical nature and can usually be measured (directly or indirectly) or estimated well through empirical relationships (Bates et al., 2004). For flood modelling for example, soil physical parameters for infiltration can be measured either directly or indirectly. Opposite to this, Mannings Surface roughness coefficient is typically estimated using field manuals with comparison terrain types containing back-calculated values (Brunner, 1995). Other parameters despite uncertainties present in these parameters, flood modelling results are influenced relatively little by changes in input parameters, and prediction of future events has often been done with success. This can be seen most evidentially in calibration-validation studies on multiple events (Grimaldi et al., 2016). These investigate the transferability of model settings and terrain parameters among multiple events in similar regions, or in the same region, but for several precipitation events. A common finding in this regard is that with increasing model complexity, per-event and per-area calibration becomes more necessary (Hessel \& Jetten, 2003; Grimaldi et al., 2016).

For integrated multi-hazard modelling, several pitfalls are significant during model development: parameterization/calibration complexity, threshold effect, uncertainty propagation and limited validation 
- For the type of modelling presented in this thesis, the surface and subsurface properties of the landscape and climatic conditions must be known to solve all the relevant equations. This leads to a large number of required parameters, predominantly spatially varying. In particular, the number of parameters can increase beyond the number required for simulating single hazards, as the interactions require a fuller description of material properties. With this increase of input parameters, the uncertainty in model output similarly increases. In a mathematical sense, each parameter tends to provide the model with a new degree of freedom. Since the value for this parameter that determines this axis of variation is unknown, model outcomes become uncertain along this axis of variation. A downfall noticed in generally in modelling is over-parameterization. This is commonly stated as: with sufficient parameters and sufficient calibration, any process can be modelled without providing actual predictive power. This pitfall must be recognized in the increased complexity of multi-hazard models and counter-acted by calibrationvalidation studies.

- A further complication here is the presence of strong threshold effects and non-linear interactions such as mass movements blocking river sections. A small variation on cohesive strength of a sloping material might mean failure occurs during an event, runout blocks a channel and a large area is impacted. These types of interactions make uncertainty analysis difficult, as strong changes might occur based on minor variations in input parameters.

- Uncertainty propagation occurs generally in modelling when a larger set of equations is solved either as a single system, or in a coupled manner. The potential variation in input parameters leads to potential variation in model outcomes for each aspect to the model. The effect of this propagation is not a divergence of model outcomes necessarily, but this is typically observed (Mergili et al., 2018).

- The limitation to validation of multi-hazard models are mainly caused by the relative scarcity of well-documented events featuring multi-hazard interactions. For some of the interactions, such as landslide-damming of rivers resulting in flooding, this is caused simply by relatively low frequencies of occurrence of these interacting processes. The low relative occurrence follows directly from the observation that not all landslides result in river-damming, and not all river floods result from landslide damming. While absolute number of occurrences lend importance to analysis of interactions, relative attention is reduced. For others types of interactions, the limitations to modelling techniques in the past might have limited research interests, such as can be argued for with runoff-initiated debris flows. For example, simulations of floods has a long history with the development of the Saint-Venant equations for shallow flow in 1871 . With the rise of computational methods for partial differential equations, the simulations of flood behavior became relevant fast (see Rossi, 1994 for an historical overview). On the other hand, multi-phase flows required a longer time to be understood and became prominent some decades later (Goodman \& Cowin, 1971). For both of these causes, validation of modelling approaches is complicated by the unavailability of data. This effect is strengthened by the increased data requirements for multi-hazard simulations. 
Several approaches have been suggested to address the parameterization issues. Among these area: parameter reduction, parameter database building and usage of remote sensing datasets.

- Parameter reduction aims to express values of specific physical parameters in terms of either already known parameters or in physical properties that are more easily obtained through measurement. This can be done either empirically (Saxton et al., 2006) or by means of physically-based equations. Examples of this approach can be found both for single-hazard models, and for multi-phase adaptive flow simulations (Boetticher et al., 2017). In particular, for flow models, rheological parameters that are usually considered an event-specific input parameters can be based on other measured material properties that were already required for the model. For soil-related data, the simulations performed in chapter 8 were supported by 13 measurements of saturated conductivity, porosity, density and texture. However, simulation of intfiltration and ground water flow requires parameters that can not be easily directly measured such as the matric suction and coefficients for the soil water retention curves. These parameters are then derived from texture data instead.

- Parameter database building, as has been proposed by others, can act to make parameters that are, although necessary, difficult to obtain, more easily estimated (Mergili et al., 2018). A strong example of this is visible in the Curve Number Method, or the USLE erosion model, empirical methods for hydrology and erosion that requires a variety of parameters (Boughton, 1989; Benavidez et al., 2018). While these would be extremely difficult to parameterize in a stand-alone study, vast ranges of parameter tables have been built to support these methods. Similar developments for simulations of hydrometeorological multi-hazard events might involve in parameters such as entrainment constants, phenomenological constants (parameters within the model that act as an activating function for certain phenomena's or processes), and rheological parameters for specific material types.

- A final approach to the parameterization issue can be found in the growing availability of global datasets and modelling resources. Usage of remotesensing based physical predictions of parameters such as ground water moisture, surface roughness and land use type is in many modelling applications already invaluable (Mason et al., 2003; Ernst et al., 2010; Sanyal et al., 2014). Additional examples are tools such as GLOBCOVER (Arino et al., 2007) or SOILGRIDS (Hengl et al., 2017), in particular in combination with extensive empirical relationships such as those by Saxton et al. (2006). While spatial resolutions for global datasets can be low, and uncertainties related to unexplained spatial variance high, these tools can be of immense value in filling gaps in available data. Other types of data, in particular related to elevation, tend to have to course resolution for usage in local-scale simulations of flow processes (Bout \& Jetten., 2018). For areas where high-resolution national datasets are not available, global commercial satellite-based elevation data might be of use. Finally, deep learning based supersampling provides a innovative field of research that is strongly influencing remote sensing datasets, and might provide ways to improve them within several years.

Dealing with the uncertainties in model outcomes can be done in a complete manner by performing a large ensemble of simulations and analyzing trends in 
the set of simulated outcomes. This approach has often been applied successfully for simulation of single-hazard dynamics (Cloke \& Pappenberger, 2009; Tiwari \& Chatterjee, 2010; Alfieri et al., 2012). By having a set of all possible model outcomes for a given range of input parameters, probabilities of occurrence can be estimated for specific process chains and outcome types. A major downside to the ensemble approach is the increased computation time. This can be partially counteracted by phenomenological selection (based on which phenomena will occur during the simulations) of relevant scenarios before running the actual simulations.

In the end, important in the uncertainty consideration is need for a comparative evaluation. When faced with multi-hazard assessment and the need to perform physically-based modelling two options might be viable: integrated multihazard modeling or using several single-hazard models. Important is then wether the uncertainties and errors interoduced by integrated multi-hazard models exceeds those that would be a result of ignoring multi-hazard interactions. For the reconstruction of processes and their interaction for Hurricane Maria on Dominica and the 2009 Scaletta event, this work provided strong evidence that uncertainties from single-hazard modelling would far outweigh the uncertainties introduced by multi-hazard modelling. Together with a consideration of data requirements and time-constraints, this should guid the potential usage of these innovative methods. Thus, considerations must be made for each specific application based on the dominance of multihazard interactions in determining hazard intensity, and the added uncertainties coming from physically-based multi-hazard models. However, general guidelines do not exist to comparatively examine the potential value of implementing these tools. Within the coming years, these will need to be developed if integrated multi-hazard models are to mature into wider application in hazard and risk-assessment.

\subsubsection{Multi-hazard Vulnerability}

For further usage of physically-based multi-hazard models in hazard and risk assessment, damage to exposed elements must be estimated from the hazard intensity. For single-hazard applications, vulnerability curves are used that relate a chosen hazard intensity description (e.g. flow height, velocity, momentum) to fractional damage for a specific type of element-at-risk (e.g. a building of specific material and structure). Numerous examples of vulnerability curves exists for individual hazards such as those collected in the ERN-Vulnerability tool (Capra, 2020). Flood damage curves can focus on properties of flow such as height, duration, velocity or compound parameters such as the Reynolds number (Hsu et al., 2011). For debris flows and landslides, impact pressure is a common parameter besides the height, velocity and momentum of the flow (Fuchs et al., 2007). For seismic damage curves, peak ground acceleration or spectral acceleration can be used (Lourenco et al., 2006; Lantada et al., 2009), although detailed spatial data on seismic accelerations is difficult to obtain due to topographical and amplification effects, and modelling of high resolution shake maps is a costly exercise (Khan et al., 2017). For the examples mentioned so far, usage of the same curves for damage prediction in multi-hazard events is not possible since the used parameters differ between hazards and curves are generally designed using a single-hazard approach. Recently, there has been some research towards 
multi-hazard vulnerability using multi-parameter vulnerability curves (Gadaris et al., 2017; Tyagunov et al., 2018; Suksuwan \& Spence, 2018). There has been, however, no real integration of vulnerability tools and the issue of calculating final damage of elements-at-risk in multi-hazard situations remains open. Finally, an additional issue here is the consequent impact of hazards, where one impacts elements and causes partial damage, followed by a second impact from another hazardous process. In these cases, the vulnerability of the elements often changes due to the previous impact (Reilly et al., 2017).

\subsubsection{Probabiliy: Rethinking Scenario Design}

To complete the usage of physically-based multi-hazard models in hazard and risk assessment, event probability must be addressed (Frattini et al., 2009; Ward et al., 2011). Both within this work, and in other studies, threshold effect have been noticed in interacting process chains (Mergili et al., 2018). These lead to major jumps in hazard intensity when certain conditions are met. Additionally, as was found in this thesis, the relationship between hazard intensity (debris flood height) and the probability assigned to a triggering event (hurricane precipitation) does not have to be one-to-one or monotonically increasing (see also the analysis for Dominica in chapter 8). These issues complicate the selection of design events. A set of rainfall events $\left\{R_{i}\right\}$ with associated return periods $\left\{T_{R_{i}}\right\}$ will induce some set of hazard intensities $\left\{I_{i}\right\}$ with return periods $\left\{T_{I_{i}}\right\}$. The return periods for the rainfall events might not be equal to the return period of the induced hazard intensity $\left(T_{R_{i}} \neq T_{I_{i}}\right)$. More concretely, precipitation events with return period 5 and 10 years might not coincide with flood height with 5 and 10 year return period.

The most direct solution to this issue is to ensure that a larger number of design events is used that describe numerous triggering processes and their return period. From the set of model outcomes, the return periods of hazard intensity can then be derived through general extreme value analysis of hazard return period for each pixel. Such an approach would result in spatially varying return periods for a single simulated event, as the triggering rainfall does no longer homogeneously describe the return period of floods throughout the area. This could be expressed as a spatially-dependent probability of exceedance.

Another issues relates to the spatial nature of the probability of occurrence for a trigger of certain intensity. The intensity of 5 -year return period precipitation for a specific point location is not equal to the 5 -year return period precipitation for a larger area. These specific event will not occur for each location simultaneously. The larger the area under consideration, the less likely simultaneous occurrence becomes. Commonly, triggers act approximately homogenously over significant areas such as watersheds. However, at the national scale simultaneous occurrence can not be assumed (Hall et al., 2003). A currently used solution to the probability issue is to abandon the concept of design scenarios altogether. Instead, a historical record or generated series of events can be used to simulate all events during a chosen time period (e.g. a 100 year record to obtain event up to a 100-year return period) (Boughton \& Droop, 2003; Diederen \& Liu, 2019). A generated timeseries of, for example, climatic variables can be used if the statistical properties of this series match the properties of the historical record. Since simulation of these long 
continuous records required increased computation time, it is typically limited to river networks, with simplified spatial distribution of processes (Blazkova \& Beven, 2009; Winter et al., 2019). Finally, for each spatial location included in the simulations, a probability distribution can be obtained based on the intensity values (Falter et al., 2015). This leads to location-specific return period values that capture accurately the probability of a specific hazard intensity on that location. The actual difference this approach would make compared to traditional design storms in application with physically-based multi-hazard modelling has yet to be investigated. Additonally, no framework exists currently that makes this technique applicable in a multi-hazard context. Other solutions include the design of design storms that better capture the range of possible behavior. This can be done either by development of a set of more detailed scenarios for which the resulting range of hazard dynamics is verified to match observed variety (Jiang et al., 2019). This approach can however not be used without a large historical dataset to verify that the designed scenarios capture all relevant potential outcomes.

\subsection{Opportunities for Improvement}

\subsubsection{Finishing the Hydro-meteorological Hazard Group}

Within a schematic depiction of natural hazards and their interactions, the hydrometeorological group provides a natural candidate for integrated modelling approaches. Currently, several processes within this group are implemented in the OpenLISEM multi-hazard modelling tool developed in this thesis. Several other hazard interactions have a potential to be included in the tool, given the currently known modelling approaches. Numerous other common multi-hazard interactions that are not yet implemented in a usable manner, such as the influence of windthrow of trees, transport of large logs and seismic influences. This section discusses some of these and states some potential approaches that might be taken to implement them. It is important to read these potential research directions in the light of a goal-based research directive. The implementation of additional processes without clear benefits can complicate the model setup and hinder its applicability. A modular approach might assist here, allowing users to turn of non-essential parts of the model. However, simulation tools with a more specific niche are typically better able to optimize and use more elegant solutions to the specific problem they adress. Despite this, increased understanding of multi-hazard interactions provides a general motive to implement additional processes.

Seismically triggered slope instability is a diverse field of research. Numerous methods for slope failure prediction incorporate seismic activity by estimating the additional forces from a peak ground acceleration value (Reid et al., 2015; Tiwari et al., 2015a,b; Locat et al., 2016). The underlying assumption about directionality of the acceleration (in direction of steepest descent, or maximal decrease in stability) have proven useful in a wide variety of applications. The accuracy and detail in prediction of ground motion due to seismic wave propagation is increasing due to advances in 3D seismic wave modelling, including topographical effects and soil-rock interactions (Shafique et al., 2008; Khan et al., 2020). Currently, such techniques have not been thoroughly implemented in a multi-hazard simulation tool that takes into account runout 
and other cascading interactions. For full integration long-term effects for slope stability in seismically active areas must be included (Zhao et al., 2016). Seismic activity often leaves areas more susceptible to slope instability and mass movements in years to come (Fan et al., 2018). This legacy-effect arises in many forms, of which only few are currently implemented in multi-hazard models. OpenLISEM Hazard captures the increase in loose material in a catchment from landslide deposits, and the increase in debris flows induced by this. Landslide dam formation after co-seismic landslide runout can be simulated in full spatial detail, but uncertainties in flow structure and entrainment prevent robust application. Additionally, slope failures are generally more likely to occur after earthquakes. To simulate this effect, alterations in the physical properties of slope materials need to be explicitly modelled. Existing approaches estimate these effect through modelling of crack formation and energy release (Zhao et al., 2016).

Extreme wind gusts can have both a direct impact on elements-at-risk, but also influence events through a variety of interactions (Ulanova, 2000; Kappes et al., 2012). A primary example of this is windthrow of trees (Quine \& Gardiner, 2007). The resulting wood material can be entrained by incoming flows and act as additional debris. Windthrow as a process might be approached through linking wind gust speeds to the design events being considered. Then, a statistically-based distribution of discrete trees can be simulated. Based on measured properties such as canopy density, height, densities of trees, root and soil properties, critical wind speeds can be estimated that provide a threshold above which tree failure occurs (Quine \& Gardiner, 2007; Byrne \& Mitchell, 2013). Beyond added flow volumes, these large logs can block culverts and prevent drainage through designed infrastructure. Approaches for these kind of multi-phase debris flows can be found in three-phase debris flow models (Pudasaini \& Mergili, 2019). A downside to these approaches is a lack of discrete elements that can interact with physical obstacles. Here, fluid-rigid body interactions might need to be implemented.

Related to wind hazard is the coastal process of storm surges (Buna et al., 2010; Xie et al., 2016). Either due to wind or pressure gradients around meteorological low pressure systems, water displacements results in a surge in coastal water levels. In particular for hurricanes, this can coincide with fluvial flooding and other hazardous processes and lead to a variety of interactions such as the backwater effect, that increase total hazard beyond the sum of individual hazards. Modelling approaches for fluvial-coastal flood interactions exist using either shallow-wave approximations or Bussinesq-type coastal models (McGuian et al., 2015; Yin et al., 2016).

\subsubsection{Temporal Integration using Continuous Modelling}

Finally, several long-term processes might be integrated into multi-hazard modelling tools. Examples here are processes induced by droughts, or wet periods. For droughts, examples are vulnerability to wildfires and vegetation decline, which can also be due to insect infestations or plagues (Taufik et al., 2017; Miller et al., 2017). For wet periods, slow moving landslides can be influenced by means of fluctuations in pore pressure (Schultz et al., 2009), and susceptibility to slope failures in general can be strongly increase (van Beek., 2002). 
The integration of multi-hazard simulations in continuous modelling can be highly relevant for early-warning systems. These provide real-time hazard predictions for an area of interest. The current hazard depends highly on the particular state of the landscape, including boundary conditions such as tide, ground water content and river base discharge. As a consequence, continuous modelling is required to obtain current estimated of these parameters.

To implement these interactions, slow processes such as groundwater flow, evapotranspiration and river discharge must be included as these directly determine the groundwater and soil moisture values. Currently, modelling approaches exist that link continuous ground water modelling to hydrology, but further integration with runoff generation, debris flows and other processes is still limited (Rengers et al., 2016; McGuire et al., 2018). A major obstacle in continuous modelling is the computational time required by expanding models such as OpenLISEM Hazard from events to longer periods. Current long-term modelling approaches commonly utilize simplifying approximations to solve timestep-critical processes such as flow or infiltration. For example, daily water balance models can include flow as a flow accumulation processes can run efficiently over decades. Potential solutions here are efficient altered timestepping for each processes or period of the simulation.

\subsection{Concluding Remarks}

Both within this thesis and other efforts, integrated physically-based multihazard modelling has become an innovative field of research. Within the past years, major steps have been made in the available methodologies to capture a growing set of multi-hazard interactions within physically-based models. Application to event reconstruction and scenario exploration has shown clear benefits but also highlighted complication arising in parameterization and uncertainty of model outcomes. Additionally, in this thesis, it was found that the relationship between trigger intensity and hazard intensity only holds as a general rule, but can deviate considerably, depending on the hazard types and complicated interactions. Although these challenges are severe, they provide exciting new directions of research. In the coming years, integrated physicallybased multi-hazard models will need to be reinforced within a proper framework that link its outcomes to multi-hazard and risk assessment. If done well, it has the potential to provide a significant jump in the predictive capabilities and accuracy of multi-hazard risk assessment that can aid decision making related to disaster risk reduction. 


\section{Bibliography}

A.R.T.A,

http://www.sitr.regione.sicilia.it/geoportale/it/metadata/details/502

(retrieved 10-04-2017)

Abe, K., \& Konagai, K. (2016). Numerical simulation for runout process of debris flow using depth-averaged material point method. Soils and Foundations, 56(5), 869-888.

Adegbe, M., Alkema, D., Jetten, V. G., Agbor, A. T., Abdullahi, I. N., Shehu, O. U., \& Unubi, A. S. (2013). Post Seismic Debris Flow Modeling Using Flo2D; Case Study of Yingxiu, Sichuan Pronvince, China. Journal of Geography and Geology, 5(3), 101.

Alcrudo, F., \& Garcia Navarro, P. (1993). A high resolution Godunov type scheme in finite volumes for the 2D shallow water equations. International Journal for Numerical Methods in Fluids, 16(6), 489-505.

Alfieri, L., Thielen, J., \& Pappenberger, F. (2012). Ensemble hydrometeorological simulation for flash flood early detection in southern Switzerland. Journal of hydrology, 424, 143-153.

Alkasawneh, W., Malkawi, A. I. H., Nusairat, J. H., \& Albataineh, N. (2008). A comparative study of various commercially available programs in slope stability analysis. Computers and Geotechnics, 35(3), 428-435.

Amirahmadi, A., Pourhashemi, S., Karami, M., \& Akbari, E. (2016). Modeling of landslide volume estimation. Open Geosciences, 8(1), 360-370.

Ardizzone, F., Basile, G., Cardinali, M., Casagli, N., Del Conte, S., Del Ventisette, C., ... \& Iovine, G. (2012). Landslide inventory map for the Briga and the Giampilieri catchments, NE Sicily, Italy. Journal of Maps, 8(2), 176-180.

Arino, O., Gross, D., Ranera, F., Leroy, M., Bicheron, P., Brockman, C., ... \& Bourg, L. (2007, July). GlobCover: ESA service for global land cover from MERIS. In 2007 IEEE international geoscience and remote sensing symposium (pp. 2412-2415). IEEE.

Arnold, J. G., Srinivasan, R., Muttiah, R. S., \& Williams, J. R. (1998). Large area hydrologic modeling and assessment part I: Model development1.

Aronica, G. T., Brigandí, G., \& Morey, N. (2012). Flash floods and debris flow in the city area of Messina, north-east part of Sicily, Italy in October 2009: the case of the Giampilieri catchment. Natural Hazards and Earth System Sciences, 12(5), 1295.

Atchley, A. L., Linn, R., Middleton, R. S., Runde, I., Coon, E., and Michaletz, S. T. (2016, December). Simulating Fire Disturbance and Plant Mortality Using Antecedent Eco-hydrological Conditions to Inform a Physically Based Combustion Model. In AGU Fall Meeting Abstracts.

Audusse, E., Bouchut, F., Bristeau, M. O., Klein, R., \& Perthame, B. T. (2004). A fast and stable well-balanced scheme with hydrostatic reconstruction for shallow water flows. SIAM Journal on Scientific Computing, 25(6), 20502065.

Baartman, J. E., Jetten, V. G., Ritsema, C. J., \& Vente, J. (2012). Exploring effects of rainfall intensity and duration on soil erosion at the catchment scale using openLISEM: Prado catchment, SE Spain. Hydrological processes, 26(7), 1034-1049. 
Baartman, J. E., Temme, A. J., Veldkamp, T., Jetten, V. G., \& Schoorl, J. M. (2013). Exploring the role of rainfall variability and extreme events in longterm landscape development. Catena, 109, 25-38.

Baartman, J., Jetten, V. G., Ritsema, C. J., \& De Vente, J. (2012b). Exploring effects of rainfall intensity and duration on soil erosion at the catchment scale using OpenLISEM. In EGU General Assembly Conference Abstracts (Vol. 14, p. 651).

Baba, T., Takahashi, N., Kaneda, Y., Ando, K., Matsuoka, D., and Kato, T. (2015). Parallel implementation of dispersive tsunami wave modeling with a nesting algorithm for the 2011 Tohoku tsunami. Pure and Applied Geophysics, 172(12), 3455-3472.

Bandara, S., Ferrari, A., \& Laloui, L. (2016). Modelling landslides in unsaturated slopes subjected to rainfall infiltration using material point method. International Journal for Numerical and Analytical Methods in Geomechanics, 40(9), 1358-1380.

Barrantes, G. (2018). Multi-hazard model for developing countries. Natural Hazards, 92(2), 1081-1095.

Barré de Saint-Venant, A.-J.-C. (1871). Théorie du mouvement nonpermanent des eaux, avec application aux crues des rivières et à l'introduction des marées dans leur lit. Comptes Rendus de l'Académie des Sciences, 73:147-154

Bartelt, P., Buehler, Y., Christen, M., Deubelbeiss, Y., Graf, C., \& McArdell, B. W. (2013). RAMMS-rapid mass movement simulation, A modeling system for debris flows in research and practice, user manual v1. 5, debris flow,. WSL Institute for Snow and Avalanche Research SLF

Bartelt, P., Buehler, Y., Christen, M., Deubelbeiss, Y., Graf, C., and McArdell, B. W. (2013). RAMMS-rapid mass movement simulation, A modeling system for debris flows in research and practice, user manual v1. 5, debris flow,. WSL Institute for Snow and Avalanche Research SLF

Bastiaanssen, W. G. M., Huygen, J., Schakel, J. K., \& Van Den Broek, B. J. (1996). Modelling the soil-water-crop-atmosphere system to improve agricultural water management in arid zones (SWATRE).

Batcher, K. E. (1968, April). Sorting networks and their applications. In Proceedings of the April 30--May 2, 1968, spring joint computer conference (pp. 307-314).

Bates, P. D. (2004). Remote sensing and flood inundation modelling. Hydrological processes, 18(13), 2593-2597.

Batjes, N. H., Ribeiro, E., and van Oostrum, A. Standardised soil profile data to support global mapping and modelling (WoSIS snapshot 2019).

Baum, R. L., Coe, J. A., Godt, J. W., Harp, E. L., Reid, M. E., Savage, W. Z.,Savage, W. H. Schulz, D. L. Brien, A. F. Chleborad, J. P. McKenna \& Michael, J. A. (2005). Regional landslide-hazard assessment for Seattle, Washington, USA. Landslides, 2(4), 266-279.

Baum, R. L., Savage, W. Z., \& Godt, J. W. (2008). TRIGRS-A Fortran program for transient rainfall infiltration and grid-based regional slope-stability analysis, version 2.0 (No. 2008-1159). US Geological Survey.

Beguería, S., Van Asch, T. W., Malet, J. P., \& Gröndahl, S. (2009). A GIS-based numerical model for simulating the kinematics of mud and debris flows over complex terrain. Natural Hazards and Earth System Sciences, 9(6), 1897-1909. 
Bell, R., and Glade, T. (2004). Multi-hazard analysis in natural risk assessments. WIT Transactions on Ecology and the Environment, 77.

Bellos, V., \& Tsakiris, G. (2016). A hybrid method for flood simulation in small catchments combining hydrodynamic and hydrological techniques. Journal of Hydrology, 540, 331-339.

Benavidez, R., Jackson, B., Maxwell, D., \& Norton, K. (2018). A review of the (Revised) Universal Soil LosS Equation ((R) USLE): with a view to increasing its global applicability and improving soil loss estimates. Hydrology and Earth System Sciences, 22(11), 6059-6086.

Berbić, J., Kuspilić, N., \& Ocvirk, E. (2016, January). Uncertanties In Flood Events Estimation. In All In One Conference 2016: 2nd International Conference On Advances In Statistics.

Bernal, G. A., Salgado-Gálvez, M. A., Zuloaga, D., Tristancho, J., González, D., and Cardona, O. D. (2017). Integration of probabilistic and multi-hazard risk assessment within urban development planning and emergency preparedness and response: Application to Manizales, Colombia. International Journal of Disaster Risk Science, 8(3), 270-283.

Beutner, E. C., \& Gerbi, G. P. (2005). Catastrophic emplacement of the Heart Mountain block slide, Wyoming and Montana, USA. Geological Society of America Bulletin, 117(5-6), 724-735.

Beven, K. J., Warren, R. O. S. S., \& Zaoui, J. A. C. Q. U. E. S. (1980). SHE: towards a methodology for physically-based distributed forecasting in hydrology. IAHS Publ, 129, 133-137.

Bieniawski, Z. T. (1967, October). Mechanism of brittle fracture of rock: part I-theory of the fracture process. In International Journal of Rock Mechanics and Mining Sciences \& Geomechanics Abstracts (Vol. 4, No. 4, pp. 395-406). Pergamon.

Blazkova, S., \& Beven, K. (2009). A limits of acceptability approach to model evaluation and uncertainty estimation in flood frequency estimation by continuous simulation: Skalka catchment, Czech Republic. Water Resources Research, 45(12).

BORGA M., P. BOSCOLO, F. ZANON, M. SANGATI, 2007: Hydrometeorological analysis of the August 29, 2003 flash flood in the eastern Italian Alps. Journal of Hydrometeorology, 8(5), 1049-1067, DOI: 10.1175/JHM593.1, ISSN: 1525-755X.

Borga, M., Boscolo, P., Zanon, F., \& Sangati, M. (2007). Hydrometeorological analysis of the 29 August 2003 flash flood in the Eastern Italian Alps. Journal of Hydrometeorology, 8(5), 1049-1067.

Boughton, W. C. (1989). A review of the USDA SCS curve number method. Soil Research, 27(3), 511-523.

Boughton, W., \& Droop, O. (2003). Continuous simulation for design flood estimation-a review. Environmental Modelling \& Software, 18(4), 309318.

Bout, B., \& Jetten, V. G. (2018). The validity of flow approximations when simulating catchment-integrated flash floods. Journal of hydrology, 556, 674-688.

Bout, B., Lombardo, L., van Westen, C. J., \& Jetten, V. G. (2018). Integration of two-phase solid fluid equations in a catchment model for flashfloods, debris flows and shallow slope failures. Environmental modelling \& software, 105, 1-16. 
Bovolo, C.I., Abele, S.J., Bathurst, J.C., Caballero, D., Ciglan, M., Eftichidi, G., Simo, B., 2009. A distributed framework for multi-risk assessment of natural hazards used to model the effects of forest fire on hydrology and sediment yield. Comput. Geosci. 35, 924-945.

Bradbrook, K. F., Lane, S. N., Waller, S. G., \& Bates, P. D. (2004). Two dimensional diffusion wave modelling of flood inundation using a simplified channel representation. International Journal of River Basin Management, 2(3), 211-223.

Braud, I., Ayral, P. A., Bouvier, C., Branger, F., Delrieu, G., Le Coz, J., ... \& Andrieu, J. (2014). Multi-scale hydrometeorological observation and modelling for flash-flood understanding.

Bravo, J. M., Allasia, D., Paz, A. R., Collischonn, W., and Tucci, C. E. M. (2011). Coupled hydrologic-hydraulic modeling of the Upper Paraguay River basin. Journal of hydrologic engineering, 17(5), 635-646.

Bristeau, M. O., \& Coussin, B. (2001). Boundary conditions for the shallow water equations solved by kinetic schemes (Doctoral dissertation, INRIA)

Brooks, S. M., Crozier, M. J., Glade, T. W., \& Anderson, M. G. (2004). Towards establishing climatic thresholds for slope instability: use of a physicallybased combined soil hydrology-slope stability model. Pure and Applied Geophysics, 161(4), 881-905.

Brunner, G. W. (1995). HEC-RAS River Analysis System. Hydraulic Reference Manual. Version 1.0. HYDROLOGIC ENGINEERING CENTER DAVIS CA.

Brunner, G. W. (2010). HEC-RAS (River Analysis System). In North American Water and Environment Congress \& Destructive Water: (pp. 3782-3787). ASCE.

Brunner, G. W. (2010). HEC-RAS river analysis system: hydraulic reference manual. US Army Corps of Engineers, Institute for Water Resources, Hydrologic Engineering Center.

Buck, K. D., Summers, K. J., Hafner, S., Smith, L. M., and Harwell, L. C. (2019). Development of a Multi-Hazard Landscape for Exposure and Risk Interpretation: The PRISM Approach. Current Environmental Engineering, 6(1), 74-94.

Bui, H. H., Fukagawa, R., Sako, K., \& Ohno, S. (2008). Lagrangian meshfree particles method (SPH) for large deformation and failure flows of geomaterial using elastic-plastic soil constitutive model. International journal for numerical and analytical methods in geomechanics, 32(12), 1537-1570.

Burston, J. M., Taylor, D., Dent, J., and Churchill, J. (2017). Australia-wide tropical cyclone multi-hazard risk assessment. Australasian Coasts and Ports 2017: Working with Nature, 185.

Burton, I., Robert W. Kates and Gilbert F. White. The Environment as Hazard (New York: Oxford University Press, 1978).

Cama, M., Lombardo, L., Conoscenti, C., \& Rotigliano, E. (2017). Improving transferability strategies for debris flow susceptibility assessment: Application to the Saponara and Itala catchments (Messina, Italy). Geomorphology.

Cama, M., Lombardo, L., Conoscenti, C., Agnesi, V., Rotigliano, E. (2015) Predicting storm-triggered debris flow events: Application to the 2009 Ionian Peloritan disaster (Sicily, Italy). Natural Hazards and Earth System Sciences, 15 (8), pp. 1785-1806. 
Cance, A., Thiery, Y., Fressard, M., Vandromme, R., Maquaire, O., Reid, M. E., \& Mergili, M. (2017, October). Influence of complex slope hydrogeology on landslide susceptibility assessment: the case of the Pays d'Auge (Normandy, France). In Journées Aléas Gravitaires.

Canelas, R., Ferreira, R. M., Crespo, A., and Domínguez, J. M. (2013, June). A generalized SPH-DEM discretization for the modelling of complex multiphasic free surface flows. In Proceedings of the 8th International SPHERIC Workshop (pp. 74-79).

CAPRA (2020) Probabilistic Risk Assessment Platform. https://ecapra.org/

Cardona, O. D., Ordaz Schroder, M. G., Reinoso, E., Yamín, L., and Barbat Barbat, H. A. (2010). Comprehensive approach for probabilistic risk assessment (CAPRA): international initiative for disaster risk management effectiveness. In 14th European Conference on Earthquake Engineering (pp. 1-10).

Carson, M. A., \& Kirkby, M. J. (1972). Hillslope form and process.

Casalbore, D., Chiocci, F. L., Mugnozza, G. S., Tommasi, P., \& Sposato, A. (2011). Flash-flood hyperpycnal flows generating shallow-water landslides at Fiumara mouths in Western Messina Strait (Italy). Marine Geophysical Research, 32(1-2), 257.

Chai, H., Liu, H., Zhang, Z., and Xu, Z. (2000): The distribution, causes and effects of damming landslides in China, Journal of the Chengdu Institute of Technology, 27, 302-307, 2000 (In Chinese).

CHARIM, "Methods for Risk Assessment", CHARIM Carribean Handbook on Risk Information Management, University of Twente, 2016, http://www.charim.net/methodology/55.

Chen, H. X., \& Zhang, L. M. (2015). EDDA 1.0: integrated simulation of debris flow erosion, deposition and property changes. Geoscientific Model Development, 8(3), 829-844.

Chen, H. X., Zhang, S., Peng, M., and Zhang, L. M. (2016). A physically-based multi-hazard risk assessment platform for regional rainfall-induced slope failures and debris flows. Engineering geology, 203, 15-29.

Chen, L., Hussin, H.Y., Ciurean, R., Turkington, T.A.R., van Westen, C.J., Chavarro, D. and Shrestha, D.P. (2014) Multi - hazard risk assessment in Fella Basin, Italy, using historical hazard inventory and GIS : extended abstract. Presented at: Analysis and management of changing risks for natural hazards : international conference, 18-19 November 2014, Padua, Italy.

Chen, L., van Westen, C. J., Hussin, H., Ciurean, R. L., Turkington, T., Chavarro-Rincon, D., and Shrestha, D. P. (2016). Integrating expert opinion with modelling for quantitative multi-hazard risk assessment in the Eastern Italian Alps. Geomorphology, 273, 150-167.

Chen, M. L., Hu, G. S., Chen, N. S., Zhao, C. Y., Zhao, S. J., \& Han, D. W. (2016). Valuation of debris flow mitigation measures in tourist towns: a case study on Hongchun gully in southwest China. Journal of Mountain Science, 13(10), 1867-1879.

Chen, W. B., and Liu, W. C. (2014). Modeling flood inundation induced by river flow and storm surges over a river basin. Water, 6(10), 3182-3199.

Chen, W. F., \& Mizuno, E. (1990). Nonlinear analysis in soil mechanics (No. BOOK). Amsterdam: Elsevier. 
Chok, Y. H., Jaksa, M. B., Kaggwa, W. S., \& Griffiths, D. V. (2015). Assessing the influence of root reinforcement on slope stability by finite elements. International Journal of Geo-Engineering, 6(1), 12.

Choudhury, B. J. (1987). Relationships between vegetation indices, radiation absorption, and net photosynthesis evaluated by a sensitivity analysis. Remote Sensing of Environment, 22(2), 209-233.

Choudhury, B. J., Ahmed, N. U., Idso, S. B., Reginato, R. J., \& Daughtry, C. S. (1994). Relations between evaporation coefficients and vegetation indices studied by model simulations. Remote sensing of environment, 50(1), 117.

Chow, V. (1959). Open channel hydraulics. McGraw-Hill Book Company, Inc; New York.

Christen, M., Kowalski, J., and Bartelt, P. (2010). RAMMS: Numerical simulation of dense snow avalanches in three-dimensional terrain. Cold Regions Science and Technology, 63(1-2), 1-14.

Cioni, R., Longo, A., Macedonio, G., Santacroce, R., Sbrana, A., Sulpizio, R., and Andronico, D. (2003). Assessing pyroclastic fall hazard through field data and numerical simulations: example from Vesuvius. Journal of Geophysical Research: Solid Earth, 108(B2).

Cipta, A., Robiana, R., Griffin, J. D., Horspool, N., Hidayati, S., and Cummins, P. R. (2017). A probabilistic seismic hazard assessment for Sulawesi, Indonesia. Geological Society, London, Special Publications, 441(1), 133152.

Ciurean, R. L., Hussin, H., Van Westen, C. J., Jaboyedoff, M., Nicolet, P., Chen, L., ... and Glade, T. (2017). Multi-scale debris flow vulnerability assessment and direct loss estimation of buildings in the Eastern Italian Alps. Natural hazards, 85(2), 929-957.

Cloke, H. L., \& Pappenberger, F. (2009). Ensemble flood forecasting: A review. Journal of hydrology, 375(3-4), 613-626.

Coan, M., Wood, E., and Reillo, P. (2007). Forest Formation and Land Cover Map Series: Dominica. http://lca.usgs.gov/lca/carland/data/dominica/dominica_lulc_final.tif.htm

Cohen, D., Lehmann, P., \& Or, D. (2009). Fiber bundle model for multiscale modeling of hydromechanical triggering of shallow landslides. Water resources research, 45(10).

CommonWealth of Dominica, Rapid Damage and Impact Assessment for Tropical Storm Erika. https://www.gfdrr.org/sites/default/files/publication/Dominica-RapidDamage-and-Needs-Assessment.pdf, retrieved 20-02-2020.

Corominas, J., Matas, G., \& Ruiz-Carulla, R. (2019). Quantitative analysis of risk from fragmental rockfalls. Landslides, 16(1), 5-21.

Corominas, J., van Westen, C., Frattini, P., Cascini, L., Malet, J. P., Fotopoulou, S., ... \& Pitilakis, K. (2014). Recommendations for the quantitative analysis of landslide risk. Bulletin of engineering geology and the environment, 73(2), 209-263.

Costa, J.E., Schuster, R.L., 1988. The formation and failure of natural dams. Geological Society of America Bulletin 100, 1054-1068

Costantini, E.A.C., Barbetti, R., Fantappiè, M., L'Abate, G., Lorenzetti, R., Napoli, R., Marchetti, A., Rivieccio, R. (2014) The soil map of Italy: A hierarchy of geodatabases, from soil regions to sub-systems. 
GlobalSoilMap: Basis of the Global Spatial Soil Information System Proceedings of the 1st GlobalSoilMap Conference, pp. 109-112.

Coulomb, C. A. (1776). Essai suruneapplication des regles des maximis et minimis a quelquesproblemes de statiquerelatifs, a l'architecture.

CRED. Natural Disasters 2018. Brussels: CRED; 2019. This document is available at: https://emdat.be/ sites/default/files/adsr_2018.pdf

Crosta, G. (1998). Regionalization of rainfall thresholds: an aid to landslide hazard evaluation. Environmental Geology, 35(2), 131-145.

Cruden, D. M., \& Varnes, D. J. (1996). Landslides: investigation and mitigation. Chapter 3-Landslide types and processes. Transportation research board special report, (247).

Cui, P., Zhu, Y. Y., Han, Y. S., Chen, X. Q., and Zhuang, J. Q. (2009). The 12 May Wenchuan earthquake-induced landslide lakes: distribution and preliminary risk evaluation. Landslides, 6(3), 209-223.

Cutter, S. L., Mitchell, J. T., and Scott, M. S. (2000). Revealing the vulnerability of people and places: a case study of Georgetown County, South Carolina. Annals of the association of American Geographers, 90(4), 713737.

Dahm, R., Hsu, C. T., Lien, H. C., Chang, C. H., \& Prinsen, G. (2014). Next generation flood modelling using 3Di: a case study in Taiwan. In $D S D$ international conference.

Dai, F. C., Lee, C. F., Deng, J. H., \& Tham, L. G. (2005). The 1786 earthquaketriggered landslide dam and subsequent dam-break flood on the Dadu River, southwestern China. Geomorphology, 65(3), 205-221.

D'Ambrosio, D., Iovine, G., Spataro, W., \& Miyamoto, H. (2007). A macroscopic collisional model for debris-flows simulation. Environmental Modeling \& Software, 22(10), 1417-1436.

DAVID, L. G., \& RICHARD, M. (2011). A two-phase debris-flow model that includes coupled evolution of volume fractions, granular dilatancy, and pore-fluid pressure. Italian journal of engineering geology and Environment, 43, 415-424.

Davies, T. R., \& McSaveney, M. J. (2009). The role of rock fragmentation in the motion of large landslides. Engineering Geology, 109(1-2), 67-79.

Davies, T. R., McSaveney, M. J., \& Beetham, R. D. (2006). Rapid block glides: slide-surface fragmentation in New Zealand's Waikaremoana landslide. Quarterly Journal of Engineering Geology and Hydrogeology, 39(2), 115-129.

Davis, P. J., \& Rabinowitz, P. (2007). Methods of numerical integration. Courier Corporation.

Dazzi, S., Vacondio, R., Dal Palù, A., \& Mignosa, P. (2018). A local time stepping algorithm for GPU-accelerated 2D shallow water models. Advances in Water Resources, 111, 274-288.

De Baets, S., Poesen, J., Reubens, B., Wemans, K., De Baerdemaeker, J., \& Muys, B. (2008). Root tensile strength and root distribution of typical Mediterranean plant species and their contribution to soil shear strength. Plant and soil, 305(1-2), 207-226.

De Risi, R., and Goda, K. (2016). Probabilistic earthquake-tsunami multihazard analysis: application to the Tohoku Region, Japan. Frontiers in Built Environment, 2, 25. 
De Risi, R., and Goda, K. (2016). Probabilistic earthquake-tsunami multihazard analysis: application to the Tohoku region, Japan. Frontiers in Built Environment, 2, 25.

De Roo, A. P. J., \& Jetten, V. G. (1999). Calibrating and validating the LISEM model for two data sets from the Netherlands and South Africa. Catena, 37(3-4), 477-493.

De Roo, A. P. J., Offermans, R. J. E., \& Cremers, N. H. D. T. (1996). LISEM: A single event, physically based hydrological and soil erosion model for drainage basins. II: Sensitivity analysis, validation and application. Hydrological processes, 10(8), 1119-1126.

De Vuyst, T., \& Vignjevic, R. (2013). Total Lagrangian SPH modelling of necking and fracture in electromagnetically driven rings. International Journal of Fracture, 180(1), 53-70.

Del Monaco, G., Margottini, C., Serafini, S., 1999. Multi-hazard risk assessment and zoning: an integrated approach for incorporating natural disaster reduction into sustainable development. Technical Report, TIGRA project (The Integrated Geological Risk Assessment), Grant No. Env4-CT96-0262. European Commission DG XII, Environment and Climate Program, Brussels.

Del Monaco, G., Margottini, C., Spizzichino, D., 2007. ARMONIA methodology for multirisk assessment and the harmonisation of different natural risk map. Technical Report D3.1.1, ARMONIA Project (Applied Multi-Risk Mapping of Natural Hazards for Impact Assessment), Grant No. 511208. Rome, 31 January 2007.

Delaney, K. B., \& Evans, S. G. (2014). The 1997 Mount Munday landslide (British Columbia) and the behaviour of rock avalanches on glacier surfaces. Landslides, 11(6), 1019-1036.

Delestre, O., Cordier, S., Darboux, F., Du, M., James, F., Laguerre, C., ... \& Planchon, O. (2014). FulISWOF: A software for overland flow simulation. In Advances in hydroinformatics (pp. 221-231). Springer, Singapore.

Delft Hydraulics. (2000). SOBEK manual and technical reference.Ermini, L., and Casagli, N., (2003). Prediction of the behavior of landslide dams using a geomorphological dimensionless index. Earth Surface Processes and Landforms 28, 31-47.

Deltares Hydraulics (1999). Delft3D-FLOW user manual. The Netherlands.

Destro, E., Amponsah, W., Nikolopoulos, E. I., Marchi, L., Marra, F., Zoccatelli, D., \& Borga, M. (2018). Coupled prediction of flash flood response and debris flow occurrence: Application on an alpine extreme flood event. Journal of Hydrology, 558, 225-237.

Dhanmeher, S. (2017). Crack pattern observations to finite element simulation: An exploratory study for detailed assessment of reinforced concrete structures.

Diederen, D., \& Liu, Y. (2019). Dynamic spatio-temporal generation of largescale synthetic gridded precipitation: with improved spatial coherence of extremes. Stochastic Environmental Research and Risk Assessment, 1-15.

Dilley, M., Chen, R.S., Deichmann, U., Lerner-Lam, A.L., Arnold, M., 2005. Natural Disaster Hotspots: A Global Risk Analysis. The World Bank Hazard Management Unit, Washington, D.C.

Dixon, B. (2005). Groundwater vulnerability mapping: a GIS and fuzzy rule based integrated tool. Applied Geography, 25(4), 327-347. 
Douglas, J., 2007. Physical vulnerability modelling for natural hazards risk assessment. Nat. Hazards Earth Syst. Sci. 7, 283-288.

Drew, D. A. (1983). Mathematical modeling of two-phase flow. Annual review of fluid mechanics, 15(1), 261-291.

Dufresne, A., Geertsema, M., Shugar, D. H., Koppes, M., Higman, B., Haeussler, P. J., ... \& Gulick, S. P. S. (2018). Sedimentology and geomorphology of a large tsunamigenic landslide, Taan Fiord, Alaska. Sedimentary Geology, 364, 302-318.

Duncan, J. M., Wright, S. G., \& Brandon, T. L. (2014). Soil strength and slope stability. John Wiley \& Sons.

Dupuy, L. X., Fourcaud, T., Lac, P., and Stokes, A. (2007). A generic 3D finite element model of tree anchorage integrating soil mechanics and real root system architecture. American Journal of Botany, 94(9), 1506-1514.

Ernst, J., Dewals, B. J., Detrembleur, S., Archambeau, P., Erpicum, S., \& Pirotton, M. (2010). Micro-scale flood risk analysis based on detailed 2D hydraulic modelling and high resolution geographic data. Natural Hazards, 55(2), 181-209.

Evans, S. G., 1986, The maximum discharge of outburst floods caused by the breaching of man-made and natural dams: Can. Geotch. J., v. 23, p. 385387.

Evans, S. G., Mugnozza, G. S., Strom, A. L., Hermanns, R. L., Ischuk, A., \& Vinnichenko, S. (2006). Landslides from massive rock slope failure and associated phenomena. In Landslides from massive rock slope failure (pp. 03-52). Springer, Dordrecht.

Falter, D., Schröter, K., Dung, N. V., Vorogushyn, S., Kreibich, H., Hundecha, Y., ... \& Merz, B. (2015). Spatially coherent flood risk assessment based on long-term continuous simulation with a coupled model chain. Journal of Hydrology, 524, 182-193.

Fan, L., Lehmann, P., McArdell, B., \& Or, D. (2017). Linking rainfall-induced landslides with debris flows runout patterns towards catchment scale hazard assessment. Geomorphology, 280, 1-15.

Fan, X., Juang, C. H., Wasowski, J., Huang, R., Xu, Q., Scaringi, G., ... \& Havenith, H. B. (2018). What we have learned from the 2008 Wenchuan Earthquake and its aftermath: A decade of research and challenges. Engineering geology, 241, 25-32.

Fan, X., Tang, C. X., Van Westen, C. J., \& Alkema, D. (2012a). Simulating dam-breach flood scenarios of the Tangjiashan landslide dam induced by the Wenchuan Earthquake. Natural hazards and earth system sciences, 12(10), 3031.

Fan, X., van Westen, C. J., Xu, Q., Gorum, T., \& Dai, F. (2012b). Analysis of landslide dams induced by the 2008 Wenchuan earthquake. Journal of Asian Earth Sciences, 57, 25-37.Federal Emergency Management Agency. (1995). National mitigation strategy: Partnerships for building safer communities.

Fellenius, W. (1936, July). Calculation of the stability of earth dams. In Transactions of the 2 nd congress on large dams, Washington, DC (Vol. 4, pp. 445-463). International Commission on Large Dams (ICOLD) Paris.

FEMA (2010) HAZUS-MH analysis levels. Department of Homeland Security, Federal Emergency ManagementAgency. http://www.fema.gov/plan/prevent/hazus/hz_levels.shtm 
Feng, L. H., \& Lu, J. (2010). The practical research on flood forecasting based on artificial neural networks. Expert Systems with Applications, 37(4), 2974-2977.

Fiedler, F. R., \& Ramirez, J. A. (2000). A numerical method for simulating discontinuous shallow flow over an infiltrating surface. International journal for numerical methods in fluids, 32(2), 219-239

Fierotti, G., \& Fierotti, G. (1988). Carta dei suoli della Sicilia (No. 631.47458). Regione siciliana, Assessorato territorio ed ambiente:.

Formetta, G., \& Capparelli, G. (2019). Quantifying the three-dimensional effects of anisotropic soil horizons on hillslope hydrology and stability. Journal of Hydrology.

Formetta, G., Antonello, A., Franceschi, S., David, O., \& Rigon, R. (2014). Hydrological modeling with components: A GIS-based open-source framework. Environmental Modeling \& Software, 55, 190-200.

Fornes, P., Bihs, H., Thakur, V. K. S., \& Nordal, S. (2017). Implementation of non-Newtonian rheology for Debris Flow simulation with REEF3D. IAHR World Congress.

Forzieri, G., Feyen, L., Russo, S., Vousdoukas, M., Alfieri, L., Outten, S., ... and Cid, A. (2016). Multi-hazard assessment in Europe under climate change. Climatic Change, 137(1-2), 105-119.

Frank, F., McArdell, B. W., Huggel, C., and Vieli, A. (2015). The importance of entrainment and bulking on debris flow runout modeling: examples from the Swiss Alps. Natural Hazards and Earth System Sciences, 15(11), 25692583.

Frattini, P., Crosta, G., \& Sosio, R. (2009). Approaches for defining thresholds and return periods for rainfall triggered shallow landslides. Hydrological Processes: An International Journal, 23(10), 1444-1460.

Fread, D. L. (1988). BREACH, an erosion model for earthen dam failures. Hydrologic Research Laboratory, National Weather Service, NOAA.

Froude, M.J., Petley, D.N. (2018) Global fatal landslide occurrence from 2004 to 2016. Natural Hazards and Earth System Sciences 18(8), pp. 21612181.

Fuchs, S., Heiss, K., and Hübl, J. (2007). Towards an empirical vulnerability function for use in debris flow risk assessment. Natural Hazards and Earth System Science, 7(5), 495-506.

Gallina, V., Torresan, S., Critto, A., Sperotto, A., Glade, T., and Marcomini, A. (2016). A review of multi-risk methodologies for natural hazards: Consequences and challenges for a climate change impact assessment. Journal of environmental management, 168, 123-132.

Gao, L. (2016). Multi-hazards modelling in urban environment under extreme storms. Hong Kong University of Science and Technology (Hong Kong).

Gao, M., Pradhana, A., Han, X., Guo, Q., Kot, G., Sifakis, E., and Jiang, C. (2018). Animating fluid sediment mixture in particle-laden flows. ACM Transactions on Graphics (TOG), 37(4), 149.

Garcia-Aristizabal, A., Marzocchi, W., 2012b. Bayesian Multi-risk Model: Demonstration for Test City Researchers. Deliverable 2.13. CLUVA project (Contract $n$ 265137). http://www.cluva.eu/deliverables/CLUVA_D2.13.pdf.

Garcia-Aristizabal, A., Marzocchi, W., Di Ruocco, A., Tyagunov, S., Vorogushyn, S., Fleming, K., and Desramaut, N. (2013). Scenarios of cascade events. Deliverable D3, 3. 
Geist, E. L., and Parsons, T. (2006). Probabilistic analysis of tsunami hazards. Natural Hazards, 37(3), 277-314.

Geist, E. L., Fritz, H. M., Rabinovich, A. B., and Tanioka, Y. (2016). Introduction to Global Tsunami Science: Past and Future, Volume I. In Global Tsunami Science: Past and Future, Volume I(pp. 3663-3669). Birkhäuser, Cham.

GFDRR (2018), Dominica, Post Disaster Needs Assessment, https://www.gfdrr.org/en/dominica-pdna-hurricanemaria, retrieved 2002-2020

Gidaris, I., Padgett, J. E., Barbosa, A. R., Chen, S., Cox, D., Webb, B., and Cerato, A. (2017). Multiple-hazard fragility and restoration models of highway bridges for regional risk and resilience assessment in the United States: state-of-the-art review. Journal of structural engineering, 143(3), 04016188

Gill, J. C., \& Malamud, B. D. (2014). Reviewing and visualizing the interactions of natural hazards. Reviews of Geophysics, 52(4), 680-722.

Gill, J. C., and Malamud, B. D. (2017). Anthropogenic processes, natural hazards, and interactions in a multi-hazard framework. Earth-Science Reviews, 166, 246-269.

Glade, T., Crozier, M., \& Smith, P. (2000). Applying probability determination to refine landslide-triggering rainfall thresholds using an empirical" Antecedent Daily Rainfall Model". Pure \& Applied Geophysics, 157(6-8), 1059.

Goda, K., and De Risi, R. (2018). Multi-hazard loss estimation for shaking and tsunami using stochastic rupture sources. International journal of disaster risk reduction, 28, 539-554.

Goda, K., and De Risi, R. (2018). Multi-hazard loss estimation for shaking and tsunami using stochastic rupture sources. International journal of disaster risk reduction, 28, 539-554.

Godschalk, D., Beatley, T., Berke, P., Brower, D., \& Kaiser, E. J. (1998). Natural hazard mitigation: Recasting disaster policy and planning. Island Press.

Godunov, S. K. (1959). A finite difference method for the computation of discontinuous solutions of the equations of fluid dynamics. Sbornik: Mathematics, 47(8-9), 357-393.

Goodman, M. A., \& Cowin, S. C. (1971). Two problems in the gravity flow of granular materials. Journal of fluid Mechanics, 45(2), 321-339.

Goswami, R., Mitchell, N. C., \& Brocklehurst, S. H. (2011). Distribution and causes of landslides in the eastern Peloritani of NE Sicily and western Aspromonte of SW Calabria, Italy. Geomorphology, 132(3), 111-122.

Government of the Commonwealth of Dominica, Needs Assessment Following Hurricane Dominica (2017)

Grady, D. E., \& Kipp, M. E. (1980, June). Continuum modelling of explosive fracture in oil shale. In International Journal of Rock Mechanics and Mining Sciences \& Geomechanics Abstracts (Vol. 17, No. 3, pp. 147-157). Pergamon.

Granger, K., Jones, T. G., Leiba, M., and Scott, G. (1999). Community risk in Cairns: a multi-hazard risk assessment. Australian Journal of Emergency Management, The, 14(2), 25.

Granger, K., Jones, T.G., Leiba, M., Scott, G., 1999. Community Risk in Cairns: A Multihazards Risk Assessment. Technical report, Australian Geological 
Survey $\quad$ Organisation
http://www.ga.gov.au/corporate_data/33548/33548.pdf)

(URL

Green, W. H., \& Ampt, G. A. (1911). Studies on Soil Phyics. The Journal of Agricultural Science, 4(01), 1-24.

Greenwood, J. R., Norris, J. E., and Wint, J. (2004). Assessing the contribution of vegetation to slope stability. Proceedings of the ICE-Geotechnical Engineering, 157(4), 199-207.

Griffiths, D. V., \& Lane, P. A. (1999). Slope stability analysis by finite elements. Geotechnique, 49(3), 387-403.

Griffiths, D.V., Huang, J., \& Dewolfe, G. F. (2011). Numerical and analytical observations on long and infinite slopes. International Journal for Numerical and Analytical Methods in Geomechanics, 35(5), 569-585.

Grimaldi, S., Li, Y., Pauwels, V. R., \& Walker, J. P. (2016). Remote sensingderived water extent and level to constrain hydraulic flood forecasting models: Opportunities and challenges. Surveys in Geophysics, 37(5), 9771034.

Grunthal, G., Thieken, A.H., Schwarz, J., Radtke, K.S., Smolka, A., Merz, B., 2006. Comparative risk assessments for the city of Cologne - storms, floods, earthquakes. Nat. Hazards 38 (1), 21-44 (URL http://link.springer.com/article/10.1007/s11069-005-8598-0).

Guo, X., Cui, P., Li, Y., Ma, L., Ge, Y., and Mahoney, W. B. (2016). Intensityduration threshold of rainfall-triggered debris flows in the Wenchuan earthquake affected area, China. Geomorphology, 253, 208-216.

Guzzetti, F., Ardizzone, F., Cardinali, M., Rossi, M., \& Valigi, D. (2009). Landslide volumes and landslide mobilization rates in Umbria, central Italy. Earth and Planetary Science Letters, 279(3), 222-229.

Guzzetti, F., Peruccacci, S., Rossi, M., \& Stark, C. P. (2007). Rainfall thresholds for the initiation of landslides in central and southern Europe. Meteorology and atmospheric physics, 98(3), 239-267.

Haynes, K., Barclay, J., \& Pidgeon, N. (2007). Volcanic hazard communication using maps: an evaluation of their effectiveness. Bulletin of Volcanology, 70(2), 123-138.

Hagemeier-Klose, M., \& Wagner, K. (2009). Evaluation of flood hazard maps in print and web mapping services as information tools in flood risk communication. Natural Hazards \& Earth System Sciences, 9(2).

Haile, A. T., \& Rientjes, T. H. M. (2005). Effects of LiDAR DEM resolution in flood modelling: a model sensitivity study for the city of Tegucigalpa, Honduras. Isprs wg iii/3, iii/4, 3, 12-14.

Hall, J. W., Dawson, R. J., Sayers, P. B., Rosu, C., Chatterton, J. B., \& Deakin, R. (2003, September). A methodology for national-scale flood risk assessment. In Proceedings of the Institution of Civil Engineers-Water and Maritime Engineering (Vol. 156, No. 3, pp. 235-247). Thomas Telford Ltd.

Han, Z., Su, B., Li, Y., Wang, W., Wang, W., Huang, J., \& Chen, G. (2019). Numerical simulation of debris-flow behavior based on the SPH method incorporating the Herschel-Bulkley-Papanastasiou rheology model. Engineering Geology, 255, 26-36.

Hao, H., Yang, X., Huang, Y., Liu, K., Zeng, Z., 2011. Emergency Investigation Report of Niujuan Catchment Debris Flows. Unpublished Report, in Chinese. Sichuan Huadi Construction Engineering Co., Ltd. 
Harp, E.L., Crone, A.J., 2006. Landslides Triggered by the October 8, 2005, Pakistan Earthquake and Associated Landslide-Dammed Reservoirs. U.S. Geological Survey Open-file Report, 2006-1052, 13

Harten A., Lax, P. D., van Leer, B. On upstream differencing and Godunov-type schemes for hyperbolic conservation laws. SIAM Review, 25(1):35-61, 1983

Harten, A. (1983). High resolution schemes for hyperbolic conservation laws. Journal of computational physics, 49(3), 357-393.

Harten, A., Lax, P. D., \& Leer, B. V. (1983). On upstream differencing and Godunov-type schemes for hyperbolic conservation laws. SIAM review, 25(1), 35-61.

Hayir, A. (2003). The effects of variable speeds of a submarine block slide on near-field tsunami amplitudes. Ocean engineering, 30(18), 2329-2342.

He, X., Hong, Y., Vergara, H., Zhang, K., Kirstetter, P. E., Gourley, J. J., ... \& Liu, C. (2016). Development of a coupled hydrological-geotechnical framework for rainfall-induced landslides prediction. Journal of Hydrology, 543, 395-405.

Hengl, T., de Jesus, J. M., Heuvelink, G. B., Gonzalez, M. R., Kilibarda, M., Blagotić, A., ... \& Guevara, M. A. (2017). SoilGrids250m: Global gridded soil information based on machine learning. PLoS one, 12(2).

Hengl, T., de Jesus, J. M., Heuvelink, G. B., Gonzalez, M. R., Kilibarda, M., Blagotić, A., ... \& Guevara, M. A. (2017). SoilGrids250m: Global gridded soil information based on machine learning. PLoS one, 12(2), e0169748.

Hessel, R., \& Jetten, V. (2007). Suitability of transport equations in modelling soil erosion for a small Loess Plateau catchment. Engineering Geology, 91(1), 56-71.

Hessel, R., \& van Asch, T. (2003). Modelling gully erosion for a small catchment on the Chinese Loess Plateau. Catena, 54(1), 131-146.

Hessel, R., Jetten, V., Liu, B., Zhang, Y., \& Stolte, J. (2003b). Calibration of the LISEM model for a small Loess Plateau catchment. Catena, 54(1), 235254.

Hessel, R., Messing, I., Liding, C., Ritsema, C., \& Stolte, J. (2003a). Soil erosion simulations of land use scenarios for a small Loess Plateau catchment. Catena, 54(1), 289-302.

Hewitt, K., and Burton, I. (1971). The Hazardousness ofa Place: A Regional Ecology of Damaging Events. Research Series, (6).

Hirabayashi, Y., Mahendran, R., Koirala, S., Konoshima, L., Yamazaki, D., Watanabe, S., ... \& Kanae, S. (2013). Global flood risk under climate change. Nature Climate Change, 3(9), 816-821.

Horritt, M. S., \& Bates, P. D. (2001). Effects of spatial resolution on a raster based model of flood flow. Journal of Hydrology, 253(1), 239-249.

Horton, A. J., Hales, T. C., Ouyang, C., \& Fan, X. (2019). Identifying postearthquake debris flow hazard using Massflow. Engineering Geology, 258, 105134.

Horton, P., Jaboyedoff, M., Rudaz, B. E. A., and Zimmermann, M. (2013). Flow$\mathrm{R}$, a model for susceptibility mapping of debris flows and other gravitational hazards at a regional scale. Natural hazards and earth system sciences, 13(4), 869-885.

Horton, P., Jaboyedoff, M., Rudaz, B., \& Zimmermann, M. (2013). Flow-R, a model for susceptibility mapping of debris flows and other gravitational 
hazards at a regional scale. Natural Hazards and Earth System Sciences, 13(4), 869.

Hovland, H. J. (1979). Three-dimensional slope stability analysis method. Journal of Geotechnical and Geoenvironmental Engineering, 105(ASCE 14549 Proceeding).

Hsu, W. K., Huang, P. C., Chang, C. C., Chen, C. W., Hung, D. M., and Chiang, W. L. (2011). An integrated flood risk assessment model for property insurance industry in Taiwan. Natural Hazards, 58(3), 1295-1309.

Hu, K., Ding, P., Wang, Z., and Yang, S. (2009). A 2D/3D hydrodynamic and sediment transport model for the Yangtze Estuary, China. Journal of Marine Systems, 77(1-2), 114-136.

Hu, W., Dong, X. J., Xu, Q., Wang, G. H., Van Asch, T. W. J., \& Hicher, P. Y. (2016). Initiation processes for run-off generated debris flows in the Wenchuan earthquake area of China. Geomorphology, 253, 468-477.

Hu, W., She, D., Shao, M. A., Chun, K. P., \& Si, B. (2015). Effects of initial soil water content and saturated hydraulic conductivity variability on small watershed runoff simulation using LISEM. Hydrological Sciences Journal, 60(6), 1137-1154.

Huang, Y. Y., Han, H., Tang, C., \& Liu, S. J. (2017). Plant community composition and interspecific relationships among dominant species on a post-seismic landslide in Hongchun Gully, China. Journal of Mountain Science, 14(10), 1985-1994.

Huang, Y., Zhang, W., Xu, Q., Xie, P., \& Hao, L. (2012). Run-out analysis of flow-like landslides triggered by the Ms 8.0 2008 Wenchuan earthquake using smoothed particle hydrodynamics. Landslides, 9(2), 275-283.

Hungr, O. (1987). An extension of Bishop's simplified method of slope stability analysis to three dimensions. Geotechnique, 37(1), 113-117.

Hungr, O., Salgado, F. M., \& Byrne, P. M. (1989). Evaluation of a threedimensional method of slope stability analysis. Canadian Geotechnical Journal, 26(4), 679-686.

Hunter, N. M., Horritt, M. S., Bates, P. D., Wilson, M. D., \& Werner, M. G. (2005). An adaptive time step solution for raster-based storage cell modelling of floodplain inundation. Advances in Water Resources, 28(9), 975-991.

Hürlimann, M., Medina, V., Bateman A., Copons, R., Altimir J., 2007. Comparison of different techniques to analyse the mobility of debris flows during hazard assessment-Case study in La Comella catchment, Andorra. In Chen \& Majors (eds.) Debris-Flow Hazard Mitigation :Mechanics, Prediction and Assessment. Millpress, Netherlands, pp. 411-422.

Hušek, M., Kala, J., Hokeš, F., \& Král, P. (2016). Influence of SPH regularity and parameters in dynamic fracture phenomena. Procedia engineering, 161, 489-496.

Hutter, K., Svendsen, B., \& Rickenmann, D. (1994). Debris flow modeling: A review. Continuum mechanics and thermodynamics, 8(1), 1-35.

Huxley, C., and Syme, B. (2016). TUFLOW GPU-Best practice advice for hydrologic and hydraulic model simulations. In 37th Hydrology and Water Resources Symposium 2016: Water, Infrastructure and the Environment (p. 195). Engineers Australia.

Hydraulics, D. (2006). Delft3D-FLOW user manual. Delft, the Netherlands.

Ikeuchi, H., Hirabayashi, Y., Yamazaki, D., Muis, S., Ward, P. J., Winsemius, H. C., ... and Kanae, S. (2017). Compound simulation of fluvial floods and 
storm surges in a global coupled river coast flood model: Model development and its application to 2007 C yclone $S$ idr in B angladesh. Journal of Advances in Modeling Earth Systems, 9(4), 18471862.

IPCC (2012). Managing the risks of extreme events and disasters to advance climate change adaptation: special report of the intergovernmental panel on climate change. Cambridge University Press.

Ishii, M. (1975). Thermo-fluid dynamic theory of two-phase flow. NASA Sti/recon Technical Report A, 75.

Ishii, M., \& Zuber, N. (1979). Drag coefficient and relative velocity in bubbly, droplet or particulate flows. AIChE journal, 25(5), 843-855.

Iverson, R. M. (2012). Elementary theory of bed sediment entrainment by debris flows and avalanches. Journal of Geophysical Research: Earth Surface, $117(\mathrm{~F} 3)$.

Iverson, R. M., \& Denlinger, R. P. (2001). Flow of variably fluidized granular masses across three dimensional terrain: 1. Coulomb mixture theory. Journal of Geophysical Research: Solid Earth, 106(B1), 537-552.

Iverson, R. M., \& George, D. L. (2014). A depth-averaged debris-flow model that includes the effects of evolving dilatancy. I. Physical basis. Proceedings of the Royal Society A: Mathematical, Physical and Engineering Sciences, 470(2170), 20130819.

Iverson, R. M., \& Ouyang, C. (2015). Entrainment of bed material by Earth surface mass flows: Review and reformulation of depth integrated theory. Reviews of geophysics, 53(1), 27-58.

Iverson, R. M., and George, D. L. (2014). A depth-averaged debris-flow model that includes the effects of evolving dilatancy. I. Physical basis. Proc. $r$. soc. $a, 470(2170), 20130819$.

Iverson, R. M., and George, D. L. (2015). Modelling landslide liquefaction, mobility bifurcation and the dynamics of the 2014 Oso disaster. Géotechnique, 66(3), 175-187.

Jafarzadeh, F., Shahrabi, M. M., \& Jahromi, H. F. (2015). On the role of topographic amplification in seismic slope instabilities. Journal of Rock Mechanics and Geotechnical Engineering, 7(2), 163-170.

Jajarmizadeh, M., Harun, S., \& Salarpour, M. (2012). A review on theoretical consideration and types of models in hydrology. Journal of Environmental Science and Technology, 5(5), 249-261.

Jakob, M., Hungr, O., \& Jakob, D. M. (2005). Debris-flow hazards and related phenomena (Vol. 739). Berlin: Springer.

Janbu, N. (1975, April). Slope stability computations: In Embankment-dam Engineering. Textbook. Eds. RC Hirschfeld and SJ Poulos. JOHN WILEY AND SONS INC., PUB., NY, 1973, 40P. In International Journal of Rock Mechanics and Mining Sciences \& Geomechanics Abstracts (Vol. 12, No. 4, p. 67). Pergamon.

Janekovic, I., Hetzel, Y., Pattiaratchi, C., Wijeratne, E. M. S., and Roland, A. (2015). Unstructured high resolution 2-way coupled storm surge-wave model for Western Australia. In Proceedings of the Australasian Coasts and Ports Conference 2015 (pp. 1-6).

Jetten (2002). LISEM, Limburg Soil Erosion Model, User's Manual

Jetten, V. G., \& de Roo, A. P. (2001). Spatial analysis of erosion conservation measures with LISEM. In Landscape erosion and evolution modeling (pp. 429-445). Springer, Boston, MA. 
Jiang, X., Yang, L., \& Tatano, H. (2019). Assessing spatial flood risk from multiple flood sources in a small river basin: A method based on multivariate design rainfall. Water, 11(5), 1031.

Jiang, Z., Huete, A. R., Chen, J., Chen, Y., Li, J., Yan, G., \& Zhang, X. (2006). Analysis of NDVI and scaled difference vegetation index retrievals of vegetation fraction. Remote sensing of environment, 101(3), 366-378.

Jordan, T. H., Chen, Y. T., Gasparini, P., Madariaga, R., Main, I., Marzocchi, W., ... and Zschau, J. (2011). Operational earthquake forecasting. State of knowledge and guidelines for utilization. Annals of Geophysics, 54(4).

Kaklauskas, G., \& Ghaboussi, J. (2001). Stress-strain relations for cracked tensile concrete from RC beam tests. Journal of Structural Engineering, 127(1), 64-73.

Kalacska, M., Sánchez-Azofeifa, G. A., Rivard, B., Calvo-Alvarado, J. C., Journet, A. R. P., Arroyo-Mora, J. P., \& Ortiz-Ortiz, D. (2004). Leaf area index measurements in a tropical moist forest: A case study from Costa Rica. Remote Sensing of Environment, 91(2), 134-152.

Kameshwar, S., and Padgett, J. E. (2014). Multi-hazard risk assessment of highway bridges subjected to earthquake and hurricane hazards. Engineering Structures, 78, 154-166.

Kappes, M. S., Keiler, M., von Elverfeldt, K., \& Glade, T. (2012). Challenges of analyzing multi-hazard risk: a review. Natural hazards, 64(2), 1925-1958.

Karssenberg, D., Schmitz, O., Salamon, P., de Jong, K., \& Bierkens, M. F. (2010). A software framework for construction of process-based stochastic spatio-temporal models and data assimilation. Environmental Modelling \& Software, 25(4), 489-502.

Kay, A. L., Reynard, N. S., \& Jones, R. G. (2006). RCM rainfall for UK flood frequency estimation. I. Method and validation. Journal of hydrology, 318(1-4), 151-162.

Kazezyılmaz-Alhan, C.M. and Medina Jr, M.A., 2007. Kinematic and diffusion waves: analytical and numerical solutions to overland and channel flow. Journal of Hydraulic Engineering, 133(2), pp.217-228.

Kern, J. S. (1995). Evaluation of soil water retention models based on basic soil physical properties. Soil Science Society of America Journal, 59(4), $1134-1141$

Khan, S., van der Meijde, M., van der Werff, H., \& Shafique, M. (2020). The impact of topography on seismic amplification during the 2005 Kashmir earthquake. Natural Hazards and Earth System Sciences, 20(2), 399-411.

Kim, J., Jeong, S., Park, S., \& Sharma, J. (2004). Influence of rainfall-induced wetting on the stability of slopes in weathered soils. Engineering Geology, 75(3), 251-262.

Kirby, J. T., Shi, F., Nicolsky, D., and Misra, S. (2016). The 27 April 1975 Kitimat, British Columbia, submarine landslide tsunami: a comparison of modeling approaches. Landslides, 13(6), 1421-1434.

Kjekstad, O., \& Highland, L. (2009). Economic and social impacts of landslides. In Landslides-disaster risk reduction (pp. 573-587). Springer, Berlin, Heidelberg.

Knighton, J., Steinschneider, S., \& Walter, M. T. (2017). A vulnerability based, bottom up assessment of future riverine flood risk using a modified peaks over threshold approach and a physically based hydrologic model. Water Resources Research, 53(12), 10043-10064. 
Komatitsch, D., Göddeke, D., Erlebacher, G., and Michéa, D. (2010). Modeling the propagation of elastic waves using spectral elements on a cluster of 192 GPUs. Computer Science-Research and Development, 25(1-2), 75-82.

Komendantova, N., Mrzyglocki, R., Mignan, A., Khazai, B., Wenzel, F., Patt, A., and Fleming, K. (2014). Multi-hazard and multi-risk decision-support tools as a part of participatory risk governance: Feedback from civil protection stakeholders. International Journal of disaster risk reduction, 8, 50-67.

Korswagen, P. A., Jonkman, S. N., and Terwel, K. C. (2019). Probabilistic assessment of structural damage from coupled multi-hazards. Structural Safety, 76, 135-148.

Korup, O.: Geomorphic hazard assessment of landslide dams in South Westland, New Zealand: Fundamental problems and approaches, Geomorphology, 66, 167-188, 2005.

Kron, W. 1999b. "Reasons for the increase in natural catastrophes: The development of exposed areas." In: Topics 2000: Natural catastrophes the current position. Munich: Munich Reinsurance Company. 82-94

Kuriakose, S. L., Devkota, S., Rossiter, D. G., \& Jetten, V. G. (2009). Prediction of soil depth using environmental variables in an anthropogenic landscape, a case study in the Western Ghats of Kerala, India. Catena, 79(1), 27-38.

Kuriakose, S. L., Van Beek, L. P. H., \& Van Westen, C. J. (2009). Parameterizing a physically based shallow landslide model in a data poor region. Earth Surface Processes and Landforms, 34(6), 867-881.

Kuriakose, S. L., Van Beek, L. P. H., \& Van Westen, C. J. (2009). Parameterizing a physically based shallow landslide model in a data poor region. Earth Surface Processes and Landforms, 34(6), 867-881.

Kurihara, Y., Bender, M. A., Tuleya, R. E., and Ross, R. J. (1995). Improvements in the GFDL hurricane prediction system. Monthly Weather Review, 123(9), 2791-2801.

Kuroiwa, J. (1988). Physical planning for multi-hazard mitigation. In Natural and man-made hazards (pp. 805-816). Springer, Dordrecht.

Kwan, J. S., \& Sun, H. W. (2006). An improved landslide mobility model. Canadian geotechnical journal, 43(5), 531-539.

Lang, D.M. 1967. Soil map of Dominica. 2 sheets

Lantada, N., Pujades, L. G., and Barbat, A. H. (2009). Vulnerability index and capacity spectrum based methods for urban seismic risk evaluation. A comparison. Natural Hazards, 51(3), 501.

Larsen, M. C., \& Torres-Sanchez, A. J. (1998). The frequency and distribution of recent landslides in three montane tropical regions of Puerto Rico. Geomorphology, 24(4), 309-331.

Lavigne, F., \& Suwa, H. (2004). Contrasts between debris flows, hyperconcentrated flows and stream flows at a channel of Mount Semeru, East Java, Indonesia. Geomorphology, 61(1-2), 41-58.

Lee, J., van den Bout, B., \& Lee, D. K. (2019, January). Analysis of flooding impact with multi-risk hazards scenario by using physically-based model. In Geophysical Research Abstracts (Vol. 21).

Lee, K. T., and Ho, J. Y. (2009). Prediction of landslide occurrence based on slope-instability analysis and hydrological model simulation. Journal of Hydrology, 375(3-4), 489-497.

Lehmann, P., J. von Rütte, and D. (2017) STEP TRAMM: Landslide Triggering Model (version 2017.8). Software available at http://www.step.ethz.ch/step-tramm.html 
LeVeque, R. J. (2002). Finite volume methods for hyperbolic problems (Vol. 31). Cambridge university press.

Li, C., Wang, C., \& Qin, H. (2015). Novel adaptive SPH with geometric subdivision for brittle fracture animation of anisotropic materials. The Visual Computer, 31(6-8), 937-946.

Li, D., Hao, H., Ma, j., Wu, X., Yan, Z., Li, G., Wang, H., Gao, J., Liu, H., Huang, Y., Yang, X., Zeng, Z., Liu, J., Gao, L., Shen, T., Cao, N., Zhang, Y., Li, Z., Liu, K., Li, D., Xian, Z., 2011. Emergency Mitigation Engineering Design on the Catastrohic Hongchun Catchment Debris Flow, Yingxiu, Wenchuan County. Unpublished report, in Chinese. Guanghan Institute of Geological Engineering Investigation.

Li, M. H., Sung, R. T., Dong, J. J., Lee, C. T., \& Chen, C. C. (2011). The formation and breaching of a short-lived landslide dam at Hsiaolin Village, Taiwan-Part II: Simulation of debris flow with landslide dam breach. Engineering Geology, 123(1), 60-71.

Li, Y., Zhou, R., Zhao, G., Li, H., Su, D., Ding, H., \& Ma, C. (2014). Tectonic uplift and landslides triggered by the Wenchuan earthquake and constraints on orogenic growth: a case study from Hongchun Gully, Longmen Mountains, Sichuan, China. Quaternary international, 349, 142152.

Li, Z., Nadim, F., Huang, H., Uzielli, M., \& Lacasse, S. (2010). Quantitative vulnerability estimation for scenario-based landslide hazards. Landslides, 7(2), 125-134.

Libersky, L. D., \& Petschek, A. G. (1991). Smooth particle hydrodynamics with strength of materials. In Advances in the free-Lagrange method including contributions on adaptive gridding and the smooth particle hydrodynamics method (pp. 248-257). Springer, Berlin, Heidelberg.

LISEM: A single event, physically based hydrological and soil erosion model for drainage basins. II: Sensitivity analysis, validation and application. Hydrological processes, 10(8), 1119-1126.

Liu, J., Shi, J., Wang, T., and Wu, S. (2018). Seismic landslide hazard assessment in the Tianshui area, China, based on scenario earthquakes. Bulletin of Engineering Geology and the Environment, 77(3), 1263-1272.

Liu, N., Zhang, J., Lin, W., Cheng, W., and Chen, Z.: Draining Tangjiashan Barrier Lake after Wenchuan Earthquake and the flood propagation after the dam break, Sci. China Ser. E., 52, 801-809, 2009.

Liu, Q., Surgi, N., Lord, S., Wu, W. S., Parrish, D., Gopalakrishnan, S., ... and Gamache, J. (2006, April). Hurricane initialization in HWRF model. In 27th Conf. on Hurricanes and Tropical Meteorology.

Liu, Z., Nadim, F., Garcia-Aristizabal, A., Mignan, A., Fleming, K., and Luna, B. Q. (2015). A three-level framework for multi-risk assessment. Georisk: Assessment and Management of Risk for Engineered Systems and Geohazards, 9(2), 59-74.

Locat, J., Turmel, D., Habersetzer, M., Trottier, A. P., Lajeunesse, P., and StOnge, G. (2016). Earthquake induced landslides in Lake Eternité, Québec, Canada. In Submarine Mass Movements and their Consequences (pp. 361370). Springer, Cham.

Loehnert, S., \& Mueller-Hoeppe, D. S. (2008). Multiscale methods for fracturing solids. In IUTAM symposium on theoretical, computational and modelling aspects of inelastic media (pp. 79-87). Springer, Dordrecht. 
Lombardo, L., Cama, M., Conoscenti, C., Märker, M., \& Rotigliano, E. (2015). Binary logistic regression versus stochastic gradient boosted decision trees in assessing landslide susceptibility for multiple-occurring landslide events: application to the 2009 storm event in Messina (Sicily, southern Italy). Natural Hazards, 79(3), 1621-1648.

Lombardo, L., Cama, M., Maerker, M., Rotigliano, E. (2014) A test of transferability for landslides susceptibility models under extreme climatic events: Application to the Messina 2009 disaster. Natural Hazards, 74 (3), pp. 1951-1989.

Lombardo, L., Fubelli, G., Amato, G., Bonasera, M. (2016) Presence-only approach to assess landslide triggering-thickness susceptibility: a test for the Mili catchment (north-eastern Sicily, Italy). Natural Hazards, 84 (1), pp. 565-588.

Lombardo, L., Opitz, T. and Huser, R. (2018a) Point process-based modeling of multiple debris flow landslides using INLA: an application to the 2009 Messina disaster. Stochastic Environmental Research and Risk Assessment To appear. Doi: 10.1007/s00477-018-1518-0

Lombardo, L., Saia, S., Schillaci, C., Mai, P. M., \& Huser, R. (2018b). Modeling soil organic carbon with Quantile Regression: Dissecting predictors' effects on carbon stocks. Geoderma, 318, 148-159.

Lourenço, P. B., and Roque, J. A. (2006). Simplified indexes for the seismic vulnerability of ancient masonry buildings. Construction and Building Materials, 20(4), 200-208.

Luna, B. Q., Blahut, J., Camera, C., van Westen, C., Apuani, T., Jetten, V., \& Sterlacchini, S. (2014). Physically based dynamic run-out modeling for quantitative debris flow risk assessment: a case study in Tresenda, northern Italy. Environmental Earth Sciences, 72(3), 645-661.

Luna, B. Q., Blahut, J., van Asch, T., van Westen, C., \& Kappes, M. (2015, April). AschFlow-A dynamic landslide run-out model for medium scale hazard analysis. In EGU General Assembly Conference Abstracts (Vol. 17, p. 13656).

Luna, B. Q., Remaître, A., Van Asch, T. W., Malet, J. P., \& Van Westen, C. J. (2012). Analysis of debris flow behavior with a one dimensional run-out model incorporating entrainment. Engineering geology, 128, 63-75.

Lupiano, V., Machado, G.E., Crisci, G.M., Di Gregorio, S. (2016) Simulations of debris/mud flows invading urban areas: A cellular automata approach with SCIDDICA. Lecture Notes in Computer Science (including subseries Lecture Notes in Artificial Intelligence and Lecture Notes in Bioinformatics), 9863 LNCS, pp. 291-302.

Lynett, P., and Liu, P. L. F. (2002, December). A numerical study of submarinelandslide-generated waves and run-up. In Proceedings of the Royal Society of London A: Mathematical, Physical and Engineering Sciences (Vol. 458, No. 2028, pp. 2885-2910). The Royal Society.

Ma, G. W., Wang, Q. S., Yi, X. W., \& Wang, X. J. (2014). A modified SPH method for dynamic failure simulation of heterogeneous material. Mathematical Problems in Engineering, 2014.

Madec, R., Komatitsch, D., \& Diaz, J. (2009). Energy-conserving local time stepping based on high-order finite elements for seismic wave propagation across a fluid-solid interface. Computer Modeling in Engineering and Sciences (CMES), 14(2), 163. 
Maeda, T., Furumura, T., Noguchi, S., Takemura, S., Sakai, S. I., Shinohara, M., ... and Lee, S. J. (2013). Seismic and tsunami wave propagation of the 2011 Off the Pacific Coast of Tohoku Earthquake as inferred from the tsunami coupled finite difference simulation. Bulletin of the Seismological Society of America, 103(2B), 1456-1472.

Malet, J.-P., Remaître, A., Maquaire, O., 2004. Runout modeling and extension of the threatened area associated with muddy debris flows. Geomorphologie: relief, processus, environnement n.3, pp. 195-210

MARCHI, L.., M. CAVALLI, M. SANGATI, M. BORGA, 2009: Hydrometeorological controls and erosive response of an extreme alpine debris flow. Hydrological Processes, 23 (19), 2714-2727, DOI: 10.1002/hyp.7362, ISSN: 0885-6087.

Martin, H., Ellis, M., and Delpesh, C. (2016). Risk Perception in a Multi-Hazard Environment: A Case Study of Maraval, Trinidad. West Indian Journal of Engineering, 39(1).

Martin, Y., Rood, K., Schwab, J. W., \& Church, M. (2002). Sediment transfer by shallow landsliding in the Queen Charlotte Islands, British Columbia. Canadian Journal of Earth Sciences, 39(2), 189-205.

Marzocchi, W., Garcia-Aristizabal, A., Gasparini, P., Mastellone, M.L., Di Ruocco, A., 2012. Basic principles of multi-risk assessment: a case study in Italy. Nat. Hazards 62, 551-573

Marzocchi, W., Mastellone, M., Di Ruocco, A., Novelli, P., Romeo, E., and Gasparini, P. (2009). Principles of multi-risk assessment: interactions amongst natural and man-induced risks. European Commission, Directorate-General for Research, Environment Directorate.

Marzocchi, W., Mastellone, M.L., Di Ruocco, A., Novelli, P., Romeo, E., Gasparini, P., 2009. Principles of multi-risk assessment: interactions amongst natural and man-induced risks. Project Report (FP6 NARAS Project), European Commission, DirectorateGeneral Research Environment, Contract No. 511264. Office for Official Publications of the European Communities, Luxembourg.

Marzocchi, W., Sandri, L., and Selva, J. (2010). BET_VH: a probabilistic tool for long-term volcanic hazard assessment. Bulletin of volcanology, 72(6), 705-716

Mase, G. T., Smelser, R. E., \& Mase, G. E. (2009). Continuum mechanics for engineers. CRC press.

Mason, D. C., Cobby, D. M., Horritt, M. S., \& Bates, P. D. (2003). Floodplain friction parameterization in two dimensional river flood models using vegetation heights derived from airborne scanning laser altimetry. Hydrological processes, 17(9), 1711-1732.

Matsui, T., \& San, K. C. (1992). Finite element slope stability analysis by shear strength reduction technique. Soils and foundations, 32(1), 59-70.

Matsui, T., \& San, K. C. (1992). Finite element slope stability analysis by shear strength reduction technique. Soils and foundations, 32(1), 59-70.

Maurel, B., \& Combescure, A. (2008). An SPH shell formulation for plasticity and fracture analysis in explicit dynamics. International journal for numerical methods in engineering, 76(7), 949-971.

McCarthy, S., Tunstall, S., Parker, D., Faulkner, H., and Howe, J. (2007). Risk communication in emergency response to a simulated extreme flood. Environmental Hazards, 7(3), 179-192. 
McGuigan, K., Webster, T., and Collins, K. (2015). A flood risk assessment of the LaHave River watershed, Canada using GIS techniques and an unstructured grid combined river-coastal hydrodynamic model. Journal of Marine Science and Engineering, 3(3), 1093-1116.

McGuire, L. A., Rengers, F. K., Kean, J. W., Staley, D. M., and Mirus, B. B. (2018). Incorporating spatially heterogeneous infiltration capacity into hydrologic models with applications for simulating post wildfire debris flow initiation. Hydrological Processes, 32(9), 1173-1187. Bunya, S., Dietrich, J. C., Westerink, J. J., Ebersole, B. A., Smith, J. M., Atkinson, J. H., ... and Cardone, V. J. (2010). A high-resolution coupled riverine flow, tide, wind, wind wave, and storm surge model for southern Louisiana and Mississippi. Part I: Model development and validation. Monthly weather review, 138(2), 345-377.

McMillan, H. K., and Brasington, J. (2008). End to end flood risk assessment: A coupled model cascade with uncertainty estimation. Water Resources Research, 44(3).

Melo, R., van Asch, T., and Zêzere, J. L. (2018). Debris flow run-out simulation and analysis using a dynamic model. Natural Hazards and Earth System Sciences, 18(2), 555.

Menin, R. G., Trautwein, L. M., \& Bittencourt, T. N. (2009). Smeared crack models for reinforced concrete beams by finite element method. RIEMIBRACON Structures and Materials Journal, 2(2).

Mergili, M., Emmer, A., Fischer, J. T., Huggel, C., and Pudasaini, S. P. (2018, April). Computer simulations of complex cascading landslide processes: what can we do and what can we learn?. In EGU General Assembly Conference Abstracts (Vol. 20, p. 10505).

Mergili, M., Emmer, A., Juřicová, A., Cochachin, A., Fischer, J. T., Huggel, C., \& Pudasaini, S. P. (2018a). How well can we simulate complex hydro geomorphic process chains? The 2012 multi lake outburst flood in the Santa Cruz Valley (Cordillera Blanca, Perú). Earth surface processes and landforms, 43(7), 1373-1389.

Mergili, M., Fellin, W., Moreiras, S. M., \& Stötter, J. (2011). Simulation of debris flows in the Central Andes based on Open Source GIS: possibilities, limitations, and parameter sensitivity. Natural hazards, 61(3), 1051-1081.

Mergili, M., Fischer, J. T., and Pudasaini, S. P. (2017, May). Process chain modelling with $r$. avaflow: lessons learned for multi-hazard analysis. In Workshop on World Landslide Forum(pp. 565-572). Springer, Cham.

Mergili, M., Frank, B., Fischer, J. T., Huggel, C., \& Pudasaini, S. P. (2018b). Computational experiments on the 1962 and 1970 landslide events at Huascarán (Peru) with r. avaflow: Lessons learned for predictive mass flow simulations. Geomorphology, 322, 15-28.

Mergili, M., Jan-Thomas, F., Krenn, J., and Pudasaini, S. P. (2017). r. avaflow $\mathrm{v} 1$, an advanced open-source computational framework for the propagation and interaction of two-phase mass flows. Geoscientific Model Development, 10(2), 553.

Mergili, M., Marchesini, I., Alvioli, M., Metz, M., Schneider-Muntau, B., Rossi, M., \& Guzzetti, F. (2014). A strategy for GIS-based 3-D slope stability modelling over large areas. Geoscientific Model Development, 7(6), 29692982. 
Mergili, M., Marchesini, I., Rossi, M., Guzzetti, F., \& Fellin, W. (2014). Spatially distributed three-dimensional slope stability modelling in a raster GIS. Geomorphology, 206, 178-195.

Miller, M. E., Billmire, M. G., Elliot, W. J., and Robichaud, P. R. (2017). Linking remote sensing and process-based hydrological models to increase understanding of wildfire effects on watersheds and improve post-fire remediation efforts.

Mohadjer, S., Ehlers, T. A., Bendick, R., Stübner, K., \& Strube, T. (2016). A Quaternary fault database for central Asia. Natural Hazards and Earth System Sciences, 16(2), 529.

Monaghan, J. J. (2000). SPH without a tensile instability. Journal of computational physics, 159(2), 290-311.

Morgan, R. P. C., Quinton, J. N., Smith, R. E., Govers, G., Poesen, J. W. A., Auerswald, K., ... \& Styczen, M. E. (1998). The European Soil Erosion Model (EUROSEM): a dynamic approach for predicting sediment transport from fields and small catchments. Earth Surface Processes and Landforms: The Journal of the British Geomorphological Group, 23(6), 527-544.

Morgenstern, N. R., \& Price, V. E. (1965). The analysis of the stability of general slip surfaces.

Morgenstern, N. R., \& Sangrey, D. A. (1978). Methods of stability analysis. Transportation Research Board Special Report, (176).

Munich Re. (2005) Topics Geo-Annual review: natural catastrophes, Munich Re-Munich Reinsurance Company, Munich

Munich Re. (2019). The natural disasters of 2018 in figures. Retrieved January, 22, 2019.Nadim et al., MATRIX Framework for multi-risk assessment

Nadim, F., and Kjekstad, O. (2009). Assessment of global high-risk landslide disaster hotspots. In Landslides-Disaster Risk Reduction (pp. 213-221). Springer, Berlin, Heidelberg.

Nadim, F., Kjekstad, O., Peduzzi, P., Herold, C., \& Jaedicke, C. (2006). Global landslide and avalanche hotspots. Landslides, 3(2), 159-173.

Nash. T, Bell. D, Davies. T, Nathan. S, 2008. Analysis of the formation and failure of Ram Creek landslide dam, South Island, New Zealand. New Zealand Journal of Geology \& Geophysics 51, 187-193.

Nearing, M. A., Ascough, L. D., \& Chaves, H. M. L. (1989). WEPP model sensitivity analysis. Water erosion prediction project landscape profi le model documentation. NSERL Report, (2).

Necas, J., \& Hlavácek, I. (2017). Mathematical theory of elastic and elastoplastic bodies: an introduction. Elsevier.

Newman, J. P., Maier, H. R., Riddell, G. A., Zecchin, A. C., Daniell, J. E., Schaefer, A. M., ... and Newland, C. P. (2017). Review of literature on decision support systems for natural hazard risk reduction: Current status and future research directions. Environmental Modelling and Software, 96, 378-409.

Newmark, N. M. (1965). Effects of earthquakes on dams and embankments. Geotechnique, 15(2), 139-160.

Ngekpe, B. E., Ode, T., \& Eluozo, S. N. (2016). Application of total-strain crack model in finite element analysis for punching shear at edge connection. International journal of Research in Engineering and Social Sciences, 6(12), 1-9. 
Nguyen, P., Thorstensen, A., Sorooshian, S., Hsu, K., AghaKouchak, A., Sanders, B., ... \& Smith, M. (2015). A high resolution coupled hydrologichydraulic model (HiResFlood-UCI) for flash flood modeling. Journal of Hydrology.

Nikolopoulos, E. I., Anagnostou, E. N., \& Borga, M. (2013). Using highresolution satellite rainfall products to simulate a major flash flood event in northern Italy. Journal of Hydrometeorology, 14(1), 171-185.

Nikolopoulos, E. I., Borga, M., Creutin, J. D., \& Marra, F. (2015). Estimation of debris flow triggering rainfall: Influence of rain gauge density and interpolation methods. Geomorphology, 243, 40-50.

Nikolopoulos, E. I., Destro, E., Bhuiyan, M. A. E., Borga, M., and Anagnostou, E. N. (2018). Evaluation of predictive models for post-fire debris flow occurrence in the western United States. Natural Hazards and Earth System Sciences, 18(9), 2331-2343.

Norbiato, D., Borga, M., Sangati, M., \& Zanon, F. (2007). Regional frequency analysis of extreme precipitation in the eastern Italian Alps and the August 29, 2003 flash flood. Journal of hydrology, 345(3), 149-166.

Novak, P., Guinot, V., Jeffrey, A., \& Reeve, D. E. (2010). Hydraulic modellingan introduction: principles, methods and applications. CRC Press.

O'Brien, J. S. (2006). FLO-2D user's manual, version 2006.01. FLO-2D Software. Inc., Nutrioso.

O'brien, J. S. (2007). FLO-2D users manual. Nutr. Ariz. June.

O'brien, J. S., \& Julien, P. Y. (1985). Physical properties and mechanics of hyperconcentrated sediment flows. Proc. ASCE HD Delineation of landslides, flash flood and debris flow Hazards.

O'brien, J. S., Julien, P. Y., \& Fullerton, W. T. (1993). Two-dimensional water flood and mudflow simulation. Journal of hydraulic engineering, 119(2), 244-261.

OpenLISEM De Roo, A. P. J., and Jetten, V. G. (1999). Calibrating and validating the LISEM model for two data sets from the Netherlands and South Africa. Catena, 37(3-4), 477-493.

Osorno, M., \& Steeb, H. (2017). Coupled SPH and Phase Field method for hydraulic fracturing. PAMM, 17(1), 533-534.

Ouyang, C., He, S., \& Tang, C. (2015). Numerical analysis of dynamics of debris flow over erodible beds in Wenchuan earthquake-induced area. Engineering Geology, 194, 62-72.

Pailha, M., \& Pouliquen, O. (2009). A two-phase flow description of the initiation of underwater granular avalanches. Journal of Fluid Mechanics, 633, 115-135.

Pappenberger, F., Beven, K. J., Hunter, N. M., Bates, P. D., Gouweleeuw, B. T., Thielen, J., and De Roo, A. P. J. (2005). Cascading model uncertainty from medium range weather forecasts (10 days) through a rainfall-runoff model to flood inundation predictions within the European Flood Forecasting System (EFFS). Hydrology and Earth System Sciences Discussions, 9(4), 381-393.

Pastor, M., Blanc, T., Haddad, B., Petrone, S., Morles, M. S., Drempetic, V., ... \& Cuomo, S. (2014). Application of a SPH depth-integrated model to landslide run-out analysis. Landslides, 11(5), 793-812.

Pastor, M., Blanc, T., Pastor, M. J., Sanchez, M., Haddad, B., Mira, P., ... \& Drempetic, V. (2007). A SPH depth integrated model with pore pressure 
coupling for fast landslides and related phenomena. In 2007 international forum on landslides disaster management (pp. 987-1014).

Pastor, M., Haddad, B., Sorbino, G., Cuomo, S., \& Drempetic, V. (2009). A depth integrated, coupled SPH model for flow like landslides and related phenomena. International Journal for numerical and analytical methods in geomechanics, 33(2), 143-172.

Peng, M., and Zhang, L. M., 2012, Breaching parameters of landslide dams: Landslides, v. 9, no. 1, p. 13-31.

Peter, D., Rietmann, M., Galvez, P., \& Ampuero, J. P. (2017). High-resolution seismic wave propagation using local time stepping.

Pitman, E. B., \& Le, L. (2005). A two-fluid model for avalanche and debris flows. Philosophical Transactions of the Royal Society A: Mathematical, Physical and Engineering Sciences, 363(1832), 1573-1601.

Pitman, E. B., and Le, L. (2005). A two-fluid model for avalanche and debris flows. Philosophical Transactions of the Royal Society of London A: Mathematical, Physical and Engineering Sciences, 363(1832), 1573-1601.

Pix4D, S. A. (2017). Pix4dmapper 3.2 user manual.

Price, N. J. (2016). Fault and joint development: in brittle and semi-brittle rock. Elsevier.

Prucha, B., Graham, D., Watson, M., Avenant, M., Esterhuyse, S., Joubert, A., ... \& Rossouw, L. (2016). MIKE-SHE integrated groundwater and surface water model used to simulate scenario hydrology for input to DRIFT-ARID: the Mokolo River case study. Water SA, 42(3), 384-398.

Pudasaini, S. P. (2012). A general two phase debris flow model. Journal of Geophysical Research: Earth Surface, 117(F3).

Pudasaini, S. P., \& Fischer, J. T. (2016). A mechanical erosion model for twophase mass flows. arXiv preprint arXiv:1610.01806.

Pudasaini, S. P., \& Hutter, K. (2003). Rapid shear flows of dry granular masses down curved and twisted channels. Journal of Fluid Mechanics, 495, 193208.

Pudasaini, S. P., \& Hutter, K. (2007). Avalanche dynamics: dynamics of rapid flows of dense granular avalanches. Springer Science \& Business Media.

Pudasaini, S. P., \& Mergili, M. (2019). A Multi Phase Mass Flow Model. Journal of Geophysical Research: Earth Surface.

Pudasaini, S. P., and Hutter, K. (2003). Rapid shear flows of dry granular masses down curved and twisted channels. Journal of Fluid Mechanics, 495, 193-208.

Pudasaini, S. P., Hajra, S. G., Kandel, S., \& Khattri, K. B. (2018). Analytical solutions to a nonlinear diffusion-advection equation. Zeitschrift für angewandte Mathematik und Physik, 69(6), 150.

Pyke, R., 1991. TSLOPE3: User Guide. Taga Engineering System and Software, Lafayette.

Quine, C. P., \& Gardiner, B. A. (2007). Understanding how the interaction of wind and trees results in windthrow, stem breakage, and canopy gap formation. Plant disturbance ecology: The process and the response, 10355.

Rabie, M. (2014). Comparison study between traditional and finite element methods for slopes under heavy rainfall. HBRC Journal, 10(2), 160-168.

Raghukanth, S. T. G., Lakshmi Kumari, K., and Kavitha, B. (2012). Estimation of ground motion during the 18th September 2011 Sikkim earthquake. Geomatics, Natural Hazards and Risk, 3(1), 9-34. 
Reiche, P. (1937). The Toreva-Block: A distinctive landslide type. The Journal of Geology, 45(5), 538-548.Richard, A., Brennan, G., Oh, W. T., \& Ileme, V. (2017). Critical height of an unsupported vertical trench in an unsaturated sand. In Proceedings of the 70th Canadian Geotechnical Conference.

Reid, M. E., \& Brien, D. L. (2012, December). Slope instability in complex 3D topography promoted by convergent 3D groundwater flow. In AGU Fall Meeting Abstracts.

Reid, M. E., Christian, S. B., \& Brien, D. L. (2000). Gravitational stability of three dimensional stratovolcano edifices. Journal of Geophysical Research: Solid Earth, 105(B3), 6043-6056.

Reid, M. E., Christian, S. B., Brien, D. L., \& Henderson, S. . (2015). Scoops3DSoftware to Analyze Three-Dimensional Slope Stability Throughout a Digital Landscape. In U.S. Geological Survey Techniques and Methods, book 14 (p. 218). https://doi.org/10.3133/tm14A1

Reid, M. E., Christian, S. B., Brien, D. L., and Henderson, S. (2015). Scoops3DSoftware to Analyze Three-Dimensional Slope Stability Throughout a Digital Landscape. Virginia: US Geological Survey.

Reilly, A. C., Guikema, S. D., Zhu, L., \& Igusa, T. (2017). Evolution of vulnerability of communities facing repeated hazards. PLoS one, 12(9), e0182719.

Rengers, F. K., McGuire, L. A., Kean, J. W., Staley, D. M., and Hobley, D. E. J. (2016). Model simulations of flood and debris flow timing in steep catchments after wildfire. Water Resources Research, 52(8), 6041-6061.

Rickenmann, D., Laigle, D. M. B. W., McArdell, B. W., \& Hübl, J. (2006). Comparison of 2D debris-flow simulation models with field events. Computational Geosciences, 10(2), 241-264.

Rickenmann, D., Laigle, D. McArdell, B.W., Hübl, J.. 2006. Comparison of 2D debris-flow simulation models with field events. Computat Geosci, 10, pp. 241-264

Rigon, R., Bertoldi, G., \& Over, T. M. (2006). GEOtop: A distributed hydrological model with coupled water and energy budgets. Journal of Hydrometeorology, 7(3), 371-388.

Ritter, A. (1892). Die fortpflanzung de wasserwellen. Zeitschrift Verein Deutscher Ingenieure, 36(33), 947-954.

Roberts, M., http://extremelearning.com.au/evenly-distributing-points-in-atriangle/ Obtained 29-01-2020

Roelvink, J. A., \& Van Banning, G. K. F. M. (1995). Design and development of DELFT3D and application to coastal morphodynamics. Oceanographic Literature Review, 11(42), 925.

Roobol, M. J. and Smith, A. L., 2004, Geologic Map of Dominica, West Indies: Geology Department, University of Puerto Rico at Mayaguez. Electronic document, available at http://www.caribbeanvolcanoes.com/dominica/content/dominicamap.p df

Roozbeh Geraili Mikola, ADONIS: A Free Finite Element Analysis Software with an Interactive Graphical User Interface for Geoengineers, GeoOttawa2017 Conference, Ottawa, October 2017

Rossi, G. (1994). Historical development of flood analysis methods. In Coping with Floods (pp. 11-34). Springer, Dordrecht. 
Rossi, G., Catani, F., Leoni, L., Segoni, S., \& Tofani, V. (2013). HIRESSS: a physically based slope stability simulator for HPC applications. Natural Hazards and Earth System Sciences, 13(1), 151.

Ruette, J. V., Lehmann, P., \& Or, D. (2013). Rainfall triggered shallow landslides at catchment scale: Threshold mechanics based modeling for abruptness and localization. Water Resources Research, 49(10), 62666285.

Salman, A. M., and Li, Y. (2018). A probabilistic framework for multi-hazard risk mitigation for electric power transmission systems subjected to seismic and hurricane hazards. Structure and Infrastructure Engineering, 1-21.

Sanders, B. F. (2008). Integration of a shallow water model with a local time step. Journal of Hydraulic Research, 46(4), 466-475.

Sanders, B. F., Schubert, J. E., \& Detwiler, R. L. (2010). ParBreZo: A parallel, unstructured grid, Godunov-type, shallow-water code for high-resolution flood inundation modeling at the regional scale. Advances in Water Resources, 33(12), 1456-1467.

Saulnier, G. M., Beven, K., \& Obled, C. (1997). Including spatially variable effective soil depths in TOPMODEL. Journal of hydrology, 202(1), 158-172.

Savage, S. B., \& Hutter, K. (1989). The motion of a finite mass of granular material down a rough incline. Journal of fluid mechanics, 199, 177-215.

Saxton, K. E., \& Rawls, W. J. (2006). Soil water characteristic estimates by texture and organic matter for hydrologic solutions. Soil Science Society of America Journal, 70(5), 1569-1578.

Scharffenberg, W. A., \& Fleming, M. J. (2006). Hydrologic modeling system HEC-HMS: User's manual. US Army Corps of Engineers, Hydrologic Engineering Center.

Scheidl, C., Rickenmann, D., \& McArdell, B. W. (2013). Runout prediction of debris flows and similar mass movements. In Landslide Science and Practice (pp. 221-229). Springer Berlin Heidelberg.

Schiermeier, Q. (2006). Insurers' disaster files suggest climate is culprit. Nature, 441(7094), 674-675.

Schilirò, L., Montrasio, L., Scarascia Mugnozza, G. (2016) Prediction of shallow landslide occurrence: Validation of a physically-based approach through a real case study. Science of the Total Environment, 569-570, pp. 134-144.

Schillaci, C., Lombardo, L., Saia, S., Fantappiè, M., Märker, M., Acutis, M. (2017) Modeling the topsoil carbon stock of agricultural lands with the Stochastic Gradient Treeboost in a semi-arid Mediterranean region. Geoderma, 286, pp. 35-45.

Schmidt, J., Matcham, I., Reese, S., King, A., Bell, R., Henderson, R., ... and Heron, D. (2011). Quantitative multi-risk analysis for natural hazards: a framework for multi-risk modelling. Natural Hazards, 58(3), 1169-1192.

Schmidt, K. M., Roering, J. J., Stock, J. D., Dietrich, W. E., Montgomery, D. R., \& Schaub, T. (2001). The variability of root cohesion as an influence on shallow landslide susceptibility in the Oregon Coast Range. Canadian Geotechnical Journal, 38(5), 995-1024.

Schmidt-Tomé, P., Kallio, H., Jarva, J., Tarvainen, T., Greiving, S., Fleischhauer, M., Peltonen, L., Kumpulainen, S., Olfert, A., Schanze, J., Bärring, L., Persson, G., Relvão, A.M., Batista, M.J. (Eds.), 2006. The Spatial Effects and Management of Natural and Technological Hazards in Europe (ESPON) Project 1.3.1. Geological Survey of Finland (URL http:// www.espon.lu). 
Schneider, P. J., and Schauer, B. A. (2006). HAZUS-its development and its future. Natural Hazards Review, 7(2), 40-44.

Schulz, W. H., McKenna, J. P., Kibler, J. D., \& Biavati, G. (2009). Relations between hydrology and velocity of a continuously moving landslideevidence of pore-pressure feedback regulating landslide motion?. Landslides, 6(3), 181-190.

Schuster, R. L., \& Fleming, R. W. (1986). Economic losses and fatalities due to landslides. Bull Assoc Eng Geol, 23(1), 11-28.

Schuster, R.L. (1993) Landslide dams - a worldwide phenomenon. Proceedings Annual Symposium of The Japanese Landslide Society, Kansai Branch, 27 April, Osaka, 1-23.

Searcy, C., Dean, K., and Stringer, W. (1998). PUFF: A high-resolution volcanic ash tracking model. Journal of Volcanology and Geothermal Research, 80(1-2), 1-16.

Sedaghat, A., Ackroyd, J. A. D., \& Wood, N. J. (1999). Turbulence modelling for supercritical flows including examples with passive shock control. The Aeronautical Journal, 103(1020), 113-125.

Seefelder, C. D. L. N., Koide, S., \& Mergili, M. (2017). Does parameterization influence the performance of slope stability model results? A case study in Rio de Janeiro, Brazil. Landslides, 14(4), 1389-1401.

Shafique, M., Van Der Meijde, M., Kerle, N., Van Der Meer, F., \& Khan, M. A. (2008). Predicting topographic aggravation of seismic ground shaking by applying geospatial tools. J Himal Earth Sci, 41, 33-43.

Sheridan, M. F., Stinton, A. J., Patra, A., Pitman, E. B., Bauer, A., \& Nichita, C. C. (2005). Evaluating Titan2D mass-flow model using the 1963 Little Tahoma peak avalanches, Mount Rainier, Washington. Journal of Volcanology and Geothermal Research, 139(1-2), 89-102.

SHRESTHA, B. B., NAKAGAWA, H., KAWAIKE, K., \& BABA, Y. (2008). Numerical simulation on debris-flow deposition and erosion processes upstream of a check dam with experimental verification.

Singh, K. P., \& Snorrason, A. (1984). Sensitivity of outflow peaks and flood stages to the selection of dam breach parameters and simulation models. Journal of hydrology, 68(1-4), 295-310.

Smith, R. E., \& Parlange, J. Y. (1978). A parameter efficient hydrologic infiltration model. Water Resources Research, 14(3), 533-538.

Somma, R. (2006) The south-western side of the Calabrian Arc (Peloritani Mountains): Geological, structural and AMS evidence for passive clockwise rotations. Journal of Geodynamics, 41 (4), pp. 422-439.

Stancanelli, L. M., Rosatti, G., Begnudelli, L., Armanini, A., \& Foti, E. (2013). Single or two-phase modeling of debris-flow? A systematic comparison of the two approaches applied to a real debris flow in Giampilieri Village (Italy). In Landslide Science and Practice (pp. 277-283). Springer Berlin Heidelberg.

Starkloff, T., \& Stolte, J. (2014). Applied comparison of the erosion risk models EROSION 3D and LISEM for a small catchment in Norway. Catena, 118, 154-167.

Stead, D., \& Wolter, A. (2015). A critical review of rock slope failure mechanisms: The importance of structural geology. Journal of Structural Geology, 74, 1-23. 
Steffen, M., Kirby, R. M., \& Berzins, M. (2008). Analysis and reduction of quadrature errors in the material point method (MPM). International journal for numerical methods in engineering, 76(6), 922-948.

Stelling, G. S. (2012). Quadtree flood simulations with sub-grid digital elevation models. Proceedings of the Institution of Civil Engineers, 165(10), 567.

Sticko, S. (2013). Smooth Particle Hydrodynamics applied to fracture mechanics.

Stokes, G. G. (1850). On the effect of internal friction of fluids on the motion of pendulums. Trans. Camb. phi1. SOc, 9(8), 106.

Stomakhin, A., Schroeder, C., Chai, L., Teran, J., \& Selle, A. (2013). A material point method for snow simulation. ACM Transactions on Graphics (TOG), 32(4), 1-10.

Strauch, R., Istanbulluoglu, E., \& Riedel, J. (2019). A new approach to mapping landslide hazards: a probabilistic integration of empirical and physically based models in the North Cascades of Washington, USA. Natural Hazards \& Earth System Sciences, 19(11).

Suksuwan, A., and Spence, S. M. (2018). Performance-based multi-hazard topology optimization of wind and seismically excited structural systems. Engineering Structures, 172, 573-588.

Sullivan-Wiley, K. A., and Gianotti, A. G. S. (2017). Risk perception in a multihazard environment. World Development, 97, 138-152

Swanson, F. J., Oyagi, N., and Tominaga, M.: Landslide dams in Japan, in: Landslide dams: process, risk, and mitigation New York: American Society of Civil Engineers Special Publication, edited by: Schuster, R. L., No. 3, 273-378, 1986.

Syme, W. J. (2001, February). TUFLOW-Two \& Onedimensional unsteady flow Software for rivers, estuaries and coastal waters. In IEAust Water Panel Seminar and Workshop on 2d Flood Modelling, Sydney.

Takahashi, T., Nakagawa, H., Harada, T., and Yamashiki, Y.: Routing debris flows with particle segregation, J. Hydraul. Eng., 118, 1490-1507, 1992.

Tang, C. L., Hu, J. C., Lin, M. L., Angelier, J., Lu, C. Y., Chan, Y. C., \& Chu, H. T. (2009). The Tsaoling landslide triggered by the Chi-Chi earthquake, Taiwan: insights from a discrete element simulation. Engineering Geology, 106(1-2), 1-19.

Tang, C., Jiang, Z., \& Li, W. (2015). Seismic landslide evolution and debris flow development: a case study in the Hongchun Catchment, Wenchuan area of China. In Engineering Geology for Society and Territory-Volume 2 (pp. 445-449). Springer, Cham.

Tang, C., Tanyas, H., van Westen, C. J., Tang, C., Fan, X., \& Jetten, V. G. (2019). Analysing post-earthquake mass movement volume dynamics with multi-source DEMs. Engineering Geology, 248, 89-101.

Tang, C., van Asch, T. W., Chang, M., Chen, G. Q., Zhao, X. H., \& Huang, X. C. (2012). Catastrophic debris flows on 13 August 2010 in the Qingping area, southwestern China: the combined effects of a strong earthquake and subsequent rainstorms. Geomorphology, 139, 559-576.

Tang, C., Van Westen, C. J., Tanyas, H., \& Jetten, V. G. (2016). Analysing post-earthquake landslide activity using multi-temporal landslide inventories near the epicentral area of the 2008 Wenchuan earthquake. Natural hazards and earth system sciences, 16(12), 2641. 
Tang, C., Zhu, J., Ding, J., Cui, X. F., Chen, L., \& Zhang, J. S. (2011). Catastrophic debris flows triggered by a 14 August 2010 rainfall at the epicenter of the Wenchuan earthquake. Landslides, 8(4), 485-497.

Tao, J., and Barros, A. P. (2014). Coupled prediction of flood response and debris flow initiation during warm-and cold-season events in the Southern Appalachians, USA. Hydrology and Earth System Sciences, 18(1), 367388.

Tarolli, P. (2014). High-resolution topography for understanding Earth surface processes: Opportunities and challenges. Geomorphology, 216, 295-312.

Taufik, M., Torfs, P. J., Uijlenhoet, R., Jones, P. D., Murdiyarso, D., and Van Lanen, H. A. (2017). Amplification of wildfire area burnt by hydrological drought in the humid tropics. Nature Climate Change, 7(6), 428.

Taylor, D., Aldridge, J., Dent, J., and Churchill, J. (2018). National Scale MultiHazard Model Platform for Extreme Cyclone Impacts on Coasts and Infrastructure. Coastal Engineering Proceedings, 1(36), 105.

Terzi, S., Torresan, S., Schneiderbauer, S., Critto, A., Zebisch, M., and Marcomini, A. (2019). Multi-risk assessment in mountain regions: A review of modelling approaches for climate change adaptation. Journal of environmental management, 232, 759-771.

Tho Sao, Nguyen. (2008). Storm surge predictions for Vietnam coast by Delft3D model using results from RAMS model. Tạp chí Khoa học kỹ thuật Thưy lợi và Môi trường, (23), 39.

Tianchi, L., \& Shumin, W. (1992). Landslide hazards and their mitigation in China. Science Press.

Tiwari, M. K., \& Chatterjee, C. (2010). Uncertainty assessment and ensemble flood forecasting using bootstrap based artificial neural networks (BANNs). Journal of Hydrology, 382(1-4), 20-33.

Tiwari, R. C., Bhandary, N. P., \& Yatabe, R. (2014). Spectral element analysis to evaluate the stability of long and steep slopes. Acta Geotechnica, 9(5), 753-770.

Tiwari, R. C., Bhandary, N. P., and Yatabe, R. (2015). 3-D elasto-plastic spectral element application to evaluate the stability of large-scale landslides. Geomechanics and Geoengineering, 10(4), 271-289.

Tiwari, R. C., Bhandary, N. P., and Yatabe, R. (2015). 3D SEM approach to evaluate the stability of large-scale landslides in Nepal Himalaya. Geotechnical and Geological Engineering, 33(4), 773-793.

Tohari, A., Nishigaki, M., \& Komatsu, M. (2007). Laboratory rainfall-induced slope failure with moisture content measurement. Journal of Geotechnical and Geoenvironmental Engineering, 133(5), 575-587.

Toro, E. F. (2013). Riemann solvers and numerical methods for fluid dynamics: a practical introduction. Springer Science \& Business Media.

Trigila, A., Iadanza, C., Esposito, C., \& Scarascia-Mugnozza, G. (2015). Comparison of Logistic Regression and Random Forests techniques for shallow landslide susceptibility assessment in Giampilieri (NE Sicily, Italy). Geomorphology, 249, 119-136.

Tsai, C. W. (2003). Applicability of kinematic, noninertia, and quasi-steady dynamic wave models to unsteady flow routing. Journal of Hydraulic Engineering, 129(8), 613-627.

Tsakiris, G., \& Bellos, V. (2014). A numerical model for two-dimensional flood routing in complex terrains. Water resources management, 28(5), 12771291. 
Tun, Y. W., Llano-Serna, M. A., Pedroso, D. M., \& Scheuermann, A. (2019). Multimodal reliability analysis of 3D slopes with a genetic algorithm. Acta Geotechnica, 14(1), 207-223.

Turner, A. K., \& Jayaprakash, G. P. (1996). LANDSLIDES: INVESTIGATION AND MITIGATION. CHAPTER 1-INTRODUCTION (No. 247).

Tyagunov, S., Vorogushyn, S., Muñoz Jimenez, C., Parolai, S., and Fleming, K. (2018). Multi-hazard fragility analysis for fluvial dikes in earthquake-and flood-prone areas. Natural Hazards and Earth System Sciences, 18(9), 2345-2354.

Ukritchon, B., Ouch, R., Pipatpongsa, T., \& Khosravi, M. H. (2017). Investigation of stability and failure mechanism of undercut slopes by three-dimensional finite element analysis. KSCE Journal of Civil Engineering, 1-12.

UN (2002) Johannesburg plan of implementation of the world summit on sustainable development. Tech. rep., United Nations, http://www.un.org/esa/sustdev/documents/WSSD_POI_PD/English/WSS D_PlanImpl.pdf, access 03 September 2009

UN first focus on multihazard UN (2002) Johannesburg plan of implementation of the world summit on sustainable development. Tech.rep., United Nations

UNDHA (1992) Internationally agreed glossary of basic terms related to disaster management. Glossary, United Nations Department of Humanitarian Affairs

UNEP (1992) Agenda 21. Tech. rep., United Nations Environment Programme, http://www.un.org/ esa/dsd/agenda21/res_agenda21_07.shtml, access 03 September 2009

UN-ISDR (2005) Hyogo framework for action 2005-1015: Building the resilience of nations and communitiesto disasters. In: World Conference on Disaster Reduction, Kobe, Hyogo, Japan

UN-ISDR (2005) Hyogo framework for action 2005-1015: Building the resilience of nations and communities to disasters. In: World Conference on Disaster Reduction, Kobe, Hyogo, Japan

UN-ISDR (2009) Global assessment report on disaster risk reduction. Tech. rep., United Nations-International Strategy for Disaster Reduction,

United Nations Office for Disaster Risk Reduction, Sendai Framework for Disaster Risk Reduction 2015-2030 (2015)

Uzielli, M., Nadim, F., Lacasse, S., and Kaynia, A. M. (2008). A conceptual framework for quantitative estimation of physical vulnerability to landslides. Engineering Geology, 102(3-4), 251-256.

Valiani, A., Caleffi, V., \& Zanni, A. (2002). Case study: Malpasset dam-break simulation using a two-dimensional finite volume method. Journal of Hydraulic Engineering, 128(5), 460-472.

Van Asch, T. W., Buma, J., \& Van Beek, L. P. H. (1999). A view on some hydrological triggering systems in landslides. Geomorphology, 30(1), 2532.

Van Asch, T. W., Tang, C., Alkema, D., Zhu, J., \& Zhou, W. (2014). An integrated model to assess critical rainfall thresholds for run-out distances of debris flows. Natural hazards, 70(1), 299-311.

Van Asch, Th.W.J., Malet, J.-P., van Beek, L.P.H., Amitrano, D., (2007). Techniques, issues and advances in numerical modelling of landslide hazard. Bull. Soc. géol. Fr., 2007, t. 178, no 2, pp. 65-88. 
van Beek, L. P. H. (2002). Assessment of the influence of changes in land use and climate on landslide activity in a Mediterranean environment (Doctoral dissertation).

van Beek, L. P. H. (2003). Assessment of the influence of changes in land use and climate on landslide activity in a Mediterranean environment (Doctoral dissertation).

van den Bout, B., \& Jetten, V. G. (2020). Catchment-scale multi-process modeling with local time stepping. Environmental Earth Sciences, 79, 115.

Van Der Knijff, J. M., Younis, J., \& De Roo, A. P. J. (2010). LISFLOOD: a GISbased distributed model for river basin scale water balance and flood simulation. International Journal of Geographical Information Science, 24(2), 189-212.

Van Leer, B. (1979). Towards the ultimate conservative difference scheme. V. A second-order sequel to Godunov's method. Journal of computational Physics, 32(1), 101-136.

Van Looy, K., Bouma, J., Herbst, M., Koestel, J., Minasny, B., Mishra, U., ... \& Schaap, M. G. (2017). Pedotransfer functions in Earth system science: Challenges and perspectives. Reviews of Geophysics, 55(4), 1199-1256.

van Westen, C. J. \& Greiving, S. (2017) Risk Assessment for Decision Making. Environmental hazards Methodologies for Risk Assessment and Management. Dalezios, N. R. (ed.). p. 31-94

van Westen, C. J., and Greiving, S. (2017). Multi-hazard risk assessment and decision making. Environmental Hazards Methodologies for Risk Assessment and Management, 31.

van Westen, C. J., and Hofstee, P. (2000). The role of remote sensing and GIS in risk mapping and damage assessment for disasters in urban areas. Fernerkundung und Naturkatastrophen, 7, 442-450.

Van Westen, C. J., Castellanos, E., \& Kuriakose, S. L. (2008). Spatial data for landslide susceptibility, hazard, and vulnerability assessment: an overview. Engineering geology, 102(3-4), 112-131.

Van Westen, C. J., Montoya, L., Boerboom, L., and Badilla Coto, E. (2002, September). Multi-hazard risk assessment using GIS in urban areas: a case study for the city of Turrialba, Costa Rica. In Proc. Regional workshop on Best Practise in Disaster Mitigation, Bali (pp. 120-136).

Van Westen, C. J., Van Asch, T. W., \& Soeters, R. (2006). Landslide hazard and risk zonation-why is it still so difficult?. Bulletin of Engineering geology and the Environment, 65(2), 167-184.

Varnes, D. J. (1978). Slope movement types and processes. Special report, $176,11-33$.

Velleux, M. L., England, J. F., \& Julien, P. Y. (2008). TREX: Spatially distributed model to assess watershed contaminant transport and fate. Science of the Total Environment, 404(1), 113-128.

Vieira, J. D. (1983). Conditions governing the use of approximations for the Saint-Venant equations for shallow surface water flow. Journal of Hydrology, 60(1-4), 43-58.

von Boetticher, A., Turowski, J. M., McArdell, B. W., Rickenmann, D., Hürlimann, M., Scheidl, C., \& Kirchner, J. W. (2017). DebrisInterMixing2.3: a finite volume solver for three-dimensional debris-flow simulations with two calibration parameters-Part 2: Model validation with experiments. Geoscientific Model Development, 10(11), 3963-3978. 
von Boetticher, A., Turowski, J. M., McArdell, B. W., Rickenmann, D., \& Kirchner, J. W. (2016). DebrisInterMixing-2.3: a finite volume solver for three-dimensional debris-flow simulations with two calibration parametersPart 1: Model description. Geoscientific Model Development, 9(9), 29092923.

von Ruette, J., Lehmann, P., Fan, L., Bickel, S., \& Or, D. (2017, April). STEPTRAMM-A modeling interface for simulating localized rainfall induced shallow landslides and debris flow runout pathways. In EGU General Assembly Conference Abstracts (Vol. 19, p. 11408).

Vousdoukas, M. I., Voukouvalas, E., Annunziato, A., Giardino, A., and Feyen, L. (2016). Projections of extreme storm surge levels along Europe. Climate Dynamics, 47(9-10), 3171-3190.

Vuong, N. T. H., Wu, T. R., WANG, C., CHU, C., Lin, C. W., \& Chuang, M. H. (2019). Numerical Study on Debris Flow. AGUFM, 2019, NH33D-0947.

Wainwright, J., and Mulligan, M. (Eds.). (2002). Environmental modelling. Wiley-Blackwell.

Wald, D. J., Worden, B. C., Quitoriano, V., \& Pankow, K. L. (2005). ShakeMap manual: technical manual, user's guide, and software guide (No. 12-A1).

Walder, J. S. and O'Connor, J. E. (1997) Methods for predicting peak discharge of floods caused by failure of natural and constructed earthen dams, Water Resour. Res., 33, 2337-48, 1997.

Wang, G., Liu, F., Fu, X., \& Li, T. (2008). Simulation of dam breach development for emergency treatment of the Tangjiashan Quake Lake in China. Science in China Series E: Technological Sciences, 51, 82-94.

Ward, P. J., De Moel, H., Aerts, J. C. J. H., \& Glade, T. (2011). How are flood risk estimates affected by the choice of return-periods?. Natural Hazards \& Earth System Sciences, 11(12).

Wasowski, J., Keefer, D. K., \& Lee, C. T. (2011). Toward the next generation of research on earthquake-induced landslides: current issues and future challenges. Engineering Geology, 122(1-2), 1-8.

WBM, B. (2010). TUFLOW user manual. GIS Based.

Westen, C. V., \& Terlien, M. J. T. (1996). An approach towards deterministic landslide hazard analysis in GIS. A case study from Manizales (Colombia). Earth Surface Processes and Landforms, 21(9), 853-868.

Westen, C. V., and Terlien, M. J. T. (1996). An approach towards deterministic landslide hazard analysis in GIS. A case study from Manizales (Colombia). Earth surface processes and landforms, 21(9), 853-868.

Wilkinson, P. L., Anderson, M. G., \& Lloyd, D. M. (2002). An integrated hydrological model for rain induced landslide prediction. Earth Surface Processes and Landforms, 27(12), 1285-1297.

Williams, J. R. (2019, October). Application of SPH to coupled fluid-solid problems in the petroleum industry. In Videos of Plenary Lectures presented at the IV International Conference on Particle-Based Methods. Fundamentals and Applications.(PARTICLES 2015).

Winter, B., Schneeberger, K., Dung, N. V., Huttenlau, M., Achleitner, S., Stötter, J., ... \& Vorogushyn, S. (2019). A continuous modelling approach for design flood estimation on sub-daily time scale. Hydrological Sciences Journal, 64(5), 539-554.

Wu, W. (2001). CCHE2D sediment transport model (version 2.1). Technical Rep. of National Center for Computational Hydroscience and Engineering NCCHE-TR-2001-03, Univ. of Mississippi. 
Xie, D. M., Zou, Q. P., and Cannon, J. W. (2016). Application of SWAN+ ADCIRC to tide-surge and wave simulation in Gulf of Maine during Patriot's Day storm. Water Science and Engineering, 9(1), 33-41

Xie, M. W., Esaki, T., Zhou, G. Y., \& Mitani, Y. (2003). Three-dimensional stability evaluation of landslides and a sliding process simulation using a new geographic information systems component. Environmental Geology, 43(5), 503-512. https://doi.org/10.1007/s00254-002-0655-3

Xie, M., Esaki, T., \& Cai, M. (2004). A GIS-based method for locating the critical 3D slip surface in a slope. Computers and Geotechnics, 31(4), 267-277.

Xie, M., Esaki, T., \& Cai, M. (2006). GIS-based implementation of threedimensional limit equilibrium approach of slope stability. Journal of geotechnical and geoenvironmental engineering, 132(5), 656-660.

Xie, M., Esaki, T., Qiu, C., \& Wang, C. (2006). Geographical information system-based computational implementation and application of spatial three-dimensional slope stability analysis. Computers and Geotechnics, 33(4-5), 260-274.

Xu, F., Zhao, Y., Li, Y., \& Kikuchi, M. (2010). Study of numerical and physical fracture with SPH method. Acta Mechanica Solida Sinica, 23(1), 49-56.

Xu, Q., Zhang, S., Li, W. L., \& Van Asch, T. W. (2012). The 13 August 2010 catastrophic debris flows after the 2008 Wenchuan earthquake, China. Natural Hazards and Earth System Sciences, 12, 201-216.

Yang, J., 2010. Emergency Investigation Report of Shaofang Catchment Debris Flows. Unpublished report, in Chinese. Sichuan Institute of Geological Engineering Investigation.

Yavari-Ramshe, S., and Ataie-Ashtiani, B. (2016). Numerical modeling of subaerial and submarine landslide-generated tsunami waves-recent advances and future challenges. Landslides, 13(6), 1325-1368.

Yee, H. C., \& Harten, A. (1987). Implicit TVD schemes for hyperbolic conservation laws in curvilinearcoordinates. AIAA journal, 25(2), 266-274.

Yin, J., Lin, N., and Yu, D. (2016). Coupled modeling of storm surge and coastal inundation: A case study in New York City during Hurricane Sandy. Water Resources Research, 52(11), 8685-8699.

Yin, J., Yu, D., Yin, Z., Wang, J., \& Xu, S. (2013). Multiple scenario analyses of Huangpu River flooding using a 1D/2D coupled flood inundation model. Natural hazards, 66(2), 577-589.

Zanke, U. (1977). Berechnung der sinkgeschwindigkeiten von sedimenten. EV.

Zhang, K., Xue, X., Hong, Y., Gourley, J. J., Lu, N., Wan, Z., ... and Wooten, R. (2016). iCRESTRIGRS: a coupled modeling system for cascading floodlandslide disaster forecasting. Hydrology and Earth System Sciences, 20(12), 5035-5048.

Zhang, L. L., Zhang, J., Zhang, L. M., \& Tang, W. H. (2011). Stability analysis of rainfall-induced slope failure: a review. Proceedings of the Institution of Civil Engineers-Geotechnical Engineering, 164(5), 299-316.

Zhang, N., Matsushima, T., \& Peng, N. (2018). Numerical investigation of postseismic debris flows in the epicentral area of the Wenchuan earthquake. Bulletin of Engineering Geology and the Environment, 1-16.

Zhao, L. H., Cheng, X., Zhang, Y., Li, L., \& Li, D. J. (2016). Stability analysis of seismic slopes with cracks. Computers and geotechnics, 77, 77-90.

Zhao, L. H., Cheng, X., Zhang, Y., Li, L., \& Li, D. J. (2016). Stability analysis of seismic slopes with cracks. Computers and geotechnics, 77, 77-90. 
Zhou, C., Shao, W., \& van Westen, C. J. (2014). Comparing two methods to estimate lateral force acting on stabilizing piles for a landslide in the Three Gorges Reservoir, China. Engineering Geology, 173, 41-53.

Zhou, F., Molinari, J. F., \& Ramesh, K. T. (2005). A cohesive model based fragmentation analysis: effects of strain rate and initial defects distribution. International Journal of Solids and Structures, 42(18-19), 5181-5207.

Zhou, W., and Tang, C. (2014). Rainfall thresholds for debris flow initiation in the Wenchuan earthquake-stricken area, southwestern China. Landslides, 11(5), 877-887.

Zhou, X. P., \& Cheng, H. (2013). Analysis of stability of three-dimensional slopes using the rigorous limit equilibrium method. Engineering Geology, 160, 21-33.

Zhu, Y. (2006). Breach growth in clay-dikes (Doctoral dissertation, TU Delft, Delft University of Technology). 


\section{Appendix A The background of OpenLISEM}

The first publication of the LISEM model was done by De Roo et al. (1994), and the further development was described by De Roo, Offermans \& Ritsema (1996) and De Roo, Wesseling \& Ritsema (1996). These early versions made use of the PCRaster Local Drainage Direction functionality to simulate a kinematic wave for overland flow. Later development was continued by Jetten \& De Roo (2001). Since then, the LISEM model has been extensively tested, used, extended and adapted. Besides published work, many reports on flooding risk and erosion have been made using the model.

De Roo \& Jetten (1999) performed a calibration and validation for a catchment in the Netherlands and a catchment in South Africa. They found that detailed data was needed to correctly predict spatial patterns in erosion and runoff. Hessel et al. (2011) performed small adaptations to the LISEM model, which allowed for better calibration to the steep slopes of a catchment in the Loess plateau in China.

Starkloff \& Stolte (2014) compared the performance of Erosion 3D and LISEM for a small catchment in Norway. While they note that LISEM requires more input data, both models performed well compared to observations. They furthermore state that the LISEM model performed better when considering both channel flow and erosion, and was less sensitive to raster resolution or digital elevation model roughness. As the authors conclude: "EROSION 3D is therefore a good planning tool, while LISEM is probably the better choice for investigation of hydrological processes in a catchment".

De Barros et al. (2014) used LISEM in a rural catchment in Southern Brazil and state the following about the performance of the model: "The LISEM model performed well in representing hydrological processes and a satisfactory performance in describing the sedimentological processes. The use of this model enabled the identification of the physical soil and surface parameters that control the magnitude and characteristics of the hydrograph and sedimentographs that reflect the degree of soil degradation experienced by the catchment due to human activity".

Bout and Jetten (2018) implemented three commonly used flow approximations for simulation flash flooding on a catchment scale and performed a comparative analysis. Later development transitioned into OpenLISEM Hazard, as is described in this thesis.

\section{B.1 Terrain and Data Description}

The Limburg Soil Erosion Model (LISEM) is a physically based numerical model with the purpose of event based runoff, flooding and erosion modelling on a catchment scale. LISEM uses a square grid to solve both cell specific processes, and the differential equations governing flow. This indirectly means input data must be provided in identical regular raster.

Emphasis is put on detail: characteristic about the model is the capacity to handle sub-gridcell surface properties (Figure A-1). A gridcell can contain a bare soil, crusted/compacted soil, vegetated surface, a road, a house and a channel. These surface characteristics are supplied in separate layers as fractions of the total cell area. The base layer is formed by the soil surface with its hydrological characteristics and the user supplies additional maps that 
trigger additional hydrological processes in the model. The presence of a vegetation will, for example, result in interception on a part of the gridcell. The presence of a house will result in roof storage and a partly impermeable surface, and a road will have sedimentation but no infiltration or erosion.

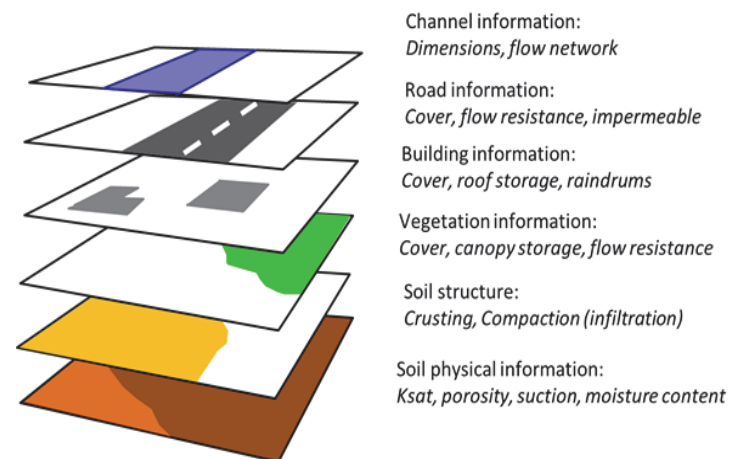

Figure A-1 Input data which is modelled on a sub-gridcell scale.

\section{B.2 Interception}

At the start of any rain-driven event, the majority of the available precipitation is intercepted by surfaces other than the soil (Linsley et al., 1982). Interception of rainfall can be calculated for vegetation, buildings and raindrums. Evaporation, which can take place from these surfaces, is not modelled within LISEM because of two reasons. First, the event-based nature of the model allows for the assumption that slow processes, such as evaporation, can be neglected. Evapotranspiration is furthermore minimal during the rainfall events that are typically modelled in LISEM, since cloud cover is generally high during these events. Interception is thus modelled as a fixed storage that takes from the precipitation before that reaches the soil layer. Rainfall that is not intercepted reaches the soil with the same intensity as the rainfall. While this is not the case in reality, trough fall intensities are only known for few tree types. Actual canopy interception is given by Equation A.1 (Aston, 1979).

$$
I_{c}=S_{\max }\left(1-e^{-k \frac{P_{c u m}}{S_{\max }}}\right)
$$

With

$I_{c}$ the total intercepted storage at a given time $(\mathrm{mm}), S_{\max }$ the maximum canopy storage $(\mathrm{mm}), \quad P_{\text {cum }}$ the total precipitation $(\mathrm{mm})$. And

A. 2

$$
\mathrm{k}=1-\mathrm{e}^{-(\text {co LAI })}
$$

$k$ a parameter related to canopy openness $(-)$, co the canopy openness $(-)$, $L A I$ the leaf area index (-).

For the maximum storage, equations for several tree types, depending on leaf area index, were found by Von Hoyningen-Huene (1981). The equations that are implemented within LISEM are provided in equation A.3.

A. 3

$$
\begin{aligned}
& \mathrm{S}_{\max }=0.935+0.498 \mathrm{LAI}-0.00575 \mathrm{LAI}^{2} \text { (Crops) } \\
& \mathrm{S}_{\max }=0.2331 \text { LA(Pinus) }
\end{aligned}
$$




$$
\begin{aligned}
& \mathrm{S}_{\max }=0.3165 \mathrm{LAI} \text { (Douglas) } \\
& \mathrm{S}_{\max }=1.46 \mathrm{LAI}^{0.56} \text { (Olive) } \\
& \mathrm{S}_{\max }=0.0918 \mathrm{LAI}^{1.04} \text { (Eucalypt) } \\
& \mathrm{S}_{\max }=0.2856 \mathrm{LAI} \text { (Broadleaved Forest) } \\
& \mathrm{S}_{\max }=0.1713 \mathrm{LAI} \text { (Bracken) } \\
& \mathrm{S}_{\max }=0.59 \mathrm{LAI}^{0.88} \text { (Clumped Grass) }
\end{aligned}
$$

Interception by roofs and raindrums is also modelled. The fraction of the rainfall that hits an area covered by these types of surfaces is stored and does not reach the soil surface. When the maximum raindrum or roof storage is reached, any extra rainfall hits the soil surface.

\section{B.3 Micro-Roughness Surface Storage}

Rainfall is first stored in micro depressions in the soil surface. When the water level in these depressions increases, runoff starts. At a micro-scale, runoff is a spatial process of ponds that fill up and overflow into each other. These ponds release little runoff until they fully overflow. Because of this runoff flow does not start immediately after the first rainfall hits the soil within LISEM. To estimate the fraction of water that is stored in these depressions, and the fraction that is used for runoff, the surface roughness is used to estimate the Micro Depression Storage (MDS) (Equation A. 4). The equation for the MDS was determined by Kamphorst et al. (2000) from 221 digital elevation models of various types of micro relief, in a wide variety of agricultural circumstances and soil types. The analysis is based on Digital Elevation Models (DEMs) of with a spatial resolution of roughly $1 \mathrm{~m}^{2}$.

A. 4

With

$$
\mathrm{MDS}=0.243 \mathrm{RR}+0.010 \mathrm{RR}^{2}+0.012 \mathrm{RR} \mathrm{S}
$$

$M D S$ the micro depressional storage $(\mathrm{m}), \mathrm{S}$ the slope $\left(\mathrm{m} \mathrm{m}^{-1}\right)$ $R R$ the standard deviation of the surface heights $(\mathrm{mm})$.

The flow width for runoff is furthermore changed depending on the estimated ponded area. The ponded fraction of a cell is given by equation A. 5 (Jetten and De Roo, 2001).

A. 5

$$
\mathrm{f}_{\mathrm{pa}}=1-\mathrm{e}^{-\mathrm{a}(\mathrm{h})}
$$

With

$f_{p a}$ the fraction of the cell area that is covered by ponds $(-), h$ the average water depth ( And A. $6 \quad \mathrm{a}=1.406 \mathrm{RR}^{-0.924}$

It is assumed that after the water volume in a cell reaches 10 percent of the micro depressions storage, the volume of water that is used for runoff is given by equation A. 6.

$$
\text { A. } 7 \quad \mathrm{~h}_{\text {runoff }}=\max \left(0.0,(\mathrm{~h}-\mathrm{SDS}) *\left(1-\mathrm{e}^{-\mathrm{h} \frac{\mathrm{h}-\mathrm{SDS}}{\mathrm{MDS}-\mathrm{SDS}}}\right)\right)
$$

With $\mathrm{h}_{\text {runoff }}$ the height of the water that is used for runoff $(\mathrm{mm})$, SDS the water height at which runoff starts $(=0.1 M D S)(\mathrm{mm})$.

When the MDS is completely filled, all remaining water is used for runoff. 


\section{B.4 Infiltration}

Infiltration is the process where water is transported downwards from the surface to the subsurface. Depending on the hydraulic conductivity and soil water content, surface water will seep into the soil. Several infiltration models are included in the LISEM model:

- The Green \& Ampt infiltration model

- Smith \& Parlange model

- $\quad$ SWATRE multilayered soil water model

These infiltration models use the empirical Darcy equation which describes a simple vertical soil water balance (Equation A. 8).

A. 8

$$
\frac{\partial \theta}{\partial \mathrm{t}}=-\mathrm{K}_{\mathrm{s}} \frac{\partial \mathrm{h}}{\partial \mathrm{z}}
$$

With $\theta$ the soil moisture content $\left(\mathrm{m}^{3} \mathrm{~m}^{-3}\right), h$ the hydraulic head $(m), z$ the vertical elevation $(m)$ and $K_{s}$ the saturated conductivity $\left(\mathrm{m} \mathrm{s}^{-1}\right)$.

\section{B.5 Green and Ampt}

The Green \& Ampt (1911) infiltration method assumes that a wetting front moves downwards into the soil layers parallel to the soil surface. Above this front, the soil is saturated, while beneath this front, the soil is completely dry. Green \& Ampt stated that, when the water height above the soil surface is assumed to be zero, a simplification of the Darcy equation for vertical water flow can be used (Equation A. 9).

$$
\mathrm{f}=-\mathrm{K}_{\mathrm{s}}\left(\frac{\mathrm{h}_{\mathrm{f}}-\mathrm{h}_{0}}{\mathrm{Z}_{\mathrm{f}}}\right)=\mathrm{K}_{\mathrm{s}}\left(\frac{\psi}{\mathrm{Z}_{\mathrm{f}}}+1\right)
$$

With $f$ the infiltration rate $\left(m s^{-1}\right), h_{f}$ the hydraulic head at the wetting front $(m), h_{0}$ the hydraulic head at the soil surface $(=0)(m), Z_{f}$ the depth of the wetting front $(m)$ and $\psi$ the matric pressure at the wetting front $(h=\psi+Z)(m)$. And

$$
\mathrm{Z}_{\mathrm{f}}=\frac{\mathrm{F}}{\theta_{\mathrm{s}}-\theta_{\mathrm{i}}}
$$

With $F$ the cumulative infiltrated water $(m), \theta_{s}$ the porosity $\left(m^{3} m^{-3}\right), \theta_{i}$ the initial soil moisture content $\left(\mathrm{m}^{3} \mathrm{~m}^{-3}\right)$.

The value of $\psi$ depends on the soil type. Using the Green \& Ampt equations (Equations), and combining these, the final equation for infiltration rate can be acquired (Equation A. 11).

$$
\mathrm{f}=\mathrm{f}_{\text {pot }}=-\mathrm{K}_{\mathrm{s}}\left(\psi \frac{\theta_{\mathrm{s}}-\theta_{\mathrm{i}}}{\mathrm{F}}+1\right)
$$

With $f_{p o t}$ the potential infiltration rate $\left(\mathrm{m} \mathrm{s}^{-1}\right)$.

This method can be applied for both a 1 layer or 2 layer system. Beneath these layers, an open or closed boundary can be chosen.

\section{B.6 Saturated Zone Groundwater flow}

The first connection between the soil water layers is a vertical flow from the wetting front to the unsaturated zone, and from the unsaturated to the saturated zone. For all of these layer interactions, the vertical flow rate is 
calculated by estimating the vertical gradient in the hydraulic height and the saturated conductivity (Equation A. 12).
A. 12
$\mathrm{Q}_{\mathrm{z}}=\theta_{\text {eff }} * \mathrm{k}\left(\theta_{\text {eff }}\right) * \Delta \mathrm{t}$

Simulation of dynamic transport of a substance, the continuity equation is that bases (Equation A.12).

A. 13

$$
\frac{\mathrm{dh}}{\mathrm{dt}}+\frac{\mathrm{dQ}_{\mathrm{x}}}{\mathrm{dx}}+\frac{\mathrm{dQ}_{\mathrm{y}}}{\mathrm{dy}}=0
$$

This equation describes the local time-change in ground water height $\mathrm{h}(\mathrm{m})$ based on the gradient in the lateral unit discharges $\mathrm{Q}\left(\frac{\mathrm{m}^{2}}{\mathrm{~s}}\right)$.

The lateral discharges are taken from darcy's law for flow of a liquid through a permeable matrix. He noted the linear relationship between flow velocity of such a liquid, and the gradient in hydraulic height (equations A.14 and A. 15)
A. 14$$
\mathrm{V}_{\mathrm{gw}, \mathrm{x}}=\mathrm{K}_{\mathrm{x}} \frac{\mathrm{dh}}{\mathrm{dx}}
$$
A. 15

$$
\mathrm{V}_{\mathrm{gw}, \mathrm{y}}=\mathrm{K}_{\mathrm{y}} \frac{\mathrm{dh}}{\mathrm{dy}}
$$

Generally, the hydraulic conductivity values depend on the material and are not dependend on the direcitno of the flow. Within OpenLISEM, for each flux the average between the hydraulic conductivity of the source and destination cell is taken. Due to the slow nature of the ground water processes, momentum is ignored, and velocity is at any moment instantaneously determined by local pressure gradients. Finally, the ground water flow equation becomes equation A. 16.

A. 16

$$
\frac{\mathrm{dh}}{\mathrm{dt}}+\frac{\mathrm{dK}_{\mathrm{x}} \frac{\mathrm{dh}}{\mathrm{dx}}}{\mathrm{dx}}+\frac{\mathrm{dK}_{\mathrm{y}} \frac{\mathrm{dh}}{\mathrm{dy}}}{\mathrm{dy}}=0
$$

Due to heating from solar radiation, and un-saturated air, water changes from liquid to gaseous phase, and is further moved by the atmosphere. Water in both the soil and plants are subject to this phase change. Generally, OpenLISEM is used for event-based simulations. In such cases, evaporation is minimal and can generally be neglected. However, when users simulate periods in-between events, evaporation and transpiration must be included for a complete water balance.

Evaporation can be limited by two factors, either the solar energy coming in through the atmosphere is not enough to evaporate the available water, or there is not enough available water for the solar radiation to evaporate. Modelling the effects of evaporation and transpiration can be done using measurements of Reference or Pan-Evaporation. This is an indication of the maximum water evaporation that occurs during a specific moment, thus, when water is not the limiting factor. To estimate this, a container with an uncovered water surface is placed in a surrounding of well-watered grass. There, the removal of water is measured from the container. The effects of vegetation are much more complicated and difficult to estimate.

To approaches can be taken to estimate evapotranspiration. First, the Penman, or a derivative version of this equation such as the Penman-Moneith equation, can be used. These equations estimate evapotranspiration based on an energy budget. The penman equation provided in equation A. 17 . 
Where $E_{\text {mass }}$ is the evaporation rate per day $(\mathrm{mm} / \mathrm{h}), \mathrm{m}$ is the slope of the saturation vapor pressure curve $(\mathrm{kPa} / \mathrm{K}), R_{n}$ is the net irradiance $(\mathrm{MJ} \mathrm{m}-2$ day$1), \gamma$ is the psychrometric constant $\left(=0.0016286 \frac{P_{k P a}}{\lambda_{v}}\right), V_{\text {wind }}$ is the wind velocity $(\mathrm{m} / \mathrm{s}), \delta e$ is the vapor pressure defecit $(\mathrm{kPa})$ and $\lambda_{v}$ is the latent heat of vaporization (MJ kg-1).

With

A. 18

$$
\mathrm{m}=\frac{\mathrm{de}_{\mathrm{s}}}{\mathrm{dT}_{\mathrm{a}}}=\frac{5336}{\mathrm{~T}_{\mathrm{a}}^{2}} \mathrm{e}^{21.07-\frac{5336}{\mathrm{~T}_{\mathrm{a}}}}
$$

Were $T_{a}$ is the air temperature $(\mathrm{K}), e_{s}$ is the vapor pressure of air, as found inside plant stoma ( $=e^{\left(21.07-\frac{5226}{T_{a}}\right)}$, by Merva, 1975)

However, due to the large number of required parameters, this method is difficult to implement in regional modelling. Instead, equations such as these are used to estimate reference evaporation at a weather station. A more practical method uses a given reference evapotranspiration and estimates actual evapotranspiration based on the crop factor and soil saturation (Equation A. 19).

$$
\mathrm{ET}_{\mathrm{ac}}=\mathrm{ET}_{\mathrm{o}} * \mathrm{~K}_{\mathrm{c}} * \sum_{\mathrm{s} \geq \mathrm{z}} \frac{\theta_{\mathrm{i}}}{\theta_{\mathrm{s}, \mathrm{i}}}
$$

Were $E T_{a c}$ is the actual evapotranspiration (mm/hour), $E T_{o}$ is the reference evapotranspiration ( $\mathrm{mm} /$ hour), $K_{c}$ is the crop factor $(-), i$ is the layer number of the soil description, $z$ is the number of the layer of interest, $\theta_{i}$ the water content of layer $\mathrm{i}(-), \theta_{s, i}$ is the saturated water content of layer $\mathrm{i}$.

The implementation is based on the work of van Beek (2002). The idea here is that with any deeper layer, the amount of evapotranspiration is limited by all saturation levels of upper layers. Thus, the deeper, the less the amount of evaporation effectively takes place. Furthermore, it limits evapotranspiration so that any higher layer will be depleted first, which is replicant of the natural process. Finally, the crop factor can change based on crop type, growth stage and agricultural practice. A large amount of crop factor estimates are available from the SWAT model database.

\section{B.7 Erosion}

For total sediment load in overland flow and simple channel flow within LISEM, the transport capacity equation by Govers (1990) is used (Equation 44). This equation was empirically derived from measurements, and is dependent on stream power. Hessel \& Jetten (2007) applied 8 different transport capacity equations to a small catchment in the Chinese Loess plateau. This extensive test showed that the transport capacity of Govers (1990) performed best due to its small sensitivity to slope and grain size (equation A.20).
A. 20
$\mathrm{T}=\rho_{\mathrm{s}} \mathrm{c}\left(\omega-\omega_{\mathrm{cr}}\right)^{\mathrm{d}}$

With $\omega$ the stream power $\left(m s^{-1}\right), \omega_{c r}$ the critical stream power $\left(\mathrm{ms}^{-1}\right)$ and $\rho_{s}$ is the density of the sediment material $\left(\mathrm{kg} \mathrm{m}^{-3}\right)$

And 


$$
\begin{aligned}
& \mathrm{c}={\frac{\left(\mathrm{D}_{50}+5\right)^{-0.6}}{0.32}}^{-0.25} \\
& \mathrm{~d}={\frac{\left(\mathrm{D}_{50}+5\right)^{0.25}}{300}}^{0.32)}
\end{aligned}
$$

With $D_{50}$ the median grain diameter $(m)$.

Detachment and deposition are based on the settlingvelocity for the median grain diameter. The deposition rate is proportional to this settling velocity (Equation A. 23).

$$
\text { A. } 23 \quad \operatorname{dep}=\mathrm{w}_{\mathrm{s}} \text { B C }
$$

With B the flow width $(\mathrm{m})$ and dep the deposition rate $\left(\mathrm{kg} \mathrm{m}^{-2} \mathrm{~s}^{-1}\right)$.

The transport capacity represents the concentration for which the sediment deposition and detachment are equal, and the concentration is thus stable. We can use this to adapt the equation for deposition (Equation A. 24).
A. 24
$\operatorname{dep}=\mathrm{w}_{\mathrm{S}} \mathrm{B} \min (0.0,(\mathrm{~T}-\mathrm{C}))$

It can be assumed that detachment follows the same form (Rauws \& and Govers, 1988), with the addition of an erosion efficiency factor when detachment takes place (Equation A. 25).
A. 25$$
\operatorname{det}=\gamma \mathrm{w}_{\mathrm{s}} \mathrm{B} \max (0.0,(\mathrm{~T}-\mathrm{C}))
$$

With det the detachment rate $\left(\mathrm{kg} \mathrm{m}^{-2} \mathrm{~s}^{-1}\right)$ and $\gamma$ the erosion efficiency coefficient $(-)$.

The erosion efficiency coefficient is based on soil cohesion and root strength, which provides extra soil cohesion, and is calculated based on equations by Rauws \& Govers (1988) (Equation A. 26).

A. 26

$$
\gamma=\min \left(1.0, \frac{1}{0.89+0.56\left(\mathrm{co}+\mathrm{co}_{\mathrm{veg}}\right)}\right)
$$

With co the soil cohesion $(\mathrm{kPa})$ and $\mathrm{co}_{\text {veg }}$ the extra soil cohesion due to vegetation $(k P a)$.

The equations by Govers where originally meant to describe rill erosion. As such, all erosion within lisem either is part of splash detachment or flow detachment in the form of rills. For the simulation of intense rainfall events, which is usually the case, sheet erosion has an insignificant magnitude when compared to rill erosion (Herweg, 1996).

\section{B.8 Settling Velocity}

In a flear fluid at rest, the fall velocity of a single sediment particl with a size up to $100 \mu \mathrm{m}$, can be calculated by a balance of drag forces and the gravitational force. The force of viscosity and the gravitational force for a spherical particle with uniform density are given in equation A. 27 and A. 28.

$$
\mathrm{F}_{\mathrm{d}}=6 \pi v \mathrm{w}_{\mathrm{s}} \frac{\mathrm{D}}{2}
$$

With $\mathrm{F}_{\mathrm{d}}$ the stokes drag force $\left(\mathrm{kg} \mathrm{m} \mathrm{s}^{-2}\right), D$ the particle diameter $(\mathrm{m})$ and $w$ the velocity $\left(\mathrm{m} \mathrm{s}^{-1}\right)$.
A. 28

$$
F_{g}=\frac{\left(\rho_{s}-\rho_{w}\right) g 4}{3} \pi\left(\frac{D}{2}\right)^{2}
$$


With $\mathrm{F}_{\mathrm{g}}$ the gravitational force $\left(\mathrm{kg} \mathrm{m} \mathrm{s}^{-2}\right), \rho_{s}$ the density of sediment $\left(\mathrm{kg} \mathrm{m}^{-3}\right)$ and $\rho_{w}$ the density of water $\left(\mathrm{kg} \mathrm{m}^{-3}\right)$.

The terminal velocity is than equal to equation A. 29.

$$
\mathrm{w}_{\mathrm{s}}=\frac{2}{18} \frac{\left(\rho_{\mathrm{s}}-\rho_{\mathrm{w}}\right)}{v} \mathrm{~g}\left(\frac{\mathrm{D}}{2}\right)^{2}
$$

\section{With}

$w_{s}$ the settling velocity (terminal velocity of the particle) $\left(\mathrm{m} \mathrm{s}^{-1}\right)$

When particles reach larger grain diameters, the assumptions that are needed for the stokes range terminal velocity do no longer hold since the drag force behaves differently at those scales. For these particles, an equation by Zanke (1977) can be used (Equation A. 30).

$$
\mathrm{w}_{\mathrm{s}}=10 \frac{v^{2}}{\mathrm{D}}\left(\sqrt{1+\frac{0.01\left(\frac{\left(\rho_{\mathrm{s}}-\rho_{\mathrm{w}}\right)}{\rho_{\mathrm{w}}} \mathrm{gD}^{3}\right)}{v}}-1\right)
$$

\section{B.9 Sediment Transport}

Transport of sediment takes place when water with a sediment concentration is transported. To model sediment flow in the 1 dimensional kinematic wave, a simple flow advection scheme is used (Equation A. 31).

A. 31

$$
\frac{\mathrm{d} S}{\mathrm{dt}}+\frac{\mathrm{d}(\mathrm{Q} \mathrm{C})}{\mathrm{dx}}=\mathrm{dep}-\mathrm{det}
$$

With $\mathrm{S}$ the sediment load $(\mathrm{kg}), \mathrm{C}$ the sediment concentration $\left(\mathrm{kg} \mathrm{m}^{-3}\right)$, dep the deposition $\left(\mathrm{kg} \mathrm{s}^{-1}, \quad \operatorname{det}\right.$ the detachment $\left(\mathrm{kg} \mathrm{s}^{-1}\right)$.

In order to implement sediment transport in the 2 dimensional kinematic wave and the saint-venaint equations for flooding, the sediment transport was similarly rewritten to 2 dimensions (Equation A. 32).

A. 32

$$
\frac{d S}{d t}+\frac{d\left(Q_{x} C\right)}{d x}+\frac{d\left(Q_{y} C\right)}{d y}=\operatorname{dep}-\operatorname{det}
$$




\section{C.1 Stress Remapping}

If, either due to degradation of strength parameters, or building numerical errors, the state of the stress tensor lies beyond the yield surface, a correction must be applied. We implement the correction scheme used by Bui et al. (2008). This scheme considers two primary ways in which the stress can have an undesired state: Tension cracking, and imperfectly plastic stress.

\section{C.2 Tension Cracking}

In the case of tension cracking, the stress state has moved beyond the apex of the yield surface, as described by Chen \& Mizuno (1990). The employed solution in this case is to re-map the stress tensor along the $I_{1}$ axis to be at this apex. The apex is provided by the yield function (Equation 0.1)

0.1

$$
-\alpha_{\phi} \mathrm{I}_{1}+\mathrm{k}_{\mathrm{c}}<0
$$

To solve for this condition, the non-deviatoric stress state is increased (since $I_{1}-\frac{k_{c}}{\alpha_{\phi}}$ is negative) to lie perpendicular to the apex point on the $I_{1}$ axis (Equation $0.2)$

0.2

$$
\widetilde{\sigma \gamma}=r s \gamma \gamma-\frac{1}{3}\left(I_{1}-\frac{k_{c}}{\alpha_{\phi}}\right)
$$

\section{C.3 Imperfect Plastic Stress}

Imperfect plastic stress described the state where the stress tensor lies above the apex, but beyond the yield criterion, thus have more stress than supported by the failure criteria that is set. This criteria is simply the yield surface itself (Equation 0.3).

0.3

$$
-\alpha_{\phi} \mathrm{I}_{1}+\mathrm{k}_{\mathrm{c}}<\sqrt{\mathrm{J}_{2}}
$$

For this state, re-mapping is done by scaling of the $J_{2}$ value (Equations $0.4,0.5$ and 0.6 ).

$$
\mathrm{r}=\frac{-\alpha_{\phi} \mathrm{I}_{1}+\mathrm{k}_{\mathrm{c}}}{\sqrt{\mathrm{J}_{2}}}
$$

$$
\widetilde{\sigma^{\gamma} \gamma}=r s^{\gamma \gamma}+\frac{1}{3} I_{1}
$$

0.6

$$
\widetilde{\sigma^{x y}}=r s^{x y}, \widetilde{\sigma^{x y}}=\mathrm{rs}^{\mathrm{xz}}, \widetilde{\sigma^{x y}}=r s^{y z}
$$

\section{C.4 Software Implementation}

The model presented in this article is part of the continued development of the OpenLISEM modelling tools. The most recent set of equations of implemented in the open-source alpha version of OpenLISEM Hazard 2. Here, we describe the details of the implementation of the model into software. 


\section{C.5 Hybrid MPM}

We utilize the MPM framework to be able to discretize part of the equations on a Eulerian regural grid, and part of the equations on the Lagrangian particles. Our distinct take on this method is the representation of the fluid phase completely as a finite element solution, while solids are simulated as discrete particle volumes. This allows the model to use the major benefits that are present when depth-averaged fluid flow is simulated in a grid. Both numerical efficiency, and high-accuracy coupling with hydrology are lacking in particle methods. For the solid phase, non-dissapative advection, fracturing and stiffness is a major benefit of the MPM approach. Since our model assumed confined fluids share their velocity with the solids, we advect the confined fluids as part of the particles. Total fluid volume is then calculated from the free fluids in the finite element data, and the gridded particle data. A flowchart of the software setup is provided in Figure 0-1.

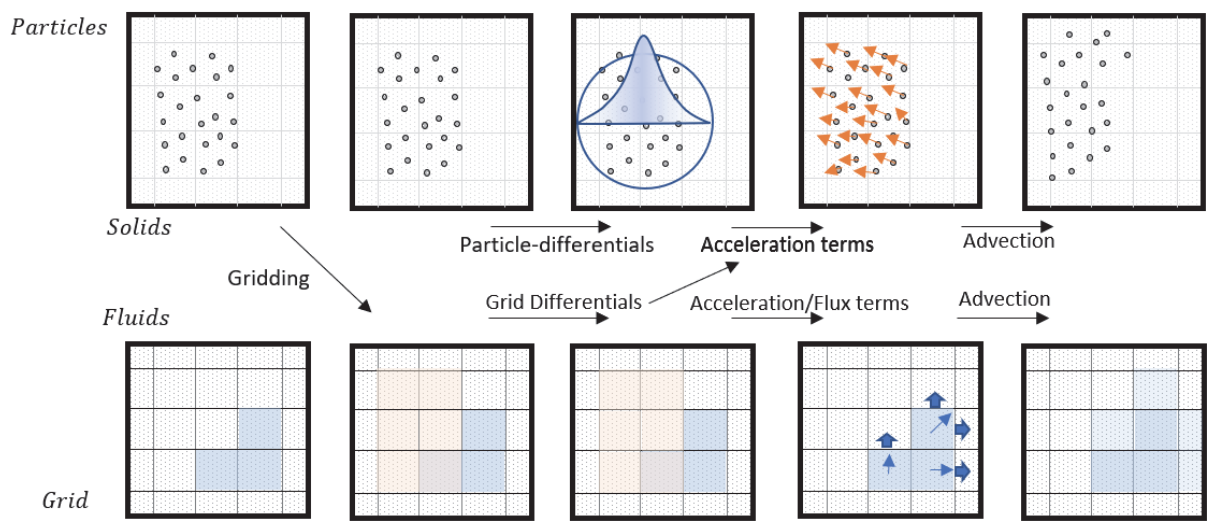

Figure $0-1$ The sub-steps taken by the software to complete a single step of numerical integration.

\section{C.6 Finite Element Solution}

We use a regular cartesian grid to describe the modelling domain. Terrain and cell-boundary based variables are re-produces using the MUSCL piecewise linear reconstruction (Delestre et al., 2014). For each cell-boundary, a left and right estimation of acceleration terms, velocity updates and new discharges is made. The left estimates use left-reconstructed variables while the other uses right-reconstructed variables. The final average flux through the boundary determines actual mass and momentum transfer. Local acceleration is averaged from the right estimate of the left boundary and left estimate of the right boundary. An additional benefit of the used scheme is the automatic estimation of continuous and discontinuous terrain. The piecewise linear reconstructions do not guarantee smooth terrain, for sharp locally variable terrain, pressure terms from vertical walls arise that block momentum. These terms allow for better estimation of momentum loss by barriers, but can be turned off if required for the simulated scenario. 


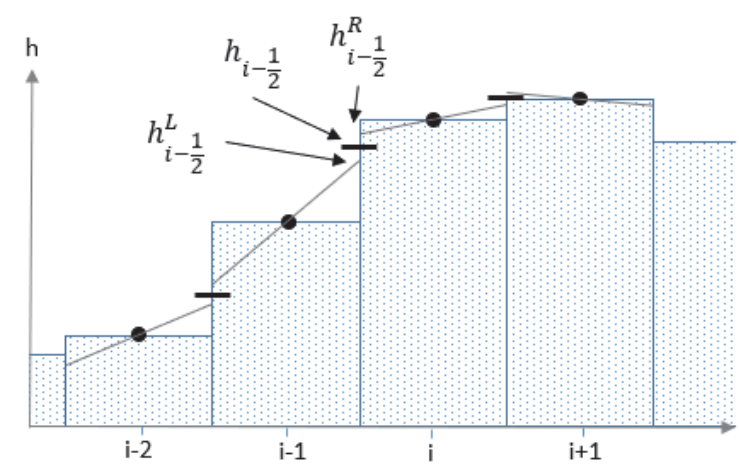

Figure 0-2 Piecewise linear reconstruction is used by the MUSCL scheme to estimate values of flow heights, velocities and terrain at cell-boundaries.

\section{C.7 GPU Acceleration Using OpenCL/OpenGL}

In order to create a more efficient setup, both the finite element and particle interactions are performed on the GPU. We utilize the OpenCL API to compile kernels written in c-style language. These kernels are compiled at the start of the simulation, and thereby allow for easy customization by users. While the usage of OpenCL 1.1 forces the usage of single precision floating point numbers, it allows for a wider range of GPU types to be supported. Finite element solutions on the GPU are straightforward, as maps are a basic data storage type for graphical processing units. Particles are stored as singleprecision floating point arrays. Within the framework of MPM, iteration of particles within a kernel is required for each timestep and particle. This effectively means $O\left(n^{2}\right)$ operations are required. Significant efficiency improvements are obtained by pre-calculation sorting. Particles are sorted based on their location within the finite element grid. Based on the id of the gridcell, a bitonic mergesort is performed. This sorting algorithm works seamlessly on parallel architecture and operates as $O\left(n \log ^{2}(n)\right)$ (Batcher, $1968)$. The then, a raster is allocated to store the first indexed occurrence within the sorted list of particles of that gridcell. Since the kernel used for the presented work extends at most to a full width of two gridcells, we must iterate over all particles present in 9 neighboring grid cells. 


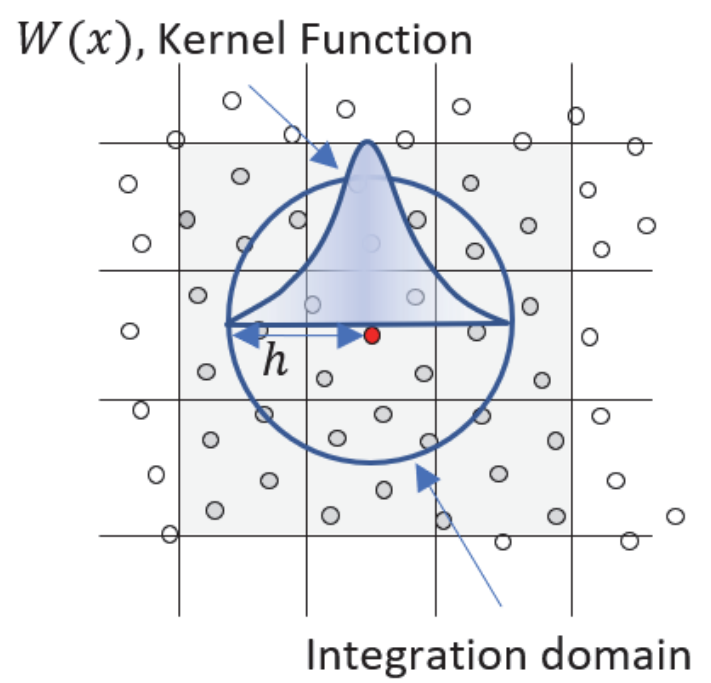

Figure 0-3 By limiting the kernel with and sorting particles before calculation, only the distance of particles in neighboring cells need to be checked, significantly reducing computational load, particularly for larger datasets.

A final benefit to the usage of OpenCL is direct access to simulation variables for visualization in OpenGL using the OpenGL/OpenCL interoperability functionality. The built-in viewing window of OpenLISEM Hazard 2.0 alpha directly uses the data to draw both particles, shapefiles and grid data using customizable shaders written in the openGL shader language. 


\section{Appendix D List of Symbols}

$\overrightarrow{F_{l a t}}$ is the vector of laterally acting forces

$|\vec{u}|_{c r}$ is the critical velocity for deposition

$|\boldsymbol{S}|$ is the norm of the shear force

$\mathcal{B}$ is the pressure propagation factor for structured solids

$B$ the flow width

$\mathrm{B}_{\mathrm{c}}$ is the flow width of the channel

$\mathrm{C}$ the sediment concentration

$c_{r}$ is a coefficient

$c_{r}$ is a coefficient for flood-channel water exchange, typically taken as 2

$\mathrm{D}$ is the deposition rate

$\mathrm{D}_{50}$ is the median grain diameter

$\mathrm{d}$ is the median grain diameter

$D$ the force demand

dep the deposition mass rate

det the detachment mass rate

$E$ Is the rate of change of the topographic surface (erosion rate)

$\mathcal{F}$ is the drag contribution from solid-like drag

$F_{d}$ the stokes drag force

$\mathrm{f}_{\mathrm{rf}}$ is the fraction of runoff entering the flood equations

$h$ is the flow height

$h$ is the kernel width (not to be confused with the flow height)

$\mathrm{h}_{\mathrm{s}}$ is the depth of the failure plane

$h_{f}$ the flood depth

$h_{r}$ is the overland flow depth

I is the infiltration

$\mathrm{m}$ is the fraction of the soil depth that is saturated from the basal boundary

$\mathrm{m}$ is the slope of the saturation vapor pressure curve $(\mathrm{kPa} / \mathrm{K})$

$\mathrm{R}$ is the rainfall

$\mathrm{S}$ is the bed slope term

$\mathrm{S}$ the sediment load

$\mathrm{S}_{\mathrm{f}}$ is the bed friction term

$\mathrm{S}_{\mathrm{f}}$ is the surface friction term

SDS the water height at which runoff starts $(=0.1 M D S)$

$\mathrm{z}_{0}$ is the lowest neighboring elevation

$\alpha$ is the first viscosity parameter

$\beta$ the second viscosity parameter

$\gamma$ is the density of the slope material

$\gamma_{\mathrm{w}}$ is the density of water

$\Pi_{i j}$ is an artificial viscosity term

$\tau$ is the shear stress

$\tau_{c}$ is the critical shear stress

$\mathrm{X}$ is the shape factor for the vertical fluid velocity profile

$A$ is the amount of value for a specific element-at-risk.

$A$ is the area of the soil occupied by roots

$C$ the force capacity

$C_{s}$ is the coefficient of suspension

$D$ the particle diameter

$D_{50}$ the median grain diameter 
$E$ is the elastic Young's Modulus

$E_{\text {mass }}$ is the evaporation rate per day,

$E T_{a c}$ is the actual evapotranspiration ( $\mathrm{mm} / \mathrm{hour}$ )

$E T_{o}$ is the reference evapotranspiration (mm/hour)

$F$ is the cumulative infiltrated water

$F$ the cumulative infiltrated water

$F_{i j}^{n} R_{i j}^{\alpha \beta}$ is an artificial stress term

FOS is the Factor of Safety (-)

$G$ is the shear modulus

$H$ is the typical height of the flow

$I(T)$ is the intensity of the event with return period $\mathrm{T}$

$I_{1}$ is the first stress invariant

$I_{c}$ the total intercepted storage at a given time

$I_{\alpha}, I_{\beta}, .$. are the hazard intensity parameters for multi-hazard vulnerability

calculations.

$J_{2}$ is the second stress invariant

$K$ is the Bulk elastic modulus

$K$ is the entrainment coefficient

$K_{a}$ is the active lateral earth pressure coefficient

$K_{c}$ is the crop factor

$K_{p}$ is the passive lateral earth pressure coefficient

$K_{S}$ is the saturated conductivity

$L$ is the typical length of the flow

$L A I$ the leaf area index

$M\left(R e_{p}\right)$ is an empirical function weakly dependent on the Reynolds number

$M D S$ the micro depressional storage

$N$ is the normal force on a plane element

$N(\boldsymbol{x})$ is the Grid-kernel function

$N_{R}$ is the Reynolds Number

$N_{R A}$ is the interfacial Reynolds Number

$P(x, T)$ is the probability of the event with return period $\mathrm{T}$ at location $\mathrm{x}$

$P_{b_{s, u}}$ is the basal pressure from

$P_{b_{c}}$ is the basal pressure from the solids, structured solids and confined fluids

$P_{b_{u}}$ is the basal pressure from the free fluids

$P_{\text {cum }}$ the total precipitation

$P_{f}$ is the fluid pressure

$R_{n}$ is the net irradiance

$R R$ the standard deviation of the surface heights

$R e_{p}$ is the particle Reynolds Number

$\vec{S}$ is the normalized slope vector

$S_{\text {max }}$ e maximum canopy storage

$S_{p}$ is the smoothing function

$T$ is the return period of the event

$T_{a}$ is the air temperature

$T_{i}$ is the root tensile strength

$U_{T, c}$ is the settling velocity of the solids, structured solids and confined fluids

$U_{T, u c}$ is the settling velocity of the unstructured solids 
$V(I(T))$ is the vulnerability of a specific element-at-risk to the impact of an event with a certain return period and intensity

$V_{\text {wind }}$ is the wind velocity

$W$ is the kernel weight function

$a_{i}$ is the cross-sectional area of the root

$c^{\prime}$ is the apparent cohesion of the soil

$c^{b}$ is the cohesion of the bed material

$c_{0}$ is the initial cohesion

$c_{p}$ is the plastic coefficient

$c_{\text {root }}$ is the added apparent root cohesive strength

co the canopy openness

$d_{50}$ is the median grain size

$\dot{e}$ is the deviatoric strain rate

$e_{S}$ is the vapor pressure of air, as found inside plant stoma $\left(=e^{\left(21.07-\frac{5226}{T_{a}}\right)}\right.$, by Merva, 1975)

$f$ is the fluid phase

$f\left(I_{1}, J_{2}\right)$ is the yield surface, or yield criterion

$f_{f c}$ is the fraction of fluids that is confined

$f_{p a}$ the fraction of the cell area that is covered by ponds

$f_{\text {pot }}$ is the potential infiltration rate

$f_{s c}$ is the fraction of solids that is structured (confining)

$f c$ is the confined fluid phase

$g$ is the gravitational acceleration

$g$ is the plastic potential function

$g\left(I_{1}, J_{2}\right)$ is the plastic potential function

$i$ is the layer number of the soil description

$i$ is the root diameter class

$k$ a parameter related to canopy openness

$k_{c}$ is the second Ducker-Prager material constant

$m$ is an exponent for $\mathcal{P}$

$n$ is Mannings surface roughness coefficient

$n_{i}$ number of roots within the diameter class

$n_{t d}$ is the turbulent dispersive coefficient

$p$ is the calibration factor for the critical velocity for deposition

$q$ is the normalized particle distance

$r$ is the distance

$s$ is the solid phase

$\dot{s}$ is the deviatoric shear stress rate tensor

$s c$ is the structured solid phase

$u_{b}$ is the basal velocity

$u_{\text {sound }}$ is the speed of sound in the material

$w_{s}$ the settling velocity (terminal velocity of the particle)

$z$ is the elevation above the failure surface

$z$ is the number of the layer of interest

$\boldsymbol{M}_{D G}$ is the drag force

$\boldsymbol{M}_{v m}$ is the virtual mass force

$\boldsymbol{T}_{c}$ is the stress tensor for eh solids, confining solids and confined fluids

$\boldsymbol{T}_{u}$ is the stress tensor for the free fluid phase

$f$ is the body force 
$\boldsymbol{u}_{\boldsymbol{c}}$ is the velocity of the solids, confining solids and confined fluids

$\boldsymbol{u}_{\boldsymbol{s}}$ is the velocity of the solids

$\boldsymbol{u}_{\boldsymbol{u}}$ is the velocity of the unconfined phase (free fluids)

$\mathcal{A}$ is the mobility of the fluid at the interface

$\mathcal{C}_{D G}$ is the drag coefficient

$\mathcal{C}_{V M G}$ is the virtual mass coefficient

$\mathcal{G}$ is the drag contribution from fluid-like drag

$\mathcal{K}$ is the absolute total mass flux

$\mathcal{P}$ the partitioning parameter for the fluid and solid like contributions to drag

$\alpha$ is the peak horizontal earthquake acceleration

$\alpha^{b}$ is the volumetric solid concentration of the bed material

$\alpha_{\Pi}$ and $\beta_{\Pi}$ are constants in the artificial viscous force

$\alpha_{c}$ is the volumetric fraction of solids, structured solids and confined fluids

$\alpha_{e q}$ is the equilibrium volumetric solid concentration

$\alpha_{f}$ is the volumetric fluid phase fraction

$\alpha_{s}$ is the volumetric solid phase fraction

$\alpha_{u}$ is the volumetric fraction of free fluids (unconfined phase).

$\alpha_{\phi}$ is the first Ducker-Prager material constant

$\beta$ is the slope angle

$\beta$ is the slope of the soil section (-)

$\gamma$ the erosion efficiency coefficient

$\gamma$ is the psychrometric constant $\left(=0.0016286 \frac{P_{k P a}}{\lambda_{v}}\right)$

$\delta$ is the Kronecker delta

$\delta e$ is the vapor pressure defecit

$\zeta$ is a shape factor for the vertical gradient in solid concentration

$\eta_{f}$ is the fluids dynamic viscosity

$\theta$ is the angle of shear distortion in the shear zone

$\theta_{s, i}$ is the saturated water content of layer $\mathrm{i}$

$\theta_{i}$ is the initial soil moisture content

$\theta_{i}$ the water content of layer $\mathrm{i}$

$\theta_{s}$ is the porosity

$\lambda$ is the plastic multiplier rate

$\lambda_{v}$ is the latent heat of vaporization

$v$ is Poisson's ratio

$\rho_{e f f}$ is the total effective density of the flow

$\rho_{f}$ is the density of fluids

$\rho_{s}$ is the density of solids

$\rho_{s c}$ is the volume-averaged density of the solids and confined fluids

$\tau_{y}$ is the yield stress

$\psi$ is the dilatancy angle

$\psi$ is the matric pressure at the wetting front $(h=\psi+Z)$

$\omega$ the stream power

$\dot{\omega}$ is the spin rate tensor

$\omega_{c r}$ the critical stream power

$\dot{\epsilon}_{\text {plastic }}$ is the plastic strain rate

$\dot{\epsilon}_{\text {total }}$ is the total strain rate

$\epsilon_{0}$ is a constant parameter for the artificial stress term

$\epsilon_{v}$ is the volumetric strain

$\epsilon_{v 0}$ is the initial volumetric strain 
$\phi$ is the internal friction angle of the soil

$\boldsymbol{\sigma}$ is the stress tensor

$\boldsymbol{\tau}_{f}$ is the fluid Gauchy stress tensor 


\section{Summary}

Hazardous events occur in many varieties throughout the world. Hydrometeorological hazards such as floods, landslides and debris flows are frequently induced by a common trigger such as extreme precipitation, for example during tropical storms. When these processes occur simultaneously, interactions can arise that alter the dynamics of the event. An example of such interactions is landslide dam formation in rivers, where deposition of mass movement material forms a natural dam that blocks a river. Another example is increased mobilization of solids by merging of debris flows and floods. Physically-based modelling of hazardous processes is a common and valuable tool in hazard and risk assessment. It can provide understanding of the processes, reconstruct past events and predict future events. The output of such models are hazard intensities and probabilities. These allow for estimating the expected losses and form the basis for decision making to reduce disaster risk. Single-hazard models, such as models for flooding, mass movements or storm surges are widely used for this purpose. These tools focus on isolated hazards and mostly ignore the interactions with other processes. For events with multi-hazard interactions, integrated multi-hazard models are required. In this doctoral dissertation, an integrated physically-based multi-hazard modelling tool was developed for use in hazard assessment. This was done using an existing open-source hydrology, runoff and erosion modelling tool. Further development was carried out to incorporate a variety of hazardous processes such as (flash) floods, slope stability, mass movement formation and entrainment of bed material.

The first component of the development of the multi-hazard modelling tool is a comparative implementation of three distinct flow models for catchmentintegrated flood simulation. Kinematic, diffusive and dynamic wave flows are calibrated on a series of events in three study areas: in China, Spain and Italy. Results showed that their integration in catchment-scale hydrology allowed for new types of interactions between these processes. This proved valuable in reconstruction of a flood event in the Fella watershed in Italy. In the second phase of the research a novel method was developed for efficient, regional simulation of slope stability and failure volumes. The iterative failure method was developed which is able to link one-to-one with hydrology and flow aspects of the simulation. This allows for a variety of interactions and feedbacks between upslope hydrology, runoff patterns and slope stability.

The third and fourth phase investigated the implementation of generalized adaptive mass movement equations and entrainment by such flows. An existing set of generalized equations was adapted to cover shallow water flows. The equations describe flow in a two-phase manner, with distinct velocities and interfacial forces such as drag, virtual mass and viscous forces. The final set of equations automatically and continuously scales internal forces based on the consistency and properties of the flow materials. Using this approach, flow types are automatically estimated and can evolve during interactions. The model was calibrated and validated on the 2009 convective storm event in Southern Sicily, where hundreds of landslides and severe flash flooding interacted in the Scaletta area. The same model was tested in the Chinese study area, where simulations were carried out to replicate the 2008-2010 Honchun co-seismic landslide process chain. Both events highlight the 
additional insight that can be gained from integrated multi-hazard modeling, but stress the need to deal with uncertainties and parameterization complexities.

The fifth phase of this work extended the set of generalized mass movement equations to include semi-structured material dynamics. By implementing a full stress-strain relationship combined with two-phase non-Newtonian generalized debris flow equations, an extensive new model was developed. In order to better support the complexities involved in solving the equations, a new depth-averaged variation on the material point method was implemented. Fluids were solved in a discrete Eulerian grid, while solids were solved using the smooth particle mathematical framework. The two phases interact using the gridding techniques used in the material point method. Comparison to flume experiments showed high likeness of fracture patterns and final deposits for cohesive blocks of organic-rich clay.

Finally the applicability of physically-based multi-hazard modelling tools to hazard assessment was investigated by replicating a multi-hazard event: the impact of hurricane Maria on the Carribean island Dominica. Integrated multihazard modelling provided several clear benefits to both process understanding and hazard accuracy. Additionally, traditional assumptions considering probabilities of events and their relationship with trigger intensity can be broken due to the non-linear complexity of multi-hazard interactions. Several key challenges remain related to model parameterization and uncertainties. Because of this, application in hazard and risk assessment requires carefull interpretation. By either using ensemble analysis or smart scenario design, a proper framework must be made that can act as a foundation for application of integrated physically-based multi-hazard modelling. The techniques presented in this work have the potential to provide a significant leap in the predictive capabilities and accuracy of multi-hazard risk assessment. 


\section{Samenvatting}

Potentieel gevaarlijke natuurlijke processen komen in veel variaties voor over de hele wereld. Hydrometeorologische rampen zoals overstromingen, aardverschuivingen en modderstromen worden vaak tegelijkertijd veroorzaakt door extreme regenval, bijvoorbeeld tijdens tropische stormen in bergachtige gebieden. Wanneer zulke processen gezamenlijk plaatsvinden, komen interacties voor die de dynamiek van de verschillende processen kunnen veranderen. Voorbeelden van zulke interacties zijn het vormen van natuurlijke dammen na aardverschuivingen, waar depositie van materiaal de rivierstroming verhindert, of het ontstaan van modderstromen door het samengaan van aardverschuivingen met waterstromen op een helling.

Om interacties zoals deze beter te kunnen begrijpen en voorspellen is fysischgebaseerd modelleren van rampen een algemeen gebruikt en waardevol hulpmiddel in gevaren-en risico analyse voor natuurrampen. Gebaseerd op gemodelleerde intensiteiten van rampen kunnen geïnformeerde beslissingen rondom risico reductie worden gemaakt. Voor enkelvoudige rampen, zoals overstromingen, aardverschuivingen en stormvloeden worden modellen breed toegepast. Deze modellen focussen zich op één enkel proces en laten meestal interacties buiten beschouwing. Voor meervoudige rampen waarbij interacties optreden, is een geïntegreerd meervoudig proces-model nodig. In deze dissertatie wordt een geïntegreerd fysisch-gebaseerd meervoudig procesmodel ontwikkeld voor gebruik in gevaren- en risicoanalyse. Voor deze ontwikkeling werd een bestaand, open-source model voor hydrologie, waterafvoer en erosie verder uitgebreid met processen zoals overstromingen, hellingsinstabiliteit, en het hellingafwaartse transport, erosie en depositie van massabewegingen.

In de eerste fase van de ontwikkelling van het model werd een vergelijkend onderzoek gedaan naar ruimtelijke integratie van overstromingsvergelijkingen in een hydrologisch model op waterscheidings-schaal. Zowel kinetisch, diffusief en dynamische stromings-benaderingen worden gekalibreerd en gevalideerd in drie studiegebieden: in China, Spanje en Italië. Resultaten laten zien dat de ruimtelijke integratie van een overstromingsmodel nieuwe interacties mogelijk maakt tussen processen die waardevol zijn voor de reconstructie van overstroming in het studie gebied in Italië. De tweede fase van het onderzoek betreft de ontwikkeling van een innovatieve methode om op regionale schaal efficiënte voorspellingen te doen van hellinginstabiliteit en het volume van massabewegingen. De iteratieve methode kan direct worden gelinkt met hydrologie en andere processen binnen een simulatie. Dit maakt verschillende interacties mogelijk tussen hydrologie, patronen in waterafvoer en hellinginstabiliteit.

De derde en vierde fasen van het onderzoek zijn gerelateerd aan de implementatie van generieke adaptieve vergelijkingen voor massabewegingen en het eroderen van bodemmateriaal. Een bestaande set vergelijkingen werd uitgebreid om ook geldig te zijn voor oppervlakkige waterstroming en werd geïntegreerd in het model. De vergelijkingen beschrijven de stroming en interacties van twee materialen met verschillende snelheden. Op het raakvlak van de twee materialen worden interacties geschat, zoals wrijving, viskeuzeen voortslepingskrachten. De uiteindelijke set vergelijkingen passen zich continu en automatisch aan door interne krachten te schalen gebaseerd op de 
consistentie en materiaaleigenschappen in de stroming. Hierdoor kunnen verschillende typen massabeweging automatisch worden gemodelleerd. Het model is gekalibreerd en gevalideerd in Zuid-Sicilië, voor de nasleep van een convectieve storm in 2009, waar honderden aardverschuivingen zich mengden met overstromingen. $\mathrm{Er}$ is ook een reconstructie gemaakt van de door de Wenchuan aardbeving veroorzaakte aardverschuivingen, en de daarop volgende modderstromen en rivierblokkeringen. Deze vonden van 2008 tot 2010 plaats in het Hongchun stroomgebied nabij het epicentrum in de provincie Sinchuan. De simulaties van deze gebeurtenissen tonen aan hoe de toepassing van het ontwikkelde model leidt tot nieuwe inzichten. Er komen daarentegen wel complicaties naar voren gerelateerd aan de invoerdata voor het model, en onzekerheden in de uitkomsten.

De vijfde fase van het onderzoek betreft de ontwikkeling van een nieuwe generieke set vergelijkingen voor gedeeltelijk gestructureerde massabewegingen. Door een volledige fysisch-gebaseerde beschrijving van interne stress en deformatie toe te voegen aan twee-fase niet-Newtoniaanse generieke massabeweging vergelijkingen, werd een omvangrijk nieuw model ontwikkeld. Om een betere numerieke oplossing te bieden voor de complexiteiten van de vergelijkingen werd een nieuwe variant op de Material Point Methode (MPM) gebruikt. Deze methode lost de fases van vloeistof en vaste materialen afzonderlijk op als hoogtegemiddeld grid en Smooth Particle (SP) respectievelijk. Interacties tussen de vloeibare en vaste materialen gaan via de grid methodes van de Material Point Methode. Laboratorium experimenten laten een goede vergelijking zien met modelresultaten wat betreft scheurvorming in materiaal, en de totale dynamiek.

Uiteindelijk wordt het potentieel voor toepassing van geïntegreerde fysischgebaseerde meervoudige procesmodellen onderzocht door toepassing op de reconstructie van gebeurtenissen, scenario's, en ensemble simulaties voor orkaan Maria op Dominica in 2017. Dit laat zien dat, hoewel geïntegreerde meervoudige procesmodellen duidelijke voordelen bieden in het begrip en de nauwkeurigheid van rampvoorspellingen, onzekerheden en moeilijkheden in dataomschrijving een hinder blijven in volledige toepassing voor gevaren- en risicoanalyse. Door ofwel ensemble analyse te gebruiken of nieuwe methoden te ontwikkelen voor het ontwerpen van scenario's moet een degelijk raamwerk worden gemaakt. Dit zou kunnen dienen als fundering voor het volledige gebruik van een geïntegreerd fysisch gebaseerd meervoudig procesmodel. De technieken in dit boek hebben de potentie een grote sprong in nauwkeurigheid te beiden voor analyze van risico voor rampen. 